Staatlichkeit und politisches Handeln in der römischen Kaiserzeit

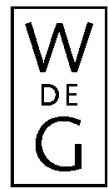




\section{Millennium-Studien}

zu Kultur und Geschichte des ersten Jahrtausends n. Chr.

\section{Millennium Studies}

in the culture and history of the first millennium C.E.

Herausgegeben von / Edited by

Wolfram Brandes, Alexander Demandt, Helmut Krasser, Hartmut Leppin, Peter von Möllendorff

Band 10

Walter de Gruyter · Berlin · New York 


\title{
Staatlichkeit und politisches Handeln in der römischen Kaiserzeit
}

\author{
Herausgegeben von \\ Hans-Ulrich Wiemer
}

Walter de Gruyter · Berlin · New York 
Der Druck wurde gefördert mit Mitteln der

Fritz Thyssen Stiftung für Wissenschaftsförderung

Diese Publikation wurde im Rahmen des Fördervorhabens 16TOA021 - Reihentransformation für die Altertumswissenschaften („Millennium-Studien“) mit Mitteln des Bundesministeriums für Bildung und Forschung im Open Access bereitgestellt. Das Fördervorhaben wird in Kooperation mit dem DFG-geförderten Fachinformationsdienst Altertumswissenschaften - Propylaeum an der Bayerischen Staatsbibliothek durchgeführt.

\section{(cc) BY-NC-ND}

Dieses Werk ist lizenziert unter der Creative Commons Attribution-NonCommercial-NoDerivatives 4.0 International Lizenz. Weitere Informationen finden Sie unter http://creativecommons.org/licenses/by-nc-nd/4.0/.

Die Bedingungen der Creative-Commons-Lizenz gelten nur für Originalmaterial. Die Wiederverwenung von Material aus anderen Quellen (gekennzeichnet mit Quellenangabe) wie z.B. Schaubilder, Abbildungen, Fotos und Textauszüge erfordert ggf. weitere Nutzungsgenehmigungen durch den jeweiligen Rechteinhaber.

$@$ Gcdruckt auf säurcfreicm Papicr, das dic US-ANSI-Norm über Haltbarkcit crfüllt.

ISBN-13: 978-3-11-019101-1

ISBN-10: 3-11-019101-6

ISSN 1862-1139

Bibliografische Information der Deutschen Nationalbibliothek

Die Deutsche Nationalbibliothek verzcichnet diese Publikation in der Deutschen Nationalbibliografie; detaillierte bibliografische Daten sind im Internet über http://dnb.d-nb.de abrufbar.

(C) Copyright 2006 by Walter de Gruyter GmbH \& Co. KG, 10785 Berlin

Dieses Werk cinschlicßlich aller seiner Teile ist urheberrechtlich geschützt. Jede Verwertung außerhalb der engen Grenzen des Urheberrechtsgesetzes ist ohne Zustimmung des Verlages unzulässig und strafbar. Das gilt insbesondere für Vervielfältigungen, Übersetzungen, Mikroverfilmungen und die Einspeicherung und Verarbeitung in elektronischen Systemen.

Printed in Germany

Umschlaggestaltung: Christopher Schneider, Berlin 


\section{Vorwort}

Die in diesem Band gesammelten Beiträge sind aus Vorträgen hervorgegangen, die - von der Einleitung einmal abgesehen - auf einer Tagung mit dem Thema „Staatlichkeit und politisches Handeln in der römischen Kaiserzeit: Der griechische Osten von Augustus bis Justinian" vorgetragen wurden. Der äußere Anlaß für diese Tagung, die vom 9. bis 11. Juli 2004 an der PhilippsUniversität Marburg stattfand, war der 65. Geburtstag von Malcolm R. Errington. Da der Jubilar sich einen Festakt stets ebenso verbeten hat wie eine Festschrift, schien ein nicht personen-, sondern ein themenzentriertes Kolloquium von Freunden und Schülern die angemessene Form, ihn für sein Wirken als Lehrer und Forscher zu ehren.

Seitdem sind zwei volle Jahre vergangen, und die akademische Lehrtätigkeit Malcolm Erringtons neigt sich nach über 30 Jahren ihrem Ende zu. Umso mehr möchten die Autoren dem Wunsch Ausdruck verleihen, daß er noch viele Jahre am lebendigen Meinungsaustausch der Forschung teilnehmen und sie durch seine streitbaren Beiträge weiterhin bereichern möge!

Dem Herausgeber, der für die Konzeption und Organisation der Tagung verantwortlich zeichnet, bleibt am Ende nur die angenehme Pflicht des Dankens. Sein Dank gilt allen Mitgliedern des Marburger Seminars für Alte Geschichte, deren tatkräftige Mithilfe den reibungslosen Ablauf der Tagung erst möglich gemacht hat, den Autoren für ihre Mitwirkung an der Tagung, die pünktliche Ablieferung der Manuskripte und die gute Zusammenarbeit bei der Drucklegung sowie den Herausgebern der Millenium-Studien für die Aufnahme des Bandes in ihre Reihe. Florian Krüpe hat die Druckvorlage erstellt und beim Korrekturlesen geholfen, Sabine Vogt das Buchprojekt beim Verlag de Gryuter betreut. Dank verdient schließlich auch die FritzThyssen-Stiftung, die sich an den Kosten der Tagung beteiligt und eine namhafte Druckbeihilfe geleistet hat. 



\section{Inhaltsverzeichnis}

Hans-Ulrich Wiemer:

Staatlichkeit und politisches Handeln in der römischen Kaiserzeit -

Einleitende Bemerkungen 1

Kostas Buraselis:

Zum hadrianischen Regierungsstil im griechischen Osten oder vom kaiserlichen Agieren und Reagieren

Matthäus Heil:

Clodius Albinus und der Bürgerkrieg von 197

Andrea Jördens:

Zum Regierungsstil des römischen Statthalters -

das Beispiel des praefectus Aegypti

Christian Marek:

Stadt, Bund und Reich in der Zollorganisation des kaiserzeitlichen

Lykien. Eine neue Interpretation der Zollinschrift von Kaunos 107

Kai Ruffing:

Städtische Wirtschaftspolitik im hellenistisch-römischen Kleinasien?

Zur Funktion der Emporia

Martin Dreher:

Die Ursprünge des Kirchenasyls und die Gesetzgebung

Theodosius' II

Dirk Henning:

Der erste „griechische Kaiser“. Überlegungen zum Scheitern des

Procopius Anthemius im Weströmischen Reich

Hartmut Leppin:

Zu den Anfängen der Kirchenpolitik Justinians 
Sebastian Schmidt-Hofner:

Die städtische Finanzautonomie im spätrömischen Reich

209

Hans-Ulrich Wiemer:

Kaiser und Katastrophe. Zur Bewältigung von Versorgungskrisen

im spätrömischen Reich

Index 


\title{
Staatlichkeit und politisches Handeln in der römischen Kaiserzeit - Einleitende Bemerkungen ${ }^{1}$
}

\author{
Hans-Ulrich Wiemer
}

I.

Das Verhältnis von politischen Strukturen und intentionalem Handeln gehört zu den Grundproblemen, die die Wissenschaft von der Geschichte ebenso beschäftigen wie die Wissenschaft von der Politik. ${ }^{2}$ Politische Institutionen ermöglichen die Ausbildung eines kollektiven Willens, verleihen ihm Richtung und Stetigkeit und statten ihn mit den Zwangsmitteln aus, deren er zu seiner Durchsetzung bedarf. Insofern bilden politische Institutionen eine notwendige Voraussetzung für politisches Handeln. Zugleich aber setzen die konkreten Formen von Staatlichkeit, unter denen politisches Handeln sich vollzieht, dem planenden Gestalten auch Grenzen: Ein Institutionengefüge gehört zu den strukturellen Bedingungen, die die politischen Akteure vorfinden und nicht ohne weiteres ändern können. Wo immer daher nach den Handlungsmustern und Handlungsspielräumen politischer Akteure gefragt

1 Ich bin Hartmut Leppin, Beat Näf, Stefan Rebenich und Sebastian Schmidt-Hofner für die kritische Durchsicht des Manuskripts und zahlreiche Hinweise zu großem Dank verpflichtet.

2 Zum gegenwärtigen Stand der politikwissenschaftlichen Institutionenforschung vgl. etwa B. G. Peters, Institutional Theory in Political Science. The „New Institutionalism“, London 2000; G. Göhler u. a., Institution - Macht - Repräsentation. Wofür politische Institutionen stehen und wie sie wirken, Baden-Baden 1997; ders. (Hg.), Institutionenwandel (Leviathan. Sonderheft 16), Opladen 1997; ders. (Hg.), Die Eigenart der Institutionen. Zum Profil politikwissenschaftlicher Institutionentheorie, Baden-Baden 1994; J. A. Schülein, Theorie der Institution. Eine dogmengeschichtliche und konzeptionelle Analyse, Opladen 1987; G. Göhler (Hg.), Grundfragen der Theorie politischer Institutionen. Forschungsstand - Probleme - Perspektiven, Opladen 1987. 
wird, steht zugleich auch die Frage auf der Tagesordnung, welche Formen von Staatlichkeit ihr Handeln bedingten. ${ }^{3}$

Die in diesem Band versammelten Beiträge, hervorgegangen aus einer Tagung an der Philipps-Universität Marburg, gehen dieses Problem anhand eines zeitlich und räumlich weit gefaßten, zugleich aber klar begrenzten und relativ homogenen Untersuchungsfeldes an: der Geschichte der römischen Kaiserzeit einschließlich der Spätantike, gesehen aus der Perspektive der östlichen, griechischsprachigen Reichshälfte. Dabei ist die räumliche Schwerpunktsetzung primär pragmatischen Gründen geschuldet. Die zeitliche Eingrenzung auf den Zeitraum zwischen Augustus und Justinian dagegen erfolgt aus Gründen, die in der Natur der Sache liegen: Da während der Herrschaft des Augustus politische Strukturen entstanden, die bis ins 6. Jahrhundert hinein Bestand hatten - von allem anderen abgesehen, die Monarchie -, ist das Imperium Romanum für diachronische Analysen des Verhältnisses von Staatlichkeit und politischem Handeln besonders geeignet; keine andere politische Formation der europäischen Geschichte hat sich über einen so langen Zeitraum behauptet. Andererseits aber war die Geschichte der römischen Kaiserzeit von einem Wandel in den Formen der Staatlichkeit begleitet, dessen Tragweite und Eigenart kontrovers diskutiert werden: Zwar hat sich die Forschung inzwischen von der durch Theodor Mommsen kanonisierten Vorstellung verabschiedet, die Entwicklung des römischen Kaisertums zerfalle einerseits in die Periode des Prinzipats als konstitutioneller, im Rahmen der republikanischen Verfassung ausgeübter Monarchie und

3 Ich verwende die Begriffe "Staat" und „Staatlichkeit" im folgenden bewußt und ohne schlechtes Gewissen für die römische Kaiserzeit, auch wenn ich mir natürlich bewußt bin, daß das Wort "Staat" erst mit der Entstehung der frühneuzeitlichen Staaten aufgekommen ist und sich daher mit spezifisch modernen Bedeutungen aufgeladen hat, die seine Verwendung im juristischen, politologischen und neuhistorischen Diskurs bestimmen (zur historischen Semantik vgl. W. Conze, Staat und Souveränität, Geschichtliche Grundbegriffe 6, 1990, 4-154). Wie U. Walter, Der Begriff des Staates in der griechischen und römischen Geschichte, in: Th. Hantos/G. A. Lehmann (Hgg.), Althistorisches Kolloquium aus Anlaß des 70. Geburtstages von Jochen Bleicken, Stuttgart 1998, 9-27 einleuchtend dargelegt hat, ist es nicht nur möglich, sondern auch sinnvoll, von Staat und Staatlichkeit in der griechisch-römischen Antike zu sprechen, wenn man sich einmal von der Vorstellung freigemacht hat, das Wesensmerkmal des Staates bestehe in seiner „Souveränität" (wie Carl Schmitt, Staat als konkreter, an eine geschichtliche Epoche gebundener Begriff (1941), in: ders., Verfassungsrechtliche Aufsätze aus den Jahren 1924-1954. Materialien zu einer Verfassungslehre, Berlin 1958, 375-385) oder in der Verfügung über ein absolutes „Monopol legitimer physischer Gewaltausübung“ (wie Max Weber, Wirtschaft und Gesellschaft, Tübingen 51972, 822). Entscheidend ist vielmehr die Institutionalisierung, d. h. Versachlichung und Verstetigung, der Erfüllung von Gemeinschaftsaufgaben, weswegen es notwendig verschiedene Grade von „Staatlichkeit“ gibt. 
der republikanischen Verfassung ausgeübter Monarchie und andererseits in die des aus dem Orient importierten Dominats als absoluter Monarchie. Gleichwohl hält auch die aktuelle Forschung daran fest, daß Staatlichkeit und politisches Handeln in der späten Kaiserzeit Formen annahmen, die sich in vieler Hinsicht von denen der früheren Kaiserzeit unterschieden. Dabei hat sich freilich der Blickwinkel, unter dem der römische Staat betrachtet wird, stark verschoben: Während Theodor Mommsen darauf ausging, das Wesen römischer Staatlichkeit von abstrakten Prinzipien und formalen Regeln her zu erfassen, richten neuere Untersuchungen ihr Augenmerk auf Veränderungen in Umfang und Art der Regierungstätigkeit einschließlich ihrer institutionellen Voraussetzungen.

Die althistorische Diskussion über Charakter und Form politischen Handelns in der römischen Kaiserzeit steht seit nunmehr fast 30 Jahren im Bann des 1977 erschienenen, bahnbrechenden und grundlegenden Werkes des Oxforder Althistorikers Fergus Millar „The Emperor in the Roman World“ (= ERW). Millar untersuchte die materiellen und personellen Grundlagen kaiserlicher Regierungstätigkeit, seine Residenzen und Reisen, seine Helfer und Berater, die Quellen seines Reichtums und die Formen, in denen er Entscheidungen kommunizierte, vor allem aber die Beziehungen zwischen dem Kaiser und seinen Untertanen und Untergebenen, seien es ritterliche oder senatorische Amtsträger, der Senat, Städte, Provinzialversammlungen, Vereine, Privatpersonen oder die christliche Kirche. An einer Fülle von Quellen versuchte er die These zu belegen, daß der Kaiser dann und nur dann aktiv geworden sei, wenn er zuvor dazu aufgefordert worden war, da ihm für eine planvoll gestaltende Politik sowohl die Mittel als auch der Wille gefehlt hätten. ${ }^{4} \mathrm{Da}$ der Kaiser weder über hinreichend leistungsfähige Informationssysteme noch über einen zentralisierten und professionalisierten, hierarchisch gegliederten Verwaltungsapparat verfügt habe, sei seine Person nicht bloß das ideelle, sondern auch das faktisch handelnde Zentrum aller Regierungstätigkeit gewesen. Darum sei er vollauf damit beschäftigt gewesen, auf Anfragen und Eingaben, Beschwerden und Bitten zu reagieren, die von seinen Untertanen und Untergebenen mündlich oder schriftlich an ihn herangetragen wurden, zumal eine konstruktive Gesellschaftspolitik von ihm auch gar nicht erwartet worden sei. Vielmehr habe das Ideal des guten Herrschers lediglich verlangt, daß er als fürsorglicher Patron für die Sorgen und Nöte

4 F. Millar, The Emperor in the Roman World (31 BC - AD 337), London 1977, 21992, 6: „It is the essential passivity of the role expected of the emperor both by himself and by others which explains the very limited and simple, governmental" apparatus which he needed". 
seiner Untertanen stets ein offenes Ohr hatte, und tatsächlich hätten die Kaiser den Großteil ihrer Zeit damit zugebracht, konkrete Einzelfallentscheidungen zu treffen. Millar hat für diesen Regierungsstil, der sich auf situatives Reagieren beschränkt, die Formel ,petition-and-response“ geprägt und an ihr auch im „Afterword“ zur zweiten Auflage von 1992 ausdrücklich festgehalten:

\begin{abstract}
„ERW also embodies a positive assertion, that the model of petition-and-response was a general and characteristic feature of the way that government' by emperors actually worked ... Whatever qualifications need to be made, I would still assert the validity of the basic proposition, that a considerable and significant range of the forms of decision-making by emperors did in fact conform to this model: for example, the receipt of embassies from cities or provincial councils; the answering of petitions (libelli) from private individuals; the hearing of cases between groups or individuals; and the answering of written consultations from office-holders, most notably provincial governors. " 5
\end{abstract}

Millar hat freilich die Außen- und Militärpolitik bei seiner Betrachtung ausdrücklich ausgeklammert ${ }^{6}$ und für einzelne Herrscher, vor allem Augustus und Konstantin, partielle Ausnahmen von der Regel gelten lassen. Mit diesen Einschränkungen aber ist "petition-and-response“ für ihn nicht bloß ein heuristisches Modell, ein Idealtyp im Sinne Max Webers, sondern die gültige Beschreibung des Regierungsstils des römischen Kaisers. Die Möglichkeit, daß ein Kaiser selbst die politische Initiative ergreift und dabei planvoll gestaltend vorgeht, ist in diesem Modell nicht vorgesehen. In diesem Sinn ist Passivität das charakteristische Merkmal des römischen Kaisertums, wie Millar es versteht.

Millars Modell ist schon frühzeitig mit gewichtigen Gründen kritisiert worden. Als erster hat Jochen Bleicken ${ }^{7}$ grundsätzliche Kritik an Millars Konzeption geäußert. Bleicken stimmte Millar zwar darin zu, das der Regierungsstil des römischen Kaisers kasuistisch gewesen sei, insofern Entscheidungen stets an Fällen getroffen worden seien, die „von unten“ an ihn he-

5 Millar, Emperor ${ }^{2}$ (wie Anm. 4), 644-645.

6 Vgl. jedoch F. Millar, Emperors, Frontiers, and Foreign Relations, 31 B.C. to A.D. 378, Britannia 13, 1982, 1-23; auch in: ders., Rome, the Greek World, and the East, Bd. 2: Government, Society, and Culture in the Roman Empire, Chapel Hill - London 2004, 160-194.

7 Zu Leben und Werk Jochen Bleickens (1926-2005) vgl. jetzt die Nachrufe von H. Leppin, HZ 281, 2005, 826-833 und U. Walter, Gnomon 78, 2006, 90-95. 
rangetragen worden seien. Er wandte jedoch ein, daß aus dem von Millar behaupteten Fehlen von allgemeinen, für alle Personen oder Personengruppen geltenden Gesetzen und aus dem Mangel an Systematik in den kaiserlichen Entscheidungen keineswegs auf Passivität und Konzeptionslosigkeit geschlossen werden dürfe. Gewiß habe das politische Handeln römischer Kaiser nicht unter dem Imperativ permanenter Innovation gestanden; es ließen sich jedoch durchaus rechtspolitische Grundsätze und auch konkrete politische Leitlinien erkennen, etwa was das Bürgerrecht, die materielle Versorgung und das Testierrecht der Soldaten angehe, aber auch in der Verleihung des Bürgerrechts an Peregrine, dem Bauernschutz, dem Verhältnis zu den zahllosen Kulten des Imperium und den Eingriffen in Belange der Städte:

\begin{abstract}
„Die Regierungsarbeit erfolgte ... in aller Regel nicht aufgrund systematischer Analysen; sie beruhte nicht auf vorausschauender Planung. Dafür fehlten nicht nur die Mittel, sondern fehlte auch die Einsicht; denn niemals verlie $\beta$ man die sichere Basis der Tradition, in der das Richtige bereits gefunden zu sein schien ... So herrschte in der kaiserlichen Aktivität die Reaktion auf die Anfrage von unten vor. Doch sie sorgte durch die Kasuistik der Entscheidungen und dadurch, daß sich in der Zentrale ein Erfahrungsschatz für die Problematik vieler Bereiche schärfte und gewisse politische Leitlinien dann als Konsequenz der wiederholten Behandlung bewußt wurden, nicht nur für eine ständige Bearbeitung und Kontrolle gesellschaftlicher Probleme, sondern es wurde durch sie bei Bedarf die geltende Ordnung auch geändert bzw. erweitert und wurden neue Bereiche staatlicher Tätigkeit entdeckt".
\end{abstract}

Nach Bleicken war diese Politik ebenso intensiv wie effektiv, weil die kaiserliche Zentrale, die er sich im Gegensatz zu Millar als funktional ausdifferenziert und komplex vorstellte, „über alles, was im Reich geschah, über Not und Unzufriedenheit, über menschliches Fehlverhalten und Treue, über neue Phänomene und den Wandel alter mit einem außergewöhnlich geringen Verwaltungsaufwand bestens unterrichtet gewesen" sei. ${ }^{8}$

Während Bleicken bei aller Kritik doch darin mit Millar übereinstimmte, daß auch er annahm, der römische Kaiser habe regiert, ohne Regelungen allgemeinen Charakters zu erlassen, sondern stets fallbezogene Entscheidungen getroffen, und keine Bestrebungen zu planvoller Gestaltung entwickelt, haben andere Kritiker die Frage aufgeworfen, ob der Eindruck, die Aktivität

8 Jochen Bleicken, Zum Regierungsstil des römischen Kaisers. Eine Antwort auf Fergus Millar (Sbb. d. wiss. Gesellschaft an der Universität Frankfurt am Main, Bd. XVIII, Nr. 5), Wiesbaden 1982; auch in: ders., Gesammelte Schriften, Bd. 2, Stuttgart 1998, 843-875, hier: $36-37=874875$. 
der Kaiser und ihrer Statthalter sei über ein situatives Reagieren nicht hinausgegangen, nicht zumindest teilweise einer überlieferungsbedingten Täuschung geschuldet ist. Nachdem bereits Werner Eck wiederholt darauf hingewiesen hatte, ${ }^{9}$ daß die epigraphische Überlieferung administrativer Dokumente keineswegs repräsentativ für den einstmals vorhandenen Bestand sein dürfte, weil ihre inschriftliche Aufzeichnung voraussetzte, daß sich interessierte Parteien davon einen Vorteil versprachen, hat vor kurzem Graham Burton für die Zeit von 14-235 n. Chr. in systematischer Untersuchung den Nachweis geführt, daß dieser Befund für die Gesamtheit der überlieferten Entscheidungen von Kaisern und Statthaltern verallgemeinert werden kann. Denn so wie die epigraphische spiegelt auch die juristische Überlieferung primär die Interessen derjenigen, die sie veranlaßten, in diesem Fall also einerseits die Interessen der Kompila toren, die die Werke der klassischen Juristen vorwiegend severischer Zeit unter Justinian exzerpierten, und andererseits die der exzerpierten Juristen selbst. Normative Regelungen allgemeinen Charakters wie mandata, leges provinciarum und statthalterliche Provinzialedikte, aber auch fiskalische Dokumente hatten deshalb eine sehr geringe Überlieferungschance. Burton zieht aus diesem Befund die Schlußfolgerung, daß das Bild eines auf persönlicher Kommunikation mit den Untertanen beruhenden, reaktiven Regierungsstils zwar nicht völlig falsch, aber doch einseitig sei, insofern der römische Staat der hohen Kaiserzeit durchaus den Willen und die Fähigkeit besessen habe, „both to create normative regulations which were binding on its subjects and to extract from its subjects a continuous flow of surplus sources". ${ }^{10}$ Jüngst hat Peter Eich diese Kritik auf breiter empirischer Grundlage erneuert und auf die Frage nach der Existenz eines bürokratisch organisierten Regierungsapparates zugespitzt. Auch Eich erhebt gegen Millar den methodischen Einwand, daß „eine Auflistung antiker Quellenstellen, die den Kaiser als rein rezeptives Organ ,reagierend' zeigen, nicht als Beleg für die Operationalisierbarkeit des Idealtyps ,petition-and-response' gelten kann“, weil ja unbestritten ist, daß „diese Form des Regierens ein integraler

9 W. Eck, Kaiserliches Handeln in italischen Städten, in: L'Italie d'Auguste à Dioclétien. Actes du colloque international, Rome 25-28 mars 1992, Rom 1994, 329-354; auch in: ders., Die Verwaltung des römischen Reiches in der hohen Kaiserzeit, Bd. 2, Basel - Berlin 1998, 297-320; ders., Administrative Dokumente und Mittel der Selbstdarstellung, ebd., 359-382; ders., Zur Einleitung. Römische Provinzialadministration und die Erkenntnismöglichkeiten der epigraphischen Überlieferung, in: W. Eck (Hg.), Lokale Autonomie und römische Ordnungsmacht in den kaiserzeitlichen Provinzen vom 1. bis 3 . Jahrhundert (Schriften des Historischen Kollegs 42), München 1999, 1-15.

10 G. P. Burton, The Roman Imperial State (A. D. 14-235): Evidence and Reality, Chiron $32,2002,249-280$. 
Bestandteil der kaiserlichen Tätigkeit war". Vielmehr sei angesichts der Tatsache, daß bereits die ersten Kaiser - im Gegensatz zu vielen frühmodernen Monarchen - auf ein funktionierendes System der Steuererhebung zurückgreifen konnten, der positive Nachweis zu erbringen, daß sich die Regierungstätigkeit des römischen Kaisers in Jurisdiktion erschöpft habe. ${ }^{11}$ Eine Reihe von Indizien weise jedoch darauf hin, daß sich im Rahmen der prokuratorischen Ämter eine ,personale Bürokratie" herausgebildet habe, die einerseits nicht mehr aus der traditionellen Führungsschicht rekrutiert wurde und ganz auf den Kaiser ausgerichtet war, andererseits aber klar definierte Kompetenzhierarchien und eine ausgeprägte Tendenz zur Professionalisierung aufgewiesen habe. Diese ,personale Bürokratie“ sei aus dem Bedürfnis nach effektiver Allokation von Ressourcen entstanden und in der außenpolitischen und militärischen Krise des 3. Jahrhunderts als Folge des aus der frühneuzeitlichen Geschichte Europas bekannten ,extractioncoercion-cycle' zur vollen Entfaltung gekommen.

Trotz dieser begründeten Kritik hat sich Millars These in der Forschung über die frühe und hohe Kaiserzeit weitgehend durchgesetzt und erfreut sich namentlich in der angelsächsischen Forschung geradezu kanonischer Geltung. Nicht ohne Berechtigung schreiben daher Hannah Cotton und Guy Rogers im Vorwort zu Millars gesammelten Schriften über das römische Kaiserreich: „After more than twenty years of scholarly reaction, The Emperor in the Roman World is now the dominant scholarly model of how the Roman Empire worked in practice" ${ }^{12}$ In vielen Arbeiten wird die Gültigkeit des „petition-and-response"-Modells für die Zeit vor Diokletian ohne weiteres vorausgesetzt. So hat etwa 1996 Simon Corcoran Millars Ansatz auf die Epoche der Tetrarchie übertragen und anhand einer detaillierten Untersuchung der für diese Zeit besonders zahlreich überlieferten Reskripte, Episteln und Edikte zu zeigen versucht, daß die Regierungstätigkeit dieser Kaiser durch ein höheres $\mathrm{Ma}$ an spontaner Aktivität gekennzeichnet sei, als dies in der früheren Kaiserzeit der Fall gewesen sei. Neben dem Preisedikt und den Verfolgungsedikten zeige auch das Verschwimmen der Unterscheidung zwischen Episteln und Edikten, daß das Modell von „petition-and-response“ nicht mehr ausreiche, wenn es darum gehe, den Regierungsstil der Tetrarchen zu

11 P. Eich, Zur Metamorphose des politischen Systems in der römischen Kaiserzeit. Die Entstehung einer „personalen Bürokratie“ im langen dritten Jahrhundert (Klio. Beiträge zur Alten Geschichte. Beihefte N. F. 9), Berlin 2005, 78-80 (Zitat auf 80).

12 Millar, Rome, the Greek World and the East II (wie Anm. 6), vii. 
beschreiben. ${ }^{13}$ John E. Lendon hat die Vorstellung, daß das innenpolitische Handeln des römischen Kaisers keinerlei Tendenz zu planvoller Gestaltung erkennen lasse, sogar noch radikalisiert, indem er seine Regierungstätigkeit auf einen durch militärische Gewalt abgesicherten Austausch von Ehre zwischen Kaiser und Untertanen reduziert. Einziges Ziel in diesem ständigen Tauziehen sei für alle Beteiligten die Steigerung der eigenen Ehre gewesen: „Roman Government did not imagine itself as a government in our sense. Its members imagined something more akin to a football league, a realm of glory, profit, and competition - and some administration". ${ }^{14}$

Während also in der Forschung zur frühen und hohen Kaise rzeit nach wie vor die Vorstellung eines passiven Staates vorherrscht, der nur auf das Begehren von Untertanen oder Fragen von Beamten hin aktiv geworden sei, zeichnet die Forschung über das Kaisertum der Spätantike seit langem und vielfach bis heute ein ganz anderes Bild: Hier dominiert die Vorstellung einer sehr aktiven, weite Bereiche der Gesellschaft regulierenden Zentrale, und der spätrömische Staat gilt weithin als Organ eines politischen Willens, der danach strebte, alle Lebensbereiche seiner Kontrolle zu unterwerfen. ${ }^{15}$ Diese Vorstellung, die sich ursprünglich aus der liberalen Abneigung gegen den monarchischen Obrigkeitsstaat speiste, hat sich unter dem Eindruck totalitärer Systeme im deutschen Sprachraum zu dem Begriff des „Zwangsstaates“ verdichtet, der nach dem Zweiten Weltkrieg weite Verbreitung erlangte. Die in diesem Begriff enthaltene, auf der Verabsolutierung des liberalen Freiheitsbegriffs beruhende Insinuation, das spätrömische Reich sei mit Nationalsozialismus und Stalinismus in eine Reihe zu stellen, war damals vielen Historikern nicht unwillkommen, wenn dieser Vergleich auch niemals ausdrücklich gezogen wurde; zudem empfahl sich der Begriff auch deswegen,

13 S. Corcoran, The Empire of the Tetrarchs: Imperial Pronouncements and Government, AD 284-324, Oxford 1996, 202: „What this demonstrates is a shift in the direction of government. No longer it is just a matter of ,petition and response, even though that itself may generate more than a single imperial document. Whatever may prompt a particular act of legislation, it is now issued in an active fashion“; vgl. 294-295: ,although rescripts are present among the letters, there is an increasing tendency for unsolicited missives to be sent to officials. This is revealed in particular by the manner in which the distinction between letters and edicts is eroded, as differences in format become less and each may be circulated with near identical texts to promulgate a single act of general legislation".

14 J. E. Lendon, Empire of Honour. The Art of Government in the Roman Empire, Oxford 1997, 236.

15 Zum Bild des spätrömischen Reiches in der modernen Historiographie seit der Renaissance vgl. allgemein S. D'Elia, Il Basso Impero nella cultura moderna dal quattrocento ad oggi, Neapel 1967 sowie A. Demandt, Der Fall Roms. Die Auflösung des römischen Reiches im Urteil der Nachwelt, München 1984. 
weil er auf alle Bereiche des gesellschaftlichen Lebens angewendet werden konnte und damit geeignet war, den Eindruck zu vermeiden, man pflege eine einseitig auf die politischen Institutionen fixierte Betrachtungsweise. ${ }^{16}$

Die Zwangsstaatsthese erlangte $u$. a. durch den einschlägigen, 1968 veröffentlichten Band der „Fischer-Weltgeschichte“ eine starke, bis heute anhaltende Breitenwirkung ${ }^{17}$ und hat sich auch in Fachkreisen lange behauptet; noch 1976 fand sie Eingang in das repräsentative „Handbuch der europäischen Geschichte". ${ }^{18}$ Und als 1985 der Bielefelder Althistoriker Rolf Rilinger ${ }^{19}$ in der Zeitschrift des deutschen Geschichtslehrerverbandes auf die analytische Unschärfe und empirische Fragwürdigkeit des mit anachronistischen Assoziationen befrachteten Begriffes hinwies, ${ }^{20}$ trat ihm in der Person von $\mathrm{Alfred} H \mathrm{Heu} \beta^{21}$ einer der angesehensten und einflußreichsten deutschen Althistoriker entgegen, der sich mit großer Vehemenz für die Auffassung aussprach, daß der spätrömische Staat als „Zwangsstaat“ zutreffend gekennzeichnet sei. ${ }^{22} \mathrm{Da} \mathrm{Heu} ß$ indessen nur rekapitulierte, was um 1960 als Forschungsstand hatte gelten können, war seinen Argumenten keine große Resonanz mehr beschieden. Heute ist die Rede vom spätrömischen „Zwangsstaat" aus dem öffentlichen Diskurs der Althistorie so gut wie völlig

16 Vgl. dazu R. Rilinger, Die Interpretation des späten Imperium Romanum als „Zwangsstaat", GWU 36, 1985, 321-340, bes. 321-325; M. Meier, Das späte römische Kaiserreich ein ,Zwangsstaat? Anmerkungen zu einer Forschungskontroverse, Electrum 9, 2003, 193-213.

17 F. G. Maier, Die Verwandlung der Mittelmeerwelt, Frankfurt/Main 1968, 34-41; 87ff. Das Werk hatte sich bis 1992 über $75.000 \mathrm{Mal}$ verkauft; die 13. Auflage ist nach wie vor lieferbar.

18 Th. Schieffer, Die spätantike Reichs- und Kultureinheit und ihre Krise, in: Th. Schieder ( $\mathrm{Hg}$.), Handbuch der europäischen Geschichte, Bd. 1: Europa im Wandel von der Antike zum Mittelalter, hgg. von Th. Schieffer, Stuttgart 1976, 51-93, hier: 72-76: „Der Zwangsstaat".

19 Zu Leben und Werk Rolf Rilingers (1942-2003) vgl. den kurzen Nachruf von Aloys Winterling, Gnomon 76, 2004, 655.

20 Rilinger, GWU 36, 1985 (wie Anm. 16), 321-340.

21 Zu Leben und Werk Alfred Heuß' (1909-1995) vgl. einstweilen H.-j. Gehrke (Hg.), Alfred Heuß - Ansichten seines Lebenswerkes. Beiträge des Symposions „Alte Geschichte und Universalgeschichte: Wissenschaftsgeschichtliche Aspekte und HistorischKritische Anmerkungen zum Lebenswerk von Alfred Heuß“, Göttingen, 16. und 17. Mai 1996, Stuttgart 1998 (dazu und zu Heuß' Verhalten im Dritten Reich vgl. S. Rebenich, HZ 271, 2000, 661-673).

22 A. Heuß, Das spätantike römische Reich kein „Zwangsstaat"? Von der Herkunft eines historischen Begriffs, GWU 37, 1986, 603-618; auch in: ders., Gesammelte Schriften in 3 Bänden, Bd. 2: Römische Geschichte, Stuttgart 1995, 1439-1454. 
verschwunden. ${ }^{23}$ Die Vorstellung indessen, der römische Staat der Spätantike habe weite Bereiche der Gesellschaft zu reglementieren und kontrollieren versucht, hat sich durchaus gehalten, und für sie scheint ja auf den ersten Blick bereits die Tatsache zu sprechen, daß uns mit dem „Codex Theodosianus" und "Codex Justinianus" umfangreiche Sammlungen der legislatorischen Aktivität spätrömischer Kaiser überliefert sind, die in der früheren Kaiserzeit keine Entsprechung haben.

In der Spezialforschung zur Geschichte des spätrömischen Reiches ist seit den 60er Jahren dagegen eine Neubewertung spätrömischer Staatlichkeit in Gang gekommen, die viele Aspekte seiner Aktivität in einem neuen Licht erscheinen läßt. Bereits 1964 hatte der an der Universität Cambridge lehrende Althistoriker A. H. M. Jones ${ }^{24}$ eine systematische und detaillierte, ganz aus den Quellen geschöpfte Darstellung des spätrömischen Staates vorgelegt, die mit vielen, bis dahin weithin akzeptierten Vorstellungen gründlich aufräumte, auch wenn dies aufgrund des nüchtern-sachlichen Stiles und des prinzipiellen Verzichts auf die Auseinandersetzung mit den Ansichten anderer Forscher zunächst nicht überall erkannt wurde. ${ }^{25}$ Während die ältere Forschung dazu geneigt hatte, sich bewußt oder unbewußt mit den städtischen Eliten zu identifizieren, sympathisierte Jones, der Mitglied der englischen Labour Party war, mit den Bauern und Handwerkern, die nur mit Mühe hätten aufbringen können, was der Fiskus ihnen abverlangt habe, und sah in Senatoren, Ratsherren und Klerikern vor allem „unnütze Esser“ (idle mouths), die Einkommen

23 Hier sei nur auf das im deutschsprachigen Raum maßgebliche Handbuch von A. Demandt, Die Spätantike. Römische Geschichte von Diocletian bis Justinian, 284-565 n. Chr. (Handbuch der Altertumswissenschaft III 6), München 1989, 447f. u. ö. verwiesen. Bei dems., Fall Roms (wie Anm. 15), 584 findet sich das Diktum: „Der sogenannte spätrömische Zwangsstaat ist ein Wahngebilde von Forschern, die gesetzliche Bestimmungen mit historischen Tatsachen verwechseln".

24 Eine adäquate Würdigung des Althistorikers A. H. M. Jones (1904-1970) ist ein Desiderat der Forschung, doch steht ein diesem Unterfangen gewidmeter Sammelband nach Auskunft von Stefan Rebenich kurz vor der Drucklegung: D. M. Gwynn (Hg.), A. H. M. Jones and the History of the Later Roman Empire. Vgl, einstweilen die Rezensionen des Hauptwerkes durch P. Brown (EHR 56, 1967, 327-343 = ders., Religion and Society in the Age of Augustine, London 1972, 46-73) und A. Momigliano (The Oxford Magazine, 4 March 1965, 264 = ders., Quarto contributo alla storia degli studi classici e del mondo antico, Rom 1969, 645-647) sowie den Nekrolog von J. M. Crook, PBSA 57, 1972, 425438.

25 A. H. M. Jones, The Later Roman Empire 284-602. A social, economic and administrative survey, 3 Bde., Oxford 1964. 
bezogen, ohne produktive Arbeit zu leisten. ${ }^{26}$ Vor allem aber stellte Jones die Auffassung, staatlicher Zwang habe die spätrömische Gesellschaft kastenartig erstarren lassen, radikal in Frage; für ihn war die soziale Mobilität in der späten Kaiserzeit keineswegs geringer, sondern vielmehr größer als in den Jahrhunderten zuvor. ${ }^{27}$

Voraussetzung und Grundlage dieser neuen Sichtweise war eine neue Deutung der juristischen Quellen. Während man die im „Codex Theodosianus" und "Codex Justinianus" gesammelten Kaiserkonstitutionen bis dahin als Beleg für eine tief in die Gesellschaft eindringende staatliche Kontrolle gewertet hatte, sah Jones in der großen Zahl von Regelungen, die sich auf denselben Sachbereich beziehen, vor allem einen Ausdruck der Tatsache, daß der spätrömische Staat seinen eigenen Gesetzen häufig nicht zur Durchsetzung verhelfen konnte. ${ }^{28}$ Der spätrömische Staat war nach Jones zwar leidlich effektiv, wenn es darum ging, den inneren Frieden zu gewährleisten und Steuern zu erheben; er sei in Ermangelung eines leistungsfähigen Erzwingungsstabes jedoch außerstande gewesen, gesellschaftliche Prozesse zu steuern und darum regelmäßig gescheitert, wenn er es - wie in der Religionsund Städtepolitik - dennoch versucht habe. ${ }^{29}$ Zugleich lieferte Jones nicht bloß erstmals eine konkrete Analyse der Faktoren, die auf die Entscheidungsbildung am Hof einwirkten, sondern ordnete die Genese und Motivation der spätrömischen Kaiserkonstitutionen in den Prozeß der Interaktion zwischen der kaiserlichen Zentrale einerseits und untergeordneten Instanzen und Personen andererseits ein: Jones stellte zwar nicht in Abrede, daß spätrömische Kaiser gelegentlich von sich aus Reformen einleiteten; in der groBen Mehrzahl der Fälle seien sie jedoch von Funktionären und korporativen

26 Jones, Later Roman Empire I (wie Anm. 25), 557-562 (Senatoren); $755-757$ (curiales); II, 808-812 (Bauern); 871f. (Handwerker und Händler); 933f. (Klerus); 1045-1047 („idle mouths").

27 Jones, Later Roman Empire II (wie Anm. 25), 1050; ders., The Caste-System in the Later Roman Empire, Eirene 8, 1970, 79-96; auch in: ders., The Roman Economy (hg. Von P.A. Brunt), Ox ford 1974, 396-418.

28 Jones, Later Roman Empire II (wie Anm. 25), 1052: „The laws themselves, by their constant iteration of the same prohibitions and their frequent condonation of past offences, show how impossible it was without any police to enforce the rules". Jones hat dem Handexemplar seines Aufsatzes über the "Caste-System in the Later Roman Empire“ am Ende den Satz hinzugefügt: „The flood of laws which endeavour to fix various categories of persons and their descendants in their occupations itself reveals the volume of the movement which they were intended to check and goes far to prove that they failed" (ders., The Roman Economy [wie Anm. 27], 418).

29 Jones, Later Roman Empire I (wie Anm. 25), 366-410: "The Administration“, bes. $406 \mathrm{ff}$. 
Interessengruppen zum Eingreifen veranlaßt worden. ${ }^{30}$ Jones hat Millars Ansatz damit in gewisser Weise vorweggenommen, ohne freilich das Reagieren zum allein bestimmenden Wesensmerkmal des Regierungsstils spätrömischer Kaiser zu erklären.

Während Jones und viele, die nach ihm kamen, vor allem die Fähigkeit des spätrömischen Staates bezweifelten, seinen politischen Willen tatsächlich durchzusetzen, kam parallel dazu eine rechtshistorische Diskussion in Gang, in welcher der normative Anspruch spätrömischer Kaiserkonstitutionen problematisiert wurde. Während die ältere Forschung diese Verfügungen als „Gesetze" von zeitlich unbegrenzter und reichsweiter Geltung, den „Codex Theodosianus" selbst folglich als Gesetzbuch von der Art des „Preußischen Landrechts" verstand, hat sich unter Rechtshistorikern seit den 1950er Jahren die Einsicht durchgesetzt, daß die im "Codex Theodosianus“ enthaltenen Verfügungen nicht bloß häufig in Reaktion auf Anliegen entstanden, die an den Kaiser in Form von Anfragen, Vorschlägen, Petitionen oder Appellationen herangetragen wurden, sondern in der Regel auch nur für den Amtsbereich des Empfängers Geltung beanspruchten, womit einem zentralen Argument für die Zwangsstaatsthese der Boden entzogen wurde. Auch wenn die bahnbrechenden Beiträge des französischen Rechtshistorikers Jean Gaudemet $^{31}$ in Deutschland erst mit einer gewissen Verzögerung rezipiert wurden - ein Rechtshistoriker vom Range Franz Wieackers vertrat bis in die 1970 er Jahre hinein die Auffassung, abgesehen von den Reskripten hätten alle Rechtssetzungsakte spätrömischer Kaiser ,als leges generales den Charakter einer allgemeinverbindlichen Rechtsetzung ${ }^{\star 32}$ gehabt -, dürfte dieser Para-

30 Jones, Later Roman Empire I (wie Anm. 25), 321-365: „The Government“, bes. $347 \mathrm{ff}$.

31 J. Gaudemet, Le partage législative dans la seconde moitié du IVe siècle, in: Studi in onore di Pietro De Francisci, Bd. 2, Mailand 1954, 319-354; auch in: ders., Études au droit romain, Bd. 1: Sources et theorie génerale du droit, Camerino 1979, 129-166; Le partage législatif au Bas-Empire d'après un ouvrage récent, SDHI 21, 1955, 319-331; auch in: ders., Études I, 167-212; La formation du droit séculier et du droit de l'église au IVe et Ve siècle, Paris 1957, 14ff. Zum romanistischen Wirken Gaudemets (1908-2001) vgl. den Nachruf von M. Humbert, ZRG.RA 119, 2002, 682-689.

32 F. Wieacker, Recht und Gesellschaft in der Spätantike, Stuttgart 1964, 58. Wieacker (1908-1994) war nicht zufällig auch einer der letzten Vertreter der „Zwangsstaatstheorie“, der noch 1974 erklärte: „Die Städte, deren wirtschaftliche Schwäche sich schon im 2. Jahrhundert ankündigt, wurden durch die Militäranarchie des 3. Jahrhunderts weiterhin zermürbt; die Verfestigung und Institutionalisierung des Ausbeutungssystems im absolutistischen Zwangsstaat hat dann ihre Autonomic wie ihre wirtschaftliche Bewegungsfreiheit endgültig erdrückt" (Die Krise der antiken Welt [Vortragsreihe der Niedersächsischen Landesregierung. Heft 50], Göttingen 1974, 26f.). Zu Wieackers Leben und Werk vgl. den Nachruf von O. Behrends, ZRG.RA 112, 1995, XIII-LXII. 
digmenwechsel in der Rechtsgeschichte heute so gut wie abgeschlossen sein, ${ }^{33}$ während er in der Althistorie noch längst nicht allgemein vollzogen ist. Nicht zuletzt Malcolm Errington hat jedoch eindrucksvoll unter Beweis gestellt, welche Resultate eine konsequente Kontextualisierung spätrömischer „Gesetze“ für die politische Geschichte des 4. Jahrhunderts zu erbringen vermag. ${ }^{34}$ Darum muß heute jede methodisch reflektierte Erörterung der Regierungstätigkeit spätrömischer Kaiser von der Erkenntnis ausgehen, daß spätrömische "Gesetze“ häufig einen eng begrenzten Geltungsbereich hatten. Damit aber hat sich die Beweislast für die Ansicht, daß der spätrömische Staat einen umfassenden Regulierungsanspruch erhoben habe, geradezu umgekehrt: Beim gegenwärtigen Diskussionsstand gilt es zu überprüfen, inwiefern und inwieweit die Regierungstätigkeit spätrömischer Kaiser über ein bloßes Reagieren auf situative Herausforderungen hinausging. ${ }^{35}$

II.

Die Tatsache, daß in der Forschung zur Spätantike bis heute das Bild eines starken Staates mit umfassendem Regelungsanspruch anzutreffen ist, während in der Forschung zur früheren Kaiserzeit das Modell eines Kaisertums vorherrscht, das nur auf Begehren der Untertanen hin tätig wird, hat sicher mehrere Ursachen. Keinesfalls sollte man die Auswirkung der unerbittlich fortschreitenden Spezialisierung unterschätzen. Die Bearbeitung der gewaltigen Mengen an lateinischen und griechischen Inschriften und Papyri, die der Forschung zum Staat der frühen und hohen Kaiserzeit als wichtigste Quelle dienen, erfordert andere Techniken und Methoden als die Interpretation der für die späte Kaiserzeit grundlegenden Rechtsquellen und handschriftlich überlieferten Aktenstücke, und nur wenige können beanspruchen, sie alle gleichermaßen zu beherrschen. Dennoch wirkt in dieser Arbeitsteilung auch eine wissenschaftsgeschichtliche Tradition nach, die das spätrömische Reich

33 Zur Einführung in den aktuellen Diskussionsstand vgl. etwa J. Harries/I. Wood (Hgg.), The Theodosian Code. Studies in the imperial law of late antiquity, London 1993; J. Harries, Law and Empire in Late Antiquity, Cambridge 1999.

34 R. M. Errington, Church and State in the First Years of Theodosius I, Chiron 27, 1997, 21-72; ders., Christian Accounts of the Religious Legislation of Theodosius I, Klio 79, 1997, 398-443.

35 Einen wesentlichen, auch konzeptionell weiterführenden Beitrag zur Analyse spätrömischer Staatlichkeit leistet jetzt S. Schmidt-Hofner, Kaiser und Gesetz. Der Regierungsstil des spätrömischen Kaisers im Spiegel des Codex Theodosianus: das Beispiel Valentinians I. (364-375 n. Chr.), Diss. Marburg 2005 (erscheint in der Reihe „Vestigia“). 
als Bruch mit den Grundprinzipien römischer, ja überhaupt antiker Staatlichkeit verstand.

Diese Tradition soll im folgenden skizziert werden. ${ }^{36}$ Die Auffassung, der römische Staat habe sich zwischen der hohen Kaiserzeit und der Spätantike grundlegend gewandelt, hat eine lange Geschichte. Im „Römischen Staatsrecht" Theodor Mommsens, dessen erster Band im Jahr der preußischdeutschen Reichsgründung (1871) erschien, wurde sie gewissermaßen kodifiziert und dadurch zu fast kanonischer Geltung erhoben. ${ }^{37}$ Für Mommsen war die von Augustus begründete Staatsordnung, die wir als Prinzipat zu bezeichnen gewohnt sind, von dem durch Diokletian und Konstantin begründeten Staat der Spätantike, für den sich unter Mommsens Einfluß der Name Dominat eingebürgert hat, ${ }^{38}$ durch eine tiefe Kluft getrennt. Momm-

36 Daß die folgenden Ausführungen den wissenschaftsgeschichtlichen Arbeiten Karl Christs sehr viel verdanken, bedarf wohl kaum der Hervorhebung, doch sei hier ein und für allemal auf sein grundlegendes Werk „Römische Geschichte und deutsche Geschichtswissenschaft“ (München 1982) verwiesen.

37 Th. Mommsen, Römisches Staatsrecht, 3 Bde., Leipzig 1871-1888, Bd. 1 \& 2, Leipzig 21887. Die Hundertjahrfeier hat einen eigenen Sammelband zu Mommsens „Staatsrecht“ hervorgebracht: W. Nippel/B. Seidensticker (Hgg.), Theodor Mommsens langer Schatten. Das römische Staatsrecht als bleibende Herausforderung für die Forschung, Hildesheim u. a. 2005. Aus der älteren Literatur bleibt insbesondere A. Heuß, Theodor Mommsen und das 19. Jahrhundert, Kiel 1956, bes. 33ff. wertvoll. Vgl. auch E. Flaig, Volkssouveränität ohne Repräsentation. Zum „Römischen Staatsrecht“ von Theodor Mommsen, in: W. Küttler u. a. (Hgg.) Geschichtsdiskurs, Bd. 3: Die Epoche der Historisierung, Frankfurt/Main 1997, 321-339; K.-J. Hölkeskamp, Theodor Mommsens ,Staatsrecht ${ }^{`}$ und die römische Verfassung in Frankreich und Deutschland, in H. Bruhns u. a. (Hgg.), Die späte römische Republik. La fin de la republique romaine. Un débat franco-allemand d'histoire et d'historiographie, Paris 1997, 93-111; W. Nippel, Der „Antiquarische Bauplatz“. Theodor Mommsens Römisches Staatsrecht, in: J. Wiesehöfer (Hg.), Theodor Mommsen: Gelehrter, Politiker und Literat, Stuttgart 2005, 165-184.

38 Drei Beispiele mögen genügen: Die Darstellung der „Römischen Staatsaltertümer“ durch den Straßburger Althistoriker Karl Julius Neumann in: A. Gercke/E. Norden (Hgg.), Einleitung in die Altertumswissenschaft, Bd. 2, Leipzig ${ }^{2} 1914$ ist für die Zeit nach Augustus in die Abschnitte „Prinzipat" und Dominat" gegliedert. Die Abhandlung von Otto Theodor Schulz, Vom Prinzipat zum Dominat. Das Wesen des römischen Kaisertums des dritten Jahrhunderts, Paderborn 1919 trägt das Begriffspaar im Titel. Ernst Hohl eröffnete die Behandlung der diokletianisch-konstantinischen Staatsordnung in der 1931 erschienenen „Propyläen-Weltgeschichte“ mit den Sätzen: „Diokletians Regierung macht staatsrechtlich Epoche. Denn dieser Kaiser hat die Monarchie im strengen Sinn, den reinen Absolutismus, endgültig aufgerichtet und die letzten Reste der augusteischen Verfassung beseitigt. An die Stelle des Prinzipates tritt das Dominat als diejenige Staatsfom, die den Kaiser nicht mehr als den ersten der Bürger, sondern als den Herrn, den dominus der Untertanen, betrachtet" (W. Goetz [Hg.], Propyläen-Weltgeschichte, Bd. 2: Hellas und 
sen sah die Staatsordnung der Kaiserzeit als Fortsetzung der republikanischen Verfassung, deren Magistratur von Augustus lediglich um ein neues Oberamt, eben den Prinzipat, erweitert worden sei. Der Kaiser war für ihn darum ein Magistrat, der seine Vollmacht vom Senat erhält und sich die Herrschaft mit diesem teilt; diese Teilung der Herrschaft zwischen Princeps und Senat wurde von ihm als Dyarchie bezeichnet. ${ }^{39}$ Mommsen wußte natürlich, daß der Princeps nicht an die für die Magistratur der Republik grundlegenden Prinzipien der Annuität und Collegialität gebunden war, und er gab sich auch keinerlei Illusionen darüber hin, daß die Art, wie er in sein „Amt“ gelangte, mit einem geregelten Verfahren nicht die entfernteste Ähnlichkeit aufwies; ${ }^{40}$ darum räumte er ein, daß er nicht als Magistrat im republikanischen Sinne verstanden werden könne. Eben deshalb aber legte Mommsen großes Gewicht auf die Feststellung, daß der Kaiser sein Amt als „Ausfluss und Organ der Volkssouveränetät" und damit im Rahmen einer überpersönlichen Rechtsordnung ausgeübt habe: „Der Principat, wie Augustus ihn geordnet hat, ist der Anlage nach wesentlich Magistratur, und zwar nicht gleich der constituirenden eine über und ausser dem Gesetz stehende, sondern durch die Gesetze begrenzt und gebunden" ".11 Der Kaiser der Spätantike dagegen übte nach Mommsen ein ,unbedingtes und unbeschränktes Herrenrecht über die Personen wie über das Gut aller Unterthanen“ aus, weshalb

Rom. Das frühe Christentum, Berlin 1931, 433). Zu Leben und Werk Hohls (1886-1957) vgl. jetzt M. Sehlmeyer/U. Walter, Unberührt von jedem Umbruch? Der Althistoriker Ernst Hohl zwischen Kaiserreich und früher DDR, Frankfurt/Main 2005.

$39 \mathrm{Zu}$ der Frage, ob sich Mommsens Theorem der Dyarchie als politischer Modus sozialer Integration zeitgemäß reformulieren läßt, vgl. jetzt A. Winterling, ,Staat', ,Gesellschaft und politische Integration in der römischen Kaiserzeit, Klio 83, 2000, 93-122; dens., Dyarchie in der römischen Kaiserzeit. Vorschlag zur Wiederaufnahme der Diskussion, in: Nippel/Seidensticker, Das römische Staatsrecht (wie Anm. 37), 177-198.

40 Th. Mommsen, Abriss des römischen Staatsrechts (Systematisches Handbuch der Deutschen Rechtswissenschaft 1. Abt. 3. Teil), Leipzig 1893, 21907, 195: „Wohl wird dieses Imperium gedacht als hervorgehend aus dem Volkswillen; aber es drückt sich dabei aus nicht in der geordneten Form der Comitien, sondern das Volk wird hier repräsentirt sei es durch das Heer oder einen beliebigen Heertheil, sei es durch den Gemeinderath. Hiermit wird also jede Auflehnung gegen den derzeitigen Inhaber der Gewalt insoweit legalisirt, dass für die Rechts- vielmehr die Machtfrage eintritt ... Legitim ist jeder, der zum Augustus ausgerufen wird, wenn er auch nur vorübergehend zum Besitz der Macht gelangt ...“; vgl. dazu Staatsrecht II (wie Anm. 37), 1144: „Daß verglichen mit dieser die Anomalie zur Norm erhebenden und die Besetzung des höchsten Amtes durch Gewalt und Unrecht geradezu heraufbeschwörenden Institution jede, auch die verkehrteste Fixierung der Regierungsfolge ein Segen für das Gemeinwesen sein würde, ist an sich klar".

41 Mommsen, Abriss (wie Anm. 40), 192. 
das spätrömische Reich „überhaupt keine feste das Regiment selber bindende Ordnung" gekannt habe. ${ }^{42}$ Dieser Übergang vom Principat hin zu einer absoluten Monarchie war nach Mommsen Ausdruck einer Orientalisierung des Kaisertums und spiegelte sich in der Entwicklung der Kaisertitulatur: „An dem terminologischen Übergang des princeps in den dominus läßt sich die innere Entwicklung der Mona rchie vom Oberamt zum Herrenthum mit größter Genauigkeit messen und verfolgen". ${ }^{43}$ Diese Definition des spätrömischen Kaisertums darf freilich nicht als Aussage über den Regierungsstil des spätrömischen Kaisers mißverstanden werden. Mommsen hob ausdrücklich hervor, daß die Selbstregierung des Kaisers in der Spätantike anders als im Prinzipat nicht mehr strukturell notwendig gewesen sei: „Das neue Ministerregiment schliesst die heimliche Mitregierung amtloser und unverantworticher Individuen wenigstens einigermassen aus und nachdem die Reichskanzlerschaft und weiter die Reichsfeldherrnschaft constituirt ist, sind die eigene Kriegführung, die eigene Rechtsprechung, die eigene Staatsleitung des Monarchen wohl zulässig, aber nicht mehr nothwendig". 44

Mommsens Epocheneinteilung war im deutschsprachigen Raum, aber keineswegs nur dort, ein langes Leben beschieden. Nicht etwa bloß der Mommsen-Schüler Otto Seeck, dessen „Geschichte des Untergangs der Alten Welt" $1895 \mathrm{zu}$ erscheinen begann, bediente sich ganz selbstverständlich dieser Periodisierung des römischen Kaisertums, auch wenn er Diocletians Reform als logische Konsequenz der früheren Zustände beurteilte. ${ }^{45}$ Auch der seit 1902 als Professor of Modern History an der Universität Cambridge lehrende britische Gräzist, Althistoriker und Byzantinist John B. Bury ${ }^{46}$ war Mommsens Kategorien zutiefst verpflichtet. Bury betonte zwar im Gefolge

42 Mommsen, Abriss (wie Anm. 40), 351.

43 Mommsen, Staatsrecht II ${ }^{3}$ (wie Anm. 37), 761.

44 Mommsen, Abriss (wie Anm. 40), 361.

45 O. Seeck, Geschichte des Untergangs der Alten Welt, 6 Bde., 1895ff., 21920-1922, Bd. 2, 8. Zu Otto Seeck (1850-1921) und seinem Hauptwerk vgl. H. Leppin, Ein „Spätling der Aufklärung“. Otto Seeck und der Untergang der antiken Welt, in: V. Losemann/P. Kneißl (Hgg), Imperium Romanum. Studien zu Geschichte und Rezeption. Festschrift für Karl Christ zum 75. Geburtstag, Stuttgart 1998, 472-491; S. Rebenich, Otto Seeck, Theodor Mommsen und die „Römische Geschichte“, ebd., 582-587 sowie dessen Einleitung zum Neudruck der „Geschichte des Untergangs“, Darmstadt 2000.

46 Zu Leben und Werk John Bagnell Burys (1861-1927) vgl. die eingehende Würdigung durch Norman H. Baynes, A Bibliography of the Works of J. B. Bury with a Memoir, Cambridge 1929, 1-124 sowie H. Temperley, The Historical Ideas of J. B. Bury, in: J.B. Bury, Selected Essays, Cambridge 1930, xv-xxxii; G. Huxley, The Historical Scholarship of John Bagnell Bury, GRBS 17, 1974, 81-104. 
Gibbons die Kontinuität staatlicher Entwicklung von Augustus bis zum Fall Konstantinopels im Jahre 1453;47 zugleich aber sprach er in seiner „History of the Later Roman Empire" (1923) davon, das römische Reich sei in den ersten Jahrhunderten nach Augustus „constitutionally a republic" gewesen, und erst von Diokletian und Konstantin endgültig in eine ,autocracy" umgewandelt worden, die keiner irdischen Instanz mehr Rechenschaft geschuldet habe (aber doch durch den Respekt vor Tradition und Brauch beschränkt gewesen sei). ${ }^{48}$ Und die seit 1923 erscheinende und 1939 abgeschlossene, renommierte "Cambridge Ancient History" endete mit dem Beginn der Alleinherrschaft Konstantins des Großen; das spätrömische Reich wurde der "Cambridge Medieval History" überla ssen. ${ }^{49}$

Besonders folgenschwer war, daß sich der bedeutendste Forscher, der in der ersten Hälfte des 20. Jahrhunderts auf dem Gebiet der antiken Sozialund Wirtschaftsgeschichte tätig war, der Exilrusse Michail I. Rostovtzeff, ${ }^{50}$ in

47 So bereits J. B. Bury, A History of the Later Roman Empire from Arcadius to Irene (395 A. D. to 800 A. D.), London 1889, Bd. 1, v-ix. Bury besorgte eine aktualisierte Neuauflage von Gibbons "History of the Decline and Fall of the Roman Empire“ (7 Bde., London 1896-1900, New and Revised edition, London 1909).

$48 \mathrm{~J}$. B. Bury, A History of the Later Roman Empire from the Death of Theodosius to the death of Justinian, Bd. 1, London 1923, 5: „The Roman Empire was founded by Augustus, but for three centuries after its foundation the State was constitutionally a republic. The government was shared between the emperor and the Senate; the emperor, whose constitutional position was expressed by the title Princeps, was limited by the rights of the senate ... The republican disguise fell away completely before the end of the third century. Aurelian adopted external fashions which marked a king, not a citizen; and Diocletian and Constantine definitely transformed the State from a republic to an autocracy. This change, accompanied by corresponding radical reforms, was, from a purely constitutional point of view, as great a break with the past as the change wrought by Augustus, and the transition was as smooth." Vgl. auch dens., The Constitution of the Later Roman Empire (The Creighton Lecture, University College, London, November 12, 1909), Cambridge 1910; auch in: ders., Selected Essays (wie Anm. 48), 99-125, hier: 121: "the action of the Roman autocrat was limited by a tradition and usage which were felt by him and by the community to be absolutely binding".

49 S. A. Cook u. a. (Hgg.), The Cambridge Ancient History, Vol. XII: The Imperial Crisis and Recovery, A.D. 193-324, Cambridge 1939; H. M. Gwatkin/J. P. Whitney u. a. (Hgg.), The Cambridge Medieval History, Vol. I: The Christian Roman Empire and the Foundation of the Teutonic Kingdoms, Cambridge 1911. Bury war an der Konzeption beider Werke beteiligt.

$50 \mathrm{Zu}$ Leben und Werk Michail Iwanowitsch Rostovtzeffs (1870-1952) vgl. neben dem aufschlußreichen Nekrolog von A. H. M. Jones, PBSA 38, 1952, 347-361 vor allem K. Christ, Von Gibbon zu Rostovtzeff. Leben und Werk führender Althistoriker der Neuzeit, Darmstadt 1972, 334-349; A. Momigliano, M. I. Rostovtzeff, The Cambridge Journal 7, 1954, 334-346 = ders., Contributo alla storia degli studi clas sici e del mondo antico, 
seiner aufsehenerregenden „Social and Economic History of the Roman Empire", die 1926 erschien und bald darauf auch ins Deutsche übersetzt wurde, der Auffassung Mommsens ausdrücklich anschloß, indem er der „aufgeklärten konstitutionellen Monarchie“ (enlightenend constitutional monarchy) der früheren Kaiserzeit die „orientalische Zwingherrschaft" (oriental despotism) der späteren Kaiserzeit gegenüberstellte: „Zum ersten Mal erhob sich jetzt das Kaisertum als ein festgefügter Bau auf starker Grundlage, aber es verlor fast gänzlich, abgesehen von ein paar belanglosen Formeln, die letzten Überreste seines konstitutionellen Charakters als oberster Magistratur des römischen Volkes" 51 Vom römischen Staat der Spätantike zeichnete Rostovtzeff mit düsteren Farben ein höchst eindringliches Bild. Sein hervorstechendstes Merkmal war demnach die systematische und organisierte Anwendung von Zwang und Gewalt, wenngleich der Begriff Zwangsstaat, für den es in den anderen gängigen Wissenschaftssprachen Europas kein Äquivalent gibt, bei Rostovtzeff nicht vorkommt (auch nicht in der deutschen Übersetzung seines Werkes). ${ }^{52}$

Der spätrömische Staat war für Rostovtzeff eine höchst effektive, zugleich aber korrupte Maschinerie zur Extraktion von Steuern, Abgaben und Dienstleistungen, die die städtische Selbstverwaltung beseitigt, die städtischen Eliten, Rostovtzeffs „,bourgeoisie“, finanziell ruiniert und überhaupt jede private Initiative im Keim erstickt habe: „Über den Trümmern eines blühenden, wohlorganisierten Staatswesens, das die uralte klassische Kultur und die Selbstverwaltung der Städte zur Grundlage hatte" erhob sich nach Rostovtzeff in der Spätantike ein Staat, „der sich auf allgemeiner Unwissenheit, auf Zwang und Gewalt, auf Versklavung und Knechtssinn, auf Bestech-

Rom 1955, 341 -354; M. A. Wes, Michael Rostovtzeff, Historian in Exile. Russian Roots in an American Context (Historia. Einzelschriften 65), Stuttgart 1990; A. Marcone (Hg.), Rostovtzeff e I'Italia, Neapel 1999. Zur Kritik seiner Deutungskategorien bleibt grundlegend: M. Reinhold, Historian of the Classic World: A Critique of Rostovtzeff, Science \& Society 10, 1946, 361-391 = ders., Studies in Classical History and Society, New York 2002, 82-100 + 132-137.

51 Rostovtzeffs Werk erschien 1926 in englischer Sprache (The Social and Economic History of the Roman Empire, 2 Bde., Oxford 1926, 21957) und 1929 in deutscher Übersetzung, für die Lothar Wickert verantwortlich zeichnete: Wirtschaft und Gesellschaft im Römischen Kaiserreich, 2 Bde., Leipzig 1929. Das Zitat steht in der de utschen Übersetzung Bd. 2, 217.

52 Allerdings kommt die deutsche Übersetzung dem Begxiff an einer Stelle recht nahe, wenn es heißt: „Im Sinne Diokletians war der Staat eine Zwangsanstalt, und Organisation bedeutete organisierte Gewal ttätigkeit“ (II 229). Diese begriffliche Verdichtung fehlt jedoch im englischen Original: "In the mind of Diocletian the state meant compulsion" (II 522). Vgl, auch Heuß, GWU 1986 (wie Anm. 17), 608-610. 
lichkeit und Unehrenhaftigkeit aufbaute“. Dieser Staat war für ihn ein „Sklavenstaat", das römische Reich der Spätantike ein ,riesiges Gefängnis für Millionen von Menschen". ${ }^{33}$ Der Gegensatz zur früheren Kaiserzeit, in welcher das wohltätige Regiment aufgeklärter Kaiser eine hohe Blüte städtischer Kultur ermöglicht habe, war in diesen hyberbolischen Formulierungen auf die Spitze getrieben. Dieses rhetorische Pathos wirkt heute unangemessen, war aber damals nicht unüblich ${ }^{54}$ und hat dem Werk darum auch keineswegs geschadet, im Gegenteil: Weil Rostovtzeff nicht wie Mommsen auf abstrakte Prinzipien rechtlicher Art abhob, sondern ein Gesamtbild der sozioökonom ischen Verhältnisse zeichnete, wurde sein Werk vielfach als zeitgemäße Überwindung einer rein staatsrechtlichen Betrachtungsweise begrüßt. ${ }^{55}$

Allerdings gab es in den 1920er und 1930er Jahren auch gewichtige Stimmen, die sich gegen eine scharfe Trennung von „Prinzipat" und „Dominat" aussprachen. So vertrat schon 1928 Ernst Stein, damals Privatdozent der Alten Geschichte an der Universität Berlin, ${ }^{56}$ in seiner „Geschichte des spätrömischen Reiches“ die Auffassung, die byzantinische Geschichte sei die organische Fortsetzung der römischen, und schlug vor, den römischen Staat der Spätantike nicht als „Dominat“, sondern als „Präfekturenverfassung“ zu

53 Rostovtzeff, Kaiserreich II (wie Anm. 51), 237-238.

54 Der für seine Sachlichkeit geschätzte Ernst Hohl wurde ähnlich pathetisch, wenn es darum ging, den spätrömischen Staat zu charakterisieren: Goetz, Propyläen-Weltgeschichte (wie Anm. 38), 436. Hohl hatte zuvor eine enthusiastische Rezension von Rostovtzeffs Werk verfaßt: DLZ 48, 1927, 1209-1213; vgl. DLZ 53, 1932, 179-180 (zur deutschen Übersetzung).

55 Als ein Beispiel unter vielen sei hier Alfred Heuß genannt, dessen Bild der Spätantike Rostovtzeff stark verpflichtet ist, bis in einzelne Formulierungen hinein: $A$. Heuß, Römische Geschichte, Braunschweig 1960, 41976, 434ff.; vgl. auch 528: „Rostovtzeffs Schilderung ist vorläufig und wahrscheinlich auf lange Zeit hinaus der Ersatz für die erstrebte und ersehnte Geschichte der römischen Kaiserzeit“; ähnlich 547.

56 Das schicksalsschwere Leben und die von großen inneren Spannungen geprägte Persönlichkeit Ernst Steins (1891-1945) hat bei G. Fellner, Ludo Moritz Hartmann und die österreichische Geschichtswissenschaft. Grundzüge eines paradigmatischen Konflikts, Wien - Salzburg 1985, 289-297 eine einfühlsame Darstellung gefunden, die erstmals auch unpubliziertes Material berücksichtigt. Zeitgenössische Urteile über ihn und sein Werk finden sich bei J.-R. Palanque, La vie et l'oeuvre d'Ernest Stein, in: E. Stein, Histoire du Bas-Empire, Tome II: De la disparition de l'empire d'Occident à la mort de Justinien, Paris-Brüssel-Amsterdam 1949, VII-XXII (mit Bibliographie) und H.-I. Marrou, Le BasEmpire vue par un héritier de Mommsen, JS 1964, 47-58 sowie in den Rezensionen des ersten Bandes seines Hauptwerkes durch N. H. Baynes, JRS 18, 1928, 217-227, E. Hohl, HZ 139, 1929, 580-582 und W. Ensslin, Gnomon 6, 1930, 496-505 und des zweiten durch A. Piganiol, JS 1950, 159-167 (= ders., Scripta varia, Bd. 3: L'Empire [Collection Latomus 133], Brüssel 1973, 377-384) und A. H. M. Jones, Historia 2, 1953/4, 352-359. 
bezeichnen. ${ }^{57}$ Stein wandte gegen Mommsen ein, daß zum einen das Prinzip der Volkssouveränität bis zum Ende des Byzantinischen Reiches Bestand gehabt habe und zum anderen die Machtfülle eines Hadrian oder Septimius Severus weder de facto noch de jure geringer gewesen sei als diejenige byzantinischer Kaiser. Auch die erbliche Bindung der Untertanen an ihren Beruf, insbesondere die der bäuerlichen Kleinpächter an ihre Scholle, sei durch die Gesetzgebung spätrömischer Kaiser lediglich juristisch festgeschrieben worden, habe aber faktisch vielfach bereits im 2. und 3. Jahrhundert bestanden. Die politische Leistung der Kaiser des 4. Jahrhunderts sah Stein „nicht so seht in der Schöpfung von neuem als in der großartigen Ordnung von regellos entstandenem Alten zu einem System ... Dieses Systematische und Uniforme, das freilich nicht mit Starrheit verwechselt werden darf, da an dem durchgebildeten Sytem im einzelnen fortwährend Änderungen vorgenommen wurden, unterscheidet am deutlichsten den byzantinischen Staat von dem des späteren Prinzipats". 58

Während der deutsche Liberale Mommsen im spätrömischen Staat Willkür und Despotie verkörpert sah, brachte Stein, der in Wien Schüler des von der Zunft geächteten Sozialdemokraten Ludo Moritz Hartmann geworden war und zeitweilig selbst der (österreichischen) Sozialdemokratie angehörte, 59 beträchtliche Sympathien für ihn auf, ja er schrieb der von Diokletian geschaffenen Staatsordnung sogar einen „demokratischen Charakter" zu, insofern sie den Senat entmachtet und einen mächtigen bürokratischen Apparat ausgebildet habe, „der nicht am wenigsten Werkzeug gegen aristokratische Tendenzen sein sollte, es im Osten auch dauernd gewesen ist und sich größ-

57 E. Stein, Geschichte des spätrömischen Reiches, Bd. 1: Vom spätrömischen zum byzantinischen Staat, Wien 1928, 178ff; vgl. dens., Untersuchungen zur spätrömischen Verwaltungsgeschichte, RhM 74, 1925, 347-394, hier: 379; auch in: ders., Opera minora selecta, Amsterdam 1968, 145-193, hier: 177: „...Präfekturenverfassung - so und nicht mit dem ganz schiefen Ausdruck, Dominat' ist die zwischen Prinzipat und Logothesien- und Themenverfassung liegende Phase innenpolitischer Entwicklung zu bezeichnen...“.

58 Stein, Geschichte I (wie Anm. 57), 1-2.

59 Für Leben und Werk Ludo Moritz Hartmanns (1865-1924) grundlegend ist die umfassende, auf archivalischen Quellen fußende Darstellung durch Fellner, Ludo Moritz Hartmann (wie Anm. 56); vgl. daneben auch W. Filla u. a. (Hgg.), Ludo Moritz Hartmannn. Der Wissenschaftler, Politiker und Volksbildner, Wien 1992; V. Herholt, Ludo Moritz Hartmann: Alte Geschichte zwischen Darwin, Marx und Mommsen, Berlin 1999. Für das enge Verhältnis, das Stein mit Hartmann verband, ist der Nekrolog aufschlußreich, den er seinem Lehrer gewidmet hat: VSWG 18, 1925, 312-332. Stein scheint die Sozialdemokratische Partei Österreichs nach der Mitte der 1920er Jahre verlassen zu haben und konvertierte 1932 zum katholischen Glauben. 
tenteils aus Niedriggeborenen zusammengesetzt hat". ${ }^{60}$ Denn für Stein fiel der bürokratisch organisierten Verwaltung des spätrömischen Reiches die Aufgabe zu, die „Staatsinteressen“ gegen die „Klasseninteressen“ der Senatsaristokratie durchzusetzen: „Das weströmische Reich ist daran zugrunde gegangen, daß es unter die Botmäßigkeit eines großgrundherrlichen Adels geraten war, der sich selbst gab, was des Staates war, so daß diesem die Machtmittel fehlten, deren er zum erfolgreichen Widerstand gegen den Ansturm der Germanen bedurft hätte ... In den Kernländern der partes Orientis aber hat es keinen solchen Adel gegeben; die Verwaltung wurde daher hier nicht zum Werkzeug einer bureaukratisch maskierten Standesherrschaft, sondern blieb die Hüterin der Staatsinteressen, und das ermöglichte die Rettung des oströmischen Reiches" ${ }^{\circ 1}$

Während Stein sein Augenmerk vor allem auf den Verwaltungsaufbau des spätrömischen Staates richtete und die von Augustus begründete Monarchie noch ganz im Sinne Mommsens als Magistratur auffaßte, ${ }^{62}$ wandte sich Mitte der 1930er Jahre Andreas Alföldi, damals Professor an der Universität Budapest, ${ }^{63}$ mit Verve gegen Mommsens Auffassung, die formelle Ausgestaltung des Kaisertums in der Spätantike sei dem Prinzipat wesensfremd und müsse daher aus dem Orient hergeleitet werden. In bis heute grundlegenden Studien zur „Monarchischen Repräsentation im römischen Kaiserreich“" wies er nach, daß die Überhöhung des Kaisers durch Ornat, Insignien und Zeremoniell und seine Erhebung in eine sakrale Sphäre keineswegs erst im 3. Jahrhundert einsetzte, sondern sich in einem langen Prozeß entwickelt hat,

60 Stein, Geschichte I (wie Anm. 57), 101; vgl. 342: „Die hohen Zivilämter der östlichen Reichshälfte ... werden seit der Mitte des V. Jahrhunderts nur noch äußerst selten von Personen vornehmer Herkunft bekleidet, vielmehr fast ausschließlich an Beamte vergeben, die sich in der subalternen Carrière ... ausgezeichnet haben; im untergehenden Westen dagegen sind die entsprechenden Ämter so gut wie völlig den italienischen und gallischen Großgrundbesitzerfamilien überantwortet, unter deren Mitgliedern sie von Hand zu Hand gehen. Während daher im Osten der bureaukratische Apparat bei aller Korruption doch wesentlich dem Staatsinteresse dienstbar blieb, konnten die Kaiser des Westens nicht verhindern, daß er hier je länger je mehr zum Werkzeug der Aristokratie herabsank, deren Klassenegoismus den Staat rücksichtslos ausbeutete"; 503-505 (vergeblicher Kampf Valentinians III. gegen die Senatsaristokratie); 511 (im Weströmischen Reich habe die einseitige Besteuerung der wirtschaftlich Schwachen ,im Interesse der herrschenden Klasse" diese und mit ihnen den Staat zugrunde gerichtet).

61 E. Stein, Untersuchungen über das Officium der Prätorianerpräfektur seit Diokletian, Wien 1922, ND Amsterdam 1962, $72 \mathrm{f}$.

62 Stein, Geschichte I (wie Anm. 57), 46ff.

63 Zu Leben und Werk Andreas Alföldis (1895-1981) vgl. K. Christ, Neue Profile der Alten Geschichte, Darmstadt 1990, 8-62. 
der bereits mit Caesar beginnt. ${ }^{64}$ Alföldi deutete diesen Prozeß als Widerstreit zweier Prinzipien, die seit Beginn der Monarchie in Rom miteinander im Widerstreit gelegen hätten: einerseits die altrömisch-republikanische Tradition, andererseits der theokratische Absolutismus. In der Spätantike habe jedoch die emotionell-religiöse Grundlegung des Kaisertums endgültig den Sieg über die juristische davongetragen.

Für diese Entwicklung machte Alföldi „die Erbsünde einer jeden Bürokratie, den übertreibenden Kult der Formeln", vor allem aber eine kulturelle Regression verantwortlich: „Augustus konnte sich noch auf kulturell hochstehende Gesellschaftsschichten stützen, denen er mit seiner einfachen Kleidung und Wohneinrichtung eine Achtung einzuflößen vermochte. Die Herrscher der Spätzeit mußten jedoch einer primitiven Menge imponieren und die Effekte ihrer Repräsentation auf deren Geschmack zuschneiden". $65 \mathrm{Al}$ földi verwendete freilich die Begriffe Prinzipat und Dominat, deren Begründung er doch selbst untergraben hatte, unbekümmert weiter und faßte den römischen Staat der Spätantike als zentralisierten Beamtenstaat auf, in welchem dem Kaiser die politische Initiative zunehmend entglitten sei: „Aus der höchstgesteigerten Aktivität der Prinzipes der Frühzeit sinkt er stufenweise in die volle Passivität zurück, bis die praefecti praetorio die Zivilverwaltung und die magistri militum die Heeresleitung sich aneignen und die letzteren als Vizekaiser im Westen die Institution selbst ersticken". .66

Stimmen wie diese blieben zunächst isoliert. Der Meinungsumschwung setzte in Deutschland erst nach dem Ende der nationalsozialistischen Gewaltherrschaft ein. Sein Ausgangspunkt war die Absage an die Prinzipatsidee als politisches Leitbild, ${ }^{67}$ die bei dem seit 1931 an der Universität Berlin leh-

64 A. Alföldi, Die Ausgestaltung des monarchischen Zeremoniells am römischen Kaiserhofe, MDAI (R) 49, 1934, 1-156; ders., Insignien und Tracht der römischen Kaiser, MDAI (R) 50, 1935, 1-171; gesammelt unter dem Titel: Die monarchische Repräsentation im römischen Kaiserreiche, Darmstadt 1970. Wichtige Ergänzungen, Differenzierungen und auch Korrekturen dazu jetzt bei F. Kolb, Herrscherideologie in der Spätantike, Berlin 2001.

65 Alföldi, MDAI (R) 50, 1935 (wie Anm. 64), 156 (= 274); vgl. auch 157 (= 274): „Man kann sich über die eiserne Konsequenz nicht genug wundern, mit der das Staatsgebäude des Dominates durchgeführt wurde. Und doch entstand es durch einen harten Zwang aus der Not der Zeit, bei dem Zurücksinken von der alten Kulturhöhe auf eine weit primitivere Stufe".

66 Alföldi, MDAI (R) 50, 1935 (wie Anm. 64), 155 (= 273).

67 Dazu grundlegend I. Stahlmann, Imperator Caesar Augustus. Studien zur Geschichte des Prinzipatsverständnisses in der deutschen Altertumswissenschaft bis 1945, Darmstadt 1988. 
renden, Adolf Hitler begeistert dienenden Althistoriker Wilhelm Weber ${ }^{68}$ zu einer jeder Vernunft spottenden Verherrlichung angeblich übermenschlichen Führertums herabgesunken war. Man wollte nun keinen Führer mehr und begann, die propagandistische Legitimierung monarchischer Herrschaft mit Mißtrauen zu betrachten. Hier ist vor allem der Kölner Althistoriker Lothar Wickert ${ }^{69} \mathrm{zu}$ nennen, der nach 1945 in bewußter Wendung gegen die staatsrechtliche Betrachtungsweise Mommsens mit Nachdruck die Auffassung vertrat, die republikanischen Formen des augusteischen Prinzipats seien als bloße ideologische Verbrämung einer in Wahrheit absoluten Herrschaft zu betrachten, ${ }^{70}$ und von daher dazu gelangte, in seinem großen RE-Artikel „Princeps" (1954) die Periodisierung der römischen Kaiserzeit in Prinzipat und Dominat als sachlich unangemessen zu verwerfen. ${ }^{71}$

Dennoch fand Mommsens Position bis in die 1960er Jahre hinein die Unterstützung einflußreicher Fachvertreter. So erklärte noch 1963 der an der Universität Belgrad lehrende Byzantinist Georg Ostrogorsky ${ }^{72}$ im „Handbuch der Byzantinischen Geschichte", der römische Prinzipat sei in der Krise des 3. Jahrhunderts untergegangen und durch den Dominat Diokletians abgelöst worden und formulierte ganz im Sinne Mommsens: „Das römische Magistratswesen räumt der byzantinischen Bürokratie das Feld. Das Kaisertum ist nicht mehr die oberste Magistratur, sondern eine despotische Gewalt ${ }^{\text {c }}{ }^{73}$ Und auch der Zürcher Althistoriker Ernst Meyer ${ }^{74}$ machte sich die

68 Zu Leben und Werk Wilhelm Webers (1882-1948) vgl. neben der Darstellung bei Christ, Deutsche Geschichtswissenschaft (wie Anm. 36), 210ff. vor allem Stahlmann, Imperator Caesar Augustus (wie Anm. 67), 155-184. Webers „Princeps“ erschien 1936 in Berlin, war aber im Manuskript bereits 1930 abgeschlossen.

$69 \mathrm{Zu}$ Leben und Werk Lothar Wickerts (1900-1989) vgl. neben dem Nachruf von H. Kloft, Gnomon 62, 1990, 475-478 vor allem die Abhandlung von I. Stahlmann, Von der Ideengeschichte zur Ideologiekritik. Lothar Wickerts Beitrag zum Verständnis des Augusteischen Principats (AAWM 1991, Nr. 9), Stuttgart 1991.

70 Der ideologiekritische Ansatz findet sich bei Wickert zuerst in dem 1947 veröffentlichten Aufsatz „Horaz und Augustus“, WJb 2, 1947, 158-172.

71 L. Wickert, Princeps, RE XXII, 1954, 1998-2296, hier: 2134 f.

72 Eine angemessene Würdigung des in St. Petersburg geborenen Byzantinisten Georg Ostrogorsky (1902-1976) liegt $\mathrm{m}$. W. bislang nicht vor; vgl. einstweilen den Nachruf von H. Hunger, Almanach der Österreichischen Akademie der Wissenschaften zu Wien 127, 1977, 539-544.

73 G. Ostrogorsky, Geschichte des byzantinischen Staates (Handbuch der Altertumswissenschaft XII 1, 2), München 1940, 31963, $24 \mathrm{f}$.

$74 \mathrm{Zu}$ Leben und Werk Ernst Meyers (1898-1975) vgl. K. Christ, Ernst Meyer (1898-1975), in: ders., Römische Geschichte und Wissenschaftsgeschichte, Bd. 3: Wissenschaftsgeschichte, Darmstadt 1983, 137-150. 
Unterscheidung zwischen Prinzipat und Dominat im Sinne Mommsens in seiner 1968 erschienenen, mehrfach neu aufgelegten „Einführung in die antike Staatskunde " uneingeschränkt zu eigen und bestritt folgerichtig jede Kontinuität zwischen dem römischen Staat der „Principatszeit“ und dem der Spätantike. ${ }^{75}$

Inzwischen haben sich die Zeiten gründlich gewandelt. Die Erforschung der Spätantike hat in den letzten 30 Jahren einen gewaltigen Aufschwung genommen, ${ }^{76}$ und Althistoriker in aller Welt betrachten diese Epoche ganz selbstverständlich als Teil des Gegenstandsbereiches ihrer eigenen Wissenschaft. ${ }^{77}$ Das kommt schon rein äußerlich darin zum Ausdruck, daß die vor kurzem abgeschlossene zweite Auflage der "Cambridge Ancient History" eben nicht mehr mit dem Jahr 324 endet, sondern der Spätantike zwei voluminöse Bände reserviert. ${ }^{78}$ Mommsens Periodisierung kann heute als über-

75 E. Meyer, Einführung in die antike Staatskunde, Darmstadt 1968, 31975, 262f.: „Tatsächlich aber hatte dieser spätrömische Staat trotz allen Anspruchs, die ungebrochene Tradition zu bewahren, mit dem alten Rom kaum noch etwas zu tun. Er ruhte auf völlig neuen Grundlagen und vom eigentlichen Wesen des alten Rom war nichts mehr übrig. An die Stelle der geschichtlich gewachsenen und immer noch bewahrten Vielfalt der Verhältnisse in den Reichsteilen war die Gleichförmigkeit eines von oben bis unten gleichmäßig organisierten und verwalteten Staates unter der Herrschaft des Kaisers als des absoluten Herrn dieses Staates getreten ... Von irgendwelcher echter Selbstverwaltung, der Anteilnahme einer freien Bürgerschaft an den Staatsgeschäften, war nichts mehr übrig, alles wurde vom Kaiser und seiner Bürokratie regiert, alle Reichseinwohner ... waren Untertanen. Von einer res publica, die auch das römische Kaiserreich der Principatszeit trotz aller kaiserlichen Macht noch mit Recht zu sein behaupten durfte, konnte keine Rede mehr sein“; vgl. auch 282f.

76 Zur Entstehung des Konzepts „Spätantike“ zur Bezeichnung einer eigenständigen geschichtlichen Epoche vgl. neben R. Herzog, Einführung in die lateinische Literatur der Spätantike, in: ders./P. L. Schmidt (Hgg.), Handbuch der lateinischen Literatur der Antike, Bd. 5: Restauration und Erneuerung. Die lateinische Literatur von 284 bis $374 \mathrm{n}$. Chr. (Handbuch der Altertumswissenschaften VIII 5), München 1989, 1-44 jetzt auch die Bemerkungen von (J. H.) W. (G.) Liebeschuetz, The Birth of Late Antiquity, AnTard 12, 2004, 253-261; zu seinen Vor- und Nachteilen dens., Late Antiquity and the Concept of Decline, NHM 45, 2001, 1-11.

77 Eine repräsentative Zusammenfassung der angelsächsischen Forschung der letzten 30 Jahre enthält der von Glen W. Bowersock, Peter Brown und Oleg Grabar herausgegebene Band „Late Antiquity. A Guide to the Post-Classical World“ (Cambridge, Mass. London 1999). Im frankophonen Bereich hat der Patristiker Henri Irénée Marrou (1904 1977) eine maßgebliche Rolle bei der Durchsetzung des Konzepts gespielt; vgl. dazu jetzt die ausführliche biographische Darstellung bei P. Riché, Henri Irénée Marrou, historien engagée, Paris 2003.

78 R. C. Blockley u. a. (Hgg.), The Cambridge Ancient History. Second Edition, Vol. XIII: The Late Empire A.D. 337-425, Cambridge 1997; Averil Cameron u. a. (Hgg.), The 
holt gelten, insofern die Ansicht, der römische Kaiser sei in den ersten beiden Jahrhunderten lediglich der oberste Magistrat des römischen Volkes gewesen, aus der wissenschaftlichen Diskussion so gut wie völlig verschwunden ist. ${ }^{79}$ Der Versuch, durch die Abstraktion rechtlicher Prinzipien das Wesen des römischen Staates zu bestimmen, gilt mittlerweile fast allgemein als Ausdruck eines überholten Wissenschaftsverständnisses. Als Jochen Bleicken sich 1978 der Mühe unterzog, das Begriffspaar Prinzipat vs. Dominat einer grundsätzlichen Kritik zu unterziehen, rannte er bereits offene Türen ein. ${ }^{80}$

Bleicken zeigte auf, daß sich zwischen der früheren und der späteren Kaiserzeit keine grundsätzliche Veränderung der Herrschaftsauffassung vollzog. Der Gedanke, der Kaiser übe seine Herrschaft als princeps im Rahmen der traditionellen Rechtsordnung aus, hat für das römische Kaisertum zwar durchaus eine Rolle gespielt; seine Wirksamkeit beschränkte sich jedoch auf das Verhältnis des Kaisers zum Senat und verlor auch in diesem Rahmen nach dem Ende der julisch-claudischen Dynastie rasch an Bedeutung. Im Verhältnis des Kaisers zu anderen Bevölkerungsgruppen, vor allem zur Armee und zu den Provinzialen, waren von Anfang an andere Konzepte von Herrschaft bestimmend - der dynastische Gedanke und die sakrale Überhöhung der kaiserlichen Person -, die schon im Laufe des 2. Jahrhunderts die Oberhand gewinnen. Zwar kam die formelle Ausgestaltung und sakrale Überhöhung des Kaisertums im späten 3. Jahrhundert zu einem gewissen Abschluß, doch waren alle ihre Elemente in Ansätzen bereits früher vorhanden. Die Anrede als dominus etwa setzte sich schon früh durch und war in der Regel auch nicht negativ konnotiert. Umgekehrt haben auch die Kaiser der Spätantike wiederholt betont, daß sie sich an die Gesetze gebunden fühlten, also keineswegs beansprucht, willkürlich über das Recht verfügen zu können. 81

Bleicken hat sich ausdrücklich gegen den Einwand verwahrt, er spreche jedem Versuch, die Geschichte der römischen Kaiserzeit zu periodisieren, von vornherein die Legitimität ab. Ihm ging es um den Nachweis, daß die Entwicklung des Kaisertums kein Kriterium für eine adäquate Periodisierung

Cambridge Ancient History. Second Edition, Vol. XIV: Late Antiquity: Empire and Successors, A.D. 425-600, Cambridge 2000.

79 Vgl. etwa Demandt, Spätantike (wie Anm. 23), 212f.; 229 f.

80 J. Bleicken, Prinzipat und Dominat. Gedanken zur Periodisierung der römischen Kaiserzeit (Frankfurter Historische Vorträge. Heft 6), Wiesbaden 1978; auch in: ders., Gesammelte Schriften, Bd. 2, Stuttgart 1998, 817-842.

81 Vgl. dazu etwa J. Karayannopoulos, Der frühbyzantinische Kaiser, ByzZ 49, 1956, 369 384; auch in: H. Hunger (Hg.), Das byzantinische Herrscherbild (Wege der Forschung 341), Darmstadt 1975, 235-257. 
der römischen Kaiserzeit liefern könne. Auch hier soll keineswegs der Auffassung das Wort geredet werden, die Entwicklung des römischen Staates zwischen Augustus bis Justinian gleiche einer Linie, die keinerlei Zäsuren aufweise. ${ }^{82}$ Der Verzicht auf die Epochenbegriffe Prinzipat und Dominat erlaubt es jedoch, die Entwicklung des römischen Sta ates unbeeinflußt von starren Epocheneinteilungen zu betrachten. ${ }^{83}$ Zugleich enthält er die Aufforderung, den Formwandel römischer Staatlichkeit nicht an einem isolierten Kriterium festzumachen, sondern in allen seinen verschiedenen Manifestationen zu untersuchen, um Kontinuitäten und Diskontinuitäten genauer beschreiben zu können.

Dabei rückt beim gegenwärtigen Forschungsstand unvermeidlich die Frage in den Vordergrund, ob sich Form und Intensität staatlicher Regulierung zwischen früherer Kaiserzeit und Spätantike tatsächlich grundlegend gewandelt hat. Ein wesentlicher Aspekt dieser Frage ist diejenige nach der Ausbildung bürokratischer Strukturen. Wann entstanden sie und wie wirkten sie sich auf die Beziehungen zwischen Regierenden und Regierten aus? Hier

82 In der Alten und Mittelalterlichen Geschichte ist das Periodisierungsproblem vor allem in der Diskussion über den Übergang vom Altertum zum Mittelalter virulent geworden; vgl. dazu die Sammelbände von P. E. Hübinger ( $\mathrm{Hg}$.), Zur Frage der Periodengrenze zwischen Altertum und Mittelalter (Wege der Forschung 51), Darmstadt 1969; ders. (Hg.), Kultu rbruch oder Kulturkontinuität im Übergang von der Antike zum Mittelalter (Wege der Forschung 201), Darmstadt 1968. Zur Definition von „Spätantike“ aus literaturwissenschaftlicher Sicht Herzog, Einführung (wie Anm. 76), 1-44. Die theoretischen Dimensionen und Probleme der Periodisierung und Epochengliederung beleuchtet am Beispiel des Epochenbegriffs „Neuzeit" F. Jaeger, Neuzeit als kulturelles Sinnkonzept, in: ders./B. Liebsch (Hgg.), Handbuch der Kulturwissenschaften, Bd. 1: Grundlagen und Schlüsselbegriffe, Stuttgart - Weimar 2004, 506-531; zur Abgrenzung und Binnengliederung der Neuzeit vgl. auch S. Skalweit, Der Beginn der Neuzeit. Epochengrenze und Epochenbegriff, Darmstadt 1982. Epochenübergreifend sind dagegen die Sammelbände von R. Herzog/R. Koselleck (Hgg.), Epochenschwelle und Epochenbewußtsein (Poetik und Hermeneutik 12), München 1987 (darin besonders R. Herzog, Epochenerlebnis ,Revolution" und Epochenbewußtsein, Spätantike` - zur Genese einer historischen Epoche bei Chateaubriand, 195-220) und J. Kunisch ( $\mathrm{Hg}$.), Spätzeit. Studien zu den Problemen eines historischen Epochenbegriffs (Historische Forschungen 42), Berlin 1990 (darin besonders A. Heuß, Antike und Spätantike, 27-90) angelegt. Einen knappen Überblick über die in den altertumswissenschaftlichen Disziplinen Alte Geschichte, Klassische Archäologie und Klassische Philologie geläufigen Epochenbegriffe vermittelt der dem Stichwort „Periodisierung" gewidmete Artikel von A. Demandt, B. Bäbler und P. Kuhlmann in: DNP 13, 1999, 996-1015.

$83 \mathrm{Daß}$ Zusammenhänge, die sonst häufig übersehen werden, deutlich hervortreten, wenn man die Spätantike nicht von der hohen Kaiserzeit trennt, demonstriert jetzt D. S. Potter, The Roman Empire at Bay, AD 180-395, London - New York 2004. 
ist einiges in Bewegung geraten, und ein neuer Konsens zeichnet sich noch nicht ab: Während etwa Peter Eich die En tstehung bürokratischer Strukturen ins 3. Jahrhundert datiert und damit eine über die traditionelle Epochengrenze hinausreichende Kontinuitätslinie zieht, ${ }^{84}$ geht Christopher Kelly in seiner Monographie „Ruling the Later Roman Empire“ (2004) ${ }^{85}$ erneut von einem schematisch gezeichneten Gegensatz zwischen hoher Kaiserzeit und Spätantike aus. Es wird zu überprüfen sein, ob das von ihm eindrucksvoll herausgearbeitete strukturelle Dilemma, vor das die Existenz einer zentralisierten Bürokratie den spätrömischen Kaiser stellte - einerseits Aufgaben delegieren und sich den formalisierten Regeln bürokratischer Herrschaftsausübung unterwerfen zu müssen, andererseits Bürokraten und Untertanen seine Allmacht spüren zu lassen - tatsächlich erst mit den Reformen Diokletians und Konstantins entstand.

III.

Auch wenn die in diesem Band versammelten Beiträge sich nicht zu einer systematischen Analyse des Problemfeldes „Staatlichkeit und politisches Handeln im römischen Kaiserreich" summieren, können sie doch allesamt als Versuche gelesen werden, das Verhältnis von intentionalem Handeln und politischen Strukturen im Römischen Kaiserreich an konkreten Beispielen zu erhellen. Dabei steht in der Mehrzahl der Beiträge die Rolle des Kaisers im Zentrum, doch wird sie aus unterschiedlichen Blickwinkeln betrachtet: Während es in einigen Beiträgen stärker darum geht, konkrete Handlungsspielräume einzelner Kaiser, etwa Hadrians, des Clodius Albinus, Anthemius' oder Justinians, auszuloten, legen andere den Schwerpunkt auf die Frage, ob sich in bestimmten Bereichen kaiserlicher Tätigkeit, etwa dem der Städte, konstante Handlungsmuster beobachten lassen. Und natürlich geht es implizit oder explizit auch immer wieder um die Frage, ob, in welchem Umfang und in welcher Weise politisches Handeln strukturbildend wirkte. Unvermeidlich fällt der Blick dabei auch auf die Provinzstatthalter einerseits und auf die lokalen Gewalten andererseits, die in die kaiserliche Verwaltung eingebunden waren. Dieser Aspekt spielt in der modernen Debatte über den Formwandel römischer Staatlichkeit eine erhebliche Rolle, da in der Regel davon ausgegangen wird, daß sich diese lokalen Gewalten in der frühen und

84 Eich, Metamorphose (wie Anm. 11).

85 C. Kelly, Ruling the Later Roman Empire, Cambridge, Mass. - London 2004, bes. 186231. Vgl. dazu meine Besprechung in der „Byzantinischen Zeitschrift" (im Druck). 
hohen Kaiserzeit eines weit größeren Handlungsspielraumes erfreuten als in der Spätantike.

Die ersten fünf Beiträge sind der früheren Kaiserzeit gewidmet. Kostas Buraselis setzt sich unter der programmatischen Überschrift „Zum hadrianischen Regierungsstil im griechischen Osten oder vom kaiserlichen Agieren und Reagieren" explizit und direkt mit Fergus Millars Modell auseinander, indem er vier konkrete Maßnahmen Kaiser Hadrians auf ihre Genese und Intentionalität hin untersucht: Maßnahmen zur Entwässerung des KopaïsBeckens, Eingriffe in die Wirtschaft Athens, die Gründung der Stadt Antinoopolis in Ägypten und die Stiftung des Panhellenion. Buraselis kommt zu dem Ergebnis, daß das Modell von „petition-and-response“ in keinem dieser vier Fälle geeignet ist, das kaiserliche Handeln adäquat zu beschreiben: So lassen sich die von Hadrian angeordneten Maßnahmen zur Entwässerung des Kopaïs-Beckens keineswegs als bloße Umsetzung einer Initiative verstehen, die von einer einzigen Stadt an ihn herangetragen wurde, sondern zeugen vielmehr davon, daß der Kaiser über ein Konzept verfügte, das die Interessen aller Anrainer berücksichtigte. Auch Hadrians Regulierung des Fischverkaufs in Eleusis bildete nach Buraselis bloß einen Teil eines umfassenderen Pakets von Maßnahmen, die der Sanierung des Handelslebens Athens dienten. Denn das sogenannte Ölgesetz, mit dem Hadrian die Produktion und den Export attischen Öls der Kontrolle städtischer Behörden unterstellte, sei von Hadrian eben deswegen erlassen worden, weil die Stadt selbst nicht in der Lage gewesen sei, ein Gesetz zu verabschieden, das gegen die Interessen eines wirtschaftlich potenten Teils der Bürgerschaft verstieß; folglich könne das Ölgesetz nicht als mechanische Reaktion auf eine städtische Initiative gedeutet werden, auch wenn der Kaiser möglicherweise durch einzelne Magistrate Athens auf das Problem der schlechten Versorgung mit preiswertem und qualitativ hochwertigem Olivenöl aufmerksam gemacht wurde. Ganz eindeutig um eine kaiserliche Initiative handelt es sich drittens bei der Gründung von Antinoopolis, dessen rechtliche Privilegierung in keiner Weise als Umsetzung lokaler Wünsche und Bestrebungen gedeutet werden kann. Die Verfassung dieser Stadt wurde offenkundig nach Vorstellungen Hadrians gestaltet. In der Frage schließlich, ob die Gründung der auf den Namen Panbellenion getauften kulturell-religiösen Vereinigung griechischer Städte auf einen Plan zurückgeht, der von Vertretern dieser Städte gefaßt und von Hadrian lediglich umgesetzt wurde, oder ob der Kaiser nicht vielmehr die treibende Kraft hinter diesem Projekt war, argumentiert Buraselis auf der Grundlage einer neuen Inschrift, in der die Initiative zu diesem Projekt eindeutig Hadrian zugeschrieben wird, für die Annahme, daß Hadrian das Panbellenion ins Leben rief, weil er damit den Zusammenhalt unter den griechi- 
schen Städten und deren Loyalität gegenüber seiner eigenen Person fördern wollte. Auch in diesem Fall also wurde das kaiserliche Handeln keineswegs durch Vorstellungen determiniert, die ihm von anderen nahegebracht worden waren.

Matthäus Heil nähert sich dem Problem, welche Rolle der Kaiser in der römischen Welt spielte, indem er einen Bürgerkrieg, oder besser, eine Folge von zeitlich rasch aufeinander folgenden Bürgerkriegen unter die Lupe nimmt („Clodius Albinus und der Bürgerkrieg von 197"). Am Beispiel der Nachfolgekrise, die das römische Reich nach der Ermo rdung des Commodus in den Jahren 193-197 erschütterte, macht er nicht bloß deutlich, daß das Fehlen verbindlicher Regeln über die Bestellung von Kaisern fast unvermeidlich Situationen herbeiführte, in denen mehrere Thronprätendenten mit militärischen Mitteln ihre Ansprüche durchzusetzen versuchten, was ja bereits Mommsen klar ausgesprochen hat, ohne deswegen freilich seine Auffassung, der Prinzipat sei als Magistratur aufzufassen, aufzugeben. Heil geht es um mehr: Er möchte zeigen, daß das Kaisertum aufgrund seiner mangelnden rechtlichen Fixierung immer wieder neu definiert werden konnte und mußte und eben deshalb offen für Veränderungen war. Denn nicht nur waren die Kaiser Personen mit sehr unterschiedlichen Neigungen und Fähigkeiten, sie mußten auch auf soziale Kräfte Rücksicht nehmen, die weder homogen noch statisch waren. Heil stellt also die Einheitlichkeit des Kaisertums grundsätzlich in Frage und betont demgegenüber die Priorität von Personen und Umständen. Da die beiden Kontrahenten der Schlacht von Lyon 197, Clodius Albinus und Septimus Severus, sich nur wenige Jahre zuvor auf eine gemeinsame Herrschaft geeinigt hatten, wobei freilich Albinus sich mit dem Titel eines Caesar begnügen mußte, wirft dieser Konflikt die Frage auf, weshalb die ursprüngliche Übereinkunft keinen Bestand hatte. Nach Heil war diese Übereinkunft auf beiden Seiten mehr als ein bloß taktisches Zweckbündnis auf Zeit, aber zugleich notwendig instabil, weil Albinus andere Vorstellungen über seine Rolle als Caesar gehabt habe als Severus: Für den einen habe dieser Titel die gleichberechtigte Mitherrschaft, wenngleich mit einem Ehrenvorsprung des Augustus, bedeutet, für den anderen lediglich die Anwartschaft auf die Nachfolge. Darum sei der Konflikt erst eskaliert, als Albinus sich in die Rolle, die Severus für ihn vorgesehen hatte, nicht fügen wollte, und auf voller Gleichberechtigung mit Severus bestanden habe. Diese Deutung, derzufolge zunächst weder Albinus noch Severus zielstrebig auf einen Bürgerkrieg hinarbeiteten, beruht auf einer revidierten Chronologie der Erhebung von Iulia Domna zur mater castrorum und von Bassianus zum Caesar: Nach Heil fallen diese Ereignisse nicht, wie die Forschung bislang annahm, in das Jahr 195, sondern in das Frühjahr 196 und sind als Reaktion auf 
eine freilich nicht näher zu bestimmende Handlung des Albinus zu deuten, die Severus als Provokation auffaßte.

Andrea Jördens unternimmt in ihrem Beitrag „Zum Regierungsstil des römischen Statthalters - das Beispiel des praefectus Aegypti" den Versuch, anhand der reichen, von ihr erstmals systematisch ausgewerteten Überlieferung aus Ägypten Aufschlüsse über Form und Selbstverständnis von Herrschaft und Regierung zu gewinnen, die in ihrer Bedeutung über die Provinz Aegyptus hinausreichen und für das ganze Reich Gültigkeit beanspruchen können. Die Grundlage ihrer Überlegungen bilden die ganz überwiegend auf Papyrus überlieferten Edikte und Rundschreiben des praefectus Aegypti, die sie unter dem Gesichtspunkt analysiert, wie dessen Handeln motiviert wird. Dabei steht die Frage im Vordergrund, ob sich bestimmte Prinzipien beobachten lassen, an denen der Statthalter sein Verhalten zu orientieren pflegte. Als Ausgangspunkt dienen zwei Texte, die besonders ausführliche Aussagen zur Motivation enthalten: ein Erlaß des Präfekten M. Sempronius Liberalis aus dem Jahre 156, den Jördens vor wenigen Jahren selbst ediert hat, und das seit langem bekannte Edikt des Ti. Iulius Alexander aus dem Jahre 68. Jördens zeigt auf, daß sich der Statthalter als „Garant von Sicherheit, Frieden, Ordnung und Gerechtigkeit" (94) darstellte, und betont, daß er für die Provinzialen stets ein offenes Ohr gehabt habe und um ihre wohlverstandenen Interessen besorgt gewesen sei, woraus hervorgehe „daß die Provinzialen hier eben nicht mehr primär als Unterworfene und damit bloße Rechtsobjekte, sondern zunehmend als eigens tändige Rechtssubjekte mit berechtigten Interessen wahrgenommen" (96) worden seien. Das Prinzip statthalterlichen Handelns erkennt Jördens demgemäß in der ,vorausschauenden Fürsorge“ ( $\pi \rho o$ vot $\alpha$ ), die sich konkret im Bemühen um „Ruhe, Ordnung, Sicherheit, Gerechtigkeit und Frieden" (100) geäußert habe und vor allem auf den Feldern der Landwirtschaft und der Rechtsordnung zur Anwendung gekommen sei. Diese „vorausschauende Fürsorge" habe sich indessen keineswegs in bloßem Reagieren auf Klagen oder Anregungen erschöpft, sondern auch die Bereitschaft und Fähigkeit umfaßt, von sich aus tätig zu werden, um weitsichtige und planvolle Lösungen für Probleme finden zu können. Jördens argumentiert, daß in dieser Hinsicht von einer Sonderstellung Ägyptens und seines Statthalters kaum die Rede sein könne; so beschränkte sich die kaiserliche Rechtsetzung im Bereich der Landwirtschaft keineswegs auf Ägypten und statthalterliche Maßnahmen etwa zur Normierung des Requisitionswesens und des Rechtsverkehrs sind auch außerhalb Ägyptens bezeugt. Das Vorbild des Kaisers war nach Jördens für alle Statthalter gleichermaßen verbindlich, und die patronale Fürsorge ein integraler Bestandteil des statthalterlichen Selbstverständnisses schlechthin. 
Christian Marek legt seinen Überlegungen zur Zollorganisation des kaiserzeitlichen Lykien („Stadt, Bund und Reich in der Zollorganisation des kaiserzeitlichen Lykien. Eine neue Interpretation der Zollinschrift von Kaunos") inschriftliche Zeugnisse zugrunde, eine Inschrift aus Myra, die seit 1975 bekannt ist, und eine aus Kaunos, die 1954 erstmals veröffentlicht wurde. Der innere Zusammenhang der beiden Texte wurde bislang nicht erkannt, weil die Forschung den kaunischen Text als städtisches Zollgesetz deutete, während der in Myra aufgezeichnete Statthalterbrief unzweifelhaft auf eine Regelung Bezug nimmt, die die Zollhoheit der Stadt gegen diejenige des Bundes abgrenzt. Marek, der die Inschrift aus Kaunos einer gründlichen Neuaufnahme unterzogen hat, kann jedoch nachweisen, daß das bislang vorherrschende Verständnis dieses Textes auf falschen Voraussetzungen beruht: Es handelt sich nicht um ein städtisches Zollgesetz, sondern um ein ganzes Dossier von Urkunden über eine private Stiftung zweier Kaunier, die den Einnahmenausfall ausgleichen sollte, der der Stadt durch eine (lokale) Befreiung des Handels vom Einfuhrzoll entstand. Da Kaunos, wie die Entzifferung des Anfangs der Inschrift ergeben hat, zu der Zeit, als die Stiftung errichtet wurde (unter Hadrian), ebenso zur Provinz Lycia gehörte wie Myra, nimmt Marek an, daß das Zollgesetz (Demosionikos Nomos), auf das in beiden Texten Bezug genommen wird, ein römisches Zollgesetz war, das für die Provinz Lycia insgesamt Geltung besaß. Seine Neuinterpretation des kaunischen Textes bestätigt in den Grundzügen das Bild, das Michael Wörrle bei der Erstpublikation des Statthalterbriefes aus Myra gezeichnet hatte: Die Zollorganisation des kaiserzeitlichen Lykien war demnach dadurch gekennzeichnet, daß der Einfuhrzoll von den Städten selbst (und zwar durch Pächter) verwaltet wurde, die jedoch einen Pauschbetrag an die Bundeskasse abführten, während der Ausfuhrzoll von Pächtern erhoben wurde, die im Namen und Auftrag des Bundes agierten. Diese zweigeteilte, wohl bereits in hellenistischer Zeit entstandene Organisation erlaubte es dem Kaiser, in der Provinz Lycia auf die Einrichtung einer separaten Verwaltung zur Erhebung eines Reichszolls zu verzichten; er konnte sich damit begnügen, einen Anteil aus den Zolleinnahmen des Bundes abzuschöpfen. Marek kontrastiert dieses System mit demjenigen, das im Zollgesetz der Provinz Asia belegt zu sein scheint: Dort erhob der Kaiser durch eigene Pächter, die in einem Ring von Zollstationen an der Westküste Kleinasiens postiert waren, einen Reichszoll auf die Ein- und Ausfuhr von Waren. In zwei unmittelbar aneinander grenzenden Provinzen bestanden demnach zur selben Zeit völlig verschieden strukturierte Systeme der Zollerhebung.

Kai Ruffing schließlich geht am Beispiel der Emporia der Frage nach, ob die Städte des römischen Kleinasien so etwas wie eine Wirtschaftspolitik 
betrieben („Städtische Wirtschaftspolitik im hellenistisch-römischen Kleinasien? Zur Funktion der Emporia ${ }^{6}$ ). Zu diesem Zweck gibt er zunächst einen umfassenden Überblick über die epigraphische Dokumentation des Phänomens, soweit es in Kleinasien anzutreffen ist. Dabei bestätigt sich die schon von Louis Robert gemachte Beobachtung, daß Emporia überwiegend in den spät hellenisierten Landschaften des nördlichen Kleinasien anzutreffen sind; die meisten Belege stammen aus Bithynien(-Pontos) und Mysien. Da es indessen auch einige wenige Belege aus dem südlichen Kleinasien gibt, ist Ruffing geneigt, in den Emporia ,nicht nur ein auf das nördliche Kleinasien (und Thrakien) beschränktes Phänomen zu sehen, sondern es für einen in Asia Minor gängigen Typus nichtstädtischer Siedlungen zu halten" (135). Die innere Verfassung und Rechtsstellung der Emporia weist viele Parallelen zu den Komai auf: In beiden Fällen handelt es sich um abhängige Siedlungen, die über eigene Ämter, eigene Einkünfte und eine eigene Gemarkung verfügten. Im Gegensatz zu den Komai stammten die Vorsteher der Emporia jedoch meist aus der Honoratiorenschicht jener Stadt, zu der sie gehörten. Aus siedlungsgeographischer Sicht lassen sich zwei Typen von Emporia unterscheiden: einerseits das Emporion als Hafensiedlung, andererseits das binnenländische Emporion. Beiden ist nach Ruffing jedoch gemeinsam, daß sie eine wirtschaftliche Funktion für eine Stadt erfüllten, was sie wiederum von den Komai unterscheide: Während die als Hafenorte anzusprechenden Emporia der Konzentration des Warenverkehrs über See und damit seiner effizienten Kontrolle und Verzollung gedient hätten, habe die wirtschaftliche Funktion der binnenländischen Emporia darin bestanden, den Warenaustausch sowohl zwischen der Landbevölkerung („Horizontaler Handel“) als auch zwischen Stadtterritorium und städtischem Zentrum („Vertikaler Handel“) zu ermöglichen. Ruffing geht davon aus, daß die kleinasiatischen Emporia anders als das thrakische Emporion Pizos, das nachweislich auf Veranlassung des Kaisers gegründet wurde, von den Städten geschaffen und betrieben wurden, da sich Kleinasien durch seinen höheren Urbanisierungsgrad grundlegend von Thrakien unterschieden habe. Für die Städte seien die Emporia ein bewußt eingesetztes Mittel gewesen, ihre Einnahmen zu steigern und ihre Versorgung mit Gütern zu verbessern. Darum zeugten die kleinasiatischen Emporia von einem bewußten Gestaltungswillen der Städte auf dem Gebiet der Wirtschaft, und insofern könne man durchaus von „städtischer Wirtschaftspolitik“ sprechen. 
IV.

Noch einmal fünf Beiträge sind dem spätrömischen Kaisertum gewidmet. Auch sie sollen kurz vorgestellt werden.

Im Mittelpunkt des Beitrags von Martin Dreher „Die Ursprünge des Kirchenasyls und die Gesetzgebung Theodosius' II." steht die Frage, welche Rolle der spätrömische Staat bei der Entwicklung des Kirchenasyls spielte. Der älteren Forschung zufolge entwickelte sich das Kirchenasyl aus einer Gewohnheit zu einer allgemein anerkannten Sitte, die auch der Kaiser stillschweigend anerkannt habe, weil es in dieser Frage keine grundsätzlichen Differenzen zur Kirche gegeben habe; eine prinzipiell gesetzliche Normierung sei jedoch niemals erfolgt. Dagegen hat Hans Langenfeld die These vertreten, daß Theodosius II. im Jahre 431 dem Kirchenasyl eine allgemeingültige rechtliche Grundlage verschafft habe; dabei stützt er sich auf eine Konstitution, die nicht bloß auszugsweise im "Codex Theodosianus" $(9,45,4)$, sondern in den „Akten" des Konzils von Chalkedon auch vollständig, wenngleich lediglich in griechischer Übersetzung überliefert ist. Dreher führt die Überlegungen Langenfelds weiter, indem er untersucht, wie sich die kirchliche Position in der „Asylfrage" zu derjenigen des Kaisers denn nun genau verhielt.

Ausgangspunkt seiner Überlegungen bildet die erwähnte Konstitution, die er noch einmal eingehend auf ihre Motivation und Genese hin analysiert. Dabei arbeitet er heraus, daß Theodosius II. das Kirchenasyl ausdrücklich als Fortsetzung vor-christlicher Traditionen darstellt. Dreher kontrastiert dann den seit Mitte des vierten Jahrhunderts faßbaren Aufstieg des Kirchenasyls als kirchlicher Sitte mit dem korrespondierenden Niedergang der Schutzfunktion heidnischer Heiligtümer, der freilich in den Quellen schwer zu greifen ist. Daß der kirchliche Diskurs über das Asylrecht sich vom kaiserlichen signifikant unterschied, verdeutlicht Dreher anhand des „Gottesstaates“ A ugustins. Während nämlich Theodosius II. das Kirchenasyl als Fortsetzung vor-christlicher Traditionen darstellt und jede transzendente Begründung vermeidet, bestreitet der Kirchenvater gerade, daß ein Tempelasyl vor Alarichs Eroberung Roms jemals respektiert worden sei, und führt die Verschonung römischer Kirchen durch die Goten auf Gottes Willen zurück. Auch die Motive, die Theodosius zur formalen Anerkennung des Kirchenasyls bewegten, waren nach Dreher keineswegs mit denen der Kirche identisch: Dem Kaiser sei es vor allem da num gegangen, den kirchlichen Wirkungsbereich zu normieren und dabei seine eigene Milde und Fürsorge zur Schau zu stellen. 
Dreher gelangt so zu dem Ergebnis, daß der Kaiser in der Asylfrage gerade aus der Konkurrenz zur Kirche heraus auf die kirchliche Linie eingeschwenkt sei. Seine Ausführungen belegen eindrücklich, weshalb das Asylgesetz von 431 einen festen Platz in der Debatte über den Regierungsstil des spätrömischen Kaisers verdient hat. Insofern nämlich die Bedeutung der Konstitution von 431, wie Dreher betont, weit über den unmittelbaren Anlaß, das kurz zuvor erfolgte Eindringen bewaffneter Sklaven in die Kathedralkirche von Konstantinopel, hinausgeht, liefert sie ein klares Beispiel dafür, wie aus dem situativen Reagieren auf ein konkretes Problem eine umfassende und allgemeingültige Regel entstehen kann; mit anderen Worten: daß Reagieren und konstruktive Politik keine unversöhnlichen Gegensätze bilden, sondern in der Praxis ineinander übergehen können.

War das politische Scheitern des Procopius Anthemius die Folge einer kulturellen Entfremdung zwischen West- und Ostrom, die dazu führte, daß dieser Kaiser den westlichen Eliten nicht als Römer, sondern als Grieche erschien? Diese Frage, die in der neueren Forschung bejaht wurde, bildet den Leitfaden des Beitrages von Dirk Henning „Der erste „griechische Kaiser". Überlegungen zum Scheitern des Procopius Anthemius im Weströmischen Reich“. Es geht also um konkrete Handlungsspielräume eines bestimmten Kaisers, aber auch um das Verhältnis von Kultur und Politik, mithin um strukturelle Determinanten politischen Handelns. Henning unterzieht zunächst die beiden einzigen Zeugnisse für die Annahme, Anthemius sei im Westen als Graeculus angefeindet worden, einer kritischen Prüfung. Dabei erweist sich der Bericht des Ennodius (V. Epiph. 53-55) über abfällige Äußerungen, die 471 in einer Versammlung ligurischer Senatoren ge fallen sein sollen, als nachträgliche Überzeichnung durch einen Autor, der zur Zeit des Akazianischen Schismas, der ersten großen Kirchenspaltung zwischen West und Ost, schrieb. Der 468 wegen Hochverrats verurteilte gallische Prätoriumspräfekt Arvandus dagegen dürfte Anthemius zwar tatsächlich als graecus imperator verunglimpft haben, wie Sidonius Apollinaris (Ep. 1,7) berichtet, war jedoch unter seinen Standesgenossen isoliert. Eine eingehende Betrachtung des historischen Kontexts aber führt nach Henning zu dem Ergebnis, daß die östliche Herkunft für Anthemius zwar ein Problem darstellte, das er durchaus erkannte und zu lösen versuchte, aber auch beträch tliche Vorteile mit sich brachte, insofern ihm die volle Unterstützung des Ostkaisers Leo eine unanfechtbare Legitimität und anfangs - bis zum Scheitern der Vandalenexpedition im Jahre 468 - auch die Verfügung über beträchtliche militärische Machtmittel einbrachte. Wenn es Anthemius nicht gelang, die westlichen Eliten hinter sich zu bringen, so lag dies nach Henning daran, daß er die italische Elite bei der Besetzung hoher Ämter nicht hinreichend berücksich- 
tigt habe. Letztlich entscheidend aber sei der Umstand gewesen, daß Anthemius den Heermeister Ricimer gegen sich aufgebracht habe, indem er zu Beginn seiner Herrschaft, als er noch über oströmische Truppen verfügen konnte, eigene Parteigänger in hohe militärische Positionen beförderte. Aus diesem Grund sei er von Ricimer beseitigt worden, nachdem Leo seine Truppen aus dem Westen wieder abgezogen hatte. Die kulturelle Entfremdung zwischen westlichen und östlichen Eliten, so lautet das Fazit der Überlegungen Hennings, war in den Jahrzehnten nach dem Ende der valentinianischen Dynastie noch keineswegs so weit fortgeschritten, daß sie Anthemius von vornherein zum Scheitern verurteilt hätte, zumal die westlichen Eliten zu dieser Zeit selbst in regionale Fraktionen gespalten gewesen seien.

Hartmut Leppin untersucht in seinem Beitrag „, $\mathrm{Zu}$ den Anfängen der Kirchenpolitik Justinians" die Frage, welche Haltung dieser Kaiser in den ersten neun Jahren seiner Herrschaft gegenüber den Miaphysiten einnahm. Die Forschung hat der Position des Kaisers in dieser Frage meist jede Konsistenz abgesprochen und seine Politik mit einem Zickzackkurs verglichen: Auf eine energische Verfolgungspolitik zu Anfang der Regierung seien Aussöhnungsversuche gefolgt, doch sei der Kaiser schon bald, um 536, wieder auf eine kompromißlos pro-chalkedonische Linie eingeschwenkt. Leppin zeigt demgegenüber auf, daß die Kirchenpolitik Justinians zwischen 527 und 536 in zweierlei Hinsicht im Zeichen der Kontinuität stand: zum einen insofern der Kaiser in dieser Zeit durchgängig den Dialog mit den Miaphysiten suchte und deshalb darauf verzichtete, das eigene Bekenntnis, das am Konzil von Chalkedon orientiert war, mit aller Schärfe durchzusetzen. Die antihäretischen Gesetze, die Justinian in dieser Zeit erließ, waren Leppins Interpretation zufolge nicht gegen die Miaphysiten gerichtet, sondern gegen gemeinsame theologische Gegner, vor allem die Nestorianer. Zum anderen weist auch der Habitus, mit welchem Justinian seine Religionspolitik praktizierte, eine bemerkenswerte Kontinuität auf, insofern der Kaiser in dieser Phase seine Bereitschaft zur Schau stellte, sich in theologischen Fragen belehren zu lassen, also die Demut des theologischen Laien über die Pflicht des christlichen Kaisers stellte, den wahren Glauben zu schützen und zu verbreiten. Diese gesprächsbereite Haltung hat in den Berichten über ein Religionsgespräch, zu dem der Kaiser 532 sowohl Chalkedonier als auch Miaphysiten einlud, besonders eindrücklichen Niederschlag gefunden. Wie Leppin herausarbeitet, erscheint Justinian nicht bloß in der zeitgenössischen chalkedonischen, sondern auch in der zeitgenössischen miaphysitischen Berichterstattung als demütiger Kaiser, der bereit ist, beide Seiten anzuhören. Allerdings erwartete Justinian natürlich, daß der Dialog zwischen den streitenden theologischen Richtungen, wie er ihn auf dem Religionsgespräch von 532 insze- 
nierte, schließlich dazu führen werde, daß sich ein Konsens herausbilde, der zu seinem eigenen Glaubensbekenntnis nicht in grundsätzlichem Widerspruch stand. Als diese Erwartung enttäuscht wurde, wandelte der Kaiser, beeindruckt durch die Persönlichkeit des Papstes Agapet, seine Methoden, berief 536 ein Konzil der in Konstantinopel anwesenden Bischöfe ein, das die Miaphysiten als Häretiker brandmarkte, und sanktionierte anschließend deren Beschlüsse. Damit hatte er sich erstmals klar auf die Seite der Chalkedonier gestellt. In den 540er Jahren gab Justinian dann seine Zurückhal tung in Glaubensfragen vollends auf, indem er zunehmend mit theologischen Argumenten in die Kirchenpolitik eingriff - mit dem Erfolg, daß er am Ende seines Lebens Miaphysiten und Chalkedoniern gleichermaßen als Häretiker galt. Der Übergang von einer eher integrativen und dialogischen, im Sinne Millars also „reaktiven“, Religionspolitik zu einer „aktiven“, die vom Kaiser initiiert und konzipiert wurde, führt bei Justinian geradewegs ins politische Scheitern.

Sebastian Schmidt-Hofner unterzieht in seinem Beitrag „Die städtische Finanzautonomie im spätrömischen Reich" die communis opinio, daß die schon in der Prinzipatszeit stetig zunehmende Kontrolle der kaiserlichen Verwaltung über die Finanzverwaltung der Städte während der ersten Hälfte des 4. Jahrhunderts in einer totalen Konfiskation der städtischen Einnahmequellen gegipfelt habe, einer Revision, indem er in eingehender Interpretation der Quellen nachweist, daß es keinen positiven Beleg für diese Auffassung gibt, sehr wohl aber zahlreiche Zeugnisse, die den Fortbestand städtischen Eigentums an Liegenschaften und Zöllen bezeugen: Das „Restitutionsedikt" Julians, das von der Forschung bislang als indirekter Beleg für eine vorhergegangene Totalenteignung der Städte von ihren Ländereien gedeutet wurde, die der Kaiser ihnen durch diese Maßnahme zurückerstattet habe, bezog sich in Wahrheit auf Tempelland in städtischer Verwaltung, das unter Julians Vorgängern nachweislich konfisziert worden war, und läßt daher keine Rückschlüsse auf städtische Ländereien zu. Ebensowenig vermag der in einer ephesischen Inschrift (I.Ephesos 42) überlieferte, von Valens an den proconsul Asiae Eutropius gerichtete Erlaß die Auffassung zu stützen, Julians Nachfolger hätten die Restitution städtischen Landes wieder rückgängig gemacht. Wie Schmidt-Hofner zeigen kann, geht es in diesem Erlaß keineswegs um den gesamten Grundbesitz der Städte in der Provinz Asia. Vielmehr ermächtigte der Kaiser Eutropius lediglich, das nach dem Tode Julians erneut konfiszierte Tempelland der Verwaltung der Städte zu übertragen. Die seit den frühen $370 \mathrm{er}$ Jahren belegte und offenbar für das gesamte Reich geltende Teilung der Einnahmen aus städtischen Einnahmequellen muß demnach anders gedeutet und erklärt werden, als die Forschung dies bislang getan hat: 
Schmidt-Hofner verweist darauf, daß sich Eingriffe der kaiserlichen Verwaltung in die städtische Finanzwirtschaft bereits in der früheren Kaiserzeit beobachten lassen, die jedoch keineswegs zu einem totalen Verlust der Steuerund Zollhoheit der Städte geführt hätten. In der Spätantike habe sich die Tendenz zur Aufsicht über die städtische Finanzwirtschaft, befördert durch den beträchtlich vergrößerten Staatsapparat, fortgesetzt und insgesamt verstärkt. Dennoch sei diese Einflußnahme ,immer punktuell und je nach Situation von unterschiedlicher Intensität" (246) geblieben. Die Quotierungsregel erscheint vor diesem Hintergrund als ambivalent: Einerseits setzt sie eine umfassende Kontrolle der kaiserlichen Verwaltung über die städtischen Einnahmequellen als selbstverständlich voraus, andererseits garantiert sie den Städten des Reiches erstmals eine partielle Finanzautonomie. Die Konsequenzen, die sich aus dieser Neuinterpretation ergeben, sind weitreichend: Die Auffassung, daß der spätrömische Staat die Finanzautonomie der Städte völlig beseitigt habe, muß relativiert werden, und die Geschichte der Finanzautonomie im spätrömischen Reich erweist sich als Teil einer längerfristigen Entwicklung, die von der früheren Kaiserzeit in die Spätantike und damit über die traditionelle Epochengrenze hinweg reicht.

Gegenstand des Beitrages „Kaiser und Katastrophe. Zur Bewältigung von Versorgungskrisen im spätrömischen Reich", für den der Herausgeber selbst verantwortlich zeichnet, ist die Frage, wie sich der im Laufe der Kaiserzeit zu beobachtende Formwandel der Staatlichkeit auf die Lebensmittelversorgung der Städte auswirkte. Mit anderen Worten: Welche Rolle spielte der spätrömische Kaiser für deren reguläre Lebensmittelversorgung und für die Bewältigung akuter Versorgungskrisen? Nach Auffassung von Jean Durliat bedeuten die Reformen Diokletians und Konstantins auf diesem Gebiet einen tiefen Einschnitt, da der spätrömische Kaiser in jeder größeren Stadt der östlichen Reichshälfte eine kostenlose Brotverteilung finanziert habe. Diese Auffassung hält freilich einer Überprüfung an den Quellen nicht stand. Richtig ist aber, daß sich die kaiserliche Fürsorge in der Spätantike nicht mehr darauf beschränkte, die Lebensmittelversorgung der Stadt Rom zu sichern; sie bezog vielmehr auch die drei anderen Metropolen des Ostens, Alexandreia (spätestens seit Diokletian), Konstantinopel (seit Konstantin I.) und Antiocheia (spätestens unter Justinian) mit ein. Die Fähigkeit und Bereitschaft der kaiserlichen Verwaltung, in diesem Bereich eine vorausschauende, planvoll gestaltende Politik zu betreiben, hatte gegenüber der früheren Kaiserzeit also erheblich zugenommen. „Gewöhnliche“ Provinzstädte jedoch versorgten sich im Normalfall noch immer ohne kaiserliche Unterstützung. Eine Analyse des unter dem Namen Josua Stylites geführten Berichts über eine verheerende Hungersnot, die in den Jahren 500-502 in den Grenzpro- 
vinzen Osrhoene und Mesopotamia herrschte, vermag dieses schematische Bild mit konkreter Anschauung zu füllen. Josuas Bericht führt in eine Welt, in der die Ratsherren die politische Führung der Stadt vollständig eingebüßt hatten. Die Erwartung, Maßnahmen gegen den Hunger zu ergreifen, richtete sich darum nicht mehr an den Stadtrat oder einzelne seiner Vertreter, wie dies in den ersten Jahrhunderten der Monarchie die Regel gewesen war, sondern primär an den Statthalter und den Kaiser selbst. Der Handlungsspielraum des Statthalters war jedoch merklich geringer als derjenige, dessen sich die Statthalter der früheren Kaiserzeit erfreut hatten, da er übergeordneten Behörden unterstellt und zur Ablieferung eines im Voraus fixierten Steuerquantums verpflichtet war. Kaiser Anastasius aber befreite die von der Hungersnot betroffenen Provinzen erst dann von der Grundsteuer, als sie ohnehin nicht mehr zahlungsfähig waren; fiskalische Interessen hatten für ihn allerhöchste Priorität. Der Bischof von Edessa konnte sich während der Hungersnot zwar als geistliches Oberhaupt der Gemeinde und als Anwalt der Armen profilieren, handelte aber unabhängig vom Statthalter und vermochte beim Kaiser kaum etwas zu erreichen. Die kirchliche Armenfürsorge schließlich war darauf ausgelegt, die Not der mittellosen Bettler zu lindern, und daher völlig überfordert, als die Stadt sich in ein Flüchtlingslager für obdachlose und hungernde Menschen verwandelte.

V.

Wie stellt sich nun das Verhältnis von Staatlichkeit und politischem Handeln, so sei abschließend gefragt, in den zehn Beiträgen dieses Sammelbandes zur römischen Kaiserzeit dar? $\mathrm{Daß}$ sie das Thema aus sehr unterschiedlichen Blickwinkeln betrachten, liegt auf der Hand. Aber auch ihre Stoßrichtung ist durchaus unterschiedlich. Einige Beiträge, die der frühen und hohen Kaiserzeit gewidmet sind, gelangen zu Ergebnissen, die sich dem traditionellen Bild eines Staates, der weder den Willen noch die Fähigkeit besitzt, das gesamte Reich administrativ zu durchdringen, und darum viele Hoheitsfunktionen lokalen Gewalten überläßt, ohne weiteres einfügen. Dies gilt für Kai Ruffings Interpretation der kleinasiatischen Emporia als Ausdruck einer Wirtschaftspolitik, die von Städten und nicht vom Kaiser ausging, aber auch für Christian Mareks Analyse des lykischen Zollsystems, das ohne die Etablierung eines kaiserlichen Verwaltungsstabes auskam, weil die vorhandenen Strukturen als ausreichend betrachtet wurden. (Der Vergleich mit der Nachbarprovinz Asia zeigt freilich auch, daß ein solcher Apparat anderswo durchaus bestand.) Andrea Jördens dagegen gelangt bei ihrer am Beispiel des praefectus Aegypti 
entwickelten Analyse statthalterlichen Handelns zu Ergebnissen, die das Millarsche Modell insofern transzendieren, als sie betont, daß die patronale Fürsorge für die wohlverstandenen Interessen der Untertanen durchaus Elemente der vorausschauenden Planung und eigenständigen Gestaltung beinhaltete. Auch Kostas Buraselis und Matthäus Heil fordern beide dazu auf, Millars Modell zu modifizieren, wenngleich auf je verschiedene Weise: Buraselis zeigt auf, daß Kaiser Hadrian keineswegs immer eines äußeren Anstoßes bedurfte, um Maßnahmen zu ergreifen, und $d a ß$ er auch dann, wenn er von anderen zum Eingreifen aufgefordert wurde, durchaus fähig und willens war, eine eigene Konzeption $z u$ entwickeln und durchzuführen. Heil dagegen stellt die Einheitlichkeit des Kaisertums als Institution grundsätzlich in Frage und versteht seine konkrete Ausgestaltung als Produkt unterschiedlicher Persönlichkeiten und Situationen.

In den fünf Beiträgen, die dem römischen Staat der Spätantike gewidmet sind, zeigen sich viele Unterschiede zur frühen und hohen Ka iserzeit, aber auch manche Gemeinsamkeiten. Neu ist das Problem von Staat und Kirche, mit dem sich Martin Dreher und Hartmut Leppin beschäftigen, aber auch die Koexistenz zweier Staaten, die sich einerseits als Teil ein und desselben Imperum Romanum verstehen, aber doch zugleich kulturell zunehmend entfremden, wie Dirk Henning verdeutlicht. Dreher und Leppin machen darüber hinaus deutlich, wie Reagieren und planvolles Gestalten auch bei spätrömischen Kaisern immer wieder ineinander übergingen, sich manchmal auch ablösten, Dreher am Beispiel der Asylpolitik Theodosius' II., der aus gegebenem Anlaß eine umfassende und allgemeingültige Regelung erließ, Leppin am Beispiel der Religionspolitik Justinians, der zunächst durchaus den Dialog suchte und sich dementsprechend zurückhielt, ab 536 aber Maßnahmen ergriff, die den wahren Glauben erzwingen sollten, im Ergebnis aber lediglich zu einer verschärften Polarisierung führten. Bei Sebastian SchmidtHofer und dem Herausgeber werden dagegen eher traditionelle Bereiche kaiserlichen Handelns thematisiert. Während dieser betont, daß sich das späte Imperium Romanum im Bereich der Lebensmittelversorgung durch eine erhebliche Zunahme der Regelungskapazität auszeichnete, ohne freilich allen Reichsbewohnern ein Existenzminimum sichern zu können oder zu wollen, legt jener den Akzent auf die Kontinuität: Die Kontrolle der kaiserlichen Verwaltung über die städtischen Finanzen begann einerseits lange vor den Reformen Diokletians und Konstantins und führte andererseits auch in der Spätantike niemals zum vollständigen Verlust der Finanzautonomie. 



\title{
Zum hadrianischen Regierungsstil im griechischen Osten oder vom kaiserlichen Agieren und Reagieren
}

\author{
Kostas Buraselis
}

\section{Einleitung}

Die bekannte, von ihrem analytischen Aspekt aus weitgehend naheliegende und in der weiteren Forschung oft erfolgreiche These von Fergus Millar, wonach die Interpretation der römischen kaiserlichen Administration dem Modell von ,petition-and-response" folgen könne und solle, steht programmatisch im Mittelpunkt dieses Kolloquiums. Nach Millar war eben der römische Kaiser, was er tat. ${ }^{1} \mathrm{Da}$ ein großer Teil dieser Tätigkeit, wie unsere Quellen reichlich bezeugen, der Beschäftigung mit und der schriftlichen und sonstigen Reaktion auf verschiedene Anträge, Gesuche und ähnliche Eingaben seitens seiner Untertanen galt, kam Millar zu dem grundsätzlichen Schluß (6):

It is the essential passivity of the role expected of the emperor both by himself and by others which explains the very limited and simple governmental' apparatus which he needed. A very large proportion of his contacts with his subjects fell into a pattern which may be called ,petition-and-responsé.

Weiter formulierte Millar seine Grundposition so (7):

If an emperor was what he did, so a whole social system can be defined in terms of the precise form of contacts between individuals and groups. We can, and must, grant

1 F. Millar, The Emperor in the Roman World (31 BC - AD 337), London 1977, 21992 (mit einem „Afterword”), $6 \mathrm{f}$. 
the acceptance, from the very beginning, by the emperor as well as by his subjects, of the assumption that he was there to listen to requests and grant favours.

So zeichnete er insgesamt, eigentlich in getreuer Nachzeichnung des Niederschlags kaiserlicher innenpolitischer Aktion in vielen Quellen - die Außenpolitik und die damit zusammenhängenden militärischen Planungen und Handlungen ausdrücklich ausgenommen ${ }^{2}-$, das Porträt eines passiven Kaisers, der sozusagen nur von seinen Untertanen berufen auf die Szene der Geschichte trat, ansonsten wohlüberlegte Absentia genießen konnte. Am Anfang der Kaiserzeit, also bei Augustus (bes. 267-268), und am Übergang zur eigentlichen Spätantike, bei Konstantin (z. B. 319-321), hat Millar diese Konstante gewiß um einiges eingeschränkt, da in diesen Perioden ein formativer, ordnender Geist kaiserlicher Politik nicht zu leugnen sei. ${ }^{3}$ Ansonsten war aber der Kaiser und sein Handeln, fast als erhabene Variante des Pawlowschen Experiments, an die Äußerung der Wünsche seiner Untertanen gebunden.

Es ist uns allen bekannt, daß diese These, an der Millar - vorsichtiger, aber nicht weniger entschieden - auch in der 1991 um ein „Afterword" ergänzten Ausgabe seines Werkes festhielt, ${ }^{4}$ in der Fachwelt vorerst eine rege Diskussion ausgelöst hat. Um hier nur einen wirklich verdienten Namen unter den Respondenten zu nennen: Jochen Bleicken hat sich in einer Spezialabhandlung eingehend und kritisch mit Millars Position auseinandergesetzt und mit m. E. gewichtigen Argumenten dieses Schema größtenteils zurückweisen

2 Millar, Emperor (wie Anm. 1), xii bzw. ix in der im Text unveränderten 2. Aufl. Zu diesen Aspekten des römischen Kaisertums vgl. seine eingehende Studie: Emperors, Frontiers and Foreign Relations, 31 B.C. to A.D. 378, Britannia 13, 1982, 1-23; auch in: ders., Rome, the Greek World, and the East, Bd. 2: Government, Society and Culture in the Roman Empire, Chapel Hill - London 2004, 160-194, wo sowohl die in administrativer Hinsicht weitgehend einschränkende Zentralität der Kaiserrolle als auch die damit verbundenen Schwierigkeiten und die praktischen Grenzen kaiserlicher Information betont (letzteres manchmal vielleicht überbetont) werden.

3 Diese Einschränkung erkennt auch J. Bleicken, Zum Regierungsstil des römischen Kaisers. Eine Antwort auf Fergus Millar, Sbb. d. wiss. Gesellschaft der Univ. Frankfurt am Main, Bd. XVIII, Nr. 5, Wiesbaden 1982, 183-215, hier: 185; auch in: ders., Gesammelte Schriften, Bd. 2, Wiesbaden 1998, 843-875, hicr: 846 ausdrücklich an.

4 Vgl. insbesondere Millar, Emperor ${ }^{2}$ (wie Anm. 1), 644: „It would of course be disingenuous to pretend that the model of 'petition-and-response', though it did in fact perform this function [gemeint ist diejenige eines idealtypischen Modells im Sinne Max Webers], was put forward solely in so neutral a way. ERW also embodies a positive assertion, that the model of 'petition-and-response' was a general and characteristic feature of the way that 'government' by emperors actually worked." 
können. ${ }^{5}$ Mein eigenes Ziel ist hier bestimmt nicht, das ganze Dossier wieder aufzublättern. Ich denke eher daran, gemäß unserem Rahmenthema die Rolle des Kaisers zwischen Agieren und Reagieren an einem konkreten Beispiel kaiserlicher Verwaltungspraxis im griechischen Osten zu überprüfen. Dabei erscheint mir die Epoche Hadrians als besonders günstiger Zugangspunkt, auf die sich meine Skepsis - wie ich mich erinnere - schon bei der ersten Lektüre des Millarschen Werkes assoziativ richtete. ${ }^{6}$

Nun ist wohl diese Themenwahl auch darum passend, weil Millar selbst Hadrians Gestalt ganz am Anfang seines Werkes mit seinem Modell in Verbindung gebracht hat. Laut einer Anekdote bei Cassius Dio (69, 6, 3) soll nämlich Hadrian einmal beim Vorbeigehen einer Frau, die ihn um etwas gebeten hatte, zunächst schroff ausgerufen haben: "Ich habe keine Zeit", als sie

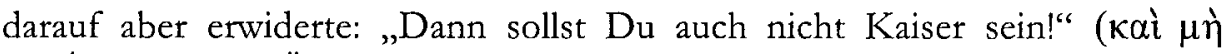
$\beta \alpha \sigma i(\lambda \varepsilon v \varepsilon)$ - die Übersetzung des Griechischen könnte auch einfach lauten: „Dann sollst Du auch nicht regieren!“ -, ihr doch Gehör geschenkt haben. Millar hat selbst darauf hingewiesen, daß diese Anekdote hellenistische Parallelen hat, die in unseren Quellen auf Philipp II., Antipatros und Demetrios Poliorketes bezogen sind, und in der einen oder anderen Form auf sie zurückgehen kann. Daß sie jedenfalls (auch?) mit Hadrian verbunden werden konnte, beweist ihre Relevanz innerhalb seines eigenen historiographischen Bildes. Gleichzeitig legt aber diese Parallelität der Überlieferung die Annahme nahe, $\mathrm{da} ß$ es dem römischen Kaiser ähnlich wie jenen makedonischen Herrschern erging; mit anderen Worten: daß dem herrscherlichen Anhören gegenüber den Untertanen in all diesen Anekdoten ein ähnlicher Stellenwert zugeschrieben wird. Nun dürfte einleuchten, daß die Annahme, die drei Makedonen hätten in Fragen der Innenpolitik eine passive Einstellung gezeigt, nicht viel für sich hat. Im Gegenteil: Man bekommt in diesen Anekdoten den Eindruck, daß der jeweilige Herrscher zwar seinen Anhörenspflichten etiquettenmäßig nachkommt, sein Interesse und seine Aufmerksamkeit indessen anderen mehr oder auch weniger dienstlichen - Geschäften gelten. Hier liegt also kein Indiz dafür vor, Hadrian dem Millarschen Modell zuzuordnen, sondern eher dafür, ihn davon zu entfernen. Nicht die Formierung kaiserlicher Politik aufgrund der Wünsche von unten wird hier evident, sondern die Bereitschaft des

5 Bleicken, Regierungsstil (wie Anm. 3). Vgl. auch besonders die Würdigungen der Bleikken schen Schrift durch W. Nippel, ZRG 102, 1985, 766-768 und G. Dobesch, AAHG 36, 1983, 275-276.

$6 \mathrm{Daß}$ sich das Problem bei jedem Kaiser, gemäß seiner Persönlichkeit, seinen Fähigkeiten und Interessen anders gestellt hat, liegt ja auf der Hand. Einen idealtypischen Kaiser zu postulieren, würde wohl einer echten historischen Fragestellung wenig helfen. 
Kaisers, sein sonstiges Programm um diese Facette günstig aufzunehmender kaiserlicher Tätigkeit zu ergänzen. ${ }^{7}$

Um weiterzukommen - da es natürlich in diesem Rahmen wenig Sinn hätte, eine Gesamtstudie der hadrianischen Innenpolitik zu unternehmen möchte ich hier eher die Millarsche These anhand von vier konkreten Maßnahmen des Kaisers im griechischen Osten überprüfen: seinen Maßnahmen zur Entwässerung des Kopä̈seckens, seinen Eingriffen in die wirtschaftlichen Satzungen Athens, und seinen inhaltlich wohl bedeutendsten Gründungen, der Stadt Antinoopolis in Ägypten und der Institution des Panbellenion in Athen.

\section{Koroneia und das Kopaïsbecken}

Aus dem westboiotischen Koroneia ist uns ein langes epigraphisches Dossier römischer Kaiserbriefe an diese Stadt erhalten, welches uns wichtige Einblicke in die Probleme der Koroneier mit der Natur und ihren Nachbarn erlaubt. ${ }^{8}$ Den chronologisch ersten der erhaltenen Briefe (GC 108) schrieb Hadrian im Jahr 125. Der Schluß des Briefes (mit der zu erwartenden Grußformel) ist in die epigraphische Verewigung dieses Dokuments nicht mit aufgenommen worden, so daß man die Möglichkeit einer vorausgegangenen Botschaft an den Kaiser - angesichts der Erwähnung eines solchen Tatbestands in vielen folgenden Dokumenten des Dossiers - nicht völlig ausschließen kann. Auf jeden Fall gewinnt man von diesem ersten Text eher den Eindruck, daß der Kaiser hiermit der Stadt sein Gesamtprogramm zur Trockenlegung des Kopaisbeckens mit speziellem Bezug auf die Belange der Koroneier und ihre Beteiligung an der Ausführung des Werkes bekanntmacht. Er berichtet nämlich, er

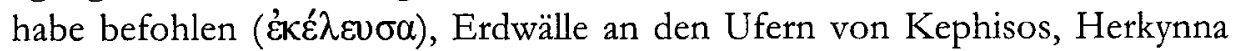
„und den anderen Flüssen“ der Gegend zu errichten, damit sie nicht wie bisher frei zusammenfließend in das Kopaïsbecken einmündeten und bei diesem unregulierten Zustand das Ackerland zu großem Teil überfluteten.

7 Bleicken, Regierungsstil (wie Anm. 3), $197=868$ hat schon auf die problematische Interpretation dieser Anekdote durch Millar hingewiesen, sie aber etwa nur durch die Devise „Anhören heißt soviel wie regieren“ ersetzen wollen. Man darf $\mathrm{m}$. E. das Bild feiner zeichnen: Dem (genauer: zumindest diesem) Kaiser war es wichtig, auf solche Petitionen zu reagieren, aber auch sonst und unabhängig von konkreten Wunschäußerungen seiner Untertanen im Sinne der Reichsinteressen zu handeln.

8 Die Texte sind bequem zugänglich bei J. H. Oliver, Greek Constitutions of Early Roman Emperors from Inscriptions and Papyri, Philadelphia 1989, Nr. 108-118. In dieser Sammlung enthaltene Texte werden im folgenden mit GC und Angabe der Nummer zitiert. 
Im Anschluß daran, und wohl im Zusammenhang mit dieser Aktion, teilt der Kaiser den Koroneiern mit, daß er ihnen ,auch Wasser bringen“ werde

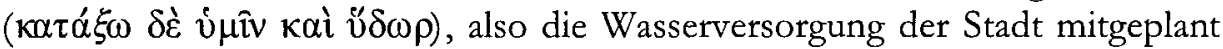
hatte. Die Kosten dieser ganzen Arbeiten hätten die technischen Spezialisten auf 65.000 Denare veranschlagt, deren Bezahlung aus dem kaiserlichen Haus-

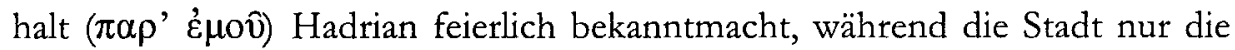
Wahl der Werkvorsteher vornehmen sollte.

Es ist nun schon richtig bemerkt worden, daß die Höhe des erwähnten Betrags etwa das Elffache der Summe darstellt, welche Epameinondas von Akraiphia wohl weniger als ein Jahrhundert vorher für die Reparatur ähnlicher Anlagen im Interesse seiner eigenen Stadt an der östlichen Seite des KopaïsBeckens ausgezahlt hatte. ${ }^{9}$ Darum ist es sehr u nwahrscheinlich, daß Hadrians Geldschenkung einer Anlage galt, welche ausschließlich Koroneia dienen sollte. Es ist aufschlußreich, daß die im obigen Brief erwähnten Flüsse Kephisos und Herkynna eigentlich im Grenzgebiet zwischen Koroneia und Orchomenos verlaufen, während der Koroneia viel nähere Phaleros hier wohl nur innerhalb der ,anderen Flüsse“ gemeint sein konnte. Des letzteren erfolgreiche Regulierung wird dann tatsächlich in einem weiteren, wohl um einige Jahre späteren Brief Hadrians an Koroneia (GC 110) angekündigt, wo die Sorge des Kaisers auf die Erhaltung dieser Anlage durch das richtige Verhalten der Koroneier gerichtet ist. Es wird deutlich, daß die Bürger der Stadt verschiedentlich die Funktionsfähigkeit der Anlagen in ihrem Bereich beeinträchtigen konnten (z.B. durch die Versetzung der Dammlinien), was Hadrian unter Androhung hoher Strafgelder an die Stadtkasse verbot.

Zwei weitere Briefe Hadrians an die Stadt (GC $111+112$ ), nach entsprechenden Botschaften der Koroneier an ihn, verraten weitere Probleme bei der Ausführung des kaiserlichen Vorhabens wegen lokaler Spannungen. Im ersteren dieser Briefe erfahren wir von Schwierigkeiten zwischen Koroneia und Orchomenos: Im Bereich der Orchomenier dürfe der Bau der Anlage nicht in Angriff genommen werden, bevor die Interessen der Koroneier von dem zuständigen - anscheinend vom Kaiser damit beauftragten - Werkvorsteher

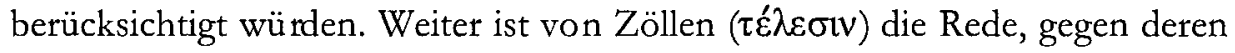
Erhebung durch die Orchomenier die Koroneier beim Kaiser protestierten und sein Versprechen erhielten, daß der Provinzstatthalter Calpurnius Longus gemäß dem ursprünglichen Willen Hadrians keine solchen Zölle gestatten werde. Im folgenden Brief nimmt Hadrian wieder Bezug auf die Anlage am

9 J. M. Fossey, The City Archive at Koroneia, Boiotia, Euphrosyne 10-11, 1980-1982, 4459, hier: 54; Oliver, GC im Kommentar zu Nr. 108-118. Vgl. den von Oliver neu herausgegebenen Beschluß für Epameinondas: GRBS 12, 1971, 227, Z. 33-37. 
Fluß Phaleros zehn Jahre nach dem Anfang der Flußbettarbeiten im weiteren

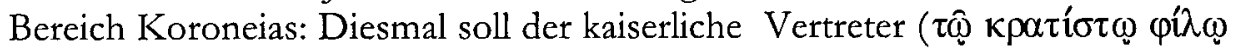
$\mu \mathrm{ov})$ Aemilius Iuncus die Beschwerden der Koroneier an Ort und Stelle beurteilen und demgemäß handeln. Ein weiterer Brief Hadrians in Bezug auf die Grenzansprüche der Koroneier gegenüber den Thisbeiern und die Korrespondenz mit weiteren Kaisern über diese und weitere Anliegen der Stadt braucht hier nicht näher erörtert zu werden.

Insgesamt entsteht aber trotz der Lückenhaftigkeit dieser Dokumente doch ein klares Bild der Beziehung Hadrians zu Koroneia: Der Kaiser hat sich sicherlich wohlwollend bemüht, die Interessen der Stadt zu fördern, keinesfalls aber unabhängig von seinem Gesamtplan für das Kopaïs-Becken und die Verbesserung der Lebensbedingungen aller Städte in diesem Bereich, umfassenden Ideen also, die ihm in dieser Form bestimmt keine städtische oder sonstige Delegation, sondern hauptsächlich seine - zumindest teilweise - eigene Kenntnis dieser Orte und ihrer Probleme suggeriert hatte. ${ }^{10}$ Notgedrungen hat er sich so in eine Schlichterrolle gefunden, die er mit Verständnis für lokalpatriotischen Geist zu spielen versuchte. Das kasuistische Bild der diesbezüglichen inschriftlichen Dokumente darf uns aber nicht darüber hinwegtäuschen, daß der Kaiser hier seinen Rahmenplan ausführte, soweit ihn gerade die lokalen Interessen vertragen konnten. Ein takt- und rücksichtsvolles Verhalten auf lokaler Ebene kann also bestimmt nicht als passiv bezeichnet werden oder die Existenz einer überlokalen Zielsetzung ausschließen.

III. Hadrian und die Regelung des wirtschaftlichen Lebens in Athen.

Hadrians Verhältnis zu Athen ist bekanntlich einer der wichtigsten Aspekte seines Werks und seiner Persönlichkeit. Es ist ja kein Zufall, daß der Kaiser hier schon vor seinem Machtantritt, also noch unter Trajan, im Jahr 112 das eponyme Archontat bekleidet hat, ${ }^{11}$ und er hat der Stadt auch danach noch mehrfach sein Interesse angedeihen lassen, wie wir auch im Teil über das Pan-

10 Vgl. A. B. Birley, Hadrian, the Restless Emperor, London 1997, 186; M. T. Boatwright, Hadrian and the Cities of the Roman Empire, Princeton 2000, 112-116, die sehr richtig auf die Tatsache hinweist, daß sich Hadrian auch anderswo (lacus Fucinus östlich von Rom, nach HA Hadrian 22,12) mit der Trockenlegung eines Sees befaßt hat. Über die Geschichte der antiken Versuche, die Kopaïs trockenzulegen, vgl. zusammenfassend A. Wilson, Land Drainage, in: Ö. Wikander (Hg.), Handbook of Ancient Water Technology, Leiden 2000, 303-317, hier: 304f. mit Verweisen auf die frühere Literatur.

Birley, Hadrian (wie Anm. 10), 64 mit 321 Anm. 21. 
bellenion sehen werden. Nun ist es für die Zwecke dieser Untersuchung wichtig festzustellen, ob diese Haltung und die entsprechenden Maßnahmen des Kaisers nur irgendwie geäußerten Bitten der Athener entsprachen oder ebenfalls darüber hinausgingen.

Ein lehrreiches Material in dieser Hinsicht liefern uns die zwei inschriftlich bekannten, gegen 125 datierten Interventionen Hadrians in das wirtschaftliche Leben Athens, sein Brief über die Regulierung des Fischverkaufs in Eleusis und verwandte Probleme (GC 77) ${ }^{12}$ und sein sogenanntes Ölgesetz (GC 92). Im ersteren Fall ordnete der Kaiser an, daß die Fischer von Eleusis beim Zugang zum lokalen (eleusinischen) Fischmarkt keine Zölle zu entrichten hätten, während ansonsten Einfuhrzölle (wohl im Piräus) erhoben wurden. Die Ausnahme für die eleusinischen Fischer in Eleusis hat man schon längst - und sicher richtig - als Vorsorge für die Verpflegung während der Mysterienfeiern ausgelegt; die generelle Beibehaltung dieser Abgaben hat Hadrian selbst in Verbindung mit seiner auch sonst geäußerten Politik der Vermehrung städtischer Einnahmen gebracht (Z. 5). ${ }^{13}$ Das kaiserliche Operationsmesser hat aber dabei weiter versucht, einen anderen und noch schädlicheren Tumor im Handel der Stadt zu entfernen.

Die Preise aller Waren ( $\pi_{\alpha} \alpha \tau \alpha$, Z. 9) wurden nach Ansicht des Kaisers dadurch in die Höhe getrieben, daß die angebotenen Waren mehrmals weiterverkauft wurden, bis sie den einfachen Konsumenten erreichten. Hadrian schränkte also in demselben Brief diesen Weiterverkauf nur auf einen Händler zwischen dem zum Markt einführenden Produzenten und dem eigentlichen Konsumenten ein, ${ }^{14}$ und legte eine Strafprozedur unter Leitung des Areopags fest. Der Brief sollte am Deigma, dem zentralen Handelsort in Piräus, wo Warenmuster präsentiert wurden, als Inschrift veröffentlicht werden.

Während nun die Regelung der eleusinischen Zustände durchaus auf ein irgendwie geartetes lokales Gesuch zurückgehen könnte, dem Hadrian stattgab, ist kaum zu glauben, daß die allgemeine Regelung über die Zwischenhändler Athens entweder durch die Stadt oder irgendeine andere Form von Verein veranlaßt wurde. Konsumentenorganisation war ja im Altertum unbe-

12 Die allgemein akzeptierte hadrianische Autorschaft beruht zugebenermaßen nur auf der Ähnlickeit der Schrift mit weiteren Inschriften dieser Zeit und natürlich dem Inhalt: vgl. Oliver, GC, S. 194.

13 Vgl. z. B. im Koroneiadossier (s. oben) den programmatischen Anfang seines Briefes GC 109. Weiter: Boatwright, Hadrian (wie Anm. 10), 90-91.

14 Vgl. J. Day, An Economic History of Athens under Roman Domination, New York 1942, 192-193, der in diesem Punkt (Beschränkung des Verbots nur auf den Fischhandel oder nicht) unnötig schwankte. 
kannt. Übrigens erwähnt der Brief keine Delegation, die dem Kaiser den Anstoß zu all diesen Maßnahmen gegeben hätte. Es ist also sehr wahrscheinlich, daß Hadrian aufgrund genauer Kenntnis der Situation am Athener Markt die punktuelle Regelung für Eleusis mit einem größeren Versuch hat verbinden wollen, das Handelsleben Athens insgesamt zu sanieren.

Einen ähnlichen Eindruck gewinnt man bei einer genauen Betrachtung des sogenannten Ölgesetzes Hadrians. Diese Inschrift, eingemeißelt am Haupteingang des „Römischen Marktes“ in Athen, steht bekanntlich unter dem abgekürzten Titel „Kapitel der Gesetzgebung Hadrians“,15 was man auch längst mit der Angabe spätantiker Chronisten in Verbindung gebracht hat, der Kaiser habe auf Wunsch der Athener eine Neuedition der Gesetze Drakons und Solons für ihre Stadt ausgearbeitet. ${ }^{16}$ Man kann nicht wissen, ob diese athenische Wunschäußerung je eine offizielle und spezifische Form angenommen hat; die Inschrift ergibt auf jeden Fall wieder eher das Bild einer energischen Intervention des Kaisers, nach seinem freien Ermessen und im eigentlichen Ediktstil, zur Behebung eines aktuellen Mißstands im Funktionieren der Stadt, d. h. des Mangels an ausreichenden Olivenölreserven. ${ }^{17} \mathrm{Hadri-}$ an scheint hier schon bestehende, vielleicht in der Praxis nicht mehr angewendete athenische Vorschriften zur Bildung einer städtischen Olivenölreserve eingeschärft und um ein genaues Kontrollverfahren ergänzt zu haben. ${ }^{18}$ Die gesamte Ölproduktion und der Ölexport sollten nunmehr sorgfältig registriert und dem Staat der jeweils vorgeschriebene Anteil abgeliefert werden. Jeglicher Versuch, diese Regelung zu umgehen, sollte bestraft werden; die Aufsicht darüber übernahm im attischen Bereich natürlich Athen, während eventuelle Anzeigen gegen unregistriert ausfahrende Händler an die jeweilige

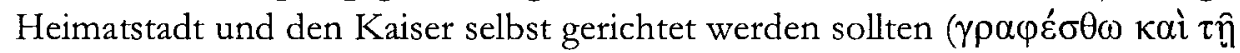

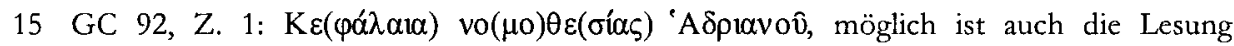

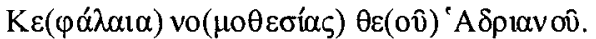

16 Besonders Hieronymus und Eusebios: die Quellenbelege zusammengestellt bei P. Graindor, Athènes sous Hadrien, Kairo 1934, 30-31. Vgl. zuletzt Birley, Hadrian (wie Anm. 10), 177, der auch den lokalen prosopographischen Hintergrund zu Hadrians Tätigkeit in Athen mit untersucht.

17 Olivers Meinung (GC, S. 238): „Hadrian appears here in his invited role of Athenian nomothetes as well as emperor. He is primarily a nomothete in a tradition going back to Draco and Solon, so that we should not refer to the law as part of an edict, though it would have had the same validity as an imperial edict" wirkt auf den ersten Blick widersprüchlich, entspricht aber schließlich der komplizierten förmlichen Seite der Situation. Die Tatsache kaiserlicher Intervention - sie wird richtig von Boatwright, Hadrian (wie Anm. 10), 91 unterstrichen - ist dabei teilweise verdeckt worden.

18 Vgl. Oliver, GC, S. 237. 


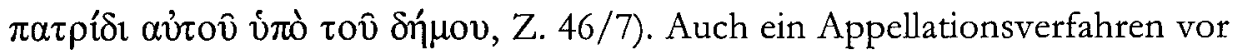
dem Kaiser oder dem Prokonsul wurde vorgesehen, während - im Sinne einer strengen Politik gegen Wucher - als Preis des Öls bei der Ablieferung an die Stadtbehörden der jeweils auf dem Land gültige (also wieder der Preis beim Produzenten) bestimmt wurde. ${ }^{19}$

Nun ist es naheliegend, daß die mißliche Situation, die Hadrian durch dieses neue bzw. erneuerte und ergänzte Gesetz zu beheben versuchte, auf ein weitgehendes, stillschweigendes Verschulden vieler athenischer Bürger zurückging, die am Ölexport mehr verdienten als an der internen Ablieferung ihrer Produktion. Die dagegen gerichtete, detaillierte Regelung Hadrians kann also schwerlich einem Beschluß des Demos mit ähnlichem Inhalt entsprungen sein. Vorausgesetzt, daß eine diesbezügliche Bitte überhaupt von athenischer Seite geäußert worden sein sollte, kann sie wohl nur von verantwortlichen städtischen Beamten vor den Kaiser gebracht worden sein, die allein kaum in der Lage gewesen wären, die Situation gegen den Willen der am Problem mit Eigengewinn beteiligten Athener zu verbessern. Hadrians Handeln wird also auch hier höchstens dem Wunsch eines Teils der Athener entsprochen haben und kaum als mehr oder weniger mechanische Reaktion auf eine spezifische Bitte zu deuten sein. Die Rolle des Kaisers war hier wieder alles andere als passiv: Sie lief eigentlich darauf hinaus, als wirksames Korrektiv städtischer Selbstparalysierung zu wirken.

\section{Antinoopolis und seine „Neugriechen“}

Hadrian hat bekanntlich eine Reihe von Städten in verschiedenen Gebieten des Reiches (besonders im Osten) gegründet, um den dortigen Urbanisierungsgrad zu steigern und seinen Namen dadurch zu verewigen. Es wäre wohl schon insgesamt verfehlt, eine solche Politik bloß als Rücksichtnahme auf lokale Wünsche und Bitten deuten zu wollen. ${ }^{20}$ Speziell im Fall der einzigen großen hadrianischen Stadtgründung im Osten jedoch, die nicht mit dem

19 Day, Economic History (wie Anm. 14), 192 erkennt hier einleuchtenderweise Hadrians Sorge um die Beseitigung von Vermittler- und ähnlichen, preissteigernden Diensten wieder. Diese Bemerkung hilft dann weiter, ein kohärenteres Gesamtbild der hadrianischen Sicht athenischer Probleme und ihrer möglichen Lösungen wiederherzustellen.

20 Über die Städtegründungen Hadrians vgl. jetzt besonders Boatwright, Hadrian (wie Anm. 10), 172-203 (mit der älteren Literatur). Ihre Analyse ergab, daß sich diese Tätigkeit des Kaisers in seine allgemeinere Politik der Förderung von Städten im Reich einordnen läßt, die als "Greco-Roman showcases" (173) und ideologische Bastionen des Kaisertums dienen konnten. 
Namen des Kaisers verbunden worden ist, dem ägyptischen Antinoopolis, darf man vielleicht ein paar weitere, hier dienliche Bemerkungen über den Sinn des kaiserlichen Handelns äußern.

Antinoopolis ${ }^{21}$ war ja dem Gedächtnis des jungen, auf rätselhafte Weise im Nil umgekommenen bithynischen Geliebten Hadrians gewidmet. Der geringen Zahl griechischer Städte, die Ägypten besessen hatte, wurde dadurch ab $130 \mathrm{n}$. Chr. eine neue hinzugefügt. Interessant scheinen mir auch in diesem Rahmen die Zusammensetzung und die speziellen Privilegien der Bürger von Antinoopolis. Hadrian hatte die erste Generation von Antinoopoliten aus der Polis Ptolemaïs und der steuermäßig privilegierten Schicht der sogenannten 6475 Hellenen des Arsinoïtes, weiter wohl auch aus römischen Veteranen rekrutiert. Die Antinoopoliten, Männer und Frauen, sollten nicht nur die üblichen Privilegien der sonstigen Griechenstädte Ägyptens genießen, sondern auch das Recht der Epigamie mit Ägyptern bzw. Ägypterinnen besitzen. Die Kinder aus solchen Ehen wurden ebenfalls Antinoopoliten, die Bürger der

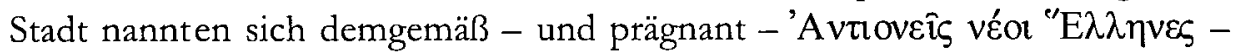
„Antinoopoliten, neue Hellenen“. Unter ihren verschiedenen weiteren (politischen, fiskalischen, juristischen und kulturellen) Privilegien, darf man vielleicht besonders erwähnen, daß sie von allen Liturgien außerhalb von Antinoopolis selbst befreit waren, was bei ihrer oft bezeugten Beibehaltung ihres Wohnorts in der Chora sehr bedeutend gewesen sein muß. Hadrian hat so seine ägyptische Gründung mit einer hohen Anziehungskraft gegenüber der Standardbevölkerung der Provinz dotiert.

Der Sinn dieser programmatisch griechischen Stadt griechisch-ägyptischer Herkunft im römischen Ägypten beschäftigt die Forschung schon lange und wird sie sicherlich weiterhin beschäftigen. ${ }^{22}$ Was aber sicher ist: Man darf

21 Ausführlich und eingehend darüber M. Zahrnt, Antinoopolis in Ägypten: Die hadrianische Gründung und ihre Privilegien in der neueren Forschung, ANRW II 10, 1, 1988, 669-706; Birley, Hadrian (wie Anm. 10), 249-257; Boatwright, Hadrian (wie Anm. 10), 190-196 (mit der neueren Literatur). Von rechtshistorischer Seite, wo die bei genauer Analyse unverkennbar römische Ausrichtung des neuen Stadtrechts unterstrichen wird, auch wichtig: F. Sturm, Ha conferito Hadriano un statuto personale speciale agli Antinoiti?, Iura 13, 1992, 83-97; J. Mélèze-Modrzejewski, L'Égypte, in: C. Lepelley (Hg.), Rome et l'integration de l'Empire, Bd. 2: Approaches régionales du Haut-Empire romain, Paris 1998, 459-460.

22 Vgl. die vorige Anm. Ich beschränke mich hier auf die Bemerkung, daß die Stadt neben der Erweiterung der gesellschaftlichen Herrschaftsbasis Roms in Ägypten, etwa ähnlich wie bei der zeitlich parallelen Entwicklung zum ius Latii maius in der westlichen Reichshälfte (nach Zahrnt), doch auch entschieden ein erweitertes Verständnis von Hellenentum und seiner Funktionsfähigkeit im römischen Interesse an den Tag legte (vgl. bes. Birley, Hadrian [wie Anm. 10], 254). 
kaum annehmen, daß die Verfassung der Stadt und die Privilegien ihrer Bewohner das Ergebnis einer irgendwie organisierten Interessenvertretung, geschweige denn die mehr oder weniger verarbeitete Form eines lokalen Gesuchs gewesen sein könnten. Weder die verpflanzten Ptolemaier und die Hellenen des Fayum noch die Ägypter und die Ägypterinnen der Chora hegten wohl solche hochfliegenden Ambitionen. Hadrian hat hier wieder nicht auf Bittschriften re agiert, sondern nach seinen eigenen persönlichen Gründen und im Sinne der Zweckmäßigkeit und sicheren Zukunftsperspektive dieser Neugründung gehandelt. Wie man sein antinoopolitisches Programm auch auffassen und deuten mag, bestimmt entsprach es hauptsächlich seinem eigenen Konzept der römischen Administration der ägyptischen Provinz. Die Initiative zu diesem komplizierten städtischen Experiment lag vollständig bei ihm, ${ }^{23}$ nur der genaue Platz der neuen Stadtanlage (der Bereich der bis dann ,stadtlosen" Heptanomia) wird ihm vielleicht - außer dem genauen Ort des Todes von Antinoos - auch durch lokal gesammelte und berücksichtigte administrative Erfahrung nahegelegt worden sein. Das Programm von Antinoopolis war also in jeder Hinsicht eine hadrianische Schöpfung.

\section{Das Panbellenion und seine Vision}

Der Fall des im Jahr 131/2 gegründeten Panbellenion Hadrians ist nicht weniger aufschlußreich. Dank neuer Texte und speziell nach den Untersuchungen von James Oliver, ${ }^{24}$ Anthony Spawforth und Susan Walker, ${ }^{25}$ Dietrich Willers, ${ }^{26}$ Christopher P. Jones ${ }^{27}$ und noch einmal Anthony Spawforth ${ }^{28}$ kann man die Grundzüge dieser Institution inzwischen bei aller Divergenz in einzelnen Punkten viel besser begreifen. Das Bild einer primär kulturell-

23 Besonders deutlich wird dies an den Phylen- und Demennamen von Antinoopolis, deren Wahl hauptsächlich auf die familiäre Namengebung Hadrians sowie griechische und ägyptische Sakraltradition zurückging; vgl. Birley, Hadrian (wie Anm. 10), 254: „There can be no question but that the choice of names was Hadrian's own".

$24 \mathrm{~J}$. H. Oliver, Marcus Aurelius. Aspects of Civic and Cultural Policy in the East, Princeton 1972, bes. $92-138$.

25 A. J. Spawforth/S. Walker, The World of the Panhellenion I, JRS 75, 1985, 78-104; II, JRS 76, 1986, 88-105.

26 D. Willers, Hadrians panhellenisches Programm. Archäologische Beiträge zur Neugestaltung Athens durch Hadrian, Basel 1990, bes. 54-67, 93-103.

27 C. P. Jones, The Panhellenion, Chiron 26, 1996, 29-56.

28 A. J. Spawforth, The Panhellenion Again, Chiron 29, 1999, 339-352, veranlaßt durch die Arbeit von Jones. 
religiösen Vereinigung aller abstammungsmäßig und/oder nach griechischem Kulturstatus vom Kaiser anerkannten belleniscben Städte, zentriert um den römischen Kult des regierenden Kaisers (also zunächst den Hadrians), mit penteterischem Tagungs- und Festsitz in Athen ist für die Beziehungen der römischen Kaiser zu den griechischen Städten bis in die Severerzeit mitprägend. ${ }^{29}$ In den letzten Jahren ist besonders die „Vaterschaft" dieser Institution diskutiert worden. Während Jones für die Interpretation eines einschlägigen Passus bei Cassius $\mathrm{Dio}^{30}$ in dem Sinne plädiert hat, daß die Idee des Panbellenion eine Initiative "der Hellenen" darstellte, die von Hadrian bloß bewilligt worden wäre, ${ }^{31}$ hat Spawforth ${ }^{32}$ mit Recht darauf hingewiesen, daß es in jener Stelle nicht um die schon früher (im oben erwähnten attischen Jahr) erfolgte Gründung der Institution, sondern um die des Tempels zu Ehren Hadrians mit seinem inzwischen anerkannten Kultepitheton Panbellenios geht.

Darüber hinaus - wie ebenfalls von Spawforth bemerkt - hat man jetzt einen wertvollen Beleg über die fragliche Initiative in dem Dekret des kleinasiatischen Thyateira für Hadrian, wie es zuletzt von Follet und PeppasDelmousou unter Zufügung neuer Fragmente ediert worden ist. Im letzteren wird eindeutig von Hadrian als dem gemeinsamen Wohltäter der Hellenen gesprochen, der ,aus ihrem Kreis jenen Kongreß zusammengerufen hat ..., das [ehrwürdigste] Panbellenion" ${ }^{33}$ Ansonsten wird im gleichen Passus sehr wahrscheinlich die offizielle Mitwirkung des Senats bei dieser kaiserlichen Entscheidung erwähnt, genau wie es beim vorausgegangenen Plan einer panhellenischen Erweiterung der delphischen Amphiktionie wieder unter Hadrian (im Jahr 125) der Fall gewesen war. ${ }^{34}$ Eine weitere Beratung Hadrians mit seinen griechischen Freunden über Sinn und Form der zu gründenden Orga-

29 Eine nützliche Skizze der Institution und Zusammenfassung der diesbezüglichen neueren Literatur bei Boatwright, Hadrian (wie Anm. 10), 147-153, die richtig die Anwendung nicht nur echt genealogischer, sondern auch kultureller Kriterien (unter dem Mantel fiktiver Genealogien) bei der Aufnahme von Mitgliedern ins Panbellenion betont (150). Es gibt also keinen Widerspruch zum Gründungsgeist von Antinoopolis.

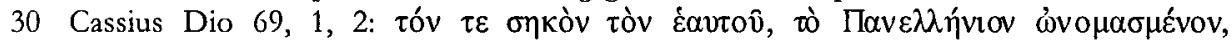

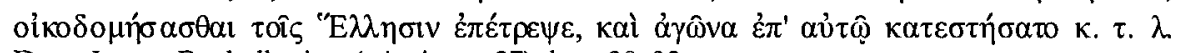
Dazu Jones, Panhellenion (wie Anm. 27), bes. 30-32.

31 Ablehnend schon Birley, Hadrian (wie Anm. 10), 344 Anm. 10.

32. Spaw forth, Panhellenion (wie Anm. 28), 345-347.

33 S. Follet/D. Peppas-Delmousou, Le décret de Thyatire sur les bienfaits d'Hadrien et le „Panthéon” d'Hadrien à Athènes, BCH 121, 1997, 291-309, hier: 296 = SEG XLVII 163,

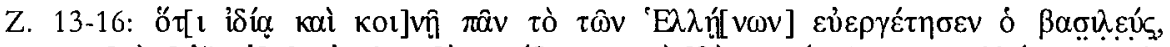

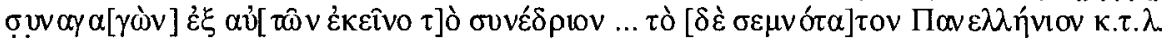
SEG XLVII 163, Z. 16-17, vgl. GC 75, II, Z. 1-6. 
nisation ist wohl auch wahrscheinlich, ${ }^{35}$ ändert aber nichts an dem grundsätzlich hadrianischen Konzept des Panbellenion.

Es würde hier zu weit führen, alle Aspekte der hadrianischen Zielse tzung bei der Gründung des Panhellenion zu erörtern. Von den Ergebnissen der einschlägigen Forschung braucht man in diesem Rahmen nur folgendes festzuhalten: Der Hauptzweck dieser großangelegten Initiative Hadrians war wohl, im stets kulturell stark sonderbewußten und differenzierten Osten des Reiches den Zusammenhalt des Griechentums unter kaiserlicher Ägide und mit der Loyalität zum Kaiser als Mittelpunkt zu fördern. ${ }^{36}$ Dies war aber wieder ein Kohärenzanstoß, der den Griechen vom Kaiser auferlegt worden war und anscheinend nie besonders deren Sympathien gewonnen hat, abgesehen von den Ehrgeizperspektiven eines Teiles der provinzialen griechischen Aristokratie. ${ }^{37}$ Wenn eine Vision hinter dem Panhellenion steckt, war sie bestimmt vorerst diejenige Hadrians und nicht der Griechen. Der Kaiser führte höchstens einen Dialog mit seinem eigenen Ideal des klassischen Griechentums, er reagierte wohl eher auf das Beispiel des Perikles mit seinem bei Plutarch (Per. 17) überlieferten Versuch eines panhellenischen Kongresses 38 als auf irgendwelche ausgesprochenen Bedürfnisse seiner griechischen Zeitgenossen. Ansonsten richtete sich das kaiserliche Handeln primär, und natürlich, nach den gesamten Reichsinteressen.

\section{Schlußfolgerung}

Um das Fazit vorzubereiten, sollte man in Bezug auf Hadrian unbedingt auch die Tatsache seiner intensiven und häufigen Präsenz an verschiedenen Punkten des Reiches unterstreichen. Ein Kaiser, der am jeweiligen Ort ein eigenes Bild der Probleme gewinnen konnte, war beides: zugänglicher und informierter als andere. ${ }^{39}$ Darum hatte das Millarsche ,petition-and-response“-Modell

35 Vgl. Birley, Hadrian (wie Anm. 10), 218; Spawforth, Panhellenion (wie Anm. 28), 342.

36 Vgl. bes. die Schlüsse in Spawforth/Walker, Panhellenion II (wie Anm. 25), 104-105.

37 Dazu Spawforth, Panhellenion (wie Anm. 28), 350-351.

38 So schon M. Sartre, L'Orient romain (31 av. J.-C. - 235 ap. J.-C.), Paris 1991, 210 Anm. 4; Birley, Hadrian (wie Anm. 10), 219. Eine Rivalität Hadrians zu den großen Gestalten der athenischen Vergangenheit ist ja zumindest in den bekannten zwei Inschriften des Hadrianstores impliziert, wo Theseus- und Hadriansstadt Athen gegenübergestellt werden.

39 Über die Bedeutung der Zugänglichkeit vgl. Millar, Emperor (wie Anm. 1), 28-40 („Imperial Journeys"). Weiter: H. Halfmann, Itinera principum. Geschichte und Typologie der Kaiserreisen im römischen Reich, Stuttgart 1986, 151-156 („Reisen und Regieren“), darin insbesondere die Bemerkung (156): „Allerdings realisierten einzig Augustus und Hadrian, 
bei ihm einen ganz anderen Stellenwert. ${ }^{40}$ Besonders bei ihm kann also schließlich in keinerlei Hinsicht die Vorstellung eines passiven, fast nur auf Petitionen reagierenden Kaisertums aufrechterhalten bleiben. ${ }^{41}$ Um Hadrians bekannte Worte darauf zu adaptieren: Animula vagula blandula in imperio sollicite circumibat. ${ }^{42}$

dieser unter dem Eindruck des augusteischen Vorbildes, mit ihren Reisen ein politisches Programm, das in erster Linie auf den Wohlstand und inneren Frieden aller Provinzen abzielte."

40 Natürlich darf man diese Dimension kaiserlicher Tätigkeit, zumal bei einem Kaiser wie Hadrian (vgl. z. B. seinen Brief an die Bürger von Aphrodisias: GC 69), kaum außer acht lassen. Sie war aber eine wohlüberlegte Ergänzung und nicht der Ersatz einer auch Initiativen ergreifenden, von bestimmten Prinzipien und allgemeineren Zielsetzungen geprägten Innenpolitik des Reiches.

41 Dieses Bild der hadrianischen Reichsadministration wird durch einen Passus des Pausanias $(1,5,5)$ weiter gestützt, wonach Hadrians Wohltätigkeit den griechischen Städten ,und

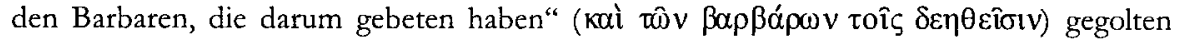
hat (freundlicher Hinweis von Michael Zahrnt). Die Spezifizierung in bezug auf die Barbaren suggeriert ja eindeutig, daß Ähnliches bei den Griechen nicht nötig und wohl nicht die Regel war.

42 HA Hadrian 25, 9. 


\title{
Clodius Albinus und der Bürgerkrieg von 197
}

\author{
Mattbäus Heil
}

\section{Die Schlacht von Lyon und die Verfassung des Römischen Reiches}

150.000 Mann sollen es gewesen sein, die an einem Wintertag im Februar 197 n. Chr. bei Lyon gegeneinander kämpften. ${ }^{1}$ Es war eine der größten Schlachten der römischen Geschichte, aber alle Beteiligten waren römische Soldaten: Es herrschte Bürgerkrieg. Am Ende des Tages hatten Tausende ihr Leben oder ihre Gesundheit verloren, aber statt zweier rivalisierender Augusti gab es nur noch einen: nicht D. Clodius Albinus, sondern L. Septimius Severus, den Mann aus Africa. ${ }^{2}$

Man könnte die Schlacht als welthistorische Episode bagatellisieren oder sie mit dem Gemeinplatz abtun, der Streit der Großen werde immer auf dem Rücken der kleinen Leute ausgetragen. Aber das Römische Reich der Kaiserzeit wird uns meist als wohlgeordnetes System vorgestellt. So verdient es Interesse, wie es zu diesem Gemetzel kam, oder besser: warum es nicht verhindert wurde, obwohl angeblich niemand den Bürgerkrieg gewollt hat.

Hier berührt man die Frage nach der Verfassung des Reiches. Bekanntlich wurde darüber viel diskutiert, ohne daß man ein allseits gesichertes

1 Zahl bei Cass. Dio 75, 6, 1. Dies wäre gut die Hälfte aller Truppen unter römischem Befehl. Die Angabe scheint grundsätzlich plausibel, müssen doch bei einer Entscheidungsschlacht alle Reserven ins Gefecht geworfen werden. Die Größe der Schlachten des Severus wird auch angesprochen von Herod. 3, 7, 7. - Alle hier angeführten Daten betreffen die Zeit „n. Chr.“, so daß im Folgenden darauf verzichtet werden kann, dies jeweils ausdrücklich anzugeben.

2 Grundlegend zu allem, was Septimius Severus betrifft, ist nach wie vor A. R. Birley, The African Emperor. Septimius Severus, London 1988. Zu Datierungsfragen ist immer noch J. Hasebroek, Untersuchungen zur Geschichte des Kaisers Septimius Severus, Heidelberg 1921 von Belang, obwohl das Werk stark revisionsbedürftig ist. - Zu Clodius Albinus siehe PIR ${ }^{2}$ C 1186. 
Ergebnis erreicht hat. Theodor Mommsen ${ }^{3}$ hatte den Principat als Amt aufgefaßt und das Kaisertum damit als konstitutionelle Monarchie avant la lettre interpretiert. Dies zu widerlegen, hat sich längst erübrigt. Ronald Syme hatte skeptisch-nüchtern geschrieben: „The principate baffles definition."4 Aber seine Darstellung der augusteischen Zeit wurde für die folgenden Epochen wohl nicht so weitergedacht, wie sie es verdient hätte. Es ist immer wieder versucht worden, das Kaisertum als festen Typus, als ein Quasi-Amt zu beschreiben. In Fergus Millars berühmten Buch „The Emperor in the Roman World“ 5 wird der römische Kaiser unausgesprochen mit einem modernen Regierungschef verglichen und nach der Innenpolitik gefragt, die dieser römische prime minister betrieb. Freilich ließ sich keine kohärente Politik feststellen, und es existierte dafür auch nicht der nötige Behördenapparat. ${ }^{6}$

Wahrscheinlich sollte man auf mehreren Ebenen zugleich weiterdiskutieren. Zum einen müßte man klären, was genau man mit, Verfassung meint. Ich möchte im Folgenden darunter verbindliche Vorschriften verstehen, wie wesentliche politische Streitfragen zu lösen sind. Doch fragt sich, ob es eine so verstandene Verfassung im Kaiserreich überhaupt je gegeben hat. Zum zweiten wäre nach der Einheitlichkeit des Kaisertums zu fragen. In der Forschung wurde sie vielleicht allzu selbstverständlich vorausgesetzt und zu schnell gefolgert, daß man die Geschichte der einzelnen Kaiser zugunsten der allgemeinen Strukturen vernachlässigen dürfe. Doch scheint es eher so, daß der Inhalt des Kaisertums jeweils neu definiert werden konnte und mußte. ${ }^{7}$ Und nur weil dem so war, konnte das Kaisertum sich verändern, so daß sich der Principat des Augustus schließlich zur quasi-sakralen Monarchie der Spätantike wandelte.

Zum dritten wäre stets zu bedenken, daß der Kaiser nur theoretisch allmächtig war. Er war gut beraten, immer im Auge zu behalten, woher seine Macht kam und wieviel sie ihm wirklich zu tun erlaubte. Er war mit sozialen Kräften und Widerständen konfrontiert, die er nicht einfach beseitigen

3 Th. Mommsen, Römisches Staatsrecht, Bd. II 2, Leipzig 31887.

4 R. Syme, The Roman Revolution, Oxford 1939, 21952, 323.

5 London 1977.

6 Für die Außenpolitik stellt das Millar selbst heraus: Emperors, Frontiers and Foreign Relations 31 B.C. to A.D. 378, Britannia 13, 1982, 1-23; auch in: ders., Rome, the Greek World, and the East, Bd. 2: Government, Society and Culture in the Roman Empire, Chapel Hill - London 2004, 160-194. Vgl. auch M. Horster, Bauinschriften römischer Kaiser. Untersuchungen zu Inschriftenpraxis und Bautätigkeit in Städten des westlichen Imperium Romanum in der Zeit des Prinzipats (Historia. Einzelschriften 157), Stuttgart 2001, wo festgestellt wird, daß es keine kohärente kaiserliche Baupolitik gab.

7 Vgl. auch A. Winterling, Caligula. Eine Biographie, München 2003. 
konnte. Und die Machtfaktoren in der Gesellschaft konnten ihre eigene Vision vom Kaisertum besitzen. ${ }^{8}$ Eine offene Diskussion wurde aber nicht zugelassen. Allenfalls auf der Ebene der praktischen Politik ließ sich ein Ausgleich oder eine Entscheidung herbeiführen. Hier spielte es durchaus eine Rolle, wer der Kaiser war, welche Lage er vorfand und wie er mit ihr umging. ${ }^{\text {? }}$

Solange ein Konsens der maßgeblichen Kräfte bestand und weitertradiert wurde, funktionierte das Imperium Romanum der Kaiserzeit erstaunlich gut. Was aber, wenn nicht? Wenn so viel von den Menschen und den Umständen abhing, wie hier behauptet wurde, dann hülfe es wenig, nach einer allgemeinen Antwort zu suchen. Man muß den einzelnen Fall betrachten. Und damit können wir zur eingangs formulierten Frage zurückkehren, warum es zu dem Bürgerkrieg gekommen ist, der in der Schlacht von Lyon gipfelte.

\section{Die Nachfolgekrise von 193-197}

Septimius Severus und Clodius Albinus waren ursprünglich keine Rivalen, sondern Verbündete. So muß man zunächst in das Vierkaiserjahr 193 zurückblicken, in dem sie zueinanderfanden. Die Wirren nach dem Tod des Commodus sind zwar schon oft behandelt worden. ${ }^{10}$ Doch lohnt es sich zu verfolgen, wie und unter welchen Umständen ihre Allianz Gestalt annahm.

Eines der zentralen Probleme einer jeden Monarchie ist die Herrschaftsnachfolge. Das Vierkaiserjahr 193 illustriert vor allem eines: daß es hierfür im Imperium Romanum keine feste Regel gab. Der Kaiser Commodus wurde am 31. Dezember 192 von Personen aus seiner engsten Umgebung ermordet.

8 Die uns vorliegenden literarischen Quellen sind wohl nur bedingt repräsentativ für die Gesamtgesellschaft. Sie gewähren Einblicke vor allem in die Gedankenwelt der Senatsaristokratie und allenfalls der gebildeten Oberschicht. Ob z. B. die Soldaten und die plebs urbana genauso dachten, erscheint fraglich, und die wenigen, indirekten Hinweise sprechen eher dagegen. Die kleinen Leute waren anscheinend weniger an einem Staatslenker interessiert, der sich als der erste Bürger gab, sondern mehr an einem starken, jovialen Alleinherrscher, der als Patron der einfachen Menschen handelte und die Großen notfalls streng in die Schranken wies.

9 Die hier vorgetragenen Überlegungen berühren sich in einigen Punkten mit denen von E. Flaig (Den Kaiser herausfordern. Die Usurpationen im Römischen Reich, Frankfurt/Main 1992 und spätere Arbeiten), ohne deren recht artifiziellen Begriffsapparat und ihre Schlußfolgerungen zu übernehmen.

10 Siehe hierzu und zum Folgenden zusammenfassend Birley, Septimius Severus (wie Anm. 2). 
Er hinterließ weder einen Sohn noch einen designierten Nachfolger. Zwar präsentierten die Mörder schon am 1. Januar 193 einen neuen Herrscher: den alten Stadtpräfekten Helvius Pertinax. ${ }^{11}$ Doch er war offenkundig eine Verlegenheitslösung.

Der Senat träumte von einer idealisierten Antoninen-Monarchie, das heißt von der Herrschaft des (in ihren Begriffen) vornehmsten Senators. Pertinax versuchte, ihrem Wunschbild geradezu exemplarisch zu entsprechen und ist damit kläglich gescheitert. Gerade im Senat war er mit erheblichen Widerständen konfrontiert. ${ }^{12}$ Pertinax war ein Aufsteiger, dem nach traditionell-senatorischen Maßstäben nicht die Stellung an der Spitze gebührte. Und an seiner Herkunft konnte er nichts ändern.

Die Prätorianergarde wurde von Pertinax vernachlässigt. Dabei gab es die Tradition, daß die Garde den Kaiser machte. Doch existierte bei ihr kein geordnetes Verfahren der politischen Willensbildung - und dies durfte es beim Militär auch nicht geben. Einflußreiche Wortführer konnten die Gardesoldaten in Krisenfällen zu Gewaltstreichen aufstacheln: Das genügte, um Pertinax zu ermorden. Eine konsistente Politik ließ sich aber darauf nicht gründen.

Nach dem Tod des Pertinax hat Didius Iulianus bei der sogenannten Auktion des Kaisertums die Prätorianer mit dem Versprechen großer Geldgeschenke auf seine Seite gebracht und so die Herrschaft erobert. Doch außer den Begünstigten dürfte es niemandem eingeleuchtet haben, daß der Sinn des Kaisertums nur in der Bereicherung von ein paar tausend Soldaten bestehen sollte. Am Ende haben nicht einmal die Prätorianer ernsthaft für Didius Iulianus gekämpft.

Die Armeen in den Provinzen übertrafen an Zahl und Kampfkraft die Prätorianergarde um ein Vielfaches. Doch spielten sie gewöhnlich keine Rolle, wenn in Rom binnen Stunden eine Entscheidung fiel. Anfang 193 war aber für einige Monate vieles offen. Selbstverständlich waren auch die Provinzheere nicht auf eine eigene Willensbildung hin organisiert. Doch mit den senatorischen Kommandeuren gab es potentiell regimentsfähige Anführer. In der labilen Situation des Frühjahres 193 meldeten drei von ihnen ihre

11 Zu seiner Herkunft und Karriere vgl. PIR ${ }^{2} \mathrm{H} 73$.

12 Siehe die Verschwörung des Q. Sosius Falco, des consul ordinarius von 193 (PIR² P 655 mit Auflistung der Zeugnisse). Er entstammte einer hochadeligen Familie; bereits sein Vater und sein Großvater waren consules ordinarii gewesen (PIR P 612 bzw. 656). Pertinax hat es nicht gewagt, diesen Mann für seinen Hochverrat zu bestrafen. - Auch die Haltung des Claudius Pompeianus, des noch lebenden Schwiegersohns Marc Aurels, blieb undurchsichtig (PIR² C 973 mit Zeugnissen). 
Ansprüche an. Es waren die Kommandeure der größten Heere: Pescennius Niger, der Legat von Syrien, Septimius Severus, der Legat von Oberpannonien, und Clodius Albinus, der Legat von Britannien (siehe Karte 1). Schon damals dürfte klar gewesen sein, daß sie ihre Soldaten würden belohnen müssen, sobald sie mit ihrer Hilfe die Herrschaft errungen hatten.

Eine Kraft wurde noch nicht erwähnt, und sie wird auch oft übersehen: die öffentliche Meinung. Von den Protagonisten der nun einsetzenden Bürgerkriege wurde sie sehr ernst genommen, am meisten wohl von Septimius Severus. ${ }^{13}$ Selbstverständlich wurde der Bürgerkrieg vom Publikum verabscheut. So versuchten die Prätendenten zu zeigen, daß sie ihn zu vermeiden trachteten oder wenigstens im Interesse eines hohen Gutes handelten. Aber - und das scheint mir wichtig - es wurde nicht nur Propaganda betrieben, sondern die Rücksichtnahme auf die öffentliche Meinung beeinflußte auch die reale Politik. ${ }^{14}$

\section{Die Ursprünge der Idee der Machtteilung}

Pescennius Niger und Septimius Severus ließen sich im Frühjahr 193 nahezu gleichzeitig von ihren Truppen zum Kaiser ausrufen, ${ }^{15}$ und die jeweiligen Nachbarprovinzen schlossen sich an. Niger verfügte über eine gewisse

$13 \mathrm{Zu}$ seiner, Öffentlichkeitsarbeit' gehörte allem Anschein nach seine Autobiographie, die in den vorliegenden Quellen wiederholt erwähnt wird (Fragmente bei H. Peter, Historicorum Romanorum Reliquiae, Bd. 2, Leipzig 1906, 118-120, siehe bes. Herod. 2, 9, 4). Ferner berief sich Severus gegenüber dem Publikum in hohem $\mathrm{Maß}$ auf Orakel und auf die Astrologie, siehe dazu besonders Z. Rubin, Civil War Propaganda and Historiography (Collection Latomus 173), Brüssel 1980. Zur Berufung auf Orakel im Albinus-Krieg siehe auch G. Alföldy, Pannoniciani augures, in: ders.: Die Krise des Römischen Reiches. Geschichte, Geschichtsschreibung und Geschichtsbetrachtung. Ausgewählte Beiträge (HABES 5), Stuttgart 1989, 139-163 (zuerst 1960, hier mit Nachträgen). - Auch Cassius Dio hatte sich in seiner Jugend daran beteiligt, indem er ein Werk über die Vorzeichen und Träume verfaßte, die die Herrschaft des Severus ankündigten (und damit als vom Schicksal gewollt legitimierten). Ein Exemplar sandte er an Severus und erhielt von diesem ein freundliches Dankschreiben (Cass. Dio 72, 23, 1).

14 Wenn man diese Öffentlichkeit als Personen fassen will, so ist nicht nur an den Senat und die Soldaten zu denken, sondern vor allem an die lokalen Eliten, den Ritterstand und an die Gebildeten - immerhin einen Kreis von Zehntausenden von Personen. Ohne deren wohlwollende Duldung konnte kein Regime auf die Dauer bestehen.

15 Bei Severus kennt man das genaue Datum: den 9. April 193, siehe P. Dura 54 (das feriale Duranum). 
Popularität in Rom. ${ }^{16}$ Severus jedoch fand eine zündende Parole: die Rache für den ermordeten Kaiser Pertinax. So konnten er und seine Anhänger ihre Rebellion als eine höchst löbliche Tat darstellen. Severus selbst nahm den Namen ,Pertinax' an und hielt zeitlebens daran fest. Der Sieg gegen Didius Iulianus gelang rasch und leicht.

Noch während Severus in höchster Eile auf Rom marschierte, hatte er Verhandlungen mit Clodius Albinus angeknüpft: Er hatte Albinus brieflich den Caesar-Titel angeboten, ${ }^{17}$ es war zum Austausch von Botschaften gekommen, und noch vor dem Sieg über Didius Iulianus war eine Einigung gelungen. Deren Inhalt wird in den griechischen literarischen Quellen als ,Teilhaberschaft ${ }^{\prime}$ des Albinus an der Herrschaft des Severus umschrieben, ${ }^{18}$ wobei unklar bleibt, ob Severus und Albinus selbst diesen schillernden Begriff verwendet haben. Konkretes ist nur den unmittelbaren praktischen Folgen zu entnehmen: Septimius Severus blieb ,Augustus', während Albinus den Titel eines ,Caesar' erhielt. Ferner nahm Albinus den Namen ,Severus‘ an. Beide amtierten im Jahr 194 gemeinsam als consules ordinarii, und in Rom wurden Münzen auch im Namen des Albinus geprägt. ${ }^{19}$ Inwieweit darüber hinaus die Details der künftigen Zusammenarbeit abgesprochen wurden, muß offenbleiben. Die taktische Bedeutung des Bündnisses ist offensichtlich: Severus sicherte sich einen freien Rücken für den Krieg gegen Didius Iulianus und vor allem für die anstehende Auseinandersetzung mit Pescennius Niger. Albinus hingegen wurde Teilhaber an einem Kaisertum, ohne selbst dafür kämpfen zu müssen. Hätten sich Severus und Niger im Bürgerkrieg gegenseitig aufgerieben, wäre er zudem wohl der lachende Dritte gewesen.

Das Zweckbündnis implizierte aber den bemerkenswerten Gedanken, daß potentielle Rivalen sich zu einer gemeinsamen Herrschaft zusammenschlossen. Inspiriert wurde er offenkundig von der jüngeren Vergangenheit:

16 Cass. Dio 74, 13, 5; 74,15, 2; Herod. 2, 7, 3-5; HA Pesc. Niger 2, 2; 3, 1: Es gab in Rom im Circus eine Demonstration für ihn.

17 Cass. Dio 75, 15, 1-2; ganz ähnlich Herod. 2, 15, 3.

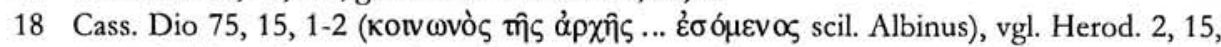

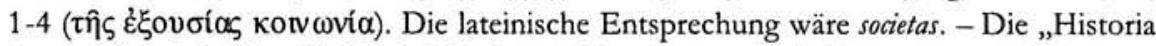
Augusta“" weicht hier ab: Nach HA Sev. 6,9 hat Severus lediglich erwogen, Albinus zu seinem Nachfolger zu ernennen (de Clodio Albino sibi substituendo cogitavit); nach HA Sev. 6, 11 wurde ein Heraclitus (PIR ${ }^{2} \mathrm{H} 88$ ) von Severus ad optinendas Britannias geschickt. Allerdings erscheint es so gut wie ausgeschlossen, daß der Emissär des Severus die Statthalterschaft an sich zu reißen suchte. Worum es tatsächlich ging, bleibt unklar; vielleicht liegt eine Verwechslung von Britannien mit Bithynien vor (vgl. HA Pesc. Niger 5, 2). Siehe auch A. R. Birley, The Fasti of Roman Britain, Oxford 1981, $295 \mathrm{f}$.

19 RIC IV 1 Clodius Alinus 1-12A; 50-63; vgl. auch Herod. 2, 15, 5. 
Bereits Hadrian hatte einen Caesar ernannt; ${ }^{20}$ auch Antoninus Pius kooptierte einen Caesar, den späteren Marc Aurel. Nach dem Tod des Pius regierten sogar zwei Augusti gemeinsam: Marc Aurel und Lucius Verus. Ferner wurde Commodus, der Sohn Marc Aurels, schon früh zum Caesar ernannt und einige Zeit nach dem Tod des Verus zum mitregierenden Augustus erhoben. Die Caesar-Ernennung bedeutete hier jeweils die Designation zum Nachfolger. Das gleiche ist bei Clodius Albinus vorauszusetzen. Die severische Propaganda spielte auch deutlich darauf an, zumal die Söhne des Severus damals erst vier und fünf Jahre alt waren. ${ }^{21}$ Allerdings war Albinus annähernd so alt wie Severus. ${ }^{22} \mathrm{Um}$ so mehr wurde die Offerte als ein Mittel dargestellt, um den Bürgerkrieg überflüssig zu machen. Mit dem AugustusRang des Severus und dem Caesar-Titel des Albinus war die Ungleichheit der Partner von Anfang an festgeschrieben. Das ist deshalb bemerkenswert, weil es zuvor auch die Herrschaft gleichberechtigter Augusti gegeben hat.

In der Antoninen-Zeit waren die Caesares und Augusti allerdings entweder zugleich Vater und Sohn oder Brüder. Allein schon deswegen durfte ein antoninischer Caesar fest mit der Nachfolge rechnen. Hingegen waren Severus und Albinus nicht persönlich aneinander gebunden - außer durch ihre Absprache. Beinahe gleichzeitig ist ein weiteres Angebot einer Samtherrschaft unterbreitet worden. Denn als Severus fast schon vor Rom stand und die Truppen des Didius Iulianus kampflos davonliefen, ließ dieser dem Severus durch einen Senatsbeschluß die Mitherrschaft antragen. ${ }^{23}$ Severus ging - selbstverständlich - nicht darauf ein. Didius Julianus wollte ganz offensichtlich nur seinen Kopf retten, und für Severus lagen in dem Angebot viele Nachteile, aber kein echter Vorteil. Schon kurz darauf fand sich Iulianus von allen Gefolgsleuten verlassen und wurde in vorauseilendem Gehorsam ermordet.

Severus trat in Rom eher als Eroberer denn als Befreier auf. Die Prätorianerkohorten wurden strafweise aufgelöst und durch ergebene pannonische Soldaten ersetzt. Die Garde spielte fortan keine politische Rolle mehr. Das Programm der ,Rache für Pertinax ' gipfelte in einer feierlichen Scheinbestat-

20 L. Aelius Caesar (PIR² C 605); vgl. auch A. R. Birley, Hadrian. The Restless Emperor, London 1997, 289-294.

21 Siehe Herod. 2, 15, 4 (Brief des Severus an Albinus); HA Pesc. Niger 4, 7 (mit Berufung auf die Autobiographie des Severus); HA Clod. Alb. 3, 4 (mit Berufung auf Marius Maximus); 10, 3. Severus war damals knapp 50. Das ungefähre Alter des Albinus kann man aus seiner Karriere erschließen. HA Clod. Alb. 4, 5 ist wertlos.

22 Vgl. auch HA Pesc. Niger 7, 1 (mit Berufung auf die Autobiographie des Severus).

23 Cass. Dio 73, 17, 2; Herod. 2, 12, 3-5; HA Did. Iul. 6, 5-9; HA Sev. 5, 7. 
tung des ermordeten Kaisers und seiner Divinisierung. ${ }^{24}$ Dem Senat zollte Severus Respekt, ließ aber erkennen, daß er das Heft in der Hand behalten wollte. Die Senatoren faßten dies als feindselig auf. Vermutlich hat Severus seine Lehre aus dem Scheitern des Pertinax gezogen. Denn er war - wie Pertinax - ein Emporkömmling und hatte nicht einmal eine glänzende Karriere absolviert. Nüchtern betrachtet, hatte er nie eine Chance, vom Senat jemals als dessen natürliches Oberhaupt respektiert zu werden. Der latente Zwist mit dem Senat bedeutete aber auch, daß seine Herrschaft von Anfang an mit einer schweren Hypothek belastet war.

Solange sich Severus in Rom aufhielt, hat er die Kaiserproklamation des Pescennius Niger verheimlicht. Schon nach 30 Tagen $^{25}$ brach er ohne Erklärung wieder auf. Offenkundig wollte er nicht zugeben müssen, daß er in einen Bürgerkrieg zog. Den Kämpfen gegen Niger ging offenbar ein kurzer, heftiger Propagandakrieg voran. Allem Anschein nach hat Severus auch ihm den Caesar-Titel angeboten. ${ }^{26}$ Severus wußte es ferner so einzurichten, daß die offenen Kämpfe von Aemilianus ${ }^{27}$ begonnen wurden, dem wichtigsten Parteigänger des Niger. Und selbst danach stellte er Niger noch ein sicheres Exil in Aussicht, forderte aber die Preisgabe des Aemilianus, der hier als Sündenbock für den Bürgerkrieg diente. ${ }^{28}$ Niger lehnte immer $a b$, hat aber möglicherweise seinerseits dem Severus - vergeblich - die Mitherrschaft angeboten. ${ }^{29}$

Der Konflikt selbst wurde militärisch entschieden. Severus erreichte einen schnellen und vollständigen Sieg. Bei Kyzikos und Issos gewannen seine Unterführer die entscheidenden Schlachten. Pescennius Niger geriet in Gefangenschaft und wurde getötet, ebenso Aemilianus; ihre Anhänger wurden bestraft. Bis Mitte 194 hatte Septimius Severus den ganzen römischen Osten unter seiner Kontrolle.

24 Cass. Dio 74, 4, 1-5; 7; HA Pert. 15, 1; HA Sev. 7, 8. Cassius Dio hat den Staatsakt als Augenzeuge miterlebt.

25 HA Sev. 8, 8; Herod. 2, 14, 5.

26 HA Pesc. Niger 4, 7; HA Clod. Alb. 3, 4. Die Angaben scheinen auf zeitgenössische Quellen aus dem Lager des Severus zurückzugehen, s. oben Anm. 21.

27 Asellius Aemilianus (PIR ${ }^{2}$ A 1211). Er war ein Verwandter des Clodius Albinus (Cass. Dio $74,6,2)$.

28 HA Sev. 8, 15; vgl. HA Pesc. Niger 4, 5; 5, 8.

29 Nach HA Sev. 8, 14 rief Niger den Severus ad participatum, was Severus aber ablehnte. Dieselbe Notiz steht auch in HA Pesc. Niger 5, 6. 


\section{Der Weg in den Krieg zwischen Albinus und Severus}

Der Gedanke, den Krieg durch die Teilung der Herrschaft zu vermeiden, war im Jahr 193 also allenthalben im Schwange, wurde jedoch meist für propagandistische Zwecke benutzt. Nur Albinus und Severus ließen sich tatsächlich auf den Versuch einer gemeinsamen Herrschaft ein. Es stellte sich nun aber die Frage, ob ihre eilig im Krieg ausgehandelte Übereinkunft mehr sein würde als ein taktisches Bündnis auf Zeit.

In den literarischen Quellen wird dies klar verneint. Vielmehr wird behauptet, Severus habe sofort gezielt die Auseinandersetzung mit Albinus gesucht. Herodian und die „Historia Augusta“ behaupten, Severus habe Boten mit Briefen an Albinus geschickt, die ihn bei einem persönlichen Gespräch ermorden sollten. Doch habe Albinus die Gefahr rechtzeitig erkannt, und unter der Folter hätten die Mordboten alles gestanden. ${ }^{30} \mathrm{Ob}$ das stimmt, scheint zweifelhaft. Herodian unterschlägt im gleichen Zusammenhang den ersten Orientkrieg des Severus, ${ }^{31}$ und ihm war auch sonst eine eingängige Dramaturgie weit wichtiger als die spröden Tatsachen. Die „Historia Augusta“ bietet Material sehr unterschiedlicher Qualität. Der Senator Cassius Dio jedoch weiß nichts von dem angeblichen Mordanschlag. Er schreibt einfach, Severus habe dem Albinus den Caesar-Titel nicht mehr zugestanden, während dieser nach der höchsten Kaiserwürde strebte. ${ }^{32}$ Allerdings war im Grunde auch er gegen Severus eingestellt.

30 Herod. 3, 5, 2-8 (Anlaß sei gewesen, daß sich Albinus mit seinem Caesar-Titel bereits wie

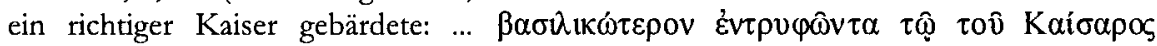
óvó $\mu \alpha \tau$ ); HA Clod. Alb. 7, 2ff. - In HA Clod. Alb. 3, 5 wird der Neid des Severus auf die Beliebtheit des Albinus und die Agitation Iulia Domnas als Motiv angegeben. - Die absurde Behauptung in HA Clod. Alb. 1, 1; 14, 2; 14, 6, Albinus habe Didius Iulianus zur Ermordung des Pertinax angestiftet, ist vielleicht eine Retourkutsche der severischen Propaganda.

31 Herod 3, 5, 1. - Zur Darstellung Herodians vgl. auch M. Zimmermann, Kaiser und Ereignis. Studien zum Geschichtswerk Herodians (Vestigia. Beiträge zur Alten Geschichte 52), München 1999, bes. 189-194.

32 Cass. Dio 75, 4, 1. Allerdings handelt es sich nicht um den Originaltext, sondern um ein späteres Exzerpt. - In HA Sev. 10, 1 wird der Beginn des Bürgerkriegs ganz knapp und ähnlich wie bei Dio geschildert. - Aus diesen wie aus den oben in Anm. 30 zitierten Stellen gewinnt man leicht den Eindruck, der Krieg sei im wesentlichen aus den Charakteren der Hauptpersonen zu erklären. Alle diese literarischen Quellen folgen jedoch einer stark personalisierten Geschichtsdeutung. 
Die moderne Forschung sieht ebenfalls in Severus den Urheber des Krieges. ${ }^{33}$ Dort kommen noch chronologische Argumente hinzu. Es wird angenommen, daß sich Septimius Severus ab 195 nicht nur als divi Marci filius (als Sohn des vergöttlichten Marc Aurel) bezeichnen ließ, sonde rn daß er im gleichen Jahr seiner Frau Iulia Domna den Titel mater castrorum verliehen habe und seinen Sohn Bassianus - den späteren Caracalla - unter dem Namen M. Aurelius Antoninus zum Caesar erhoben habe. Dies wäre in der Tat eine Kampfansage an Albinus gewesen. Entsprechend wird gelegentlich auch behauptet, Albinus sei schon Ende 195 zum hostis (zum Staatsfeind) erklärt worden. ${ }^{34}$

Wäre dem so, hätte Severus aber den fundamentalen strategischen Fehler begangen, Albinus zum Krieg herauszufordern, während er selbst und sein Heer noch im Orient gebunden waren. Und Albinus hätte so einfältig sein müssen, über ein Jahr einfach zuzuwarten, obwohl er nichts mehr zu verlieren hatte. In den literarischen Quellen findet sich nichts von all dem, obwohl es bestens zu ihrer antiseverischen Tendenz gepaßt hätte. Ein genauerer Blick auf die Zeugnisse legt überdies nahe, daß die CaesarErhebung Caracallas und ebenso der neue Titel Iulia Domnas erst in das Frühjahr 196 gehören. ${ }^{35}$ Und der „Historia Augusta“ zufolge wurde Albinus erst nach dem Ausbruch der offenen Kämpfe zum bostis erklärt. ${ }^{36}$ Auch alle sonstigen Indizien sprechen gegen eine bostis-Erklärung vor $196 .{ }^{37}$

33 Siehe zusammenfassend Birley, Septimius Severus (wie Anm. 2) 115-120, bes. 117. Etwas ausgewogener ist die Ansicht, sowohl Severus als auch Albinus hätten schlichtweg die Alleinherrschaft an sich reißen wollen, so Zimmermann, Kaiser (wie Anm. 31), bes. 187 und 191-193. Er folgt darin einer in den literarischen Quellen angelegten Meinung, die die Dinge aber sichtlich simplifiziert (vgl. auch Anm. 32).

34 Birley, Septimius Severus (wie Anm. 2) 120; D. Kienast, Römische Kaisertabelle. Grundzüge einer römischen Kaiserchronologie, Darmstadt 21996, 161 (mit Verweis auf Cass. Dio 75, 4, 2-6).

35 Siehe hierzu unten die Anhänge.

36 HA Clod. Alb. 9, 1 (im Kontext nachweislich zutreffender Informationen).

37 Für eine Datierung auf 195 wurde Cass. Dio 75, 4, 2-6 angeführt (s. oben Anm. 34). Der Autor berichtet dort, daß das Volk von Rom an den Saturnalien im Circus spontan für den Frieden demonstriert hat. Die Episode wird meist - und zweifellos zurecht - auf Dezember 195 datiert (anders beispielsweise F. Millar, A Study of Cassius Dio, Oxford 1964, 16; 141). Jedoch spricht nichts für einen Zusammenhang mit einer bostis-Erklärung, im Gegenteil: Dio schildert die Friedensdemonstration als eine Art Omen, als eine göttlich inspirierte Ahnung, die sich später bewahrheiten sollte. Dies setzt geradezu voraus, daß Albinus damals noch nicht zum bostis erklärt worden war. Denn sonst hätte es keiner prophetischen Gabe bedurft, um den Krieg vorherzusehen. 
Die Datierungsfragen sind hier mehr als bloße Quisquilien. Aus der revidierten Chronologie ergibt sich, daß Severus nach dem Ende des Pescennius Niger nicht sofort den Krieg gegen Clodius Albinus vom Zaun gebrochen hat. Vielmehr war der Weg in den neuen Bürgerkrieg bemerkenswert lang. Es lohnt sich, die Stationen durchzugehen.

Bei Albinus besitzt man keine festen Daten; man weiß nur, was er überhaupt tat: Zwischen Mitte 194 und Ende 196 hat er seine Provinz Britannien verlassen, ist nach Gallien übergesetzt und hat dort ohne Absprache mit Severus den Augustus-Titel angenommen. ${ }^{38}$ Er besetzte unter anderem Lyon und ließ dort Münzen prägen, die ihn als Augustus zeigen. ${ }^{39}$ Das Prägevolumen ist so groß, daß er die Münzstätte für längere Zeit unter seiner Kontrolle gehabt haben muß. Doch hat er den Beinamen ,Severus' sehr lange beibehalten. Es gibt nur eine einzige Inschrift, in der er fehlt, ${ }^{40}$ und diese stammt wohl erst aus der allerletzten Zeit vor seinem Untergang.

Auf sichererem Boden stehen wir bei Septimius Severus. Hier ist zunächst und vor allem festzuhalten, daß er nach dem Sieg über Pescennius Niger einen Krieg gegen die Parther und ihre Verbündeten im Orient führte. Dieser dauerte das ganze Jahr 195 über noch an. ${ }^{41} \mathrm{Ab}$ der ersten Hälfte dieses Jahres führte Severus die Siegerbeinamen Partbicus Arabicus und Partbicus Adiabenicus. ${ }^{42}$ Er beanspruchte also Teilerfolge, aber noch nicht den vollkommenen Parthersieg. Clodius Albinus erhielt an dem Titel keinen Anteil.

Ferner erscheint Severus ab der ersten Hälfte dieses Jahres auf Münzen und Inschriften als divi Marci filius (als Sohn Marc Aurels), öfters auch als Pius, was äquivalent gewesen zu sein scheint. ${ }^{43}$ Bei dieser merkwürdigen Selbstadoption sollte man bedenken, daß sein Regime inzwischen neue Rechtfertigungsstrategien benötigte. Denn das Programm der ,Rache für Pertinax war

38 Vgl. auch HA Sev. 10, 1: ... bellum civile Clodi Albini nuntiatum est, qui rebellavit in Gallia; HA Pesc. Niger 2, 1 (mit falscher zeitlicher Einordnung).

39 RIC IV 1 Clodius Albinus 13-49; 64.

40 W. Spickermann, Weihung zum Heile des Clodius Albinus, Laverna 7, 1996, 92-102 = AE 2000, 1848.

41 Siehe H. Halfmann, Itinera principum. Geschichte und Typologie der Kaiserreisen im Römischen Reich (HABES 2), Stuttgart 1986, 216f.; Kienast, Kaisertabelle (wie Anm. 34), 156.

42 RIC IV 1 Severus Nr. 41 und 55 (mit imp. IV), Nr. 58, 62, 690, 696 (mit imp. V); CIL VIII 306 = ILS 417; CIL X 7272; AE 1984, 373; P. Fam. Tebt. 47 (vom 14. August 195), P. Oxy. 3167 (vom September 195).

43 Divi Marci filius: RIC IV 1 Severus Nr. 686; CIL VIII 24004 - Pius: AE 1984, 373; IGR I $1290=$ SB 8392 (Juli/August 195), P. Fam. Tebt. 47 (vom 14. August 195); BGU 199. 
erfüllt, und der ,Rebell' Niger war besiegt. Der erfolgreiche Kampf gegen äußere Feinde gehörte stets zum Kern des Kaisertums. Ferner berief sich Severus vielfach auf Orakel und auf die Astrologie, d. h. er behauptete, das allmächtige Schicksal selbst habe ihn zum Kaiser ausersehen. ${ }^{44}$ Aber das ungeheuere legitimatorische Potential der Antoninen-Monarchie stand ungenutzt im Raum, und die Distanzierung von Commodus verlor mit dem wachsenden Zeitabstand immer mehr an Bedeutung. So lag es für Severus nahe, hier anzuknüpfen und das wichtige Thema nicht unbesetzt zu lassen. Ob die Verwandtschaftsfiktion im Reich buchstabengetreu geglaubt wurde, darf man bezweifeln. Man konnte sie vielleicht auch als das dezidierte Versprechen auffassen, daß alles wieder so werden sollte wie in der guten alten Zeit.

Clodius Albinus wurde in die fiktive Verwandtschaft nicht miteinbezogen, allerdings vorerst auch niemand anderer. Severus kehrte hervor, daß er der legitime Herrscher war - er allein. Clodius Albinus konnte darin eine Zurücksetzung und eine Provokation sehen, aber er hätte sich auch eine harmlosere Deutung zu eigen machen können. Eine unmißverständliche Kriegserklärung war dies jedenfalls nicht.

Am Ende des Jahres demonstrierte das Volk von Rom im Circus spontan für den Frieden. ${ }^{45}$ Offenbar zeichnete sich allmählich die Möglichkeit eines Bürgerkrieges ab. Anfang 196 brach Severus den Orientkrieg ab und kehrte in den Westen zurück. Das war allem Anschein nach eine grundsätzliche Änderung seiner Pläne. ${ }^{46}$ So liegt es überaus nahe, daß Albinus gegen Ende 195 etwas getan hatte, das Septimius Severus als unerträglich auffaßte. Man könnte vermuten, daß er z. B. Britannien verlassen hatte und nach Gallien übergesetzt war, womit er nach Meinung des Severus seine Befugnisse weit überschritt.

Möglicherweise hat sich Albinus ab irgendeinem Zeitpunkt seinerseits auf die Antoninen berufen: ${ }^{47}$ In der „Historia Augusta“ findet sich die seltsame Nachricht, Commodus habe Albinus zu seinem Nachfolger designiert, dieser habe aber von seinem Nachfolgerecht zunächst keinen Gebrauch gemacht. ${ }^{48}$ Vielleicht haben seine Propagandisten derartige Gerüchte ausgestreut. Sie hätten Albinus eine Legitimation verschafft, die nicht von Severus abhing.

44 Siehe dazu besonders Rubin, Propaganda (wie Anm. 13).

45 Cass. Dio 75, 4, 2-6; siehe oben Anm. 34 und 37.

46 Vgl. auch Cass. Dio $75,4,1$.

$47 \mathrm{Ob}$ Albinus damit auf Severus reagierte oder sogar als erster mit dem Rückbezug auf die Antoninen begann, läßt sich gegenwärtig nicht sagen.

48 HA Sept. Sev. 6, 9; HA Clod. Alb. 2, 1 ff; 3, 1. 3; 6, 3-5; 13, 4-9. 
Irgendwann wurde dann auch die Erzählung vom angeblichen Mordplan des Severus in Umlauf gesetzt, die zeigen sollte, daß Albinus nicht der Unruhestifter war, sondern das unschuldige Opfer.

Im April 196 verlieh Severus dann seiner Gattin den Titel mater castrorum. Es war dies der Titel, den Faustina II., die Gattin Marc Aurels, getragen hatte. ${ }^{49}$ Und wohl im Frühjahr des gleichen Jahres erhob er seinen ältesten Sohn zum Caesar und benannte ihn um; er hieß fortan M. Aurelius Antoninus. ${ }^{50}$ Ferner ließ sich Septimius Severus ab etwa der ersten Hälfte des Jahres als divi Commodi frater bezeichnen. ${ }^{51}$ Der Rückbezug auf die Antoninen wurde also sehr stark forciert, und jetzt schloß Severus ausdrücklich seine eigene Familie ein, nicht aber seinen Caesar Clodius Albinus. Der Caesar-Titel Caracallas bedeutete die faktische Aufkündigung der Samtherrschaft mit Albinus. Denn dieser durfte sich von da ab keinerlei Hoffnung mehr machen, jemals mit Billigung des Severus die Herrschaft über das Reich erben zu können.

Überraschenderweise wurde Caracalla in Viminacium an der Donau zum Caesar ernannt, und überraschenderweise geschah dies auf der Durchreise, $d$. h. auf dem Rückweg aus dem Orientkrieg. ${ }^{52}$ Das macht den Eindruck einer halb improvisierten Aktion. Anzumerken ist ferner, daß Caracalla damals erst acht Jahre alt war, ${ }^{53}$ daß er also seinen Rang noch lange nicht persönlich ausfüllen konnte. ${ }^{54}$ All das legt die Vermutung nahe, daß der Staatsakt von Viminacium die Reaktion auf eine weitere, provozierende Tat des Albinus gewesen ist. Möglicherweise hatte sich dieser inzwischen eigenmächtig zum Augustus ernannt. Und möglicherweise sollten die neuen Titel der SevererFamilie vor allem eines deutlich machen: den entschiedenen Widerspruch.

49 Zum Datum siehe unten Anhang 1.

50 HA Sev. 10, 3f,; zum Datum siehe unten Anhang 2.

51 CIL VIII 1333. $754=23107.12401 .23819 .25500$; CIL XIV 113-114 (mit Addenda S. 613); ILAfr 613 = IAM II 387. - Die Inschrift CIL VIII 9317, die angeblich von 195 stammt, ist nur durch eine schlechte Abschrift bekannt und heute verloren.

52 HA Sev. 10, 3; Näheres unten bei Anm. 94.

53 Geboren war er am 4. 2. 188. Das Tagesdatum ist aus P. Dura 54 bekannt, das Jahr errechnet sich aus Cass. Dio 78, 5, 4f. und 78, 6, 5. - Nach HA Sev. 16, 3 und HA Diad. 6,8 wäre er bereits 186 geboren. Das scheint aber nicht zuzutreffen.

54 Severus hat dabei die Option verworfen, seinen eigenen, echten Bruder P. Septimius Geta als dynastische Reserve heranzuziehen. Möglicherweise traute er Getas Loyalität und Fähigkeit nicht genügend oder wollte vermeiden, daß es später zwischen dem Bruder und dem Sohn zum Streit kam. In jedem Fall hätte die Einbeziehung Getas die Botschaft verunklärt, die von dem Staatsakt von Viminacium ausging. 
Clodius Albinus hingegen hat den Severus-Beinamen zunächst nicht abgelegt. Ferner hat er offensichtlich bewußt darauf verzichtet, in aller Eile auf Rom zu marschieren, obwohl Severus noch weit entfernt war. Damit hätte er sich zwar einen militärischen Vorteil verschafft, doch zugleich auch den Eindruck vermittelt, ohne Not den Bürgerkrieg zu beginnen. Allem Anschein nach hat Albinus die Wahrung seines öffentlichen Ansehens für wichtiger gehalten als den kurzfristigen militärischen Vorteil.

So konnte dann Septimius Severus etwa im Sommer 196 in Rom einziehen. Auf einen Triumph verzichtete er ebenso wie auf den Siegernamen Partbicus. 55 Mit der Zurückhaltung demonstrierte er, daß er den Krieg als noch nicht beendet betrachtete. Oder anders gesagt: Septimius Severus ließ die Welt wissen, daß Clodius Albinus den Kampf gegen die äußeren Feinde der res publica Romana massiv behindert habe.

Severus ließ ferner die Alpenpässe besetzen. ${ }^{56}$ Wohl gegen Ende 196 fand dann ein erstes Gefecht statt, das Albinus gegen einen Unterführer des Severus gewann. ${ }^{57}$ Und wohl erst danach ließ Severus den Caesar Albinus zum bostis, zum Staatsfeind erklären, nämlich als er nachweislich Bürgerblut vergossen hatte. ${ }^{58}$

\section{Worum ging es?}

Es sind also mindestens anderthalb Jahre voll höchster Spannung vergangen, bevor Severus und Albinus wirklich die Waffen gegeneinander kehrten. Selbst wenn man über den einen oder anderen Punkt der hier vorgestellten Chronologie noch diskutieren kann, scheint das Prinzipielle klar: Es kam zu einer schrittweisen Eskalation; Aktion und Reaktion schaukelten sich gegenseitig so weit auf, bis keine friedliche Lösung mehr möglich war. Damit

55 HA Sev. 9, 10-11, eine Notiz, die vielleicht auf zeitgenössische Pamphletistik zurückgeht. Denn daß Severus aus Furcht vor den Parthern den Parthicus-Titel abgelehnt habe, ist sicher eine übelwollende Unterstellung seiner Feinde.

56 Herod. 3, 6, 10.

57 Cass. Dio 75, 6, 2 (Sieg über Virius Lupus, vgl. HA Sev. 10, 7; HA Clod. Alb. 9, 1; zur Stellung des Lupus vgl. W. Eck, Die Statthalter der germanischen Provinzen vom 1.-3. Jahrhundert [Epigraphische Studien 14] Köln - Bonn 1985, 188f.). In die gleiche Zeit werden die Aktionen des Freischärlers Numerianus (PIR² N 198) gehören. Severus verdeutlichte, daß er diesen nicht beauftragt hatte.

58 So ausdrücklich HA Clod. Alb. 9, 1 (vgl. oben Anm. 36). - Auch der neue Bürgerkrieg ging mit einem heftigen Propagandakrieg einher, in dem man vor persönlichen Verunglimpfungen nicht zurückschreckte, vgl. HA Clod. Alb. 10, 1f.; 11, 4. 
ging ein Propagandakrieg einher, in dem jede Seite der anderen die Schuld zuzuschieben suchte. Hier könnte man die Frage stellen, ob die Eskalation zu verhindern gewesen wäre. Oder anders: Beruhte der Krieg letztlich nur auf wechselseitigen Überreaktionen? Dies wäre aber wohl zu naiv gedacht. Severus und Albinus traten mit deutlich verschiedenen Konzepten von Kaiserherrschaft an die Öffentlichkeit, die einander letztlich ausschlossen.

Severus legte größten Wert darauf, der oberste Herr des Reiches zu sein und zu bleiben. Darüber hat er nie mit sich reden lassen. Einen rangniedrigeren Teilhaber hätte er wohl akzeptiert, wenn dieser sich unterordnete. Klar scheint, daß er 194/195 zunächst keine Anstalten machte, um seinen Bündnispartner rasch wieder loszuwerden. Albinus hingegen forderte in der Öffentlichkeit die volle Gleichberechtigung mit Severus - nicht weniger, aber auch nicht mehr. Er wollte diesen nicht beseitigen, aber er wollte die gemeinsame Herrschaft nach dem Prinzip völliger Parität gestaltet wissen.

Es kann gut sein, daß beide Seiten geheime Hintergedanken verfolgten. Aber für den Erfolg im Ringen um die öffentliche Zustimmung zählte zunächst nur, was öffentlich vorgebracht wurde. Hier sprach der Augenschein gegen Clodius Albinus: Er hatte sich 193 mit dem Caesar-Rang begnügt und stellte nun zusätzliche Forderungen. Aber man muß ihm zubilligen, daß er unter einem Caesar möglicherweise etwas anderes verstanden hatte als Severus. Er betrachtete sich anscheinend als vollwertigen Mitherrscher. Der Caesar hätte demnach nur in der öffentlichen Ehre hinter dem Augustus zurückgestanden. Severus sah hingegen in einem Caesar offensichtlich nur den designierten Nachfolger, weiter nichts. Trifft das zu, dann wollte Albinus mit seinen Nachforderungen nur eine Klarstellung erreichen, während Severus darin eine Rebellion sah.

Wenn dies zutrifft, waren Severus' Vorstellungen eher durch die Tradition gedeckt als die des Albinus. Und die Alleinherrschaft eines einzigen Augustus war eine in sich stimmige Konstruktion, während es unklar blieb, wie zwei nahezu gleichberechtigte Herrscher nebeneinander regieren sollten, die weder verwandt noch sonst fest aneinander gebunden waren. ${ }^{59}$ Aber man kann deswegen nicht sagen, daß die Konzeption des Albinus falsch und unzulässig gewesen sei. In der römischen Welt der Kaiserzeit existierte keine Instanz, die dies hätte autoritativ beurteilen können; es gab kein festes, geordnetes Schlichtungsverfahren, dem sich auch ein Caesar und ein Augustus hätten unterwerfen müssen. So konnte der Konflikt am Ende nur

59 Immerhin war dies nicht unmöglich, wie später Diocletian und Maximian bewiesen. Allerdings verdankte Maximian seine Stellung ausschließlich seinem Kollegen, dem er sich offensichtlich stets verpflich tet fühlte. 
durch den freiwilligen Verzicht einer Seite oder eben mit Gewalt bereinigt werden.

Der Senat hat hier nichts zu einer Lösung beige tragen, sondern den Streit noch verschärft. Denn ein wesentlicher Teil der (vornehmen) Senatoren nahm Kontakt mit Albinus auf und sympathisierte offen mit ihm. Allem Anschein nach hofften sie, den ungeliebten Severus mit Hilfe des Albinus wieder loszuwerden. Für Severus bedeutete dies eine zusätzliche, existentielle Herausforderung.

\section{Der Krieg und die Folgen}

Doch zurück zu den Ereignissen: ${ }^{60}$ Der Kriegsplan des Albinus war recht durchsichtig. Er stand in der Region von Lyon und wartete offenkundig, bis im Frühjahr 197 die Alpenpässe schneefrei wurden, um dann von Südfrankreich her nach Oberitalien einzudringen (siehe Karte 2). ${ }^{61}$ Die Partei des Severus agierte wesentlich einfallsreicher. Dabei kam ihr zustatten, daß sie Raetien kontrollierte und daß Albinus nicht alle Gebiete des gallischgermanischen Raums hatte in seine Gewalt bringen können: Trier wurde von dessen Truppen vergeblich belagert und von der Mainzer Legion (legio XXII Primigenia) verteidigt. ${ }^{62}$ Severus und seine Heerführer konzentrierten ihre Hauptmacht daher nicht - wie zu erwarten - in Oberitalien, sondern auf dem scheinbaren Nebenkriegsschauplatz in Raetien und Obergermanien (siehe Karte 3). Und bereits im Winter 196/197 stießen sie von dort aus über Burgund nach Süden vor, wobei ihnen vielleicht ein milder Winter zu Hilfe kam. Albinus und seine Armee wurden offenbar vollkommen überrascht und gerieten unversehens in eine äußerst schwierige Lage. Für ihre eigenen Offensivpläne war die Jahreszeit noch zu früh, und ein Rückzug hätte soweit überhaupt durchführbar - die faktische Aufgabe Galliens bedeutet und wohl den Zusammenbruch des Regimes nach sich gezogen. So mußte sich Albinus zu einer Entscheidungsschlacht stellen, in der ihm nur ein vollständiger Sieg geholfen hätte.

60 Zum Kriegsverlauf siehe Birley, Septimius Severus (wie Anm. 2), 121-26, wo auch die Quellenbelege angeführt sind.

61 Sein Feldzug wäre dann nach dem gleichen Drehbuch verlaufen wie der des Vitellius von 69 - oder wie später der Constantins von 312 oder der Napoleons von 1796.

62 CIL XIII 6800 (aus Mainz, 197 nach dem Albinus-Krieg gesetzt); siehe Birley, Septimius Severus (wie Anm. 2), 122. 
Die Schlacht fand am 19. Februar 197 knapp nördlich von Lyon statt. Albinus kam einem Erfolg sehr nahe. Denn Septimius Severus nahm hier erstmals persönlich an einer Schlacht teil. Sein Flügel geriet in höchste Bedrängnis und wurde zurückgeworfen. ${ }^{63}$ Severus selbst verlor sein Pferd und mußte fliehen - und dabei alle seine kaiserlichen Rangabzeichen wegwerfen, um sich unkenntlich zu machen. Einer seiner Unterführer namens Laetus konnte jedoch mit einer Kavallerieattacke die Truppen des Albinus zurückwerfen. ${ }^{64}$ Die Schlacht endete mit einem vollständigen Sieg des Severus.

Albinus beging Selbstmord oder wurde getötet. Severus erbeutete unter anderem dessen Korrespondenz und ersah aus ihr das ganze Ausmaß der Kollusion führender Senatoren mit seinem Feind. Marc Aurel soll die Korrespondenz des Rebellen Avidius Cassius ungelesen verbrannt haben, als sie ihm in die Hände fiel. ${ }^{65}$ Septimius Severus dachte nicht daran, in gleicher Weise Milde walten zu lassen - sei es aus Zorn, oder sei es, weil er nicht glaubte, daß die Senatoren ihm die Milde danken würden.

Nach seiner Rückkehr nach Rom hielt er ein Strafgericht über die Anhänger des Albinus - oder aus seiner Sicht über die Kollaborateure mit dem Landesfeind. In den literarischen Quellen wird die Zahl der Hinrichtungen deutlich übertrieben ${ }^{66}$ - in der offenkundigen Absicht, Severus als besonders grausam erscheinen zu lassen. ${ }^{67}$ Ferner wurde Caracalla zum imperator destinatus erhoben ${ }^{68}$ - ein ad hoc erfundener Titel, der eine Zwischenstufe

63 Siehe Cass. Dio 75, 6, 6f.; Herod. 3, 7, 3; HA Sev. 11, 2 vgl. 18, 9; Vict. Caes. 20, 25. Die militärischen Details sind nicht recht klar; anscheinend war Severus in eine von Albinus vorbereitete Falle gestolpert.

64 Die Krise hatte später aber noch ein Nachspiel: Laetus (PIR I 373 ) brüstete sich sehr damit, daß Severus ihm den Sieg verdankte. Doch wurde ihm vorgeworfen, absichtlich gezögert zu haben, um am Ende selbst Kaiser zu werden, und schließlich wurde er hingerichtet (Cass. Dio 75, 6, 8; Herod. 3, 7, 3f;; ob er mit einem anderen Kommandeur namens Laetus - PIR ${ }^{2}$ L 69 - identisch war, bleibt unklar). Der Vorwurf gegen Laetus erscheint unplausibel, aber die tatsächlichen Hintergründe lassen sich kaum aufklären. Allerdings muß in jeder Schlacht mit Fehlleistungen und Koordinationsproblemen gerechnet werden. Zudem kann in einem Bürgerkrieg jede Eigenwilligkeit eines Unterführers rasch mißdeutet werden.

65 Cass. Dio 71, 29, $2 \mathrm{f}$.

66 HA Sev. 13, 1-9; vgl. G. Alföldy, Eine Proskriptionsliste in der Historia Augusta, in: ders., Krise (wie Anm. 13), 164-178 (Erstveröffentlichung 1968, hier mit Nachträgen).

67 Severus bestand auch gegenüber dem Senat darauf, als divi Commodi frater zu gelten, und ließ Commodus divinisieren: Cass. Dio 75, 7, 4. Manche Senatoren mokierten sich darüber, aber geholfen hat es nichts: Cass. Dio 76, 9, 3 (Pollenius Auspex, siehe PIR ${ }^{2}$ P 537). Klare Belege für diesen Titel gibt es erst ab 197: AE 1983, 872; CIL VIII 6994 = ILAlg. 
zwischen Caesar und Augustus konstruierte. Damit sollte wohl die 196 getroffene Nachfolgeregelung bekräftigt werden, ohne den Augustus-Titel an einen Sieg im Bürgerkrieg zu knüpfen.

Bereits im Sommer des Jahres 197 brach Severus mit seiner Familie erneut in den Orient auf und setzte den Krieg gegen die Parther fort. ${ }^{69}$ Vor der Öffentlichkeit wollte er sich wohl weniger als Mann des Bürgerkriegs, sondern als Sieger über die gemeinsamen äußere Feinde präsentieren.

In militärischer Hinsicht ist dies auch gelungen. Im Januar 198 wurde die parthische Hauptstadt Ktesiphon erobert. Unmittelbar darauf nahm Severus den Titel Parthicus maximus an: Erst damit war aus seiner Sicht der Krieg beendet. Gleichzeitig wurde sein Sohn Caracalla zum Augustus und sein anderer Sohn Geta zum Caesar erhoben. ${ }^{70}$ Die Nachfolgeregelung zugunsten der eigenen Familie wurde also dezidiert mit dem Parthersieg verbunden.

Die hier begründete Samtherrschaft folgte dem Modell derjenigen von Marc Aurel und Commodus. Auch wenn sie formal der Herrschaftsorganisation ähnelte, die Clodius Albinus gefordert hatte, so unterschied sie sich inhaltlich grundlegend davon: Severus blieb der eigentliche Herrscher, so wie es Marc Aurel gewesen war.

\section{Ausblick}

Septimius Severus war kein Revolutionär, nicht einmal ein großer Reformer. Seine Gesetzgebung und seine sonstigen Taten zeigen eher eine sozialkonservative Grundhaltung. Seinen Talenten und seinem Naturell nach war er soweit man das überhaupt sagen kann - kein Militär, sondern eher ein Jurist. Aber seine Herkunft und sein Weg zur Macht hatten dazu geführt, daß er sich vor allem auf seine Soldaten stützen mußte. Dabei ist es geblieben. Noch

2, 559; CIL VIII $5700=$ ILAlg 2, 567; P. IFAO 12; RIC IV 1 Caracalla Nr. 6. Ein terminus ante quem - der 4. oder 7. Mai 197 - ergibt sich aus CIL XIII 1754, vgl. J. Fitz, When did Caracalla become imperator destinatus?, Alba Regia 8/9, 1968, 285f. In der wohl unmittelbar nach der Schlacht von Lyon gesetzten Inschrift CIL XIII 6800 fehlt der Titel noch. Fitz (ebd.) erwägt, die Ernennung könne zu Caracallas Geburtstag am 4. April erfolgt sein. Das ist möglich, aber nicht beweisbar. - HA Sev. 14, 3: Caesarem dein Bassianum Antoninum a senatu appellari fecit decretis imperatoriis insignibus bezieht sich offenkundig auf die Erhebung zum imperator destinatus. - Zu einem möglicherweise ebenfalls damit zu verbindenden Kaiserbrief aus Aizanoi siehe unten Anhang 3.

69 Die Parther hatten während des Bürgerkriegs Mesopotamien besetzt und Nisibis belagert, das aber gehalten werden konnte: Cass. Dio 75, 9, 1.

70 HA Sev. 16, 3-5; HA Geta 5, 3, vgl. P. Dura 54. 
auf dem Totenbett soll er seinen Söhnen geraten haben: „Seid einig, bereichert die Soldaten und verachtet alles übrige."71 Septimius Severus ist damit zum ersten der Soldatenkaiser geworden. Er hat Männern von der Art eines Maximinus Thrax und eines Aurelian den Weg bereitet, obwohl er sie vermutlich verachtet hätte.

War dies unausweichlich? Das römische Kaisertum konnte verschieden aufgefaßt und ausgestaltet werden. Und gerade weil dem so war und die jeweils geltende Form erst im politischen Prozeß gefunden werden mußte, ist es zur Schlacht von Lyon gekommen. So muß es offen bleiben, ob die Geschichte denselben Verlauf genommen hätte, wenn Severus in dieser Schlacht gefallen wäre und Clodius Albinus das Kaisertum erobert hätte. Gewiß hätte auch Albinus seinen Soldaten Dank abstatten müssen. Aber er hätte z. B. zu einem weit besseren Verhältnis mit dem Senat finden können. Wie er seine Chancen genutzt hätte, können wir aber nicht wissen.

\section{Anhang 1: Iulia Domna mater castrorum}

Die moderne Forschung scheint sich einig zu sein, daß Julia Domna den prestigeträchtigen Titel mater castrorum am 14. April 195 erhielt. ${ }^{72}$ Das Datum ist freilich nicht überliefert, sondern wird durch eine Kombination mehrerer Zeugnisse erschloßen. ${ }^{73}$ Bei genauerer Prüfung erweist sich aber eines der herangezogenen Testimonien als nicht tragfähig. Gesichert ist das Tagesdatum, der 14. April: Dieser Tag wurde später in Ägypten als Jahresfest begangen. ${ }^{74}$ Das Jahr glaubt man hingegen einem Zeugnis aus Nordafrika entnehmen zu können: der Inschrift vom Architrav des Saturn-Tempels der Stadt Thugga. ${ }^{75}$ Zwar ist der Inschriftenträger in viele Stücke zerbrochen,

71 Cass. Dio $76,15,2$.

72 So z. B. PIR ${ }^{2}$ I 663; Kienast, Kaisertabelle (wie Anm. 34), 167; E. Kettenhofen, Die syrischen Augustae in der historischen Überlieferung. Ein Beitrag zum Problem der Orientalisierung (Antiquitas III 24), Bonn 1979, 80 mit 230 Anm. 42.

73 Die Münzen sind in diesem Fall unergiebig: RIC IV 1 Sev. 563a/b; 567; 568-569; 648A; $650 ; 860 ; 880 ; 884$ sind nicht datiert. In Alexandria wird lulia Domna erst ab dem Jahr 8 des Severus $(=199 / 200)$ als mater castrorum tituliert. Ebensowenig helfen die Provinzialmünzen aus dem Reichsosten weiter.

74 BGU 362, Sp. 11, Z. 15-17 (Abrechnung eines Tempels in Arsinoe): 10 ' sc. Pharmouthi

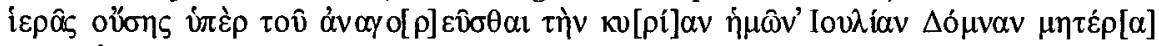

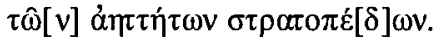

75 CIL VIII $26498=$ M. Khanoussi/L. Maurin, Dougga, Fragments d'histoire. Choix d'inscriptions latins éditées, traduites et commentées (I ${ }^{\text {er }}$ - IVe siècles), Bordeaux - Tunis, 
doch ist der Text lesbar, wenn auch an etlichen Stellen beschädigt. Aus der Kaisertitulatur des Septimius Severus (genauer: tri[b. pote]st. III cos. II in Fr. 6a/6b) ergibt sich eine zweifelsfreie Datierung in die Zeit zwischen dem 10. 12. 194 und dem 9. 12. 195. Bestätigt wird sie durch die Nennung des Clodius Albinus als Caesar, die später eradiert wurde. Auch Iulia Domna wird erwähnt (Fr. 8). Angeblich steht im unmittelbar anschließenden Fr. 9: [Aug(ustae) matris castr]orum..$^{76}$ Diese Lesung stammt von L. Poinssot ${ }^{77}$ und wurde von allen späteren Editoren übernommen. Der Erstherausgeber L. Carton hatte zu dem Fragment jedoch lapidar bemerkt: ,illisible ".78 Ebenso notierte der letzte Bearbeiter, $\mathrm{Z}$. Ben Abdallah: la surface épigraphe est complètement illisible depuis sa découverte; on ne distingue que la dermière lettre. ${ }^{79}$

Poinssot kann also wohl kaum alle vier angeblich erhaltenen Buchstaben gesehen haben, die dann zwingend zu [castr]orum zu ergänzen wären. Allem Anschein nach hat er nur konjiziert - zumal der Titel in späteren Inschriften überaus häufig vorkommt. Als Erstbeleg scheidet die Inschrift damit aus. ${ }^{80}$

Die frühesten eindeutigen Zeugnisse für den Titel mater castrorum stammen aus dem Jahr 196 und lassen sich mit Zeugnissen verbinden, in denen Caracalla bereits den Caesar-Titel führt. ${ }^{81}$ Stünde Iulia Domnas Titel tatsächlich bereits in der Inschrift aus Thugga, müßte man sich darüber wundern, daß sie so lange das einzige Zeugnis geblieben ist. So bleibt bei der gegenwärtigen Zeugnislage nur ein Schluß: Iulia Domna wurde erst am 14. April 196 zur mater castrorum ernannt. ${ }^{82}$

2000, Nr. 38.

76 Iulia Domna steht am Ende der kaiserlichen Personen; in Fr. 10 folgt: opus templi Saturni etc.

77 Siehe den app. crit. von CIL VIII 26498

78 Ebd.

79 In: Khanoussi/Maurin, Dougga (wie Anm. 75), Nr. 38. Trotzdem wird hier im Inschriftentext die angebliche Lesung Poinssots wiederholt.

80 Was in Fr. 9 wirklich stand, läßt sich derzeit nicht ergründen. Es muß sich nicht zwingend um einen Titel der Kaiserin gehandelt haben. Der Text könnte sich auch bereits auf den in Fr. 10 erwähnten Tempelbau beziehen.

81 CIL XII 4345 stammt von der Basis einer Statue, die Iulia Domna gewidmet war. Caracalla wird dort bereits als M. Aurelius Antoninus Caesar erwähnt; die Datierung auf 196 ergibt sich aus dem Titel des Septimius Severus (Arabicus Adiabenicus, tr. p. IIII, imp. VIII). - In IAM 2, 387 = ILAfr 613 (AE 1916, 89) aus Volubilis wird Caracalla ebenfalls als M. Aurelius Antoninus Caesar genannt; die Datierung ergibt sich wiederum aus dem Titel des Severus. - CIL XIV 120 (aus Ostia) ist selbst nicht datiert, doch wurde das Monument zusammen mit der Basis einer Statue für Caracalla alias M. Aurelius Antoninus Caesar gefunden, die fest auf 196 datiert ist (CIL XIV 121). - Siehe auch PIR² I 663.

82 Dem steht nicht entgegen, daß gelegentlich auch nach diesem Datum der Titel noch 


\section{Anhang 2: Das Datum der Caesar-Erhebung Caracallas}

Während früher angenommen wurde, Caracalla habe erst seit 196 den Caesar-Titel geführt, ${ }^{83}$ wird in der modernen Literatur vielfach die Meinung vertreten, er sei bereits im Jahr 195 in diesen Rang erhoben worden. ${ }^{84}$ Angeführt werden Konstitutionen, die im „Codex Iustinianus“ überliefert sind, ein Brief des Severus an die Bürger von Aizanoi und vor allem eine Inschrift aus Ulcisia castra (heute Szentendre).

Die Zeugnisse aus dem „Codex Iustinianus" 85 scheiden allerdings aus. Denn wie ein Blick in den Index lehrt, sind dort 66 Konstitutionen des Septimius Severus aus der Zeit von 193-197 überliefert, aber nur bei dreien wird Septimius Severus als alleiniger Augustus genannt, während Caracalla unerwähnt bleibt. ${ }^{86}$ In allen anderen Fällen haben die spätantiken Redaktoren regelmäßig und mechanisch den Namen Caracallas als Augustus ergänzt, also anachronistisch die spätere Normalform hergestellt. Der inschriftlich überlieferte Kaiserbrief aus Aizanoi ist seit langem umstritten - gerade was die Datierung betrifft (siehe auch Anhang 3). Von zentraler Bedeutung ist daher die Inschrift aus Ulcisia castra im heutigen Ungarn. ${ }^{87}$

Diese wurde von S. Soproni an Hand der Titulatur des Septimius Severus auf 195 datiert. 88 Der Text lautet:

fehlt, so z.B. in AE 1971, 28 aus Rom, einer Weihung für die Kaiserfamilie vom 29. 6. 196.

83 Siehe zum Beispiel RIC IV 1 S. 54; vgl. ferner das Referat der älteren Forschung bei D. Magie, Roman Rule in Asia Minor to the End of the Third Century After Christ, Princeton N.J. 1950, $1541 \mathrm{f}$.

84 Birley, Septimius Severus (wie Anm. 2), 117-120. - Kienast, Kaisertabelle (wie Anm. 34), 162 bleibt unentschieden. - Sehr viel Material zur Entwicklung der Titulatur findet sich bei A. Mastino, Le titolature di Caracalla e Geta attraverso le iscrizioni (Indici), Bologna 1981.

85 Magie, Asia Minor (wie Anm. 83), $1541 \mathrm{f}$. verwies auf CJ 9, 41, 1, eine Konstitution vom 1. 1. 196, als deren Urheber impp. Severus et Antoninus $A A$. bezeichnet werden. Ihm folgen unter anderem S. Soproni, Die Caesarwürde Caracallas und die syrische Kohorte von Szentendre, Alba Regia 18, 1980, 39-51 und J. H. Oliver, Greek Constitutions of Early Roman Emperors from Inscriptions and Papyry, Philadelphia, 1989, 433. Allerdings hätte auffallen sollen, daß Caracalla damals noch nicht Augustus war, die Kaisertitulatur also in jedem Fall anachronistisch ist. - Hasebroek, Septimius Severus (wie Anm. 2), 87 verweist auf die Konstitution CJ 4, 9, 1 [recte 4, 19, 1] vom 30. 6. 196. Hierzu gilt das Gesagte analog.

86 CJ $2,47,1 ; 4,14,1 ; 2,3,1$.

87 RIU III $840=$ AE 1982,817 .

88 Soproni, Caesarwürde (wie Anm. 85). 


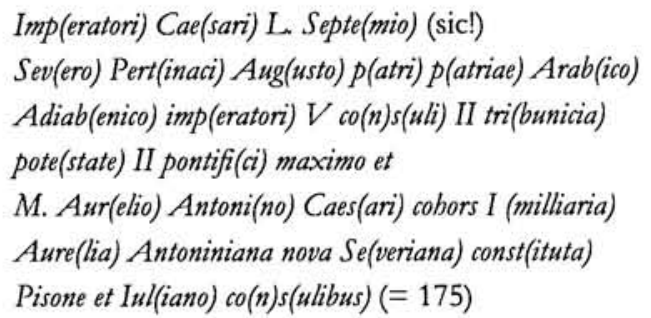

In der vorletzten Zeile stand ursprünglich Aure(lia) Antonina S(urorum). Die Einheit ist also offensichtlich bald nach der Errichtung des Monuments umbenannt und die Inschrift nachträglich angepaßt worden. ${ }^{89} \mathrm{Im}$ übrigen macht diese nicht den Eindruck, als sei ein Könner am Werk gewesen. Der Text weist nicht nur zahlreiche Ligaturen auf, sondern auch viele ungewöhnliche Abkürzungen und einen erstaunlichen Fehler im Namen des Kaisers. Die Titulatur des Severus, von der die Datierung abhängt, ist in sich inkonsistent. Denn seine hier erwähnte zweite tribunicia potestas umfaßt die Zeit von Dezember 193 bis Dezember 194. Die fünfte Imperator-Akklamation nahm Severus jedoch erst in der ersten Hälfte von 195 an, ${ }^{90}$ auf die dann rasch imp. VI und imp. VII folgten. Auch den Titel Arabicus Adiabenicus trug Septimius Severus erst ab 195. Soproni glaubte, daß tribunicia potestate II einfach zu tribunicia potestate III zu verbessern sei. Das ergäbe zwar eine konsistente Nomenklatur des Kaisers (und eine klare Datierung auf 195), aber bei der ohnehin fehlerhaften Inschrift bliebe zu fragen, ob nicht auch anderes falsch sein könnte und z. B. auch bei der - von Soproni akzeptierten - Angabe der Imperator-Akklamationen ein paar Hasten vergessen worden seien. In jedem Fall steht die angeblich früheste Bezeugung Caracallas als Caesar auf Konjektur, und als einziges Zeugnis reicht sie kaum aus. ${ }^{91}$

$89 \mathrm{Da}$ dies im Jahr 212 geschehen sei, wie im Kommentar zu RIU III 840 behauptet wird, ist ganz unbewiesen.

90 Auch an den Münzen läßt sich ersehen, daß es die Kombination von tr. pot. II mit imp. $V$ nicht gab.

91 Soproni, Caesarwürde (wie Anm. 85), 40 meinte, die Inschrift sei aus Anlaß des zwanzigjährigen Bestehens der Einheit gesetzt worden, was ebenfalls auf 195 führen würde. Allerdings wurden solche Jubiläen in der römischen Armee gar nicht gefeiert. Auch die Vicennalien der Kaiser können nicht als Parallele herangezogen werden, da diese sich aus vota decennalia begründeten. Solche vota gab es für Truppenverbände nicht. Der sehr ungewöhnliche Hinweis auf das Gründungsdatum diente wohl eher dazu, diskret zu verdeutlichen, daß die Kohorte ihren Beinamen nicht nach dem neuen Caesar M. Aurelius Antoninus (d. h. Caracalla) führte, sondern nach dem allseits verehrten Kaiser Marc Aurel. 
Eindeutige inschriftliche Zeugnisse sowie eindeutig datierte Papyri gibt es erst ab dem Jahr 196. ${ }^{92}$ Die Untertanen werden kaum lange gezögert haben, dem neuen Caesar ihre Reverenz zu erweisen. Wollte man die CaesarErhebung - unter Berufung auf die Inschrift aus Ulcisia castra - auf 195 datieren, müßte man einen zeitlichen Hiat erklären.

In der Münzprägung zeigt sich ein ähnlicher Befund: Es gibt keine Anspielung auf die Caesar-Erhebung, die auf 195 datiert werden müßte. Den frühesten Hinweis bietet wohl der (undatierte) Typus RIC IV 1 Caracalla 3-4 (Aureus/Denar), der auf seiner Vorderseite die Legende M. Aur. Antonius Caes. trägt und auf der Rückseite Severi Aug. Pii fil. Möglicherweise ist er mit dem Münztypus RIC IV 1 Severus 72 (Aureus) zu verbinden, der auf der Vorderseite L. Sept. Sev. Pert. Aug. imp. VII und auf der Rückseite Severi Aug. Pii fil. bietet. Denn die Parole Severi Aug(usti) Pii fil(ius) spielt sonst keine Rolle. Die siebente Imperator-Akklamation des Severus findet man auf anderen Münzen sowohl zusammen mit tr. pot. III (Dezember 194 - Dezember 195) als auch mit tr. pot. IV (Dezember 195 - Dezember 196). ${ }^{93}$ Es ist also gut möglich, daß beide Typen erst im Frühjahr 196 emittiert wurden.

Schließlich kollidiert das Datum 195 mit der literarischen Überlieferung. Denn in der „Historia Augusta“ wird berichtet, Caracalla sei in Viminacium (ca. $55 \mathrm{~km}$ östlich von Belgrad an der Donau gelegen) zum Caesar erhoben worden, und zwar auf der Durchreise. ${ }^{94}$ An der Glaubwürdigkeit der Notiz ist kaum zu zweifeln, und sie wird in der Forschung weithin akzeptiert. Es ist aber auszuschließen, daß sich Severus und Caracalla im Jahr 195 in Viminacium aufhielten. Wie ihr Itinerar zeigt, sind sie erst im Frühjahr 196 aus dem

92 Die früheste genau datierte Inschrift ist AE 1971, 28 vom 29. 6. 196. Siehe ferner IAM 2, 387 (Severus mit tr. p. IIII, imp. VIII), CIL XIV 114 und addenda ebd. S. 613, vgl. auch auch AE 1968, 8b = Denkm. Kaiserreiter 54 (vom 1. 1. 197) - Papyri: P. Ryl. 169. - Im Kommentar zu RIU III 840 wird angegeben, CIL X 3341 stamme aus dem Dezember 195. Jedoch ist die Inschrift durch tr. pot. IIII und imp. VIII des Severus datiert, stammt also aus der Zeit zwischen dem 10.12. 195 und dem 9. 12. 196. Ferner wird auf die Inschrift CIL III 14507 verwiesen: eine Weihung von Legionären, die [Cle]ment. et Prisco cos. - also 195 - entlassen worden sind. Die Inschrift ist jedoch stark beschädigt, und das Entlassungsdatum der Soldaten liefert nur einen terminus post quem.

93 Für letzteres siehe RIC IV 1 Severus 70-71A und 714-717, ferner die Inschrift CIL X 6437 (CIL XI 8 ist nur handschriftlich überliefert). - Keine Grundlage hat die Auffassung, Septimius Severus habe Ende 195 bereits seine achte Imperator-Akklamation angenommen, vgl. unten Anm. 101.

94 HA Sev. 10, 3: et cum iret contra Albinum, in itinere apud Viminacium filium sum maiorem Bassianum adposito Aurelii Antonini nomine Caesarem appellavit, ut fratrem suum Getam ab spe imperii, quam ille conceperat, summoveret. 
Orient nach dem Westen gereist, um gegen Clodius Albinus zu ziehen. ${ }^{95}$ Soproni nahm daher Zuflucht zur Hypothese, Caracalla sei zweimal zum Caesar erhoben worden, nämlich einmal 195 und einmal im Frühjahr 196 in Viminacium. ${ }^{96}$ Dies ist jedoch eine offensichtliche Notlösung, die sich durch nichts stützen läßt.

Man darf vielmehr festhalten, daß die Caesar-Erhebung aller Wahrscheinlichkeit nach im Frühjahr 196 stattfand. Caracalla wurde vor dieser Zeit auch nicht als ,M. Aurelius Antoninus' bezeichnet; jedenfalls gibt es dafür keinen Beleg (außer der Inschrift aus Ulcisia castra). ${ }^{97}$

\section{Anhang 3: Der Brief des Septimius Severus an die Stadt Aizanoi}

Schwierigkeiten bereitet seit langem die Datierung und Einordnung eines Briefs von Septimius Severus an die Stadt Aizanoi in der Provinz Asia, der durch eine - heute verlorene - griechische Inschrift bekannt ist. ${ }^{98}$ In dem Brief bedankt sich der Herrscher bei den Bürgern von Aizanoi für eine Gratulationsgesandtschaft. Deren Anlaß wird ebenso wortreich wie unspezifisch umschrieben: „Die Freude, die ihr wegen der Erfolge (oder: weil die Dinge richtig geordnet wurden) hegt und weil mein Sohn Marcus Aurelius Antoninus - mit gutem Glück! - zu den Hoffnungen auf die Herrschaft aufstieg und dem Vater beigeordnet wurde, habe ich aus euerem Beschluß ganz klar erkannt usw.".99

$\mathrm{Zu}$ datieren ist der Brief nur anhand der Kaisertitulatur des Severus. Er trägt den Siegerbeinamen Arabicus Adiabenicus und wird als Sohn Marc Aurels und Bruder des Commodus bezeichnet; ferner werden die dritte

95 Siehe die Zusammenstellung der Daten bei Halfmann, Kaiserreisen (wie Anm. 41), 217

96 Soproni, Caesarwürde (wie Anm. 85), 43.

97 Aus HA Sev. 10, 3-6 ergibt sich klar, daß die Umbenennung und die Caesarerhebung simultan erfolgten. - Bemerkenswerterweise wurde danach nur noch bei einer einzigen Erwähnung des neuen Caesar dessen altes Cognomen ,Bassianus' hinzugefügt: in einer Inschrift aus Tunesien, die auf 197 datiert ist (AE 1904, 75). Es handelt sich offenkundig um ein Versehen, weil die Inschriftensetzer noch nicht genau genug verstanden hatten, welche Namensform politisch gewollt war.

98 ILS $8805=$ Oliver, Constitutions (wie Anm. 85), Nr. 213. Der Text beruht auf Abschriften von A. de Laborde und Ph. Le Bas aus dem 19. Jahrhundert, die den Stein noch gesehen haben.

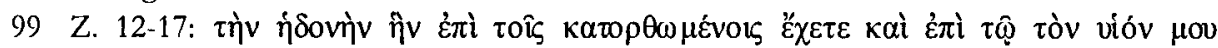

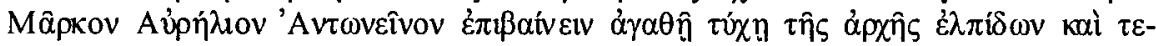

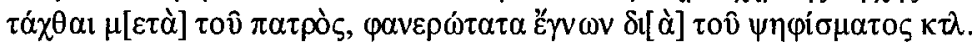


tribunizische Gewalt, die achte Imperator-Akklamation und der zweite

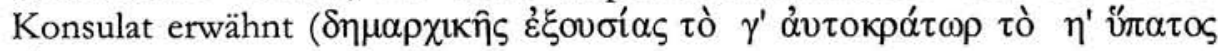
$\tau$ ò $\beta^{\prime}$ ). Die verschiedenen Elemente passen aber auch hier nicht zusammen. Die dritte tribunizische Gewalt würde auf die Zeit zwischen dem 10. 12. 194 und dem 9. 12. 195 führen; die achte imperator-Akklamation ist aber nur zusammen mit der vierten und fünften tribunizischen Gewalt belegt, was sich an der Reichsmünzprägung zuverlässig nachverfolgen läßt. ${ }^{100}$ Dies wäre die Zeit zwischen dem 10.12. 195 und dem 9. 12. 196 bzw. zwischen dem 10. 12. 196 und dem 9. 12. 197.

Etliche Forscher haben sich an die tribunicia potestas gehalten und den Brief auf 195 datiert. ${ }^{101}$ Träfe das Datum zu, müßte Caracalla in diesem Jahr zum Caesar erhoben worden sein, und die Bürger von Aizanoi hätten aus eben diesem Anlaß ihre Gratulationsgesandtschaft geschickt. ${ }^{102}$ Dem sind jedoch nicht nur die oben angeführten Gründe entgegenzuhalten. Auch die Inschrift aus Aizanoi ist wohl anders zu datieren. Bereits frühere Editoren hatten einen Schreib- oder Lesefehler in der Inschrift vermutet und die

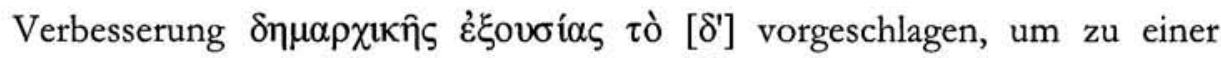
konsistenten Kaisertitulatur zu gelangen. ${ }^{103}$ Dies würde in die Zeit von Dezember 195 bis Dezember 196 führen.

Doch gibt es noch eine weitere, bislang kaum beachtete Lösungsmöglichkeit, auf die es hinzuweisen gilt: Paläographisch läge es am nächsten, an der fraglichen Stelle $\Gamma^{\mathfrak{c}} \mathrm{zu}, \mathrm{E}^{\mathrm{c}} \mathrm{zu}$ verbessern. Dann wäre von der fünften tribunizischen Gewalt die Rede gewesen, die in die Zeit vom 10.12. 196 bis

100 RIC IV 1 Severus Nr. 83; 90; 722; 724; 733 bzw. 87; 489; 726.

101 So Oliver, Constitutions (wie Anm. 85), S. 433 und Birley, Septimius Severus (wie Anm. 2), 119. Oliver (ebd.) übergeht das Problem der inkonsistenten Titulatur mit der Bemerkung: , ... the eighth imperial salutation cannot be dated much earlier than December (scil. 195)“. Doch gibt es sonst kein Zeugnis für imp. VIII aus der Zeit vor dem Wechsel von tr. pot. III zu tr. pot IV am 10. Dezember 195. Auch Birley (ebd.) gibt mit Bezug auf diese Inschrift an, Severus sei noch vor Ende $195 \mathrm{imp}$. VIII geworden. Den im Kaiserbrief erwähnten Erfolg identifiziert er (wie Oliver) mit der Einnahme der Stadt Byzantion. Diese ist aber ihrerseits schwer zu datieren: Byzantion soll der Belagerung durch die Truppen des Severus mehr als drei volle Jahre getrotzt haben (Cass. Dio 74, 12,1) und Severus soll vom Fall der Stadt erfahren haben, als er sich noch in Mesopotamien aufhielt (Cass. Dio 74, 14, 2). Jedoch kann die Belagerung frühestens im Sommer 193 begonnen haben, und Severus hat sich spätestens im Frühjahr 196 wieder auf den Rückweg aus dem Orient gemacht.

102 Ebd.

103 Vgl. den Kommentar bei Oliver, Constitutions (wie Anm. 85), Nr. 213 und das Referat bei Magie, Asia Minor (wie Anm. 83), 1542. 
9. 12. 197 gehörte. Diese ist zusammen mit der achten ImperatorAkklamation gut belegt. Mit dem im Brief erwähnte Erfolg müßte demnach der Sieg bei Lyon und mit Caracallas Rangerhöhung seine Ernennung zum imperator destinatus gemeint sein. Das Dokument müßte also in die Zeit bald nach beiden Ereignissen gehören. Allerdings glaubt man zu wissen, daß Septimius Severus bereits anläßlich der Schlacht bei Lyon seine neunte Imperator-Akklamation angenommen hat. ${ }^{104}$ Demnach wäre bei der hier

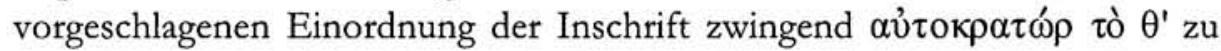
erwarten.

Aber genau besehen ist dieser Zeitansatz der neunten Akklamation seinerseits nicht gesichert, sondern beruht lediglich auf einer Vermutung. Denn eigentlich weiß man nur, daß tr. pot. $V$ (aus der Zeit vom 10.12. 196 bis 9. 12. 197) zusammen mit imp. VIII, imp. IX und imp. $X$ belegt sind, ferner daß imp. IX auf Münzen zusammen mit der Parole profectio Augusti erscheint, ${ }^{105}$ was sich offensichtlich auf den Aufbruch in den zweiten Partherkrieg bezog, und schließlich daß imp. $X$ auf Münzen mit Vict(oriae) Partbicae verbunden wurde, ${ }^{106}$ also offenkundig bereits in die Zeit des neuen Partherkrieges gehörte. Spätestens im Spätherbst $197 \mathrm{muß}$ also imp. X erreicht gewesen sein, und demnach wird der Kaiser vor dem Spätsommer die neunte Akklamation angenommen haben.

Die zehnte Akklamation ist ohne weiteres mit den Kampfhandlungen im zweiten Partherkrieg zu verbinden. Die vorherrschende Hypothese verbindet die neunte Akklamation nun einfach mit dem uns bekannten großen Erfolg in dem dafür in Frage kommenden Zeitraum - mit der Schlacht von Lyon. Stillschwiegend wird dabei unterstellt, daß Septimius Severus sich nicht gescheut habe, den Bürgerkrieg, das große Blutbad unter Römern, offen wie einen Sieg über äußere Feinde zu feiern, ${ }^{107}$ wiewohl es darüber keine Nachrichten gibt. Ob sich Severus tatsächlich dazu hinreißen ließ, der Öffentlichkeit gegenüber einen derartigen Zynismus an den Tag zu legen, kann man aber bezweifeln, zumal wir wissen, daß er selbst sich als untadeligen Sieger darzustellen suchte. ${ }^{108}$

104 Siehe z. B. Kienast, Kaisertabelle (wie Anm. 34), 157; RIC IV S. 54.

105 RIC IV 1 Severus Nr. 106; 740A.

106 RIC IV 1 Severus Nr. 121; vgl. Nr. 120: Vict(oria) Aug(ustorum).

107 Die senatorische Geschichtsschreibung leistet solchen Vermutungen Vorschub, bemüht sie sich doch sichtlich, Septimius Severus als grausamen Sieger hinzustellen, siehe Cass. Dio 75, 7, 3-4 (der hier erklärtermaßen - und charakteristischerweise - von Severus' eigener Version abweicht), vgl. Herod. 3, 7, 7; HA Sev. 11, 5-9; HA Clod. Alb. 9, 3-7.

108 Cass. Dio 75, 7, 3-4 (vgl. die vorausgehende Anm.). 
Zudem gibt es ein statistisches Problem: Nach der vorherrschenden Meinung hätte Septimius Severus die Kombination der Titel tr. pot. $V$ und imp. VIII nur in der Zeit vom 10.12. 196 bis zum 19.2. 197 getragen, also wenig länger als zwei Monate, die Kombination der Titel tr. pot. $V$ und imp. IX hingegen mindestens ein halbes Jahr. Doch gibt es recht viele Inschriften und etliche Münztypen mit tr. pot. V und imp. VIII. ${ }^{109}$ Diejenigen mit tr. pot. $V$ und imp. IX sind - anders als man erwarten sollte - nicht wesentlich zahlreicher, sondern eher weniger. ${ }^{110}$

Schließlich scheint eine in diesem Zusammenhang bedeutsame lateinische Inschrift übersehen worden zu sein: Die Bürger der Gemeinde Sigus in Nordafrika - $35 \mathrm{~km}$ südöstlich von Cirta gelegen - haben für Caracalla ein Monument errichtet, in dessen Inschrift er als M. Aurelius Antoninus Caes(ar) imp(erator) destinatus angesprochen wird. ${ }^{111}$ Dem Namen wird eine ausführliche Filiation beigefügt, in der sein Vater Septimius Severus mit den Titeln [tr]ib. pot. V, imp. VIII, cos. [II, pr]ocos. erscheint. Er trägt also die gleiche Titulatur, wie sie hier für die Inschrift aus Aizanoi postuliert wurde, und diese gehört in die Zeit, als Caracalla bereits imperator destinatus war.

Sofern dem Steinmetzen kein Fehler unterlaufen ist (worauf nichts hindeutet), kann sich die neunte Imperator-Akklamation des Severus also nicht auf die Schlacht bei Lyon beziehen. Vielmehr kann sie der Kaiser erst einige Zeit danach angenommen haben, ungefähr im späten Frühjahr oder Sommer 197. Der Anlaß bleibt unbekannt; es könnte sich zum Beispiel um einen siegreich bestandenen Zwischenfall an der Partherfront gehandelt haben. ${ }^{112}$

Der hier unterbreitete Vorschlag, den Kaiserbrief aus Aizanoi ins Jahr $197 \mathrm{zu}$ datieren, steht also im Einklang mit der Zeugnislage. Auch die unpräzise Sprache des Dokuments ließe sich aus den Zeitumständen gut erklären: Es ging um den Sieg im Bürgerkrieg, den Severus angeblich nicht gewollt und stets bedauert hat. Deshalb wurde es vermieden, von einem

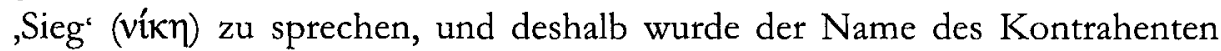
totgeschwiegen. Und was Caracallas neuer, ad hoc erfundener Rang eigentlich bedeuten sollte, konnte man nur mit unscharfen Wendungen umschrei-

109 Inschriften: CIL VI 40600; CIL VIII $5700=$ ILAlg 2, 567; CIL X $6079=$ ILS 420; AE 1969/70, 697; AE 1981, 38; AE 1983, 872; vgl. AE 1975, 870 (ergänzt); Münzen: RIC IV 1 Severus $87 ; 489 ; 726$.

110 Inschriften: CIL VIII 26255 = ILS 9401; VIII 26256, Münzen: RIC IV 1 Severus 101; 738.

111 CIL VIII 5700 (vgl. VIII 19113) = ILAlg 2, 567. Name und Titel stehen im Dativ.

112 In Frage käme z. B. die erfolgreiche Abwehr der parthischen Belagerung von Nisibis, Cass. Dio $75,9,1$. 
ben. Möglicherweise gab es dafür auch noch keinen griechischen Terminus. ${ }^{113} \mathrm{Ob}$ im Text wirklich,$\Gamma^{`}$ und nicht,$E^{`}$ stand, ließe sich freilich abschließend nur am Stein selbst klären. Dieser ist aber bislang nicht wieder aufgefunden worden. ${ }^{114}$

113 Anderswo findet man die Formulierung $\alpha$ (aus Messene) - eine Lehnübersetzung des lateinischen imperator destinatus.

114 L. Schumacher, Die politische Stellung des Clodius Albinus (193-197 n. Chr.), JRGZ 50, 2003 [2004], 355-369 ist erst nach Manuskriptabschluß erschienen, sodaß hier nicht mehr näher darauf eingegangen werden kann. Die Überlegungen Schumachers berühren sich in etlichen Punkten mit denen, die hier vorgetragen wurden. Das betrifft auch Kernfragen der Chronologie (so die Bewertung von RIU III 840 und die Datierung der CaesarErhebung Caracallas auf 196). Zu diskutieren bliebe aber, ob sich die Rechtsstellung des Albinus als Caesar so genau bestimmen läßt, wie Schumacher vermutet, und ob Septimius Severus seinen Caesar Clodius Albinus tatsächlich bereits 195 unmißverständlich zum Bürgerkrieg provoziert hat. 


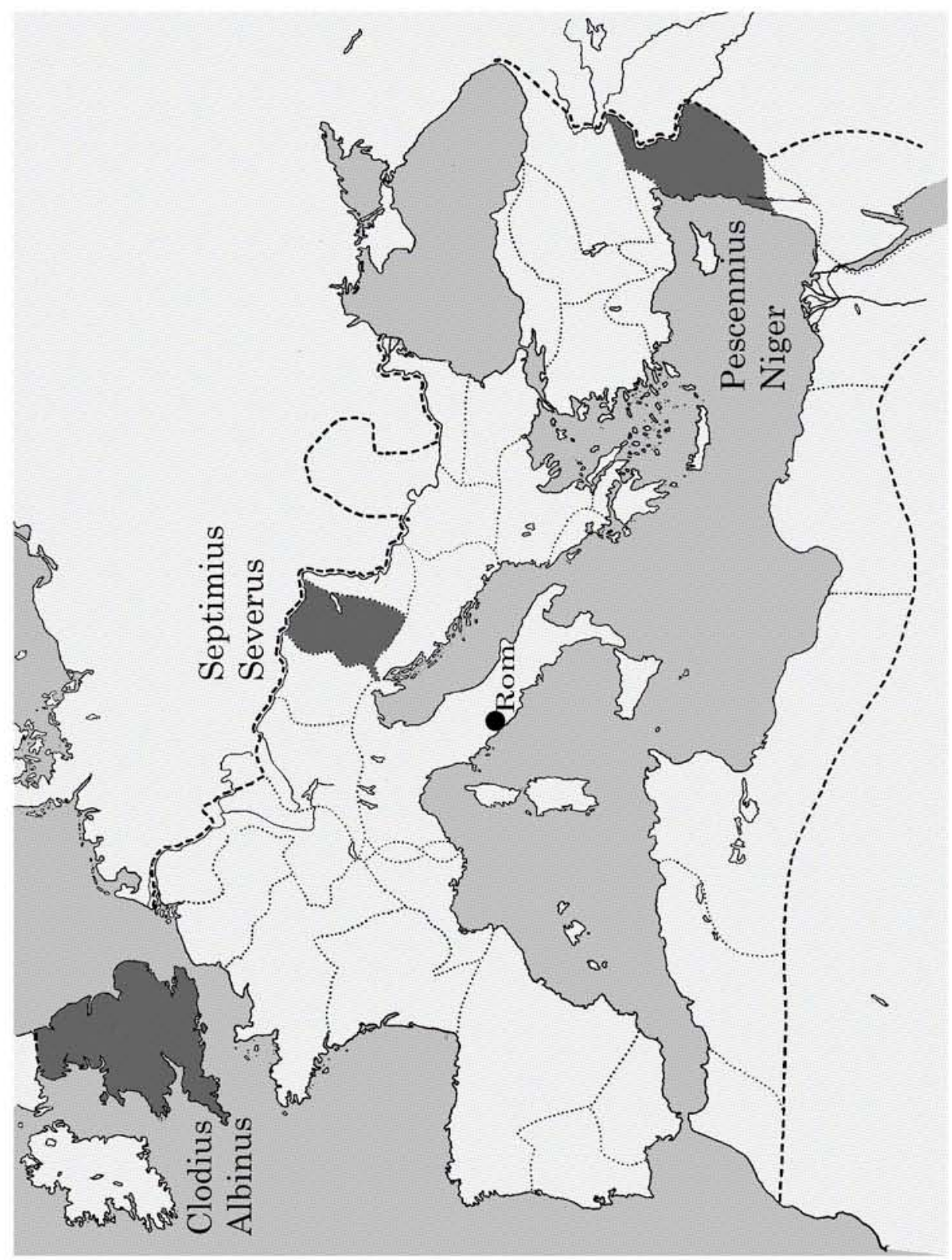

Abbildung 1: Die Prätendenten von 193 n. Chr. 


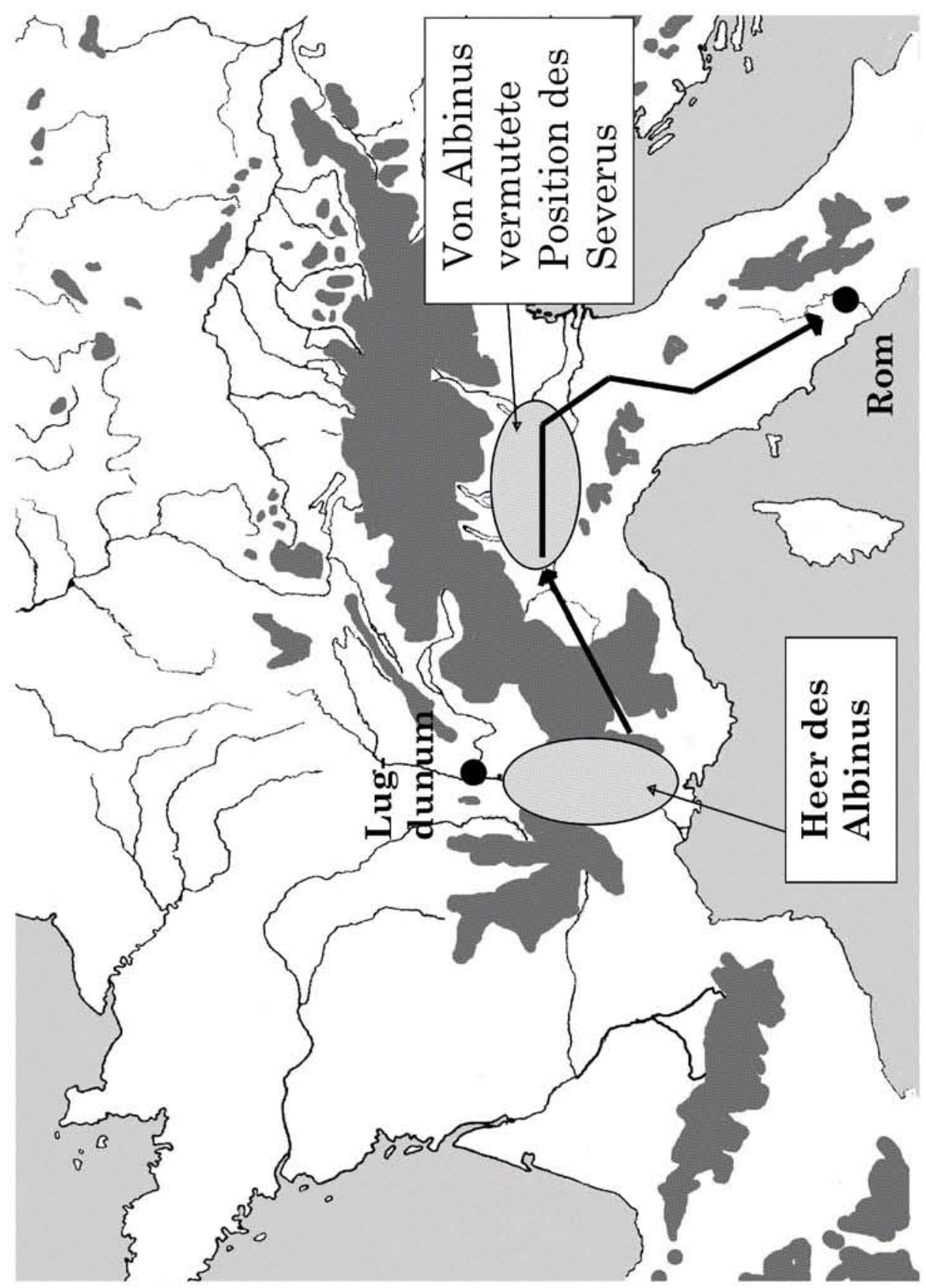

Abbildung 2: Der Kriegsplan des Clodius Albinus im Jahre 197 n. Chr. 


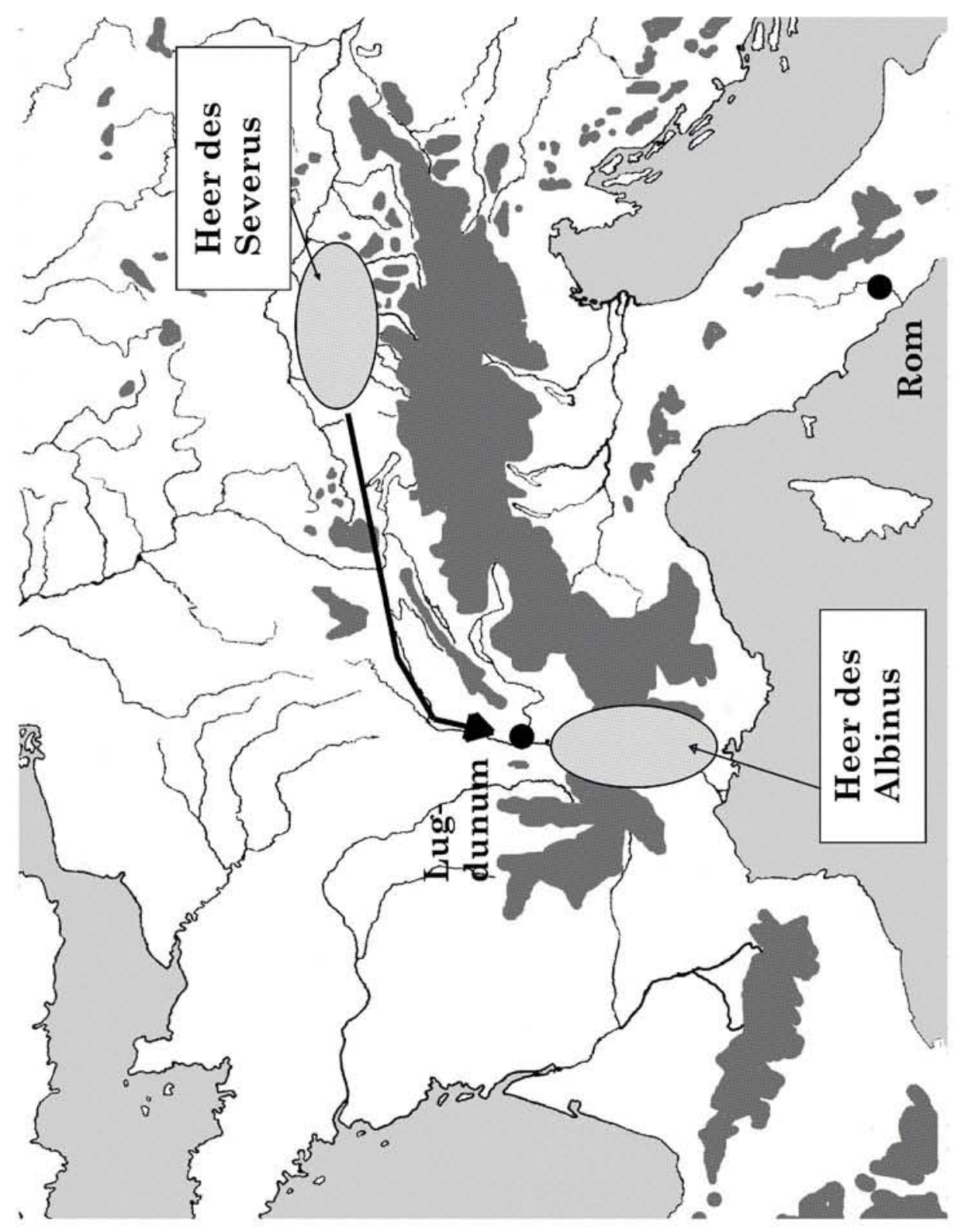

Abbildung 3: Der Kriegsverlauf des Jahres 197 n. Chr. 



\section{Zum Regierungsstil des römischen Statthalters - das Beispiel des praefectus Aegypti*}

Andrea Jördens

Während der Regierungsstil des römischen Kaisers seit den späten 1970er Jahren, genauer seit dem Erscheinen von Fergus Millars Buch „The Emperor in the Roman World", 1 Gegenstand einer lebhaften Forschungsdiskussion ist, wurde dem Regierungsstil des römischen Statthalters ungleich weniger Aufmerksamkeit zuteil. Dies ist insofern erstaunlich, als vieles dafür spricht, daß die Statthalter sich bei ihrer Amtsführung in den Provinzen an dem kaiserlichen Vorbild orientierten. Aus ihrem Regierungsstil sollten sich daher durchaus auch Rückschlüsse auf die Form und das Selbstverständnis von Herrschaft und Regierung im Römischen Reich allgemein ziehen lassen. Gleichwohl wurden nur wenige Versuche in diese Richtung unternommen, die sich zudem meist auf den als typisch aufgefaßten Statthalter senatorischen Ranges konzentrieren. Der Präfekt von Ägypten wird dagegen üblicherweise ausgeblendet, da er ja nur Ritter und Ägypten bekanntermaßen ohnehin ein Sonderfall gewesen sei. Nicht selten dürfte der eigentliche Grund allerdings vor allem darin zu suchen sein, daß „die für diese Provinz typische Überlieferung ... so umfangreich und komplex (ist), daß die ägypti-

* Angesichts des Umstandes, daß ich nicht zum engsten Schülerkreis von R. Malcolm Errington zähle, war es für mich eine besondere Ehre, im gegebenen Rahmen einen Vortrag halten zu dürfen; für die Einladung möchte ich Hans-Ulrich Wiemer herzlich danken. - Die hier gedruckte Fassung behält den Vortragsstil bei, von größeren Änderungen wurde abgesehen. Papyruseditionen sind wie üblich zitiert nach J. F. Oates u. a. (Hgg.), Checklist of Editions of Greek, Latin, Demotic and Coptic Papyri, Ostraca and Tablets (BASP Suppl. 9), o. O. 52001; sofern nicht ausdrücklich anders angegeben, li egen sämtliche erwähnten Daten nach Christus.

1 F. Millar, The Emperor in the Roman World (31 BC - AD 337), London 1977, 21992. 
sche Statthalterschaft ein eigenes Thema ist", 2 wie eine neuere Arbeit zum Thema freimütig eingestand.

Im folgenden will ich mich bemühen, etwas mehr Licht in diese ägyptischen Quellenmassen zu tragen. Denn meiner Überzeugung nach sind sie, auch wenn es manche Besonderheiten gegeben haben mag, immer noch diejenigen Quellen, die den tiefsten Einblick in das Funktionieren römischer Herrschaft über eine Provinz erlauben. Aussagekräftig für unsere Fragestellung dürften dabei in erster Linie die statthalterlichen Verlautbarungen von allgemeiner Relevanz sein, das heißt aus formaler Sicht am ehesten die Edikte sowie diejenigen Rundschreiben, die mit einem Publikationsbefehl versehen und also für eine breitere Öffentlichkeit bestimmt waren. Drei Fragen werden dabei vor allem zu beantworten sein:

- Wodurch sah sich der Statthalter zu seinem Eingreifen veranlaßt?

- Wie begründete er sein Handeln?

- Welchen Prinzipien folgte er dabei?

Hier erhebt sich freilich sofort ein grundsätzliches methodisches Problem: Wie ernst sind die Begründungen, die für das jeweilige Handeln angeführt werden, und vor allem die ethischen Rückbindungen zu nehmen? Denn der Verdacht, daß es sich in erster Linie um propagandistische Äußerungen handelt, liegt keineswegs allzu fern, und er wird zugegebenermaßen auch kaum je völlig zu entkräften sein. Gleichwohl sind zwischen dieser Quellengattung und etwa kaiserlichen Verlautbarungen, wie sie in den spätantiken Kodifikationen vorliegen, signifikante Unterschiede zu vermerken. Denn in diesem Fall haben wir nicht allein die normativen Aussagen vor uns, sondern können sie immer wieder auch an dem konkreten Handlungskontext überprüfen, in den sie eingebettet sind; finden sie ihren Widerhall doch ebenso im administrativen Alltag wie in den vielfältigen Reaktionen der Bevölkerung. Damit läßt sich in einzigartiger Weise zugleich auch ein kohärentes Bild von der Wirksamkeit der kaiserlichen Normen gewinnen; denn wir sehen hier keineswegs nur die davon abgeleiteten Willenserklärungen der Statthalter, sondern stets auch ihre mehr oder weniger erfolgreiche Umsetzung in die Wirklichkeit vor uns.

$\mathrm{Zu}$ den schon genannten drei Fragen, die im Zentrum meines Vortrages stehen werden, gesellen sich indes rasch weitere, sehr viel umfassendere; so

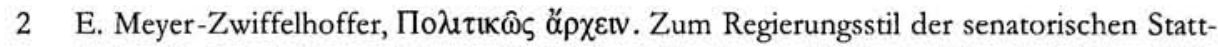
halter in den kaiserzeitlichen griechischen Provinzen (Historia. Einzelschriften 165), Stuttgart 2002, 46. 
etwa die, ob sich womöglich bestimmte Bereiche ausmachen lassen, auf denen der Statthalter bevorzugt in dieser Weise tätig wurde. Gab es sozusagen Politikfelder, die immer wieder im Mittelpunkt statthalterlicher Aufmerksamkeit standen? In diesem Fall wäre allerdings anzunehmen, daß sie auch im Mittelpunkt der kaiserlichen Aufmerksamkeit standen, da anders derartige Aktivitäten kaum zu erklären sind. Dies führt zugleich zu der Frage nach längerfristigen politischen Leitlinien, die etwa auch in der kaiserlichen $\mathrm{Ge}$ setzgebung ihren Niederschlag fanden. Es wird sich, wie ich hoffe, zeigen lassen, daß unter diesem Aspekt auch die ägyptische Evidenz einen Beitrag zu der Debatte zu leisten vermag, ob das Imperium Romanum nur beherrscht oder aber regiert oder gar verwaltet wurde. ${ }^{3}$

Beginnen möchte ich mit einem Text, den ich selbst vor einigen Jahren ediert habe. Im Hintergrund stehen dabei Auseinandersetzungen um ertragsreduziertes, sogenanntes $v \pi$ ó $\gamma_{0} \gamma_{0}$-Land, das der Staat zu Sonderkonditionen an die Bauern vergab, um Meliorationsarbeiten zu fördern; auf die Details ist hier nicht einzugehen. Am 14. Juni 156 hat dazu der Präfekt M. Sempronius Liberalis eine Verfügung getroffen, deren Einleitung, von den erwähnten Details einmal abgesehen, geradezu charakteristisch für derartige Verlautbarungen ist: ${ }^{4}$

3 Mir ist bewußt, daß die in der Forschung entwickelten Modelle kaiserlicher Herrschaft ungleich komplexer sind, als es diese schlagwortartig vergröbernden Begriffe anzuzeigen vermögen. Wie auch von Hans-Ulrich Wiemer, dem ich für die freundliche Zusendung seines Manuskripts und eine eingehende Diskussion dieser Fragen herzlich danken möchte, in der Einleitung zu diesem Band nachgezeichnet, hat diese Komplexität freilich häufig Anlaß zu Mißverständnissen gegeben und mitunter willkürlich getrennt, wenn nicht gar in Gegensatz gestellt, was wesentlich zusammengehört. Es sei daher erlaubt, die ge samte Bandbreite von einer zwar personalen, aber rein reaktiven Herrschaft über einen Regierungsstil, der durchaus auch eigenständigen Gestaltungswillen erkennen läßt, bis hin zu einem entpersonalisierten, bürokratischen Staat auf diese Weise auf den Punkt zu bringen.

4 P. Louvre E $10491+10493+10495$ B, Z. 6-23 (14. 6. 156, ed. A. Jördens, Chiron 31,

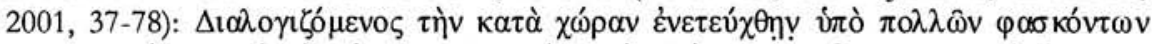

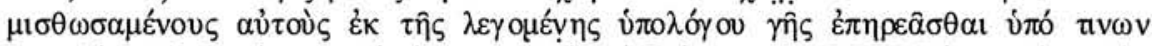

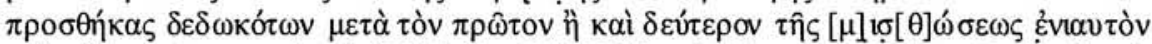

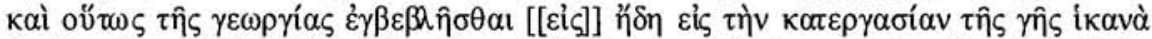

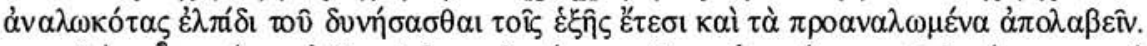

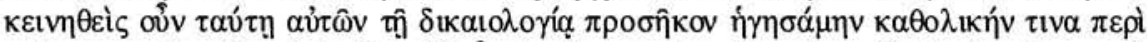

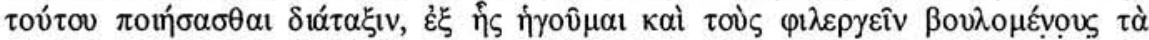

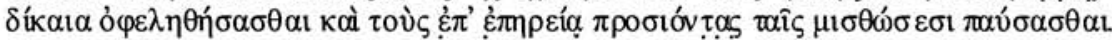




\begin{abstract}
Als ich den conventus, die jährliche Gerichtsreise, in Unterägypten abhielt, wurden mir von vielen Leuten Bittschriften übergeben folgenden Inhalts:

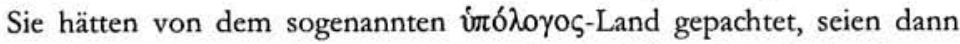
aber übervorteilt worden von Leuten, die Zuschläge daraufgelegt hätten nach dem ersten oder auch zweiten Jahr der Pacht. So seien sie aus der Bebauung vertrieben worden, obwohl sie bereits für die Bewirtschaftung des Landes das Notwendige aufgewendet hatten in der Hoffnung, in den folgenden Jahren auch das im Voraus Aufgewendete wieder herausbekommen zu können. Bewegt von diesem ihrem Vorbringen hielt ich es also für angemessen, diesbezüglich eine allgemeine Regelung zu erlassen, nach der, wie ich denke, sowohl diejenigen, die das Land bewirtschaften wollen, in ihren Rechten unterstützt werden als auch diejenigen, die sich mit Mitteln der Übervorteilung um die Pachtung bemühen, damit ein Ende machen ...
\end{abstract}

Als charakteristisch sind hier gleich mehrere Punkte festzuhalten. Dazu gehören in der Begründung des statthalterlichen Handelns die zahlreichen Eingaben, auf die der Präfekt reagiert; dann der Inhalt der Klagen, nämlich die erlittene Übervorteilung, غ̇ $\pi \hat{\jmath} \rho \varepsilon \imath \alpha$, und der damit verbundene Anspruch auf

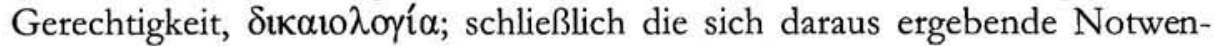

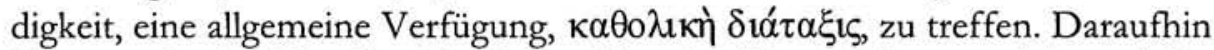
benennt der Präfekt die Absichten, die seine Neuregelung verfolgt; wieder

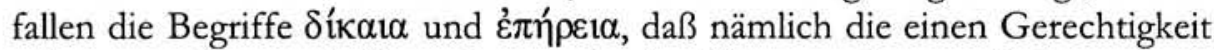
erlangen sollen und die anderen mit der Übervorteilung aufhören. Auch wenn es mancherlei Zweifel geben mag, ob die Maßnahme des Präfekten ihren Zweck erreichte - die folgenden, freilich sehr viel fragmentarischeren Bestimmungen scheinen keinen grundsätzlichen Wandel des Verfahrens anzudeuten -, war der Tenor der Verfügung klar: Dem Bedrückten sollte Gehör geschenkt, der Mutwillige dagegen in seine Schranken gewiesen werden; Gerechtigkeit, Ruhe und Ordnung sollten wieder im Lande einkehren.

$\mathrm{Da}$ diese Verfügung nicht in die Form eines Ediktes, sondern in die eines Rundschreibens an die Strategen der Mittleren Epistrategie gekleidet ist, soll uns hier nicht weiter bekümmern. Dies formale Problem habe ich schon andernorts erörtert und gezeigt, daß dies als Angleichung an die kaiserliche Rechtsetzung zu verstehen ist, die ebenfalls durch Edikte wie durch Briefe, epistulae, erfolgen konnte; nicht zufällig bezeichnet Liberalis seinen Erlaß

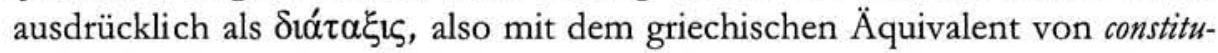


tio. ${ }^{5}$ Rundschreiben wie Edikte konnten gleichermaßen Fragen allgemeiner Relevanz wie Spezialfälle betreffen; ${ }^{6}$ daher ist die Form oft nicht oder nur durch Zufall festzustellen, wenn lediglich die zentralen Partien einer Verlautbarung erhalten sind, Präskript und Ende jedoch fehlen.

Der einleitende Verweis auf die Bittschriften, durch die sich der Statthalter zu seinem Eingreifen veranlaßt sieht, findet sich in einer ganzen Reihe dieser Texte wieder. ${ }^{7}$ Der bedeutendste darunter dürfte wohl das große Edikt des Ti. Iulius Alexander vom 6. Juli 68 sein, das überhaupt die umfangreichste statthalterliche Verlautbarung ist, die wir kennen. ${ }^{8}$ Ausnahmsweise ist dies Edikt nicht nur auf Papyrus, sondern auch inschriftlich überliefert, was, wie ich hier vielleicht erwähnen darf, dazu führte, daß meine erste intensivere Beschäftigung mit ihm auf das Inschriftenseminar bei Malcolm Errington zurückgeht.

5 Vgl. nur Gaius 1, 5 constitutio principis est, quod imperator decreto vel edicto vel epistula constituit; eingehend hierzu A. Jördens, Erlasse und Edikte. Ein neuer Erlaß des Präfekten M. Sempronius Liberalis und die Frage der statthalterlichen Rechtsetzungskompetenz, in: G. Thür/J. Vélissaropoulos-Karakostas (Hgg.), Symposion 1995. Vorträge zur griechischen und hellenistischen Rechtsgeschichte (Korfu, 1.-5. September 1995), Köln - Weimar Wien 1997, 325-352.

6 Hierzu bes. R. Katzoff, Sources of Law in Roman Egypt: The Role of the Prefect, ANRW II 13, Berlin - New York 1980, 807-844, zum Inhalt bes. 821f. (irrig insoweit Meyer-Zwiffelhoffer [wie Anm. 2], 318); ders., Prefectural Edicts and Letters, ZPE 48, 1982, 209-217. Als eklatantesten Fall eines Spezialedikts mag man den von Katzoff lediglich als Descriptum beschriebenen P. Berl. Leihg. II 46 Sp. IV (Z. 1; 4; 136) anführen, in dem M. Petronius Mamertinus die Suche nach zwei entflohenen Liturgen anordnet.

7 Vgl. außer dem im folgenden zitierten Edikt des Ti. Iulius Alexander etwa auch P. Fouad

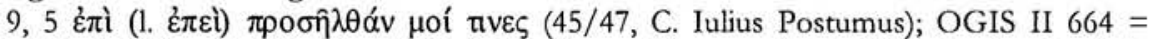

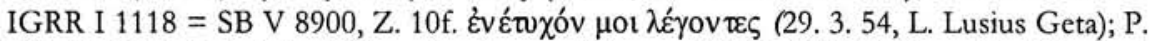

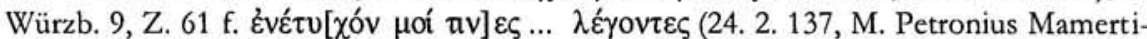

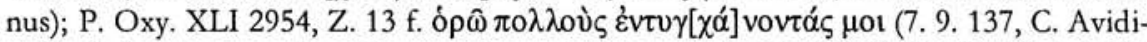
us Heliodorus); so wohl auch zu ergänzen in P. Louvre E 10491+10493+10495 A, 2 (Z.

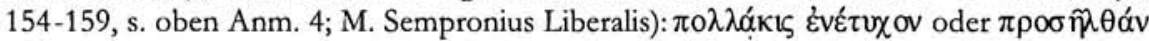

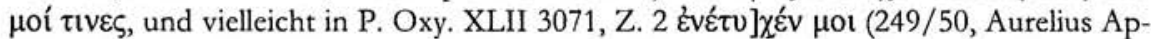
pius Sabinus). Vgl. zudem auch das kaiserliche Edikt SB XIV $11863=$ P. Mich. IX $529=$ J. H. Oliver, Greek Constitutions of Early Roman Emperors from Inscriptions and $\mathrm{Pa}$ -

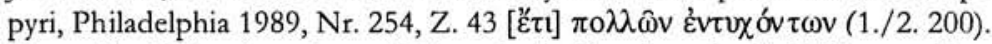

8 Die maßgebliche Ausgabe, auf die auch die Einteilung in die 17 Paragraphen zurückgeht, wurde besorgt von G. Chalon, L'édit de Tiberius Julius Alexander. Étude historique et ex égétique (Bibl. Helv. Rom. 5), Olten - Lausanne 1964. Allerdings wäre besser nur von 16 Paragraphen zu sprechen, da der erste lediglich aus dem Publikationsvermerk des zu-

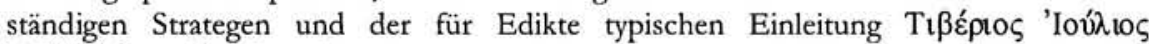
'A $\lambda \hat{\varepsilon} \xi \alpha v \delta \rho \circ \varsigma \lambda \varepsilon ́ \gamma \varepsilon ı$ besteht. 
$\mathrm{Da}$ in den insgesamt 17 Paragraphen des Ediktes die verschiedensten Probleme behandelt sind, nimmt kaum wunder, daß sich sogar mehrfach Bezüge auf die eingereichten Bittschriften finden. ${ }^{9}$ Das erste $\mathrm{Mal}$ ist dies freilich in eine allgemeine Aussage zum statthalterlichen Selbstverständnis eingebettet. Diese Präambel - wohl ein Reflex auf die Thronbesteigung Galbas, mit der ein neues Zeitalter anzubrechen schien - ist so einzigartig, daß eine Wiedergabe in vollem Umfang lohnt: ${ }^{10}$

\begin{abstract}
Alle Sorge wende ich dafür auf, daß die Stadt - d. h. natürlich Alexandreia - in der gebührenden Stellung verbleiben kann, die von den Kaisern empfangenen Wohltaten genießend, und Ägypten in dauerhaft gutem Zustand bereitwillig zur allgemeinen Wohlfahrt und dem allergrößten Glück der jetzigen Zeiten beitragen kann, ohne beschwert zu sein von neuen und ungerechten Steuereintreibungen; denn fast seit dem Moment, wo ich die Stadt betrat, wurde ich um Hilfe angerufen von Leuten, die Eingaben einreichten, zu wenigen oder in Massen, von den hier Wohlhabendsten wie den Bauern im Lande, die die zuletzt entstandenen Bedrückungen beklagten. Daher ließ ich nicht ab, soweit es in meiner Macht stand, die drängenden Probleme zu richten. Damit ihr aber um so bereitwilliger alles von dem uns zum Heil des gesamten Menschengeschlechtes erglänzenden Wohltäter Augustus Imperator Galba erhofft, sowohl zum Heil wie zum Genuß, und erkennt, daß ich mich um die zu eurer Hilfe gehörigen Dinge gekümmert habe, habe ich notwendigerweise bezüglich jeden einzelnen
\end{abstract}

9 Die Belege bei Chalon, L'édit (wie Anm. 8), 54, bes. Anm. 5.

10 Chalon, L'édit (wie Anm. 8), \ $2=$ I. Prose $57=$ OGIS II $669=$ IGRR I $1263=$ SB V

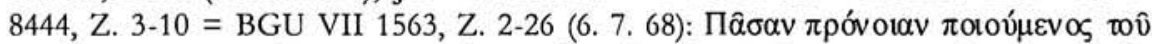

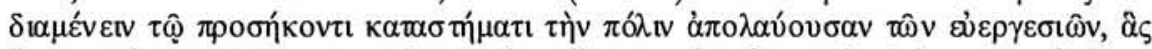

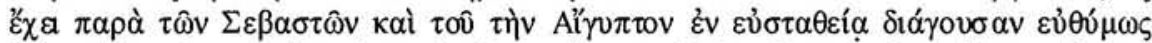

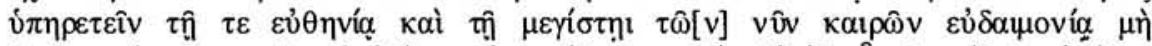

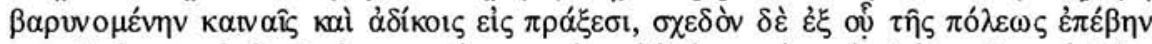

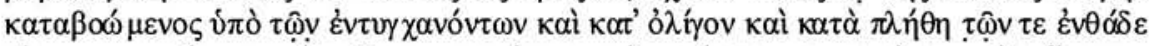

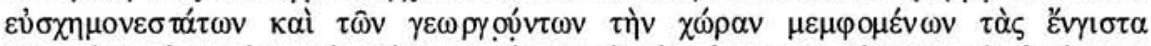

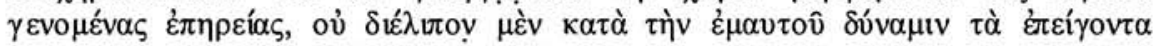

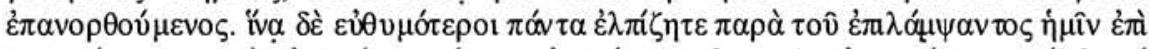

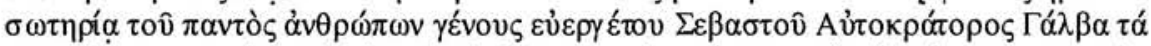

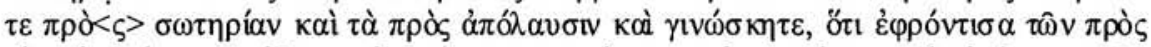

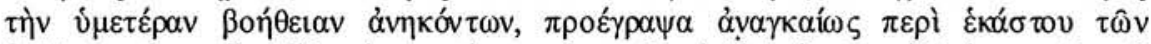

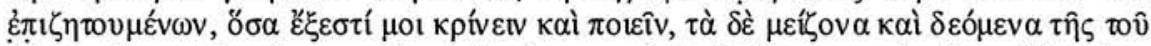

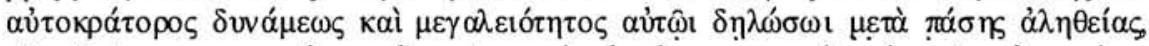

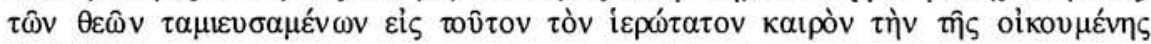

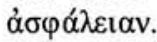


Gesuches eine Verfügung getroffen, soweit es mir möglich ist, zu entscheiden und zu tun; die bedeutenderen Dinge aber, die der Macht und Erhabenheit des Kaisers bedürfen, werde ich ihm in aller Wahrheit darlegen, wobei die Götter für diesen heiligsten Moment die Sicherheit des Erdkreises beschirmen.

Es ist kaum Zufall, daß am Anfang hier die Fürsorge, $\pi \rho$ óvor $\alpha$, steht. Denn eben sie bildete die Leitlinie statthalterlichen oder besser herrscherlichen Handelns, und entsprechend haben auch andere Präfekten sie betont an den Beginn ihrer Verlautbarungen gestellt. ${ }^{11}$ Wie sehr sie damit dem kaiserlichen Vorbild verpflichtet waren, mag man daraus ersehen, daß auch Claudius in seinem Brief an die Alexandriner auf seine eigene $\pi \rho o^{\prime}$ or $\alpha$ sowie die seines Präfekten Balbillus hinweist; ${ }^{12}$ ähnlich empfiehlt auch Trajan den Alexandrinern seinen Präfekten Pompeius Planta mit den Worten, daß dieser ,mit aller Sorgfalt für ihren wohlgeordneten Frieden und ihre Wohlfahrt und die Ge-

11 So etwa A. Avillius Flaccus in W. Chr. 13, Z. 6 (34/35); M. Petronius Mamertinus in P. Osl. III 79, Z. 2 (134/35); L. Baebius Aurelius Iuncinus in BGU XI 2056, Z. 2 (212); vgl. auch das Rundschreiben des Ti. Claudius Subatianus Aquila SB XIV $11935=$ PSI X 1148 descr., Z. 8f. (4. 1. 210), wohl zu Beginn des dispositiven Teils, sowie die mit entsprechenden Wendungen eingeleiteten Weitergaben statthalterlicher Anordnungen durch nachgeordnete Funktionsträger etwa in P. Oxy. XLVII 3339, Z. 3 (18. 12. 191, zu Larcius Memor) oder P. Yale I 61, Z 4 (22. 5. 208-210, zu Ti. Claudius Subatianus Aquila); allgemein auch P. Oxy. II 237, Sp. VI, Z. 2 (186); SB XIV 11478, Z. 6 (210/11); P. Rein. I 51, Z. 5 (3. Jhdt.); P. Stras. VIII 734, Z. 11 (2. Hälfte 3. Jhdt.). Folgerichtig finden sich auch in den Eingaben wiederholt Appelle an die statthalterliche $\pi$ póvota, vgl. etwa P. Lugd. Bat. VI 15, Z. 93 (107/108, zit. 114/15); P. Oxy. XII 1468, Z. 8 (256-258, kommiss. Präfekt); P. Stras. VI 596, Z. 10 (376).

12 P. Lond. VI 1912 = Oliver, Constitutions (wie Anm. 7), Nr. 19, Z. 103 bzw. 105f. (10. 11. 41). Wie ein Echo darauf erscheint die Ehreninschrift I. Prose $55=$ OGIS I $666=$

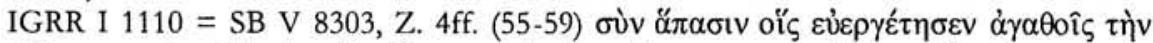

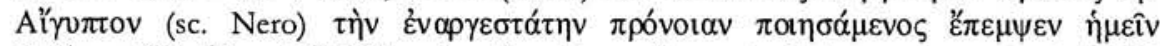

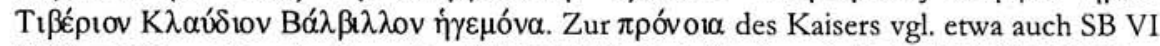
9528 = Oliver, Constitutions, Nr. 297, Z. 6 (Ende 1./Anfang 2. Jhdt. [69/70?]); P. Oxy. XXXIII 2664, Z. 3 (245-249, mit BL VIII 260); P. Oxy. XXXI 2558, Z. 2 (303-306). Insofern wäre noch zu prüfen, ob das verschiedenen Emendationen unterworfene kaiserli-

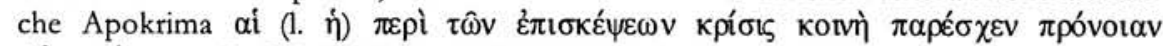
Aìyotíors aus P. Col. VI $123=$ SB VI 9526, Z. 23f. = Oliver, Constitutions (wie Anm. 7), Nr. 231 (14. 3. 200, mit BL IV 19) nicht auch in dem Sinne zu deuten ist, daß „die allgemeine Entscheidung bezüglich der Episkepseis Ausdruck der Fürsorge für die Ägypter war", und also über eine bloße Berücksichtigung ihrer Interessen (so zuletzt wieder Oliver, Constitutions (wie Anm. 7), S. 455 ,... gave consideration to Egyptians"), weit hinau sgeht. 
rechtigkeit sowohl im allgemeinen wie im einzelnen sorgen werde", $\mu \varepsilon \tau \grave{\alpha}$

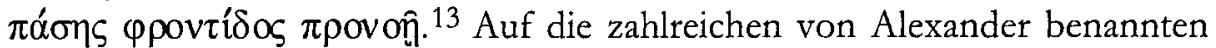

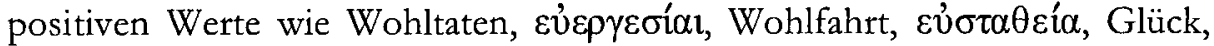

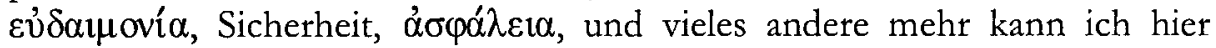
kaum im einzelnen eingehen, ebensowenig wie auf die grundsätzlich hochinteressanten Ausführungen zu den unterschiedlichen Entscheidungskompetenzen von Statthalter und Kaiser. Soviel sollte jedoch deutlich geworden sein, daß der römische Statthalter hier als Garant von Sicherheit, Frieden, Ordnung und Gerechtigkeit erscheint, nicht anders als Sempronius Liberalis es 90 Jahre später tut.

Der konkrete Anlaß war in beiden Fällen freilich unterschiedlicher Natur. Alexander scheint letztlich ohne einen solchen $z u$ agieren, allenfalls die Thronbesteigung Galbas wäre als solcher anzusehen. Denn entgegen seiner durchaus suggestiven Darstellung wurde er nicht etwa bald nach Amtsantritt tätig, sondern ließ erst zwei Jahre bis zur Verkündung seiner Maßnahmen verstreichen. Liberalis führt dagegen ausdrücklich seine jährliche Konventsreise an, die natürlich für die Bewohner des flachen Landes, der Cbora, ideale Gelegenheit zur Überreichung von Petitionen bot. Erwähnt sei nur der berühmte Fall der 1804 Eingaben, die der praefectus Aegypti Subatianus Aquila an gerade einmal zweieinhalb Tagen erhielt, als der Konvent im mittelägyptischen Arsinoitonpolis tagte. Auch hiervon wissen wir übrigens nur, weil dies seinerseits Anlaß zu einer allgemeinen Neuregelung gab, hier der Bearbeitungsweise von Petitionen. ${ }^{14}$

Anders als in anderen Provinzen wurde beim ägyptischen Konvent freilich nicht nur Gericht gehalten, sondern auch die Amtsführung der Gaubehörden überprüft. Die hierbei zu erlangenden Kenntnisse über die Situation im Lande trugen ebenfalls immer wieder dazu bei, daß der Präfekt sich zum Handeln veranlaßt sah. Denn vermutlich ist es auf diese Gelegenheiten zurückzuführen, wenn er einige Regelungen ganz allgemein damit begründet, daß er ,etwas erfahren' habe, wie es etwa in einem schlichten

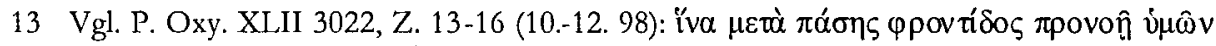

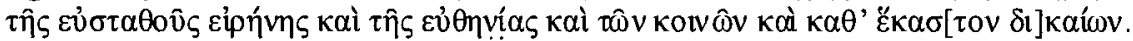

14 Vgl. nur P. Yale I 61 (22. 5. 208-210); hierzu bes. R. Haensch, Die Bearbeitungsweisen von Petitionen in der Provinz Aegyptus, ZPE 100, 1994, 487-546. Ein Bezug auf Eingaben während des Konvents scheint etwa auch in P. Osl. III 79 vorzuliegen, vgl. Z. $5 \mathrm{f}$. (134/135, M. Petronius Mamertinus). Zum Konvent allgemein vgl. zuletzt ebenfalls R. Haensch, Zur Konventsordnung in Aegyptus und den übrigen Provinzen des römischen Reiches, Akten XXI Congr. Intern. Pap. Berlin 13.-19. 8. 1995 (APF. Beiheft 3), Stuttgart - Leipzig 1997, 320-391. 
$\pi v v \theta \alpha ́ v o \mu \alpha$ zum Ausdruck kommt. ${ }^{15}$ Gelegentlich ist auch auf Mängelrügen verwiesen, die aller Wahrscheinlichkeit nach eher untergeordneten Amtsträgern als Petenten zuzuschreiben sind. ${ }^{16}$ Mitunter wurde der Präfekt sogar auf Initiative eines einzelnen Gaustrategen hin tätig. ${ }^{17}$ Als zusätzliche Stütze mochten außerdem eigene Nachforschungen dienen. ${ }^{18}$

$\mathrm{Da} \beta$ der Präfekt überhaupt vermerkt, daß er - auf welche Weise auch immer - von bestimmten Mißständen erfahren hatte, zeugt bereits von einer besonderen Aufmerksamkeit, ja Zuwendung gegenüber den Provinzialen. Zwar folgt in den meisten Fällen mehr oder weniger unvermittelt die Anordnung, auf welche Weise die Dinge künftig zu handhaben seien. Dies erinnert

15 Vgl. z. B. SEG VIII $794=$ OGIS II $665=$ IGRR I $1262=$ SB V 8248, Z. 15 ff. kai

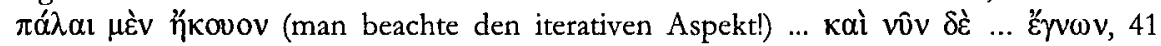

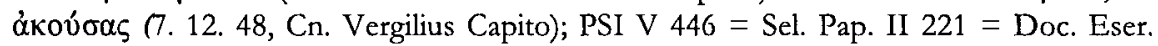
Rom. 49, Z. 3 ĖлÉ $\gamma \nu \omega v$ (5./6. 9. 133-136, M. Petronius Mamertinus); P. Princ. II $20 \mathrm{a}=$

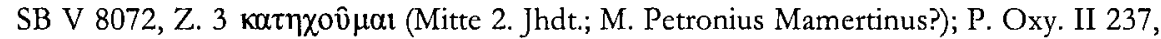

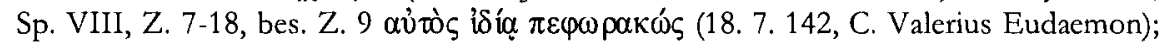
SB XX $14662=$ BGU II $372=$ W. Chr. 19, Sp. I, Z. $3 \pi v v \theta \alpha \dot{v o \mu[\alpha ~(29 . ~ 8 . ~ 154, ~ M . ~}$ Sempronius Liberalis); P. Lips. II 145 verso, Z. $72 \pi v v \theta \alpha ́ v]$ o $\mu \alpha 1$ (18. 1. 189, Q. Tineius Demetrius); P. Oxy. VIII 1100, Z. $6 \mu \alpha v \theta \alpha ́ v \omega v$ (206, Ti. Claudius Subatianus Aquila); P. Oxy. XXXIV 2704, Z. $5 \mu \alpha v \theta$ óvw (4./14. 2. 292, Titius Honoratus); vgl. auch BGU IV

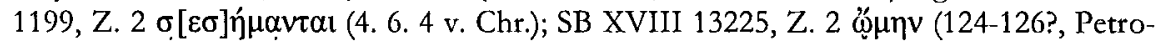

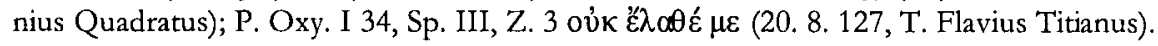
So im übrigen auch bei den Prokuratoren, vgl. etwa im Schreiben des procurator Neapolis

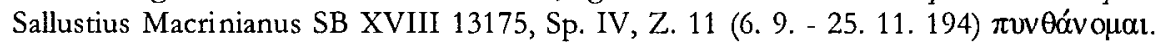
Auch hier ist das eigentliche Vorbild erneut bei den Kaisern zu suchen, vgl. neben dem unten besprochenen Edikt Hadrians von 136 (s. unten Anm. 40) auch P. Oxy. XLVII 3364, $6 \dot{\varepsilon} \pi \varepsilon \dot{i} \pi 0 \lambda \lambda$ où $\pi v v \theta \alpha v[o ́ p \Leftrightarrow \theta \alpha$ (Sept. Severus und Caracalla, zit. 25. 2. 209) und bes. die zahlreichen Belege für $\mu \alpha v \theta a ́ v \omega$ nach dem von V. I. Anastasiadis und G. A. Souris herausgegebenen Index zu Oliver, Constitutions (wie Anm. 7), Berlin - New York $2000,120$.

16 So etwa, mit ausdrücklichem Verweis auf den Konvent, in PSI XIV 1406, Z. $3 f$.

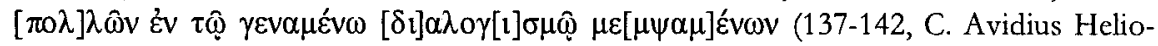

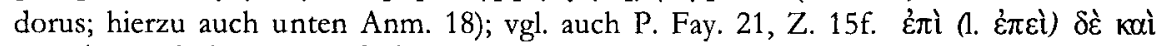

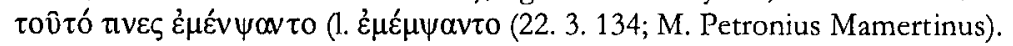

17 So in P. Oxy. II 237, Sp. VIII, Z. 27-43 = M. Chr. 192 = Jur. Pap. 59 = Sel. Pap. II 219 = FIRA I 60, Z. 28, wonach der oxyrhynchitische Stratege auf ein Problem aufmerksam gemacht hatte (1. oder 31. 10.89, M. Mettius Rufus).

18 So etwa in P. Oxy. II 237, Sp. VIII, Z. $21-27$, bes. Z. 21f. bzw. P. Merton III 101, 3 (8.

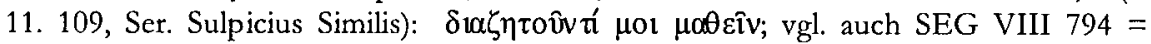

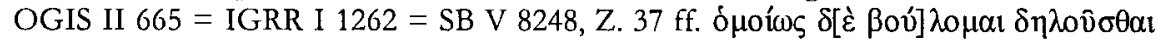

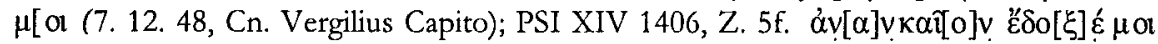

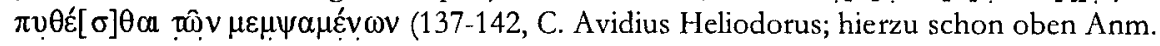
16). 
daran, daß statthalterliche Maßnahmen grundsätzlich keiner Begründung bedurften, weswegen andere Verfügungen sich auch von vornherein auf knapp gefaßte Anweisungen beschränken. Gleichwohl gibt der häufiger anzutreffende Bezug auf Klagen oder Berichte zu erkennen, daß die Provinzialen hier eben nicht mehr primär als Unterworfene und damit bloße Rechtsobjekte, sondern zunehmend als eigenständige Rechtssubjekte mit berechtigten Interessen wahrgenommen werden.

Sempronius Liberalis wie auch Iulius Alexander gehen sogar noch sehr viel weiter, indem sie die ihnen vorgetragenen Klagen ausdrücklich als berechtigt anerkennen. Dies scheint freilich in der Tat eine Eigenheit dieser beiden Statthalter oder, um vorsichtiger zu sein, dieser beiden Verlautbarungen gewesen zu sein. Über die Motive, von denen sich der Statthalter bei seinen Maßnahmen lenken ließ, geben außer diesen beiden Erlassen aber immerhin noch einige weitere Auskunft. ${ }^{19}$

Der bekannteste dieser Texte stammt erneut von Sempronius Liberalis, nämlich das große Reintegrationsedikt vom 29. August $154 .{ }^{20} \mathrm{Nach}$ der umfänglichen Einleitung hatte sich die offenbar schon länger bestehende Krisensituation aufgrund der anhaltenden Fluchtbewegungen nunmehr so verschärft, daß Liberalis sich zu tiefgreifenden Reformen genötigt sah, um wieder Ruhe und Ordnung in das Land zu bringen. Die von ihm angekündigten $\mathrm{Maßnahmen} \mathrm{sind} \mathrm{dabei} \mathrm{geradezu} \mathrm{ein} \mathrm{Paradebeispiel} \mathrm{für} \mathrm{das} \mathrm{Modell} \mathrm{von} \mathrm{Zuk-}$ kerbrot und Peitsche, deren geschickte Kombination offenbar als einziges noch Abhilfe versprach. Trotz der nur knapp bemessenen Fristen für die in Aussicht gestellte Amnestie sind die Zugeständnisse und der geradezu werbende Ton doch deutlich. Hervorgehoben wird erneut die Sorge des Kaisers für alle Menschen, da ihr allein die allseits erhoffte Wiederherstellung des Friedens im Lande zu danken sei.

Um eine besondere Form kaiserlicher Gunst geht es in einem Edikt von Liberalis' Vorgänger L. Munatius Felix, mit dem er sich im Frühjahr 151 an die Bürger der hadrianischen Gründung Antinoopolis wendet. ${ }^{21}$ Leider ist hiervon wenig mehr als die wortreiche Präambel erhalten, die die Stadt noch einmal des von beiden Kaisern bezeigten Wohlwollens versichert, welches

19 Nicht hier einzubeziehen ist allerdings der ungewöhnliche, offenbar im Rahmen bürgerkriegsähnlicher Auseinandersetzungen entstandene P. Mil. Vogl. II $47=$ CPJ II $435=$ Acta Alex. IX C (14. 10. 115?, M. Rutilius Lupus?), dessen Natur unklar ist; vgl. bes. M. Pucci, C.P.J. II 158, 435 e la rivolta ebraica al tempo di Traiano, ZPE 51, 1983, 95-103.

20 SB XX $14662=$ W. Chr. $19=$ BGU II 372; hierzu bes. S. Strassi Zaccaria, L'editto di M. Sempronius Liberalis, Trieste 1988.

21 P. Iand. VII 140, 15-23. 
sich nunmehr in einem weiteren beneficium bestätige. Wenn die Ergänzungen, wofür alles spricht, das Richtige treffen, war es dem Präfekten hier nicht nur darum getan, eben diese neuen Privilegien bekannt zu machen, sondern auch darum, der in so hohen Ehren stehenden Stadt ebenfalls Reverenz zu erweisen.

Ein weiterer bedeutender Erlaß vom Ende des 2. Jhdts., dessen Urheber vermutlich in $Q$. Aemilius Saturninus zu suchen ist, gilt dem Verbot von magischen Praktiken. ${ }^{22}$ Nach Auffassung des Präfekten war dies die einzige Lösung, die Menschen vor den Gefahren ihrer eigenen Leichtgläubigkeit zu schützen. Orakel, Prozessionen oder sonstige Scharlatanereien, die nur scheinbares Wissen um das Übernatülliche und die Zukunft vorgaukelten, werden daher gleichermaßen untersagt. Möglicherweise ist dies auch im $\mathrm{Zu}$ sammenhang mit der bevorstehenden Reise des Septimius Severus zu sehen, da man eine Konfrontation des Kaisers mit womöglich negativen Weissagungen verhindern wollte. Dennoch liegt der Hauptakzent unverkennbar darauf, den Schaden von der allzu vertrauensseligen Masse zu wenden, die stets erst im Nachhinein erkennt, wie sehr sie betrogen wurde.

Relativ eingehende Begründungen für das statthalterliche Handeln finden sich auch in vier anderen Edikten, die im wesentlichen administrative Belange betreffen. Das eine davon ist nurmehr sehr fragmentarisch erhalten, scheint ursprünglich aber sehr umfangreich gewesen zu sein und hatte die Veränderungen zum Inhalt, die sich durch die von Hadrian neugeschaffene Prokuratur des Arcbiereus für die Tempel ergaben. ${ }^{23}$ Man kann annehmen, daß in der offenbar sehr ausführlichen Präambel auch die Vorteile dieses Amtes für die Bevölkerung zur Sprache kamen.

Das zweite Edikt bezieht sich dagegen auf eine vermeintlich sehr viel speziellere Angelegenheit, nämlich die Organisation des in jedem Gau einge-

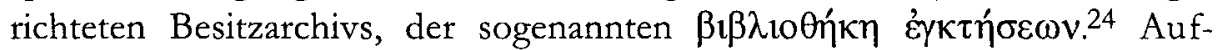
grund langer Vernachlässigung der Aktenführung waren die privaten und öffentlichen Besitzverhältnisse im Oxyrhynchites völlig undurchsichtig geworden, weswegen der Stratege im Jahr 89 bei M. Mettius Rufus vorstellig wird. Der Präfekt verfügt nun nicht nur eine Neuaufnahme des oxyrhynchitischen Materials, sondern gleich eine Neuordnung des gesamten Verfahrens, und zwar für ganz Ägypten. Dabei geht es vor allem darum, daß den Vertragschließenden nicht aus Unkenntnis Nachteile entstünden; daher müsse

22 SB XVI $12144=$ P. Coll. Youtie I $30(198 / 99)$.

23 SB XII 11236 (120-124, T. Haterius Nepos).

24 P. Oxy. II 237, Sp. VIII, Z. 27-43 = M. Chr. 192 = Jur. Pap. $59=$ Sel. Pap. $11219=$ FIRA I 60 (1. oder 31. 10. 89, M. Mettius Rufus). 
sichergestellt sein, daß die Akten jederzeit nachprüfbar seien, was für die früheren Geschäfte ebenso zu gelten habe wie für alle zukünftigen.

Rechtssicherheit war schließlich auch das Thema der beiden letzten

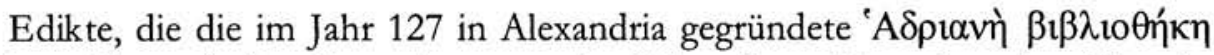
betreffen, mit der ein zweites zentrales Urkundenarchiv neben dem Nanaion eingerichtet wurde..$^{25}$ Das erste der beiden Edikte enthält dazu detaillierte Regelungen, die hier freilich nicht im einzelnen darzulegen sind. $\mathrm{Zu}$ archivieren waren dort jedenfalls sowohl Steuerakten wie Privaturkunden, damit, wie der Präfekt ausdrücklich erklärt, „,nicht allein die Staatseinkünfte offensichtlich werden, sondern dieselbe Sicherheit auch allen anderen zuteil werde". 26 Fünf Monate später schärft er in einem zweiten Edikt diese neuen Vorschriften noch einmal ein; denn wie er etwas indigniert feststellt, schickten die enchorischen Notare „die Sicherheitsurkunden lieber überall anders hin als in

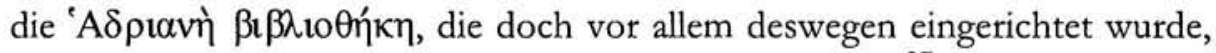
damit nichts an ungebührlichen Taten unbekannt bleibe" 27

Auch hier tritt der Präfekt erneut als Sachwalter der wohlverstandenen Interessen der Bevölkerung auf, zu deren Wahrnehmung sie selbst sich oft, wie vor allem diesem letzten Edikt, aber auch dem Erlaß gegen religiöse Verführer zu entnehmen war, außerstande zeigt. Ruhe, Ordnung, Sicherheit sind jedenfalls die immer wiederkehrenden Ziele seines Handelns, und zwar auch dort, wo er sich nicht so explizit darüber äußert wie in den bisher besprochenen Dokumenten.

Verschiedentlich sind die im konkreten Fall verfolgten Absichten immerhin noch in einem knappen Finalsatz benannt. Das deutlichste Beispiel hierfür bieten die bekannten Publikationsbefehle. Ob zu dem darin angeordneten öffentlichen Aushang nun noch genauere Angaben gemacht wurden oder nicht - etwa dazu, daß er außer in der Gauhauptstadt auch noch an anderen Orten oder daß er etwa in besonders großer und klarer Schrift vor-

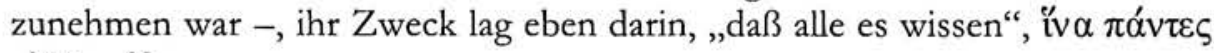
$\varepsilon i \delta \omega \hat{\sigma} .^{28}$

25 P. Oxy. I $34=$ M. Chr. 188 (22. 3. bzw. 20. 8. 127, T. Flavius Titianus).

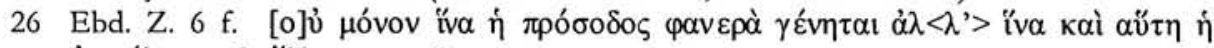

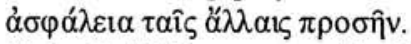

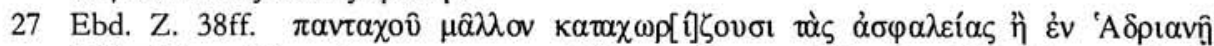

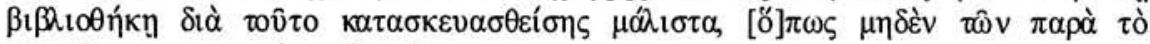

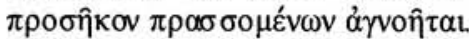

28 Hierzu zuletzt Jördens, Chiron 31, 2001 (wie Anm. 4), 58f.; 68f. mit zahlreichen Belegen. Die größte Abweichung von dieser relativ festen Formel findet sich in dem Edikt P. 
In einem solchen Finalsatz legt etwa auch C. Vibius Maximus in seinem berühmten Edikt aus dem Jahr 104 seine Absichten klar. Berühmt ist es deswegen, weil es im Zusammenhang mit dem Zensus die Rückkehr an den heimischen Herd befahl und daher immer gern als Parallele für das Gebot des Kaisers Augustus angesehen wurde. ${ }^{29}$ Dem Finalsatz zufolge war die korrekte Abwicklung des - im übrigen bereits laufenden - Zensus jedoch nur ein Zweck des Rückkehrgebots; mindestens ebenso wichtig, wenn nicht auf lange Sicht sogar wichtiger dürfte die im zweiten Teil des Satzes betonte Kontinuität der bäuerlichen Tätigkeiten gewesen sein. ${ }^{30}$ Die ordnungsgemäße Durchführung der landwirtschaftlichen Arbeiten hatte auch Sempronius Liberalis bei dem eingangs zitierten Erlaß zur vं ó́ nalsätze zeigen ebenso die Erwartungen des Ti. Iulius Alexander, wenn er etwa darauf abhebt, daß nicht durch Manipulationen von Amtsträgern der private Geschäftsverkehr behindert werde oder daß bei Fiskalprozessen auch der Denunziant ein Risiko zu tragen habe. ${ }^{32}$ Dasselbe Bemühen um Gerechtigkeit, hier freilich in privaten Rechtsverhältnissen, finden wir auch bei $\mathrm{C}$. Valerius Eudaemon, der die Ansprüche der Kreditgeber gegen betrügerische Schuldner zu stärken sucht. ${ }^{33}$ In anderen Fällen läßt sich indes nur noch erkennen, daß mit der Neuregelung etwas für die Zukunft erreicht ${ }^{34}$ oder gesetzwidriges Handeln unterbunden werden soll. ${ }^{35}$

Die Prinzipien, nach denen der Präfekt handelte, werden demgegenüber sehr viel seltener mit gleicher Deutlichkeit dargelegt. Manchmal sind sie zu-

Lond. VI 1912, Sp. I (10. 11. 41, L. Aemilius Rectus), dessen einziger Inhalt in dem Publikationsbefehl des angefügten kaiserlichen Briefes an die Alexandriner besteht.

29 Nach Luk. 2, 1-5; eingehend dazu demnächst A. Jördens, Studien zum praefectus Aegypti. Statthalterliche Verwaltung in der römischen Kaiserzeit (Historia. Einzelschriften 175), Einleitung zu Kap. II; zuletzt H. Cotton, The Roman Census in the Papyri from the Ju-

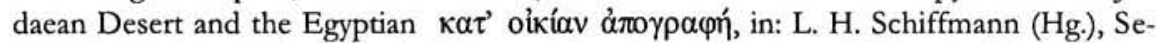
mitic Papyrology in Context. A Climate of Creativity (Culture and History of the Ancient Near East 14), Leiden - Boston 2003, 105-122.

30 P. Lond. III 904, Z. 18-43 (S. 125) = W. Chr. 202 = Jur. Pap. 2 a = Sel. Pap. II 220 (6./7. 104, C. Vibius Maximus), bes. Z. 24ff. Eigentliches Thema ist freilich die Regelung des Verfahrens für diejenigen Personen, denen aufgrund besonderer Bedingungen ausnahmsweise der Verbleib in Alexandreia zu gestatten war.

31 P. Louvre E 10491+10493+10495 B (14. 6. 156; s. oben Anm. 4), bes. Z. 34ff.

32 Vgl. nur Chalon, L'édit (wie Anm. 8), @ 5 Z. 18 f. bzw. \12 Z. 42.

33 P. Oxy. II 237, Sp. VIII, Z. 7-18 (18. 7. 142), bes. Z. 16 f.

34 So in der Verfügung des M. Sempronius Liberalis gegen unzulässige Praktiken bei der Steuererhebung P. Louvre E 10491+10493+10495 A (154-159; s. oben Anm. 4), bes. Z. 5 f.

35 P. Prag. II 122, Sp. II, Z. 1-10 (28. 12. 191, Q. Tineius Demetrius), bes. Z. 7. 
mindest mittelbar zu erschließen, wenn etwa das Verhalten, das ein statthal-

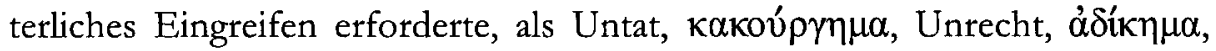
Bedrückung, غ̇ $\pi \hat{\eta} \rho \varepsilon \iota \alpha$, oder mit anderen negativen Begriffen gekennzeichnet wird. ${ }^{36}$ Besonders fällt dies bei denjenigen Edikten ins Auge, die jede Form von Mißbrauch amtlicher Befugnisse durch Militär und untergeordnete Funktionsträger mit scharfen Worten geißeln, ${ }^{37}$ was durchaus eine pikante Note besaß, da die Täter zu einem guten Teil zugleich für die Verbreitung der Verfügungen zu sorgen hatten. Derartige Charakterisierungen verweisen natürlich implizit darauf, daß das statthalterliche Handeln durch die entgegengesetzten Begriffe geprägt war, der Präfekt sich also e meut als Hüter des Rechts, der Sicherheit und der Ordnung verstand.

Nun wird der Wunsch, daß die Maßnahmen größere Sicherheit schaffen, einen besseren oder glücklicheren Zustand herbeiführen sollen, mitunter zwar auch explizit geäußert. ${ }^{38}$ Von dem stets präsenten Prinzip der Gerechtigkeit ist dagegen erstaunlich selten die Rede. Auch dies ist, so muß man daraus folgern, wie selbstverständlich in den Begriffen von $\pi$ póvot $\alpha$ und

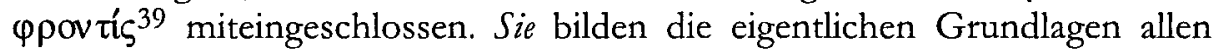
statthalterlichen Wirkens, während alles weitere nur Ausfluß des hiervon durchdrungenen Selbstverständnisses ist.

Soviel zu den ägyptischen Quellen. Sie zeigen uns, daß nicht nur einzelne außergewöhnliche Verlautbarungen wie das große Edikt des Ti. Iulius Alexander, sondern auch die weniger spektakulären Erlasse des administrativen Alltags klaren Leitlinien folgten. Stets standen Ruhe, Ordnung, Sicherheit, Gerechtigkeit und Frieden im Mittelpunkt, deren oberster Garant letztlich

36 So z. B. in P. Oxy. XXXVI 2754, Z. 8 (27. 3. 111, Ser. Sulpicius Similis); PSI XIV 1406, Z. 7 (137-141, C. Avidius Heliodorus); P. Oxy. II 237, Sp. VIII, Z. 7-18 (18. 7. 142, C. Valerius Eudaemon), bes. Z. 12; zu غ̇ $\pi \hat{\rho} \rho \varepsilon \ltimes$ vgl. nur die oben zitierten I. Prose $57=$ OGIS II $669=$ IGRR I $1263=$ SB V 8444, Z. $6=$ BGU VII 1563, Z. 12 (6. 7. 68, Ti. Iulius Alexander; s. oben Anm. 10) und P. Louvre E 10491+10493+10495 B, Z. 10.22 (14. 6. 156, M. Sempronius Liberalis; s. oben Anm. 4).

37 Vgl. nur W. Chr. 439 = P. Lond. III 1171 verso (c) (S. 107) (29. 4. 42, L. Aemilius Rectus); I. Prose $53=$ H. G. Evelyn White/J. H.Oliver, The Temple of Hibis in El Khârgeh Oasis, Bd. II: Greek Inscriptions, New York 1938, 1 ff. Nr. $1=$ SEG VIII $794=$ SB V 8248 = OGIS II 665 = IGRR I 1262 (Z. 21-25 auch in Doc. Eser. Rom. 48; 7. 12. 48; Cn. Vergilius Capito); PSI V $446=$ Sel. Pap. II $221=$ Doc. Eser. Rom. 49 (5./6. 9. 133 136, M. Petronius Mamertinus); P. Princ. II $20 \mathrm{a}=$ SB V 8072 (Mitte 2. Jhdt.; M. Petronius Mamertinus?); P. Oxy. VIII 1100 (206; Ti. Claudius Subatianus Aquila).

38 Vgl. etwa W. Chr. 13, Z. 7 (34/35, A. Avillius Flaccus); BGU IV 1086, Sp. II, Z. 2 (2./3. 160, 183 oder 215?); vgl. auch BGU I 288, Z. 7 (10.3.145, L. Valerius Proculus).

39 Vgl. etwa P. Oxy. XII 1408, Z. 2 (211-213, L. Baebius Aurelius Iuncinus). 
der Kaiser war. Der Statthalter war dabei nicht mehr und nicht weniger als sein Vertreter vor Ort, der in seinem Namen die Einhaltung dieser Prinzipien in der gesamten Provinz zu gewährleisten hatte. Dazu aber reichte es nicht aus, nur die Eingaben der Bevölkerung entgegenzunehmen und zu bearbeiten; auch unabhängig davon bedurfte es eines stets offenen Ohres, um mögliche Probleme so früh zu erfassen, daß eine Heilung noch mit den üblichen Mitteln zu erreichen war. Voraussetzung hierfür war eine intensive Kommunikation, sei es mit den lokalen Honoratioren - die es natürlich auch in Ägypten gab - oder untergeordneten Amtsträgern; unter Umständen hatte der Statthalter sogar eigene Nachforschungen in die Wege zu leiten, um den Dingen auf den Grund $z u$ gehen. Nichts anderes bedeuten jedoch die fast austauschbaren Begriffe $\pi$ póvota und $\varphi \rho$ ovtís, die vorausschauende Fürsorge.

Die Felder, auf denen der Präfekt dabei vorzugsweise tätig wird, sind schon verschiedentlich angeklungen. Einen zentralen Bereich stellte hierbei stets die Landwirtschaft dar, da sich in einem reinen Agrarland wie Ägypten Störungen rasch zu echten Krisen ausweiten mochten; daß bekanntlich auch die Versorgung Roms von seiner ordnungsgemäßen Bebauung abhängig war, wird noch hinzugekommen sein. Um die Sicherung von Ruhe und Ordnung ging es auch in den Edikten, die sich gegen die offenbar häufigen Übergriffe von Militär und Amtsträgern auf die Bevölkerung wandten; auch der Erlaß gegen die Wahrsager wäre hier zu nennen. Immer wieder ist aber auch die Rechtssicherheit bestimmendes Thema. Dies betrifft keineswegs nur die Gesetzgebung zum Archivwesen, sondern ebenso auch Fragen des Prozessrechts, des Ehe- und Familienrechtes, des Verhältnisses zwischen öffentlichrechtlichen und privatrechtlichen Ansprüchen und gelegentlich auch rein privatrechtliche Schuldverhältnisse. Schließlich sei noch auf zwei große Bereiche hingewiesen, die ich hier weitgehend ausgeklammert habe, weil die diesbezügliche Gesetzgebung sich meist auf bloße Klarstellungen oder Anweisungen beschränkt: die Anerkennung von Privilegien bestimmter Bevölkerungsgruppen und die Verwaltung der Tempel.

Ich möchte hiervon nur drei Felder herausgreifen, die mir besonders geeignet erscheinen, das Wirken des ägyptischen Statthalters in einen allgemeineren Rahmen einzuordnen. Dies ist einerseits die Fürsorge für die Landwirtschaft, andererseits die Gesetzgebung zum Requisitionswesen und zum dritten schließlich die Stärkung der Rechtssicherheit im Geschäftsverkehr. Selbstverständlich kann ich dies nurmehr kurz anreißen, so daß eine ausführlichere Behandlung bei anderer Gelegenheit stattfinden muß. Dennoch seien wenigstens einige Bemerkungen hierzu erlaubt. 
Gerade die Fürsorge für die Landwirtschaft war immer wieder auch Gegenstand kaiserlicher Rechtsetzung. $\mathrm{Zu}$ erinnern wäre hier insbesondere an verschiedene Verfügungen Hadrians, von denen wir zwei erneut nur aus den Papyri kennen. Eine davon betrifft eine Reduktion der Pachtzinsen für öffentliches Land, die möglicherweise auf Schäden aus den vorausgegangenen jüdischen Unruhen reagierte; ${ }^{40}$ die andere enthielt das Zugeständnis, einen Teil dieser Pachtzinsen auf mehrere Jahre zu strecken, da zwei niedrige Nilschwellen eine Mangellage herbeigeführt hatten. ${ }^{41}$ Die hohe Wertschätzung dieses Edikts aus dem Jahre 136 ist allein schon daraus zu ersehen, daß es in immerhin vier Exemplaren überliefert ist. Der ausführlichen Präambel zufolge hatte Hadrian von der Notsituation erfahren - $\pi v \theta$ ó $\mu \varepsilon v o \varsigma$ - und sich daher zur Gewährung dieser $\varphi \lambda \lambda \alpha v \theta \rho \omega \pi i \alpha$ gehalten gesehen. Auch hier mündet die Kenntnisnahme also direkt in ein tätiges Handeln. Der bekannteste Fall kaiserlicher Fürsorge für die Landwirtschaft ist jedoch zweifellos die sogenannte lex Hadriana de rudibus agris, die wie der eingangs erörterte Erlaß des Liberalis eine befristete Abgabenfreiheit bei Meliorationsarbeiten zugestand. ${ }^{42}$

Nun bezog sich die lex Hadriana in erster Linie auf kaiserliche Ländereien, was vielleicht auch für die entsprechenden Absichten des Pertinax anzunehmen ist, von denen Herodian berichtet. ${ }^{43}$ Dies galt jedoch offenbar nicht für eine vergleichbare Anordnung Aurelians, mit der er die civitatum ordines zur Bewirtschaftung brachliegenden Landes zu bewegen suchte. ${ }^{44}$ Hier wie bei Constantin, der seine Verfügungen weiter ausbaute, ${ }^{45}$ ist die für die

40 Das Edikt von 117 ist bislang lediglich aus Zitaten in Pachtangeboten aus dem Apollonopolites Heptakomias bekannt; vgl. dazu demnächst Jördens, Studien (wie Anm. 29), Kap. XI C 3.

41 SB III 6944 (A/B), P. Oslo III 78 = FIRA $1^{2} 81$ (C), P. Heid. VII 396 (D) = Oliver, Constitutions (wie Anm. 7), Nr. 88 (noch ohne D). Hierzu auch Jördens, Studien (wie Anm. 29), Kap. X C 5.

42 Am vollständigsten in CIL VIII 26416 = FIRA I2 102 (198-209); vgl. bes. D. Flach, Inschriftenuntersuchungen zum römischen Kolonat in Nordafrika, Chiron 8, 1978, 441 . 492; ders., Die Pachtbedingungen der Kolonen und die Verwaltung der kaiserlichen Güter in Nordafrika, ANRW II 10, 2, Berlin - New York 1982, 427-473; D. P. Kehoe, The Economics of Agriculture on Roman Imperial Estates in North Africa (Hypomnemata. Untersuchungen zur Antike und ihrem Nachleben 89), Göttingen 1988 mit weiterer Literatur; hierzu auch Jördens, Studien (wie Anm. 29), Kap. XI D 1 b.

43 Vgl. nur Herod. 2, 4, 6; hierzu wie zum folgenden Jördens, Studien (wie Anm. 29), Kap. XI D 1c.

44 Zitiert in CJ 11, 59 (58), 1 (zwischen 312 und 337, Constantin).

45 CJ $11,59(58), 1$. 
schwierigen Anfangsjahre zugesagte Steuerfreiheit freilich bereits mit Zwangsmaßnahmen gekoppelt. In der hohen Kaiserzeit war dies noch anders. Wie gering die Zugeständnisse Hadrians im einzelnen auch gewesen sein mögen, spiegelt sich darin doch dieselbe patronale oder, wie der Kaiser selbst sagt, menschenfreundliche Grundhaltung, die wir auch in den verschiedenen Erlassen der Präfekten antreffen.

Für die statthalterlichen Edikte zum Requisitionswesen, die immer wieder die Entgeltlichkeit der in Anspruch genommenen Dienste einschärfen und unautorisierte Übergriffe striktest untersagen, lassen sich inzwischen ebenfalls Parallelen aus anderen Reichsteilen anführen. Hier wäre vor allem das große Edikt des Statthalters von Galatien Sex. Sotidius Strabo Libuscidianus aus frühtiberischer Zeit zu nennen, das über die Pflichten und Rechte der Stadt Sagalassos im Rahmen des römischen Transportsystems unterrichtet. ${ }^{46}$ Erinnert sei aber auch an eine in Tegea gefundene Verfügung des Claudius, ${ }^{47}$ in einer syrischen Inschrift enthaltene mandata Domitians ${ }^{48}$ oder das Reskript Caracallas an die Einwohner von Takina in der Provinz Asia. ${ }^{49}$ In dem Bemühen, klare Regeln zu schaffen, nach denen der vorhandene Bedarf gedeckt werden konnte, aber jeglichen Mißbrauch zu unterbinden, geben sie durchweg eine aufgeschlossene Haltung der römischen Verwaltung gegenüber den Provinzialen zu erkennen, die Kaisern wie Statthaltern gleichermaßen zu eigen war. Auch hier begegnen im übrigen wieder die Schlüsselbegriffe $\pi \rho o ́ v o r \alpha$ und $\varphi \rho o v \tau i ́ c .50$

$\mathrm{Da}$ nicht nur der Nutzen für die römische Verwaltung, sondern auch die Sicherung der Interessen der Einwohner durchaus ein Anliegen der Statthalter war, zeigen insbesondere die Maßnahmen im Be reich des Rechtsverkehrs. Erwähnt sei nur der Erlaß des legatus Augusti pro praetore Q. Veranius, der sich im Jahr 43 zu einer grundlegenden Reform des Urkundswesens in der neu eingerichteten Doppelprovinz Lycia et Pamphylia genötigt sah. ${ }^{51}$ Beurkundete Rechtsgeschäfte, an denen nachträglich Veränderungen vorgenommen wurden, büßten demzufolge ihre Rechtswirksamkeit ein. Erneut ist

46 SEG XXVI 1392 (14-21 [vor 19?], mit SEG XXXVI 1208).

47 CIL III $7251=$ ILS I $214(49 / 50)$.

48 IGLS V $1998=$ SEG XVII $755=$ AE 1958, 236 = Oliver, Constitutions (wie Anm. 7), Nr. 40 (81-83).

49 SEG XXXVII 1186, Z. 1-11 (212/13).

50 Vgl. etwa IGLS V 1998 = SEG XVII $755=$ AE 1958, 236 = Oliver, Constitutions (wie

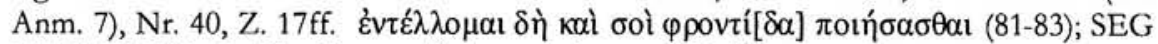

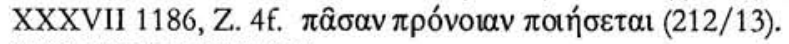

51 SEG XXXIII 1177 (43). 
das Ziel dieser Verfügung in einem Finalsatz dargelegt, daß nämlich „die Vertragschließenden ... ein Ende damit machen sollen, ihrer eigenen Sicherheit entgegenzuarbeiten ". ${ }^{52}$ Auch hier versteht sich der Statthalter demnach als Sachwalter der wohlverstandenen Interessen der Provinzialen; nicht zufäl-

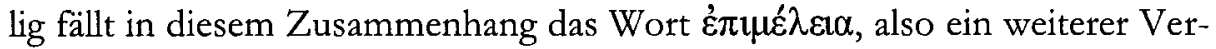
weis auf den Fürsorgegedanken. Dies erklärt auch, warum Veranius sich nicht vor einem derart tiefen Eingriff in die städtische Autonomie scheut. Es bestätigt zugleich, daß die Sorge für die Rechtssicherheit im Geschäftsverkehr eine der zentralen Aufgaben des kaiserzeitlichen Statthalters war, wie wir auch bei der Reorganisation der Gauarchive durch Mettius Rufus sahen.

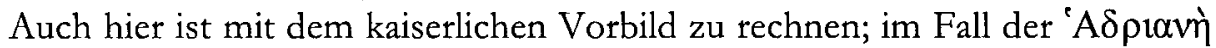
$\beta \iota \beta \lambda$ เo ihren Namen, sondern auch ihre Existenz dem regierenden Kaiser verdankte, selbst wenn dies letztlich wohl auf Empfehlung des Präfekten hin geschah.

Diese wenigen Beispiele bieten jedenfalls Beleg genug dafür, daß von einer vermeintlichen Singularität Ägyptens und seines Statthalters, was die Grundlagen und Prinzipien seines Handelns betrifft, kaum die Rede sein kann. Auch die Zugehörigkeit der Präfekten zum Ritterstand kann hierfür nicht in Anschlag gebracht werden. Denn wie bei den senatorischen Statthaltern gab es darunter wohl auch durchschnittliche, oft aber ebenso hochgebildete und keineswegs zweitrangige Persönlichkeiten. Unter Antoninus Pius übernahm etwa der bedeutende Jurist L. Volusius Maecianus das Amt, ${ }^{53}$ während unter Marc Aurel der ehemalige Rhetoriklehrer des Commodus und spätere Suffektkonsul T. Taius Sanctus Präfekt wurde. ${ }^{54}$ Der schillerndste Fall bleibt indes weiterhin Ti. Iulius Alexander, der Neffe Philons und Schwager der jüdischen Prinzessin Berenike, den wir aus Dialogen seines Onkels noch als jungen Philosophen kennen. ${ }^{55}$ Immer wieder haben wir es zudem mit nächsten Verwandten bekannter senatorischer Amtsträger zu tun wie etwa T. Haterius Nepos, dessen Namensvetter wohl im Zusammenhang mit dem Bar Kochba-Aufstand als letzter Senator die ornamenta triumphalia

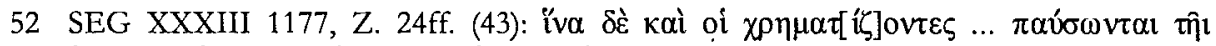

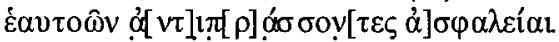

$53 \mathrm{Zu}$ ihm vgl, nur W. Kunkel, Herkunft und soziale Stellung der Juristen, Graz - Wien Köln ${ }^{21967,174 f f . ~}$

54 Hierzu bes. W. Eck, Aius 2, RE Suppl. XIV, 1974, $40 f$.

55 De prov., de animalibus, bisher nur in armenischer Übersetzung vorliegend. Zu ihm bes. A. Barzanò, Tiberio Giulio Alessandro, Prefetto d'Egitto (66/70), ANRW II 10, 1, Berlin - New York 1988, 518-580. 
erhielt, ${ }^{56}$ oder C. Avidius Heliodorus, übrigens einem weiteren $a b$ epistulis, dessen Sohn Avidius Cassius als Statthalter Syriens Marc Aurel zu stürzen versuchte. ${ }^{57}$ Wie wohl die meisten praefecti Aegypti gehörten sie zu der Spitzengruppe ritterlicher Amtsträger, die, wie schon Géza Alföldy feststellte, politisch und sozial engstens mit den Senatoren verbunden war. ${ }^{58}$ Substantielle Differenzen im statthalterlichen Handeln waren insofern von vornherein kaum zu erwarten, was sich durch unsere Beobachtungen weiter bestätigt hat.

Kann man das Wirken dieser Amtsträger, wie im Titel des Vortrags behauptet, mit Recht als Regierungsstil bezeichnen? Ich meine ja. Denn dies geht weit hinaus über eine bloße Herrschaft, die sich im wesentlichen als übergeordneter Bezugspunkt für die Bevölkerung versteht, ohne je zu eigenständigem Tun willens und imstande zu sein. Auch wenn nicht $\mathrm{zu}$ bestreiten ist, daß weite Teile des statthalterlichen Handelns den Klagen oder auch Anregungen von außen geschuldet waren, haben wir doch nicht nur einen Amtsträger vor uns, der sich allenfalls auf Bitten hin als schlichtende Kraft widerstreitender Interessen betätigt. Das Mosaik von Details, das die Papyri enthüllen, läßt vielmehr zunehmend den Typus eines Statthalters erkennen, der auf der Basis sorgfältiger Problemanalysen von sich aus die Initiative ergreift, um unbefriedigende Situationen zu bereinigen, und dem wir mit gutem Grund umfassendere Planungsentwürfe mit klaren Zielvorstellungen unterstellen dürfen. Gewiß waren diese Fähigkeiten, je nach persönlichem Zuschnitt des jeweiligen Amtsträgers, unterschiedlich ausgeprägt, und nur selten ist zu sehen, wie weit sich dies in die Wirklichkeit umsetzen ließ. $\mathrm{Da} \beta$ es gleichwohl einen solchen eigenständigen Gestaltungswillen gab, wird freilich kaum mehr in Abrede zu stellen sein.

Wenn diese Rolle des Statthalters in dem immer wiederkehrenden Begriff der $\pi$ póvol $\alpha$ ihren charakteristischen Ausdruck fand, schloß dies demzufolge über die patronale Fürsorge hinaus offenkundig auch ein planvolles politi-

56 Vgl. nur W. Eck, Kaiserliche Imperatorenakklamationen und ornamenta triumphalia, ZPE 124, 1999, 223-227, bes. 226f.; zum Verwandtschaftsgrad - „aut frater aut filius" H. Dessau, Komm. zu ILS I 1058. Angesichts des gleichen Praenomens wäre allerdings wohl eher an einen Cousin als einen Bruder zu denken.

$57 \mathrm{Zu}$ den familiären Verbindungen bes. R. Syme, Avidius Cassius, His Rank, Age and Quality, Bonner Historia-Augusta-Colloquium 1984/1985, Bonn 1987 (Antiquitas IV 19), 207-222; auch in: ders., Roman Papers, Bd. 5, Oxford 1988, 689-701.

58 G. Alföldy, Die Stellung der Ritter in der Führungsschicht des Imperium Romanum, Chiron 11, 1981, 169-215, bes. 206; auch in: ders., Die Römische Gesellschaft. Ausgewählte Beiträge, Wiesbaden 1986 (Heidelberger Althistorische Beiträge und Epigraphische Studien 1), 162-209, bes. 199. 
sches Wirken mit ein. Stärker als bisher vermeint ist der Akzent damit auf den vorausschauenden, in die Zukunft weisenden Aspekt dieses Begriffes gelegt, der die ursprünglich auch im Deutschen in eins gefaßte Vorstellung von Fürsorge und Vorsorge zugleich beschreibt. Wohlverstandene $\pi \rho o ́ v o ı \alpha$ hieß folglich nicht nur Petitionen gegenüber grundsätzlich offen zu sein, sondern sich gegebenenfalls selbst kundig zu machen, um Mißstände möglichst frühzeitig zu erkennen, gegebenenfalls auch drohende Probleme zu antizipieren und durch planende Weitsicht, tätiges Handeln und rasches Eingreifen dem Land und seiner Bevölkerung Ruhe, Ordnung und Sicherheit zu bewahren. Dabei lassen sich durchaus bestimmte Bereiche feststellen, denen stets ein besonderes Augenmerk galt, so vor allem das Rechtswesen und die Landwirtschaft.

Das kaiserliche Vorbild, an dem sich die Präfekten dabei orientierten, besaß auch für die anderen Statthalter Verbindlichkeit. Nur folgerichtig wurde das dem patronalen Gedanken innewohnende Verantwortungsgefühl für die Bevölkerung schließlich Teil des statthalterlichen Selbstverständnisses. Trotz mancherlei Klagen hören wir denn auch bezeichnenderweise nichts mehr von derart krassen Verstößen gegen diese Prinzipien, wie sie in der Republik bekanntlich noch gang und gäbe waren. Allein mit dem Konzept von aequitas und providentia, in dem auch berechtigte provinziale Interessen Anerkennung erfuhren - letztlich also der Idee des Gemeinwohls und sogar gewissen Vorstellungen von Rechtsstaatlichkeit -, war es Kaisern wie Statthaltern möglich, trotz eines minimalen Verwaltungsaufwandes über lange Zeit hinweg in einem riesigen Raum die römische Herrschaft zu sichern. Der nicht abreißende Strom der Petitionen, die keineswegs wohlfeil, sondern durchaus mit erheblichem finanziellen und zeitlichen Aufwand verbunden waren, ist wohl der beste Beweis für das ungebrochene Vertrauen der Bevölkerung in die römische Administration und ihre Bereitschaft, aber auch die Befähigung, diesen von ihr vertretenen Prinzipien immer wieder Geltung zu verschaffen. 


\section{Stadt, Bund und Reich in der Zollorganisation des kaiserzeitlichen Lykien. Eine neue Interpretation der Zollinschrift von Kaunos*}

\section{Christian Marek}

„Der einzige Bereich, in dem fast jeder Provinzbewohner - ob peregrinen Rechts, latinischer oder römischer Bürger - kontinuierlich von der römischen Verwaltung aktiv betroffen wurde, war die Steuererhebung."1 Dieser Satz von Werner Eck läßt sich ohne weiteres in die moderne Staatenwelt übertragen, wo Steuererhebung jedermann ebenso kontinuierlich und aktiv betrifft, wie - so könnte man hinzufügen - Steuersenkung Regenten beim Volk beliebt macht. Auf Steigerung seiner Beliebtheit reichsweit hatte es denn auch schon im Jahre $58 \mathrm{n}$. Chr. der römische Kaiser Nero abgesehen, als er aufgrund sich häufender Beschwerden gegen die Zollpächter erwog, ob man nicht sämtliche Zölle überall einfach abschaffen solle. Die entsetzten Senatoren hatten Mühe, ihm das auszureden: Zwar zeuge sein Vorhaben von magnitudo animi, doch die realen Konsequenzen eines solchen Geschenks an die Menschheit kämen einer dissolutio imperii gleich, denn wenn erst einmal die Zölle aufgehoben seien, werde bald auch die Aufhebung der Tribute verlangt werden. Schließlich einigte man sich wenigstens auf die Beseitigung von Mißständen und auf Sonderregelungen. Das kaiserliche Edikt befahl, daß die

* Für die ehrenvolle Einladung, an der Marburger reunion von Schülern und Freunden zu Ehren Malcolm Erringtons teilnehmen zu dürfen, und für Hinweise zum Manuskript bedanke ich mich herzlich bei Hans-Ulrich Wiemer.

1 W. Eck, Der Kaiser, die Führungsschichten und die Administration des Reiches (von Vespasian bis zum Ende der antoninischen Dynastie), in: ders., Die Verwaltung des römischen Reiches in der Hohen Kaiserzeit, Bd. 2, Basel 1998, 3-145, hier: 132. 
diesbezügliche Gesetzeslage, bis dahin der Öffentlichkeit nicht zugänglich, künftighin publiziert werde. ${ }^{2}$

Zoll ist in der Antike eine Abgabe, die bei Überschreiten bestimmter Grenzen auf Handelswaren erhoben wurde. Zölle wurden an verschiedenen Kategorien von Grenzen erhoben, zuoberst an der Außengrenze des Imperium. Wir wissen von der Verzollung der über das Rote Meer importierten Güter des Ostafrika-, Arabien- und Indienhandels (Aromata, Gewürze, Perlen, Edelsteine, Seide etc.), daß in Alexandreia 25\% auf den Warenwert aufgeschlagen wurden. Die Zollgrenzen im Innern des Imperium orientierten sich an der Binnengliederung in Provinzen, waren aber nicht mit den Grenzen einzelner Provinzen identisch. Zollbezirke im Westen faßten mehrere Provinzen zusammen, und die Zöllner des portorium Asiae saßen u. a. am Bosporus. Provinzen waren wie Ägypten in Gaue oder wie Asia in Diözesen und Stadtterritorien unterteilt, und auch an diesen Grenzen wurden (sicher in Ägypten) Zölle erhoben. ${ }^{3}$ Was Art und Höhe des Zolls betrifft, so sind 2,5prozentige Wertzölle der gallischen und der spanischen Provinzen sowie Asiens bekannt.

Um die Organisation von Zöllen im römischen Weltreich auf regionaler bzw. lokaler Ebene zu ergründen, sind wir auf Textzeugnisse angewiesen, in denen zumeist von Sonderregelungen, Privilegien, Zusätzen oder Modifikati-

2 Tac. Ann. 13, 50-51: Eodem anno crebris populi flagitationibus immodestiam publicanorum arguentis dubitavit Nero an cuncta vectigalia omitti iuberet idque pulcberrimum donum generi mortalium daret. sed impetum eius, multum prius laudata magnitudine animi, attinuere senatores, dissolutionem imperii docendo, si fructus quibus res publica sustineretur deminuerentur: quippe sublatis portoriis sequens ut tributorum abolitio expostularetur. plerasque vectigalium societates a consulibus et tribunis plebei constitutas acri etiam tum populi Romani libertate; reliqua mox ita provisa ut ratio quaestuum et necessitas erogationum inter se congrueret. temperandas plane publicanorum cupidines, ne per tot annos sine querela tolerata novis acerbitatibus ad invidiam verterent. ergo edixit princeps ut leges cuiusque publici, occultae ad id tempus, proscriberentur; omissas petitiones non ultra annum resumerent; Romae praetor, per provincias qui pro praetore aut consule essent iura adversus publicanos extra ordinem redderent; militibus immunitas servaretur, nisi in iis quae veno exercerent; aliaque admodum aequa quae brevi servata dein frustra babita sunt. manet tamen abolitio quadragesimae quinquagesimaeque et quae alia exactionibus inlicitis nomina publicani invenerant. temperata apud transmarinas provincias frumenti subvectio, et ne censibus negotiatorum naves adscriberentur tributumque pro illis penderent constitutum.

3 Vgl. H.-J. Drexhage, Einflüsse des Zollwesens auf den Warenverkehr im römischen Reich. Handelshemmend oder handelsfördernd?, MBAH 13, 2, 1994, 1-15; H.-J. Drexhage/H. Konen/K. Ruffing, Die Wirtschaft des römischen Reiches. Eine Einführung, Berlin 2002, 145ff., 268f. mit Literaturangaben. Von den älteren Standardwerken sind hervorzuheben: M. Rostovtzeff, Geschichte der Staatspacht in der römischen Kaiserzeit, Leipzig 1904, bes. 363ff.; S. J. de Laet, Portorium, Étude sur l'organisation douanière chez les Romains, surtout à l'époque du Haut-Empire, Brügge 1949; F. Vittinghoff, Portorium, RE XXII, 1953, 346-399, bes. 384ff. 
onen die Rede und nur jeweils ein begrenztes Segment des zugrundeliegenden Systems zu erkennen ist, während das System als ganzes weitgehend im Verborgenen bleibt. Von vornherein ist mit erheblichen Unterschieden in den über 40 Provinzen zu rechnen, was deren vorrömische Tradition, Art und Umfang administrativer Strukturen in älterer Zeit betrifft. Im Orient blickte die Zollerhebung durch staatliche Autoritäten gewiß vielerorts auf eine sehr viel längere Geschichte und ein differenzierteres Regelwerk zurück als in manchen Regionen des Westens. Bei der Methode der Erhebung ist allgemein zwischen zwei Systemen, Pacht und Regie, zu unterscheiden. In der römischen Geschichte vollzieht sich von der Zeit der Republik bis in die mittlere Kaiserzeit ein, allerdings nicht gleichmäßiger und überall eintretender, Wandel: Das System der Pacht weicht allmählich dem System der Regie, an die Stelle großer privater Pachtgesellschaften tritt zunehmend die Erhebung durch staatliche Organe und subalternes Personal. Dieser Übergang ist etwa in der Zeit der Antonine vollzogen, Ägypten, Syrien und Palästina indessen behalten eine Sonderstellung. ${ }^{4}$

Eine unserer wichtigsten Quellen für das Zollwesen im römischen Reich sind Inschriften. Der Ortsname Turicum (Zürich) etwa findet seine früheste schriftliche Erwähnung als Name einer Zollstation auf dem Grabstein des Kindes eines Zöllners der statio Turicensis quadragesimae Galliarum, d. h. einer Zollstation zur Erhebung des 2,5-prozentigen Zolls auf den Warenwert bei Überschreiten der Grenze der gallischen Provinzen. ${ }^{5}$ Es gibt aber auch ausführlichere Texte, die Einblick in gesetzliche und organisatorische Aspekte bieten. Drei der umfangreichsten Zollinschriften aus dem Imperium, eine davon noch unveröffentlicht, gehen in die neronische Zeit zurück und verdanken ihre Entstehung offensichtlich der oben erwähnten Initiative des Kaisers. Sie stammen alle aus dem östlichen Teil des Reiches: Palmyra, Andriake und Ephesos. Die längste ist der 1881 gefundene Zolltarif von Palmyra. Eine $5 \mathrm{~m}$ breite beschriftete Wand südlich der Agora ist in über 400 Zeilen in griechischer und palmyrenischer Sprache beschriftet mit zwei Texten: erstens einem vom Stadtrat am 18. April $137 \mathrm{n}$. Chr. erlassenen Zollgesetz, zweitens einem

4 Für Ägypten vgl. P. J. Sijpesteijn, Customs Duties in Graeco-Roman Egypt (Studia Amstelodamensia ad epigraphicam, ius antiquum et papyrologicam pertinentia 17), Zutphen 1987.

5 CIL XIII $5244=$ ILS $1562=$ E. Howald/E.Meyer, Die römische Schweiz. Texte und Inschriften mit Übersetzung, Zürich 1940, Nr. 260. 
älteren Gesetz, das auf ein Edikt des neronischen Legaten C. Licinius Mucianus aus dem Jahr 68/9 n. Chr. zurückgeht. ${ }^{6}$

Das 1989 bekannt gewordene und seitdem sehr intensiv diskutierte Zollgesetz von Ephesos ${ }^{7}$ bezieht sich auf die gesamte Provinz Asia und spricht $u$. a. von Zollgrenzen, Anlage und Positionierung von Zollstationen, Sonderzöllen und Zollbefreiung, Deklarationspflicht und Konfiskationsrecht. Es handelt sich um ein Gesetz aus der Zeit der Republik, das durch Zusätze Zug um Zug ergänzt, $62 \mathrm{n}$. Chr. unter Nero in Rom archiviert und in einer griechischen Übersetzung in der Provinzhauptstadt Ephesos veröffentlicht wurde. Ohne Zweifel verdanken wir diese Inschrift der bei Tacitus bezeugten, durch das Edikt Neros verfügten Veröffentlichungspflicht, ut leges cuiusque publici, occultae ad id tempus, proscriberentur.

Ebenfalls in die Zeit Neros scheint eine in Andriake, neben dem hadrianischen Getreidespeicher kürzlich entdeckte, 87-zeilige Zollinschrift zu gehören, deren Edition Burak Takmer (Antalya) vorbereitet. Wir befinden uns am Fundort des Steins bei einem der wichtigsten Handelshäfen Lykiens, in einer unter Claudius neu eingerichteten Provinz des Imperium. Um die Zollorganisation dieser Provinz, Lycia, wird es in den folgenden Überlegungen gehen. Ausgangspunkt ist die neue Interpretation zweier längst bekannter Dokumente, von denen das eine aus unmittelbarer Nähe, aus Myra, das andere aus einer nicht weit entfernten Küstenstadt westlich davon, aus Kaunos, stammt.

6 CIS II 3, 3913; IGRR III 1056; OGIS 629; dazu K. Brodersen, Das Steuergesetz von Palmyra, in: E. M. Ruprechtsberger (Hg.), Palmyra - Geschichte, Kunst und Kultur der syrischen Oasenstadt (Linzer Archäologische Forschungen 16), Linz 1987, 153-162; M. Zahrnt, Zum Fiskalgesetz von Palmyra und zur Geschichte der Stadt in hadrianischer Zeit, ZPE 62, 1986, 279-293; J. F. Matthews, The Tax Law of Palmyra: Evidence for Economic History in a City of the Roman East, JRS 74, 1984, 157-180; J. Teixidor, Le tarif de Palmyre. Une commentaire de la version palmyrienne, Aula Orientalis 1, Barcelona 1983, 235-252.

7 Editio princeps: D. Knibbe/H. Engelmann, Das Zollgesetz der Provinz Asia, EA 14, 1989, 1-206. Aus der umfangreichen Literatur zu diesem Text seien hervorgehoben: M. Heil, Einige Bemerkungen zum Zollgesetz aus Ephesos, EA 17, 1991, 9-18; C. Nicolet, Le Monumentum Ephesenum et les dîmes d'Asie, BCH 115, 1991, 465-480; ders., Le Monumentum Ephesenum et la délimination du portorium d'Asie, MEFRA 105, 1993, 929-959; V. T. Spagnola, Lex portus Asiae. Un nuovo documento sull'appalto delle imposte, in: Atti del congresso della società italiana di storia del diritto sul tema „I rapporti contrattuali con la pubblica amministrazione nell'esperienza storica-giuridica“, Torino 17-19 ottobre 1994, Napoli 1996, 3-74; M. Dreher, Die Lex Portorii Asiae und der Zollbezirk Asia, EA 26, 1996, 111-127; ders., Das Monumentum Ephesenum und das römische Zollwesen, MBAH 16, 2, 1997, 79-95; C. Nicolet, Le Monumentum Ephesenum, la loi Terentia Cassia et les dîmes d'Asie, MEFRA 111, 1999, 191-215; G. D. Merola, Autonomia locale - governo imperiale. Fiscalità e amministrazione nelle province asiane, Bari 2001, bes. $203 \mathrm{ff}$. 
Man kann dieses Dokument als die Königin der Inschriften von Kaunos bezeichnen. Sie ist eingemeißelt an der Wand eines Brunnenhauses, das am Rande der Hafenagora aus den Trümmern wiederaufgerichtet wurde. ${ }^{8}$ Die Inschrift in mindestens drei Kolumnen (insgesamt 179 Zeilen) bedeckt heute die Stirnseite des rechten (südwestlichen) Antenvorsprungs auf vier Lagen (I-IV) und Teile der südwestlichen Außenwand von der obersten bis zur zweituntersten Lage mit insgesamt 24 Blöcken. Entdeckt wurden die beschrifteten Blöcke in den 50er Jahren des 20. Jahrhunderts von George E. Bean. Er hatte eine Rekonstruktion des schwierigen Textes vorgenommen, als die Blöcke noch nicht wieder an ihrem ursprünglichen Ort in der Mauer versetzt worden waren, was eine bewundernswerte Leistung darstellt. ${ }^{9}$ Seit Ende der 90er Jahre habe ich mehrere Kampagnen in Kaunos mit der gründlichen Neuaufnahme dieser Inschrift verbracht. Es stellte sich heraus, daß ganze Textpartien Bean unbekannt geblieben waren. Ich komme zu Ergebnissen, die das Verständnis des ganzen Dokumentes in einem erheblichen Maße verändern. Die wichtigsten Ergebnisse sollen im folgenden vorgestellt werden. ${ }^{10}$

Um auf die Problematik der Inschrift von Kaunos hinzuführen, nehme ich am besten von jener Zollinschrift von Myra meinen Ausgang, die $1966 \mathrm{im}$ Theater dieser lykischen Stadt entdeckt wurde. Es handelt sich um ein Platte von $80 \mathrm{~cm}$ Höhe, oben gebrochen; der erhaltene Teil ist, wie aus der Gruß-

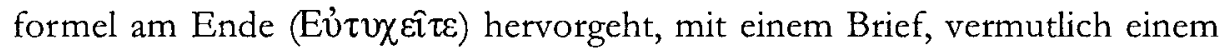
Statthalterbrief, beschriftet, der ziemlich sicher aus hadrianischer Zeit stammt. Er ist 1975 von Michael Wörrle mit ausführlichem Kommentar ediert worden: ${ }^{11}$

8 C. Ișik, Die Ausgrabungen in Kaunos bis zur Entdeckung der Bilingue, in: W. Blümel/P. Frei/Chr. Marek (Hgg.), Colloquium Caricum. Akten der Internationalen Tagung über die karisch-griechische Bilingue von Kaunos, 31. 10. - 1. 11. 1997 in Feusisberg bei Zürich, Berlin 1998, 183-202, hier: 192f.

9 G. E. Bean, Notes and Inscriptions from Caunus II, JHS 74, 1954, 85-110, hier: 97-99 Nr. 38 = SEG XIV 639.

10 Eine eingehende Behandlung der epigraphischen Problematik und ausführliche Interpretation des Textes wird im Rahmen einer neuen Edition erfolgen: C. Marek, Die Inschriften von Kaunos (Vestigia. Beiträge zur Alten Geschichte 55), München 2006, Nr. 35. Ich verweise hier auf die Abschnitts- und Zeilenzählung von Beans Text.

11 M. Wörrle, Zwei neue Inschriften aus Myra zur Verwaltung Lykiens in der Kaiserzeit, in: J. Borchardt (Hg.), Myra. Eine lykische Metropole in antiker und byzantinischer Zeit, Berlin 1975, 255-300, hier: 286-300 = SEG XXXIII 1147. 


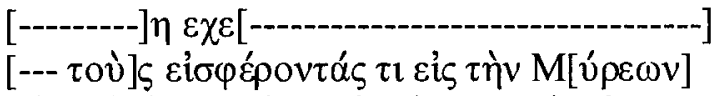

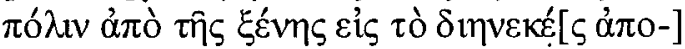

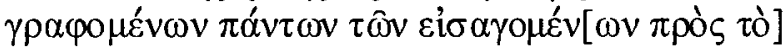

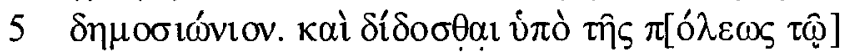

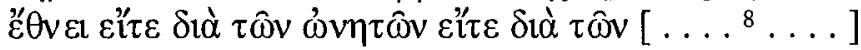

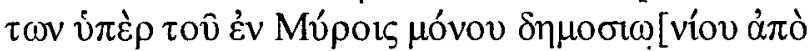

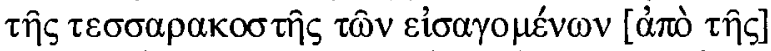

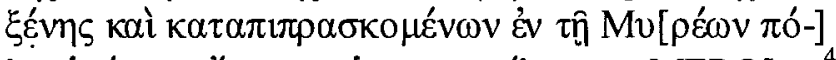

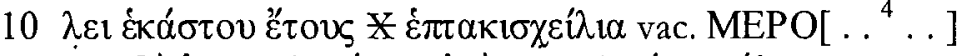

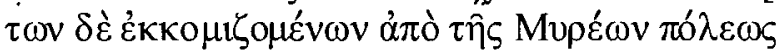

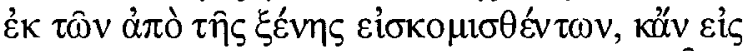

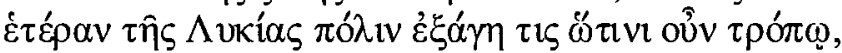

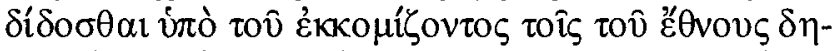

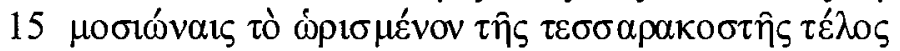
ì نं

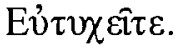

[-- sollen diejenigen], die etwas aus der Fremde in die Stadt Myra einführen, stets [--], nachdem alle Einfuhrgüter an das Demosionion schriftlich deklariert worden sind, (Zoll zahlen ? - oder: nach Deklaration an das Demosionion zahlen?). Und die Stadt soll dem Bund (Ethnos), sei es durch die Pächter, sei es durch die [--], allein für das Demosionion in Myra von der 2,5-prozentigen Abgabe (Tessarakoste) auf Einfuhrgüter aus der Fremde, die in der Stadt Myra verkauft werden, jedes Jahr 7000 Denare zahlen. [--] auf diejenigen Güter, die aus der Fremde eingeführt, aus der Stadt Myra aber wieder ausgeführt werden, auch wenn irgend jemand sie, wie auch immer, in eine andere Stadt Lykiens ausführt, soll der Exporteur den Pächtern des Bundes (Ethnos) den festgesetzten Zoll der 2,5-prozentigen Abgabe (Tessarakoste) zahlen oder der Beschlagnahme unterliegen, gemäß dem Zollgesetz (Demosionikos Nomos).

Gehabt Euch wohl!

Wörrle hat in diesem Text vier verschiedene Bestimmungen erkannt:

1) eine Deklarationspflicht,

2) einen Zoll unter städtischer Verwaltung (geht aus Z. 5 hervor): 2,5\% auf

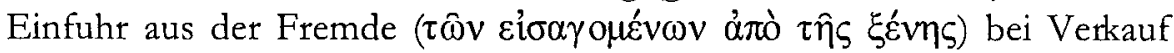

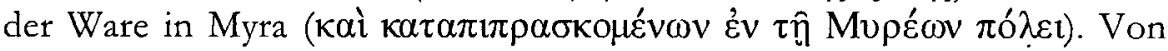


diesen Zolleinnahmen muß die Stadt jedes Jahr eine Pauschale von 7.000 Denaren an den Lykischen Bund abführen.

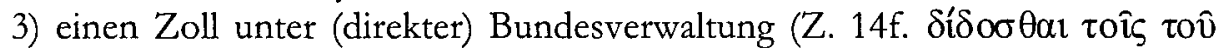

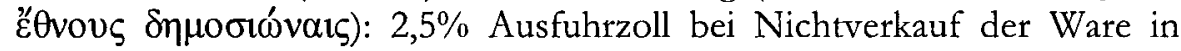
Myra und ihrer Wiederausfuhr, nicht nur, wenn die Ware Lykien wieder verläßt, sondern auch, wenn sie innerhalb Lykiens weitertransportiert wird

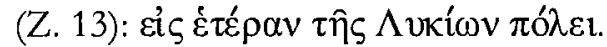

4) das Institut des commissum, d. h. das Recht des Zöllners, im Falle des Zollbetrugs selbsthilfeähnliche Zwangsmittel anzuwenden -, Konfiskation der Ware oder, wenn diese nicht greifbar war, Pfandnahme ${ }^{12}$ - kommt zur

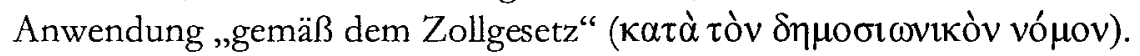

Gegen Wörrles Interpretation dieser Urkunde haben Helmut Engelmann 1985 und Hertha Schwarz 2001 die These von einer lykischen Zollunion aufgestellt. ${ }^{13}$ Auf Ware, die nach Lykien hereinkam, so die beiden Forscher, sei grundsätzlich nur einmal Zoll erhoben worden: Entweder bei Verkauf in der der Außengrenze des Zollbezirkes nächstgelegenen Stadt (in diesem Fall die Stadt Myra), unter städtischer Hoheit. Oder bei Wiederverlassen des Territoriums dieser Stadt an der Außengrenze - egal, in welche Richtung, sei es ins Innere Lykiens, sei es wieder aus dem lykischen Bezirk heraus - unter Bundeshoheit. Von da an habe man die Ware zollfrei in ganz Lykien bewegen können. Das Dokument, so macht Schwarz geltend, habe überhaupt nichts mit dem römischen portorium zu tun, sondern sei eine rein innerlykische Angelegenheit.

Zunächst einmal birgt die Theorie von der Zollunion Lykiens eine Konsequenz in sich, die Engelmann und Schwarz nicht ausgeführt haben: Nehmen wir an, ein Händler aus Alexandreia verkaufte nur die Hälfte seiner Ware in Myra. Die andere Hälfte mußte er wieder ausführen, zahlte Zoll und erhielt dafür eine Quittung. Er fuhr westwärts und führte die Restware in Patara ein. Die Stadt Patara durfte dann keinen Zoll erheben. Der Grund: Diese Ware war schon einmal in einer anderen lykischen Stadt angeboten und dort verzollt worden. Der Gemeinde konnten Zolleinnahmen nur dann zufließen, wenn Ware aus der Fremde direkt nach Patara kam. Völlig abge-

12 Dazu G. Klingenberg, Der Verfall nicht deklarierter Sachen im römischen Zollrecht, Graz 1977.

13 H. Engelmann, Die Zollinschrift von Myra, ZPE 59, 1985, 113-119; H. Schwarz, Soll oder Haben? Die Finanzwirtschaft kleinasiatischer Städte in der Römischen Kaiserzeit am Beispiel von Bithynien, Lykien und Ephesos (29 v. Chr. - 284 n. Chr.), Bonn 2001, 395ff.; H. Schwarz, Anmerkungen zu der Zollinschrift aus Myra, EA 33, 2001, 15-38. 
schnitten davon wären die binnenländischen Städte Lykiens gewesen. Der ganze Lykische Bund wäre zweigeteilt gewesen in Städte mit Zollprivileg (an der Außengrenze) und Städte ohne Zollprivileg (im Binnenland). Ob diese Konsequenz für ein Modell der Organisation des lykischen Zollwesens annehmbar ist, bleibt zumindest fraglich.

Des weiteren ist jedoch zu fragen, ob die Theorie externer Evidenz standhalten kann. Problematisch erscheint in dieser Beziehung das Beispiel von Oinoanda, einer Stadt im Binnenland, die gemäß der 1988 veröffentlichten Stiftungsurkunde des Demosthenes durchaus Zölle erhob. Darauf sind Wörrle und Schwarz mit je verschiedener Interpretation eingegangen. ${ }^{14}$ Entscheidendes zur Lösung des Problems trägt nun aber die Zollinschrift von Kaunos bei. Sie ist nie in diese Diskussion einbezogen worden, und das hat seinen Grund in dem seit Beans Bearbeitung vorherrschenden Verständnis des Dokumentes. In wesentlichen Punkten erweist sich dieses Verständnis als falsch:

Erstens datiert die Inschrift nicht in das 1. Jh. n. Chr., sondern ist hadrianisch wie die Inschrift aus Myra. Das ergibt die erstmalige Entzifferung ihres Anfangs. Zweitens - und das ist von größerer Tragweite - steht daselbst nach der Kaisertitulatur die Jahresdatierung nach einem Erzpriester des Lykischen Bundes geschrieben. Die Stadt Kaunos muß folglich zu dieser Zeit Mitglied des Bundes gewesen sein und mithin zur römischen Provinz Lycia gehört haben, d. h. zu derselben Provinz wie die Stadt Myra. Sie muß, wenn man von einer Organisation des römischen Zollwesens auf Provinzebene wie in Asia ausgeht, demselben Zollbezirk, nämlich dem lykischen, angehört und denselben gesetzlichen Bestimmungen unterlegen haben. Drittens aber handelt es sich bei der Inschrift von Kaunos nicht um ein städtisches Zollgesetz, wie bisher angenommen, sondern um ein ganzes Urkundendossier über eine private Stiftung zweier Kaunier. Der starke Textverlust auf der Ante und auf Teilen der Wand macht eine genaue Bestimmung der einzelnen Urkunden des Dossiers zwar unmöglich. Handelt es sich um Dekrete des Rates, der Volksversammlung und des Rates oder um Erlasse einer höheren Instanz? Die ausführlichen Zollregularien stehen aber jedenfalls in Zusammenhang mit dem Stiftungszweck.

Worin besteht dieser und was wird von diesen beiden Männern gestiftet?

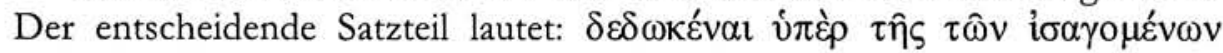

14 M. Wörrle, Stadt und Fest im kaiserzeitlichen Kleinasien. Studien zu einer agonistischen Inschrift aus Oinoanda (Vestigia. Beiträge zur Alten Geschichte 39), München 1988, 213f.; Schwarz, Finanzwirtschaft (wie Anm. 13), 369-371; dies., EA 332001 (wie Anm. 13), 34-35 Anm. 30. 


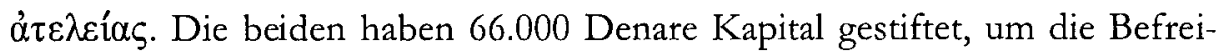
ung des Handels vom Einfuhrzoll zu finanzieren - eine private Subvention öffentlicher Einkünfte, einmalig bisher in unserer epigraphischen Dokumentation, wenn man von einer kurzen Inschrift aus Xanthos (TAM II 291) absieht. Dieser Stiftungszweck ist im Hinblick auf das wirtschaftliche Denken und Handeln in der Antike bemerkenswert. Stifter übernehmen häufig die Finanzierung von Leistungen, die für die Bürgerschaft erbracht werden, und entlasten damit den Haushalt ihrer Heimatstadt, gleichgültig, ob es sich um die Errichtung von Bauwerken, um die Bezahlung von Festen und Wettkämpfen oder um die Herstellung von Münzgeld handelt. Im vorliegenden Fall jedoch dient die Stiftung dem Zweck, die Stadt gegen das Risiko zu versichern, daß ihr durch eine Befreiung des Handels vom Einfuhrzoll ein Ausfall an Einnahmen entsteht. Hinter der Stiftung steht also der Wille, durch eine partielle Atelie den Import von Waren nach Kaunos zu fördern. Damit scheint eine gewisse Einschränkung der Aussage Moses I. Finleys notwendig zu sein, es habe in der Antike „nicht die geringste Vorstellung davon (gegeben), wie man die inländische Produktion schützen, lebensnotwendige Importe herbeiführen und eine Zahlungsbilanz pflegen könnte". ${ }^{15}$ Eine solche Vorstellung muß in Kaunos vorhanden gewesen sein, auch wenn sie auf ein einfaches Problem, die qualitative und quantitative Verbesserung und wohl auch Verbilligung des Warenangebotes, gerichtet war.

Auf den zweiten Blick indessen liefert das kaunische Beispiel auch eine Bestätigung der Gedanken, die Finley zum Thema „Der Staat und die Wirtschaft" (so ist das einschlägige Kapitel überschrieben) geäußert hat. Denn die in Kaunos eingeführte Atelie für Importwaren bedeutete lediglich eine punktuelle Ausnahme von einem in der ganzen Provinz gültigen Zollsystem, das, wie zu zeigen sein wird, Importe und Exporte im Prinzip völlig gleich behandelte; zudem wurde sie durch die Spendabilität privater Stifter abgesichert. Insofern scheint Finley durchaus Recht zu behalten, wenn er feststellt: „Niemals gibt es einen Hinweis darauf, daß die Befreiung von Hafenzöllen als ein (angemessener oder unangemessener) Beitrag zu der Konkurrenzfähigkeit des Empfängers in Handel oder Herstellung verstanden wurde; sie hatte dieselbe Bedeutung wie reservierte Plätze im Theater." 16

Ich skizziere im folgenden kurz den Aufbau des Textes, soweit er noch erkennbar ist: Nach der Stiftungsankündigung ist zunächst eine allgemeine Zollpflicht formuliert. Dann wird, zusammen mit den Namen der Stifter, die gestiftete Geldsumme und der Verwendungszweck genannt. Es folgen Be-

15 M. I. Finley, Die antike Wirtschaft, München 21984, 193.

16 Ebd. 
stimmungen, bei denen wiederholt Bezug genommen wird auf einen Demosionikos Nomos. Erst im folgenden Abschnitt wird die von der Stiftung getragene Zollbefreiung näher beschrieben, wobei vor allem deutlich wird, daß sie nur für Ware gilt, die zum Verkauf in Kaunos bestimmt ist:

„Alle, die etwas aus dem Ausland einführen, zu Wasser oder zu Lande, was es auch ist, ob es zum Eigenbedarf oder zum Verkauf hier bestimmt ist, unterliegen keinerlei Zahlungspflicht auf Hafenzoll, ${ }^{17}$ wenn es sich nicht um Ware handelt, die ausdrücklich als zollpflichtig definiert ist, wobei die Pächter des Hafenzolls weder Geld auf die Einfuhrgüter kassieren dürfen, wie es auf die jeweilige Warenklasse festgesetzt ist, noch von den eingeführten Gütern selbst etwas nehmen dürfen, sei es als Zoll, sei es im Namen einer Spende an Aphrodite, sei es als irgendeine sonstige Gebühr." “18

Verkaufswillige Händler erhalten einen zusätzlichen Anreiz: Ist ihre Ware zum Verkauf in Kaunos bestimmt, mithin zollfrei eingeführt worden, findet jedoch wider Erwarten keinen Absatz, so darf sie in angemessener Frist zollfrei wieder ausgeführt werden:

„Die Fremden, die zu Schiff ankommen und etwas verkaufen wollen, und die ebenfalls nach ihrer Ankunft das Privileg der Zollfreiheit auf Einfuhrgüter haben, unterliegen nicht dem Ausfuhrzoll oder irgendeiner als Spende an Aphrodite deklarierten Abgabe, soweit es sich um Ware handelt, die, eingeführt von ihnen und an Land gebracht, unverkauft bleibt, unter der Bedingung daß sie < selber> dieselbe Ware innerhalb von 20 Tagen wieder auf die Schiffe laden und ausführen. Und auch diejenigen Fremden sollen weder dem Ausfuhrzoll noch irgendeiner Spende an Aphrodite unterliegen, die etwas zum Verkauf auf dem Landweg hereinbringen, soweit es sich um Ware handelt, die sie nicht verkaufen können und die sie selbst auf demselben

17 Der Begriff $\dot{\varepsilon} \lambda \lambda_{\imath} \mu \varepsilon ́$ viov steht in Kaunos für die Gesamtheit der Zolleinnahmen auf den Warenumschlag zu Wasser und zu Lande (!), und nicht für eine Hafengebühr. Die ausführliche Beweisführung für diese Interpretation wird im Corpus der Inschriften von Kaunos (siehe Anm. 10) erfolgen.

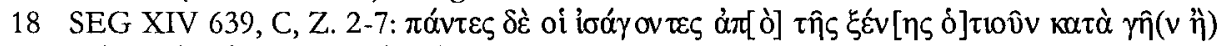

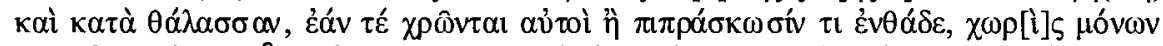

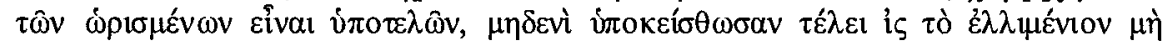

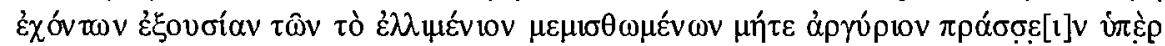

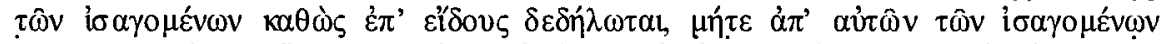

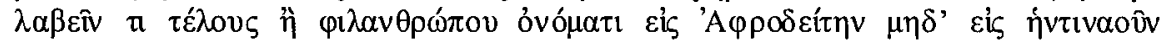

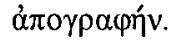




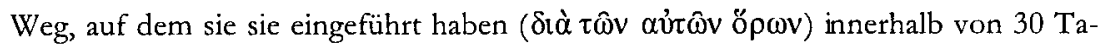
gen ausführen.“19

Aus der Interpretation dieses Abschnitts und anderer Textstellen treten auffällige Beziehungen zu der Zollurkunde aus Myra zutage, auf die ich im folgenden nacheinander eingehe:

\section{Demosionikos Nomos}

Bean hat (1954) diesen Nomos für ein städtisches, nur in Kaunos gültiges Zollgesetz angesehen, und die Forschung ist ihm darin gefolgt. Niemand hat nach der Publikation der Myra-Inschrift (1975), wo derselbe Begriff Demosionikos Nomos, vorkommt, darauf hingewiesen, daß ein solcher Nomos in zwei nicht weit voneinander entfernten Städten, in Kaunos wie in Myra, existierte. $\mathrm{Da}$ Kaunos, wie wir jetzt wissen, zum Zeitpunkt der Stiftung zum Lykischen Bund gehört, kann nicht von zwei verschiedenen Gesetzen die Rede sein, einem Bundesgesetz in Myra und einem städtischen Gesetz in Kaunos. Es ist nahezu zwingend, daß damit auf ein Zollgesetz für ganz Lykien verwiesen wird.

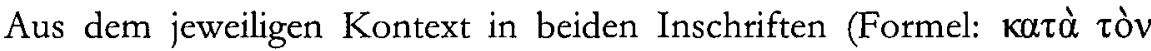

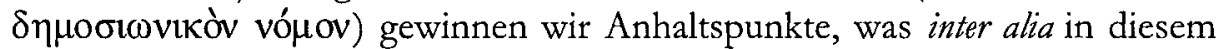
Gesetz stand. In Kaunos definierte es bestimmte Waren, die in jedem Fall zollpflichtig blieben, also der durch die Stiftung ermöglichten Befreiung vom

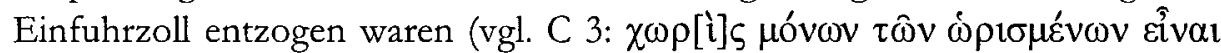

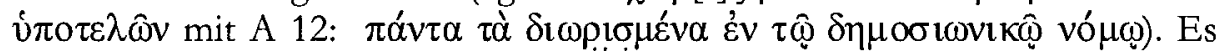
regelte in Kaunos wie in Myra die Beschlagnahme durch die Zöllner (commissum). Es regelte in Kaunos (B 9f.) die grundsätzliche Befreiung von der Zollpflicht bei Ware für den Eigenbedarf und bestimmte einen Sondertarif bei Ausfuhr von Sklaven. Für nahezu jede dieser gesetzlichen Bestimmungen liegen eindeutige Parallelen aus dem römischen Zollgesetz von Ephesos

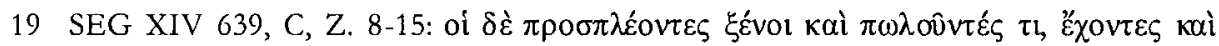

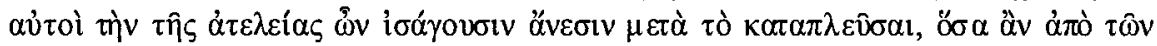

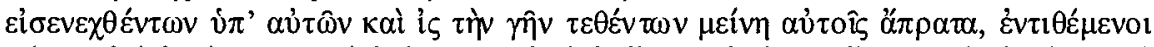

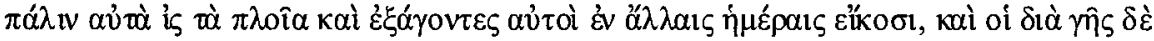

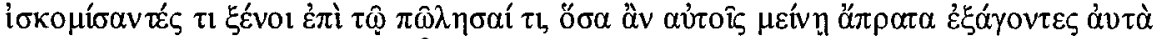

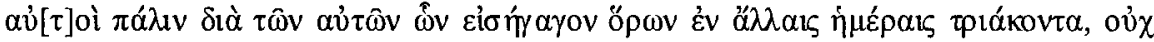

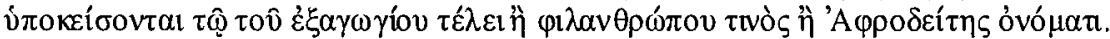


vor, ${ }^{20}$ auch dies ein klares Indiz, daß wir es hier mit nichts anderem zu tun haben als einem von den Römern erlassenen Zollgesetz der Provinz Lycia, dem Gegenstück des Zollgesetzes von Asia.

\section{Zollhoheit}

Aus dem Text in Kaunos geht klar hervor: Außer den im Zollgesetz definierten Waren unterliegt der Zollpflicht auch weiterhin grundsätzlich der gesam-

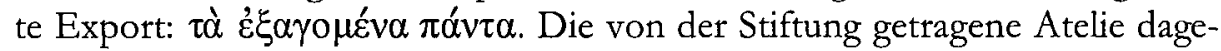
gen betrifft ausschließlich den Importzoll auf die zum Verkauf in Kaunos bestimmte Ware (und deren Wiederausfuhr innerhalb von Fristen). Das ist eine sehr auffällige Parallele zu der Tatsache, daß es in Myra eine Hoheit der Stadt nur über Importzoll gab, nicht dagegen über Exportzoll, und über Importzoll auch nur dann, wenn die Ware in der Stadt verkauft wurde. Man kann auf Grund dieser Parallele und der Tatsache der Zugehörigkeit zu demselben Zollbezirk vermuten, daß wie Myra auch Kaunos die Hoheit nur über Zölle auf Einfuhren besaß unter exakt derselben Bedingung, sodaß wohl auch die Kaunier aus den Zolleinnahmen von am Ort verkaufter Ware eine Jahrespauschale an den Bund abführen mußten. Die private Stiftung dürfte dann so bemessen gewesen sein, daß aus den Zinseinnahmen die Zahlungsverpflichtung gegenüber dem Bund auf jeden Fall eingelöst werden konnte.

\section{Ausfuhrzoll}

Das Territorium von Kaunos bildet sowohl an der Land- wie an der Seeseite die Außengrenze des Zollbezirkes Lykien. Aus der oben zitierten Passage (C) geht hervor, daß die zollfreie Wiederausfuhr nicht verkaufter Ware in bestimmter Frist beschränkt ist auf den Ort, wo die Ware eingeführt wurde. Bei einer Zollunion Lykiens, wie Engelmann und Schwarz sie vertreten, hätte der fällige Zoll bei Ausfuhr an jeder Stelle erhoben werden können (und müssen). Warum also hier der Zwang zur Wiederausfuhr am Ort der Einfuhr? Der Sinn dieser Bestimmung ist es, die zum Verkauf in Kaunos angemeldete, dann aber dort nicht verkaufte Ware von einfacher Transitware zu unterscheiden. Das aber impliziert, daß bei Warenausfuhr an anderer als an der Einfuhrstelle ein Zoll fällig wurde, der vom Importzoll verschieden war. Fol-

20 Konfiskation: $\iint 19,38$; Eigenbedarf: $\int \S 35,37$ (vgl. $₫ 25-27$ für Staat und Militär); Sklaven: $\iint 3,41,51$. 
gerichtig lesen wir an mehreren Stellen (in C 14, D 11, E 9.14, F 6-7.9) von

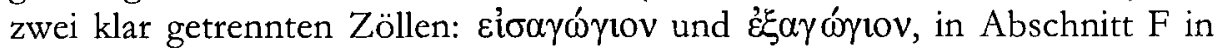

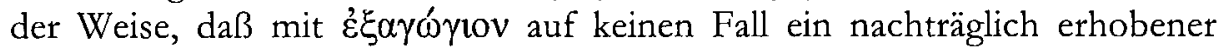
Einfuhrzoll gemeint sein kann. Unter der Voraussetzung, daß Kaunos zum Lykischen Bund gehörte, dürfte damit die Theorie von der Zollunion Lykiens in hadrianischer Zeit als gescheitert gelten.

\section{Zollhöhe}

Über die Zollhöhe erfahren wir Grundsätzliches an zwei Stellen der Inschrift aus Kaunos: In A 12 ist im Zusammenhang mit der Zollpflicht von einem Wertzoll in Höhe von 5\% die Rede. In C 5f, werden den Zöllnern - auf Grund der Atelie - zwei Arten der Zollerhebung verboten:

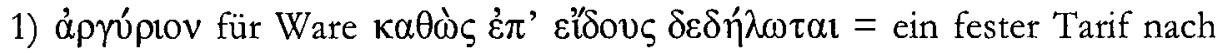
Warenklasse; diese Regelung dürfte etwa auf Sklaven zutreffen. Es muß ein Katalog dieser Waren mit Angaben der Zollhöhe existiert haben.

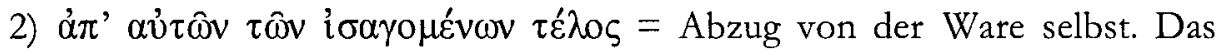
kommt auf einen prozentualen Wertzoll hinaus.

Für die zweite Art der Verzollung zeigt sich wiederum eine auffällige Beziehung zum Zolldokument von Myra. Der fünfprozentigen Abgabe (Eikoste) in Kaunos steht dort eine 2,5-prozentige (Tessarakoste) gegenüber, genau die Hälfte. Wenn man nicht annehmen will, daß Händler in Kaunos normalerweise den doppelten Zoll zu zahlen hatten wie in einer Hafenstadt desselben Zollbezirks weiter östlich, dann drängt sich folgende Vermutung auf: Der Lykische Bund erhob bei jeder Grenzüberschreitung 2,5\%, die doppelte Verzollung ergibt also 5\%. Sehen wir uns die Bestimmung in der Myra-Inschrift näher an. Der in Zeilen 10-15 gemeinte Ausfuhrzoll, die Tessarakoste, wäre

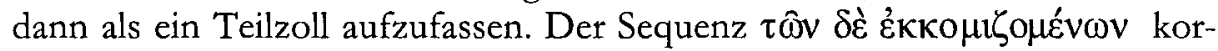
respondierte im verlorenen, oberen Teil der Inschrift offensichtlich ein mit

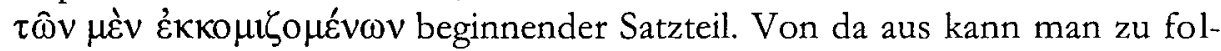
gender Überlegung gelangen: Es handelt sich bei dieser Urkunde, wie aus der Grußformel am Schluß deutlich wird, um einen Kaiser- oder, wahrscheinlicher, einen Statthalterbrief, dessen Ausführungen - wie üblich - die Entscheidung in einem Streitfall herbeiführen. Sehr wichtig ist nun die in der ersten Zeile gerade noch erhaltene Buchstabensequenz, die man m. E. kaum

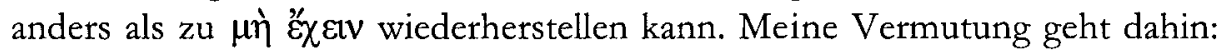


Dem Bundeszoll war infolge einer von der Stadt Myra gewährten Atelie ein Einnahmeausfall entstanden. Vielleicht hatte der Bund daraufhin versucht, die Hoheit über die Zölle ganz an sich zu ziehen. Jedenfalls ging eine Klage, von welcher Partei auch immer, an den Statthalter. Der Statthalter vertbot die

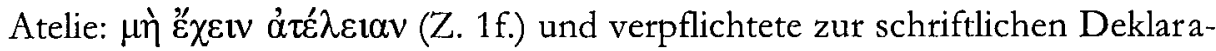
tion. Zugleich aber beschränkte er die Zollhoheit des Bundes auf Transit bzw. Export und bestätigte der Stadt ihre Hoheit über den Zoll auf am Ort verkaufte Ware.

Damit wäre aus der kombinierten Interpretation der beiden Dokumente aus Kaunos und Myra die kaiserzeitliche Zollorganisation Lykiens in den Grundzügen sichtbar: Überschritt eine von außen in diesen Bezirk hereingebrachte Ware die Grenze, so gab es zwei Möglichkeiten:

1) Die Ware wurde in der Hafenstadt oder einer Stadt an der Außengrenze auf der Landseite verkauft. Dann durfte diese Stadt Zoll einnehmen. Kaunos durfte darauf (und nur darauf) Atelie gewähren. Die Stadt mußte aus diesen Einnahmen jedoch eine Jahrespauschale an den Bund abführen, und wenigstens diese Summe mußte in Kaunos aus der Stiftung aufzubringen sein.

2) Wurde (von den Sondervergünstigungen in Kaunos abgesehen) Ware wieder ausgeführt, erhob der Bund durch seine Pächter Zoll, und zwar doppelt, Ein- und Ausfuhrzoll, insgesamt $5 \%$.

Hieraus ergibt sich für die Finanzorganisation des Lykischen Bundes die Schlußfolgerung, daß er zwei getrennte Kassen mit Zolleinnahmen füllte: Erstens eine Zollkasse aus den Einkünften seiner Zöllner, zweitens eine Zollkasse aus den Einkünften der städtischen Pauschalzahlungen. Rom brauchte den lykischen Zoll bloß noch aus den beiden Bundeskassen abzuschöpfen.

Die gewohnte Zuordnung von Kaunos zur kaiserzeitlichen Provinz Asia hätte uns eigentlich schon nach der Veröffentlichung des Monumentum Ephesenum verdächtig erscheinen können. Denn die Zollinschrift von Kaunos paßt nicht mit dem zusammen, was in dem Zollgesetz über die Organisation des asiatischen Zollbezirks zu lesen ist. Hier gab es zwischen Bosporus und Pamphylien einen Ring von über 20 Küstenstädten, in denen die Pächter des römischen portorium die Ein- und Ausfuhr von Waren besteuerten. Über eine Zollhoheit einzelner Städte ist nichts bekannt. Eine Befreiung der Händler vom Einfuhrzoll in einem oder mehreren dieser Häfen wäre mit diesem System unvereinbar. Die Annahme hingegen, daß in Kaunos neben dieser römischen Zollverwaltung noch eine städtische existiert habe, daß die Zollbe- 
freiung sich einzig auf dieses städtische Zollsystem beziehe und ein nur in dieser Stadt gültiges, weil von ihr erlassenes Gesetz vorliege, bedeutete eine unerhörte fiskalische Ausnahme für eine Hafenstadt an der Außengrenze des Zollbezirkes. Es gibt keinen Hinweis darauf, daß Kaunos ein solches Privileg besessen haben könnte, und der erhaltene Text enthält nicht die geringste Andeutung einer Koexistenz einer römischen mit einer städtischen Zollverwaltung. Das Problem besteht nicht länger, seit wir wissen, daß Kaunos zur Zeit der Abfassung des Zolldokumentes der Provinz Lycia angehörte. Mehr noch: Jetzt wird deutlich, daß zwei lykische Städte sich auf dasselbe Zollgesetz beziehen, und daß die Zollverwaltung in beiden Städten im Prinzip gleich organisiert war. Eben mit dem in diesen beiden Zollreglementen zitierten Demosionikos Nomos fassen wir nichts anderes als die in Form eines Gesetzes von römischen Autoritäten verfügte Grundlage der Organisation der Zölle in ganz Lykien, in welchem u. a. die Verzahnung der Zollerhebung durch die Städte und durch den Bund geregelt war.

Diese Zollorganisation ersparte es dem römischen Fiskus, das lykische portorium durch eigene publicani oder procuratores an allen Außengrenzen erheben zu müssen; er brauchte bloß die Zahlungen entgegenzunehmen, die der lykische Bund an ihn abführte. Das kaiserzeitliche Zollwesen Lykiens war mithin völlig anders konstruiert als das in Asien. Die Verwaltung der Einfuhrzölle übte jede Stadt für sich aus, und diese Einnahmen flossen auch in ihre Kasse, wenn die Ware am Ort verkauft wurde. Dafür entrichtete jede Stadt eine feste Zollsteuer an den Bund. Bundesangelegenheit dagegen blieb die Zollerhebung auf grenzüberschreitende Ware an jeder Außen- und Binnengrenze, solange die Ware nicht verkauft wurde. Wahrscheinlich wurde dieses System bereits vom Städtebund geschaffen und mit in die Provinz unter Claudius eingebracht. ${ }^{21}$ Die Römer haben es im wesentlichen so belassen und - vielleicht wiederum unter Nero - eine schriftliche Fixierung (und Veröffentlichung?) geltender gesetzlicher Grundlagen und Rahmenordnungen (Zollhöhe, Zollbefreiung bei Eigenbedarf, Beschlagnahmerecht der Zollpächter) verfügt. Wieder einmal zeigt sich, wie wenig Rom geneigt war, historisch gewachsene Systeme umzukrempeln, dies umso weniger, wenn sie zum Nutzen der Herrscher funktionierten.

21 Zur Problematik der Provinzialisierung vgl. H. Brandt/F. Kolb, Lycia et Pamphylia. Eine römische Provinz im Südwesten Kleinasiens, Mainz 2005, $21 \mathrm{ff}$. 



\title{
Städtische Wirtschaftspolitik im hellenistisch-römischen Kleinasien? Zur Funktion der Emporia*
}

\author{
Kai Ruffing
}

Die Frage, ob es in der griechisch-römischen Welt so etwas wie Wirtschaftspolitik gab, ist einer der hauptsächlichen Konfrontationspunkte in der sogenannten Jahrhundertdebatte um den Charakter der antiken Wirtschaft. ${ }^{1}$ Während man in der neueren Forschung insbesondere in Bezug auf die römische Kaiserzeit einen unbefangenen Umgang mit Begriffen wie Baupolitik, Geldpolitik, Finanzpolitik und anderen mehr feststellen kann, wird die Existenz einer ,Wirtschaftspolitik' häufig vehement verneint. ${ }^{2}$ Diese Ablehnung resul-

* Mein Dank gilt Hans-Joachim Drexhage, Elmar Schwertheim sowie Hans-Ulrich Wiemer für die kritische Lektüre des Manuskriptes. Herrn Schwertheim habe ich darüber hinaus dafür zu danken, daß er mir Einsicht in noch unpublizierte Inschriften aus Kyzikos ge-

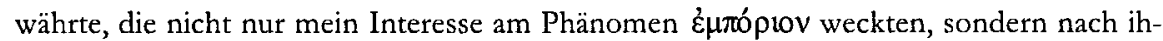
rer Publikation auch die Kenntnis über die kleinasiatischen غ̇ $\mu \pi$ ó $\rho$ l $\alpha$ vertiefen werden. Armin Schulz habe ich schließlich für die großzügige Teilhabe zu danken, die er mir an seinen Kenntnissen über Alexandreia Troas und an den Ergebnissen der dortigen Grabungen gewährte.

1 Vgl. als Überblick über die Diskussion um den Charakter der antiken Wirtschaft M. Polfer, L'archéologie de l'artisanat et le debat sur la nature de l'économie romaine: quelques réflexions critiques, in: ders. ( $\mathrm{Hg}$.), L'artisanat romain: évolutions, continuités et ruptures

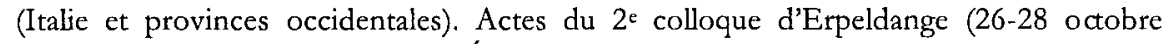
2001), organisé par le Séminaire d'Études Anciennes du Centre Universitaire de Luxembourg et Instrumentum (Monographies Instrumentum 20), Montagnac 2001, 7-17, hier: $7-10$.

2 Vgl. H.-J. Drexhage/H. Konen/K. Ruffing, Die Wirtschaft der römischen Kaiserzeit in der modernen Deutung: Einige Überlegungen, in: K. Strobel ( $\mathrm{Hg}$.), Die Ökonomie des Imperium Romanum. Strukturen, Modelle und Wertungen im Spannungsfeld von Mo- 
tiert aus der Überzeugung, daß ,die Wirtschaft' damals nicht als autonomer Bereich sozialen Handelns begriffen worden sei und daher auch nicht zum Objekt politischer Entscheidungen habe gemacht werden können. Gerade diese Auffassung wird jedoch in der aktuellen Forschung zu Recht zurückgewiesen, da ihr ein irriges Konzept der Ökonomie der modernen Welt zugrun de liegt, und daher ein Abrücken von den neoprimitivistischen Grundpositionen gefordert. ${ }^{3}$

Was die kaiserzeitlichen Städte angeht, wurde zudem nicht selten angenommen, daß sie kaum noch über eigene Einkünfte verfügt hätten, weil Steuern und Zölle ja seit der Einverleibung des jeweiligen Gebietes in das Imperium Romanum an das Reich übergegangen seien. ${ }^{4}$ Da man davon ausging, daß öffentliche Aufgaben im Rahmen des sogenannten Euergetismus durch private Spenden finanziert worden seien, blieb wenig Raum für die Annahme einer städtischen Wirtschaftspolitik überhaupt, da die Städte gemäß der vorherrschenden Meinung ja kaum noch als wirtschaftlich agierende Subjekte auftraten. Demgegenüber zeichnen neuere Untersuchungen ein gänzlich anderes Bild der städtischen Wirtschaft, indem sie zeigen, daß die Städte auch in der römischen Kaiserzeit über erhebliche Einkünfte verfügten, und zwar sowohl solche privatrechtlicher Art - etwa aus der Verpachtung von Ländereien und Immobilien - als auch solche staatsrechtlicher Art - beispielsweise aus Zöllen und Gefällen. ${ }^{5}$ Angesichts eines solchen Befundes stellt sich die Frage, inwieweit die kaiserzeitlichen Städte Maßnahmen ergriffen, die als Ausdruck einer Wirtschaftspolitik bezeichnet werden können. Wirtschaftspolitik soll dabei im Gefolge der modernen wirtschaftswissenschaftlichen Theorie als die Gestaltung des Wirtschaftsablaufes, der Wirtschaftsstruktur und

dernismus und Neoprimitivismus. Akten des 3. Trierer Symposiums zur Antiken Wirtschaftsgeschichte (Pharos 17), St. Katharinen 2002, 1-66, hier: 6-8.

3 Vgl. dazu A. Eich, Die politische Ökonomie des antiken Griechenland (6.-3. Jahrhundert v. Chr.) (Passauer Historische Forschungen 14), Köln-Weimar-Wien 2006, 44-63.

4 Gegen eine Überwertung des Euergetismus für die Finanzen der Städte wandte sich jüngst W. Eck, Der Euergetismus im Funktionszusammenhang der Kaiserzeitlichen Städte, in: M. Christol/O. Masson (Hgg.), Actes du Xe Congrès International d'Épigraphie Grecque et Latine, Nimes, 4-9 octobre 1992, Paris 1997, 305-331. Vgl. ferner Drexhage/Konen/Ruffing, Wirtschaft (wie Anm. 2), 55-61; S. Cramme, Die Bedeutung des Euergetismus für die Finanzierung städtischer Aufgaben in der Provinz Asia, Phil. Diss. Köln 2001, 24+29-30.

5 Vgl. insbesondere die grundlegende Arbeit von H. Schwarz, Soll oder Haben? Die Finanzwirtschaft kleinasiatischer Städte in der Römischen Kaiserzeit am Beispiel von Bithynien, Lykien und Ephesos (29 v. Chr. - 284 n. Chr.), Bonn 2001. Vgl. auch Cramme, Euergetismus (wie Anm.4). 
der wirtschaftlichen Rahmenbedingungen durch staatliche Beschlußorgane definiert werden; durch dieses staatliche Agieren werden also die bestehenden Zustände an das gewünschte Ziel angepaßt. ${ }^{6}$

Einen geeigneten Ansatzpunkt für die Betrachtung einer solchen Fragestellung liefert das Emporion, das besonders gut in den Inschriften Kleinasiens dokumentiert ist. Mit dem Begriff Emporion werden sowohl in der Forschung als auch in den Quellen verschiedenste Vorstellungen verbunden. In ersterer reicht das Spektrum hierbei von der Gleichsetzung des Emporion mit dem von Karl Polanyi entwickelten, hinsichtlich seiner Anwendbarkeit auf die Gegebenheiten der mediterranen Welt kontrovers diskutierten Konzept des port of trade bis hin zur Applizierung des Begriffes auf Baulichkeiten, etwa eine Markthalle. ${ }^{7}$ Während in den epigraphischen Quellen ein sehr technischer Gebrauch des Wortes festzustellen ist, gilt solches mitnichten für die literarische Überlieferung, in der eine wenig präzise Verwendung anzutreffen ist. ${ }^{8}$ Hinzuweisen ist hier auch auf die lebhafte Diskussion des Terminus Emporion im Kontext der Erforschung der griechischen Kolonisation, wurden mit ihm doch häufiger griechische Gründungen charakterisiert, ohne daß man einen Beleg für das Wort aus der vorklassischen Zeit anführen könnte; darüber hinaus entwickelte die ältere Forschung die Vorstellung, üblicherweise sei die Gründung eines Emporion die gewöhnliche Vorstufe zur Entstehung einer Polis gewesen. ${ }^{9}$ Ähnliches nahm man auch für die römische Kaiserzeit an.

6 Vgl. Drexhage/Konen/Ruffing, Wirtschaft (wie Anm. 2), 8-9.

7 Zur Diskussion des Konzeptes des port of trade vgl. T. J. Figueira, Karl Polanyi and ancient Greek trade: the port of trade, Ancient World 10, 1984, 15-30; A. Bresson, Les cités grecques et leurs emporia, in: A. Bresson/P. Rouillard (Hgg.), L'emporion, Paris 1993,

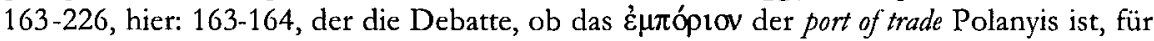
noch nicht abgeschlossen hält; A. W. Johnston, Emporia, emporoi and Sicilians. Some epigraphical aspects, Kokalos 39/40, 1993/1994, 155-169, hier: 155-156, der sich für eine Modifizierung des Modells von Polanyi ausspricht und eine Übersetzung von غ́ $\mu \pi$ ópюv mit dem neutraleren englischen Wort , mart vorzieht, um in eine Gastkultur impla ntierte Siedlungen zu bezeichnen. Als Markthalle wird in der Forschung das in einer Inschrift (I. Laodikeia am Lykos $50=$ IGR IV $863=$ CIG III 3938) genannte é $\mu \pi$ ó $\rho$ เov in Laodikeia am Lykos betrachtet: vgl. T. R. S. Broughton, Roman Asia Minor, in: T. Frank (Hg.), An Economic Survey of Ancient Rome, Bd. IV, Baltimore 1938, 505-918, hier: 769; H. W. Pleket, Greek Epigraphy and Comparative Ancient History: Two Case Studies, EA 12, 1988, 25-37, hier: 35.

8 Vgl. R. Étienne, L'emporion chez Strabon, in: Bresson/Rouillard, L'emporion (wie Anm. 7), 23-46; P. Counillon, L'emporion des géographes grecs, ebd. 47-57.

9 Vgl. E. Lepore, L'emporion: alcuni problemi storiografici e metodologici, Pact 20, 1988, 47-53. Vgl. ferner M. Lombardo, Emporoi, Emporion, Emporitai: Forme e dinamiche 
M. I. Rostovtzeff interpretierte die Implantierung von Emporia in Thrakien als Ausdruck des Anliegens der römischen Regierung, „nuclei“ für die Entwicklung von Städten zu schaffen. ${ }^{10}$ Ferner neigt die moderne Forschung häufig dazu, dem Emporion grundsätzlich eine maritime Orientierung zuzusprechen. ${ }^{11}$

Im Jahr 1993 legte dann Alain Bresson eine profunde Analyse des Wortgebrauchs vor, die für die weitere Forschung konstitutiv werden sollte. Der französische Gelehrte unterschied in diesem Kontext zwischen einer ,axe de la vie commerciale" und der "axe de la vie politique“. Dementsprechend handelt es sich bei dem Emporion einerseits um einen Ort, der dem Warenaustausch oder dem Handel diente. In diesen Bereich gehört das Emporion als juristisch und institutionell verankerte Entität, wie etwa das des Piräus, ${ }^{12}$ mit dem auch das Emporion von Delos vergleichbar ist. ${ }^{13}$ Darüber hinaus ist Bres-

della presenza greca nella penisola iberica, in: G. Urso ( $\mathrm{Hg}$.), Hispania Terris Omnibus Felicior. Premesse ed esiti di un processo di integrazione, Pisa 2002, 73-86, bes. 79-84.

10 Vgl. M. I. Rostovtzeff, The Social and Economic History of the Roman Empire, 2 Bde., Oxford 21957, hier: Bd. 1, 251.

11 Vgl. in diesem Sinne schon K. Lehmann-Hartleben, Die antiken Hafenanlagen des Mittelmeeres. Beiträge zur Geschichte des Städtebaues im Altertum (Klio. Beiträge zur Alten Geschichte. Beiheft 14), Leipzig 1923, 28-45. Vgl. ferner J. Vélissaropoulos, Le monde de l'emporion, DHA 3, 1977, 61-85; dies., Les nauclères grecs. Recherches sur les institutions maritimes en Grèce et dans l'Orient hellénisé, Genf - Paris 1980, 29-56.

12 Selbiges ist epigraphisch gut dokumentiert: IG ${ }^{3} 1101 \mathrm{~A}+\mathrm{B}$ (5. Jh. v. Chr.); IG $\mathrm{I}^{3} 427$, 71; SEG XXVI 72, Z. 20-22 (375/374 v. Chr.); SEG XXXVI 147 A fr. b/c, Z. $18 \mathrm{mit}$ app. crit. (ca. 368 v. Chr.) ; IG II 1629 (325/324 v. Chr.): vgl. dazu insbesondere Bresson, Emporia (wie Anm. 7), 171-177; SEG XXV 112, Z. 34 (196/195 v. Chr.); SEG XXXIV 94, Z. 22 (181/180 v. Chr.); SEG XXXII 132 = IG II 903 (176/175 v. Chr.) Zum É $\mu \pi$ óptov im Piräus vgl. R. Garland, The Piraeus from the Fifth to the First Century B.C., London 1987, 83-95. S. auch Ph. Gauthier, De Lysias à Aristote (Ath. pol., 51,4): le commerce du grain à Athènes et les fonctions des sitophylaques, RHDFE 59, 1981, 5-28.

13 SEG XLVII 1218 (157/156 v. Chr.); ID 1417 A I, Z. 69-70 mit SEG XXXVI 731 app. crit. zu Z. $42-45$ (156/155 v. Chr.); SEG XXXII 218 = IG II 2336, Z. 26; 65; 110; 176

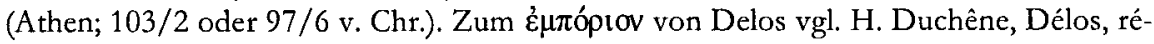
alités portuaires et emporion, in: Bresson/Rouillard, L'emporion (wie Anm. 7), 113-125; ders. / Ph. Fraisse, Le paysage portuaire de la Délos antique. Recherches sur les installations maritimes, commerciales et urbaines du littoral délien (Exploration Archéologique de Délos 39), Paris 2001, 127-134. In einer delischen Inschrift ist darüber hinaus von einem Dionysion genannten Emporion die Rede, mit dem offenbar regelmäßige Handelsverbindungen bestanden. Siehe ID 1655 (nach 166 v. Chr.): 'A

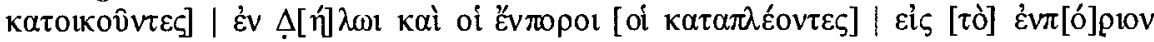

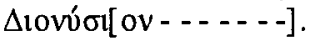


son zufolge hierunter auch eine menschliche Gemeinschaft zu verstehen, die insbesondere dem Warenaustausch gewidmet ist. Andererseits ist nach seiner Analyse eine Gegenüberstellung von Emporion und Polis feststellbar, wobei das erstere die mindere Rechtsqualität bezeichnet. Darüber hinaus kann auch eine Polis als Emporion tituliert werden, und zwar immer dann, wenn hierdurch die Beziehung der Ausnutzung zwischen der dominierenden und der dominierten Stadt ausgedrückt werden soll. ${ }^{14}$ Ausdrücklich nahm Bresson von seinen Überlegungen die kaiserzeitlichen Emporia aus. ${ }^{15}$

Die für diese in der Forschung maßgebliche Position ist die von Louis Robert. Ihm zufolge handelt es sich bei dem insbesondere aus dem kaiserzeitlichen Thrakien und Bithynien bekannten Emporion um einen Marktort, nicht zwangsläufig am Meer, sondern durchaus auch auf dem ,platten' Land gelegen, mit einer besonderen Rechtsstellung versehen, der in einem Abhängigkeitsverhältnis zu einer mehr oder weniger weit entfernten Stadt steht, sich aber nicht als Stadtteil derselben verstehen läßt; solche Emporia finden sich nach Ansicht Roberts insbesondere in den spät hellenisierten Gebieten, in denen die städtischen Territorien über eine besonders große Ausdehnung verfügten. ${ }^{16}$ Seine diesbezüglichen Ansichten erfuhren zuletzt eine Modifizierung durch Pierre Debord, der mit dem Wort sehr verschiedene Realitäten beschrieben sieht, die komplexer als die von Robert herausgearbeiteten Sachverhalte sind. ${ }^{17}$ Christof Schuler betrachtet schließlich die Emporia als Gemeinden, die „weniger agrarisch als von ihrer wirtschaftlichen Funktion geprägt" sind. ${ }^{18}$

Wirtschaftsgeschichtlich betrachtet wurden den Emporia bislang vor allem drei Funktionen zugesprochen, nämlich erstens diejenige eines von einer Polis

14 Vgl. Bresson, Emporia bei Bresson/Rouillard, L'Emporion (wie Anm. 7), bes. 223-225. Vgl. dazu M. H. Hansen, Emporion. A study of the use and meaning of the term in the archaic and classical periods, in: Th. Heine Nielsen (Hrsg.), Yet More Studies in the Ancient Greek Polis (Historia. Einzelschriften 117), Stuttgart 1997, 83-105; J. Hind, Colonies and ports-of-trade on the northern shores of the Black Sea: Borysthenes, Kremnoi and the „other Pontic emporia“ in Herodotos, ebd. 107-116.

15 Vgl. Bresson, Emporia (wie Anm. 7), 225 Anm. 197.

16 Vgl. L. Robert, A travers l'Asie Mineure. Poètes et prosateurs, monnaies grecques, voyageurs et géographie, Paris 1980, 75; dens., Études anatoliennes. Recherches sur les inscriptions grecques de l'Asie Mineure, Paris 1937 (ND Amsterdam 1970), 244.

17 Vgl. P. Debord, Comment devenir le siège d'une capitale impériale: le „parcours“ de la Bithynie, REA 100, 1998, 139-165, hier: 159-162.

18 Vgl. Chr. Schuler, Ländliche Siedlungen und Gemeinden im hellenistischen und römischen Kleinasien (Vestigia. Beiträge zur Alten Geschichte 50), München 1998, 26 Anm. 53. 
scharf geschiedenen Bereichs, der eine Interaktion zwischen Polisbürgern und Fremden ermöglichte. In diesem Kontext ist insbesondere an Häfen zu denken, die in unmittelbarer Nähe bzw. nicht allzuweiter Entfernung von der jeweiligen Polis lagen, so daß Emporion schließlich zu einem Synonym für „Handelshafen“ wurde. ${ }^{19}$ Bekanntestes Beispiel hierfür ist der Piräus. Ferner suchte man in diesem Kontext Entwicklungslinien vom Emporion über die römische statio bis hin zu den mittelalterlichen Fondachi Italiens aufzuzeigen, ${ }^{20}$ für die die Seerepubliken und hier insbesondere Venedig die bekanntesten Beispiele liefern.

Darüber hinaus ist als zweiter Typus des Emporion derjenige anzuführen, der in ein barbarisches bzw. nicht-griechisches Umfeld implantiert wurde und hierdurch den Handel zwischen Griechen (später auch Römern) und Nichtgriechen ermöglichte. ${ }^{21}$ Bekannteste Beispiele sind die bei Herodot genannten Emporia an der Nordküste des Pontos Euxeinos. ${ }^{22}$

Drittens beschreiben Emporia die Wirtschaftszone (,zone commerciale") einer Polis insofern, als es sich bei ihnen um von einem Zentrum abhängige Orte handelt, die nicht unbedingt dem Außenhandel dienen müssen, sondern auch eine "Drainagefunktion" haben und dementsprechend den Warenaustausch auf dieses Zentrum zuleiten. Bei solchen Emporia kann es sich sowohl um städtische als auch dörfliche Gebilde handeln. Ein Beispiel für die Funktion der Emporia als bestimmender Elemente der Wirtschaftszone einer Stadt liefern etwa die Poleis, welche über eine Peraia verfügten, die sie ökonomisch ausbeuteten. ${ }^{23}$

Zusammenfassend läßt sich somit der Gebrauch des Begriffes in den antiken Quellen und der modernen Forschung folgendermaßen beschreiben. In den literarischen Quellen seit Herodot bezeichnet der Begriff Emporion zunächst den Ort, an dem Emporoi agieren; insbesondere wird die Begrifflichkeit dann auf Orte angewendet, an denen griechische Händler in einem außergriechischen Umfeld tätig waren. Mit dieser Vorstellung verbunden war die Er-

19 Vgl. Vélissaropulos, DHA 3, 1977 (wie Anm. 11), 61-62; dies., Nauclères (wie Anm. 11), 29-32; Bresson, Emporia (wie Anm. 7), 165-169.

20 Vgl. Lehmann-Harleben, Hafenanlagen (wie Anm. 11), 39.

21 Vgl. Bresson, Emporia (wie Anm. 7), 177-185.

22 Vgl. zu diesen Hind, Colonies (wie Anm. 14). Kaiserzeitliche Beispiele liefert etwa der „Periplus Maris Erythraei“ mit den dort genannten $\varepsilon$ étópla: vgl. zu diesen L. Casson, The Periplus Maris Erythraei. Text with Introduction, Translation, and Commentary, Princeton 1989, 274276.

23 Vgl. Bresson, Emporia (wie Anm. 7), 201-214. Zur „Drainagefunktion“ dörflicher દ̇ $\mu \pi$ ópla vgl. Debord, REA 100, 1998 (wie Anm. 17), 159. 
reichbarkeit des Emporion auf dem Meer. Seit Thukydides wird das Wort in der griechischen Literatur ganz allgemein zur Bezeichnung von Handelsplätzen gebraucht, insbesondere von solchen Örtlichkeiten, in denen aufgrund der verkehrsgeographischen Voraussetzungen verschiedene Warenflüsse zusammenkamen oder die Interaktion einer Polis mit fremden Händlern vonstatten ging. In den griechischen Inschriften aus dem kaiserzeitlichen Thrakien und insbesondere Kleinasien hingegen findet sich ein etwas anderer Wortgebrauch. Dort bezeichnet das Emporion gewöhnlicherweise eine mit einer besonderen Rechtsstellung versehene, einer Polis untergeordnete, eigenständige Siedlung. In der modernen Forschung wurden mit dem Emporion viel weitergehende Vorstellungen verknüpft. So wurde der Begriff als Konzept für den port of trade vereinnahmt bzw. als übliche Vorstufe einer Entwicklung zur Polis verstanden. Meist wurde ihm dabei eine grundsätzliche maritime Orientierung zugesprochen.

Mit dem Begriff Emporion verbinden sich somit verschiedenste Vorstellungen, was an sich schon eine Behandlung des Themas vor dem Hintergrund der seither publizierten Quellen gerechtfertigt erscheinen läßt. Die folgenden Ausführungen werden sich gleichwohl auf einige mit den Emporia verbundene Problemkreise zu beschränken haben. Ihren Ausgangspunkt werden sie von der epigraphischen Überlieferung nehmen, da hier im Gegensatz zu der literarischen und subliterarischen Überlieferung ein technischer Gebrauch der Begrifflichkeit von vornherein zu erwarten ist. Dementsprechend wird in einem ersten Schritt ein Überblick über die epigraphisch in Kleinasien nachzuweisenden Emporia gegeben, die dann - soweit erkennbar einem der genannten Typen zuzuordnen sein werden. In einem zweiten Schritt wird auf die Interaktion zwischen Polis und Emporion und die körperschaftlichen Rechte des letzteren eingegangen. Instruktiv ist in diesem Kontext eine nähere Betrachtung der thrakischen Verhältnisse und hier insbesondere des Emporion Pizos für die Kaiserzeit, da aufgrund der besonders guten Überlieferungslage die thrakischen Emporia als Parallele für Teile des angesprochenen Fragenkomplexes zu betrachten sind. ${ }^{24}$ In einem dritten Schritt

24 Ähnliches gilt auch für die spätklassische Zeit, wo die bekannte Pistiros-Inschrift einen tiefen Einblick in die Interaktion zwischen Griechen und Nichtgriechen in einem

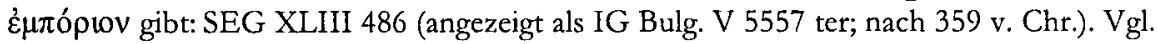
zu dieser Inschrift Johnston, Kokalos 39/40, 1993/1994 (wie Anm. 7), 155-157; I. von Bredow, Das Emporion Pistiros in Thrakien, Orbis Terrarum 3, 1997, 109-120; A. Avram, Notes sur l'inscription de l'emporion de Pistiros en Thrace, Il Mar Nero 3, 1997/98, 37-46. Siehe ferner die in BCH 122, 1998, 247-371 versammelten Abhandlungen zu diesem Text sowie G. R. Tsetskhladze, Pistiros in the system of the Pontic emporia (Greek 
wird nach den ökonomischen Funktionen der dörflichen Emporia zu fragen sein. Standen hierbei in der Forschung vor allem die Dienste, die das Emporion für das jeweilige Zentrum zu leisten imstande war, im Mittelpunkt der Aufmerksamkeit, wird hier auch kurz zu betrachten sein, welche wirtschaftlichen Auswirkungen die Verbindung zwischen der übergeordneten Polis und ihrer Niederlassung auf das ,platte Land hatten. Abschließend gilt es dann auf der Grundlage der so gewonnenen Ergebnisse die Frage zu stellen, inwieweit die Emporia als Elemente einer Wirtschaftspolitik der Städte in Kleinasien zu gelten haben.

\section{II.}

Über ein Emporion in Verbindung mit seinen Häfen dürfte Alexandreia Troas verfügt haben. Jenes wird in zwei Grabinschriften erwähnt, in denen das

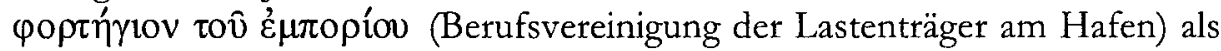
begünstigte Körperschaft einer Grabmult auftritt. ${ }^{25}$ Die von $\varphi$ o $\tau \gamma$ ó $\varsigma$ abgeleitete, sehr ungewöhnliche Bezeichnung für die Berufsvereinigung weist deutlich auf einen maritimen Kontext, so daß man das Emporion im Umfeld der Häfen von Alexandreia Troas zu suchen haben wird. ${ }^{26}$ Fraglich ist allenfalls, ob hiermit das gesamte Hafenareal oder nur ein bestimmter Bezirk in jenem gemeint ist.

Mit dem phrygischen Apameia tritt eine im Binnenland gelegene Stadt in Erscheinung, die über ein Emporion verfügte, wie die Nennung eines Emporiarches in einer Grabinschrift nahelegt. ${ }^{27}$ Ein solcher findet auch Erwähnung in einer Grabinschrift aus dem karischen Aphrodisias, ${ }^{28}$ womit ein weiteres binnenländisches Zeugnis vorliegt. In beiden Fällen wird die Erwähnung die-

trading and craft settements in the hinterland of the northern and eastern Black Sea and elsewhere), in: M. Domaradzki (Hg.), Pistiros et Thasos. Structures économiques dans la péninsule balkanique aux VII ${ }^{\mathrm{e}}$ - II ${ }^{\mathrm{c}}$ siècles avant J.-C., Opole 2000, 233-246. Zum archäologischen Befund in und zur Geschichte von Pistiros vgl. J. Bouzek/M. Domaradzki/Z. H. Archibald, Pistiros I. Excavations and Studies, Prag 1996; M. Domaradzki, Problèmes des emporia en Thraces, in: ders. (Hg.), Pistiros et Thasos, a.a.O. 29-38.

25 I. Alexandreia Troas 151 (3. Jh. n. Chr.); I. Alexandreia Troas 152 (2./3. Jh. n. Chr.).

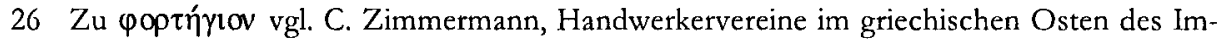
perium Romanum (Römisch-Germanisches Zentralmuseum. Forschungsinstitut für Vorund Frühgeschichte 57), Mainz 2002, 23, die es als lokale Einzelerscheinung auffaßt. Zu

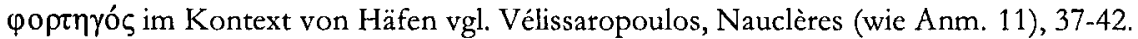

27 IGR IV 796.

28 SEG XLV $1505=\operatorname{AE~1995,~} 1523$ (2./3. Jh. n. Chr.). 
ses Amtes bislang freilich nicht mit der Existenz einer als Emporion verfaßten dörflichen Siedlung in Verbindung gebracht, sondern anders interpretiert. Im Falle von Apameia dachte man zunächst an den Vorsteher einer Berufsvereinigung von Händlern, da nach Ausweis der Inschrift auch die Mitglieder ( $\sigma v v \beta 1 \omega \hat{\tau} \alpha \mathrm{l}$ ) einer solchen ihren Beitrag zur Errichtung des Grabmales leisteten. ${ }^{29}$ Ähnliches gilt auch für den Emporiarches aus Aphrodisias. Da in dem freilich fragmentarischen Text auch die Berufsvereinigung der Leineweber erwähnt wird, mutmaßte Joyce Reynolds in der editio princeps, es handele sich um den Vorsteher eines Leinenmarktes. ${ }^{30} \mathrm{Da}$ jedoch das Amt des Emporiarches ansonsten in der bisherigen Überlieferung ausschließlich in Verbindung mit dörflichen oder besser nicht städtischen Ansiedlungen verbunden ist, die als Emporion qualifiziert werden, ${ }^{31}$ und nichts gegen die Existenz binnenländischer Emporia spricht, die anderweitig belegt sind, ${ }^{32}$ scheint wenig dagegen einzuwenden zu sein, die Erwähnung der Emporiarchen mit der Existenz solcher Ortschaften auf dem Territorium der jeweiligen Polis in Verbindung zu bringen. 33

Interessant ist die Erwähnung desselben Amtes in einer ephesischen Inschrift. ${ }^{34} \mathrm{Da}$ für Ephesos anderweitig auch das Amt des Limenarches belegt ist, dürfte der Emporiarches nicht für den eigentlichen Stadthafen zuständig gewesen sein, sondern für den Hafenort Panormos, ${ }^{35}$ der angesichts der Proble-

29 Vgl. IGR IV 796 adn.

30 J. Reynolds, The Linen-Market of Aphrodisias in Caria, in: F. E. König (Hg.), Arculiana. Ioanni Boegli anno sexagesimo quinto feliciter peracto amici, discipuli, collegae, socii dona dederunt, Avenches 1995, 523-527, hier: 525.

31 SEG XXXIV 1107; I. Nikaia 1071; I. Side $76=$ I. Side Bean $127=$ AE 1966, 465. Für Thrakien siche das Beispiel Pizos: IG Bulg. III 1690 (a+e) $=$ Syll. ${ }^{3} 880=$ IGR I 1500 (= 766). Siehe ferner IG Bulg. II 695, wo wahrscheinlich ebenfalls ein Emporiarch als Vor-

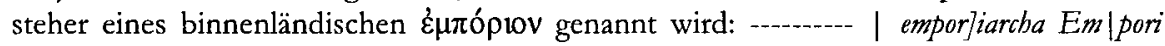
Piretensium | de suo posuit.

32 Vgl. Robert, A travers l'Asie mineure (wie Anm. 16, 75.

33 Vgl. Robert, Études anatoliennes (wie Anm. 16), 245: „Plutôt que ,le chef d'une associa-

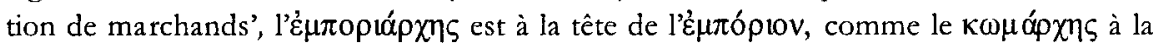
tête de la $\kappa \omega \mu \eta$ “; Robert bezieht sich hier insbesondere auf IGR IV 796.

34 SEG XXXIV 1107.

35 Vgl. H. W. Pleket, The Roman State and the Economy: the Case of Ephesos, in: Entretiens d'archéologie et d'histoire Saint-Bertrand-de-Comminges. Économie antique. Les échanges dans l'Antiquité: le rôle de l'État, Saint-Bertrand-de-Comminges 1994, 115-126, hier: 121 
matik der Versandung des unmittelbar in der Stadt gelegenen Hafens seit der Kaiserzeit immer größere Bedeutung gewonnen haben dürfte. ${ }^{36}$

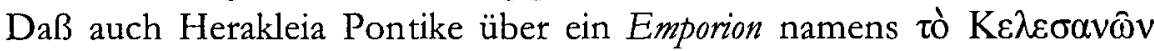
$\dot{\varepsilon} \mu \pi$ ópiov verfügte, zeigt eine im Jahr 1962 von Friedrich Karl Dörner angezeigte Inschrift. ${ }^{37} \mathrm{Im}$ Verbund mit einem westlich davon gefundenen Horosstein, der die Grenze zwischen Prusias ad Hypium und Herakleia Pontike markiert haben wird, ${ }^{38}$ hat die Vermutung Dörners, das in seiner Lage nicht zu bestimmende Emporion habe das fruchtbare Tal des Kocaman Su erschlossen, einiges für sich. ${ }^{39}$

Kyzikos verfügte offenbar über mehrere Emporia. ${ }^{40}$ Jedenfalls ist zumindest eines auf Prokonnesos nachzuweisen; ${ }^{41}$ ein weiteres, das mit dem modernen Gönen zu identifizieren ist, wird als Empfänger einer Grabmult erwähnt. ${ }^{42}$

Das in einer fragmentarischen Ehreninschrift des dritten nachchristlichen Jahrhunderts aus Laodikeia am Lykos erwähnte Emporion wurde bisher als

36 Jedenfalls nennt Strab. 14, 1, 20 einen Tempel der Artemis Ephesia in Panormos, was man als Zeichen einer engen Verbindung zwischen Ephesos und dem Hafenort zu werten haben wird. Zur Topographie der ephesischen Häfen vgl. Lehmann-Hartleben, Hafenanlagen (wie Anm. 11), 202-204. Zu Panormos und seiner Identifizierung mit dem modernen Alaman Gölü vgl. R. Meriç, Zur Lage des ephesischen Außenhafens Panormos, in: Lebendige Altertumswissenschaft. Festgabe zur Vollendung des 70. Lebensjahres von Herrmann Vetters dargebracht von Freunden, Schülern und Kollegen, Wien $1985,30-32$.

37 BE 1963, 264. Vgl. F. K. Dörner, Vorbericht über eine im Herbst 1961 ausgeführte Reise in Bithynien, AAWW 99, 1962, 30-35, hier:Ä 33; Robert, A travers l'Asie mineure (wie Anm. 16), 75-76. Vgl. Sahin, I. Nikaia, 197a: das Emporion lag an der Straße, die von Prusias ad Hypium nach Herakleia Pontike führte.

38 I. Prusias Hyp. 135. Vgl. Dörner, AAWW 99, 1962 (wie Anm. 37), 32.

39 Vgl. Dörner, AAWW 99, 1962 (wie Anm. 37), 33.

40 Diese Vermutung äußerte bereits Louis Robert, der eine Herkunft von I. Perinthos 311 = CIG IV 7019 mit der Nennung eines é $\mu \pi$ ópıv aus dem Territorium von Kyzikos nicht ausschloß und daher zu der genannten Annahme gelangte: BE 1979, 372. Anders jedoch ders., Hellenica II, Paris 1946, 136-137 („de la région de Panion et d'HéracléePérinthe'). Vgl. zur Annahme einer Herkunft vom Territorium von Kyzikos auch SEG XXVIII 976. Vgl, auch BE 1966, 254.

41 BE 1979, 372.

42 I. Kyzikos 581; bei dem in dieser Grabinschrift genannten Emporion muß es sich nicht zwangsläufig um das von Gönen handeln. Da der Stein als Spolie verbaut war und lediglich seine Herkunft aus dem Territorium von Kyzikos gesichert ist, mag es sich durchaus um ein drittes Emporion handeln. 
Markthalle interpretiert. ${ }^{43}$ Angesichts des oben bereits über die Emporia von Apameia und Aphrodisias Gesagten erscheint es allerdings nicht unmöglich, auch dieses Emporion als eigenständige Ortschaft zu interpretieren. Dafür sprechen auch die in dem Text genannten Berufsvereinigungen, namentlich

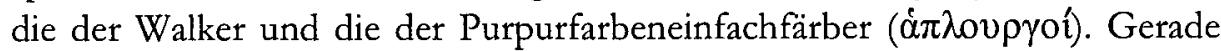
im Falle der Walker erscheint eine Tätigkeit derselben in einer Markthalle zwar nicht ausgeschlossen zu sein, hätte aber zur Bedingung, daß die Produktion und die Verhandlung der Stoffe an unterschiedlichen Orten vor sich ging. Denn der Betrieb von Walkereien setzt das reichliche Vorhandensein von Wasser in unmittelbarer Nähe voraus, wovon man im Falle der Ansässigkeit von Walkern in einer Markthalle wohl kaum ausgehen können wird. Darüber hinaus darf der Betrieb einer Walkerei mit Fug und Recht als umweltbelastend - man denke nur an den reichlichen Gebrauch von Urin und Schwefel - angesehen werden. Daher löste man etwa im syrischen Antiocheia

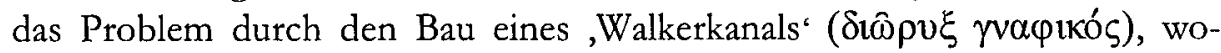
durch man nicht nur die Wasserversorgung der Walkereien gewährleistete, sondern selbige auch außerhalb der Stadt anzusiedeln vermochte. ${ }^{44}$ Das eben Gesagte gilt unter anderen Vorzeichen auch für Färbereien. ${ }^{45}$ Die Ansässigkeit von Walkern und Färbern in einer Markthalle scheint daher zwar nicht ausgeschlossen zu sein; diese Annahme jedoch, daß es sich bei dem in der Inschrift genannten Emporion um eine Ortschaft auf dem Territorium von Laodikeia handelt, darf ohne Zweifel die größere Wahrscheinlichkeit für sich beanspruchen.

Sicher epigraphisch bezeugt sind zwei binnenländische Emporia auf dem Territorium von Nikaia in Bithynien. Eines namens Tataion lag in Luftlinie ca. $55 \mathrm{~km}$ östlich von Nikaia an der Straße nach Ankyra, die sowohl wirtschaftlich als auch militärisch von großer Bedeutung war. ${ }^{46}$ Ein weiteres lag wahrscheinlich in der Nähe des modernen Mahdumlar, woher eine Grabinschrift stammt, derzufolge ein Emporion als Begünstigter einer Stiftung auf-

43 I. Laodikeia am Lykos $50=$ CIG III $3938=$ IGR IV 863. Vgl. Broughton, Roman Asia Minor (wie Anm. 7), 769, Pleket, Comparative Ancient History (wie Anm. 7), 35 sowie Th. Corsten, 1. Laodikeia am Lykos, 103 Anm. zu Z. 2.

44 SEG XXXV 1483 = AE 1986, 694 (73-74 n. Chr.); vgl. D. Feissel, Deux listes de quartiers d'Antioche astreintes au creusement d'un canal (73-74 après J.-C.), Syria 62, 1985, 77-103, bes. 88-89. Zum Prozeß des Walkens und den dabei zur Anwendung kommenden Substanzen vgl. H. Blümner, Technologie und Terminologie der Gewerbe und Künste bei Griechen und Römern Bd. 1, Leipzig 21912 (ND Hildesheim 1969), 173-183.

45 Zum Prozeß des Färbens vgl. Blümner, Technologie (wie Anm. 44), 229-233 + 248-256.

46 I. Nikaia 1071. Vgl. dazu den Kommentar von Sencer Şahin auf 195a-197a. 
tritt. ${ }^{47}$ Auch die Konkurrentin Nikomedeia verfügte nach Ausweis einer Grabinschrift aus dem 3./4. Jahrhundert n. Chr. über ein Emporion namens Kalos Agros. ${ }^{48}$

Prusias ad Hypium wiederum besaß ein Emporion an der Küste des Pontos, wie eine aus dem modernen Akçeşehir, dem antiken Dia stammende Ehreninschrift zeigt. Besonderes Interesse verdient der Grund der Ehrung, nämlich die Steigerung der Einnahmen durch die Bemühungen des also Gelobten. ${ }^{49}$ Eine Ehreninschrift für einen Emporiarches weist die Existenz eines Emporion auf dem Territorium von Side oder in der Stadt selbst nach. ${ }^{50}$ In Smyrna wiederum bildete das Emporion einen Stadtbezirk im Hafen, wie ein

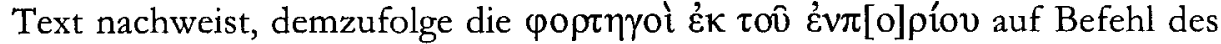
Prokonsuls und des Rates vier Stufen zugeteilt bekamen. ${ }^{51}$

Insgesamt betrachtet sind Emporia, die als nichtstädtische Siedlungen aufgefaßt werden können, somit überwiegend im nördlichen Kleinasien epigraphisch nachzuweisen, $d . h$. in der Hauptsache in Bithynien und Mysien (s. Abb. 1). Dies mag mit der Implantierung dieser Siedlungen insbesondere in Regionen in Zusammenhang gebracht werden, die - wie insbesondere Bithynien - ursprünglich wenig hellenisiert waren und die somit der wirtschaftlichen Erschließung größerer Territorien durch die griechischen Städte dienten. ${ }^{52}$ Einen prägenden Einfluß kann man auch den naturräumlichen Gegebenheiten unterstellen, die an der nördlichen Küste Bithyniens die Gründung kleinerer Emporia favorisierten..$^{53}$ Allerdings stammt der Großteil der Zeugnisse aus der römischen Kaiserzeit. Dies mag einerseits mit der allgemeinen

47 I. Nikaia 1422; vgl. dazu Şahin, I. Nikaia, 197a.

48 SEG XXXVII 1072. Nach Auskunft der aus dem 7. Jh. n. Chr. stammenden Vita des Heiligen Theodoros von Sykeon fanden sich auf dem Territorium von Nikomedeia noch

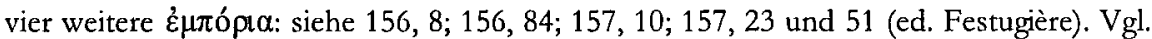
dazu BE 1974, 574; Şahin, I. Nikaia, 199a.

49 I. Prusias Hyp. 29 = SEG XXX 1441 = IGR III 1427. Zur Wiederherstellung von Z. 8-9 vgl. C. Marek, Pontus et Bithynia. Die römischen Provinzen im Norden Kleinasiens, Mainz 2003, 102 Anm. 7. Vgl. dazu Robert, A travers l'Asie mineure (wie Anm. 16), 74 76. Siehe ferner BE 1958, 477, 327 und BE 1963, 264. Literarisch sind in der Region noch Kales, Lilaios, Elaios und Psylla als é $\mu \pi$ ópı $\alpha$ bezeugt: vgl. Counillon, L'emporion (wie Anm. 8), 54-55.

50 I. Side $76=$ AE 1966, 465 (kaiserzeitlich). Vgl. dazu die Anm. von J. Nollé zu Z. 4.

51 I. Smyrna $713=$ IGR IV 1414.

52 Vgl. Robert, Études anatoliennes (wie Anm. 10), 244; ders., A travers l'Asie mineure (wie Anm. 16), 75. Vgl. auch C. Marek, Stadt, Ära und Territorium in Pontus-Bithynia und Nord-Galatia (Istanbuler Forschungen 39), Tübingen 1993, $126 \mathrm{f}$.

53 Vgl. Marek, Stadt, Ära und Territorium (wie Anm. 52), 8. 
Überlieferungslage in Verbindung zu bringen sein; andererseits könnte man hierin auch ein Indiz für das Prosperieren der Wirtschaft insbesondere im Nordteil des kaiserzeitlichen Kleinasien sehen, der einen Reflex in der Anlage von Emporia findet. Dies gilt insbesondere für den Handel zwischen dem Schwarzen Meer und dem Mediterraneum, der sich in der Zeit der Antoninen und im dritten nachchristlichen Jahrhundert intensivierte und für den die Häfen Bithyniens und der Propontis Relaisstationen bildeten. ${ }^{54}$ Gleichwohl empfehlen die darüber hinaus existierenden Hinweise auf Emporia, hierin nicht nur ein auf das nördliche Kleinasien (und Thrakien) beschränktes Phänomen zu sehen, sondern es für einen in Kleinasien gängigen Typus nichtstädtischer Siedlungen zu halten.

\section{III.}

Betrachtet man nun die Interaktion zwischen Emporion und Polis näher, sind in einem ersten Schritt die Beamten, die dem ersteren vorstanden, sowie deren soziale Stellung von Interesse. Der das Emporion leitende Beamte wird in den Texten der römischen Kaiserzeit gewöhnlich als Emporiarches bezeichnet. ${ }^{55}$ In zwei Fällen ist es möglich, über die Person dieses Amtsträgers Nä-

54 Vgl. M. I. Rostovtzeff, Pontus, Bithynia and the Bosporus, PBSA 22, 1916-1918, 1-22, hier: 7-9; Debord, REA 100, 1998 (wie Anm. 17), 159. O. Bounegru, Der westliche Pontosraum und seine Handelsbeziehungen in der römischen Kaiserzeit, MBAH 19, 2, 2000, 109-121, hier: 115-117. S. auch F. Millar, Emperors, kings and subjects: the politics of two-level sovereignty, SCI 15, 1996, 159-173, hier: 171; auch in: ders., Rome, the Greek World, and the East, Bd. 2: Government, Society and Culture, Chapel Hill - London 2004, 229-245, hier: 243.

55 IGR IV 796 (Apameia); SEG XLV 1505 (Aphrodisias; 2./3. Jh. n. Chr.); SEG XXXIV 1107 (Ephesos); I. Nikaia 1071 (Nikaia); I. Side $76=$ AE 1966, 465 (Side). S. auch den

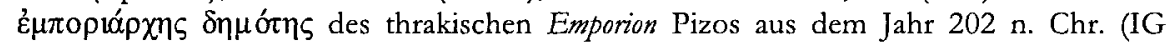
Bulg. II 1690 [a+e] = Syll. ${ }^{3} 880=$ IGR I 1500 [= 766]) sowie den empor]iarcha des Emporium Piritensium (IG Bulg. II 695). Einen weiteren möglichen Beleg bildet eine Inschrift

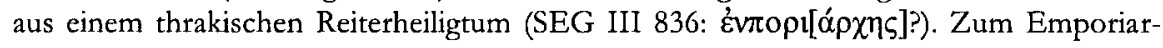
chen vgl. L. Robert, Inscriptions de Bithynie copiées par Georges Radet, REA 42, 1940, 302-322, hier: 307-308; Debord, REA 100, 1998 (wie Anm. 17), 159. In den Inschriften der hellenistischen Zeit, die allerdings nicht aus Kleinasien stammen, werden die Beam-

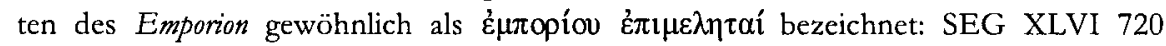
(Amphipolis; 200-170 v. Chr.); SEG XLVII 1218 (Delos; 157/156 v. Chr.); I. Milet Delph. $140=$ Staatsverträge III $482=$ I. Cret. I viii 6, Z. 1-39) (Milet; nach 260 v. Chr.). S. auch SEG XXXVI 147 A fr. b/c, Z. 18 mit app. crit. (Athen; ca. 368 v. Chr.):

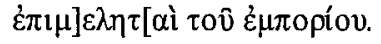


heres zu erfahren. In Side war der Emporiarches Decimus Iunius Zenodotus tätig, der wohl seitens der Polis eine Ehrung erfuhr; abgesehen von dieser Funktion war er Priester der Göttin Roma, Demiurros und auf Lebenszeit Priester des Dionysos. Außerdem hatte er offenbar die Stadt in einem Prozeß vor dem Kaiser erfolgreich vertreten. ${ }^{56}$ Angesichts der genannten Funktionen und Ämter wird man ihn ohne weiteres zur lokalen Elite in Side rechnen können. Nach Auskunft einer Weihinschrift für Zeus Archagathos aus dem Emporion Tataion auf dem Territorium von Nikaia war der Emporiarches M. Cassius Poplianus Nicadas - abgesehen von der Bekleidung des genannten Amtes - auch Oinoposiarches auf Lebenszeit, Gymnasiarchos, Grammateus und Epimeletes für die Errichtung eines Tempels. Wenn er die genannten Ämter und Funktionen nicht in dem Emporion selbst ausübte, was nicht ausgeschlossen werden kann, wird man ihn ebenfalls als einen Angehörigen der lokalen Oberschicht der Stadt Nikaia betrachten können. ${ }^{57}$ Sollte er in der Tat seine Ämter im Emporion selbst ausgeübt haben, hätte man es mit einer Entwicklung zu tun, die insofern zu der der Dörfer (Komai) parallel verlief, als auch diese sich in der Terminologie und Struktur ihrer Ämter im Verlauf der Kaiserzeit der Polis annäherten. ${ }^{58}$ Angesichts der Vielzahl der genannten Ämter wird man jedoch eher der Auffassung zuneigen, daß diese in der Polis ausgeübt wurden und somit auch in diesem Fall den Emporiarches als Angehörigen der lokalen Oberschicht der Polis zu betrachten haben. Nach Ausweis dieser beiden Inschriften wird man also mit einigem Recht davon ausgehen dürfen, daß die Emporiarchen der lokalen Oberschicht der Polis entstammten.

56 I. Side $76=$ AE 1966, 465. Zur Person vgl. Nollé, I. Side 76, Anm. zu Z. 6.

57 I. Nikaia 1071. Vgl. dort 201a die Feststellung Şahins, daß der Geehrte die Ämter des Oinoposiarchen, Gymnasiarchen, Grammatews und des Epimeleten im Emporion selbst bekleidet habe. Für Dörfer in Kleinasien ist der $\gamma \rho \alpha \mu \mu \alpha \tau \varepsilon u ́ s ~ b e l e g t$, so daß man dieses Amt auch als eines interpretieren kann, das im Emporion selbst ausgeübt wurde: vgl. Schuler, Ländliche Siedlungen (wie Anm. 18), 241-242. Selbiges gilt auch für den Oinoposiarchen: vgl. SEG XXXI 1069, 286 sowie Schuler, ebd. 69. Eine Ausübung der genannten Funktionen im Emporion erscheint daher als möglich. In diesem Fall wird man dann freilich $\gamma v \mu v \alpha \sigma \alpha^{\prime} \rho \chi \eta \varsigma$ als ,Festspielleiter' zu verstehen haben. In diesem Sinne ist $\gamma u \mu v \alpha \sigma i \alpha \rho \chi i ́ \alpha$ in einem dörflichen Kontext in den kleinasiatischen Inschriften bezeugt (Vgl. S. ÖğütPolat/S. Şahin, Katalog der bithynischen Inschriften im Archäologischen Museum von

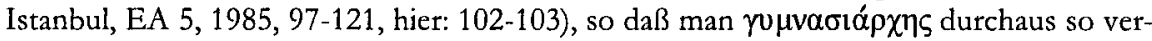
stehen kann. Anders Marek, Pontus et Bithynia (wie Anm. 49), 78, der Publianus zu Recht als einen Angehörigen einer reichen Bürgerfamilie der Metropole betrachtet.

58 Vgl. Schuler, Ländliche Siedlungen (wie Anm. 18), 290. 
Die Bewohner eines Emporion werden in den kaiserzeitlichen Inschriften

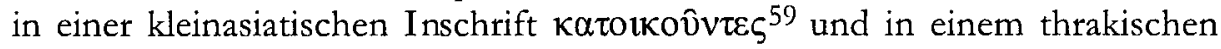
Text als oikń $\tau o \rho \varepsilon \zeta^{60}$ bezeichnet. Man darf diesen beiden Urkunden einen technischen Gebrauch der Wörter unterstellen, handelt es sich im ersten Fall

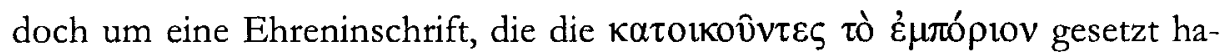
ben, und im zweiten Fall um eine Urkunde, die im Zuge der Gründung eines Emporion verfaßt wurde. Weniger technisch ist die Bezeichnung der Einwohner in einer weiteren Inschrift. In einem aus dem 3./4. Jh. n.Chr. stammen-

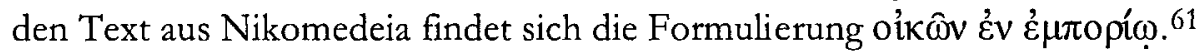

Sowohl die Terminologie für den Vorsteher des Emporion als auch die für seine Bewohner rücken es in die Nähe des Dorfes, der Kome. ${ }^{62}$ Der Emporiarches findet folgerichtig seine Entsprechung im Komarches. ${ }^{63}$ Besonde-

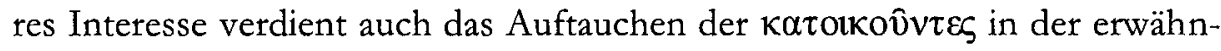

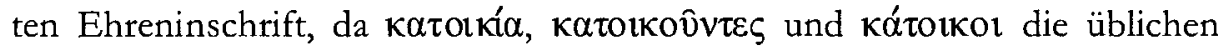
Bezeichnungen für den Personenverband bilden, der ein Dorf bewohnt. ${ }^{64}$ Eine weitere Analogie zwischen den Komai und den Emporia ergibt sich daraus, daß beide als Begünstigte von Grabbußen auftreten können. Darüber hinaus liefern die Zeugnisse, in denen sie als Empfänger solcher Zahlungen zu finden sind, einen Hinweis auf die Existenz einer eigenen Kasse, ${ }^{65}$ zu der auch Stiftungen beigetragen haben. ${ }^{66}$ Die Emporia haben somit über eine eigene Kasse und damit auch eine eigene Kassenführung verfügt.

59 I. Prusias Hyp. $29=$ SEG XXX $1441=$ IGR 1111427.

60 IG Bulg. III 1690. (a+e) = Syll. ${ }^{3} 880=$ IGR I 1500 (= 766) (Pizos; 202 n. Chr.). In einem

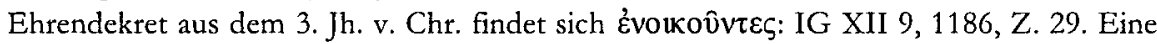

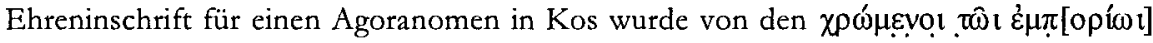
verfaßt: I. Cos EV 230 (1. Jh. v./1. Jh. n. Chr.).

61 SEG XXXVII 1072.

62 Zur Terminologie vgl. Schuler, Ländliche Siedlungen (wie Anm. 18), 12-15 sowie 17-32 zur $k \hat{\omega} \mu \eta$.

63 Vgl. zu diesem Schuler, Ländliche Siedlungen (wie Anm. 18), 233-235.

64 Vgl. Schuler, Ländliche Siedlungen (wie Anm. 18), 33-36. Vgl. ferner 297-303 mit einer Übersicht über die Belege für die genannten Begrifflichkeiten.

65 Vgl. für das Dorf Schuler, Ländliche Siedlungen (wie Anm. 18), 245. In folgenden Tex ten werden غ̇ $\mu \pi$ ópı $\alpha$ als Empfänger einer Grabmult genannt: I. Kyzikos 581 und BE 1979, 372 (Kyzikos/Prokonnesos). Außerhalb Kleinasiens finden sich Belege hierfür in I. Perinthos 311 = CIG IV 7019 (Perinthos; nach $212 \mathrm{n}$. Chr.) und IGR I 811 (Bisanthos).

66 In I. Nikaia 1422 tritt ein é $\mu \pi$ ópюv als Empfänger einer Stiftung auf, ohne daß man angesichts des fragmentarischen Zustandes des Textes Näheres eruieren könnte. 
Schließlich dürften die Emporia wie auch die Komai über eine eigene Gemarkung verfügt haben. ${ }^{67}$ Folgt man den genannten Analogien zwischen Komai und Emporia, darf man von einer ähnlichen Verfaßtheit ausgehen. Dies würde bedeuten, daß man eine Unterordnung des Emporion unter die Polis unter Beibehaltung einer gewissen Selbständigkeit konstatieren kann. ${ }^{68}$ Allerdings bestand zwischen beiden ein gewichtiger Unterschied, der sich in der Person des Komarches bzw. Emporiarches manifestiert. Während jene häufig in den Dörfern gewählt wurden, ${ }^{69}$ scheint es sich bei letzteren meist um Angehörige der städtischen Honoratiorenschicht gehandelt zu haben. ${ }^{70}$ Auch dieser Sachverhalt legt nicht nur eine direkte Bestellung durch die Stadt nahe, sondern dokumentiert auch das lebhafte Interesse der Poleis an ihren Emporia. $^{71}$

Für die Unterordnung der Emporia unter die Poleis läßt sich den kleinasiatischen Inschriften noch ein weiterer Hinweis entnehmen. Es handelt sich um eine Ehreninschrift aus dem modernen Akçeşehir, das zum Territorium

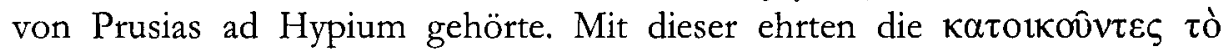
غ̇ $\mu \pi$ ópıov einen gewissen M. Aurelius Chrysenius Damatrius, weil er die Einnahmen des Emporion gesteigert, zur Errichtung von Gebäuden beigetragen und dadurch für die Herrichtung des Emporion für die Stadt gesorgt hatte. Der Geehrte war darüber hinaus Bitbyniarches, Pontarches und Logistes. ${ }^{72}$ Die erzielte Steigerung der Einnahmen des Emporion dürfte auf durch ihn in seiner Amtszeit getroffene fiskalische Regulierungen zurückgehen, wodurch man eine Unterordnung des Emporion unter die Polis als gegeben betrachten

67 Zur Gemarkung der Dörfer vgl. Schuler, Ländliche Siedlungen (wie Anm. 18), 30-32. Eine eigene Gemarkung eines Emporion ist in einem Text aus Kyzikos belegt, dessen Veröffentlichung Elmar Schwertheim in nächster Zeit besorgen wird.

68 Für die $\kappa \omega ́ \mu \eta$ vgl. Schuler, Ländliche Siedlungen (wie Anm. 18), 29-30.

69 Vgl. Schuler, Ländliche Siedlungen (wie Anm. 18), 232.

70 Vgl. Nollé, I. Side 76 Anm. zu Z. 4.

71 Gleichwohl sind nur wenige städtische Eingriffe in die Dörfer belegt: vgl. Schuler, Ländliche Siedlungen (wie Anm. 18), 277-278.

72 I. Prusias Hyp. $29=$ SEG XXX $1441=$ IGR III 1427. Zum Amt des émı $\pi$ ó̉ $\varepsilon \omega \varsigma$ vgl. Ameling, I. Prusias Hyp., 21-22 mit der Vermutung, es könne sich bei die-

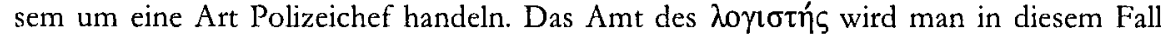
mit einer innerstädtischen Funktion in Verbindung zu bringen haben, wie es auch in Prusias häufiger bezeugt ist: vgl. Ameling, I. Prusias Hyp., 22. 
kann, da hier ein Angehöriger der lokalen Oberschicht in seiner Funktion als Logistes im Emporion tätig ist. ${ }^{73}$

Noch deutlicher wird diese Unterordnung unter die Städte anhand einer kurzen Betrachtung der thrakischen Emporia. Hier sei zunächst auf das Beispiel von Discoduraterae verwiesen. Regelmäßig haben in diesem Ort entweder die Polis oder Boule und Demos von Augusta Traiana den Kaiser als ihren Gründer geehrt, wobei das Emporion stets explizite Erwähnung findet. ${ }^{74} \mathrm{Im}$ Jahr 270/271 n. Chr. wird dort dann Aurelian auf dieselbe Weise durch Boule und Demos von Nicopolis ad Istrum geehrt. ${ }^{75}$ Folglich gehörte Discoduraterae nun nicht mehr zur Provinz Thracia, sondern zu Nicopolis ad Istrum und damit zur Moesia inferior. Die Ehrungen der Kaiser, die Rat und Volk in ,ihrem' Emporion vornehmen, zeigen deutlich die Unterordnung unter die jeweilige Polis. In eine ähnliche Richtung weist auch die in einem weiteren Emporion von Augusta Traiana namens Thouidas durch einen Ratsherrn vorgenommene Weihung für Zeus Okkonenos. ${ }^{76}$ Man wird nicht fehl in der Annahme gehen, daß dieser Ratsherr einer offiziellen Tätigkeit in dem genannten Emporion nachging.

Am deutlichsten werden die Zusammenhänge in der bekannten Urkunde, die die Gründung des Emporion Pizos, das gleichzeitig als Station im cursus publicus dienen sollte, ${ }^{77}$ zum Gegenstand hat. Der genannte Text setzt sich

73 Vgl. Robert, A travers l'Asie mineure (wie Anm. 16), 74; Ameling, I. Prusias Hyp. 29 Anm. zu Z. 4f.; Debord, REA 100, 1998 (wie Anm. 17), 161; Marek, Pontus et Bithynia (wie Anm. 49), 78.

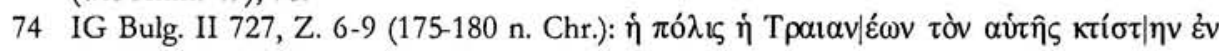

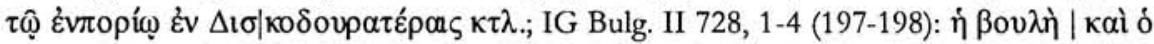

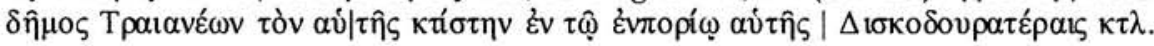
Siehe ferner IG Bulg. II 731 (235-238 n. Chr.), IG Bulg. II 732 (244-249 n. Chr.), IG Bulg. V 5257 (244-249 n. Chr.) sowie IG Bulg. II 733 (v. 270-275 n. Chr.) mit ähnlichen Formulierungen.

75 IG Bulg. II 734 = IGR I 591. Zu Nicopolis ad Istrum gehörte ferner das Emporium Piritensium: IG Bulg. II 695; AE 1965, 128. Der dort erwähnte Priester ist auch in CIL III 7437 belegt, wodurch die Zugehörigkeit des Emporion zu dieser Stadt gesichert ist: Vgl. AE 1965,128 adn.

76 IG Bulg. V 5634 = SEG XXXII 679 (kaiserzeitlich).

77 Vgl. zu seiner Funktion als Station im cursus publicus A. Kolb, Transport und Nachrichtentransfer im Römischen Reich, Berlin 2000 (Klio. Beiträge zur Alten Geschichte. Beihefte N. F. 2), 211. Daß hier in Thrakien nach Auskunft der Inschrift gerade die bestehenden und die neugegründeten $\varepsilon \dot{\mu} \pi$ óp $\iota \alpha$ offensichtlich als Stationen im cursus publicus zu dienen hatten, wird man möglicherweise mit der Reichweite von Märkten und Tagesmarschleistungen in Verbindung zu bringen haben. Zu den Einzugsbereichen der Märkte vgl. unten 143 mit Anm. 100. Zu den Tagesmarschleistungen zu Lande mit verschiedenen Ver- 
aus der Weihung anläßlich der Gründung des Emporion Pizos im Jahr $201 \mathrm{n}$. Chr., einer Liste von 173 Personen aus neun Komai, die die Einwohner bildeten, und schließlich dem Edikt des kaiserlichen Legaten Q. Sicinnius Clarus über die Einrichtung mehrerer Emporia zusammen. ${ }^{78} \mathrm{Im}$ Gegensatz zum üblichen Vorgehen ordnete Clarus an, die Leitung der Emporia nicht wie üblich Emporiarchen, sondern Toparchen zu übertragen, was als eine Aufwertung des Amtes zu verstehen ist. ${ }^{79}$ Ferner konstatiert der Legat in seinem Edikt ausdrücklich die Abhängigkeit der Emporia von einer Stadt. ${ }^{80}$

Die bisherigen Ausführungen weisen also die Existenz zweier Typen von Emporia im kaiserzeitlichen Kleinasien nach. Vergleichsweise breit dokumentiert sind Emporia, die aufgrund der Terminologie für Bewohner und Amtsträger sowie der ihnen eigenen körperschaftlichen Rechte als Pendant zu den Dörfern betrachtet werden können. Anders als diese scheinen sie jedoch in einem sehr viel engeren Verhältnis zu den übergeordneten Poleis gestanden zu haben. Es kann sich bei ihnen - siedlungsgeographisch gesprochen - um eigenständige Hafensiedlungen handeln; das binnenländische Emporion hat gleichwohl als Normalität zu gelten. In zwei Fällen (Alexandreia Troas und Smyrna) ist das Vorhandensein eines Emporion im unmittelbar am Stadtgebiet befindlichen Hafen zu erkennen. Auf die letzteren wird angelegentlich der Betrachtung der wirtschaftlichen Funktionen der Emporia noch einmal zu sprechen zu kommen sein.

Wie bereits bemerkt, sind es insbesondere die Städte Bithyniens und von Pontos, die offenbar ein System von Emporia etabliert haben, um diese wirtschaftlich zu erschließen. Besonders ragen hier nach Ausweis der geographischen Quellen die Städte an der kleinasiatischen Nordküste, namentlich $\mathrm{He}$ rakleia Pontike (und auch Sinope) hervor. ${ }^{81}$ Fraglich muß bleiben, in welche Zeit dieses ,System 'zurückgeht, da Belege für dieses erst im „Periplus Ponti Euxini" des Arrian bzw. in der pseudoarrianischen Bearbeitung dieser Schrift auftauchen. ${ }^{82}$ Auch die binnenländische Erschließung durch die Einrichtung

kehrsmitteln vgl. Kolb a. a. O. 308-317. Gleichwohl scheint das Motiv der Funktion im cursus publicus nicht im Vordergrund gestanden zu haben, da man ansonsten im Rahmen der Privilegierung der neuen Bewohner (IG Bulg. III 1690 e, Z. 60-65) diese wohl kaum von der unentgeltlichen Gestellung von Transportmitteln ausgenommen hätte.

IG Bulg. III $1690(\mathrm{a}+\mathrm{e})=$ Syll. $^{3} 880=$ IGR I $1500(=760)$.

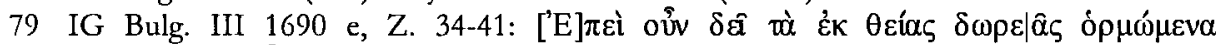

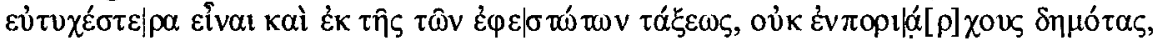

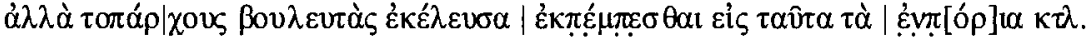

80 IG Bulg. III 1690 e, Z. 87-90 mit dem Kommentar von G. Mihailov zur Stelle.

81 Vgl. Debord, REA 100, 1998 (wie Anm. 17), 159.

82 Vgl. die Übersicht bei Counillon, L'emporion (wie Anm. 8), 56-57. 
von Emporia im technischen Sinn des Wortes ist zumindest epigraphisch vor der Kaiserzeit nicht nachzuweisen. Allerdings wartet Pierre Debord mit einer interessanten Vermutung in bezug auf Kieros, das nachmalige Prusias ad Hypium, auf. Im Rahmen der Auseinandersetzungen zwischen Antiochos I. und Nikomedes I. im Jahr 279 v. Chr. unterstützte Herakleia Pontike den Bithynier mit einem erheblichen Geldbetrag, wofür die Stadt Kieros, Tios und die Landschaft Thyni(a)s zurückerhielt. ${ }^{83}$ Erst im Rahmen der Rückeroberung von Kieros durch Prusias I. um $200 \mathrm{v}$. Chr. wird selbiges ausdrücklich als Polis bezeichnet, ${ }^{84}$ so daß es nach Ansicht von Debord verlockend wäre, in Kieros ein binnenländisches Emporion von Herakleia Pontike zu sehen. 85

Möglicherweise wird man in den großen Heiligtümern des zentralen und östlichen Kleinasien ebenfalls Emporia zu vermuten haben, die aufgrund ihrer Lage an der Königsstraße von Sardeis nach Susa und ihrer überregionalen Ausstrahlung schon lange vor der Kaiserzeit dem Handel zwischen Angehörigen verschiedener Ethnien einen auch institutionell festgezurrten Rahmen boten. Jedenfalls werden etwa Pessinous und Komana Pontike von Strabon als Emporia tituliert, der hier möglicherweise auf länger bestehende Zustände abstellt. ${ }^{86}$ Angesichts des wenig technischen Gebrauchs, den Strabon vom Wort Emporion macht, ${ }^{87}$ ist dies nicht unwahrscheinlich, aber eben auch nicht zweifelsfrei zu belegen. So wird man die Existenz von Emporia im vorrömischen Kleinasien als wahrscheinlich betrachten dürfen. Nachgewiesen ist sie epigraphisch und damit zweifelsfrei erst für die Kaiserzeit, wofür man nicht zuletzt die wirtschaftliche Prosperität, die Kleinasien erlebte, verantwortlich machen dürfte.

IV.

Im überwiegenden Teil der Fälle handelt es sich also bei den epigraphisch nach weisbaren Emporia - siedlungsgeographisch betrachtet - um eigenständige Orte, die ein geregeltes Marktgeschehen ermöglichten und die offenbar in

83 Memnon FGrHist 434 F 9, 4. Vgl. dazu Ameling, I. Prusias Hyp., 1.

84 Memnon FGrHist 434 F 19, 1.

85 Vgl. Debord, REA 100, 1998 (wie Anm. 17), 159-160.

86 Strab. 12, 5, 3; Strab. 12, 3, 36. Vgl. dazu P. Debord, A spects sociaux et économiques de la vie religieuse dans l'Anatolie gréco-romaine (Études Préliminaires aux Religions Orientales dans l'Empire Romain 88), Leiden 1982, 11 -15. Vgl. auch Debord, REA 100, 1998 (wie Anm. 17), 160 zum bei Strab. 12, 5, 2 genannten Beispiel Tabion.

87 Vgl. Rouillard, L'emporion (wie Anm. 8), 35. 
einem engen Abhängigkeitsverhältnis zu ihrer übergeordneten Polis standen. Strukturell betrachtet weisen sie zwar Affinitäten zum Dorf auf, sind aber dennoch von diesem durch die Betonung der wirtschaftlichen Funktion deutlich unterschieden.

Um die wirtschaftlichen Funktionen der Emporia näher zu betrachten, gilt es zunächst einen Blick auf ihre geographische Lage zur übergeordneten Polis zu werfen. Einen guten Ausgangspunkt hierfür liefert das im Binnenland liegende Prusias ad Hypium, das mit dem modernen Akçeşehir, dem antiken Dia, über ein Emporion am Schwarzen Meer verfügte, ${ }^{88}$ mit dem es über eine Paßstraße verbunden war. Der Hypios selbst war offenbar lediglich in begrenztem Umfang für die Schiffahrt nutzbar, so daß der Fluß angesichts der fehlenden Wassertiefe wohl hauptsächlich zum Flößen von Holz benutzt wurde. ${ }^{89}$ An der Mündung des Hypios in den Pontos Euxeinos läßt sich eine kleine Ansiedlung oder eine Hafenstation bestenfalls vermuten, nachgewiesen ist solches indes nicht, auch wenn das Mündungsgebiet nach Auskunft des Memnon bei Unwettern als Zufluchtsort für Schiffe dienen konnte. ${ }^{90}$ Das genannte Emporion, das einen für kleine Schiffe geeigneten Hafen besaß, ${ }^{91}$ hat somit für Prusias eine solche Funktion wahrgenommen, wodurch die Stadt einen Anschluß an den Warenverkehr im Pontos Euxeinos und damit auch an die Routen in das Mediterraneum gewann. In diesem Fall kann man also von der ,klassischen' Hafensituation des Emporion sprechen, das der Abwicklung des Warenaustausches einer Polis über das Meer dient.

Etwas anders ist die Sache bereits im Falle von Herakleia Pontike gelagert. Dessen Territorium begann ca. $10 \mathrm{~km}$ östlich von Dia, wo die Grenze zwischen diesem und Prusias ad Hypium verlief. Weitere $2 \mathrm{~km}$ östlich hiervon ist das oben genannte Emporion durch eine Inschrift nachgewiesen. $.^{92} \mathrm{Ar}-$ rian nennt in seinem „Periplus“ des Pontos Euxeinos auf der Strecke nach Herakleia noch Lilaios und Kales als Emporia, ${ }^{93}$ die somit ebenfalls zu Herakleia Pontike gehört haben. Der anonyme Verfasser des „Periplus Ponti Euxini" fügt dem noch Elaios hinzu. ${ }^{94}$

88 I. Prusias Hyp. $29=$ SEG XXX $1441=$ IGR III 1427.

89 Vgl. hierzu sowie zur Lage von Prusias Ameling, I. Prusias Hyp., 6-7.

90 Vgl. Ameling, I. Prusias Hyp., 6. Zur Zufluchtsmöglichkeit für Schiffe in der Mündung des Hypios siehe Memnon FGrHist 434 F 29, 2, wo solches für einen Teil der Flotte des Mithridates berichtet wird.

91 Periplus Ponti Euxini 9.

92 BE 1963, 264.

93 Arr. per. p. E. 13, 2. Vgl. auch Periplus Ponti Euxini 9.

94 Periplus Ponti Euxini 9. 
Billigt man den beiden geographischen Quellen einen gewissen Informationsgehalt für die hier betrachtete Frage zu, verfügte Herakleia Pontike also über mehrere an der Küste liegende Emporia, obgleich es doch - wie Arrian betont - selbst über einen Hafen für Schiffe verfügte. ${ }^{95}$ Hier kann also von der klassischen Hafensituation der Emporia überhaupt keine Rede sein. Vielmehr wurde das Territorium westlich von Herakleia Pontike über diese Emporia offenbar systematisch wirtschaftlich erschlossen. Dies bedeutet mit anderen Worten eine Einbeziehung der Küstenebenen südwestlich der Stadt in ihren Wirtschaftsraum, worauf gleich noch näher einzugehen sein wird. Hierdurch ist wiederum eine Vergrößerung des von der Stadt wirtschaftlich dominierten Gebietes gegeben, das sie durch in der Hierarchie unter ihr stehende Siedlungen nutzen kann. Gerade das genannte Gebiet zeichnete sich durch gute Bodenbedingungen für die Landwirtschaft aus; die Geomorphologie der Landschaft im Süden und Osten von Herakleia ließ eine Erweiterung ihres Einflußbereiches lediglich nach Westen zu, ${ }^{96}$ so daß die Installierung von Emporia an den genannten Orten nur folgerichtig erscheint. Darüber hinaus bildeten die Emporia gewiß auch Stützpunkte für die von den Herakleoten intensiv betriebene Fischerei. ${ }^{97} \mathrm{Da}$ die genannten Emporia an der Küste lagen, verfügten sie über eine gute Verkehrsanbindung an die Stadt.

Solches läßt sich aber auch für die binnenländischen Emporia zeigen, für die Nikaia das beste Beispiel liefert. Jene Stadt verfügte - wie oben bereits geschildert - nach Ausweis der Inschriften über ein Emporion namens Tataion, das ca. $55 \mathrm{~km}$ ostwärts der Stadt an der Straße nach Ankyra lag. ${ }^{98}$ Ein weiteres lag beim modernen Mahdumlar. ${ }^{99}$ Betrachtet man die Entfernung zwischen Nikaia und Tataion, stellt man eine ungefähre Entsprechung mit dem üblichen Einzugsbereich eines Marktes fest, der ca. 15-20 km beträgt. ${ }^{100}$

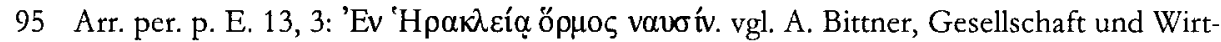
schaft in Herakleia Pontike. Eine Polis zwischen Tyrannis und Selbstverwaltung (A sia Minor Studien 30), Bonn 1998, 125-150 zum vorrömischen Handel Herakleias insbesondere über das Meer.

$96 \mathrm{Zu}$ den landschaftlichen Gegebenheiten in der Umgebung von Herakleia Pontike vgl. Bittner, Herakleia (wie Anm. 95), 117-118. Vgl. ferner ebd. 118-121 zur dortigen Landwirtschaft.

97 Vgl. Bittner, Herakleia (wie Anm.95), 123.

98 I. Nikaia 1071.

99 I. Nikaia 1422.

$100 \mathrm{Vgl}$. J. Bintliff, Going to Market in Antiquity, in: E. Olshausen/H. Sonnabend (Hgg.), Stuttgarter Kolloquium zur historischen Geographie des Altertums 7, 1999: Zu Wasser und zu Land. Verkehrswege in der antiken Welt (Geographica Historica 17), Stuttgart 2002, 209-250, hier: 216-217. 
Dies bedeutet cum grano salis nichts anderes als eine Erschließung der außerhalb des Einzugsbereiches des Marktes von Nikaia liegenden Gebietes durch das Emporion Tataion. Auch hier kann man also mit einigem Recht von einer bewußten Erweiterung der Wirtschaftszone von Nikaia durch das Emporion insofern ausgehen, als durch die Implantierung von Tataion als von der Polis abhängigem Ort an dieser Stelle ein Gebiet für den Markt von Nikaia vereinnahmt wurde, das andernfalls verschlossen geblieben wäre. Durch die Straße verfügte das Emporion dann auch über eine treffliche Verkehrsanbindung an seine Polis.

Versteht man nun diese Emporia als eigenständige Siedlungen, die den institutionellen, baulichen und verkehrstechnischen Rahmen für periodisches (?), häufig stattfindendes Marktgeschehen (d. h. Abhaltung eines Marktes mehrere Male im Monat) lieferten, darf man ihnen aus wirtschaftsgeschichtlicher Sicht betrachtet folgende Funktionen zuschreiben, nämlich:

1. die Ermöglichung des horizontalen Handels, d. h. den Warenaustausch zwischen der Landbevölkerung im Einzugsbereich des jeweiligen Emporion, was den Ausgleich von Überschüssen und Defiziten in den jeweiligen Familien bedeutet,

2. die Bewegung von Gütern, insbesondere Nahrungsmitteln, in diesbezüglich defizitäre Areale, mit anderen Worten in Städte, was unter dem Stichwort des internen Handels zu subsumieren ist, sowie schließlich

3. die Zentralortfunktion, namentlich die Distribution ,exotischerer ${ }^{\prime} \mathrm{Nah}$ rungsmittel und teurerer handwerklicher Erzeugnisse aus der übergeordneten Polis an die Landbevölkerung.

Damit verbunden erhält diese die Möglichkeit, ihre Erträge zu monetarisieren, was auf der anderen Seite die Entstehung einer Nachfrage nach Gütern bewirkt, die über die Gewährleistung der unmittelbaren Subsistenz hinausgeht. Hierdurch wurden ländliche Regionen dem Handel und Handwerk der übergeordneten Stadt als Absatzgebiete erschlossen. ${ }^{101}$

101 Vgl. dazu L. De Ligt, Fairs and Markets in the Roman Empire. Economic and Social Aspects of Periodic Trade in a Pre-Industrial Society (Dutch Monographs on Ancient History and Archaeology 11), Amsterdam 1993, 6-10; vgl. ferner ebd. 123-124 zur Auffassung der غ̇ $\mu \pi$ ópl $\alpha$ als Orte, die der Durchführung periodischer Märkte dienten. Zur Einrichtung und dem Unterhalt von Märkten vgl. die grundlegende, ausführliche Zusammenstellung von Belegen bei J. Nollé, Nundinas instituere et habere. Epigraphische Zeugnisse zur Einrichtung und Gestaltung von ländlichen Märkten in Afrika und in der Provinz Asia, Hildesheim-Zürich-New York 1982. 
Betrachtet man die genannten Sachverhalte aus der Sicht der ländlichen Bevölkerung bzw. der ländlichen Wirtschaft und der sie tragenden Personenkreise, gelangt man zu dem Schluß, daß durch die Etablierung ländlicher Emporia keineswegs lediglich eine ,Ausbeutung des Landes gegeben ist. Ganz im Gegenteil bedeutete die Schaffung dieser Marktflecken eine Monetarisierung der in ihrem Einzugsbereich befindlichen Gebiete, wodurch um so leichter der Schritt von der Subsistenzökonomie zur Marktökonomie vollzogen werden konnte. Somit wäre die Erschließung größerer Territorien durch Emporia neben der Besteuerung und dem Pachtwesen als ein bestimmender Faktor für die erstaunlich breite Monetarisierung insbesondere des Römischen Reiches in der Kaiserzeit zu betrachten. ${ }^{102}$

Abschließend bleibt nach der Funktion der unmittelbar am Siedlungszentrum, im Hafen liegenden Emporia zu fragen, die man in einem anderen Zusammenhang als die bisherigen zu sehen hat. Ihre Funktion als Kontaktzone zwischen Bürgern der Polis und Fremden werden sie insbesondere nach der Einverleibung der jeweiligen Städte in das Imperium Romanum zumindest in Hinsicht auf die damit einhergehenden juristischen Rahmenbedingungen zunehmend verloren haben, obgleich Emporia dieser Art in der Kaiserzeit für die Nordküste des Pontos Euxeinos belegt sind, wofür Tanaïs als epigraphisch dokumentiertes Exempel zu nennen ist. ${ }^{103}$ Vielmehr scheint man innerhalb des Reiches das Konzept der Zusammenfassung bzw. des freiwilligen Zusammenschlusses von Kaufleuten in einzelnen Häusern bzw. Gebäudeare-

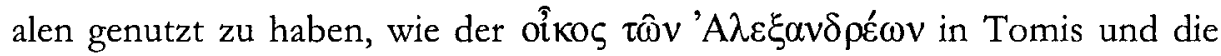
stationes der Tyrer in Rom und Puteoli zeigen. ${ }^{104}$ Dieses Konzept erinnert in der Tat an die mittelalterlichen Fondachi, was man für das Emporion keineswegs ohne weiteres behaupten kann. Um so mehr stellt sich die Frage, welche

102 Zum Zusammenhang zwischen Besteuerung und Monetarisierung vgl. K. Hopkins, Taxes and Trade in the Roman Empire (200 B.C. - A.D. 400), JRS 70, 1980, 101-125; K. Hopkins, Rome, Taxes, Rents and Trade, in: W. Scheidel/S. von Reden (Hgg.), The Ancient Economy, Edinburgh 2002, 191-230. Zum Zusammenhang zwischen Pachtsystem und Monetarisierung vgl. P. Ørsted, Öffentliche Ökonomie, Besteuerung und Produktion im Römischen Reich ca. 100 v. Chr. bis 250 n. Chr., MBAH 16, 1, 1997, 35-56.

103 I. Bosp. 1237 = IOSPE II 423 (193 n. Chr.); vgl. SEG XLVI 920; I. Bosp. $1243=$ IOSPE II 428 (192 n. Chr.); I. Bosp. 1244 (Z. 1-10= IOSPE II 436) (3. Jh. n. Chr.). Als weiterer möglicher Beleg ist I. Bosp. 1257 anzuführen.

104 ISM II 153; vgl. dazu Bounegru, MBAH 19, 2, 2000 (wie Anm. 54), 115. IG XIV $830=$ OGIS $594=$ IGR I 421 (174 n. Chr.). Freilich könnten diese Häuser bzw. Gebäudekomplexe auch in Arealen angesiedelt gewesen sein, die als $\dot{\varepsilon} \mu \pi$ ópıov betrachtet wurden, nachzuweisen ist solches freilich nicht. 
Funktion denn die unmittelbar am Siedlungszentrum liegenden Emporia erfüllten.

Für solche Emporia sind im hier behandelten Kontext Alexandreia Troas und Smyrna als Beispiele anzuführen. ${ }^{105} \mathrm{Da}$ das Gelände des antiken Smyrna modern überbaut ist, lassen sich zur möglichen topographischen Situation eines Emporion dort keine Aussagen machen. Wesentlich günstiger stellt sich die Situation in Alexandreia Troas dar. Die Stadt besaß drei Häfen, zwischen denen sich, durch ein Diateichisma vom übrigen Stadtgebiet abgetrennt, ein ummauerter Bezirk befindet. Auffälligerweise ist der südlich hiervon liegende Hafen lediglich auf seiner Nordseite von einer Mauer umwehrt. Als Erklärung für die Abgrenzung des genannten Areals vom restlichen Stadtgebiet durch eine Mauer scheiden eine Verkleinerung desselben sowie fortifikatorische Gründe aus. Aufgrund dieser Situation äußerte bereits Armin Schulz die Vermutung, bei dem abgetrennten Bereich könne es sich um ein separates Stadtgebiet gehandelt haben, das wirtschaftlichen Zwecken diente bzw. modern ausgedrückt eine ,Freihandelszone' darstellte; unterstützt wird dies noch durch den Sachverhalt, daß Alexandreia Troas seit $12 \mathrm{v}$. Chr. über die volle Zollhoheit verfügte. ${ }^{106}$ In der Tat hat es viel für sich, das genannte Stadtareal mit dem epigraphisch nachgewiesenen Emporion in Verbindung zu bringen, das dementsprechend einen leicht zu kontrollierenden Raum für eine Lagerung von noch nicht verzollten Waren bot.

Hinweise, die eine solche Interpretation des Emporion und des archäologischen Befundes unterstützen, finden sich in Papyri aus dem römischen Ägypten. In dem bekannten, in das zweite nachchristliche Jahrhundert datierenden

105 I. Alexandreia Troas 151 (3. Jh. n. Chr.); I. Alexandreia Troas 152 (2./3. Jh. n. Chr.); I. Smyrna 713 = IGR IV 1414 (Smyrna).

106 A. J. P. H. Schulz, Die Befestigungsanlage von Alexandreia Troas, in: Studien zum antiken Kleinasien V (Asia Minor Studien 44), Bonn 2002, 33-58, hier: 39-40 mit Anm. 32 mit dem Hinweis auf $₫ 44$ (Z. 103-105) der lex portorii provinciae Asiae (ed. H. Engelmann/D. Knibbe, Das Zollgesetz der Provinz Asia. Eine neue Inschrift aus Ephesos,

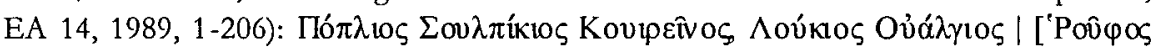

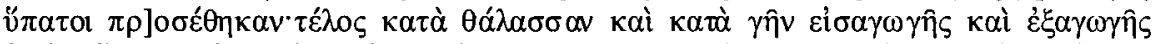

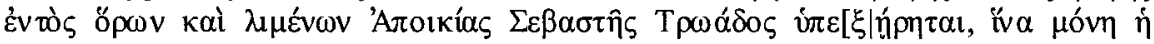

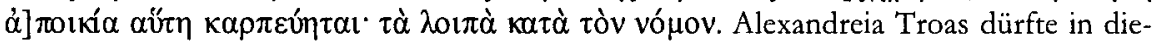
ser Hinsicht keinen Sonderfall darstellen. Zwar besaß es als Kolonie einen privilegierten Status, jedoch darf man mit einiger Gewißheit davon ausgehen, daß die Städte Kleinasiens insgesamt auch auf Polis-Ebene Zölle erheben konnten: vgl. Schwarz, Finanzwirtschaft (wie Anm. 5), 369-385 sowie 395-401; vgl. auch Cramme, Euergetismus (wie Anm. 4), 49-50. Somit dürfte das Konzept des Freihafens auch für Städte Sinn machen, die nicht in ähnlicher Weise privilegiert waren. 
„Muziris-Papyrus"107 findet sich unter anderem die Vereinbarung, die aus dem Indienhandel stammenden Waren durch die Östliche Wüste in die öffentlichen Zollverwahrungslager in Koptos zu transportieren (óvoí $\sigma \omega \ldots$...

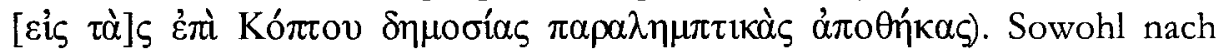
Auskunft des Papyrus als auch der literarischen Quellen wurden dann die Waren in Koptos auf Schiffe umgeschlagen, um später der Verzollung durch die Tetralogie in Alexandreia im dortigen Zollager ('̉ 'A $\lambda \varepsilon \xi \alpha v \delta \rho \varepsilon i \alpha$ $\tau \hat{\eta} \varsigma$

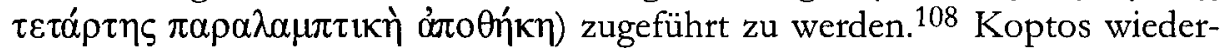
um war über einen Kanal mit dem Nil verbunden ${ }^{109}$ und muß dementsprechend über einen Hafen verfügt haben, wo die Umladung der Waren aus dem Zollager auf Schiffe vo tgenommen wurde.

Als Platz für diese Zollager hat Fabienne Burkhalter jüngst den Fundort der Inschrift vorgeschlagen, die den berühmten „Tarif von Koptos“ enthält, der sich östlich der Gaumetropole auf einem kleinen Hügel fand. Hierdurch wäre eine bauliche Trennung zwischen der Metropole und einem Areal gegeben, das man als ,Freihafen' bezeichnen kann. ${ }^{110}$ Bemerkenswerterweise charakterisiert Plinius denn auch Koptos als dem Nil sehr nahe liegendes Emporion für Waren aus Indien und Arabien (Coptos, Indicarum Arabicarumque mercium Nilo proximum emporium). ${ }^{111}$ Auch wenn man wiederum von einem nicht technischen bzw. übertragenen Gebrauch des Wortes bei Plinius respektive seiner Quelle auszugehen hat, ist es dennoch nicht ausgeschlossen, hierin einen Hinweis auf die Existenz eines Emporion bei Koptos zu sehen.

Eine Verbindung zwischen Zollangelegenheiten und einem Emporion läßt sich noch anhand einer aus Aquileia stammenden Weihinschrift für Iuppiter Optimus Maximus, das numen Augusti des Antoninus Pius und den Genius der Kolonie beweisen. Nach Auskunft dieser Inschrift hatte der kaiserliche Sklave Eutyches, vil(icus) vect(igalis) Illyric(i), I praep(ositus) q(uin)q(uasigesimae) die beiden stationes des Emporion auf eigene Kosten erweitern und wiederherstellen lassen. ${ }^{112}$ Hieraus ergibt sich, daß einerseits das Konzept des Freihafens in Zollangelegenheiten nichts ungewöhnliches war und dieses andererseits

107 SB XVIII 13167 (r), 3-4.

108 Strab. 16, 4, 24; Plin. nat. 6, 102. SB XVIII 13167 (r), Z. 7-8.

109 Strab. 16, 4, 24; 17, 1, 44.

110 Vgl. F. Burkhalter, Le "Tarif de Coptos», Le douane de Coptos, les fermiers de l'apostolion et le préfet du désert de Bérénice, Topoi Suppl. 3, 2002, 199-233, hier: 202 208.

111 Plin. nat. 5, 60.

112 I. Aquileia 265. Ein weiteres Beispiel für ein Emporium auf italischem Boden liefert Puteoli: CIL X $1698=$ CIL I2 $^{2} 131=$ ILS II 1 5383. S. dazu auch Cic. Att. 5, 2, 2. 
mit dem Begriff Emporion in Verbindung zu bringen ist. ${ }^{113}$ Dieses in einem baulich von der Stadt abgetrennten Bereich unterzubringen, wie es für Alexandreia Troas angesichts des bisher Gesagten mit einiger Sicherheit zu vermuten ist, brachte für die Stadt mehrere Vorteile, namentlich die Vermeidung von Mehrfachverzollungen im Verbund mit der Möglichkeit einer strikten Kontrolle des Warenverkehrs sowie seiner Fokussierung auf dieses Areal. ${ }^{114}$ Dies wiederum dürfte zu einer möglichst effizienten Erhebung der Zölle beigetragen haben, die somit der Stadt optimierte Einkünfte lieferten. Solches wird man nicht nur im Falle von Alexandreia Troas zu unterstellen haben, sondern bei der Zollerhebung allgemein auf der Ebene des Reiches und der der Städte.

\section{V.}

Die kleinasiatischen Emporia erweisen sich somit auf der einen Seite als siedlungsgeographisch selbständige Siedlungen, die Marktfunktionen für eine übergeordnete Polis erfüllten, und auf der anderen Seite als zolltechnisch exterritoriale Gebiete, die eine Konzentration und Überwachung des Warenverkehrs und damit eine effiziente Zollerhebung ermöglichten. Was berechtigt uns, sie als Ausdruck städtischer Wirtschaftspolitik zu betrachten?

Die Annahme, daß die kleinasiatischen Emporia in der Regel auf städtische Initiative gegründet wurden, scheint naheliegend, auch wenn der einzige Text, der von der Gründung eines Emporion in der römischen Kaiserzeit spricht, von einer kaiserlichen Initiative berichtet. ${ }^{115}$ Dieses Beispiel darf jedoch nicht verallgemeinert werden, weil sich Kleinasien aufgrund der weit stärkeren und über einen viel längeren Zeitraum gewachsenen Urbanisierung von Thrakien fundamental unterschied. Die hier untersuchten epigraphischen Zeugnisse beweisen jedenfalls, daß die kleinasiatischen Emporia nicht bloß auf städtischem Territorium lagen, sondern diesen auch administrativ unterstellt waren. Zudem steht außer Zweifel, daß die Städte aus den Emporia Einkünfte zogen, an ihrer Gründung also materiell interessiert waren. ${ }^{116}$ Das fiskalische

$113 \mathrm{Zu}$ diesem Ergebnis kam bereits Lehmann-Hartleben, Hafenanlagen (wie Anm. 11), 44 45 , der diesen Schluß ebenfalls lediglich auf Indizien aufbauen konnte.

114 Zur durch das é $\mu \pi$ ópıv gegebenen Möglichkeit der Kontrolle und der Fokussierung des Warenverkehrs vgl. Bresson, Emporia (wie Anm. 8), 223.

115 IG Bulg. III 1690. $(\mathrm{a}+\mathrm{e})=$ Syll. $^{3} 880=$ IGR I $1500(=766)$.

116 Eindeutig belegt im Falle von Prusias ad Hypium: I. Prusias Hyp. 29 = SEG XXX 1441 = IGR III 1427 mit Marek, Pontus et Bithynia (wie Anm. 49), 102 Anm. 7. 
Motiv der Steigerung der städtischen Einkünfte war jedoch nicht allein bestimmend; neben ihm stand die Gewährleistung der Versorgung der Stadt durch eine Ausweitung ihrer über den Markt zugänglichen Wirtschaftszone.

Insofern diente die Gründung der kleinasiatischen Emporia also durchaus einer Zielsetzung, die man als wirtschaftlich bezeichnen kann, auch wenn sie nicht dem entspricht, was Finley und seine Anhänger darunter verstanden haben, wohl aber moderneren Definitionen von Wirtschaftspolitik. $\mathrm{Da}$ die Intensivierung des Warenaustausches eine bewußt erstrebte Folge der Gründung von Emporia war, dürfte jedenfalls kaum zu bestreiten sein. 


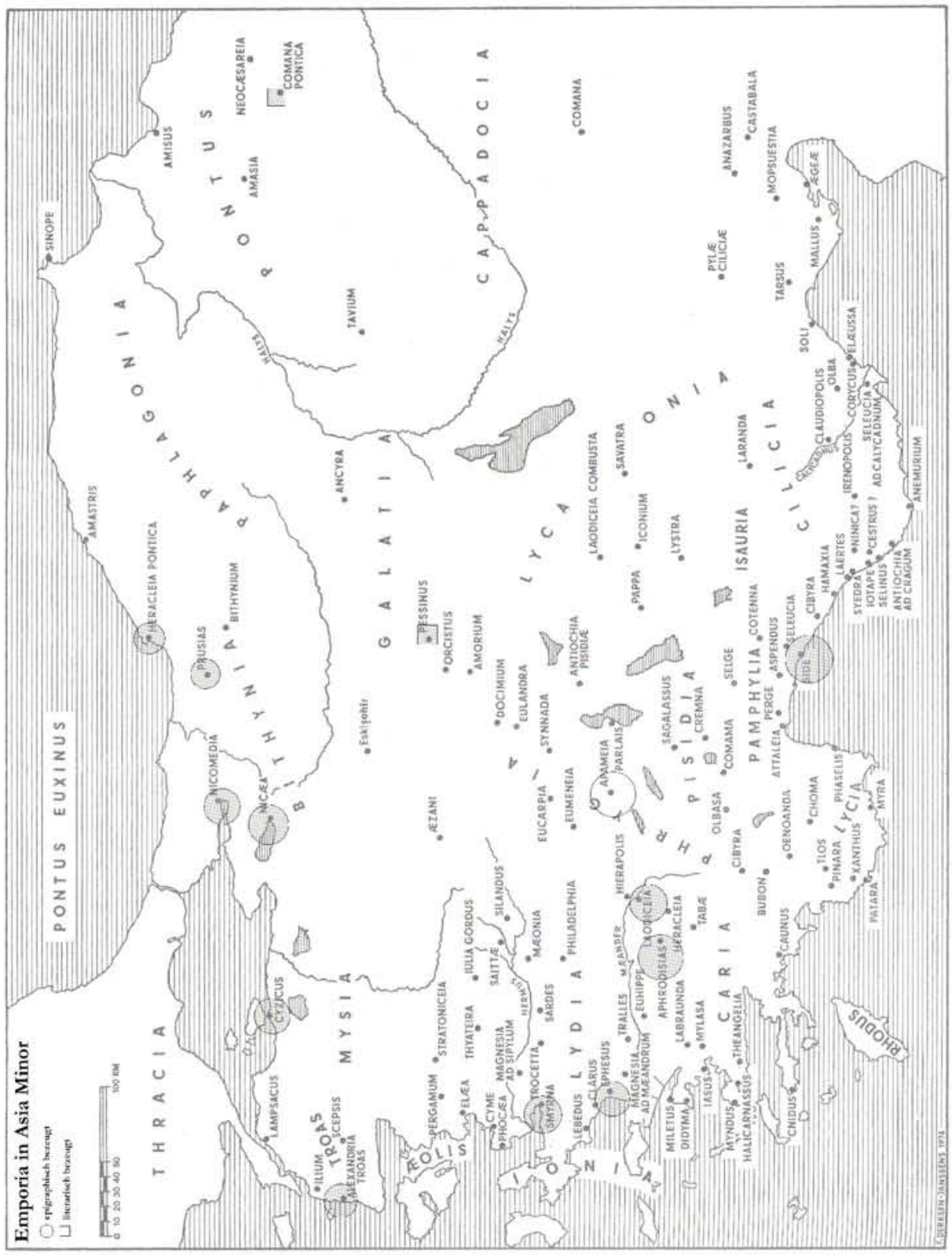

Abbildung 1: Emporia in Asia Minor

Karte aus ANRW II 7, 2, 1980, 600 


\title{
Die Ursprünge des Kirchenasyls und die Gesetzgebung Theodosius' II. ${ }^{1}$
}

\author{
Martin Dreher
}

I.

Pateant summi dei templa timentibus - „Offen sein sollen die Tempel des höchsten Gottes für diejenigen, die in Furcht sind“. Der programmatische Satz leitet das Exzerpt ein, das einer Konstitution des Theodosius' II. vom 23. 3. 431 entnommen wurde. In den „Codex Theodosianus“ $(9,45,4)$ aufgenommen, hat sie im Jahre 438 Gültigkeit für das Gesamtreich erlangt. Die Bedeutung des zitierten Satzes war lange Zeit verkannt.

Es besteht weitgehende Einigkeit in der Forschung, daß der Beginn des Kirchenasyls, wie im folgenden die Zuflucht von verfolgten oder bedrohten Personen in eine Kirche genannt werden soll, ${ }^{2}$ in der innerkirchlichen Entwicklung lag und daß der Staat erst allmählich mit seiner Gesetzgebung in diese Entwicklung eingegriffen hat. Die Kaiser haben das kirchlich fundierte und beanspruchte Asyl zunächst teils akzeptiert, teils untersagt, schließlich aber sehr grundsätzlich festgeschrieben. Dieser Prozeß verlief mehrschichtig und keineswegs geradlinig. Um die Funktion des Staates bei dieser Entwicklung präzise zu bestimmen, genügt es nicht, wie es die frühere Forschung getan hat, eine grundsätzliche Übereinstimmung zwischen Kirche und christlichen Kaisern hinsichtlich des Asyls festzustellen. Die weithin akzeptierten

1 Der vorliegende Beitrag lag auch einem Vortrag zugrunde, der unter dem Titel „Vom Tempelasyl zum Kirchenasyl. Kontinuität oder Neubeginn?" im Juli 2004 an der Universität Bielefeld gehalten wurde. Stefan Rebenich danke ich für die Einladung, den Teilnehmern des Marburger Kolloquiums für die fruchtbare Diskussion.

2 Einführende Bemerkungen zum Kirchenasyl bei M. Dreher, Das antike Asyl. Von den griechischen Ursprüngen bis zur christlichen Spätantike, Tyche 11, 1996, 79-96, hier: 94f. Vgl. auch M. Dreher (Hg.), Das antike Asyl. Kultische Grundlagen, rechtliche Ausgestaltung und politische Funktion (Akten der Gesellschaft für griechische und hellenistische Rechtsgeschichte 15), Köln u. a. 2003, 5f. 
Ausführungen von Leopold Wenger z. B. lassen zumindest implizit erkennen, daß sie dem Staat eine durchgehend passive Rolle zumessen. Wenger meint, daß die Kaiser das Kirchenasyl deshalb nicht per Gesetz anerkannt hätten, weil es sowieso schon allgemeine Gültigkeit besessen habe: ${ }^{3}$ „Eine allgemein das Asylrecht verleihende Konstitution findet sich in der Überlieferung nicht vor, insbesondere kein zuweilen angenommenes Gesetz Konstantins. Die kaiserlichen Konstitutionen, die sich mit dem A(sylrecht) befassen, rechnen vielmehr mit dem $\mathrm{A}$ (sylrecht) als einer bestehenden Tatsache und können vom juristischen Standpunkt aus etwa" - und nun zitiert Wenger seine eigene, klassisch gewordene Formulierung von $1931^{4}$ - ,,,als Ausführungsverordnungen zu einem auf kirchlicher Rechtsbasis ruhenden, ${ }^{5}$ von der Kirche dem Staate gegenüber durchgesetzten Prinzip bezeichnet werden“". Wenger und mit ihm die meisten Gelehrten setzen also eine nur implizite Anerkennung des Kirchenasyls von Seiten des Staates voraus und bestreiten, daß es jemals eine grundsätzliche Einführung des allgemeinen Asylrechts für Kirchen gegeben habe. So formuliert zuletzt Harald Siems: „In einer ersten Phase wird das Kirchenasyl durch spätantike Kaisergesetze bestimmt. Sie schaffen allerdings keine Grundlegung des Asylrechts, sondern beginnen mit Einschränkungen“; oder: „Die Kaiserkonstitutionen vom Ende des 4. Jh. beginnen mit Begrenzungen eines bereits bestehenden Asylrechts ". 6

Allerdings gab es in jüngerer Zeit auch einzelne Stimmen, die der Formalisierung oder Institutionalisierung des Kirchenasyls durch den Staat etwas

3 L. Wenger, Asyltecht, RAC I, 1950, 836-844, hier: 840f.

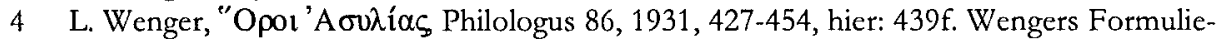
rung habe auch ich selbst in meinem kurzen Abriß des antiken Asyls zustimmend zitiert: Dreher, Tyche 11, 1996 (wie Anm. 2), 1996, 94. Die damit akzeptierten Implikationen werden nunmehr durch die hier folgenden Aus führungen revidiert.

5 Was die kirchliche Grundlage des Asyls betrifft, so setzt Wenger eine ausgearbeitete kirchliche Theorie voraus, die jedoch nicht erwiesen werden kann, vgl. die ausführliche Wide rlegung von $\mathrm{H}$. Langenfeld, Christianisierungspolitik und Sklavengesetzgebung der römischen Kaiser von Konstantin bis Theodosius II., Bonn 1977, 201 ff. Wenger befindet sich damit im Gegensatz zu E. Herman, Zum Asylrecht im byzantinischen Reich, OrChrP 1, 1935, 204-238, der das Gewohnheitsrecht als Quelle des Asylrechts herausstellt. Von beiden ist diese grundlegende Differenz zu Unrecht als nur geringfügig heruntergespielt worden. Die Diskussion ist noch einmal sehr umsichtig aufgearbeitet von C. Traulsen, Das sakrale Asyl in der Alten Welt. Zur Schutzfunktion des Heiligen von König Salomo bis zum Codex Theodosianus, Tübingen 2004, $295 \mathrm{ff}$.

6 H. Siems, Asyl in der Kirche? Wechsellagen des Kirchenasyls im Mittelalter, in: Dreher, Asyl (wie Anm. 2), 266f; vgl. ebd.: „Eine Magna Charta des Kirchenasyls als rechtlichen Gründungsakt hat es anscheinend nicht gegeben“. Siems weist allerdings (in Anm. 3) auf die gleich vorzustellende Arbeit von Hans Langenfeld hin. 
mehr Gewicht beimessen. In ihrer einschlägigen Arbeit ${ }^{7}$ sieht Anne Ducloux diese Sanktionierung in zwei Konstitutionen gegeben. Sie nennt die des Honorius für das Westreich vom 21. 11. $419^{8}$ und die Theodosius' II. für das Ostreich vom 23. 3. 431 (= CTh 9, 45, 4). Gleichzeitig betont sie aber sehr stark, daß die beiden Gesetze kein neues Recht gesetzt hätten: „La loi de 419, pas plus que celle de 431 , ne crée le droit d'asile. Ces deux constitutions le légalisent respectivement dans chaque pars imperii." Herausgebildet hat sich das Asylrecht, das ist die Grundthese ihrer Arbeit, in drei Stufen: erstens „l'usage“ (die Gewohnheit); zweitens „la coutume“ (die feste, allgemein akzeptierte Sitte); und drittens ,la loi“ (die gesetzliche Sanktionierung dieser Sitte).

7 A. Ducloux, Ad ecclesiam confugere. Naissance du droit d'asile dans les églises, Paris 1994.

8 Ein Teil des Textes ist erhalten als "Constitutio Sirmondiana" 13. Da diese Konstitution nicht in den "Codex Theodosianus" aufgenommen wurde, hat sie ihre Gültigkeit schon im Jahr 438 wieder verloren. Langenfeld, Christianisierungspolitik (wie Anm. 5), $124 \mathrm{ff}$. hat aufgezeigt, daß CSirm 13 nicht ein allgemein praktiziertes kirchliches Asylrecht sanktionierte, sondern konkret zu Unrecht Gefangenen, die in eine Kirche fliehen konnten, ihren dortigen Aufenthalt erleichtern sollte. Honorius habe damit vorrangig die Rechtssicherheit in den Provinzen verbessern, aber auch seine Privilegierungspolitik gegenüber der katholischen Kirche fortsetzen wollen. Ihm folgt G. Franke, Das Kirchenasyl im Kontext sakraler Zufluchtnahmen der Antike. Historische Erscheinungsformen und theologische Implikationen in patristischer Zeit, Frankfurt/Main u. a. 2003, 351f., $438 \mathrm{f}$. mit zusätzlichen Argumenten aus den Schriften des Augustinus. Wenn der Analyse Langenfelds etwas vorzuwerfen ist, dann allenfalls, daß sie zu einseitig darauf beharrt, die weströmische Gesetzgebung unter Honorius in den ersten beiden Jahrzehnten des 5 . Jahrhunderts nur als ganz eingeschränkte Schutzmaßnahmen zu verstehen, die ,zunächst den Geistlichen gegen aggressive Donatisten, dann den Sklaven gegen ihre häretischen Herren und schließlich den tenuiores gegen korrupte Beamte Sicherheit verbürgen" sollten (126). Auch wenn die Intentionen des Kaisers andere waren als die Anerkennung des Kirchenasyls, und auch wenn die Konstitutionen deshalb in den "Codex Theodosianus" nicht unter 9, 45 (De bis, qui ad ecclesias confugiunt) eingeordnet wurden (sondern unter 16, $6,4 ; 16,5,40 ; 16,8,19)$, so bedeuten sie doch gleichzeitig eine implizite Anerkennung der Praxis, Bedrängten und Verfolgten in den Kirchen Schutz zu gewähren. Das tut allerdings der Hauptthese Langenfelds keinen Abbruch, daß diese Gesetzgebung sorgfältig zu unterscheiden sei von der positiven, ausdrücklichen Anerkennung des Kirchenasyls durch Theodosius II. Traulsen geht hier wieder einen Schritt hinter Langenfeld zurück, wenn er die Konstitution vom 21.11. 419 als „entscheidenden Schritt hin zu einer Anerkennung der Kirchenflucht" bezeichnet (287) und wenn er meint, die rechtliche Anerkennung des Kirchenasyls im Westen sei nur zurückhaltender, schrittweise und in Abhängigkeit von politischen Gegebenheiten erreicht worden, im Osten hingegen „mit einem Paukenschlag“" (288). Denn nicht das jeweilige Verfahren macht den Unterschied aus; vielmehr sind die Intention, die Zielrichtung und damit auch der Inhalt der Gesetze im Westen und Osten verschieden. 
Ducloux kommt das Verdienst zu, die praktische und auch theoretische Entwicklung des Kirchenasyls gründlicher und unter Auswertung von mehr Quellenmaterial als die vorausgehende Forschung analysiert zu haben. Bei der uns interessierenden Frage des staatlichen Eingreifens bleibt sie aber, trotz vermeintlicher Neuerungen, weitgehend auf der Linie ihrer Vorgänger. ${ }^{9}$ $\mathrm{Da} \beta$ sie in dieser Hinsicht über die bisherigen Interpretationen nicht hinauskommt, liegt im wesentlichen daran, daß sie den Begriff des Asylrechts nicht angemessen definiert. Einmal wird er als allgemeines, über dem staatlichen stehendes, göttliches Recht verwendet, das das staa tliche einschließt und deshalb nicht vom Staat geschaffen wurde $(8 ; 207)$, und einmal als positives, staatliches Asyl-Recht (13). Wenn sie also auch die allgemein akzeptierte Sitte als Asylrecht bezeichnet, so ist schon begrifflich vorgegeben, daß dieses Asylrecht nicht erst durch staatliches Eingreifen en tstehen kann.

Was Ducloux nicht gelang, hat, etwa zwanzig Jahre vor ihr, Hans Langenfeld in einer hervorragenden Dissertation geleistet, die 1977 veröffentlicht, aber von Ducloux völlig übersehen wurde. ${ }^{10}$ Langenfeld unterscheidet $\mathrm{zu}$ Recht das Asylrecht oder die Asylie als „ein vom Recht anerkanntes Schutzprinzip auf religiöser Basis" von der Flucht zu Kultstätten, die keine rechtliche Verbindlichkeit besaß und die er, aus der griechischen Tradition heraus, als Hiketie bezeichnet. ${ }^{11}$ Langenfeld hat auf dieser Basis überzeugend nachgewiesen, daß die Kaiser das Kirchenasyl vor 431 nie grundsätzlich anerkannt hatten, und daß erst die Konstitution 9, 45, 4 aus dem Jahr 431 ausdrücklich ein allgemeines Asylrecht für alle christlichen Kirchengebäude und für grundsätzlich alle Hilfesuchenden schuf: ${ }^{12}$ „Das Asylrecht der Kirchen hat folglich erst Theodosius II. mit dem Ostererlaß des Konzilsjahres 431 begründet. Er

9 Dabei liegt Ducloux, Droit d'asile (wie Anm. 7), ohne sich selbst in diese Kontroverse (s.oben Anm. 5) einzuordnen, mehr auf E. Hermans Linic, indem sie das Gewohnheitsrecht betont; aber sie bindet, gerade durch die Heranziehung zahlreicher AugustinusTexte, auch die christliche Theorie sehr stark mit ein, wenngleich sie sie nicht in dem Umfang wie L. Wenger für normsetzend hält. Weitere berechtigte Kritik am Buch von Ducloux übt die Rezension von M. Babo, ZKG 109, 1998, 411-414.

10 Auch ich selbst hatte die Arbeit in meinem Aufsatz von 1996 (s. oben Anm. 2) übersehen.

11 Langenfeld, Christianisierungspolitik (wie Anm. 5), 108; das Zitat übernimmt Langenfeld aus O. Henssler, Formen des Asylrechts und ihre Verbreitung bei den Germanen, Frankfurt/Main 1954, 10. Bei Dreher, Asyl (wie Anm. 2), 1ff., wird versucht, eine kohärente Begtifflichkeit zum Asyl zu entwickeln.

12 Beachte vor allem den Nachweis Langenfelds (Christianisierungspolitik [wie Anm. 5], 127ff.), daß die Abschnitte 9, 45, 1-3 noch keine solche Anerkennung des Asylrechts bedeuten. 
wollte offenbar das Vorbild des orientalisch-hellenistischen Asylwesens direkt auf die neuen christlichen Verhältnisse übertragen" ${ }^{13}$ Die These Langenfelds ist bisher nur vereinzelt zustimmend aufgenommen worden. ${ }^{14}$

Bei Langenfeld deutet sich auch, wenngleich oft nur implizit, jedenfalls stärker als bei den anderen Forschern, die unterschiedliche Interessenlage von Staat und Kirche hinsichtlich des Asyls an. In der übrigen Forschung erscheinen die christlichen Kaiser nämlich im allgemeinen, um es drastisch zu formulieren, als Erfüllungsgehilfen kirchlicher Forderungen, als verlängerter Arm der Kirche. Die Kaiser hätten, so der Tenor, das Kirchenasyl schon immer respektiert und lediglich einige Ausnahmen festgelegt, die meist sogar im Interesse der Kirche selbst gelegen hätten, da sie gegen Häretiker und Andersgläubige wie Juden oder Manichäer gerichtet gewesen seien; und

13 Langenfeld, Christianisierungspolitik (wie Anm. 5), 140.

14 J. Herrmann, Cod. Theod. 9, 45: De his, qui ad ecclesias confugiunt (1979), in: J. Herrmann, Kleine Schriften zur Rechtsgeschichte, hg. v. G. Schiemann, München 1990, 351 362. Herrmann übernimmt und bekräftigt die Ergebnisse Langenfelds, ohne ihnen etwas neues hinzuzufügen; vgl. dens., Kaiserliche Erlasse zum kirchlichen Asylschutz für Sklaven (1984), ebd., 364-372, hier: 366f. Weitere Zustimmung hat Langenfeld in der Reihe der jüngsten Veröffentlichungen zum antiken Asyl gefunden. J. Derlien, Asyl. Die religiöse und rechtliche Begründung der Flucht zu sakralen Orten in der griechisch-römischen Antike, Marburg 2003 (vgl. meine Rezension, die allerdings überwiegend ablehnend ist, in: Gymnasium 112, 2005, 475f.), bes. 359, stimmt in vieler Hinsicht, Franke, Kirchenasyl (wie Anm. 8), 438ff. grundsätzlich mit ihm überein. Traulsen, Das sakrale Asyl (wie Anm. 5) folgt Langenfeld über weite Strecken, distanziert sich aber von dessen vermeintlicher These, „die Kaiserkonstitution CTh 9, 45, 4 als erste und einzige Rechtsquelle des Kirchenasyls zu erweisen" (267 Anm. 2; 296 Anm. 167). Sosehr nun Traulsen daran recht tut, die „Wurzeln des kirchlichen Asylrechts“ (293) - besser sollte er, da er selbst die Existenz eines von der Kirche formulierten Asylrechts bestreitet und eigentlich die staatliche Anerkennung des Kirchenasyls meint, hier und im folgenden etwa von einem „Asylrecht der christlichen Kirchen" sprechen, wie ich es an anderer Stelle vorgeschlagen habe (Dreher, Asyl [wie Anm. 2], 5) und wie er selbst an späterer Stelle (306) formuliert -, nicht nur auf die Kaiserkonstitutionen als einzige Rechtsquelle zurückzuführen, sondern auch besonders auf die Bedeutung der bischöflichen Intervention hinzuweisen, sosehr hat er Unrecht darin, daß er Langenfeld einen „formalen Standpunkt" vorwirft, der historische Erscheinungen unter eine vorgefaßte Definition subsumiere (296 Anm. 167). Denn Langenfeld mißachtet keineswegs, wie Traulsen behauptet, die Bedeutung der Rechtswirklichkeit, insbesondere die faktische Bedeutung kirchlicher Asylgewährung und die Interventionspraxis der Bischöfe, unterscheidet diese Ebene aber begrifflich sehr genau von der Ebene der Rechtsetzung. Traulsen (dessen Arbeit ich im allgemeinen sehr hoch schätze, vgl. demnächst meine Besprechung in der ZRG) fällt in diesem Punkt hinter den von Langenfeld erreichten Erkenntnisstand zurück, weil er normative Rechtsakte und faktische Entwicklungen als gleichwertige, auf derselben Ebene liegende Faktoren für die Entstehung des Asylrechts der Kirchen behandelt. 
schließlich, ab Ende des 4. oder Anfang des 5. Jahrhunderts, hätten sie das Asyl auch per Gesetz grundsätzlich akzeptiert in dem Sinn, daß sie es, wie oben schon gezeigt, zustimmend voraussetzten. Indem Langenfeld die grundsätzliche Akzeptanz des Kirchenasyls durch die Kaiser für die Zeit vor 431 abstreitet, treten die divergierenden Interessen von Kaiser und Kirche bei ihm deutlicher hervor. Die Kaiser lagen nämlich, was das Asyl betrifft, zunächst nur in geringem Umfang auf der kirchlichen Linie. Sie zögerten, auch wenn sie in der Praxis mehrfach den Schutz einer Kirche respektierten, doch, diese Räume grundsätzlich ihrer allumfassenden Rechtsgewalt zu entziehen und behielten sich durchaus ein letztes Eingriffsrecht auch in die kirchlichen Räume vor.

Auf der Grundlage der Untersuchungsergebnisse Langenfelds, die ich weitgehend akzeptiere und gegen die traditionelle Auffassung weiter stärken möchte, soll im folgenden danach gefragt werden, wie sich die kirchliche und die kaiserliche Position nicht nur in praktischer Hinsicht auswirkten, sondern auch von der theoretischen Begründung ihrer Handlungsweisen her voneinander unterschieden. Dabei konzentriert sich die Betrachtung auf die Zeit Theodosius' II. (408-450), der wie gesagt das kirchliche Asylrecht erstmals staatlicherseits garantiert hat. Ausgangspunkt muß die relativ ausführliche Begründung sein, die Theodosius selbst in sein Gesetz aufgenommen hat. Aufschlußreich ist darin vor allem die Haltung zur vorchristlichen Asyltradition. Sie unterscheidet sich auffällig, was bislang meines Erachtens nicht beachtet wurde, von der zeitnahen Einstellung kirchlicher Repräsentanten. Diese Differenz, die in einem Vergleich des theodosianischen Gesetzes mit Augustinus' "Civitas dei“ verdeutlicht werden soll, gibt Hinweise darauf, worauf es den kirchlichen und weltlichen Mächten ankam, wie sie sich selbst in der damaligen ,Asyldebatte darstellen wollten und wie wir uns letztlich den Übergang vom heidnischen Asyl zum christlichen Kirchenasyl vorstellen könnten.

II.

Gehen wir also aus von der erwähnten Konstitution vom 23. März 431, einem an den praefectus praetorio Orientis gerichteten Reskript. ${ }^{15}$ Aussagekräftig ist in dieser Hinsicht weniger die um das Proömium verkürzte Fassung, die unter 9, 45, 4 in den „Codex Theodosianus" aufgenommen wurde, sondern die

15 Die Datierung ist von Ducloux, Droit d'asile (wie Anm. 7), 218ff., noch einmal ausführlich begründet worden. 
vollständige Fassung, die in diesem Fall ausnahmsweise überliefert ist, und zwar in griechischer Übersetzung zusammen mit den „Akten“ des Konzils von Ephesos von 431; der Text wird in der Literatur oft als basilikos nomos bezeichnet. ${ }^{16}$ In unserem Zusammenhang ist vor allem die Präambel des Gesetzes interessant, in der Theodosius die Motive seines Handelns ausbreitet.

Der Kaiser beginnt mit einem Verweis auf alte Gewohnheiten und auf die Ordnung des Naturgesetzes, die eine Verehrung des Göttlichen schon immer geboten hätten, zieht also gerade die christlichen Traditionen und die Regelungen seiner christlichen Vorgänger, auf die in anderen Konstitutionen durchaus hingewiesen wird, ${ }^{17}$ nicht heran. $\mathrm{Daß}$ die alten Gewohnheiten weit hinter die christliche Vergangenheit zurückgehen, zeigt schon das erste Wort der Konstitution, $\dot{\alpha} \rho \chi \alpha i ́ \alpha$, welches auf das etwas später folgende Substantiv

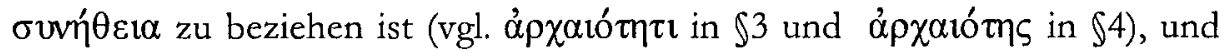
wird dann durch die Zuordnung der hier beschworenen Gottesfurcht $(\varepsilon \dot{\sigma} \varepsilon \hat{\beta} \beta \varepsilon 1 \alpha)$ in die Zeiten des Irrglaubens direkt ausgesprochen. Der rheto-

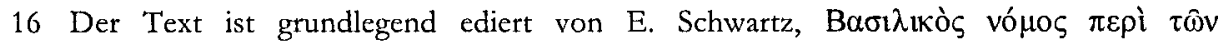

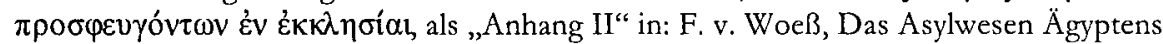
in der Ptolemäerzeit und die spätere Entwicklung, München 1923, 253-272 und wird danach hier zitiert. Weitere Ausgaben: Acta Conciliorum Oecumenicorum I 1, 4, 61-65, ed. E. Schwartz = V 437-446 ed. Mansi mit lateinischer (Rück-)Übersetzung. Das Proömium des Gesetzes ist als „Annexe XXI 2“ abgedruckt bei Ducloux, Droit d'asile (wie Anm. 7), 286f.; Langenfeld, Christianisierungspolitik (wie Anm. 5), 133f. bietet eine Inhaltsangabe. Franke, Kirchenasyl (wie Anm. 8), 443 Anm. 22 druckt ebenfalls den griechischen Text des Proömiums ab und vergleicht nachfolgend die verschiedenen Versionen des gesamten Gesetzes. Eduard Schwartz (bei Woeß, Asylwesen, 260f.) hat darauf aufmerksam gemacht, daß der vorliegende griechische Text eine Übersetzung aus dem lateinischen Original ist. Demgegenüber hält Derlien, Asyl (wie Anm. 14), 349; 355; 357, die griechische Fassung für das Original und dementsprechend den Auszug im „Codex Theodosianus“ für eine Übersetzung; da er keine Begründung gibt, dürfte es sich um eine Verwechslung handeln. Eine englische Übersetzung findet sich bei P. R. Coleman-Norton, Roman State and Christian Church, Bd. 2, London 1966, 654-662 Nr. 400. In seine Zusammenstellung der „Kaiserkonstitutionen über das Asylrecht der Kirchen“ hat Traulsen, Das sakrale Asyl (wie Anm. 5), 315ff. nur den Teil aus dem „Codex“ aufgenommen.

Zur Bedeutung der praefationes in den Kaiserkonstitutionen und dem Umgang der Kompilatoren des "Codex Theodosianus" damit vgl. M. Stachura, Zur Motivation der Häretikerverfolgung im Spiegel von Gesetzestexten der theodosianischen Dynastie, Electrum 9, 2003, 249-262, hier: 250ff.

17 Vgl. etwa das Asylgesetz Kaiser Leos von 466 CJ 1, 12, 6. Weitere Beispiele bei Langenfeld, Christianisierungspolitik (wie Anm. 5), 135. Ein Vergleich wird dadurch erschwert, $\mathrm{da}$ die Proömien nicht in die Gesetzessammlungen aufgenommen und deshalb im allgemeinen nicht erhalten sind. 
risch kunstvoll gebildete lange erste Satz schließt dementsprechend mit dem Begriff $\theta \varepsilon ́ \mu 1 \zeta$, der sogar auf die Frühzeit der paganen Rechts- und Kultvor-

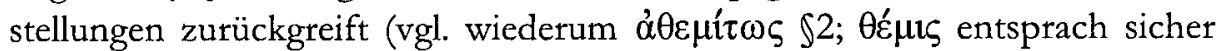
dem lateinischen fas, wie Mansi treffend rückübersetzt). Die Konstitution führt den Gedanken (in \$3) folgendermaßen fort: Wenn bereits der heidnische Irrglaube seine Altäre, Tempel und Götterstatuen so intensiv verehrt habe, müßten die Christen, denen Gott selbst die wahre Religion gebracht habe, diese Frömmigkeit noch übertreffen. Der Kaiser müsse die Religion, das Wohl und die Sicherheit der Menschen, und auch die kirchlichen Gebäude und die heiligen Altäre schützen. Und $\$ 4$ führt die Vorgängereinrichtun-

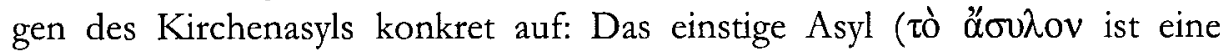
Rückübersetzung des lateinischen asylum mit einem Substantiv, das in der griechischen Sprachtradition bis dahin nicht vorkommt ${ }^{18}$ ) habe die in Prozesse Verstrickten geschützt, indem es die grenzenlose Macht ( $\alpha \dot{v} \theta \varepsilon v \tau i ́ \alpha)$ der Gesetze zurückgedrängt habe (diese Relativierung der Gesetzesmacht ist in einer Verlautbarung des staatlichen Souveräns besonders bemerkenswert).

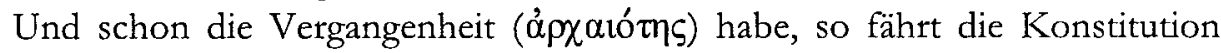
fort und baut hier zweifellos eine Klimax auf, um den Verzagten

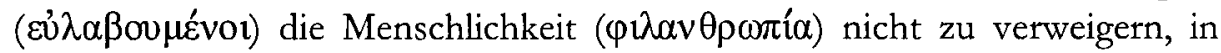

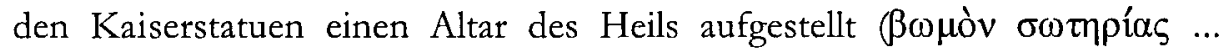

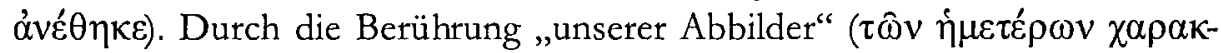
$\tau \eta \dot{\rho} \rho v)$ erlangten die Flüchtigen Befreiung von allen Schrecken und könnten sich ihrer Sicherheit erfreuen. Und wenn schon diese Statuen, so münden die einleitenden Darlegungen des Gesetzes in eine comparatio ad maius, ${ }_{19}^{19}$ aufgrund

18 Vgl. E. Schlesinger, Die griechische Asylie, Diss. Gießen 1933, 7, ohne Berücksichtigung der vorliegenden Stelle.

19 Das Argument ist später durchaus auch von der kirchlichen Seite verwendet worden, es findet sich z. B. in den Beschlüssen des Konzils von Mâcon (a. 585), c. 8: Si enim mundani principes suis legibus censuerunt, ut, quicumque ad eorum statuas fugiret, inlaesus babeatur, quanto magis bi permanere debeant indemnati, qui patrocinia immortalis regni adepti sunt celestis? (Concilia Galliae a. 511 - a. 695. Ed. C. de Clercq [CCL 148A], Turnhout 1963, 243). Während des Kolloquiums hat mich Michal Stachura, der eine Monographie über das strafrechtliche Vokabular der Religions-Gesetzgebung vorbereitet, freundlicherweise darauf aufmerksam gemacht, daß sich in den Gesetzen der spätantiken Kaiser nicht wenige begriffliche Beziehungen auf die vorchristliche kaiserliche Gesetzgebung finden. Als engste Parallele hat er mir schriftlich Nov. Val. 18 genannt, in welcher der Manichäismus als superstitio paganis quoque damnata temporibus, inimica publicae et bostis fidei Cbristianae bezeichnet wird, womit der Kaiser sich auf das Gesetz von Diokletian Coll. 15, 3 beziehen dürfte. Die Struktur des Arguments ist hier, so schreibt Stachura, ähnlich wie in dem theodosianischen Gesetz: „Was schon von heidnischen Kaisern verurteilt wurde, soll umso mehr vom christlichen Kaiser verurteilt werden, da es nicht nur gegen 
der königlichen Majestät den Elenden so viel Schutz geboten haben: wieviel mehr Hilfe muß denen gewährt werden, die an den heiligsten (also den christlichen) Altären Zuflucht suchen? ${ }^{20}$ Direkt an diese rhetorische Frage schließt sich der Satz an, der hier ganz am Anfang in der Fassung des „Codex Theodosianus" zitiert wurde, und der in dem nun hergestellten Originalzusammenhang, nach dieser weitausgreifenden Begründung, noch plastischer und emphatischer als formale gesetzliche Anerkennung des Kirchenasyls hervortritt: Pateant summi dei templa timentibus.

Anschließend legt das Gesetz fest, daß der schützende Bezirk über Altar und Kirchenräume hinausgreifen und die unmittelbar anschließenden, kirchlichen Zwecken dienenden Häuser, Gärten, Bäder, Höfe und Säulengänge umfassen solle. Durch die Ausweitung des Schutzbezirks sollte vermieden werden, daß sich die Schutzsuchenden an den hochheiligen Altären zum Essen niederlassen oder dort übernachten, „was die Geistlichen aus ehrenvoller Rücksicht zu verbieten, die Flüchtlinge aus Frömmigkeit zu unterlassen haben" (CTh 9, 45, 4, §5). Nach diesen konkreten bzw. praktischen Regelungen, auf welche die moderne communis opinio die eigentliche Neuerung des Gesetzes und damit dessen Entstehungsgrund beschränkt, wird noch einmal klar ausgesprochen, was mit Langenfeld als die wirkliche neue Bestimmung gesehen werden muß: Niemand dürfe es wagen, die Schutzsuchenden mit

christlichen Kaiser verur teilt werden, da es nicht nur gegen den römischen Staat, sondern auch gegen den christlichen Glauben gerichtet ist.“

20 Die Argumentation, neben den Kaiserstatuen noch auf Tempel erweitert, findet sich in den Akten zweier späterer Konzilien wieder: Conc. Arausicanum (a. 441), c. 5 (ed. Ch. Munier, CCL 148, Turnhout 1963, 79), Conc. Matisconense (a. 585), c. 8 (ed. F. Maaßen, MGH Concilia I, 168); vgl. J. Gröll, Die Elemente des kirchlichen Freiungsrechtes mit besonderer Berücksichtigung der österreichischen Entwicklung dargestellt (Kirchenrechtliche Abhandlungen, 75/76), Stuttgart 1911, ND Amsterdam 1965, 255. Sofern die kaiserliche Kanzlei den Gedanken nicht bereits von uns unbekannten kirchlichen Äußerungen übernommen hat, wurde die kaiserliche comparatio von seiten der Kirche offenbar schnell aufgegriffen.

Den betreffenden Abschnitt der Präambel zitiert Traulsen, Das sakrale Asyl (wie Anm. 5), 307, um den gewissen Vorbildcharakter heidnischer Asylstätten zu belegen: Wenn die heidnische Religion schon "die humane Wohltat der Zuflucht bot", durfte „die wahre Religion, der die bumanitas Verpflichtung war, dahinter nicht zurückstehen“. $\mathrm{Ob}$ auch dieser Text allerdings, wie Traulsen zu Beginn des Abschnitts (306) behauptet, nur die äußere Kontinuität des Kirchenasyls zum heidnisch-griechischen Asylwesen belegt, während von einer "rechtlichen und inhaltlichen Diskontinuität" auszugehen sei, erscheint sehr fraglich, wenn man, was Traulsen versäumt, den gesamten Text der Präambel auswertet. Auch wäre der Text Traulsen bei seiner löblichen, aber letztlich unzureichend umgesetzten Forderung nützlich gewesen, daß ,kirchliche und staatliche Sichtweisen ... präziserweise unterschieden werden müssen“ (298). 
„frevlerischer Hand“ aus den kirchlichen Räumen wegzureißen (Nec in extrabendos eos conetur quisquam sacrilegas manus inmittere ...). Zuwiderhandelnden wird sogar die Todesstrafe angedroht!

Im Hinblick auf die Motivation des Gesetzes soll noch auf eine Beobachtung von Langenfeld hingewiesen werden, daß nämlich in der lateinischen Fassung des Gesetzes im „Codex Theodosianus" der Begriff templum allein zehnmal für christliche Gotteshäuser verwendet wird, während er an allen anderen 35 Stellen des "Codex" heidnische Tempel bezeichnet. Ebenso steht der Begriff ara an den fünf anderen Stellen des "Codex“, an denen er vorkommt, für heidnische Opferstätten und lediglich in unserem Asylgesetz für den christlichen Altar. Diese Beobachtung ist noch dahingehend zu präzisieren, daß sie auf den auch lateinisch überlieferten, in den „Codex Theodosianus" übernommenen Hauptteil des Gesetzes beschränkt ist. In der Präambel hingegen verhält es sich genau umgekehrt: die griechischen Termini vaoí ( $\$ 3)$ und $\beta \omega \mu$ oí ( $\$ 3$ und 4), die zweifellos, wie im Hauptteil des Gesetzes bestätigt, die lateinischen Begriffe templum und ara wiedergeben, sind hier den heidnischen Einrichtungen vorbehalten, während der christliche Altar zweimal $(\$ 2$ und 3) mit dem speziell im Neuen Testament verwendeten Ausdruck

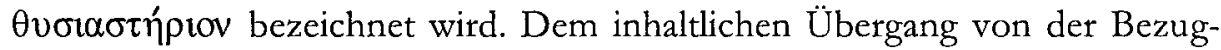
nahme auf das heidnische Asyl in der Präambel auf die Anerkennung und Ausgestaltung des christlichen Asyls im Hauptteil entspricht also die bewußte Übertragung der paganen Begrifflichkeit auf kirchliche Einrichtungen. Parallel dazu ließe sich noch auf die Formulierung toù $\pi \rho 0 \sigma \varphi \varepsilon u ́ \gamma o v \tau \alpha \varsigma$ i $(\$ 5)$ hinweisen, die die traditionelle Bezeichnung biketai, lateinisch zweifellos (confugientes) supplices, übernimmt. Langenfeld zieht folgenden Schluß: „Wenn ein Kaiser mit solchem Nachdruck die Erinnerung an den verabscheuten Götzendienst wachruft und die verpönten Ausdrücke im christlichen Sinne umdeutet, so hat er offenbar die Absicht, auch ... die durch sie bezeichnete Einrichtung auf die christliche Ära zu übertragen. Theodosius wollte $431 \ldots$ die bei der Unterdrückung des Heidentums im 4. Jh. vernichtete Institution der Asylie, wie sie sich im orientalisch-hellenistischen Bereich ausgeprägt hatte, den sakralen Bauten der Staatskirche als Privileg verleihen."21 Langenfeld hätte allerdings gerade an der Stelle, an der er zu Recht auf den bewußten Anschluß des Kaisers an die heidnische Tradition verweist, besser darauf

21 Langenfeld, Christianisierungspolitik (wie Anm. 5), 136f. Hingegen ist Ducloux, Droit d'asile (wie Anm. 7), 6, der Meinung, für die kaiserliche Anerkennung des Asylrechts sei das Tempelasyl kein Modell gewesen, da aus dem ganzen 4. Jh. kein Zeugnis mehr für Tempelasyl vorliege. Gegenüber den eindeutigen Formulierungen des Gesetzes ist das jedoch ein sehr schwaches Argument. 
verzichtet, seine Aussage dadurch zu konterkarieren, daß er Theodosius gleichzeitig Klassifizierungen wie „verabscheuter Götzendienst“ und „verpönte Ausdrücke" für die heidnischen Einrichtungen unterstellt.

$\mathrm{Ob}$ den Autoren des Gesetzes bekannt war, daß der Zwölfgötteraltar in Athen, der schon seit früher Zeit immer wieder als Zufluchtsstätte in Anspruch genommen wurde, auch als Altar des Gottes des Mitleids verehrt und daher als bomos Eleou bezeichnet wurde, ${ }^{22}$ kann nicht gerade als wahrscheinlich gelten. Auch wenn daher kein direkter Bezug auf diese griechische Tradition angenommen werden kann, so ergibt sich doch eine inhaltliche Parallele zur christlichen misericordia, die in der kirchlichen Begründung des Asyls eine exponierte Stellung einnimmt. ${ }^{23}$

Blicken wir noch etwas genauer auf die beiden Institutionen, in deren Tradition sich der Kaiser hier stellt. Die erste Institution ist das asylum, worunter nicht der Schutz für Bedrohte zu verstehen ist, den nach griechischem Verständnis alle Heiligtümer geboten haben und der uns seit der archaischen Zeit bis weit in die römische Zeit hinein im Osten des Mittelmeerraumes als Hikesia oder Hiketeia belegt ist. ${ }^{24}$ Vielmehr ist auch an dieser Stelle unter asylum ein staatlicherseits als Asylstätte anerkanntes Heiligtum zu verstehen. ${ }^{25}$ $\mathrm{Da}$ der Begriff nunmehr diese Bedeutung besaß, exläutert der um 400 entstandene Vergil-Kommentar des Servius: boc (sc. asylum) autem non est in omnibus templis, nisi quibus consecrationis lege concessum est (ad Aen. 2, 761). Die Praxis, bestimmte Heiligtümer durch die Verleihung der Asylia zu privilegieren, hatte sich allerdings erst in hellenistischer Zeit herausgebildet. ${ }^{26} \mathrm{Da}$ die ursprüngliche, aber auch im Hellenismus weiterwirkende griechische Tradition alle Heiligtümer als geschützte Zufluchtsstätten ansah, mag den Verfassern unserer Konstitution entweder unbekannt gewesen sein oder als irrelevant gegolten haben. Vielleicht wollte man an diese Tradition auch bewußt nicht erinnern, um die Wichtigkeit der nun folgenden formalen Anerkennung des Kirchenasyls durch den Kaiser nicht zu relativieren. Das Asylgesetz des Theodosius setzt die Aussage über das ő $\sigma u \lambda o v$ jedenfalls in die Vergangenheitsform,

22 Vgl. Derlien, Asyl (wie Anm. 14), 105 mit Quellen- und Literaturangaben. Vgl. jedoch den Verweis des Libanios auf den Altar des Eleos in seinem „Presbeutikos“ (Or. 15, 39) mit H.-U. Wiemer, Libanios und Julian. Studien zum Verhältnis von Rhetorik und Politik im vierten Jahrhundert n. Chr. (Vestigia. Beiträge zur Alten Geschichte 46), München 1995, 232ff. (freundlicher Hinweis von U. Wiemer).

23 Vgl. Wenger, Asylrecht (wie Anm. 3), 840.

24 Vgl. Dreher, Tyche 11, 1996 (wie Anm. 2), 83ff.

25 So auch Langenfeld, Christianisierungspolitik (wie Anm. 5), 136.

26 Vgl. Dreher, Tyche 11, 1996 (wie Anm. 2), 89ff. 
betrachtet mithin die Schutzsuche in staatlich anerkannten (heidnischen) Tempeln, wir können kurz von Tempelasyl sprechen, klar als eine vergangene Praxis, eine abgeschlossene historische Entwicklungsph ase. ${ }^{27}$

Obwohl wir über das Ende des Tempelasyls in der historischen Praxis viel zu wenig wissen, bestätigt ein Blick auf die Gesamtsituation die Implikation unseres Asyldekrets, daß es zu Beginn des 5. Jahrhunderts nicht mehr in Anspruch genommen wurde. Bis wann das Tempelasyl sich in der östlichen Mittelmeerwelt gehalten hat, läßt sich nicht genau feststellen. Wenn die literarischen Quellen seit dem ersten Jahrhundert keine konkreten Asylfälle mehr überliefern, so hat das nicht unbedingt zu bedeuten, daß das Tempelasyl völlig verschwunden war. Hätte es keine Bedeutung mehr gehabt, so hätten die kleinasiatischen Städte schwerlich Münzen geprägt, auf denen sie das Asylrecht ihres jeweiligen Hauptheiligtums propagierten. Wir kennen zahlreiche solche Prägungen, etwa aus Mopsouestia in Kilikien oder Tyana in Kappadokien, und besonders viele aus Perge in Pamphylien, die mindestens bis ins späte dritte Jahrhundert reichen; ${ }^{28}$ die letzte mir derzeit bekannte Asylmünze wurde in Perge unter Kaiser Tacitus geprägt, der von 275-276 regierte. ${ }^{29}$

Mit diesem Zeitrahmen stimmt überein, daß auch die papyrologische Dokumentation zu den Asylformen in Ägypten im späten dritten Jahrhundert zu Ende geht. ${ }^{30}$ Es gibt viele Gründe dafür, daß unsere Quellen über das

27 Die Formulierung des Gesetzes ist hier sehr nüchtern und deutet in ihrem zweiten Teil, in dem ein Gegensatz zwischen asylum und leges aufgebaut wird, nicht nur eine gewisse Distanz, sondern vielleicht sogar eine leichte Kritik an der heidnischen Asyltradition an.

28 Vgl. vorläufig Dreher, Tyche 11, 1996 (wie Anm. 2), 93 mit Anm. 61. Die bislang umfangreichste Zusammenstellung gibt Franke, Kirchenasyl (wie Anm. 8), 8f. mit Anm. 44; 44f., der allerdings sehr strenge Maßstäbe anlegt und einen Bezug der allermeisten Münzen auf die „sakrale Zufluchtsasylie“ bestreitet. Derlien, Asyl (wie Anm. 14), 324, kennt anscheinend nur einen kleinen Teil dieser Asylmünzen. Traulsen, Das sakrale Asyl (wie Anm. 5) befaßt sich nicht mit diesem Problem und zieht keine numismatischen Quellen heran.

29 SNG Deutschland 18, Nr. 4759. Aus der Zeit des Tacitus stammt auch die Inschrift aus Perge, mit der sich die Stadt ihrer Asylie rühmt, vgl. P. Weiß, Auxe, Perge. Beobachtungen zu einem bemerkenswerten städtischen Dokument des späten 3. Jahrhunderts $\mathrm{n}$. Chr., Chiron 21, 1991, 353-392, der auch auf die Asylmünzen eingeht. Das Asyl von Perge war also unzweifelhaft noch wichtig für die Stadt. Wie häufig es in der Praxis von Schutzbedürftigen aufgesucht wurde, geht aus den genannten Zeugnissen, die eher propagandistischen Charakter für eine große Öffentlichkeit hatten, natürlich nicht hervor.

30 Zu Ägypten vgl. Woeß, Asylwesen (wie Anm. 16), 221 ff.; B. Palme, Asyl und Schutzbrief im spätantiken Ägypten, in: Dreher, Asyl (wie Anm. 2), 203f. Zur Alltäglichkeit s. U. Sinn, Das Heraion von Perachora. Eine sakrale Schutzzone in der korinthischen Peraia, 
Tempelasyl versiegen, aber keinen überzeugenden Grund dafür, daß die Einrichtung selbst, die fest im Alltagsleben verwurzelt gewesen sein dürfte, vor der christlichen Ära ihr Ende gefunden hätte.

Zweifellos ist die Bedeutung des Tempelasyls dann aber parallel zum Aufstieg der christlichen Kirche zurückgegangen. In der Zeit Konstantins war seine Rolle sicherlich nur noch sehr gering, und die Verfügung des Constantius aus dem Jahr 356, alle Tempel zu schließen, hat zwar keinen flächendeckenden Erfolg gehabt, könnte aber die Attraktivität des Tempelasyls nahezu zum Erliegen gebracht haben. ${ }^{31}$ Allerdings liegen auf der anderen Seite auch die Anfänge des Kirchenasyls im Dunkeln. Da der Anteil der Sklaven an den frühen christlichen Gemeinden hoch war, könnte man sich vorstellen, daß gerade im Bereich des Sklavenasyls der Umschwung besonders stark gewesen ist, ${ }^{32}$ aber die Quellen lassen keine derartige Rekonstruktion zu. Erste konkrete Fälle für die Zuflucht in Kirchen werden erst aus der Zeit ab 350 berichtet und betreffen nicht Sklaven, sondern prominente Persönlichkeiten, denn die Geschichtsschreibung konzentriert sich auch in dieser Hinsicht auf die Herrschenden. Beginnend mit der - allerdings wahrscheinlich unhistorischen - Zuflucht des Kaisers Constans in einen „Tempel“ (voós), wie Zonaras sagt, unter dem aber vielleicht eher eine christliche Kirche zu verstehen ist, im Jahr 350, hören wir von mehreren Kaisern, Usurpatoren und hohen Amts- und Würdenträgern, die aufgrund von politischen Umständen Asyl suchen. ${ }^{33}$ Aber sowohl bei diesen Beispielen als auch in den indirekten Zeugnissen, vor allem in den noch davorliegenden, nämlich 343 gefaßten Beschlüssen des Konzils von Serdica ${ }^{34}$ ist meist nicht zu entscheiden, ob der im allgemeinen verwendete Ausdruck ad ecclesiam confugere

MDAI (A) 105, 1990, 53-116, hier: 75ff. Zum Fortbestand des Tempelasyls generell Franke, Kirchenasyl (wie Anm. 8), 43ff. mit weiteren Quellenverweisen.

31 Ähnlich Traulsen, Das sakrale Asyl (wie Anm. 5), 267f. Derlien, Asyl (wie Anm. 14), 358, spricht deswegen von einer höchstens 90 -jährigen Unterbrechung der Möglichkeit, an Kultplätzen staatlich garantierten Schutz vor Zugriff zu erhalten, bis zum Gesetz von 431.

32 Langenfeld, Christianisierungspolitik (wie Anm. 5), 196, vermutet allerdings das Gegenteil. Zu einigen Spezifika des Sklavenasyls vgl. besonders H. Bellen, Studien zur Sklavenflucht im römischen Kaiserreich (Forschungen zur antiken Sklaverei 4), Wiesbaden 1971.

$33 \mathrm{Zu}$ Constans s. Zonar. 13, 6, 11f. Eine „Liste der ,Asylfälle erstellen u. a. Langenfeld, Christianisierungspolitik (wie Anm. 5), 145ff.; Traulsen, Das sakrale Asyl (wie Anm. 5), 268ff.; 350f.; vgl. auch die Zusammenstellung bei Ducloux, Droit d'asile (wie Anm. 7), 35ff., nachdem sie zu Recht den Fall des heiligen Martin, den sie auf 326 datiert, noch einmal überzeugend ausgeschieden hat (15ff.).

34 Vgl. zu diesem Konzil detailliert H. Hess, The Early Development of Canon Law and the Council of Serdica, Oxford 2002. 
witklich eine konkrete Flucht in einen kirchlichen Raum und damit einen Asyltatbestand im eigentlichen Sinn bezeichnet, oder ob der Ausdruck im übertragenen Sinn die Zuflucht zur Kirche als Gemeinde, als Institution, beziehungsweise zu ihren Repräsentanten, im allgemeinen den Bischöfen, meint. ${ }^{35}$ Damit sich die Zuflucht zu einer religiös geschützten Stätte überhaupt herausbilden kann, müssen entsprechende Baulichkeiten, hier also Kirchengebäude vorhanden sein. Auch das war eigentlich erst im vierten Jahrhundert, ab der Regierungszeit Konstantins des Großen, in größerem Umfang gegeben, ${ }^{36}$ wenngleich vereinzelt eventuell auch früher schon Kirchen gebaut wurden. ${ }^{37}$

Es ist von vornherein klar, daß die Möglichkeiten der Menschen, in einer Situation der Bedrohung in einer Kirche Zuflucht zu suchen, und ihre Chancen, dadurch ihre Situation zu verbessern, auch in jeder anderen Hinsicht von den örtlichen Gegebenheiten abhingen. Es kam an auf die Größe der jeweiligen Gemeinde und deren Bereitschaft, die Flüchtigen zu schützen; vor allem kam es auf die Stellung, das Ansehen und die Durchsetzungskraft des Bischofs an, der sich bei den weltlichen Autoritäten für seine Schützlinge einsetzte, woraus sich das bereits recht formalisierte Institut der Interzession entwickelt hat; und nicht zuletzt war bei der Zuflucht in eine Kirche entscheidend, ob die weltliche Autorität der Kirche und ihrer Aufforderung zur Barmherzigkeit überhaupt Gehör schenkte, was oft auf die Frage hinauslief, ob der verantwortliche Amtsträger selbst Christ war oder nicht. Diese und weitere Bedingungen für die Herausbildung des Kirchenasyls sind in den wissenschaftlichen Arbeiten zum Thema eingehend untersucht und in ihren Entwicklungsschritten dargestellt worden.

35 Die Formulierung des Konzils von Serdica, saepe contigit ut ad misericordiam ecclesiae confugiant, ist offenkundig im übertragenen Sinn gebraucht (Can. 5 ed. Turner $=$ Can. 8 ed. Hefele-Leclerc, danach Ducloux, Droit d'asile [wie Anm. 7], 263f.; vgl. 26ff. mit Übersetzung). Die Mehrdeutigkeit des Ausdrucks wird auch von Langenfeld, Christianisierungspolitik (wie Anm. 5), 159; 173f. betont.

36 Bei seiner Untersuchung, welche kirchlichen Räumlichkeiten gegebenenfalls als $\mathrm{Zu}$ fluchtsstätten genutzt wurden, konnte Franke, Kirchenasyl (wie Anm. 8), 503ff., den Quellen kaum konkrete Anhaltspunkte entnehmen. Vgl. auch Ducloux, Droit d'asile (wie Anm. 7), $231 \mathrm{ff}$.

37 Im Juni 2004 wurde in der Presse gemeldet (Frankfurter Allgemeine Zeitung vom 24. 6. 2004 unter Berufung auf die Jordan Times), man habe in Jordanien eine Basilika ausgegraben, die noch aus dem 2. Jahrhundert stammen soll und damit die älteste bekannte Kirche des Landes wäre. 
Die zweite Institution, auf die im Gesetz des Kaisers Theodosius Bezug genommen wird, ist das Kaiser- oder Statuenasyl. ${ }^{38}$ Zunächst sind die darauf gerichteten Formulierungen deutlich positiver und emphatischer als beim Tempelasyl. Die Pbilanthropia, die (Mit-)Menschlichkeit, die sowohl griechische als auch lateinische (bumanitas) vorchristliche Vorbilder hat, ${ }^{39}$ solle, so das Gesetz, den bedrängten Flüchtlingen nicht verweigert werden, und die Statuen selbst werden mit „Altären der Rettung“ gleichgesetzt. Der Kaiser

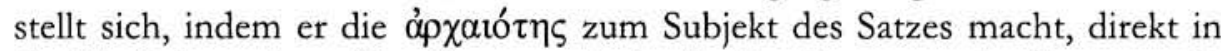
die Tradition seiner Vorgänger, und da die Anerkennung des Statuenasyls durch die römischen Kaiser mindestens bis Tiberius zurückgeht, ${ }^{40}$ sind das eben nicht nur die christlichen, sondern auch die heidnischen Vorgänger in seinem Amt. Zweimal schließt sich der Kaiser mit dem Gebrauch des Possessivpronomens im pluralis maiestatis persönlich in diese Tradition ein: $\dot{\varepsilon} v \tau 0 \hat{\imath} \varsigma$

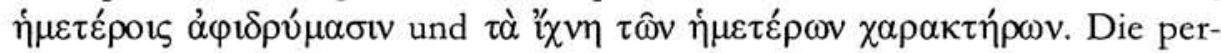
sönliche Eingebundenheit des Kaisers sowie der durchgängige Gebrauch des Präsens in dieser Passage (,diejenigen, die zu den Statuen fliehen, sollen sich ihrer Sicherheit erfreuen" usw.) zeigen deutlich, daß das Statuenasyl, eben im Unterschied zu dem der Vergangenheit angehörigen Tempelasyl, als ein Phänomen auch der Gegenwart vorausgesetzt ist. ${ }^{41}$

Konkrete Fälle von Zufluchtssuche an Kaiserstatuen sind schon für die frühere Zeit selten, aber für das 3. und 4. Jahrhundert ebensowenig überliefert wie Fälle von Tempelasyl. Neben dem basilikos nomos von 431 existiert allerdings noch ein weiteres Gesetz, das indirekt belegt, daß die Praxis des Statuenasyls fortbestand. Die Konstitution 9, 44, 1 von 386 gilt zu Recht als

38 Vgl. dazu grundsätzlich R. Gamauf, Ad statuam licet confugere. Untersuchungen zum Asylrecht im römischen Principat, Frankfurt am Main 1999; ders., Ad statuas confugere in der frühen römischen Kaiserzeit, in: Dreher, Asyl (wie Anm. 2), 177-202; ferner Dreher, Asyl (wie Anm. 2), 5; 10.

39 Philanthropie im Zusammenhang mit Zuflucht z. B. Plut. Thes. 36, 4. Vgl. Bellen, Sklavenflucht (wie Anm. 32), 69; Gamauf, Asylrecht (wie Anm. 38), 122ff. zur bumanitas, deren Bedeutung allerdings bei der Sklavengesetzgebung als gering eingestuft wird. Die Pbilanthropia Theodosius' II. wird auch von den Kirchenhistorikern Sokrates, Sozomenos und Theodoret gepriesen, vgl. H. Leppin, Von Constantin dem Großen zu Theodosius II. Das christliche Kaisertum bei den Kirchenhistorikern Socrates, Sozomenus und Theodoret (Hypomnemata. Untersuchungen zur Antike und ihrem Nachleben 110), Göttingen 1996, 135; 138. Vgl. auch Derlien, Asyl (wie Anm. 14), 109.

40 Bellen, Sklavenflucht (wie Anm. 32), 67f.; Gamauf, ad statuas confugere (wie Anm. 38), 53, hält auch schon die Regierungszeit des Augustus für möglich.

41 Das hat Langenfeld, Christianisierungspolitik (wie Anm. 5), 136, verkannt, der das im Gesetz angesprochene Statuenasyl zu Unrecht den ,alten“, d. h. vorchristlichen Verhältnissen zuordnet. 
erste formale Anerkennung des Statuenasyls, das bis dahin von Seiten des Staates nur implizit anerkannt und durch einige Ausführungsbestimmungen, besonders für die Sklavenflucht zu den Statuen, geregelt wurde. ${ }^{42}$ Das Statuenasyl hatte mithin und sicherlich nicht zufällig ein ganz ähnliches Schicksal wie das Kirchenasyl, ${ }^{43}$ nur daß die Kaiser jenem weltlichen Asyl von Anfang an positiver begegneten. Bezeichnenderweise nennt auch jenes Gesetz, wie das von 431, die Furcht als erstes Motiv, das die Zuflucht in Gang setze: eos, qui ad statuas vel evitandi metus ... causa confugerint. Und nicht zufällig ist es im neunten Buch des "Codex Theodosianus" unter dem Titel 44 De his qui ad statuas confugerint, der nur aus diesem einzigen Text besteht, direkt vor dem Titel $45 \mathrm{De}$ his qui ad ecclesias confugerint plaziert. ${ }^{44}$ Die oben zitierte Formulierung des basilikos nomos $(\$ 4)$, die Kaiserstatuen seien als $\beta \omega \mu$ ò

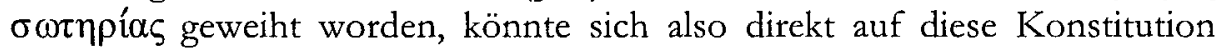
beziehen. Jedenfalls wurde das Gesetz von 386 nicht nur in den „Codex Theodosianus“, sondern auch (als 1, 25, 1) in den „Codex Justinianus“ aufgenommen, was ebenfalls nahelegt, daß das Statuenasyl bis ins 6. Jahrhundert hinein praktische Bedeutung behielt. ${ }^{45}$

Ob das Statuenasyl im Verhältnis zum aufkommenden Kirchenasyl am Ende des 4. Jahrhunderts noch attraktiv war, läßt sich in Ermangelung von

42 Als frühesten Nachweis für die Anerkennung des Asylrechts für Freie sehen das Gesetz an: Th. Mommsen, Römisches Strafrecht, Leipzig 1899, 461; P. Timbal Duclaux de Martin, Le droit d'asile, Paris 1939, 30; Langenfeld, Christianisierungspolitik (wie Anm. 5), 113; A. D. Manfredini, ,Ad ecclesiam confugere', ,ad statuam confugere' nell'età di Teodosio I, AARC 6, 1986, 39-58, hier: 49; D. Fruscione, Das Asyl bei den germanischen Stämmen im frühen Mittelalter, Köln u. a. 2003, 8.

43 Vgl. oben Anm. 8.

44 CTh 9, 44, 1 (Valentinian, Theodosius, Arcadius, 386) $=$ CJ 1, 25, 1 : eos, qui ad statuas vel evitandi metus vel creandae invidiae causa confugerint, ante diem decimum neque auferri ab aliquo neque discedere sponte perpetimur; ita tamen, ut, si certas habuerint causas, quibus confugere ad imperatoria simulacra debuerint, iure ac legibus vindicentur; sin vero proditi fuerint artibus suis invidiam inimicis creare voluisse, ultrix in eos sententia proferatur.

„We suffer those persons who have taken refuge at the statues of the Emporers, either for the purpose of avoiding danger or of creating ill will, neither to be taken away by anyone before the tenth day nor to go away of their own accord; provided that, if they had definitive reasons for which they had to flee to the statutes of the Emporers, they shall be protected by the law and the statutes. But if they should be revealed to have wished to create ill will against their enemies by their own artifices, an avenging sentence shall be pronounced against them."

45 Bellen, Sklavenflucht (wie Anm. 32), 74f. geht zumindest für die von ihm nur betrachteten Sklaven von einer mehr oder weniger nahtlosen „Ablösung“ - auch bei ihm in Anführungszeichen - des Statuenasyls durch das Kirchenasyl aus. 
Quellenzeugnissen über konkrete Fälle nur aus dem Charakter der jeweiligen rechtlichen Konsequenzen vermuten. Von der Ausgangslage her müßte das Kirchenasyl die größere Anziehungskraft ausgeübt haben, denn es bot ebenso wie das Tempelasyl allen Verfolgten, ob sie im Recht oder im Unrecht waren, Schutz, während das Statuenasyl für Rechtsbrecher nicht gelten sollte. ${ }^{46}$ In der Praxis mußte dieser Unterschied aber erst einmal rechtsförmig festgestellt werden, so daß auch die Prozeduren des Statuenasyls den unmittelbaren Zugriff der Verfolger verhinderten. In höchster Not werden sich die Bedrohten sowieso einfach der nächstgelegenen Zufluchtsmöglichkeit, ob Statue oder Kirche, zugewandt haben. Die Attraktivität des Statuenasyls dürfte auch davon abhängig gewesen sein, wie man die im Gesetz von 386 genannte Frist von neun Tagen interpretiert, in der niemand die Asylanten wegführen durfte, aber auch sie selbst die Statue nicht verlassen durften. Mußten die Flüchtlinge tatsächlich neun Tage an der Statue ausharren, wie ein wörtliches Verständnis nahelegt, dürfte die Anziehungskraft der Kaiserstatuen im Vergleich zu den Kirchen, in denen sie auf eine Betreuung und Versorgung durch die Geistlichen und durch Gemeindemitglieder hoffen konnten, sehr gering gewesen sein. Wurden die zu den Statuen Geflüchteten jedoch vom zuständigen Amtsträger in vorläufigen Gewahrsam genommen, wie Langenfeld annimmt, ${ }^{47}$ wäre die Attraktivität größer gewesen; allerdings läßt der Gesetzeswortlaut ein solches Verständ nis kaum zu. ${ }^{48}$ Prinzipiell ließe sich anführen, daß gerade dann, wenn Zuflucht vor einer staatlichen Instanz, etwa dem Steuereintreiber, gesucht wurde, die Zuflucht zu einer anderen staatlichen Instanz, die ähnliche Interessen vertrat und mit der ersten womöglich eng kooperierte, sicherlich weniger aussichtsreich erscheinen mußte als die Zuflucht zur weitgehend eigenständigen Kirche, die sich zumindest grundsätzlich für den Schutz aller Verfolgten einzuse tzen versprach.

46 So Gamauf, ad statuas confugere (wie Anm. 38), 189, der damit aber die Komplexität des Problems nicht ganz au sleuchtet.

47 Langenfeld, Christianisierungspolitik (wie Anm. 5), 113.

48 So auch Franke, Kirchenasyl (wie Anm. 8), 191 mit Anm. 285. Die Ansicht Bellens, Sklavenflucht (wie Anm. 32), 75; 78, das Kirchenasyl sei für Sklaven eine Verschlechterung gegenüber dem Statuenasyl, erscheint in jedem Fall fraglich. Die Schwierigkeiten, die sie beim Verfahren an den Statuen erwartete, waren letztlich wohl kaum weniger belastend als die Einschränkungen beim Kirchenasyl, vgl. Gamauf, Asylrecht (wie Anm. 38); dens., ad statuas confugere (wie Anm. 38), 192. 
III.

Stellen wir nun den gesetzlichen, kaiserlichen Äußerungen die Ausführungen eines der prominentesten Kirchenvertreter am Beginn des 5. Jahrhunderts gegenüber, die nämlich des Aurelius Augustinus, des Bischofs von Hippo Regius in Nordafrika. Augustinus hat sein Werk „De civitate dei contra paganos" im wesentlichen als Antwort auf die Vorwürfe konzipiert, die den Chri sten nach der Einnahme Roms durch Alarich im Jahr 410 von seiten der traditionell Gläubigen gemacht wurden. Besonders die nichtchristliche römische Senatsaristokratie legte nämlich den Verlust der Stadt den Christen zur Last, die für die Vernachlässigung der traditionellen Kulte verantwortlich seien. Dadurch habe man das Wohlwollen und den Schutz der altrömischen Gottheiten verloren. ${ }^{49}$

Augustinus geißelt zunächst $(1,1)$ die Undankbarkeit seiner Feinde, die jetzt nicht in der Lage wären, gegen den Gottesstaat zu Felde zu ziehen, wenn sie sich bei der Plünderung Roms ihr Leben nicht durch die Flucht in eine christliche Kirche gerettet hätten. Die Goten (die schlicht nur barbari genannt werden) hätten den Schutz der römischen Kirchen zu Ehren Christi respektiert und die dorthin Geflohenen ganz im Gegensatz zur üblichen Kriegspraxis verschont. Im zweiten Kapitel behauptet der Bischof, es sei bis dahin noch überhaupt nie vorgekommen, daß in einem Krieg Tempelflüchtlinge verschont worden seien, und führt die Troiasage als Zeugnis dafür an, daß im Gegenteil Götterbilder und Tempel ungestraft mit Blut befleckt worden seien. $\mathrm{Ob}$ Augustinus seine Behauptung wirklich für wahr hält oder ob er sie wider besseres Wissen macht, was angesichts der zahlreichen, aus der griechisch-hellenistischen Welt überlieferten Fälle von respektiertem Tempelasyl wahrscheinlicher ist, kann hier dahingestellt bleiben. Die Behauptung dient ihm jedenfalls zu dem Schluß, daß die heidnischen Götter und Tempel keinerlei Schutz gewähren könnten, ja sogar ihrerseits des menschlichen Schutzes bedürften: Neque enim bomines a simulacro, sed simulacrum ab bominibus servabatur. Ein Vergleich zwischen dem Asyltempel der Juno, in dem nach Vergils Beschreibung bei der Plünderung Troias die Beute und die Gefangenen zum Abtransport gesammelt wurden, und den Zufluchtskirchen, die bei der Plünderung Roms ein Ort der Rettung waren, soll den Gegensatz noch weiter illustrieren (1,4). Im Anschluß an das troianische Beispiel hält Augu-

49 Nur beiläufig erwähnt auch Derlien, Asyl (wie Anm. 14), 360 das Thema Augustinus, ohne die Stelle zu zitieren oder darauf einzugehen. Herangezogen, aber nicht sehr au sführlich interpretiert wird der Augustinus-Text von Franke, Kirchenasyl (wie Anm. 8), 279f.; 325; $417 f$. 
stinus den Römern selbst vor, niemals ein Asylrecht respektiert zu haben (1, 6). Legatur nobis quae templa excipere solebant, ut ad ea quisquis confugisset liberaretur?, fragt der Autor scheinheilig und wiederum im Gegensatz zur historischen Wahrheit, denn auch er hätte in der Literatur zahlreiche Zeugnisse dafür finden können, daß die Römer seit dem frühen 2. Jahrhundert die Asylia griechischer Heiligtümer auch formal anerkannt haben. Und wenn er weiterfragt: An illi faciebant et scriptores earundem rerum gestarum ista reticebant?, gibt er vor, nichts davon gelesen zu haben. Kein römischer Feldherr, weder Marcellus in Syrakus noch Fabius in Tarent, habe Mord und Gefangennahme in irgendeinem Tempelbezirk untersagt. Auf die Verschonung der christlichen Kirchen Roms konnten die Goten also nicht von selbst gekommen sein $(1,7)$. Ihr historisch neues und unerwartetes Verhalten „ist dem Namen Christi und dem christlichen Zeitalter zuzuschreiben"; wer das nicht sehe, sei blind.

Mehrfach in den ersten hier referierten sieben Kapiteln des "Gottesstaates" begründet Augustinus das ehrfürchtige Verhalten Alarichs und seiner Goten, die bekanntlich dem arianischen Glauben anhingen, allein mit der Vorsehung Gottes, mit dem Respekt vor dem christlichen Gott, mit der Wirkung des Namens Christi. Während alle anderen Quellen, auch die christlichen, ${ }^{50}$ berichten, es sei Alarich gewesen, der den Befehl zur Verschonung der Kirchen und der dorthin Geflohenen erteilt habe, nennt Augustinus diesen Befehl nicht ausdrücklich, sondern deutet ihn nur indirekt an, indem er im zweiten und sechsten Kapitel erwähnt, daß es vorher noch nie einen solchen Schonungsbefehl gegeben habe. Zugunsten des göttlichen Wirkens will der Autor den Gotenkönig offenbar nicht einmal als mögliches Instrument Gottes erscheinen lassen, um keinen Gedanken an mögliche eigenständige machtpolitische Kalkulationen des menschlichen Urhebers aufkommen zu lassen.

Zu der zentralen Behauptung des Augustinus, es habe vor dem Goteneinfall weder ein formales noch ein faktisches Tempelasyl existiert, steht nun die oben referierte Gesetzesbegründung des Theodosius von 431 in direktem Widerspruch, und auf diesen Gegensatz soll es mir letztlich vorrangig ankommen. Während der Kaiser, wie gesehen, seine Maßnahme, die Anerkennung des Kirchenasyls, durch den Bezug auf das einstige Tempelasyl und auf das Statuenasyl seiner Vorgänger motiviert, leugnet der Kirchenmann die Existenz des Tempelasyls überhaupt und erwähnt das Statuenasyl, obwohl es in seiner Zeit noch aktuell gewesen sein muß, mit keinem Wort. Und wäh-

50 Allgemein vgl. A. Piganiol, Le Sac de Rome. Vue d'ensemble, Paris 1964. Zur Diskussion der wichtigsten Quellen vgl. u. a. Ducloux, Droit d'asile (wie Anm. 7), 134ff. Zu den Berichten der Kirchenhistoriker vgl. Leppin, Kaisertum (wie Anm. 39), $144 f$. 
rend der Kirchenvater die Schutzwirkung der Kirchenräume direkt und ausschließlich auf den Willen Gottes und, ein bißchen verschlüsselt im Begriff von den christlichen Zeiten, auf das Wirken der Kirche selbst zurückführt und alle Andeutungen auf eine weltliche Tradition oder gar Mitwirkung vermeidet, scheint der erste Mann des Staates umgekehrt ausschließlich die weltliche Tradition zu kennen. Obwohl das von den heidnischen Kaisern zugelassene Statuenasyl inzwischen auf seine christlichen Vorgänger und ihn selbst übergegangen war, meidet er in Bezug auf die Anerkennung des Kirchenasyls jeden Hinweis auf eine christliche Begründung. Das Gesetz gibt keinerlei Hinweis auf die Bemühungen kirchlicher Institutionen wie die des Konzils von Karthago 401, auf dessen Beschluß hin zwei abgesandte Bischöfe den Kaiser Honorius um ein Gesetz baten, welches angeklagte Personen, die in einer Kirche Zuflucht suchten, vor der Abführung schützen sollte, ${ }^{51}$ und es gibt erst recht keinen Hinweis auf die schon bisher praktizierte Gewohnheit, in den Kirchen Schutz und Zuflucht zu suchen. Natürlich will auch das Gesetz ausdrücklich der christlichen Religion und der Ehre des christlichen Gottes dienen. Aber die Perspektive ist die, daß als handelndes Subjekt und als Urheber der Maßnahme immer der Kaiser selbst in seinem pluralis maiestatis herausgehoben wird. Dieser Befund läßt im übrigen einmal mehr zweifeln an der These von Eduard Schwartz, daß Theodosius II. „die ,Frömmigkeit immer wichtiger war als die Wahrung der staatlichen Autorität" ${ }^{52}$

Diese gegensätzliche Gewichtung wird noch durch die Wahl der jeweiligen Begrifflichkeit unterstrichen. Während Augustinus die Sphäre der heidnischen Heiligtümer ganz scharf von der der christlichen trennt, indem er die ersteren immer als templa bezeichnet, die letzteren nur als basilicae, loca martyrorum o. ä., ${ }^{53}$ so hat, wie oben referiert, die kaiserliche Kanzlei in dem Gesetz von 431 ganz betont die althergebrachte Terminologie, gerade das Wort vaó $\zeta$, also templum, auch für die christlichen Stätten verwendet. Durch den vorstehenden Vergleich zwischen Äußerungen des Augustinus und Theodosius II. könnte man zunächst versucht sein, einen bewußten Bezug des $\mathrm{Ge}$ -

51 Concilia Africae a. 345 - a. 525. Ed. Ch. Munier (CCL 149), Turnhout 1974, 194, Z. 393 396: ... ut pro confugientibus ad ecclesiam, quocumque reatu involutis, legem de gloriosissimis principibus mereantur, ne quis eos audeat abstrabere. „... damit sie für diejenigen, die in eine Kirche flüchten, in welches Verbrechen sie auch immer verwickelt sein mögen, von den ruhmreichsten Kaisern ein Gesetz erlangten, daß niemand es wagen dürfe, sie von dort wegzuziehen“. Vgl. Langenfeld, Christianisierungspolitik (wie Anm. 5), 126; 151; Hess, Canon Law (wie Anm. 34), 204; Traulsen, Das sakrale Asyl (wie Anm. 5), 283.

52 Schwartz bei Woeß, Asylwesen (wie Anm. 16), 253.

53 Beobachtet von Ducloux, Droit d'asile (wie Anm. 7), $139 \mathrm{f}$. 
setzes von 431 auf die Schrift des nordafrikanischen Bischofs für möglich zu halten, der im Jahr zuvor gestorben war, die ersten drei Bücher der „Civitas dei" aber schon 413 veröffentlicht hatte. Eine Abhängigkeit wäre auch deshalb naheliegend, weil einerseits neben Augustinus kaum ein anderer christlicher Autor überhaupt auf das pagane sakrale Asyl Bezug genommen hat, und unter diesen wenigen Autoren Augustinus derjenige ist, der sich bei weitem am ausführlichsten geäußert hat, ${ }^{54}$ und weil andererseits die Bezugnahme auf die vorchristliche Asyltradition in Gesetzestexten sowohl des Theodosius II. selbst als auch von anderen Kaisern singulär ist. ${ }^{55}$ Einem solchen Bezug steht aber zunächst entgegen, daß das Gesetz in keiner Weise auf den AugustinusText oder auf andere kirchliche Äußerungen anspielt. Generell ist Augustinus selbst im Osten, zumindest im griechischsprachigen Milieu, kaum rezipiert worden; und die Eroberung der Stadt Rom, die seine Ausführungen veranlaßt hatte, hat für das Ostreich auch nicht annähernd die Bedeutung gehabt, die sie für das Westreich besaß. ${ }^{56}$ Es handelt sich daher doch um zwei getrennte Diskurse aus zwei ganz verschiedenen Milieus. ${ }^{57}$ Augustinus' "Civitas dei“ ist ein Höhepunkt der spätantiken kirchlichen Apologetik. Die weltliche Macht hingegen wollte Rechtssicherheit für das Reich herstellen. Mit Gesetzen wie dem vorliegenden unterstrich sie einmal mehr, daß ihre allumfassende $\mathrm{Zu}$ ständigkeit auch die kirchlichen Angelegenheiten einschloß. Mit der Anerkennung des Kirchenasyls mag der Kaiser einem langgehegten Wunsch der Kirche entsprochen haben. In einen direkten Dialog mit der kirchlichen Apologetik trat er jedoch nicht.

Der konkrete Anlaß für die Konstitution von 431 mag zwar der Einbruch bewaffneter Sklaven in die Kathedrale von Konstantinopel im vorausgehenden Jahr gewesen sein. Der Kirchenhistoriker Sokrates schildert sehr drastisch $(7,33)$, wie diese verzweifelten Sklaven zunächst einige Kleriker töteten, direkt im Altarraum campierten und sich zuguterletzt dort selbst den Tod gaben. Auf diesen Vorfall verweist der basilikos nomos in den Paragraphen 2

54 Die Zusammenstellungen von Franke, Kirchenasyl (wie Anm. 8), notieren unter den griechischen Kirchenvätern allenfalls indirekte Anspielungen auf das Tempelasyl (263f.) und für die lateinische Patristik bis zum 5. Jahrhundert neben Augustinus nur kurze Bemerkungen von Hieronymus und Tertullian (324ff.). Auch unter den Autoren, die auf das Romulus-Asyl Bezug nehmen, ist Augustinus der ausführlichste, vgl. ebd. $327 \mathrm{ff}$., zusammenfassend 434.

55 Nebenbei bemerkt auch von Franke, Kirchenasyl (wie Anm. 8), 447.

56 Vgl. Leppin, Kaisertum (wie Anm. 39), 270f. bzw. 144f. Hartmut Leppin hat diese Gesichtspunkte auch in der Diskussion des Marburger Kolloquiums noch einmal bekräftigt.

57 Das hat auch Stefan Rebenich in der Diskussion des Bielefelder Vortrags unterstrichen, wie Anm. 1. 
und 10 , so daß unstrittig ist, daß das Gesetz die Wiederholung eines solchen Falles in der Zukunft ausschließen sollte. ${ }^{58}$ Aber wie in vielen anderen Fällen greift es zu kurz, eine Regelung wie das vorliegende Asylgesetz lediglich auf eine unmittelbare Reaktion auf ein bestimmtes Ereignis zu reduzieren. Vielmehr sehen wir hier paradigmatisch, wie die dramatische Entweihung eines Asylortes den Anstoß für eine Neukonzeption der kaiserlichen Haltung zum Kirchenasyl, für eine grundlegende Regelung von allgemeiner Bedeutung gibt: Die Reaktion erweitert sich zu gestaltendem Handeln.

Denn wenn es dem Asylgesetz nur um eine Antwort auf den Vorfall in Konstantinopel gegangen wäre, so hätte man eine viel schärfere Regelung erwarten müssen, die auf der Linie der bisherigen kaiserlichen Beschränkungen der Kirchenzuflucht gelegen hätte und mindestens die Einschränkungen, die Theodosius dann tatsächlich ein Jahr später für schutzsuchende Sklaven verfügen sollte, bereits jetzt erlassen hätte.

Das vorliegende Gesetz aber zeigt schon darin, daß es äußerst vorsichtige und gegenüber der Kirche rücksichtsvolle Ausführungsbestimmungen enthält, an, daß seine vorrangige Blickrichtung in eine andere Richtung zielte. Zwar verbietet es den Asylsuchenden ausdrücklich, bewaffnet in die schutzbietenden Kirchenräume zu kommen; aber wer dagegen verstößt, soll von den Klerikern zum Ablegen der Waffen aufgefordert werden, nachdem der Bischof informiert worden ist. Bei einer Weigerung sollen die Betreffenden zwar aus dem Asyl entfernt werden, aber nicht ohne Unterrichtung des Bischofs und nicht ohne kaiserlichen Befehl oder richterliche Verfügung.

Gegenüber den bisherigen Vorschriften des Kaisers, die Bischöfe und Kleriker sogar mit Strafen bedroht hatten, wenn sie bestimmte Kategorien von Schutzsuchenden gesetzwidrig schützten, wird die Kirche hier geradezu mit Samthandschuhen angefaßt, während diejenigen, welche das Kirchenasyl verletzen sollten, ihrerseits mit der schwersten, der Todesstrafe, bedroht werden. Der Wechsel der Zielrichtung hängt mit der grundsätzlichen formalen Anerkennung des Kirchenasyls in ebendieser Konstitution zusammen. Und diese Neuerung kann nicht allein auf den Vorfall in Konstantinopel zurückgeführt werden. Dafür muß man eine längerfristige Entwicklung voraussetzen, und das in den Augen nicht nur des Augustinus, sondern vieler Christen vorbildliche Verhalten des Gotenkönigs Alarich mag daran einen gewissen Anteil gehabt haben. Dem Barbaren Alarich bei der grundsätzlich unbeschränkten Anerkennung des Kirchenasyls nicht nachzustehen, kann auch ohne direkte Kenntnis der provozierenden Ausführungen des Augustinus

58 Dabei beläßt es dann aber z. B. Ducloux, Droit d'asile (wie Anm. 7), 220. 
den Entschluß des Theodosius mitbeeinflußt haben. Dazu kam ohne Zweifel das Anliegen der Kirche, die schon immer alle Flüchtigen schützen wollte, und die sicherlich bestrebt war, möglichst stetig einen en tsprechenden Druck auf den Kaiser auszuüben. Frühere christliche Kaiser waren auch schon in diese Richtung gegangen, indem sie den kirchlichen Schutz für einzelne Gruppen anerkannt bzw. andere Gruppen davon ausgeschlossen hatten. ${ }^{59}$

Trotz dieser Konvergenz vertreten beide Seiten, die kirchliche und die kaiserliche, ihre jeweilige Perspektive und halten sich von der jeweils anderen fern. Es zeigt sich auch auf dem Gebiet des Asylwesens, das in der Gesamtentwicklung der Spätantike zweifellos nur ein Nebenschauplatz ist, daß bei aller Einigkeit in dem grundsätzlichen Ziel, die christliche Religion zu fördern, kirchliche und weltliche Instanzen sich doch immer wieder distanziert zueinander verhalten, ihre Bereiche sorgfältig voneinander trennen, zum Teil unterschiedliche, zum Teil sogar gegensätzliche Interessen geltend machen; 60 letzteres gilt gerade, wenn wir an die auch nach 431 noch erfolgten Einschränkungen des nunmehr gewonnenen Asylrechts denken, von denen an dieser Stelle aber nicht mehr die Rede sein kann. Nicht weniger als in den meisten anderen Epochen auch ist das Asylrecht der spätantiken Kaiser im wesentlichen ein Instrument zur Durchsetzung allgemeinerer Interessen und damit wesentlich Asylpolitik. ${ }^{61}$

Es ergibt sich also das Paradox, daß gerade aus unterschiedlichen ideologischen Begründungen, gerade aus einer gewissen Konkurrenz heraus die Kaiser auf die kirchliche Linie eingeschwenkt sind und das Kirchenasyl grundsätzlich anerkannt haben. Weitere Gründe dafür könnte man darin suchen, daß die Kaiser dieses Feld nicht der Kirche allein überlassen wollten, daß auch sie ihre Milde und Fürsorge unter Beweis stellen und dadurch nicht zuletzt ihre Herrschaft legitimieren wollten. Vielleicht trug Theodosius II. auch der Tatsache Rechnung, daß das Statuenasyl keine wirkliche Alternative mehr zum Kirchenasyl darstellte, obwohl es vom ersten Theodosius 386 gerade zu diesem Zweck formal legitimiert worden war. ${ }^{62}$ Dazu traten prakti-

59 Vgl. Langenfeld, Christianisierungspolitik (wie Anm. 5), $127 \mathrm{ff}$.

60 Eine Parallele wäre z. B. der Streit zwischen Theodosius und dem Mailänder Bischof Ambrosius über die Rettung von zum Tode Verurteilten, vgl. Langenfeld, Christianisierungspolitik (wie Anm. 5), 171f. mit Quellenangaben.

61 Ähnlich Langenfeld, Christianisierungspolitik (wie Anm. 5), 199; vgl. auch M. Dreher, Das Asyl. Theoretische Begründung, rechtliche Ausgestaltung und politische Funktion von der Antike bis zur Neuzeit, in: M. Kerner (Hg.), Eine Welt - Eine Geschichte. 43. Deutscher Historikertag in Aachen, München 2001, 36-41, hier: 41.

62 So Langenfeld, Christianisierungspolitik (wie Anm. 5), 115. 
sche Gründe. Es kann der kaiserlichen Zentrale nicht entgangen sein, daß die gesetzlichen Regelungen und die manchmal willkürlichen und sogar gesetzeswidrigen Vorgehensweisen der staatlichen Amtsträger immer wieder zu übermäßigen Härten gerade gegenüber den unteren Bevölkerungsschichten führten. Die Kirche konnte, nicht nur im Asylbereich, zahlreiche solcher Härten abfangen oder kanalisieren. Wenn die Kleriker nun auch offiziell für die Schutzsuchenden zuständig waren, wenn sie sich um deren Betreuung und nicht zuletzt auch materielle Versorgung kümmerten, so konnte man darauf hoffen, daß damit auch Erleichterungen und Entlastungen für die weltlichen Instanzen verbunden sein würden. ${ }^{63}$ Eine Parallele dazu wäre die Einrichtung der episcopalis audientia auf dem Gebiet der Gerichtsbarkeit. ${ }^{64}$

63 Der umgekehrte Schluß von Langenfeld, Christianisierungspolitik (wie Anm. 5), 140, die Einschränkungen des Asylprivilegs durch CTh 9, 45, 5 seien wiederum eine Erleichterung für die Kleriker, die dann weniger „Scherereien“ hätten, geht meines Erachtens allerdings zu weit.

64 Vgl. M. R. Cimma, L'audientia episcopalis nelle costituzioni imperiali da Costantino a Giustiniano, Turin 1989. 


\section{Der erste ,griechische Kaiser“. Überlegungen zum Scheitern des Procopius Anthemius im Weströmischen Reich}

\section{Dirk Henning}

\section{Einleitung}

Im Jahre 1959 veröffentlichte der Romancier und Essayist Frank Thiess (1890-1977) in einem Hamburger Verlag ein Sachbuch, in dem er die vermeintlich „dunklen Jahrhunderte“ des Oströmischen Reiches zwischen dem Tode Justinians I. im Jahre 565 und dem Regierungsantritt Leons III. im Jahre 717 darstellte. Thiess wählte für sein Buch den Titel „Die griechischen Kaiser", um auf diese Weise die seiner Meinung nach weitgehend unbekannte Tatsache herauszustellen, daß es sich bei dem griechisch geprägten, mittelalterlichen Reich von Byzanz um eine direkte Fortsetzung des Imperium Romanum der Antike handelte. ${ }^{1}$

Wohl ohne es zu ahnen, konfrontierte der Autor seine Leser so mit einem der wirkungsmächtigsten staatstheoretischen Probleme des Mittelalters, nämlich dem „Zwei-Kaiser-Problem“, dem Streit zwischen Byzanz und dem Westen um das Erbe des zerfallenen Römischen Weltreiches und um das damit verbundene Kaisertum. Byzanz konnte in dieser Auseinandersetzung zwar auf eine unanfechtbare staatsrechtliche Kontinuität verweisen, blieb jedoch propagandistisch in einer Defensivposition, da es die unmittelbare Herrschaft über die Keimzelle des einstigen Imperium, die Stadt Rom und

1 F. Thiess, Die griechischen Kaiser. Die Geburt Europas, Hamburg/Wien 1959. Zu Person und Werk des zu Lebzeiten heftig umstrittenen, heute jedoch fast in Vergessenheit geratenen Autors siehe nun Y. Wolf, Frank Thiess und der Nationalsozialismus (Unters uchungen zur deutschen Literaturgeschichte 114), Tübingen 2003. 
Italien, früh verlor und sich in der Folge zu einem völlig gräzisierten Staatswesen entwickelte. ${ }^{2}$

Um so energischer indes beharten die Kaiser in Konstantinopel auf ihrem „Römertum“, das seit dem frühen 9. Jahrhundert, in Reaktion auf die Kaiserkrönung Karls des Großen im Westen, sogar Eingang in ihre Titulatur fand. Als Basileis ton Romaion, als „Kaiser der Römer", bezeichneten sich die byzantinischen Herrschet bis 1453 ostentativ. Die intellektuelle Oberschicht Konstantinopels pflegte klassisches Griechisch und verdammte Latein als Barbarensprache, wies zugleich aber jeden Zweifel am eigenen Römertum entrüstet von sich. Hätte Frank Thiess den Titel seines Buches „Die griechischen Kaiser" 1000 Jahre zuvor in Konstantinopel formuliert, der Verlust zumindest der Nasenspitze wäre ihm sicher gewesen.

\section{Problemstellung}

Dieser scheinbar paradoxe, mittelalterliche Streit um Griechen- und Römertum reicht zurück bis in die Spätantike, in die Zeit der Auflösung der Westhälfte des Imperium Romanum im späten 5. Jahrhundert. Mit dem Tode Kaiser Valentinians III. erlosch 455 das letzte bedeutende Kaiserhaus, das beide Reichshälften regiert hatte, nämlich die theodosianische Dynastie. Es folgte im Weströmischen Reich eine Phase von Machtkämpfen und Bürgerkriegen, an der sich schon bald die auf Reichsboden siedelnden germanischen Völker beteiligten. Innerhalb zweier Jahrzehnte wurden so insgesamt neun Kaiser erhoben und wieder gestürzt. Am Ende stand der territoriale Zerfall des Westreiches, die Eliminierung des Kaisertums und die Machtübernahme in Italien durch das germanisch dominierte Militär. ${ }^{3}$

$\mathrm{Zu}$ den zahlreichen ephemeren Herrschergestalten, die während dieser Krise um die Macht kämpften, gehörte auch ein Oströmer, nämlich der aus Konstantinopel stammende und mit Unterstützung des Ostkaisers Leo I. nach Italien entsandte Procopius Anthemius. Anthemius gehörte den prominentesten Kreisen Konstantinopels an, besaß verwandtschaftliche Beziehungen sowohl zur konstantinischen wie zur theodosianischen Dynastie und

2 Überblicksdarstellung zuletzt bei H. H. Anton, Zweikaiserproblem, Lexikon des Mittelalters 9, 1999, 720-723 (mit älterer Literatur).

3 Zum folgenden sei auf meine Monographie Periclitans res publica. Kaisertum und Eliten in der Krise des Weströmischen Reiches 454/5-493 n.Chr. (Historia. Einzelschriften 133), Stuttgart 1999, verwiesen. Da sich dort umfassende Quellenbelege und Literaturangaben finden, ist die Dokumentation hier auf das Nötigste beschränkt worden. 
hätte im Jahre 457 um ein Haar den östlichen Thron bestiegen. Zehn Jahre später versuchte er sein Glück erneut, diesmal im Westen. Tatsächlich gelang es Anthemius, sich hier mehr als fünf Jahre lang, von 467 bis 472 , zu behaupten. Am Ende scheiterte aber auch er wie nahezu sämtliche seiner Vorgänger und Nachfolger in dieser Spätphase. Unter den dramatischen Begleitumständen einer Armeerevolte mit Belagerung und Eroberung Roms wurde Anthemius durch den germanischen Heermeister Ricimer gestürzt und ermordet. ${ }^{4}$

In einem Punkt allerdings unterschied sich das Schicksal des Anthemius von demjenigen der anderen Herrschergestalten seiner Zeit: Wie einige Quellen behaupten, wurde von den Gegnern des Kaisers im Kampf um die Macht die griechische Herkunft des Anthemius thematisiert, dabei sogar ein Gegensatz zwischen Graecus und Romanus konstruiert, mit dem Ziel, die Autorität des Kaisers zu beschädigen. In der Forschung hat sich einzig John Michael O'Flynn in einem kurzen Artikel aus dem Jahr 1991 mit diesem Phänomen beschäftigt. Er hält diese Quellenaussagen für glaubhaft und folgert aus ihnen, daß bereits zu dieser Zeit eine tiefgreifende Entfremdung zwischen Ostund Westrom erfolgt sei, daß die führenden gesellschaftlichen Kräfte des Westreiches schon im späten 5. Jahrhundert in den Eliten des Ostreiches nicht mehr Römer, sondern Griechen erblickt hätten, ja noch schlimmer: Fremde, die ihnen ferner standen als die germanischen Barbaren ihrer unmittelbaren Umgebung. Diese Kluft zwischen Ost und West, so O'Flynn weiter, sei für das Scheitern des Anthemius in Italien ursächlich gewesen. Es führe von ihr eine Kontinuitätslinie bis hinein ins hohe Mittelalter, zum eingangs geschilderten Zwei-Kaiser-Problem des 9. bis 13. Jahrhunderts. ${ }^{5}$

Die Quellenbasis, auf die O'Flynn seine weit ausgreifende These stützt, ist allerdings recht dünn und, wie sich zeigen wird, brüchig. Der historische Kontext ihrer Entstehung, aber auch der Regierungszeit des Anthemius selbst, bleibt weitgehend unberücksichtigt. Das Ziel der folgenden Ausführungen ist es deshalb, an diesen Punkten anzusetzen und O'Flynns These einer entsprechenden Prüfung zu unterziehen. Letztlich geht es dabei um die Frage, ob ein Zusammenhang - und wenn ja, in welchem Maße - zwischen der östlichen Herkunft des Anthemius und seinem Scheitern im Weströmischen Reich bestand, oder, zugespitzt formuliert, ob Anthemius Thron und Leben verlor, weil er ein ,griechischer Kaiser" war.

4 Person und Schicksal des Anthemius: Henning, Krise (wie Anm. 3), 42-46.

5 J. M. O'Flynn, A Greek on the Roman throne: the fate of Anthemius, Historia 40, 1991, 122-128. O'Flynns Thesen wurden jüngst weitgehend unkritisch übernommen von $P$. MacGeorge, Late Roman Warlords, Oxford/New York 2002. 


\section{Schriftquellen}

Zwei Quellen geben Hinweise darauf, daß die griechische Herkunft des Anthemius in der Auseinandersetzung des Kaisers mit seinen innenpolitischen Gegnern eine Rolle spielte:

Magnus Felix Ennodius, Bischof von Pavia zur Zeit des Königs Theoderich, berichtet in der von ihm verfaßten Vita seines Amtsvorgängers Epiphanius über dessen diplomatisches Geschick im Umgang mit den Mächtigen seiner Zeit. ${ }^{6}$ Epiphanius wurde aufgrund seiner Fähigkeiten in den 470er Jahren insgesamt dreimal mit heiklen Vermittlungsmissionen zwischen verfeindeten Parteien betraut. So vertrat er im Jahre 475 die Interessen des Kaisers Iulius Nepos bei den Westgoten und um 477 die ligurische Senatsaristokratie vor Odoaker. Bereits 471 hatte er im Auftrag des Heermeisters Ricimer und der ligurischen Provinzialversammlung versucht, eine Beilegung des Konfliktes zwischen Ricimer und Kaiser Anthemius zu erreichen. Dieser Vermittlungsversuch wird von Ennodius zwar als erfolgreich dargestellt, scheiterte aber in Wahrheit.

Für unser Thema von Bedeutung ist die Vorgeschichte dieser Mission, nämlich die Suche nach einem geeigneten Vermittler. Ennodius zufolge befragte Ricimer die ligurischen Senatoren mit den Worten: Quis est, qui Galatam concitatum revocare possit et principem? („Wer ist es, der den aufgeregten Galater und Princeps zur Besinnung bringen kann?") Die Provinzialversammlung schlägt daraufhin Bischof Epiphanius von Pavia vor, quem venerari possit quicumque, si est catbolicus et Romanus, amare certe (...) et Graeculus („den jeder verehren kann, wenn er ein Katholik und Römer ist, und den gewiß sogar ein Griechlein lieben kann"). ${ }^{7}$ Alle diese Schmähungen beziehen sich auf Anthemius, der hier als Galata concitatus und Graeculus verunglimpft und in direkten Gegensatz zu einem catholicus et Romanus gesetzt wird, dem also sowohl Rechtgläubigkeit wie auch Römertum abgesprochen werden.

6 Zu Ennodius und der Epiphanius-Vita zuletzt A. Gillett, Envoys and Political Communication in the Late Antique West, 411-533, Cambridge 2003, 148-171; S. A. H. Kennell, Magnus Felix Ennodius. A Gentleman of the Church, Michigan 2000, passim. Unersetzt ist nach wie vor M. Cesa, Ennodio. Vita del beatissimo Epifanio vescovo della chiesa $\mathrm{Pa}$ vese (Biblioteca di Athenaeum 6), Como 1988.

7 Ennod. V. Epiph. 53-55. - Die drastischen Formulierungen des Textes werden in seiner bislang einzigen deutschen Übersetzung durch M. Fertig, Magnus Felix Ennodius und seine Zeit. 2. Abschnitt: Vita S. Epiphanii, in: Jahres-Bericht über die KöniglichBayerische Studien-Anstalt zu Landshut in Niederbayern für das Schuljahr 1859/60, Landshut 1860,5 , nicht adäquat wiedergegeben. 
Zweifel an der Authentizität dieser von Ennodius wiedergegebenen Aussagen drängen sich deshalb geradezu auf. Wir erleben hier einen eklatanten Fall von Majestätsbeleidigung, begangen durch führende gesellschaftliche Kräfte des Westreiches gegenüber ihrem regierenden Souverän, und dies angeblich während der Vorbereitung einer diplomatischen Friedensmission zu eben diesem Souverän. Schon dieses Faktum spricht gegen die Glaubwürdigkeit der Darstellung. Ennodius war sicher bis zu einem gewissen Grad über die Regierungszeit und das Schicksal des Anthemius informiert, und dieses Schicksal hatte - wie noch zu zeigen sein wird - auch Probleme des Kaisers mit seiner Herkunft sowie mit der römischen Kirche eingeschlossen. $\mathrm{Daß}$ Ennodius Jahrzehnte zurückliegende Äußerungen jedoch im Wortlaut gekannt haben sollte, ist - wie so oft im antiken Quellenbestand - auszuschließen. Wir können davon ausgehen, hier nicht den Originalton des Heermeisters Ricimer oder der ligurischen Senatoren, sondern vielmehr denjenigen des Ennodius selbst vor uns zu haben. Die „Vita Epiphanii“ entstand in den 490er Jahren, als unter dem Pontifikat des Papstes Gelasius (492-496) das seit 483 zwischen Rom und Konstantinopel bestehende, sogenannte Akazianische Schisma, die erste große Kirchenspaltung zwischen Ost und West, besondere Virulenz erlangte. Es ist gut vorstellbar, daß die damals im italischen Klerus verbreitete, heftige Ablehnung der oströmischen Positionen Ennodius bei seiner Schilderung die Feder führte. Das Bestreiten der Rechtgläubigkeit und des Römertums des Anthemius, das Ennodius der ligurischen Aristokratie in den Mund legt, paßt in der hier zum Ausdruck gebrachten Schärfe jedenfalls sehr viel besser in seine eigene Zeit als in diejenige des Anthemius. ${ }^{8}$

8 Bereits in der Amtszeit seines Vorgängers Felix III. (483-492) hatte Gelasius als Diakon maßgeblich am Ausbruch des Schismas zwischen Ost und West mitgewirkt. Während seines eigenen Pontifikates verschärfte sich der Ton zwischen Rom und Konstantinopel weiter. Unter dem Schutz des ostgotischen Königs Theoderich wagte erstmalig ein Papst eine offene Konfrontation mit dem Kaiser. Vom Höhepunkt des Schismas, aus dem Jahre 495, datiert ein Brief des Gelasius an die Bischöfe der Provinz Dardania, in dem der Papst explizit auf das Beispiel des Anthemius verweist: Anthemius habe während seiner Herrschaft in Rom Häretiker (sc. Makedonianer, s. unten) unterstützen wollen, sei vom damaligen Papst Hilarus aber gezwungen worden, dies zu unterlassen (Gelas. ep. 26, 11, ed. A. Thiel, Epistolae Romanorum pontificum genuinae et quae ad eos scripta sunt, Bd. 1: A S. Hilaro usque ad S. Hormisdam, Braunsberg 1868). Diese Unterstellung mangelnder Rechtgläubigkeit des Anthemius deckt sich auffallend mit den etwa zeitgleich entstandenen Formulierungen des Ennodius. - Zu Gelasius vgl. R. Schieffer, Gelasius I., Lexikon des Mittelalters 4, 1999, 1197; G. Händler, Die abendländische Kirche im Zeitalter der Völkerwanderung (Kirchengeschichte in Einzeldarstellungen, Bd. I, 5), Berlin 1987, 90f. Wie Kennell, Ennodius (wie Anm. 6), 206-208, betont, zeigt sich im Gesamt- 
Als zweiter Beleg für die Bedeutung der griechischen Herkunft des Anthemius gilt ein Brief des gallischen Senators und späteren Bischofs von Clermont Sidonius Apollinaris aus dem Jahre 469, also aus der Regierungszeit des Anthemius. ${ }^{9}$ Sidonius berichtet in diesem Schreiben über die Anklage und Verurteilung des ehemaligen gallischen Prätorianerpräfekten Arvandus wegen Hochverrats, die kurz zuvor in Rom stattgefunden hatte. Arvandus wurde des crimen laesae maiestatis für schuldig befunden aufgrund eines von ihm verfaßten Schreibens an den Westgotenkönig Eurich, in dem er diesen aufforderte, keinen Frieden mit dem, so wörtlich, graecus imperator zu schlieBen. ${ }^{10}$

Im Unterschied zur „Vita Epiphanii““ ist dieser Beleg zeitgenössisch und stammt von einem Augenzeugen, der sowohl Anthemius als auch Arvandus persönlich kannte und beide vor Ort in Rom erlebt hatte. Der Aussage des Sidonius Apollinaris kommt deshalb ein ungleich höheres Gewicht zu als derjenigen des Ennodius. Das hochverräterische Schreiben wurde während des Arvandus-Prozesses als Beweismittel vorgelegt, und Sidonius zufolge bestritt der Angeklagte zu keiner Zeit dessen Authentizität. Es ist deshalb davon auszugehen, daß Arvandus den Kaiser tatsächlich offen als graecus verunglimpft, ihm also das Römertum abgesprochen hatte.

Nicht statthaft hingegen erscheint es, mit O'Flynn diese Haltung für die weströmische Oberschicht insgesamt zu postulieren. Die Arvandus-Affäre war ein Einzelfall, der juristische Konsequenzen nach sich zog. Gerade die Tatsache, daß es Standeskollegen des ehemaligen Präfekten waren, die in Rom als Ankläger auftraten, belegt die Isolierung des Arvandus. Zwar verfolgten jene gallischen Aristokraten, die sich in den Besitz seines Schreibens gebracht hatten und es den Richtern präsentierten, vorrangig persönliche Motive. Dies ändert jedoch nichts an ihrer offiziell zur Schau gestellten Ablehnung des Schreibens und seiner Inhalte.

werk des Ennodius ein durchaus unterschiedliches Bild des griechischen Ostens, abhängig von Auftraggeber und Adressat des jeweiligen Werkes.

9 Sid. ep. 1, 7. Datierung des Briefes nach Helga Köhler, C. Sollius Apollinaris Sidonius. Briefe. Buch I. Einleitung-Text-Übersetzung-Kommentar, Heidelberg 1995; André Loyen, Sidoine Apollinaire, Bd. 2: Lettres (Livres I-V), Paris 1970.

10 Zum Arvandus-Prozeß: H. C. Teitler, Un-Roman activities in late antique Gaul: the cases of Arvandus and Seronatus, in: J. Drinkwater/H. Elton (Hgg.), Fifth-century Gaul: a crisis of identity?, Cambridge 1992, 309-317; Jill Harries, Sidonius Apollinaris, Rome and the barbarians: a climate of treason?, ebd., 306f.; dies., Sidonius Apollinaris and the Fall of Rome. AD 407-485, Oxford 1994, 92-94; D. Henning, Messius Phoebus Severus und die Chronologie der praefecti Urbi unter Kaiser Anthemius (467-472), ZPE 108, 1995, 154f.; ders., Krise (wie Anm. 3), 165 mit Anm. 255. 


\section{Historischer Kontext ${ }^{11}$}

Konstantinopel hatte im Verlauf des 5. Jahrhunderts wiederholt in die $\mathrm{Ge}$ schicke des Westreiches eingegriffen, verstärkt seit Ausbruch der dortigen Dauerkrise nach 455. Diese Eingriffe waren in Italien nicht immer begrüßt worden und hatten zu mancherlei Spannungen geführt. Der vom oströmischen Kaiser Leo I. unternommene Versuch, mit Anthemius einen eigenen Kandidaten für den westlichen Kaiserthron zu lancieren, stellte zweifellos den Höhepunkt der östlichen Einflußnahme dar. Daß es sich noch dazu um einen Kandidaten mit griechischer Muttersprache und ohne jede Beziehung in den Westen handelte, vereinfachte die Lage wohl kaum.

Auf der anderen Seite waren sich Leo und Anthemius dieser Problematik bewußt. Von Anfang an trafen sie Maßnahmen, um die Legitimität des Thronkandidaten zu unterstreichen, sein „Römertum“ hervorzuheben und seine Akzeptanz durch die westlichen Eliten zu befördern. Seit 466 verhandelte Leo mit den politisch relevanten Kräften des Westreiches, d. h. dem Senat und vor allem dem Heermeister Ricimer als dem eigentlichen Machthaber vor Ort, um den Boden für Anthemius zu bereiten. Anschließend wurde dieser noch im Osten zum Caesar erhoben, so wie einst Valentinian III., der letzte Kaiser, der von Konstantinopel aus nach Rom entsandt worden war. Die Parallele war durchaus beabsichtigt: In Italien eingetroffen, ließ sich Anthemius im Frühjahr 467 auf dem Landgut ad duas lauros zum Kaiser erheben, an jener Stelle also, an dem die weströmische Dauerkrise zwölf Jahre zuvor mit der Ermordung Valentinians III. ihren Anfang genommen hatte. Der neue Kaiser stellte sich damit gezielt in die Nachfolge des letzten Vertreters der theodosianischen Dynastie, die noch einmal beide Hälften des Imperium zusammengeführt hatte.

Die Idee der Reichseinheit, die er auf diese Weise beschwor, zog sich als roter Faden ebenso durch den Panegyrikus, den Sidonius Apollinaris am 1. Januar 468 anläßlich der Konsulatsübernahme des neuen Herrschers in Rom vortrug. Darüber hinaus versuchte Anthemius, sich gezielt in altrömische Traditionen zu stellen: Er residierte in Rom statt in Ravenna und ließ hier Münzen mit „klassischen“ Legenden wie SALVS REI PVBLICAE oder GLORIA REI PVBLICAE prägen. Wie zuletzt Valentinian III. führte der Kaiser Reparaturarbeiten am Kolosseum durch, ferner an Thermen und Aquädukten der Stadt Rom. Die Stellung des Senats erfuhr durch die Über-

11 Vgl. Henning, Krise (wie Anm. 3), passim. 
tragung des oben genannten Arvandus-Prozesses an ein senatorisches Standesgericht eine besondere Aufwertung.

Jedoch unterliefen Anthemius während seiner Regierungszeit auch Fehler, die durchaus in Zusammenhang mit seiner Herkunft standen. Der neue Kaiser traf in Italien mit einem umfangreichen oströmischen comitatus ein, dem zahlreiche Griechen und nicht wenige Heiden angehörten. Ein Heide, der in Alexandreia lebende Messius Phoebus Severus, wurde für 470 zum Konsul erhoben und avancierte anschließend zum Stadtpräfekten. Vergleichbares hatte die Stadt Rom seit sechzig Jahren nicht mehr erlebt. Ein weiterer bekennender Heide, der Dalmater Marcellinus, erhielt ein Heermeisteramt verliehen. Dem Griechen Philotheus schließlich, einem engen Freund des Anthemius und Anhänger der als häretisch verdammten Makedonianischen Glaubensrichtung, wurde in Rom die Einrichtung neuer Versammlungstäume (conciliabula nova) für "verschiedene Sekten" gestattet. ${ }^{12}$ Diese offen zur Schau gestellte, religiöse Toleranz des Kaisers provozierte heftigen Widerstand seitens der römischen Kirche und ihres Bischofs Hilarus.

Auch im Umgang mit der Senatsaristokratie bewies Anthemius keine glückliche Hand. Knapp 100 Jahre zuvor hatte in einer vergleichbaren Situation der aus Spanien gebürtige Kaiser Theodosius I. (379-395) vor der Aufgabe gestanden, seine Herrschaft im Ostreich durchzusetzen. Wie jüngst Hartmut Leppin hervorhob, war Theodosius - dem Außenseiter - die Gewinnung der Konstantinopolitaner Eliten durch die Verbindung mit einer ihrer „Schlüsselgestalten“, dem Redner Themistios, gelungen. ${ }^{13}$ Anthemius hingegen wählte 467 als seine „Schlüsselgestalt“ in Rom ausgerechnet den Gallier Sidonius Apollinaris, der gegenüber dem stadtrömischen Establishment ebenso eine Außenseiterposition einnahm wie er selbst, ja, den die römischen Senatoren elf Jahre zuvor an der Seite seines Schwiegervaters, des ephemeren Kaisers Avitus, aus der Stadt gejagt hatten. Diesem Sidonius Apollinaris wurde nun die Ehre zuteil, den Panegyrikus auf den Konsulatsantritt des neuen Kaisers halten zu dürfen. Anschließend wurde er zum Stadtpräfekten ernannt.

12 Philotheus: Gelas. Ep. 26, 11 (wie Anm. 8). - Heidentum des Marcellinus: Dam. V. Isid. Epit. Phot. $91+$ F 157-158, ed. C. Zintzen, Damascii vitae Isidori reliquiae, Hildesheim $1967=$ F 69A + D-E, ed. P. Athanassiadi, Damascius. The Philosophical History. Text with translation and notes, Athen - Oxford 1999; Marc. Com. s. a. 468, ed. Th. Mommsen, MGH AA XI, 89f. - Heidentum des Severus: Dam. Epit. Phot. $108=77$ Athanassiadi.

13 H. Leppin, Theodosius der Große - Auf dem Weg zum christlichen Imperium, Darmstadt 2003, 57-63. 
Mit den geschilderten Maßnahmen brüskierte Anthemius einen wichtigen Teil der weströmischen Eliten und konterkarierte zugleich seine Versuche, das eigene „Römertum“ zu beweisen. Ob für diese Fehler sein unterschiedlicher kultureller Hintergrund, mangelnde Vorbereitung oder einfach Unfähigkeit verantwortlich waren, sei dahingestellt. Auf jeden Fall dürfte Anthemius auf diese Weise ursprünglich vorhandene Ressentiments gegen seine griechische Herkunft vollauf bestätigt haben. ${ }^{14}$

Und dennoch: Es existieren keine Hinweise für eine hieraus resultierende, offene Ablehnung des Kaisers oder gar für ein Bestreiten seiner Legitimität. Im Gegenteil: Mit Anthemius war zum ersten Mal seit 455 ein Herrscher auf den weströmischen Thron gelangt, an dessen Erhebung die Entscheidungsträger in Ost und West gleichermaßen mitgewirkt hatten. Seine staatsrechtliche Legitimität war unanfechtbar und wurde in den folgenden Jahren selbst von den Gegnern des Kaisers zu keiner Zeit angezweifelt oder auch nur thematisiert. Zwar riefen die Fehler des Anthemius eine oppositionelle Haltung von Teilen der Senatsaristokratie und der Kirche hervor. Diese Ablehnung schlug aber nicht in offenen Widerstand um, sondern erschöpfte sich in distanziertem Abwarten. Andere Teile der Aristokratie, etwa die einflußreiche gens Decia, vor allem aber die großen Senatorenfamilien Galliens, kooperierten auch weiterhin mit dem Kaiser. Mit einer Regierungszeit von mehr als fünf Jahren zählte Anthemius letztlich zu den erfolgreichsten weströmischen Herrschern dieser Periode.

Ausschlaggebend für den Sturz des Anthemius waren schließlich dieselben Kräfte, die seit 455 das Schicksal aller weströmischen Kaiser bestimmt hatten: die Armee und das hohe Offizierskorps unter der Führung des Ersten Heermeisters. ${ }^{15}$ Im Laufe des 5. Jahrhunderts hatte das Amt des Ersten Präsentalen Heermeisters (magister utriusque militiae et patricius) im Westreich einen gewaltigen Bedeutungszuwachs erfahren, während das Kaisertum immer mehr an Gestaltungsspielraum verlor. Vor allem nach 455, in einer Phase

14 Möglicherweise ist die Personalpolitik des Anthemius als Versuch einer Bündelung von Kräften zu verstehen: Durch Sidonius Apollinaris konnte die gallische Aristokratie für den Kaiser gewonnen werden, durch Marcellinus das seit 454 vom Westreich abgespaltene Dalmatien. Die praktizierte, religiöse Toleranz sollte wohl Altgläubige sowie die verschiedenen christlichen Konfessionen ansprechen. In Italien und der Stadt Rom - und damit im Zentrum der kaiserlichen Macht - dominierten jedoch andere Kräfte das politische Geschehen. Der „katholische“ Klerus und große Teile der senatorischen Aristokratie vor Ort erblickten in diesen Versuchen nur einen Affront. Die Fraktionalisierung der weströmischen Eliten, die Anthemius offenbar überwinden wollte, war bereits viel zu weit fortgeschritten.

15 Henning, Krise (wie Anm. 3), 245-260. 
schwacher, rasch wechselnder Kaiser stellte der Heermeister in wachsendem Maße jene Konstante dar, auf die sich das Beziehungsgeflecht der gesellschaftlichen Eliten ausrichtete. Seit es den Heermeistern gelungen war, die Loyalität der Truppen auf die eigene Person statt auf diejenige des Kaisers zu konzentrieren, war ein Regieren gegen sie nicht länger möglich. Mit der Ermordung Valentinians III. scheiterte schließlich der letzte Versuch des Kaisertums, sich aus dieser Umklammerung zu befreien.

Von 456 bis zu seinem Tode im Jahre 472 bekleidete der aus westgotischsuebischem Adel stammende Ricimer das Amt des Ersten Heermeisters. In diesen sechzehn Jahren stürzte bzw. erhob er insgesamt fünf weströmische Kaiser. Ricimer, nicht die Kaiser, war damit der zentrale Machtfaktor des Westreiches. Er residierte in Mailand, im Hauptquartier der italischen Feldarmee, und betrieb von hier aus eine Politik, an deren erster Stelle nicht das Wohl des Imperium, sondern die Bewahrung der eigenen Position stand. Bis zur Erhebung des Anthemius waren alle Versuche der verschiedenen Kaiser, sich Ricimer gegenüber durchzusetzen, gescheitert.

Diese Umstände waren in Konstantinopel, wo zeitweise eine ähnliche Entwicklung gedroht hatte, wohl bekannt. Der Ostkaiser Leo I. bereitete die Entsendung seines Protegés Anthemius deshalb durch intensive Verhandlungen mit Ricimer vor, in deren Mittelpunkt die Sicherung der Machtstellung des Heermeisters sowie - als herausragendes Zugeständnis - seine Anbindung an das neue Herrscherhaus durch eine Ehe mit der Anthemius-Tochter Alypia standen. Ricimer gab sich damit anfänglich zufrieden und unterstützte die Thronerhebung des Anthemius.

Schon bald jedoch verschlechterte sich das Verhältnis beider zueinander. Anthemius war in Begleitung einer großen oströmischen Armee nach Italien gekommen, die Nordafrika von den Vandalen zurückgewinnen sollte. Die Unterstützung durch diese Truppen verlieh ihm aber zugleich eine militärische Machtstellung, gegen die sich Ricimers Möglichkeiten eher bescheiden ausnahmen. Parallel dazu beförderte der neue Kaiser etliche Parteigänger in hohe militärische Positionen und erweckte so den Eindruck, Konkurrenz zur bisher einzigartigen Stellung des Ersten Heermeisters schaffen zu wollen. Ricimer, der zum ersten Mal befürchten mußte, ins machtpolitische Abseits zu geraten, reagierte entsprechend negativ auf diese Entwicklung. Erst das Scheitern des Vandalenfeldzuges im Sommer 468 und der anschließende Abzug der oströmischen Truppen aus Italien eröffnete ihm jedoch die Möglichkeit, aktiv gegen Anthemius vorzugehen. Er ließ nun den Zweiten Präsentalen Heermeister, den vom Kaiser ernannten Dalmater Marcellinus, ermorden und durch einen Offizier seines Vertrauens ersetzen. Im Jahre 470 folgte der offene Bruch mit Anthemius. Ricimer zog sich nach Mailand zurück und 
traf Vorbereitungen für ein militärisches Vorgehen gegen den Kaiser. Nach anfänglichen Verhandlungsversuchen, in deren Rahmen auch die bei Ennodius geschilderte Mission des Bischofs Epiphanius von Pavia zu verstehen ist, eskalierte die Situation im Herbst 471 schließlich zum offenen Bürgerkrieg. Ricimer marschierte auf Rom, schloß Anthemius dort ein und erhob mit Anicius Olybrius einen Gegenkaiser seiner Wahl. Nach neunmonatiger Belagerung fiel die Hauptstadt im Juli 472 schließlich in Ricimers Hand. Anthemius fand dabei den Tod.

Halten wir fest: Als primäre Ursache für das Scheitern des Anthemius ist seine Konfrontation mit dem mächtigen Ersten Heermeister des Westreiches anzusehen. In dieser Hinsicht ist kein Unterschied zwischen seiner Regierungszeit und derjenigen seiner unmittelbaren Vorgänger bzw. Nachfolger in Italien auszumachen. Die griechische Herkunft des Anthemius besaß keinen erkennbaren Einfluß auf die Ereignisse, seine Unterstützung durch Konstantinopel nur insofern, als sie den Ausbruch der Konfrontation deutlich verzögerte.

\section{Zusammenfassung}

Aus den Schriftquellen läßt sich für eine gezielte Verunglimpfung des Anthemius aufgrund seiner griechischen Herkunft als Nicht-Römer nur ein einziges zeitgenössisches Beispiel, nämlich der bei Sidonius Apollinaris überlieferte Fall des Arvandus, finden. Dieses Beispiel aber ist nicht verallgemeinerungsfähig. Ihm gegenüber stehen zahlreiche Belege für die Ablehnung einer solchen Sichtweise durch die senatorische Aristokratie. Die Schilderung des Ennodius dagegen dürfte zwar im Großen und Ganzen auf verläßlichen Informationen beruhen, ist jedoch in ihren Details - und vor allem in der Gegenüberstellung von graecus und catbolicus et Romanus, unter dem Eindruck aktuellen Zeitg eschehens, ex eventu, geformt.

Aus dem historischen Kontext der Jahre um 467 geht hervor, daß Leo und Anthemius selbst die östliche Herkunft des Thronanwärters als Problem bei der Durchsetzung seiner Herrschaft im Westen begriffen. Entsprechende Ressentiments könnten also bei Teilen der westlichen Eliten durchaus vorhanden gewesen sein. Obwohl Anthemius diese Ressentiments durch ungeschickte Maßnahmen sogar noch schürte, scheinen sie auf sein weiteres Schicksal aber keinen erkennbaren Einfluß gewonnen zu haben. Die eingangs formulierte, zugespitzte Frage, ob die bloße griechische Herkunft des Anthemius für seinen Sturz verantwortlich war, kann deshalb klar verneint werden. 
Im Gegenteil: Man kann sogar postulieren, daß es gerade diese Herkunft war, die Anthemius eine vergleichsweise lange Regierungszeit von über fünf Jahren ermöglichte. Die uneingeschränkte Unterstützung des Kaisers durch seinen oströmischen Kollegen nämlich versah ihn mit einer herausragenden Legitimität und anfänglich auch mit umfangreichen Machtmitteln, die in dieser Form kein anderer Westkaiser der Periode aufzuweisen hatte. Möglicherweise war es eben diese unanfechtbare Legitimität des Anthemius, die seine Gegner dazu zwang, andere Angriffspunkte gegen den Kaiser zu suchen, und letztlich seine griechische Herkunft ins Felde zu führen. Entscheidend für seinen Sturz wurde dieser propagandistische Versuch jedoch nicht.

Die tiefe Kluft zwischen den gesellschaftlichen Eliten des alten und des neuen Rom, die John O'Flynn bereits im 5. Jahrhundert für gegeben hält, entstand in einem langsamen, fast schleichenden Prozeß, der die gesamte Spätantike und das Frühe Mittelalter einschloß. Sie wurde anfänglich kaum wahrgenommen, später noch lange Zeit hindurch von einem immer wieder aufscheinenden Gefühl der Zusammengehörigkeit überbrückt, das tatsächliche Entfremdung als bloße Meinungsverschiedenheit interpretierte. In der Agonie des Weströmischen Reiches nach 455 war dieser Proze $\beta$ bereits angelaufen, jedoch weder zu einem Abschluß gelangt noch in seiner zukünftigen Tragweite für die Zeitgenossen überhaupt erkennbar. Kennzeichnend für diese Periode war vielmehr eine Regionalisierung der Oberschicht, in deren Folge beispielsweise der stadtrömischen Aristokratie ihre gallischen Standesgenossen fremder erschienen als die oströmischen. $\mathrm{Da} \beta$ der Westen eines Tages diese gerade erst beginnende, innere Fragmentierung wieder überwinden, mehr oder weniger einheitlich dem Osten gegenübertreten und ihm gar das Römertum absprechen würde, war zur Zeit des Procopius Anthemius gänzlich unvorstellbar. Die Kontinuitätslinie, die O'Flynn von dieser Zeit bis zum „Zwei-Kaiser-Problem“ des Mittelalters zieht, ähnelte - wenn überhaupt - weit mehr einer Zick-Zack-Linie als einer Geraden. 


\title{
Zu den Anfängen der Kirchenpolitik Justinians*
}

\author{
Hartmut Leppin
}

Zoras ließ sich nicht alles bieten: Mehrere Jahre hatte der Miaphysit als Stylit in der Region um Amida verbracht, da erschienen - es muß Anfang der dreiBiger Jahre des 6 . Jahrhunderts gewesen $\operatorname{sein}^{1}$ - Anhänger des Konzils von Chalkedon unter seiner Säule und zwangen ihn, von dort herabzusteigen, so berichtet sein Hagiograph, Johannes von Ephesos ${ }^{2}$. Zornentbrannt faßte Zoras daraufhin den Entschluß, zum Kaiser zu gehen, um ihn über den wahren Glauben zu unterrichten; zehn Schüler begleiteten ihn.

Verhindern konnte man Zoras' Marsch auf Konstantinopel offenbar nicht, doch Briefe gingen an die Hauptstadt, um das Eintreffen eines Störenfrieds anzukündigen. Was war zu tun? Sollte man die kleine Asketentruppe einfach zurückschicken? Sollte der Kaiser sie ignorieren? Schließlich hatte Justinian mehr als genug zu tun: Die Verhältnisse an der Ostgrenze erforderten seine ständige Aufmerksamkeit, die Arbeiten an seinen Gesetzessammlungen waren im Gange, im Vandalenreich zeichneten sich vielversprechende Veränderungen ab. Doch der Kaiser verhielt sich ganz anders, als man erwarten würde: Er bereitete den Empfang des Heiligen Mannes gründlich vor,

* Für Hilfe danke ich insbes. M. Keßler (Frankfurt/Main), A. Luther (Berlin) und M. Meier (Tübingen).

1 Vgl. dazu W. H. C. Frend, The Monks and the Survival of the East Roman Empire in the Fifth Century, P\&P 54, 1972, 3-24, hier: 20f. J. A. S. Evans, The Age of Justinian. The Circumstances of Imperial Power, London/New York 1996, 111 bringt die Ankunft des Zoras in Konstantinopel ohne Begründung mit der Ankunft des Severus dort 534/5 in Zusammenhang; S. Ashbrook Harvey, Asceticism and Society in Crisis. John of Ephesus and The Lives of the Eastern Saints, Berkeley - Los Angeles - London 1990, 84 denkt an 535.

2 Hg. und übers. von E. W. Brooks, PO 17-19, Paris 1923-1925. Beat. Or. 2 ist die Vita des Zoras. Ein vergleichbarer Fall ist Berenicianus, s. Ps. Zach. Rhet. 8, 5. Zu Zoras vor allem Ashbrook Harvey, John of Ephesus (wie Anm. 1), $44 \mathrm{f}$. 
denn er verpflichtete Senatoren zum Kommen und versammelte zahlreiche Bischöfe. ${ }^{3}$

Als der Asket vor dem Kaiser erschien, legte der Herrscher ihm, wie ausdrücklich gesagt wird, in versöhnlicher Weise seine theologischen Auffassungen dar. ${ }^{4}$ Was ein rechter syrischer Mönch ist, läßt sich indes von freundlichen kaiserlichen Worten nicht einwickeln. Er kümmert sich auch nicht um die Übrigen, sondern er spricht direkt den Kaiser an. Das tat auch Zoras, in keiner Weise von der Kulisse eingeschüchtert. Er trat also nicht dem Kaiser als einem Repräsentanten von etwas Größerem gegenüber, sondern - in der Manier eines alttestamentarischen Propheten - dem Herrscher als einem einzelnen. ${ }^{5}$ Dabei machte er ihn in grotesk überzogener Weise für die Verfolgung der Kirche Gottes, für das Blutvergießen und für das Konzil von Chalkedon verantwortlich.

Der Kaiser jedoch wagte es nicht, ihn zu schlagen, sondern erklärte mit geballter Faust, man dürfe Chalkedon nicht schmähen, und verlangte von dem Mönch ein Wunder, um seine Behauptungen zu beweisen. Doch Zoras schmetterte ihm entgegen, daß der wahrhaft Gläubige nicht nach Zeichen frage, daß Justinian aber am eigenen Leib ein Zeichen erleben werde. Unter diesen Worten verließ er den Kaiser - offenbar ungehindert. Justinian wurde am nächsten Tag am Haupt getroffen und verlor den Verstand, vor allem aber bildete sich eine entstellende Schwellung am Kopf, so daß Theodora ihn im Palast verbergen mußte. ${ }^{6}$ Erst das Gebet des Zoras vermochte den Kaiser von dem Leid zu erlösen, der zum Dank den Anhängern des Asketen Ver-

3 Ehrenvoller war indes der Empfang des chalkedonischen Sabas, dem Wagen und Bischöfe entgegengesandt wurden, s. Cyr. Scyth. V. Sabae 71.

$4 \mathrm{Da}$ dies versöhnlich geschehen sei, glaubt nicht jeder: Das entsprechende Wort in der

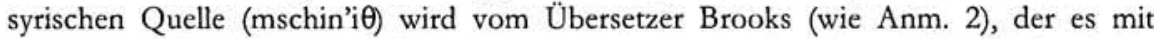
"gently " wiedergibt, angezweifelt: „There is perhaps some error here. If it is right, the intention must be to charge the Chalcedonians with lukewarmness." (23 Anm. 1).

5 Johannes bezieht sich auf 1 . Reg. 22, 31. Das Zitat paßt nach modernen Kriterien nicht ganz, denn es handelt sich um das Gebot des syrischen Königs an den Obersten der Streitwagen, der nur gegen den König Israels, Ahab, kämpfen soll. Wie weit die Szene stilisiert ist, zeigt sich schon daran, daß Zoras für das Griechische eigentlich eines Dolmetschers bedurfte (s. Joh. Eph. Beat. Or. 44 [PO 18, 663]), ein direkter Schlagabtausch zwischen Kaiser und Mönch also nicht möglich war.

6 Möglicherweise wird diese Nachricht von Prokop bestätigt: H. A. 12, 23, wo lediglich von einer gewaltigen Schwellung die Rede ist, aber nicht von Zoras. Ashbrook Harvey, John of Ephesus (wie Anm. 1), 180 Anm. 171 möchte die eingehender erzählte Episode Proc. Aed. 1, 6, 5 darauf beziehen. Doch ist das Krankheitsbild, das in den "Aedificia“ blaß bleibt, in den "Anekdota“ dem näher, was bei Johannes von Ephesos geschildert wird. 
sammlungsfreiheit gewährte. Zoras selbst, der in der nächsten Zeit auf der anderen Seite des Bosporos als religiöse Autorität residierte, blieb im Kontakt mit dem Kaiser. ${ }^{7}$

Eine Anekdote wie die eben referierte Auseinandersetzung zwischen Kaiser und Heiligem Mann zeigt Justinian in einer vermeintlich ungewohnten Rolle. ${ }^{8}$ Der Kaiser, der im neuzeitlichen Geschichtsbewußtsein wie kein anderer den Machtanspruch des spätantiken Kaisertums verkörpert, nimmt es hin, daß ein schwacher Mönch ihn tadelt - ein Mönch, der sich überdies seinen dogmatischen Vorstellungen verweigert. Gerade dies scheint mir aber typisch für die Kirchenpolitik nicht nur in den frühen Jahren Justinians zu sein, zu der ich einige Überlegungen anstellen möchte. Justinians Position war, so wird im allgemeinen behauptet, zu Beginn seiner Regierung, wie es sein Onkel vorgegeben habe, von einer energischen Verfolgungspolitik bestimmt, die in den dreißiger Jahren kurzzeitigen Aussöhnungsversuchen mit den Miaphysiten gewichen sei, doch um 536 habe der Kaiser wieder eine hart chalkedonische Linie verfolgt. ${ }^{9}$ Mit einem von Eduard Schwartz eingeführten Bild spricht man gerne von einem Zickzackkurs ${ }^{10}$.

7 Beat. Or. 2, PO 17, 25 f. Daß ein Mönch einer anderen Glaubensrichtung vom Kaiser mit Freundlichkeit empfangen werden konnte, zeigt auch die Begegnung zwischen Anastasius und dem Chalkedonier Sabas, s. Cyr. Scyth. V. Sab. 51, wo der Kaiser als

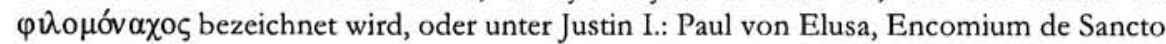
Theognio 21, hg. von S. Vailhé, AB 10, 1891, 78-113.

8 Vgl. aber zur Zugänglichkeit des Kaisers Proc. H. A. 13, 1-3; 15, 12.

9 Grundlegend nach wie vor E. Stein, Histoire du Bas-Empire, Paris/Brüssel 1949, Bd. 2, 369ff.; vgl. ferner R. Haacke, Die kaiserliche Politik in den Auseinandersetzungen um Chalkedon (451-553), in: A. Grillmeier/H. Bacht (Hgg.), Das Konzil von Chalkedon. Geschichte und Gegenwart, Bd. 2: Entscheidung um Chalkedon, Würzburg 31974, 95177, hier: 152 ff.; J. Meyendorff, Imperial Unity and Christian Divisions, Crestwood 1989, $207 \mathrm{ff}$; immer noch nützlich H. S. Alivisatos, Die kirchliche Gesetzgebung des Kaisers Justinian I. (Neue Studien zur Geschichte der Theologie und der Kirche 17), Berlin 1913; W. H. C. Frend, The Rise of the Monophysite Movement. Chapters in the History of the Church in the Fifth and Sixth Centuries, Cambridge 1972, 255ff.; vgl. O. Mazal, Justinian I. und seine Zeit. Geschichte und Kultur des Byzantinischen Reiches im 6. Jahrhundert, Köln u. a. 2001, $203 \mathrm{ff}$.

10 E. Schwartz, Zur Kirchenpolitik Justinians, SBAW 1940, Nr. 2, 32-81, hier: 32; auch in: ders., Gesammelte Schriften, Bd. 4, Berlin 1960, 276-326, hier: 276; grundlegend auch ders., Kyrillos von Skythopolis (Texte und Untersuchungen 49, 2), Leipzig 1939; dort ist 395 von der „unsicher schwankenden Passivität des Kaisers“ die Rede. S. zum Bild des Zickzackkurses die Belegsammlung bei M. Meier, Das andere Zeitalter Justinians. Kontingenzerfahrung und Kontingenzbewältigung im 6. Jahrhundert $\mathrm{n}$. Chr. (Hypomnemata. Untersuchungen zur Antike und zu ihrem Nachleben 147), Göttingen 2003, 274 Anm. 215 , der sich seinerseits davon distanziert. 
Einen anderen Ansatz hat jüngst indes Karl-Heinz Uthemann verfolgt, indem er in überzeugender Weise die Kohärenz der theologischen Position Justinians während der ersten Jahre herausgearbeitet hat. ${ }^{11}$ In diese Richtung möchte ich weiterdenken, ${ }^{12}$ indem ich aufzuzeigen versuche, daß die Politik Justinians während der ersten Jahren durchaus konsistent war, ${ }^{13}$ und zwar insofern, als er zum einen nach einer gemeinsamen Linie von Miaphysiten und Chalkedoniern suchte, zum anderen den Habitus eines demütigen Herrschers einnahm, der sich von Glaubensautoritäten belehren lassen wollte; man könnte in diesem Sinne von einer reaktiven Grundhaltung sprechen.

Noch als Caesar formulierte Justinian in einem Brief an den Papst Hormisdas eine theopaschistische Lehre, ${ }^{14}$ also die Lehre, daß einer aus der Trinität gelitten habe. Diese Lehre wird mit den Aktivitäten skythischer Mönche in Verbindung gebracht, die sich um eine anti-nestorianische Interpretation der Beschlüsse von Chalkedon bemühten und insofern den Miaphysiten entgegenkamen; indes wurden die Lehren dieser Mönche vom Papst abgelehnt. Bereits hier zeigt sich somit Justinians Neigung zum Ausgleich mit den Mi-

11 K. H. Uthemann, Kaiser Justinian als Kirchenpolitiker und Theologe, Augustinianum 39, 1999, 5-83, hier: 46f. Der Aufsatz bietet eine sorgsam aufbereitete Darstellung der Stationen von Justinians Kirchenpolitik mit ausführlichen Literaturhinweisen; weniger nuanciert ist P. T. Gray, The Defense of Chalcedon in the East (451 - 553), Leiden u. a. 1979, 53ff.; seine Position ist zusammengefaßt in „The Legacy of Chalcedon. Christological Problems and their Significance", in: M. Maas ( $\mathrm{Hg}$.), The Cambridge Companion to the Age of Justinian, Cambridge 2005, 215-238. Gray schlägt vor, von Anti-Chalkedoniern zu sprechen; das aber würde auch Dyophysiten bzw. Nestorianer ei nschließen.

12 In manchem ergeben sich Berührungspunkte zu K. L. Noethlichs, Iustinianus (Kaiser), RAC 19, 1999, 668-763, hier: 689. Meyendorff, Imperial Unity (wie Anm. 9), insbes. 246, wendet sich zwar auch gegen das Bild vom „Zickzack“, indem er die konsequent chalkedonische Orientierung Justinians herauszuheben versucht, beurteilt aber sein Verhältnis zu den Miaphysiten ganz anders, als es hier getan wird.

13 Üblicherweise sieht man 531 einen Bruch oder jedenfalls Wandel, s. z. B. Schwartz, Kirchenpolitik Justinians (wie Anm. 10), 39-284; J. Speigl, Die Synode von 536 in Konstantinopel, OS 43, 1994, 105-153, hier: 108f., der 108 von einer „Wiedervereinigungspolitik seit 531“ spricht. Meier, Zeitalter Justinians (wie Anm. 10), 278, der in den 30er Jahren lediglich eine „kurzfristige Gesprächsbereitschaft" erkennt oder 288 eine dauerhaft antimonophysitische Politik erkennt.

$14 \mathrm{Zu}$ ihnen A. Grillmeier, Jesus der Christus im Glauben der Kirche, Bd. II 2: Die Kirchen in Konstantinopel im 6. Jahrhundert, Freiburg u. a. 22004, 338ff.; J. Speigl, Formula Iustiniani. Kircheneinigung mit kaiserlichen Glaubensbekenntnissen (Codex Iustinianus I 1, 5-8), OS 44, 1995, 105-134, hier: 106ff. Meier, Zeitalter Justinians (wie Anm. 10), $215 \mathrm{ff}$ betrachtet die Formel als ungeeignet für eine Kompromißfindung, urteilt aber dabei möglicherweise zu sehr ex eventu, da sie in der Tat die Einheit nicht herbeiführte. Doch das war in den ersten Regierungsjahren nicht absehbar. 
aphysiten. Vasiliev erkennt sogar einen mildernden Einfluß Justinians auf die Politik Justins, sieht aber in einem Häretikergesetz, das offenbar 527 während der gemeinsamen Regierungszeit Justins und Justinians entstand, einen Ausdruck der Verschärfung. Doch fällt bei diesem Gesetz auf, daß es die Miaphysiten nicht ausdrücklich nennt. ${ }^{15}$

Und das scheint ein spezifisch justinianisches Element zu sein: Bestimmungen zu religiösen Fragen ergehen während der ersten Regierungsjahre Justinians in dichter Folge. ${ }^{16}$ Als er 527 die Alleinherrschaft antrat, tat er etwas, was an Theodosius den Großen gemahnte: Er veröffentlichte bald ein Glaubensbekenn tnis. ${ }^{17}$ Zwar klingt darin auch die theopaschistische Formel an, ${ }^{18}$ doch nicht in der klassischen, im Streit gewissermaßen verbrauchten Version. Auch sonst sind die Formulierungen des Textes dergestalt, daß eine eindeutige Festlegung auf bestimmte, besonders umstrittene Schlagworte vermieden wird; vor allem das Wort $\varphi v ́ \sigma 1 \zeta$, das in der Debatte so wichtig war, wird vermieden. ${ }^{19}$ Als essentiell definiert Justinian in der Praefatio seines Gesetzes gegen die Häretiker das Homoousios und den Glauben, daß Maria Theotokos, die Gottesgebärerin sei, worin ein eindeutig anti-nestorianisches Bekenntnis liegt. Anders als Theodosius benennt Justinian auch keine Normalbischöfe, andererseits aber explizit bestimmte häretische Gruppen bzw.

15 CJ 1, 5, 12; 1, 5, 12, 17 trifft eine Sonderregelung für arianische Goten. A. A. Vasiliev, Justin the First. An Introduction to the Epoch of Justinian the Great (DOP Studies 1), Cambridge/Mass. 1950, 132ff, insbes. $221 \mathrm{ff}$.

16 Vgl. M. Maas, Roman History and Christian Ideology in Justinianic Reform Legislation, DOP 40, 1986, 17-31, hier: 25; Speigl, OS 43, 1994 (wie Anm. 13), 111ff.; Meier, Zeitalter Justinians (wie Anm. 10), 200.

17 CJ 1, 1, 5; die Formulierungen sind weitaus vager als im Henotikon Zenos (Evagr. H. E. 3, 14; anders Haacke, Chalkedon [wie Anm. 9], 154). Die Datierung - gewöhnlich wird 527 angegeben - ist nicht ganz gesichert; als Teil des „Codex Iustinianus“ muß der Text aus den Anfängen der Regierung stammen; CJ 1, 1, 6, 3 verweist offenbar darauf zurück. Ohne Begründung datiert Mazal, Justinian (wie Anm. 9), 205 den Text auf 533 und meint daher, daß Justinian zu Beginn seiner Regierungszeit anti-miaphysitisch gesonnen gewesen sei. Zu der theologischen Offenheit vgl. Noethlichs, Iustinianus (wie Anm. 12), 689, der die Nähe zu den Debatten des Konzils von Ephesos hervorhebt; zu Theodosius I. vgl. H. Leppin, Theodosius der Große - Auf dem Weg zum christlichen Imperium, Darmstadt 2003, 68ff.

$18 \int 1$. Anders akzentuiert bei Grillmeier, Jesus der Christus (wie Anm. 14), 355. Möglicherweise ist auf diese Passage die Äußerung Vict. Tun. s. a. 529 (MGH AA XI, 197)zu beziehen, der seiner Grundhaltung gemäß hier Theodora am Werke und Verfolgungsmaßnahmen eingeleitet sieht.

19 Das muß auch Speigl, OS 43, 1994 (wie Anm. 13), 113 anerkennen, obwohl er bemüht ist, dem Text ein klares Bekenntnis Justinians zu entlocken. 
ihre Anführer. Darunter findet sich zwar mit Eutyches ( $(3)$ jemand, den Chalkedonier gerne den Miaphysiten zuschlugen - aber dieser Lehrer wurde gewöhnlich auch von den Miaphysiten abgelehnt. Anders als in einem späterem, 541 vorgelegten Häretikerkatalog, ${ }^{20}$ der die Anhänger des Severus anführt, werden keine Miaphysiten ausdrücklich genannt. Damit war, und darin setze ich mich von der üblichen Interpretation ab, die scharf antimiaphysitische Politik Justins ${ }^{21}$ zwar nicht formell zurückgenommen, faktisch aber aufgehoben. Justinian signalisierte wohl, ohne seinen Onkel zu desavouieren, ein Ende der harten Repressionspolitik gegenüber den Miaphysiten.

Dieser Öffnung gegenüber den Miaphysiten korrespondierte eine Verschärfung der Politik gegenüber den eigentlichen Häretikern im Sinne Justinians, aber auch Manichäern - gegen die er besonders streng vorging -, Juden und Samaritanern, die er zunehmend unter diesem Begriff faßte. Ihnen wurden wesentliche bürgerliche Rechte genommen und die Religionsausübung untersagt. ${ }^{22}$ Was in diesen Edikten angelegt ist, prägte die Politik Justinians für die nächsten Jahre: Dogmatische Äußerungen, sofern er sie überhaupt machte, blieben vage, dafür wurden gemeinsame Gegner von Chalkedoniern und Miaphysiten mit ungewöhnlicher Energie bekämpft. Heiden gerieten vor allem 529/30 unter Druck, wobei es Justinian inzwischen nicht mehr allein um die Praktiken des Heidentums, sondern um die Gesinnung der Menschen ging. ${ }^{23}$ Die bekannteste Folge der kaiserlichen Politik bestand darin, daß die Akademie in Athen allmählich ein Ende fand und die Philosophen zunächst in das Persische Reich zogen. ${ }^{24}$ Die Samaritaner wurden ebenfalls hart bedrängt - nicht zuletzt aufgrund der Anklagen eines Mönches; ${ }^{25}$ diese Politik mündete in einen verheerenden Aufstand. Auf der anderen Seite erschienen

20 Nov. Iust. 109 pr.; vgl. 115, 3, 14 (542), wo ausdrücklich von den Akephalen, eine verbreitete Bezeichnung für die Miaphysiten, die Rede ist, und zwar in Ergänzung von CJ 1, 5,19 von 529.

21 Vgl. Stein, Histoire II (wie Anm. 9), 230ff.; Haacke, Chalkedon (wie Anm. 9), $141 \mathrm{ff.}$

22 CJ 1, 5, 12 (dafür, daß es noch in der Zeit der gemeinsamen Herrschaft erlassen worden ist, spricht CJ 1, 5, 18,4); auch die anderen antihäretischen Bestimmungen haben zunächst keinen spezifisch anti-miaphysitischen Akzent, s. CJ 1, 5, 13-22; Nov. Iust. 11, 5; 17,$11 ; 37,5-1$, s. den Überblick bei Alivisatos, Justinian (wie Anm. 9), $32 \mathrm{ff}$.

23 Vgl. dazu Meier, Zeitalter Justinians (wie Anm. 10), 203ff., der zu Recht betont, daß mit diesen Verfolgungen auch politische Zwecke erfüllt werden sollten; vgl. Theoph. a. m. 6022; Mal. 18, 42 Thurn; Proc. H. A. 11, 31 f.

24 Vgl. dazu Al. Cameron, The Last Days of the Academy at Athens, PCPhS n. s. 195, 1969, 7-29; R. Thiel, Simplikios und das Ende der neuplatonischen Schule in Athen (AAWM 1999, Nr. 8), Stuttgart 1999; Meier, Zeitalter Justinians (wie Anm. 10), $207 \mathrm{ff}$.

25 Cyr. Scyth. V. Sab. 71. 
528 zwei Barbarenfürsten in Konstantinopel, die sich und damit ihr Volk zum Christentum bekehren ließen. ${ }^{26}$

Der Kaiser war somit offenkundig bestrebt, die Erwartung, er müsse ein Vorkämpfer des Glaubens sein, zu erfüllen. Darin eiferte er dem Vorbild seines Onkels nach, doch mit einem erkennbar moderateren Kurs gegenüber den Miaphysiten, die er, wenn ich recht habe, nicht mehr als Häretiker bezeichnet sehen wollte.

Für 531 hört man zwar davon, daß die Miaphysiten von Antiocheia und überhaupt im Osten sich bedrängt gefühlt hätten, doch ging dies auf die Initiative eines - in seiner Region durchaus mächtigen - Bischofs zurück, des entschieden anti-miaphysitischen Ephraim. ${ }^{27}$ Unter den Verhältnissen des 6. Jh.s ist nicht zu erwarten, daß die kaiserliche Religionspolitik in allen Reichsteilen unmittelbar wirksam wurde; formell aufgehoben waren die Regelungen Justins ja nicht, und das Häretikergesetz Justinians erlaubt vielfältige Deutungen, so daß Ephraim sich ganz im Recht gefühlt haben kann.

Jedenfalls steuerte Justinian ohne Zweifel in Konstantinopel weiter einen anderen Kurs: Der miaphysitische Historiker Ps.-Zacharias Rhetor berichtet, daß der Kaiser im fünften Jahr seiner Regierung Miaphysiten aus der Verbannung zurückgerufen, somit eine Maßnahme seines Vorgängers rückgängig gemacht habe. ${ }^{28}$ Dies lag in der Konsequenz der bisherigen Politik Justinians und steht in einem engen zeitlichen, bei Zacharias sogar in einem darstellerischen Zusammenhang mit dem Nika-Aufstand. Ob auch ein kausaler $\mathrm{Zu}$ sammenhang bestand, muß offen bleiben. Immerhin war seit diesem Ereignis der Faktor städtische Bevölkerung, die zu einem großen Teil miaphysitische Tendenzen handgreiflich bekämpft hatte, besser unter Kontrolle - insofern hatte der kaiserliche Handlungsspielraum sich erweitert.

26 Der Heruler Grepes bzw. Gretes (PLRE IIIA, 555) sowie der Hunne Grod (PLRE IIIA, 557 f.); vgl. zum komplexen Zusammenhang zwischen äußerer Politik und Religionspolitik K. L. Noethlichs, Quid possit antiquitas nostris legibus abrogare? Politische Propaganda und praktische Politik bei Justinian I. im Lichte der kaiserzeitlichen Gesetzgebung und der antiken Historiographie, ZAC 4, 2000, 116-132, hier: 126.

27 Mal. 18, 64 Thurn; bei Joh. Eph. Beat. Or. werden verschiedentlich (21 [PO 17, 293f.]; 35 [PO 18, 620f.]; 58 [PO 19, 224]; vgl. 24 [PO 18, 522f.]; 50 [PO 19, 153]) ausdrücklich Kirchenleute, zumal Ephraim von Antiocheia, nicht aber Justinian verantwortlich gemacht. Das läßt sich nicht allein aus der prinzipiell loyalen Haltung des Autors gegenüber dem Kaisertum erklären, da er bisweilen - etwa im Kontext der Vita des Zoras - auch Kritik am Kaiser übt.

28 Zach. Rhet. H. E. 8, 5; vgl. 8, 4; 9, 15; vgl. Joh. Eph. Beat. Or. 35 (PO 18, 619 f.), der von einer Erlaubnis spricht, in das alte Kloster zurückzukehren. 
Möglicherweise gehört der Marsch des Zoras nach Konstantinopel und sein Aufenthalt dort in jenen Kontext, auch wenn Johannes von Ephesos etwas anderes glauben machen will. ${ }^{29}$ Nicht alle Miaphysiten hatten indes bereits so viel Vertrauen zum Kaiser und dem unruhigen Mob von Konstantinopel gefaßt, daß sie sich tatsächlich in die Hauptstadt begaben; Severus von Antiocheia, ihr Exponent, etwa blieb zunächst fern. Immerhin stand denen, die kamen, jetzt ein verläßlicher Treffpunkt zur Verfügung, der kaiserliche Palast, in dem Theodora über die Sicherheit ihrer Glaubensfreunde wachte, ${ }^{30}$ auch später noch, als sie ungleich stärker bedrängt wurden.

Einen weiteren Versuch eines Ausgleichs zwischen den theologischen Richtungen bedeutet es, daß Justinian einige der Miaphysiten, abgesetzte Bischofe aus dem Antiochener Patriarchat sowie ausgewählte Chalkedonier für 532 zu einem ungefähr paritätisch besetzten Religionsgespräch nach Konstantinopel einlud. ${ }^{31}$ Die Quellenlage für dieses Ereignis ist einzigartig: Wir haben einen chalkedonisch orientierten Bericht des Innocentius von Maroneia, eines der Teilnehmer, in Briefform ${ }^{32}$ sowie einen miaphysitisch ausgerichteten eines unbekannten Autors, den Sebastian Brock vor einiger Zeit entdeckt hat und der durch einen zweiten, kürzeren, der schon länger bekannt war, ergänzt wird. ${ }^{33}$

29 Vgl. etwa Schwartz, Kyrillos (wie Anm. 10), 392f.; Speigl, OS 43, 1994 (wie Anm. 13), 109.

30 Eine plastische Schilderung bei Joh. Eph. Beat. Or., 47 (PO 18, 676-684); vgl. Ashbrook Harvey, John of Ephesus (wie Anm. 1), 86ff. Ihren Einfluß sollte man indes keinesfalls überschätzen, zumal sie das eindeutige Bekenntnis zu Chalkedon nicht verhindern konnte, s. H. Leppin, Theodora und Iustinian, in: H. Temporini-Vitzthum ( $\mathrm{Hg}$.), Die Kaiserinnen Roms. Von Livia bis Theodora, München 2002, 437-481; H. Leppin, Kaiserliche Kohabitation: Von der Normalität Theodoras, in: C. Kunst/U. Riemer (Hgg.), Grenzen der Macht. Zur Rolle der römischen Kaiserfrauen, Stuttgart 2000, 75-85.

31 S. P. Brock, The Orthodox-Oriental Conversation of 532, Apostolos Barnabas 41, 1980, 219-228; auch in: ders., Syriac Perspectives on Late Antiquity, Aldershot u. a. 1984, Nr. XI; J. Speigl, Das Religionsgespräch mit den severianischen Bischöfen in Konstantinopel im Jahre 532, AHC 16, 1984, 264-285; Grillmeier, Jesus der Christus (wie Anm. 14), 244ff.; $361 \mathrm{ff}$; Uthemann, Augustinianum 39, 1999 (wie Anm. 11), 27ff. Zum Datum Stein, Histoire II (wie Anm. 9), 378. - Frend, Monophysite Movement (wie Anm. 9), 260ff. vermutet, daß der Wunsch der Miaphysiten, eine Kirchenorganisation durch eigene Weihungen $u$. ä. aufzubauen, der Anlaß für Justinians Maßnahme war.

32 E. Schwartz (Hg.), Acta conciliorum oecumenicorum, 4 Bde., Berlin - Leipzig 1914 1984, im folgenden zitiert als ACO mit Angabe des Bandes und des Faszikels, hier: ACO IV 2, 169-184. Es handelt sich um die lateinische Übersetzung eines griechischen Briefes.

33 S. Brock, The Conversations with the Syrian Orthodox under Justinian, OCP 47, 1981, 87-121; auch in: ders., Studies in Syriac Christianity. History, Literature and Christianity, 
Aus den Gemeinsamkeiten der Texte läßt sich der Verlauf der Verhandlungen im Groben rekonstruieren. ${ }^{34}$ Die Debatten, denen Gespräche des Kaisers mit beiden Gruppen vorausgingen, erstreckten sich über drei Tage. Sie wurden nicht vom Kaiser, der dies ausdrücklich ablehnte (I, $\ 5$ ), geleitet, ${ }^{35}$ sondern von Strategius, einem Angehörigen des höchst einflußreichen Geschlechts der Apionen, der den magister officiorum vertrat und es später zum comes sacrarum largitionum bringen sollte. ${ }^{36}$ Am dritten Tag nahm der Kaiser, der sich an den Abenden immer hatte über den Stand der Gespräche informieren lassen, ${ }^{37}$ das Gespräch auf, in der Hoffnung, eine kompromißbereite Gruppe vorzufinden, doch blieb die Distanz zwischen den Diskutanten erhalten.

Es versteht sich, daß die Verfasser der jeweiligen Texte darüber unterschiedlicher Ansicht sind, welche der beiden Gruppen die stärkeren Argumente vorgetragen habe. Ebenso wenig überrascht es, wenn nur Innocentius zu berichten weiß, daß mit Philoxenus von Doliche sich ein Miaphysit bei diesem Anlaß zum Chalkedonismus bekehrt habe. Wichtig sind für meine Fragestellung die Unterschiede in der Darstellung der Rolle des Strategius und des Kaisers.

Innocentius, der Chalkedonier, berichtet über eine an die Orientales, die Miaphysiten, gerichtete Einleitungsrede des Strategius. Darin heißt es, der Kaiser habe das Gespräch einberufen non ex auctoritate principali, sed paterna et sacerdotali compunctione (I, $\mathbb{8}$ ), nicht aufgrund seiner kaiserlichen Autorität, sondern aufgrund seiner väterlichen und priesterlichen Gewissensnot. Der Kaiser will also hier nicht als Herrscher in Erscheinung treten. Allerdings ist sein Anspruch, aus väterlicher und priesterlicher Gewissensnot - gemeint ist natürlich die Gewissensnot über die Lage der Kirche - ein Religionsgespräch einzuberufen, in gewisser Weise noch höher, da der Kaiser hier nicht zwischen der weltlichen und der kirchlichen Sphäre trennt, sondern sich mit den

Aldershot u. a. 1992, Nr. XIII) sowie PO 13, 192-196, der geraffte Text, bei Brock a.a.O. 113-117. Mit Brock be nenne ich die längere Version als $\mathrm{H}$, die kürzere als $\mathrm{S}$, den Brief des Innocentius als I.

34 Vgl. die Übersicht bei Brock, OCP 47, 1981 (wie Anm. 33), 118 f.

35 Nicht einmal dem Wunsch der Miaphysiten, ihr Glaubensbekenntnis vor ihm und hohen Würdenträgern verlesen zu lassen, kommt er nach, sondern erklärt, er werde es lesen, wenn er die Zeit dafür finde $(\mathrm{H}, \mathbb{\$} 1)$ - allerdings sorgt er dafür, daß die Chalkedonier es

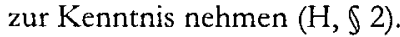

36 PLRE II, 1034-1036.

37 Nach Auskunft die Miaphysiten taten dies allerdings allein die Chalkedonier, s. H, \& 33 f. 
Priestern in eins setzt, ${ }^{38}$ wenn er sich mit dem Adjektiv paternus nicht sogar über sie stellt. Strategius selbst berichtet den Gesprächsteilnehmern von der Bekehrung seines eigenen Vaters zum chalked onischen Glauben - Chalkedon wird ausdrücklich erwähnt - durch die Kaiser ${ }^{39}$ und setzt damit einen deutlichen Akzent, auch wenn er die Beteiligten zu einem friedlichen Gespräch auffordert, ${ }^{40}$ wie es der Kaiser schon im Vorgespräch gegenüber denn Chalkedoniern getan hatte $(\mathrm{I}, \S 4 \mathrm{f}$ ) $)$.

In den miaphysitischen Quellen bleibt diese Rede unerwähnt; bei ihnen erscheint Strategius indessen als jemand, der verschiedentlich in die Debatten gezogen wird, während er zufolge des Eindrucks, den Innocentius vermittelt, nach seiner Einführungsrede gar nicht mehr eingreift. So lehnt er den Wunsch der Miaphysiten ab, ein Protokoll führen zu lassen, mit der Begründung, er sei dazu nicht befugt $(H, \$ 11)$. An anderer Stelle kommt Strategius den Miaphysiten entgegen, indem er ihnen die Verlesung eines für die dogmatischen Debatten wichtigen Briefes gestattet $(\mathrm{H}, \mathbb{1} 19)$.

Ganz verschieden wird der dritte Tag geschildert. Laut Innocentius sucht der Kaiser zunächst das Gespräch mit dem Bischof von Konstantinopel, Epiphanios, und mit den Chalkedoniern, wobei - wie anläßlich der Auseinandersetzung mit Zoras - der Senat zugegen ist, an dessen Seite die chalkedonischen Bischöfe sich niederlassen dürfen. Auch jetzt geht es offenbar darum zu zeigen, daß der Kaiser nicht für sich allein stehe, sondern etwas Größeres repräsentiere. Danach lädt Justinian die übrigen Teilnehmer hinzu, und spricht mit ihnen, wie Innocentius beteuert, bemerkenswert mild $(I, \S 80)$ - obwohl die Sitzverteilung ja schon ein eindeutiges Signal der Zurücksetzung ist. Einmal mehr versucht Justinian, seine theopaschistischen Vorstellungen ins Spiel zu bringen, denen die Chalkedonier unter ausführlichen Qualifizierungen zustimmen (I, $₫ 83-86$ ).

Nach Abschluß dieser Gespräche lädt der Kaiser die Chalkedonier erneut in den Palast, um dort zu berichten, daß er im Michaels-Oratorium ${ }^{41}$ für eine Einigung der Kirche gebetet und so Philoxenus gewonnen habe (I, \87-89).

38 Papst Vigilius erkennt allerdings Justinian auch noch einen sacerdotalis animus zu (Coll. Av. 92,2 ), und dieses Zeugnis ist nicht isoliert, so daß man jener Äußerung kein zu großes Gewicht beimessen sollte.

$39 \mathrm{Zu}$ Apion (2), der sich unter Anastasius als Miaphysit hervorgetan hatte, PLRE II, $111 \mathrm{f}$. Die Hintergründe der Konversion sind nicht klar.

40 Wobei das Gespräch von vornherein nicht ganz symmetrisch ist, weil die Miaphysiten lediglich Fragen an die Chalkedonier stellen sollen.

41 Zu seiner mutmaßlichen Lage im Bereich des Palastes s. R. Janin, La géographie ecclésiastique de l'empire byzantin, Bd. I 3, Paris 1953, 355. 
Fortan habe der Kaiser, so schließt Innocentius, durch seine Güte noch viele Miaphysiten, wenn auch keine Bischöfe bekehrt. Das chalkedonische Schreiben endet also mit der Verheißung, daß das Religionsgespräch Grundlagen für ihre weitere Stärkung geschaffen habe.

Während in der chalkedonischen Version der Abschlußtag zu einer Feier kaiserlicher Milde wird und der Kaiser als weitgehend zurückhaltend in dogmatischen Fragen erscheint, zeigen die Miaphysiten, die den dritten Tag erheblich ausführlicher, allerdings nicht ohne Unterschiede schildern, Justinian stärker in die Auseinandersetzungen verstrickt. Ihre Berichte atmen das Gefühl der Benachteiligung, andererseits zeichnen sie ein lebendiges Bild vom Kaiser bei seinen Bemühungen, einen Kompromiß zu finden. Der Kaiser versucht, eine Brücke zu bauen, indem er erklärt, daß die Miaphysiten eigentlich rechtgläubig seien und sich lediglich in der Abendmahlsfrage störrisch anstellten $(H, \ 36)$. Die Miaphysiten antworten ausweichend. Danach fordert der Kaiser die Miaphysiten auf, sich mit den Bischöfen von Rom, Alexandreia, Antiocheia und Jerusalem in Verbindung zu setzen, um deren Posi-

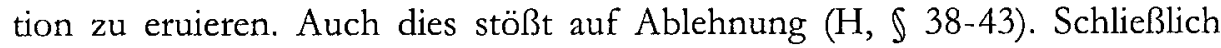
fragt der Kaiser enttäuscht, welches Mittel die Bischöfe denn vorschlagen würden, um einen Kompromiß zwischen den vier Patriarchaten zu erreichen, und erhält keine Antwort ( $\mathrm{H}, \S 40 \mathrm{f}$.). Als der Kaiser das Verhältnis der Miaphysiten zum Patriarchen von Alexandreia zu eruieren versucht, bricht der Text $a b$.

Der geraffte miaphysitische Text berichtet wie $\mathrm{H}$, daß der Kaiser die Miaphysiten dazu zu bringen sucht, sich mit den vier Patriarchaten in Verbindung zu setzen $(S, \mathbb{S}$ ), ebenso wird erwähnt, daß der Kaiser um einen Vorschlag bittet, den Frieden in den Kirchen zu erreichen $\left(S, \int 5\right)$. Ansonsten bringt die kürzere Fassung - die möglicherweise dem verlorenen Teil des detaillierten Berichtes entspricht - ganz andere Aspekte. So versucht der Kaiser hier, den Bischöfen die Zusage abzugewinnen, daß sie keine Weihen oder Taufen außerhalb ihres Kreises vornehmen würden; doch diesem Ansinnen entziehen sie sich. ${ }^{42}$ Justinian macht noch einen sehr weitgehenden Kompromißvorschlag, nämlich das Konzil von Chalkedon insofern zu akzeptieren, als es Eutyches verurteilt habe ${ }^{43}$ - womit er zwar im Geist seiner bereits referierten Gesetzgebung weiterdenkt, doch mit dem großen Unterschied, daß jetzt der Begriff „Chalkedon“ auftaucht. Wieder verweigern sich die Bischöfe. Als der Herrscher auf eine persönliche Unterredung mit ihrem

42 S, $₫ 4$; vgl. zum Thema $H, \S 10$.

$43 \mathrm{~S}, \mathbb{9}$. Damit verzichtete er letztlich auf die theologischen Inhalte der Konzilsbeschlüsse, vgl. Grillmeier, Jesus der Christus (wie Anm. 14), 438. 
Oberhaupt Severus drängt, behaupten die Bischöfe, sie würden seinen Aufenthaltsort nicht kennen ( $\left.S, \int 4\right)$. Zwar wird der Ton zeitweise gereizter; der Kaiser droht mit Verbannung, doch geht das Motiv in der weiteren Debatte unter. Wie die Diskutanten auseinandergehen, wird nicht mehr berichtet.

Gemeinsam ist beiden miaphysitischen Texten, daß die Miaphysiten sich auf Argumentationen nicht einlassen, sondern den kaiserlichen Wünschen mit formalen Einwänden - sie wüßten bestimmte Dinge nicht, sie könnten anderes nicht entscheiden etc. - entgegentreten. Zwar wird deutlich, daß die Miaphysiten sich benachteiligt fühlen, doch ein hartnäckiges Bemühen des Kaisers um einen Kompromiß wird ebenfalls sichtbar.

Es ist schwer zu entscheiden, welcher Quelle im Einzelnen zu folgen ist ich neige insgesamt mehr den allen Anschein nach weniger stilisierten, die eigenen Vertreter nicht immer in ein vorteilhaftes Licht rückenden miaphysitischen Texten zu, die trotz ihres polemischen Untertons ein stimmiges Bild des kaiserlichen Verhaltens bieten -, doch ist eines klar, und das sei noch einmal betont: Der Kaiser ist selbst in der miaphysitischen Version, die ihn natürlich als Freund der Chalkedonier zeichnet, nicht das dogmatische Rauhbein, als welches er später erscheint. Er ist vielmehr jemand, der es zu vermeiden sucht, in die inhaltlichen Debatten hineingezogen zu werden. Justinian gerät auch nicht in Erregung über das Verhalten der Miaphysiten, das durch Starrheit und Ausweichmanöver gekennzeichnet ist. Er verzichtet darauf, die kaiserliche Macht auszuspielen; die typische Untugend des Herrschers, die Neigung zum Zorn, bricht nicht durch. Offenbar gebärdete Justinian sich, diesen Schluß erlauben beide Versionen, nach wie vor als der Kaiser, der bereit war, alle anzuhören.

Allerdings nahm er anscheinend für sich in Anspruch, in einer Nahbeziehung zu Gott zu stehen, wie sein Gebet im Michaels-Oratorium verdeutlicht und letztlich auch die Motivation der Einladung zum Gespräch. Vergleicht man den Verlauf dieses Religionsgesprächs mit dem eines anderen, nämlich jenem von Konstantinopel 383, zu dem Theodosius der Große geladen hatte, ${ }^{44}$ so werden bemerkenswerte Unterschiede deutlich.

Theodosius hatte laut dem Kirchenhistoriker Sokrates aufgrund des Rats eines Novatianers das Verfahren vorgegeben, indem er die Teilnehmer auf-

44 Socr. H. E. 5, 10, 6-28; vgl. R. Lim, Public Disputation, Power and Social Order in Late Antiquity, Berkeley/Los Angeles/London 1995, 202f;; M. Wallraff, Der Kirchenhistoriker Sokrates. Untersuchungen zu Geschichtsdarstellung, Methode und Person (Forschungen zur Kirchen- und Dogmengeschichte 68), Göttingen 1997, 275ff., der gegenüber den Einzelheiten des Berichtes skeptisch ist; Leppin, Theodosius (wie Anm. 17), $83 \mathrm{f}$. 
forderte, auf der Grundlage der Väter eine Debatte zu führen, wobei er offenbar anwesend blieb. Nachdem auf diese Weise eine zielführende Debatte nicht zustande gekommen war, hatte er von allen teilnehmenden Gruppen Glaubensbekenntnisse eingefordert, sich zurückgezogen und war die Texte unter Gebet durchgegangen. Schließlich verlieh Gott ihm die Etkenntnis, daß das Nizänische Bekenntnis das richtige sei.

Justinian war da weitaus zurückhaltender. Weder griff er so massiv in das Verfahren ein, noch hatte er sich Glaubensbekenntnisse vorlegen lassen, geschweige denn, daß er kraft eigenen Glaubens darüber entschieden hätte; er beschränkte sich vielmehr auf einige Kompromißvorschläge. Auch wenn Justinian die persönliche Nähe Gottes gesucht hatte ${ }^{45}$ - wie sie ja jedem Christen offensteht -, so hatte er lediglich für die Einigung unter den $\mathrm{Ge}$ sprächsteilnehmern gebetet. Falls Justinian von dem Religionsgespräch unter Leitung des Theodosius wußte, muß es ihm zu denken gegeben haben, daß das Projekt 150 Jahre zuvor gelungen war, so daß seither die Gegner von Nizäa im theodosianischen Reich keine Gefahr mehr darstellten - während sein Religionsgespräch in einen Fehlschlag mündete.

Das Scheitern des Religionsgesprächs von Konstantinopel 532 führte zu keinen rabiaten Aktivitäten Justinians, doch erließ er 533 an die Bewohner Konstantinopels und einer Reihe anderer Städte, nicht aber Alexandreias, eine Konstitution, in der er sich unter Berufung auf die Lehre der Kirche und ihrer Priester eindeutig gegen Nestorius und Eutyches wie auch Apollinaris wandte, bei der positiven Formulierung des Glaubens jedoch weiterhin auf alle Formeln verzichtete, welche die Miaphysiten provozieren konnten, während er die theopaschistische Formel bestätigte. ${ }^{46}$ Allerdings verwies er in zeitgleichen Schreiben an den Patriarchen von Konstantinopel Euphemios und an Papst Johannes II. von Rom auch einmal auf die vier Konzilien, womit die Miaphysiten nicht einverstanden sein konnten. ${ }^{47}$ Eine Abweichung vom bisherigen Kurs bedeutet das indes nicht, weil ja schon auf dem Religionsgespräch des Jahres 532 Justinian die inhaltlich entleerte Akzeptierung von Chalkedon angeboten hatte. Beide Schreiben wurden übrigens in den

45 Wie sehr Justinian Respekt vor den Prärogativen kirchlicher Institutionen in dogmatischen Dingen zeigt, betont W. Enßlin, Justinian I. und die Patriarchate Rom und Konstantinopel, SO 35, 1959, 113-127.

46 CJ 1, 1, 6; vgl. Grillmeier, Jesus der Christus (wie Anm. 14), 362f.; Speigl, OS 44, 1995 (wie Anm. 14), 116f. bezieht die tuvós des $\$ 1$ auf die Akoimeten, die die Hauptzielscheibe der Kritik gewesen seien - möglicherweise zu Recht. Gray, Legacy (wie Anm. 11), 231 will den Einfluß des Leontius erkennen.

47 CJ 1, 1, 7; vgl. Speigl, OS 44, 1995 (wie Anm. 14), 118 ff.; s. auch Coll. Av. 84, 17. 
„Codex Iustinianus“ aufgenommen, so daß man nicht unterstellen darf, der Kaiser habe ein doppeltes Spiel getrieben.

Von einer schweren, systematischen Bedrängung der Miaphysiten kann auch in diesen Jahren keinesfalls die Rede sein; der Kaiser wurde zwar aktiver, aber er schlug die Tür nicht vor ihnen zu. ${ }^{48}$ Weitaus härter griff er die Akoimeten an, Mönche, die eine besonders radikale, den Theopaschismus verwerfende Deutung des Chalkedonismus vertraten und die versucht hatten, den Papst gegen Justinian in Stellung zu bringen. ${ }^{49}$

$\mathrm{Zu}$ einem Ausgleich gelangte Justinian mit dem wichtigsten Exponenten der chalkedonischen Gegenseite, Papst Johannes II., denn dieser konnte sich wenigstens zu einer indirekten Anerkennung der theopaschistischen Formel in einer leicht umakzentuierten Gestalt und einer Abkehr von den Akoimeten verstehen. ${ }^{50}$ In den Kirchen Konstantinopels sollte ferner künftig auf kaiserliche Anordnung ein Hymnos gesungen werden, der eine theopaschistische Wendung enthielt und der auch den Severianern genehm war. ${ }^{51}$ Damit hatte das chalkedonische Lager eine größere Geschlossenheit gewonnen, ohne sich zu deutlich gegenüber den Miaphysiten abzugrenzen.

Etwas anderes trat alsbald in den Vordergrund. Im November 533 war es bei einem Erdbeben in Konstantinopel zu einem Massenauflauf von protestierenden Gegnern des Chalcedonense gekommen, ${ }^{52}$ was man als Indiz ihrer Stärke nehmen konnte. Vor allem aber wartete man darauf, daß Severus nach Konstantinopel komme. Es bestand die Chance, daß der Kaiser selbst mit dem wichtigsten Miaphysiten spreche, wie er es ja ausdrücklich wünschte. Als der abgesetzte Bischof von Antiocheia 535 endlich eintraf, ${ }^{53}$ wurde er vom Kaiser mit allen Ehren empfangen und scheint ihn nachhaltig beeindruckt zu haben. Schon dies muß die Chalkedonier irritiert haben. Überdies gelangte

48 Hierin folge ich Uthemann, Augustinianum 39, 1999 (wie Anm. 11), 34ff.

49 Speigl, OS 44, 1995 (wie Anm. 14), 117; vgl. Mazal, Justinian (wie Anm. 9), 206.

50 Grillmeier, Jesus der Christus (wie Anm. 14), 357; Speigl, OS 44, 1995 (wie Anm. 14), $122 \mathrm{ff}$; Uthemann, Augustinianum 39, 1999 (wie Anm. 11), 34ff. Der Bedeutungsverlust der Akoimeten beschleunigte sich, s. Uthemann a.a.O., 35. Zur Umakzentuierung vgl. L. Abramowski, Die Mosaiken von S. Vitale und S. Apollinare in Classe und die Kirchenpolitik Kaiser Justinians, ZAC 5, 2001, 289-341, hier: $312 \mathrm{f}$.

51 Theoph. a m. 6028; vgl. Uthemann, Augustinianum 39, 1999 (wie Anm. 11), $38 f$.

52 Chron. Pasch. 629 B/C Dindorf.

53 Zur Datierung Stein, Histoire II (wie Anm. 9), 382 Anm. 1; vgl. Joh. Eph. Beat. Or. 48 (PO 18, 687). Ps.-Zach. Rhet. 9, 19 und Evagr. H. E. 4, 10 führen den Empfang des Severus auf den Einfluß Theodoras zurück, doch das ist nicht nötig, wenn man das Verhalten Justinians beim Religionsgespräch 532 vor Augen hat, wo er ja schon nach Severus verlangt hatte. 
535 mit Theodosios ein Freund des Severus dank massiver Unterstützung vom Hof auf den Bischofstuhl von Alexandreia - allerdings war sein Konkurrent ebenfalls ein Miaphysit aus der Richtung der Julianisten; ein Chalkedonier spielte bei den Auseinandersetzungen keine Rolle. Vor allem aber bestieg, ebenfalls 535, Anthimos den Bischofsstuhl von Konstantinopel, der sich als unsicherer Kantonist erwies. Zuvor hatte er als Bischof von Trapezunt an dem Religionsgespräch von 532 auf der Seite der Chalkedonier teilgenommen, jetzt erweckte er jedoch den Eindruck, er sei ein Severianer. Die Waage schien sich zu Ungunsten der Chalkedonier zu neigen.

Da trat Anfang 536 unversehens ein dritter kirchlicher Akteur auf den Plan, Agapet, der neue Bischof von Rom, ein entschiedener Anhänger Chalkedons, der vom ostgotischen König Theodahat in diplomatischer Mission in den Osten geschickt worden war. Er sollte - die Vorbereitungen zum Gotenkrieg waren im Gange - darum bitten, daß die kaiserlichen Truppen, die Italien bedrohten, abgezogen würden. Mit diesem Anliegen, das er möglicherweise auch gar nicht offensiv vertreten hat, drang er nicht durch; mit einem anderen erzielte er dafür einen um so größeren Erfolg: 54

Agapet, der schon zuvor wegen kirchenorganisatorischer Fragen mit Justinian in Streit geraten war, war von Mönchen, zu denen viele strenge Chalkedonier zählten, über die kirchenpolitischen Zustände in der Hauptstadt unterrichtet worden. Da gab es ja nach wie vor Zoras mit seiner Anhängerschaft, ${ }^{55}$ und da gab es eben einen Bischof, dessen Bekenntnis zu Chalkedon nicht eindeutig schien. Agapet trug dies dem Kaiser vor, der daraufhin die Absetzung des Konstantinopolitaner Patriarchen verfügte; dies wurde, durchaus nachvollziehbar, damit begründet, daß Anthimos durch die Translation von einem Bischofssitz auf den anderen und somit in unkanonischer Weise zum Amt bestellt worden war. ${ }^{56}$ Eine dogmatische Frage verknüpfte sich mit einer kirchenrechtlichen, und Agapet scheint dies genutzt zu haben.

Agapet inszenierte sich bei dieser Gelegenheit, wenn man dem „Liber pontificalis", der in dieser Passage eine zeitnahe, allerdings westliche, von

54 Zu Agapets Wirken in Konstantinopel E. Caspar, Geschichte des Papsttums. Von den Anfängen bis zur Höhe der Weltherrschaft, Bd. 2: Das Papsttum unter byzantinischer Herrschaft, Tübingen 1933, $221 \mathrm{ff}$.

$55 \mathrm{Zu}$ den Angriffen Agapets auf Zoras, vgl. Joh. Eph. Beat. Or. 2 (PO 17, 26ff.). Schließlich verwünschte Zoras ihn zu Tode.

56 Nov. Iust. 42. Joh. Eph. Beat. Or. 48 (PO 18, 685f.); vgl. Joh. Eph. H. E. 1, 42, wo er sicherlich zu Unrecht suggeriert, Anthimos habe von sich aus auf den Thron verzichtet. 
Sympathie für Agapet erfüllte Quelle repräsentiert, ${ }^{57}$ trauen darf, in ähnlicher Weise, wie wir es bei Zoras gesehen hatten: Er zeigte Parrhesie und beschimpfte den Kaiser nach Kräften, ja, er ging so weit, daß er diesen als neuen Diokletian bezeichnete.

Ein schlechter Kaiser hätte angesichts solcher Anwürfe mit Zorn reagiert, aber Justinian tat dies genauso wenig wie im Falle des Zoras. Bemerkenswert ist, was der „Liber pontificalis“ über dieses Ereignis schreibt: Tunc piissimus Augustus gaudio repletus bumiliavit se sedi apostolice et prostravit ante papam Agapetum. „Da demütigte sich der tieffromme Kaiser, von Freude erfüllt, vor dem apostolischen Sitz und warf sich vor dem Papst Agapet nieder." Was hier geschildert oder wenigstens imaginiert wird, ist eine Facette des Justinian-Bildes, die man nicht unbeachtet lassen sollte: Man traute dem Kaiser zu, sich ähnlich zu erniedrigen, wie es Theodosius vor Ambrosius getan hatte ${ }^{58}$ - daß nicht jeder es ihm zutraute, zeigt sich darin, daß die Handschriften auch die vagere Lesart adoravit statt prostravit anbieten; das bumiliavit aber ist textkritisch gesichert. Der Kaiser hätte somit, ganz gleich, wie man die Lesung auffaßt, seinen Richtungswechsel in Konstantinopel damit motiviert, daß er von einem geeigneten Mann, eben Agapet, belehrt worden wäre. Das war nach christlicher Auffassung untadelig. Allerdings geht aus späteren Bemerkungen Justinians hervor, daß er durchaus noch Anthimos zur Umkehr zu bewegen versucht hatte, ${ }^{59}$ daß die Entscheidung also keineswegs schlagartig erfolgte. ${ }^{60}$ Welches Ansehen Agapet dennoch genoß, zeigen Glaubensschriften Justinians und des Patriarchen Menas, des Nachfolgers von Anthimos, die Agapet vorgelegt wurden, der im übrigen in seiner zustimmenden, auch die Zugeständnisse des

57 Zur Agapet-Vita im „Liber Pontificalis“ s. L. Duchesne, Introduction, in: ders., Le liber pontificalis. Texte, introduction et commentaire Bd. 1 (BEFAR 3, 1), Paris 1886, ICCLXII, hier: XLVIII, der zeigt, daß sie von einem Zeitgenossen verfaßt sein muß; zum Autor auch P. Hildebrand, Die Absetzung des Papstes Silverius (537). Eine quellenkritische Untersuchung, HJb 42, 1922, 213-249, hier: 217, der ihn auf kurz nach 538 datiert.

58 Bei der Begrüßung des Sabas durch Justinian taucht schon früher in einem vergleichba-

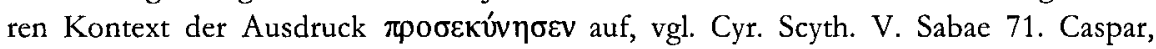
Papsttum II (wie Anm. 54), 225, der den Bericht des „Liber pontificalis“ anzweifelt, sieht hier lediglich eine kurzfristige Unterbrechung von Justinians in seinen Augen cäsaropapistischem Vorgehen.

59 Nov. Iust. 42 pr.

60 Agapet berichtet selbst in einem Brief an den Bischof Petros von Jerusalem von diesem Ereignis (ACO III, 152f.) - wobei er sich auf die Unterstützung der $\beta \alpha \sigma \lambda \varepsilon \varepsilon \hat{\varsigma} \varsigma$ - also offenbar auch Theodoras beruft (153, Z. 1f.; vgl. 10 zur Einsetzung des Menas) 
Johannes im wesentlichen bestätigenden Antwort kühl hervorhob, daß einem Laien keine Lehrautorität zustehe. ${ }^{61}$

Ein solcher Triumph, wie ihn Agapet erzielt hatte, mußte unter Chalkedoniern als Ausdruck überlegener Heiligkeit gewertet werden. Ps. Zacharias Rhetor indes, der Miaphysit, schreibt den Erfolg der Tatsache zu, daß Agapet wie Justinian lateinischsprachig gewesen sei, außerdem habe Justinian ihn aufgrund der Bedeutung Italiens begünstigt. ${ }^{62}$ Das ist angesichts der kriegerischen Entwicklungen sicherlich nicht von der Hand $z u$ weisen, wäre aber doch zu kurz gegriffen, zumal Justinian auch in kritischen Situationen seiner Italienpolitik keine Scheu hatte, hart gegen Päpste vorzugehen. ${ }^{63}$ Man sollte eine personalisierende Interpretation nicht von vornherein ausschließen: Offenbar war Justinian von der Gestalt des Papstes nachhaltig beeindruckt andererseits hatte Anthimos stillschweigende Übereinkünfte mit Severus und Theodosios I., dem Patriarchen von Alexandreia, getroffen, ${ }^{64}$ so daß Justinian allen Grund hatte, diesem Personenkreis zu mißtrauen.

Alles schien nach dieser Begegnung auf eine ideale Beziehung zwischen Kaiser und Papst hinauszulaufen, da geschah etwas Unvorhersehbares: Agapet starb am 22. April 536. Hier hatten die Zeitgenossen gewissermaßen die Nagelprobe für das Wirken des Heiligen Mannes vor sich. Der rasche Tod eines Beteiligten in einer entscheidenden Phase stellte die Wahrhaftigkeit seiner Lehren evident in Frage. Die Gefolgsleute des Zoras wußten zu berichten, daß ihr Held Agapet für seine lasterhaften Äußerungen eine mehrere Meter lange Zunge in den Hals gebetet habe, an der er erstickt sei. ${ }^{65}$ Rasches Handeln war angesichts solcher Triumphgefühle gefordert.

Die Anhänger Agapets ließen sich in der Tat nicht lähmen, sie drangen auf ein Konzil der in Konstantinopel präsenten Bischöfe, auf eine Endemousa. Die vereinigten Mönche Konstantinopels sowie Vertreter vor allem palästinischer Klöster, die einen Stützpfeiler des Chalkedonismus bildeten und von deren Brüdern eine nicht geringe Zahl in der Hauptstadt lebte, ${ }^{66}$ setzten sich

61 Coll. Av. 89-91, insbes. 91, Z. 3 mit Speigl, OS 44, 1995 (wie Anm. 14), 130 ff.

62 Ps.-Zach. Rhet. 9, 19.

63 Vgl. Noethlichs, ZAC 4, 2000 (wie Anm. 26), $126 f$.

64 Vgl. den Brief des Severus an Theodosius bei Ps.-Zach. Rhet. 9, 23.

65 Welche Triumphgefühle der Tod Agapets bei seinen Gegnern auslöste, zeigt der Bericht bei Joh. Eph. Beat. Or. 2 (PO 17, 30f.) - Ich sehe kein Indiz dafür, daß Justinian sich in dieser Situation als Testamentsvollstrecker Agapets gefühlt habe (so Schwartz, Kirchenpolitik Justinians [wie Anm. 10], 287).

$66 \mathrm{Zu}$ ihnen K. Trampedach, Reichsmönchtum? Kyrill von Skythopolis und das politische Selbstverständnis der Mönche Palästinas im 6. Jahrhundert, Millennium 2, 2005, 271-295. 
an die Spitze dieser Bewegung. Wieder sind wir über die Versammlung recht gut unterrichtet, da Protokolle und Dokumente des Konzils vorliegen. ${ }^{67}$ Der Kaiser hatte es einberufen, der noch von Agapet geweihte Nachfolger des Anthimos, Menas, stand ihm als Ortsbischof vor. Eröffnet wurde es bereits am 2. Mai 536, wenige Wochen nach Agapets Tod.

Man bemühte sich um formale Korrektheit: Die Mönche fragten eigens, ob sie eintreten dürften, ebenso der Vertreter der Politik, der Referendar Theodoros ( $(57)$, der erläuterte, daß der Kaiser eben auf Bitten der Mönche das Konzil einberufen habe, und das entsprechende Schreiben verlesen ließ: 68

Der Brief berichtet nach langen Bekundungen der Loyalität, wie $\mathrm{zu}$ erwarten, daß Anthimos zu Unrecht Bischof geworden sei und Unfrieden gestiftet habe. Dann folgt eine bemerkenswerte Beschreibung der kaiserlichen Rolle: Er hätte natürlich die Häretiker vertreiben können, erklären die Mönche, doch habe er es vorgezogen, den kanonisch korrekten Weg zu gehen und den Priestern zu gehorchen, zumal dem Urteil des Bischofs von Rom. Da habe Gott Agapet nach Konstantinopel entsandt. ${ }^{69}$ Dieser habe, von den Mönchen über die schlimmen Zustände informiert, das Gespräch mit Anthimos verweigert. Überdies hätten andere Bischöfe und Mönche den Kaiser um die Bekehrung der Häretiker oder ihre Vertreibung aus Kirche und Stadt ersucht (Z. 21 ff.). Diesen ganz berechtigten Bitten sei Agapet zuvorgekommen, indem er die Häretiker abgesetzt habe und die Bitte der Mönche an den Kaiser, das zu Ende zu führen, was die Mönche erbeten hätten, weitergeleitet habe (Z. 36ff.).

Nach der Darstellung des Briefes der Mönche, der, wie gesagt, an den Kaiser gerichtet und von ihm weitergeleitet worden war und daher gewiß nicht das Ziel haben konnte, den Kaiser als Schwächling dastehen zu lassen, ist eindeutig Agapet der Motor der Geschehnisse. Agapet ergreift die Initiative, der Kaiser folgt ihm. Das Handeln des Papstes zwang demnach den Kaiser zu einer Reaktion. Offenbar erwartete man, daß Justinian diese Deutung teile, und das erscheint auch nach dem, was wir gesehen haben, durchaus plausibel: Der Kaiser hatte bislang stets seinen Respekt vor religiösen Instanzen demonstriert, er hatte sie um ihren Rat ersucht - was innerhalb seiner bisherigen Politik konsistent war.

67 ACO III, 27-189.

68 Zu ihm PLRE IIIB, 1248.

69 ACO III, 132, Z. 4 ff. 
Im zweiten Teil des Briefes wird kurz der Tod Agapets erwähnt (S. 133, 1-3); der Kaiser solle jetzt, da Agapet Gott näher sei, seine Maßnahmen zur Vollendung führen, dann werde Gott ihm alle Feinde unterwerfen und ihn im Himmel vielfach belohnen.

Man könnte diese Konzilsdokumente als Belege für die politische Schwäche des Kaisers lesen, doch sind sie offenbar Spiegel kaiserlichen Wollens. Er war demnach, wie sich erneut zeigt, nicht bestrebt, als derjenige zu erscheinen, der sich in kirchlichen Belangen kraft eigener Gewalt durchzusetzen vermochte. Dementsprechend war die Kirchenversammlung umgekehrt nicht zuletzt eine Inszenierung von Loyalität gegenüber dem Kaiser, dessen Rechtgläubigkeit und guter Wille allenthalben hervorgehoben wurde.

Allerdings blieb als eine Peinlichkeit bestehen, daß es nicht gelang, des abgesetzten Anthimos habhaft zu werden, der den Vorladungen keine Folge geleistet hatte, ${ }^{70}$ daß also in diesem Punkte die Grenzen der Macht des Kaisers in der Hauptstadt sichtbar wurden. Die Beschlüsse als solche entsprachen den Vorstellungen Agapets und nunmehr wohl auch des Kaisers. Anthimos, Severus und andere Miaphysiten wurden als häretisch gebrandmarkt. Der Kaiser sanktionierte diese Beschlüsse am 25. Juli 536 mit der Novelle 42, wobei er im Proömium ausdrücklich erklärt, daß er sich dem Votum der Priester anschließe; ${ }^{71}$ mit dieser Novelle bekannte der Kaiser sich überdies ausdrücklich zu Chalkedon und verbannte eine Reihe von Miaphysiten darunter übrigens auch, namentlich genannt, Zoras ${ }^{72}$ - aus Konstantinopel und überhaupt den bedeutenderen Städten. Auch in den nächsten Jahren setzte er sie mit Härte und relativ großer Konsequenz durch. Die Miaphysiten wurden aus der Öffentlichkeit gedrängt. ${ }^{73}$

Es wäre unangemessen, hier mit Eduard Schwartz von einem Triumph des Kaisers zu sprechen. ${ }^{74}$ Er hatte zwar jetzt für sich eine Lösung gefunden, doch der integrative Ansatz, den er fast zehn Jahre lang erprobt hatte, war gescheitert. Es war kein langgehegter Plan des Kaisers, ein bestimmtes Dog-

70 Laut Joh. Eph. Beat. Or. 48 (PO 18, 686) hatte Theodora ihn verborgen; allerdings ist der Bericht über Anthimos von zahlreichen Fehlern durchsetzt.

71 In Nov. Iust. 42, 3, pr. erklärt er in Hinblick auf Zoras, daß das Votum der Priester allein ausreiche und durch das des Kaisers lediglich verstärkt werde.

72 Nov. Iust. 42.

73 Bemerkenswert die Bewertung durch Liberatus Brev. 159 (ACO II, 5, 138, Z. 32f.): Hoc ergo modo unitas facta est ecclesiarum anno $X$ imperii gloriosi Iustiniani Augusti. Bei den chalkedonischen Mönchen Palästinas wurde diese Synode in eine Reihe mit den vier Ökumenischen gestellt, s. Schwartz, Praefatio zu ACO III, S. X; vgl. auch das Lob bei Evagr. H. E. $4,11$.

74 Schwartz, Kirchenpolitik Justinians (wie Anm. 10), 290. 
ma zu etablieren, der hier durchgesetzt wurde. Offenbar hatte er vielmehr nach seinen langen Bemühungen den Eindruck gewonnen, daß letztlich eine klare Positionsbestimmung die Grundlage des Erfolges sei und mochte sich durch das Charisma Agapets einerseits, die Tricksereien von Anthimos und seinen Freunden andererseits bestätigt fühlen. Diese Politik exekutierte er fortan mit zunehmender Härte.

Es hat sich gezeigt, daß die ersten neun Jahre der justinianischen Religionspolitik im Zeichen der Kontinuität stehen. Von Anfang an zielte der Kaiser darauf, die Miaphysiten einzubinden und damit auf ihr Erstarken zu reagieren, nicht so sehr darauf, das eigene Bekenntnis in aller Schärfe zu verbreiten, zumal dies in den Provinzen ohnehin kaum möglich war. Der aggressive Tonfall der antihäretischen Gesetze täuscht, denn er richtet sich gar nicht gegen die Miaphysiten, sondern gegen gemeinsame theologische Gegner. Sie gehören in den Kontext anderer Gesetze, die gegen Gruppen wie die Heiden oder Samaritaner gerichtet sind. Die Identifizierung gemeinsamer Feinde sollte wohl eine gemeinsame Identität begründen.

Kontinuität bestand auch darin, mit welchem Habitus der Kaiser seine Religionspolitik praktizierte. Zwar spürte er offenbar, und das entsprach nun einmal der kaiserlichen Rolle, die Verpflichtung, sich für den wahren Glauben einzusetzen, zwar hatte er ohne Zweifel auch bestimmte Vorstellungen davon, wie der wahre Glaube aussehe - das Konzil von Chalkedon war für ihn wenigstens formal nicht antastbar, die theopaschistische Formel vertrat er mit Konsequenz -, doch besaß er eine prinzipielle, zumindest zur Schau getragene Bereitschaft, sich belehren zu lassen. Hierin wird eine gewisse Widersprüchlichkeit in der Rolle des christlichen Kaisers sichtbar: Er mußte den wahren Glauben vertreten, aber er war, jedenfalls für ernsthafte Theologen, nicht derjenige, der den wahren Glauben von sich aus zu erkennen vermochte.

Die Rolle dessen, der sich belehren läßt, nahm Justinian so ernst, daß er bei religiösen Konflikten stets als der zuhörende, zur Buße bereite und nicht zornmütige Herrscher auftrat; ${ }^{75}$ selbst im Falle des Zoras, der die Miaphysiten in provozierender Weise vertrat und dessen Begegnung mit dem Herrscher selbst durch eine feindselige Quelle in dieser Weise geschildert wird.

75 Selbst gegenüber den Manichäern gab es Gesprächsversuche, s. Lim, Public Disputation (wie Anm. 44), 105f. Noethlichs, ZAC 4, 2000 (wie Anm. 26), 126 betrachtet die ganze Regierungszeit Justinians als die eines ,wirklich Suchenden". 
Justinians Milde ging so weit, daß sie auf der Synode von 536 sogar sanft getadelt wurde. ${ }^{76}$

Was sich wandelte, waren die Methoden. Schien es Justinian zunächst ausreichend, die gemeinsamen Feinde zu identifizieren, so zeigt das Religionsgespräch von 532, daß er nunmehr zu inhaltlichen Aussagen gelangen wollte. Doch all das scheiterte; es befriedete die Verhältnisse nicht. Erst die Begegnung mit Agapet und der Betrug der Miaphysiten scheint einen Bruch bewirkt zu haben, und es mußte der Eindruck entstehen, daß die Endemousa 536 schließlich zu einem klaren Ergebnis geführt hatte. Wurden nicht Unruhestifter wie Zoras vertrieben? Hatte der Kaiser sich nicht klar auf die Seite der Chalkedonier gestellt? Hatte der Kaiser nicht zu einem klaren Bekenntnis gefunden?

Tatsächlich wurde die Synode von 536 zeitweise in eine Reihe mit den vier großen, Ökumenischen Konzilien gestellt, tatsächlich agierte Justinian nun ungleich selbstbewußter als zuvor: Das Mönchtum wurde diszipliniert, Papst Vigilius merklich härter angefaßt als seine Vorgänger, in Alexandreia ein konsequent chalkedonischer Kurs gesteuert. War damit die Religionspolitik Justinians zu einem Zielpunkt gelangt?

Für einige Jahre mochte es so scheinen, doch der Eindruck verflüchtigte sich bald, nicht nur weil der Versuch, in Alexandreia Ruhe zu schaffen, scheiterte. Seit den vierziger Jahren griff Justinian verstärkt mit theologischen $\mathrm{Ar}$ gumenten in die Kirchenpolitik ein. ${ }^{77}$ Einen ersten Höhepunkt erreicht dies im origenistischen Streit. ${ }^{78}$ In dem 542/3 publizierten Edikt gegen die Origenisten forderte er etwa, nachdem er sich eingehend zu theologischen Probleme geäußert hat, die Einberufung einer Endemousa, um diese Fragen entsprechend zu behandeln; ${ }^{79}$ anders als in der Novelle 42, mit der er auf das Konzil von 536 reagierte, erklärte er hier nicht, daß er sich dem Votum der kirchlichen Autoritäten anschließe. Vielmehr nahm er die Lehrautorität eines Laien

76 ACO III, 43, Z. 19-24.

77 Vgl. Meier, Zeitalter Justinians (wie Anm. 10), $278 f$.

78 Der Streit, der von gebildeteren Mönchen ausging (vgl. E. Schwartz, Kyrillos [wie Anm. 10], 388 sowie D. Hombergen, The Second Origenist Controversy. A New Perspective on Cyril of Scythopolis' Monastic Biographies as Historical Sources for Sixth-Century Origenism, Rom 2001, 231ff., der allerdings hervorhebt, daß auch auf der Gegenseite Gebildete standen) brachte eine Intellektualisierung der Debatten mit sich, die möglicherweise Justinians Vertrauen in seine eigenen geistigen Gaben stärkte.

79 ACO III, 189-214, insbes. 207, Z. 30-208, Z. 17. Natürlich waren auch an diesen Maßnahmen Bischöfe nicht unbeteiligt. Justinian handelte, so heißt es, auf Initiative Ephraims von Antiocheia, setzte dann seine Schrift auf und überließ sie Menas und seiner Synode zur Zustimmung, s. Cyr. Scyth. V. Sab. 191. 
in Anspruch, die der verehrte Agapet ausdrücklich abgelehnt hatte. ${ }^{80}$ Es war nicht mehr eine kurze Kompromißformel wie die theopaschistische, um die es hier ging, sondern eine ausführliche theologische Erörterung.

Von einem völligen Wandel der Politik Justinians ist indes auch für die spätere Epoche nicht auszugehen. Das Beharren auf der theopaschistischen Formel in den Anfängen Justinians zeigt, auch wenn die Wendungen Kompromißcharakter hatten, daß der Kaiser an bestimmten Überzeugungen festhielt; umgekehrt lassen sich auch in der späteren Zeit immer wieder Versuche des Kaisers beobachten, mit Vertretern anderer Richtungen ins Gespräch zu kommen; immer wieder ließ er sich offenkundig auch von einzelnen Christen beeindrucken, selbst wenn er ihren Lehren ablehnend gegenüberstand. ${ }^{81}$ Doch eine religiöse Integration führte er nicht herbei; vielmehr bildete sich gerade unter seiner Herrschaft eine eigene miaphysitische Kirche heraus. Noch seine Hinwendung zum Aphthartodoketismus am Ende seines Lebens mag ein Versuch gewesen sein, Chalkedonier und Miaphysiten aneinander anzunähern. Eben dadurch aber isolierte der Kaiser sich vollends, der nunmehr auch bei den Chalkedoniern als Häretiker galt.

80 Coll. Av. 91, 3; vgl. Meiers Deutung der Religionspolitik in dieser Phase: Zeitalter Justinians (wie Anm. 10), 273ff.

81 Seine Bereitschaft, auf Heilige Männer zu hören, bleibt auch später bestehen, selbst im Falle von Miaphysiten, s. Joh. Eph. Beat. Or. 47 (PO 18, 680); die Provokationen des Mares, die nach 536 erfolgt sein dürften, nahm er gelassen hin, s. Joh. Eph. Beat. Or. 36 (PO 18, 428ff.). 


\title{
Die städtische Finanzautonomie im spätrömischen Reich*
}

\author{
Sebastian Schmidt-Hofner
}

Der schlanke, lediglich über einen kleinen bürokratischen Apparat gebietende Staat der Prinzipatszeit war nur funktionsfähig, weil er in den Städten des Reiches über eine gewachsene Struktur politischer Gemeinwesen verfügte, die die römische Herrschaft vor Ort sicherten, mehr oder minder eigenverantwortlich die meisten staatlichen Hoheitsfunktionen ausübten und der Zentralgewalt dabei insbesondere die Steuererhebung abnahmen. Der römische Staat der Prinzipatszeit war deshalb auf die Funktionsfähigkeit seiner munizipalen Substruktur angewiesen, und aus diesem Grunde ist das Verhältnis von Stadt und Staat für die Charakterisierung von Staatlichkeit und politischem Handeln in der römischen Kaiserzeit von eminenter Bedeutung.

Dies gilt ohne Einschränkung auch für das spätrömische Reich. Zwar bildete der spätantike Staat einen in bislang ungekanntem Maße komplexen Verwaltungsapparat aus, doch änderte dies nichts daran, daß der Staat für das lokale Regiment weiterhin subsidiärer politischer Strukturen bedurfte. In der Tat wurde die Stadt als basale politische Organisationseinheit flächendeckend - auch in Ägypten - erst durch Diokletians Reichsreform etabliert, und die Erhebung der Reichssteuern lag nun fast vollständig in der Hand der Städte. Allerdings hatte sich das Verhältnis von Stadt und Staat gegenüber der Prinzipatszeit erheblich gewandelt: Die Städte hatten viele Autonomierechte verloren, während die kaiserliche Bürokratie zunehmend in die Gemeinden hineinregierte und sie in mancherlei Hinsicht auf den Status eines Vollzugsorgans ohne eigenständigen politischen Handlungsspielraum reduzierte. Als besonders folgenreicher Aspekt dieser Entwicklung gilt der Forschung der Verlust der städtischen Finanzautonomie, also der eigenverantwortlichen

* Ich danke Malcolm Errington, Hans-Ulrich Wiemer, Christian Witschel und den Teilnehmern des Marbu rger Kolloquiums für ihre Anregungen zu diesem Beitrag. 
Verfügung der Gemeinden über ihre Einnahmen aus Steuern, Zöllen, Landbesitz und anderen Geldquellen. Seit Wilhelm Liebenams klassischer Arbeit über die „Städteverwaltung im Römischen Kaiserreiche" 1 besteht in der Forschung Konsens, daß die kaiserliche Finanzverwaltung bereits in der Prinzipatszeit eine Tendenz entwickelte, die Finanzwirtschaft der Städte ihrer Kontrolle zu unterwerfen, dabei insbesondere die Steuererhebung und das Zollwesen monopolisierte und die Gemeinden so ihrer wichtigsten Einnahmequellen beraubte. Die Städte seien deshalb finanziell immer mehr in die Abhängigkeit von kaiserlicher Unterstützung und dem Euergetismus reicher Bürger geraten und ansonsten darauf angewiesen gewesen, ihren Finanzbedarf durch das zunehmend Zwangscharakter gewinnende Liturgienwesen zu decken. Diese Entwicklung habe weitreichende Folgen gehabt, denn langfristig habe der Verlust der Finanzautonomie den Niedergang der Städte als selbstverwalteter politischer Gemeinwesen vorangetrieben und infolge dessen auch den finanziellen und sozialen Niedergang des Dekurionenstandes befördert. Auch andere Krisensymptome wie den Niedergang der monumentalen städtischen Bautätigkeit führt man auf diese Entwicklung zu rück. Der Verlust der städtischen Finanzautonomie gilt daher als ein wesentlicher Faktor für den Untergang der antiken Stadtkultur. ${ }^{2}$

Was in der Prinzipatszeit mit der zunehmenden Einflußnahme der kaiserlichen Finanzverwaltung auf die städtischen Finanzen ihren Anfang genommen habe, sei, so will es die Forschung, im Zuge der Stabilisierungs- und Zentralisierungsbestrebungen zu Beginn des vierten Jahrhunderts zum Abschluß gekommen, als der Kaiser, wahrscheinlich Konstantin, die städtischen Einnahmen nicht nur de facto, sondern auch de iure dem Staatseigentum einverleibt habe: Neben diversen kleineren Finanzposten habe dieser Konfiskationsakt die städtischen Ländereien einschließlich ihres Pachtzinsaufkommens, die Einnahmen aus lokalen Steuern und die Zolleinkünfte betroffen, also insbesondere auch die stetig fließenden und ertragreichsten Finanzquellen der Gemeinden. Bezeugt ist dieser Konfiskationsakt jedoch nicht, weshalb man zum Nachweis seiner Historizität eine Reihe indirekter Belege anführt. Deren wichtigste sind eine Konstitution Kaiser Julians, die man als umfassende Restitution der konstantinischen Konfiskation deutet, eine ephesische Inschrift aus der Regierungszeit Kaiser Valens', in der man

1 W. Liebenam, Städteverwaltung im Römischen Kaiserreiche, Leipzig 1900.

2 Zusammenfassend zuletzt J. H. W. G. Liebeschuetz, The Decline and Fall of the Roman City, Oxford 2001, 104-220; für den Zusammenhang mit dem Niedergang der Bautätigkeit s. z. B. B. Ward-Perkins, From Classical Antiquity to the Middle Ages: Urban Public Building in Northern and Central Italy, Oxford 1984, hier: $21 \mathrm{f}$. 
die Revokation der julianischen Maßnahme bzw. die erneute Enteignung der städtischen Einnahmen vorausgesetzt sehen möchte, und eine in mehreren Konstitutionen bezeugte Maßnahme der Kaiser Valentinian und Valens, die eine Aufteilung städtischer Einnahmen zwischen Staat und Gemeinden vorsieht und damit nach der gängigen Auffassung ebenfalls die Rekonfiskation belegt. Aus diesen und einigen weiteren Quellen konstruiert man dabei folgende Historie: Julian, der „Städtefreund“, habe Konstantins Konfiskationsakt rückgängig gemacht, doch sei diese Maßnahme Episode geblieben. Denn seine Nachfolger Valentinian und Valens hätten die für den Fiskus desaströse Restitution gleich zu Beginn ihrer Herrschaft widerrufen, als sie für die gewaltigen Verluste des gescheiterten Perserfeldzuges ihres Vorgängers aufkommen mußten. Fortan hätten die Städte also wieder für jede Ausgabe bei den Finanzbehörden vorstellig werden müssen. Die Langwierigkeit und Anfälligkeit dieses Verfahrens für Selbstbereicherungsversuche der Bürokratie habe, wie die ephesische Inschrift bezeuge, Valentinian und Valens im Laufe ihter Regierung von der Notwendigkeit überzeugt, den Städten einen gewissen eigenständigen Handlungsspielraum wiederzugeben: Obgleich der Fiskus weiterhin zwei Drittel der Einkünfte einzog, sei den Städten deshalb Anfang der 370er Jahre die eigenständige Verfügung über wenigstens ein Drittel davon überlassen worden, ohne daß jedoch das formale Eigentumsrecht und damit die Eingriffsmöglichkeit der kaiserlichen Verwaltung aufgegeben worden sei. Die Enteignung sei also nicht aufgehoben, ihre Folgen für die Gemeinden seien jedoch gemindert worden; diese Lösung habe sich als dauerhaft tragfähig erwiesen und deshalb fortan Bestand gehabt.

Das geschilderte Szenario besitzt in der Forschung kanonischen Rang, seit es A. H. M. Jones in seinem monumentalen Werk zur spätrömischen Verwaltungsgeschichte festgeschrieben hat. ${ }^{3}$ Und obwohl sich in bezug auf die Prinzipatszeit mittlerweile Kritik an der herkömmlichen Auffassung von der systematischen Unterwerfung städtischer Einkünfte unter staatliche Kontrolle vernehmen läßt, ist es nach wie vor die communis opinio der Forschung, $\mathrm{da}$ es im vierten Jahrhundert zu besagtem Konfiskationsakt gekommen sei. $^{4}$

3 A. H. M. Jones, The Later Roman Empire 284-602. A Social, Economic and Administrative Survey, 3 Bde., Oxford 1964.

4 Ausgangspunkt der Debatte ist heute J. H. W. G. Liebeschuetz' Aufsatz, The Finances of Antioch in the Fourth Century A.D., BZ 52, 1959, 344-356; die wichtigsten Beiträge seitdem: ders., Antioch: City and Imperial Administration in the Later Roman Empire, Oxford 1972, 149-155; ders., Decline (wie Anm. 2), 175-180; Jones, Later Roman Empire (wie Anm. 3), 732f, u. ö.; C. Lepelley, Les Cités de l'Afrique romaine au Bas-Empire, Bd. 1, Paris 1979, 61-72; ders., Temoignages épigraphiques sur la contrôle des finances muni- 
Lediglich ein einziger, Fergus Millar, hat einmal, wenn auch an entlegener Stelle, Bedenken angemeldet, ob die Quellen dieses Postulat wirklich rechtfertigen. ${ }^{5}$ Diese Bedenken sind, wie die folgende Untersuchung zeigen wird,

cipales par le gouvernement à partir du reigne de Dioclétien, in: Il capitolo delle entrate nelle finanze municipali in occidente ed in oriente. Actes Rome 1996, Rom 1999, 235 247; D. Simon, Das frühbyzantinische Emphyteuserecht, in: J. Modrzejewski/D. Liebs (Hgg.), Symposion 1977, Köln u. a. 1982, 365-422, hier: 379f.; G. Bonamente, Le città nella politica di Giuliano l'Apostata, AFLM 16, 1983, 33-96, hier: 46-59; A. Chastagnol, La legislation sur les biens des villes au IVème siècle à la lumière d'une inscription d'Ephèse, AARC 6, 1986, 77-104, hier: 85-89; F. Ausbüttel, Die Verwaltung der Städte und Provinzen im spätantiken Italien, Frankfurt/Main 1988, 65-69; P. Voci, Nuovi studi sulla legislazione romana tardoantica, Padua 1989, 97f,; R. Delmaire, Largesses sacrées et res privata. L'aerarium impérial et son administration du IVe au VIe siècle, Rom 1989, 276-282 + 644-657; G. D. Merola, Autonomia doganale nella tarda antichità intorno a CIL 3, 7151-7152, AARC 13, 2001, 277-292, hier: 285-293, sowie dies., Autonomia locale, governo imperiale. Fiscalità e amministrazione nelle province asiane, Bari 2001, 134139. Die exakte Datierung der Konfiskation ist umstritten: Liebeschuetz, Antioch, 152 plädiert für ein Datum vor 342 (gefolgert aus CTh 9, 17,2, s. unten); Chastagnol, AARC 6, 1986 für 356-358; Delmaire, Largesses sacrées, 650f. und Lepelley in: Finanze municipali, 243-245 für einen Zeitpunkt vor dem Jahr 358 (gefolgert aus CTh 4, 13, 5, s. unten). In bezug auf die Verwaltung des Gemeindelandes nach Valentinians Reform folgt Delmaire a. a. O. 652-655 nicht dem hier geschilderten Szenario der Forschung: Da es vor Justinian keinen Beleg dafür gibt, daß die Quotierungsregel auch im Osten angewandt wurde, will er dort das in I.Ephesos 42 belegte System individueller Zuweisungen (s. dazu später) annehmen. Im Westen habe sich die Quotierung zunächst auf die aus den städtischen Einnahmequellen gewonnenen Einkünfte bezogen, erst später (CJ 4, 61, 13, 431) auf die Verwaltung jener Quellen selbst; dies wiederum sei 451 (NMarc 3) auch im Osten angewandt worden. Dieses Szenario ist schon deswegen nicht überzeugend, weil Delmaire in bezug auf die vectigalia diese Änderungen nicht annimmt, sondern von einem seit den 370er Jahren in allen Reichsteilen einheitlichen und unveränderten System ausgeht. Vor allem aber verkennt es die Eigenart der einschlägigen juristischen Quellen: ihre Entstehung in Reaktion auf konkrete Probleme und die Tatsache, daß nur die wenigsten Rechtsentscheide überliefert sind, bringt den methodischen Vorbehalt mit sich, daß die juristische Überlieferung kein vollständiges Bild der Rechtsentwicklung liefert. Dies aber bedeutet, daß auch ein erst im fünften Jahrhundert zum ersten Mal explizit belegtes Rechtsinstitut schon längst in Gebrauch gewesen sein kann. Das gilt über die hier behandelten juristischen Quellen hinaus für alle Kaiserkonstitutionen der Spätantike: Vgl. dazu und zu anderen Aspekten der Interpretation spätrömischer Kaiserkonstitution die 2006 in der Reihe „Vestigia" erscheinende Marburger Dissertation des Verfassers mit dem Titel „Kaiser und Gesetz. Der Regierungsstil des spätrömischen Kaisers im Spiegel des Codex Theodosianus: das Beispiel Valentinians I.“.

5 F. Millar, Italy and the Roman Empire: Augustus to Constantine, Phoenix 40, 1986, 295 312, hier: 305f.; auch in: ders., Rome, the Greek World and the East, Bd. 2: Government, Society and Culture in the Roman Empire, Chapel Hill - London 2004, 372-398, hier: 384. Auch Simon in: Symposion 1977 (wie Anm. 4), 379f. und Ausbüttel, Verwaltung 
vollauf berechtigt. Denn im folgenden wird anhand einer vollständigen Revision des Quellenmaterials nachgewiesen werden, daß die Quellenlage viel einfacher zu deuten ist, wenn man akzeptiert, daß es weder unter Konstantin noch unter Valentinian noch zu irgendeinem anderen Zeitpunkt eine globale Konfiskation städtischen Eigentums gegeben hat. Im Gegenteil wird sich sogar zeigen, daß im vierten Jahrhundert - nämlich in der bereits erwähnten, bislang aber mißinterpretierten „Aufteilung“ der städtischen Gelder zwischen Stadt und Staat unter Valentinian und Valens - zum ersten Mal in einer langen Geschichte staatlicher Kontrollversuche eine explizite Zusicherung der freien Verwendung städtischer Einnahmen durch die Gemeinden bezeugt ist. Da die Quellen umgekehrt jedoch ebensowenig Zweifel daran lassen, daß die kaiserliche Bürokratie in der Spätantike zumindest partiell in das städtische Finanzwesen eingriff, ergibt sich die Notwendigkeit, das Zusammenspiel von kaiserlicher Bürokratie und munizipaler Selbstverwaltung im Bereich der

(wie Anm. 4), 66 weisen darauf hin, daß der Quellenbefund eine Globalkonfiskation unter Konstantin nicht hergibt, ziehen sie jedoch nicht grundsätzlich in Zweifel, sondern erklären die Quellenlage mit einer graduellen oder unsystematischen Konfiskation. Auch J. Durliat, Les finances publiques de Dioclétien aux Carolingiens (282-889), Sigmaringen 1990, 143-145 meint, es habe nie eine Konfiskation gegeben; außerdem habe sich die Quotierungsregel nicht auf städtische Einkünfte, sondern auf die Steuereinnahmen des Reiches bezogen. Die These ist eine Konsequenz seiner von W. Goffart, Caput and Colonate. Towards a History of Late Roman Taxation, Toronto 1974 übernommenen, in: J. Durliat, Le salaire de la paix sociale dans les royaumes barbares, in: H. Wolfram/A. Schwarcz (Hgg.), Anerkennung und Integration: zu den wirtschaftlichen Grundlagen der Völkerwanderungszeit (400-600). Symposion Stift Zwettl 1986, Wien 1988, 21-72 zuerst vertretenen Auffassung, die Barbaren hätten nicht Ländereien zugewiesen bekommen, sondern Steuergelder, und zwar zwei Drittel des Gesamtaufkommens, während das verbleibende Drittel an die Städte ging. Dieses Arrangement sei der schon seit Valentinian bestehenden Regelung gefolgt, die deswegen aber eben auf Staatseinnahmen, nicht auf städtische Einkünfte bezogen gewesen sei. Gegen die Kritik von W. Liebeschuetz, Cities, Taxes and the Accomodation of the barbarians: the theories of Durliat and Goffart, in: W. Pohl ( $\mathrm{Hg}$.$) , Kingdoms of the Empire. The Integration of Barbarians in Late$ Antiquity, Leiden u. a 1997, 135-151, will J. Durliat, Cité, impôt et intégration des barbares, ebd. 153-179, nun seine zuvor nur postulierte These durch Quellen untermauern, die zeigen sollen, daß die Quotierungsregel sich nicht auf städtische Einkünfte bezogen habe. Seine Argumente sind jedoch unhaltbar: Die wichtigsten Einwände hat bereits Liebeschuetz a. a. O. 150f, benannt; hier sei noch darauf hingewiesen, daß der Behauptung Durliats, reditus rei publicae (z. B. in CTh $14,3,7$ ) sei der Terminus technicus für Staatseinnahmen, Dutzende von Belegen vor allem aus dem Bereich der Domänenverwaltung entgegenstehen, die zweifelsfrei zeigen, $\mathrm{da} \beta$ der canon von fundi rei publicae eindeutig das Pachtzinsaufkommen von (ehemals) städtischem Besitz meint. Außerdem ignoriert er CTh 5, 14, 35 oder CJ 4, 61, 13, wo die durch Valentinians Quote aufgeteilten städtischen Einkünfte unmißverständlich von Staatseinnahmen abgegrenzt werden. 
Finanzwirtschaft jenseits der Konfiskationsthese neu zu definieren. Diese Neudefinition wird sich nicht auf die Spätantike beschränken. Denn mit dem angeblichen Konfiskationsakt zum Zeitpunkt der Epochenwende von der Prinzipatszeit zur Spätantike fällt auch die herkömmliche Zäsur in der Geschichte der städtischen Finanzwirtschaft, so daß das Verhältnis von Stadt und Staat im Bereich der Finanzwirtschaft sich nur in der Gesamtschau über die sechshundertjährige Geschichte des römischen Kaisertums beschreiben läßt. Ein wesentliches Kapitel der spätantiken Stadtgeschichte wird dabei in gänzlich neuem Licht erscheinen.

\section{Julians Restitutionsedikt}

An den Iden des März $362^{6}$ erließ Kaiser Julian in Konstantinopel eine Konstitution an den Prätoriumspräfekten von Oriens, Salutius Secundus, von der ein Fragment im „Codex Theodosianus" als CTh 10, 3, 1 überliefert ist:

Possessiones publicae civitatibus iubemus restitui ita ut iustis aestimationibus locentur, quo cunctarum possit civitatium reparatio procurari.

Wir befehlen, daß den Städten Ländereien in öffentlichem Besitz zurückerstattet werden, und zwar so, daß sie nach einer gerechten Abschätzung zugeteilt werden, damit so die Wiederherstellung vieler Städte besorgt werden kann. ${ }^{7}$

Eine Gruppe von Ländereien, die als possessiones publicae bezeichnet werden, soll also, so befiehlt der Kaiser, den Städten zurückerstattet werden; diese Restitution wird mit der Auflage verbunden, daß die aus ihrer Verpachtung gewonnenen Einkünfte für Baumaßnahmen genutzt werden. Dieselbe Maßnahme dürfte auch Ammian meinen, wenn er berichtet, Julian habe den Städ-

6 In der Literatur liest man meist das von O. Seeck, Regesten der Kaiser und Päpste für die Jahre 311 bis 476 n. Chr. Vorarbeit zu einer Prosopographie der christlichen Kaiserzeit, Stuttgart 1919, 134 und 210 emendierte Datum des 13. März 362. Seeck wollte die überlieferte Datierung auf die Iden des März deswegen verbessern, weil vom 13. März eine Reihe anderer Konstitutionen Julians stammt, die in irgendeiner Weise mit dem Thema „Stadt" befaßt sind. Keine von ihnen ist jedoch thematisch so eng verwandt (CTh 11, 16, 1 betrifft Liturgien, 12, 1, 50 Steuerimmunitäten), daß die Emendation des Datums von CTh 10, 3, 2 zwingend wäre.

7 Übersetzung (wie auch im folgenden) durch den Verfasser. 
ten vectigalia cum fundis wiedergegeben, also Ländereien samt ihren Einkünften aus dem Pachtzins. ${ }^{8}$

Gemeinhin geht man davon aus, daß in diesen beiden Quellenbelegen eine globale Restitution des städtischen Grundbesitzes überliefert ist, mit der Julian, der Förderer der Städte und der munizipalen Selbstverwaltung, die Enteignung dieser Ländereien im Zuge der Konfiskation der städtischen Einnahmequellen unter Konstantin habe rückgängig machen wollen. Da ein einschlägiger Konfiskationsakt wie gesagt nicht überliefert ist, gilt Julians Erlaß als einer der Hauptbelege dieser Globalenteignung. Bereits vor einigen Jahren hat jedoch Hans-Ulrich Wiemer gewichtige Einwände gegen diese Deutung vorgebracht. ${ }^{9}$ Wiemer macht zum einen geltend, daß die vermeintlich massive Kursänderung bei Ammian lediglich in einer beiläufigen Notiz Erwähnung findet, im „Prosphonetikos"des Libanios (der immerhin ein ebenso glühender Verfechter munizipaler Rechte wie Bewunderer Julians war) nur en passant vermerkt ist und im „Epitaphios" nicht einmal einer Erwähnung für würdig erachtet wird. ${ }^{10} \mathrm{Zum}$ anderen führt Wiemer eine ganze Reihe von Belegen aus literarischen, epigraphischen und juristischen Quellen an, die zweifelsfrei belegen, daß die Städte auch vor dem „Restitutionsakt“ Julians Eigentumsrechte an Grundbesitz und anderen Einkommensquellen besaßen und ausübten:

So belegen die unter der Bezeichnung „Landlisten“ geläufigen Steuerdokumente aus dem Hermopolites in den 350er Jahren mehrmals die Verpach-

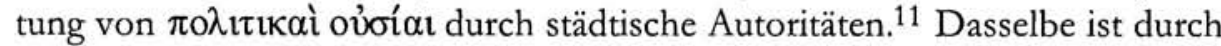
Libanios für das syrische Antiocheia belegt, als er Anfang der 360er Jahre, noch unter Kaiser Constantius II., für die Verpachtung von Gemeindeland an die städtischen Lehrer plädierte; ${ }^{12}$ in beiden Fällen konnten die Städte also ein wichtiges Besitzrecht ausüben. Weiterhin berichtet Ammian, der Bischof von Alexandreia habe Constantius die Konfiskation von städtischen Immobilien im ägyptischen Alexandreia insinuiert; ${ }^{13}$ daraus läßt sich schließen, daß

8 Amm. 25, 4, 15; der Einwand, vectigal könne nicht den Pachtzins meinen, ist von H.-U. Wiemer, Libanios und Julian: Studien zum Verhältnis von Rhetorik und Politik im vierten Jahrhundert n. Chr., München 1995, 103 Anm. 94 mit guten Gründen widerlegt worden. Außerdem meint vectigal in Verbindung mit fundi auch anderswo den Pachtzins: so z. B. in CTh 5, 15, 14; 5, 15, 15; 5, 15, 17.

9 Wiemer, Libanios (wie Anm. 8), 102-107.

10 Lib. Or. 13,45 f.

11 P. Landlisten G 184; 235; 271; F 127; 137; 474.

12 Lib. Or. 31, 16-20.

13 Amm. 22, 11, 6. 
sie bis dahin in städtischem Eigentum gelegen haben müssen. Auch über eigene Steuertitel konnten die Städte offenbar verfügen: Im Jahre 331 bestätigte ein epigraphisch überlieferter Brief Konstantins der Gemeinde Orkistos in Phrygien, daß sie der Stadt Nakoleia, zu deren Stad tterritorium sie bis kurz zuvor gehört hatte, keine Abgaben mehr leisten müsse, da sie mittlerweile selbst Stadtrecht erlangt hatte. ${ }^{14}$ Der Brief reagiert auf eine Klage von Orkistos, weil Nakoleia weiterhin Tribut einforderte - offenbar sah die Stadt Nakoleia sich also auch nach der vermeintlichen Enteignung unter Konstantin dazu berechtigt, in eigenem Namen Abgaben zu erheben.

Diese Quellen zeigen unzweifelhaft, daß von einer vollständigen Konfiskation städtischer Ländereien und anderer Einnahmequellen zu irgendeinem Zeitpunkt vor Julian keine Rede sein kann. Daraus läßt sich folgern, daß die Konfiskation nie universaler Natur war. Die Quellenlage erlaubt aber einen noch weitergehenden, bislang nicht gesehenen Schluß: nämlich den, daß die Historizität des Enteignungsaktes grundsätzlich in Zweifel gezogen werden kann. Diese Zweifel sind vollauf berechtigt, denn nicht eine einzige Quelle vermag ihn direkt oder indirekt zu belegen. Weder unter Diokletian noch unter Konstantin gibt es dafür irgendeinen positiven dokumentarischen oder literarischen Beleg, obwohl eine beiden Herrschern feindlich gesonnene historiographische Tradition existiert, die sich eine so einschneidende Maßnahme sicherlich nicht hätte entgehen lassen: Laktanz geht gleich zweimal ausführlich und polemisch auf die Fiskalpolitik Diokletians ein und zählt dabei auch deren angeblich desaströse Folgen für die Städte auf. ${ }^{15}$ Eine Globalenteignung ihrer Einkünfte hätte dabei nicht fehlen dürfen. Einen ganzen Kata$\log$ fiskalpolitischer Untaten Konstantins gegenüber den Städten verzeichnet Zosimos; auch bei ihm verlautet jedoch nichts von der doch bestens zur Aussageabsicht des Autors passenden Enteignung ihrer Ländereien und Gefälle. ${ }^{16}$ Bezeugt ist unter Konstantin und seinen Nachfolgern lediglich eine groBe Zahl von Konfiskationsakten an den Besitzungen heidnischer Heiligtümer, die zuweilen in städtischer Verwaltung lagen, ${ }^{17}$ doch stehen diese Maßnahmen in einem spezifischen politischen und religiösen Kontext und dürfen deshalb nicht als Beleg für eine globale Enteignung sämtlicher städtischer Einkommensquellen in Anspruch genommen werden.

14 MAMA VII 305 \$III; vgl. zuletzt den Kommentar von D. Feissel, L'adnotatio de Constantin sur le droit de la cité d'Orkistos en Phrygie, AnTard 7, 1999, 255-267.

15 Lact. Mort. pers. 7 und 23.

16 Zos. 2, 38, 4.

17 Vgl. die unten in Anm. 24 genannte Literatur. 
In der Forschung wird mangels direkter Belege eine Reihe von Zeugnissen aus der ersten Hälfte des vierten Jahrhunderts als indirekte Belege für die Enteignung namhaft gemacht. Diese Interpretation der Zeugnisse hält jedoch einer Überprüfung in keinem Fall stand. In der Konstitution CTh 4, 13, 5 bestätigte Kaiser Constantius II. einem Vikar von Africa im Jahre 358 die offenbar schon länger gebräuchliche Regelung, daß den Städten seines Sprengels ein Viertel der vectigalia zur Reparatur öffentlicher Gebäude zur Verfügung gestellt werden könne. Bei diesen vectigalia, so lautet die gängige Interpretation des Dokumentes, handele es sich um städtische Zolleinnahmen, die folgerichtig zu irgendeinem Zeitpunkt vorher konfisziert worden sein müßten. Dieser Schluß ist jedoch keineswegs zwingend. Denn einmal davon abgesehen, daß einem Erlaß, der seinem Adressaten zufolge zunächst einmal ausschließlich im Vikariat Africa Geltung besaß, keine reichsweite Regel zu entnehmen ist, gibt es keinerlei Anhaltspunkt dafür, daß hier städtische vectigalia gemeint waren. Genauso gut könnte die Formulierung beispielsweise Einkünfte aus Reichszöllen im Sinn haben, die den Städten im Zuge kaiserlicher Munifizenz überwiesen werden sollten. ${ }^{18}$ Derselbe Einwand entkräftet auch den Aussagewert einer Notiz in der Konstitution CTh 9, 17, 2, die den Statthaltern im Jahre 342 die Verwendung von Spolien aus Grabmälern für Baumaßnahmen untersagt, „da sie diese aus den vectigalia und anderen titult ${ }^{* 19}$ bestreiten sollten: In wessen Namen diese vectigalia erhoben wurden, ist auch dieser Aussage nicht zu entnehmen.

Ein Indiz für die Konfiskation städtischer Liegenschaften will man schließlich auch in einem Brief des Libanios aus der Regierungszeit Julians entdeckt haben, in dem er die Restituierung eines Gebäudes an die Stadt Tyrus erwähnt, das durch Konstantin oder Constantius II. an einen Günstling verschenkt worden war. ${ }^{20}$ Eine vorangehende globale Konfiskation des städtischen Grundbesitzes setzt freilich auch das nicht voraus. Denn abgesehen davon, daß unbekannte Hintergründe ein punktuelles kaiserliches Eingreifen in das städtische Vermögen rechtfertigen mochten, gibt es auch hier andere

18 Vectigal kann in der spätrömischen Verwaltungssprache unspezifisch für Abgaben jeglicher Art stehen (s. z. B. oben Anm. 8), doch in der weit überwiegenden Zahl meint der Begriff Zollabgaben. Eine terminologische Differenzierung zwischen Lokal- und Reichszöllen läßt sich dabei nicht feststellen: Vgl. die Wortuntersuchungen bei Delmaire, Largesses sacrées (wie Anm. 4), 275f. und D. Nonnis/C. Ricci (Hgg.), Vectigalia municipali ed epigrafia: un caso dell' Hirpinia, in: Finanze municipali (wie Anm. 4), 41-59, hier: $56-$ 59, sowie bei Merola, AARC 13, 2001 (wie Anm. 4), 285-293.

19 ... nam ex vectigalibus vel aliis titulis aedificare debuerunt.

20 Lib. Ep. 828; vgl. zu den Einzelheiten des Vorgangs Liebeschuetz, Antioch (wie Anm. 4), 152 Anm. 1. 
Erklärungsmöglichkeiten: Der Staat nahm, wie noch zu zeigen sein wird, unabhängig von der Frage nach dem Eigentum an den städtischen Einkommensquellen immer wieder Einfluß auf die Verpachtung städtischer Ländereien. Außerdem war die hier betroffene Immobilie vielleicht gar nicht in städtischem Grundbesitz gelegen, sondern stammte aus dem unter Julian restituierten Eigentum der Tempel, das sich häufig in der Verwaltung der Städte befand. ${ }^{21}$

Keiner der angeblichen indirekten Belege für eine Konfiskation in der ersten Hälfte des vierten Jahrhunderts erzwingt also die Annahme einer Globalenteignung zu irgendeinem Zeitpunkt vor der Regierungszeit Julians. Ergänzt man dieses Ergebnis um die zuvor genannten Zeugnisse für das Fortbestehen einer eigenständigen Verfügung der Städte über Liegenschaften und Steuertitel, so ergibt sich daraus, daß die These einer Konfiskation im frühen vierten Jahrhundert nicht nur jeden positiven Belegs ermangelt, sondern im Gegenteil sogar einer ganzen Reihe von Quellen direkt widerspricht. Daß die Forschung trotz dieser Quellenlage an der These der Globalenteignung festhält, erklärt sich daraus, daß die Zeugnisse unter der Prämisse gelesen werden, unter Julian habe eine umfassende Restitution der städtischen Liegenschaften und anderer Einkommensquellen an die Gemeinden stattgefunden (was das Postulat eines vorangehenden, ebenso umfassenden Konfiskations-

21 Zuweilen liest man als Argument für die Existenz des Konfiskationsaktes, daß Constantius II. im Jahre 355 durch Julian für Wohltaten gegenüber den Städten gepriesen worden sei, die unter seinen Vorgängern Mangel gelitten hätten (Iul. Or. 1, 42D-43A). Aus diesem topischen Herrscherlob geht freilich nicht mehr als ein vager Hinweis auf kaiserlichen Euergetismus hervor, sicher jedoch kein zwingender Schluß auf eine vorangehende Konfiskation. In CJ 11, 42, 1 (Diokletian) wird die Umwidmung von Geldern, die Spiele finanzieren sollten, für Baumaßnahmen angeordnet; wenn es sich dabei nicht ohnehin um kaiserliche Z uschüsse handelt, impliziert das zwar eine Einflußnahme des Kaisers auf die Verwendung städtischer Finanzen, nicht aber deren totale Enteignung (vgl. aber Delmaire, Largesses sacrées [wie Anm. 4], 649 und Lepelley in: Finanze municipali [wie Anm. 4], 242-244). Dasselbe gilt für die zahlreichen Belege, die die Kontrolle städtischer Baumaßnahmen durch die Statthalter bezeugen, darunter auch eine unten noch zu behandelnde Inschrift aus Chalkis aus dem Jahr 359, wo der Statthalter die Verwendung

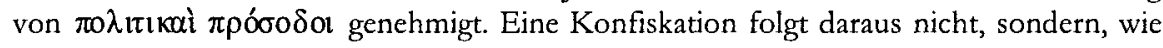
später noch ausgeführt werden wird, lediglich eine Aufsichtsfunktion. Lepelley a. a. O. 244f. schließlich will in einem dakischen Meilenstein (AE 1992, 1510), der mit den Worten recuperata re publica [---] in antiquam ce(n) suram dignitatemque reuocauit endet, die Restitution der fundi rei publicae durch Julian bestätigt sehen. Dieser Schluß ist nicht nachvollziehbar. Auch der Bauboom in Afrika seit 364, den ders., Cités de l'A frique (wie Anm. 4), $101-106$ an den julianischen Restitutionsakt knüpfen wollte, ist an sich kein hinreichender Beweis für die Konfiskation und Restitution sämtlicher städtischer Einnahmequellen. 
aktes nach sich zieht). Gibt man jedoch diese, wie die Untersuchung gezeigt hat, durch nichts gestützte Prämisse auf, folgt daraus, daß Julians Maßnahme nicht der Revokation einer globalen Konfiskation unter Konstantin gedient haben kann - weil es diese nie gegeben hat.

Diese Lösung hat den unzweifelhaften Vorzug, die Quellenlage ohne die Annahme eines Totalverlusts in der Überlieferung der angeblichen Konfiskation und ohne das zweifelhafte Zeugnis vermeintlicher indirekter Belege erklären zu können. Wie ist dann jedoch der „Restitutionsakt“ Julians zu deuten? Wiemer hat den überzeugenden Vorschlag gemacht, daß Julians Maßnahme nicht der Gesamtheit des städtischen Grundeigentums galt, sondern lediglich die Besitzungen der enteigneten städtischen Heiligtümer betraf. Die beiden Quellenbelege lassen diese Interpretation zu: Die Konstitution CTh 10, 3, 1 bezeichnet die betroffenen Ländereien mit der unspezifischen Vokabel possessiones publicae, die auch das Tempelland meinen kann, ${ }^{22}$ Ammian spricht lediglich von vectigalia cum fundis, also vom Pachtzinsaufkommen nicht näher eingegrenzter Ländereien. Daß die betroffenen Liegenschaften in der Konstitution nicht exakt benannt werden, stellt kein Gegenargument dar: Die mangelnde Präzision mag sich aus der fragmentarischen Überlieferung des Textes erklären, könnte aber auch dem Umstand geschuldet sein, daß die Kaiserkonstitutionen zumeist in Reaktion auf konkrete Anliegen - hier vielleicht eine Petition einer oder mehrerer Städte - entstanden, bei denen dem Verfasser ebenso wie dem oder den Adressaten der kaiserlichen Verlautbarung deren konkreter Sachbezug geläufig war. Nicht zuletzt gilt es auch zu beachten, daß die sachliche Prägnanz in dieser Textgattung häufig der notorischen Neigung spätrömischer Hofjuristen zum Opfer fiel, die Begrifflichkeit der Verwaltungssprache ihrem sprachlichen oder literarischem Geschmack anzupassen.

Überzeugungskraft gewinnt Wiemers Interpretation dadurch, daß die Restitution des Tempellands sich in einen bestens bezeugten historischen Kontext einfügt und Julians Maßnahme dadurch überdies einen - im Unterschied zu dem hinsichtlich seiner Originaliät und Intensität bezweifelbaren

22 Vgl. A. H. M. Jones, The Greek City: From Alexander to Justinian, Oxford 1940, 227229; A. Bowman, The Town Councils of Roman Egypt, Toronto 1971, 97f. für Quellen, die die städtische Verwaltung von Tempelgütern belegen und damit die Bezeichnung von Tempelland als possessiones publicae rechtfertigen; vgl. jetzt auch A. d'Hautcourt, Les cités grecques et les revenus de leurs sanctuaires. L'exemple de l'Asie Mineure à l'époque romaine, in: Finanze municipali (wie Anm. 4), 249-260. 
Programm zur „Städteförderung“23 - klar konturierten und überzeugenden Motivationszusammenhang gewinnt. Denn anders als die vermeintliche Globalenteignung sind Konfiskationen von Tempelbesitz unter Konstantin und seinen Nachfolgern reichlich bezeugt. ${ }^{24}$ Und daß gerade Julian diese Eingriffe rückgängig machen wollte, erklärt sich im Zusammenhang seiner paganen Restaurationspolitik von selbst. In der Tat werden vor diesem Hintergrund auch die lediglich beiläufigen Bemerkungen eines Ammian oder Libanios verständlich: Denn die Religionspolitik Julians einschließlich der Renaissance der Tempel würdigen jene beiden Bewunderer des Kaisers zweifellos in angemessener Weise, während die Rückgabe ihres Grundbesitzes in diesem Zusammenhang nur ein administratives Detail darstellte. Ebenjene Passage in Libanios' „Prosphonetikos" liefert im übrigen noch ein weiteres, starkes Argument dafür, daß Julians Restitution nicht das gesamte Gemeindeland betraf, sondern nur den Tempelbesitz. Denn ihr Resümee läßt an der religionspolitischen Motivation der Maßnahme keinen Zweifel: „Die Verehrung in den Tempeln“, so heißt es dort, „wieder einzuführen, nachdem sie unterdrückt worden war, ist nicht weniger, als sie zum ersten Mal einzuführen“. ${ }^{25}$

\section{Die Quotierungsregel}

Für die Frage nach den Eigentumsverhältnissen an den städtischen Finanzquellen bleibt also festzuhalten, daß es für die gesamte erste Hälfte des vierten Jahrhunderts bis zum Tode Julians keinen einzigen Quellenbeleg für den von der Forschung postulierten globalen Konfiskationsakt städtischen Eigentums gibt. Wie aber stellt sich das Problem in der zweiten Jahrhunderthälfte und darüber hinaus, im fünften und sechsten Jahrhundert, dar? Gab es, wie die Forschung meint, eine (erneute) Konfiskation gleich zu Beginn der Regierung Valentinians und Valens'? Gibt es aus dieser Zeit einen Quellenbeleg für einen solchen Enteignungsakt, sei er vor oder nach Julian? Die Antwort muß, wie der folgende Abschnitt zeigen wird, auch hier negativ ausfallen.

23 Vgl. die Untersuchung von E. Pack, Städte und Steuern in der Politik Julians: Untersuchungen zu den Quellen eines Kaiserbildes, Brüssel 1986, 57-259.

24 Quellen bei Delmaire, Largesses sacrées (wie Anm. 4), 641-643 + 648-656; vgl. zuletzt D. Metzler, Ökonomische Aspekte des Religionswandels in der Spätantike: Die Enteignung der heidnischen Tempel seit Konstantin, Hephaistos 3, 1981, 27-40; B. Enjuto Sánchez, Las disposiciones judiciales de Costantino y Juliano a propósito de las tierras de los templos paganos, Gerión 18, 2000, 407-423.

Lib. Or. 13, 46. 
Am 7. September $374^{26}$ stellte Kaiser Valentinian in Mainz einen Erlaß an den Prokonsul von Africa, Paulus Constantius, aus, der im „Codex Theodosianus" als Konstitution 4, 13, 7 überliefert ist:

Ex reditibus rei publicae omniumque titulorum ad singulas quasque pertinentium civitates duae partes totius pensionis ad largitiones nostras perveniant, tertia probabilibus civitatum deputetur expensis.

Von den Einkünften der Stadt und allen Abgaben, die einzelnen Städten gehören, sollen zwei Teile der Gesamteinnahmen an die sacrae largitiones gehen, der dritte aber soll den billigenswerten Ausgaben der Städte zur Verfügung gestellt werden.

Das Dokument setzt also einen Schlüssel fest, nach dem gewisse, hier nicht näher spezifizierte städtische Einkünfte zwischen Gemeinde und Fiskus aufgeteilt werden sollen. Um welche Einkünfte es sich dabei handelte, geht aus

26 Die überlieferte Subskription der Konstitution verzeichnet den Ausstellungsort "Mainz" sowie „7. September 375“, wobei weder ein datum noch ein propositum oder sonst ein Datierungsvermerk überliefert ist. Da die Einfügung eines datum aus chronologischen Gründen in diesem Jahr ausscheidet (im Herbst 375 stand Valentinian an der Donau, der Adressat Paulus Constantius war tot: s. PLRE I, 227 s. v. Constantius 11), ein propositum ohnehin (Konstitutionen an den Prokonsul von Afrika werden nicht in Mainz proponiert), bleibt nur ein datum und die Verbesserung der Jahresangabe in das Jahr 374. Paläographisch ist das einleuchtend, da im Jahr 375 mit einem Postkonsulat von 374 datiert wurde und die Überlieferung daher leicht gestört worden sein kann. Außerdem ist bekannt, daß sich Valentinian im Jahr 374 in Mainz aufhielt, weil er dort einen Friedensvertrag mit dem Alamannenkönig Macrianus schloß: Amm. 30, 3, 4 (das Jahresdatum geht unzweifelhaft aus 30, 3, 1 hervor). Die Konstitution muß also am 7. September 374 in Mainz gegeben worden sein: so auch Seeck, Regesten (wie Anm. 6), $86+244$ sowie F. Pergami, La legislazione di Valentiniano e Valente 364-375 (Materiali per una palingenesi delle costituzioni tardo-imperiali 2, 4), Mailand 1993, 636f. Pergami (619f.) folgert daraus, daß dann auch das Datum der gleich zu behandelnden Konstitution CTh 15, 1, 18 verbessert werden müsse, die ein propositum am 26. Januar 374 verzeichnet; da ihre Anordnungen die in CTh 4, 13, 7 festgehaltenen Maßnahmen jedoch bereits voraussetzten, müsse man sie nach CTh 4, 13, 7 datieren, wofür sich wiederum die Verbesserung der Konsulatsangabe in das Postkonsulat 375 anbiete. Das ist deswegen nicht zwingend, weil CTh 4, 13, 7, wie die Untersuchung zeigen wird, selbst ein Implementierungszeugnis war, das die in ihm geschilderte Verfahrensreform in einem konkreten Fall bestätigte. Da die Datierungskriterien von CTh 15, 1, 18 aber in sich vollkommen schlüssig sind, sollten sie nicht willkürlich verändert werden; das spätere Datum von CTh 4, 13, 7 kann wie gesagt anderweitig erklärt werden. Es bleibt für CTh 15, 1, 18 also bei dem überlieferten propositum am 26. Januar 374. 
der Parallelüberlieferung hervor: Am 26. Januar $374^{27}$ wurde in Sirmium die Konstitution CTh 15, 1, 18 an den Prätoriumspräfekten von Italien, Afrika und dem Illyricum, Sextus Petronius Probus, proponiert. Die Konstitution behandelt die Frage, was zu tun sei, wenn bei der Finanzierung von Bauvorhaben, die aus städtischen Geldern bestritten werden, Engpässe auftreten:

Si civitatis eius res publica tantum in tertia pensionis parte non habeat, quantum coeptae fabricae poscat inpendium, ex aliarum civitatum rei publicae canone praesumant, tertiae videlicet portionis.

Wenn das Stadtvermögen dieser Stadt im dritten Teil der Einkünfte nicht soviel besitzt, wieviel die Kosten des angefangenen Bauwerks erfordern, sollen sie das aus den Pachteinnahmen des Haushalts anderer Städte in Anspruch nehmen, allerdings nur aus dem dritten Teil.

Die Konstitution richtet also, wahrscheinlich in Reaktion auf einen konkreten Fall, eine Art von „Finanzausgleich“ zwischen den Städten ein, nach welchem Einnahmen einer Stadt für Bauprojekte einer anderen verwandt werden dürfen, ${ }^{28}$ begrenzt aber die Zugriffsmöglichkeit im Interesse der betroffenen Städte auf ein Drittel des canon. Für das Verständnis der valentinianischen Quotierungsregel bedeutsam ist, daß eine Stadt für Baumaßnahmen nur über ein Drittel ihrer pensiones verfügen kann; ein Dossier von Konstitutionen aus dem Jahr 395, in dem diese Bestimmung - wiederum in bezug auf ein konkretes Problem - bestätigt wird, zeigt, daß der Begriff pensio eine Einnahme bezeichnet, die, wie es dort heißt, „,von den Liegenschaften und Ländereien einer Stadt als jährliche Abgabe erbracht wird". ${ }^{29}$ Mit pensio meint die Konsti-

27 Zum Datum s. die vorhergehende Anm.

28 Das Modell machte, wie spätere Belege für dieses Verfahren zeigen, Schule: CTh 15, 1, 26 (390) an Polemius, Prätoriumspräfekt von Italien und dem Illyricum (PLRE I, $710 \mathrm{~s}$. v. Polemius 5; Africa ist in seiner Amtsbezeichnung immer ausgespart, doch ist kein anderer Präfekt für Africa zu dieser Zeit bekannt) ermöglicht für den Fall, daß die eigenen Steuer- und Zolleinnahmen einer Stadt, die vectigalia, erschöpft sind, für Baumaßnahmen die Inanspruchnahme der vectigalia anderer Städte.

29 ... ex locis fundisve rei publicae annua praestatione confertur. so CTh 15, 1, 33 vom 5. Juli 395 an einen Vincentius, aller Wahrscheinlichkeit nach Vikar in Britannien oder Gallien (s. unten Anm. 32), wo bestätigt wird, daß die Städte zur Reparatur von Gebäuden (moenia) nicht mehr als den dritten Teil des canon in Anspruch nehmen dürfen; nach der Ausfertigung desselben Bescheids an den comes sacrarum largitionum (CTh 15, 1, 32) vom 21. Juni 395 ging es konkret um Arbeiten an einer Thermenheizung. Beinahe wörtlich dasselbe wiederholt als Replik auf eine Petition einen Monat später noch einmal CTh 5, 14, 35 vom 6. August an den Nachfolger des Eusebius, Hadrianus. Offenbar hatte also eine Stadt im Amtsbereich des Vincentius - erfolglos - beantragt, mehr als das ihr zustehende Drittel 
tution CTh 15, 1, 18 also den canon, den Pachtzins von städtischem Land, und in der Tat gestattet sie denn auch nur die Inanspruchnahme des canon anderer Städte. ${ }^{30}$

Der Finanzausgleich soll dann greifen, wenn, wie oben zitiert, „das Stadtvermögen im dritten Teil der Einkünfte" nicht ausreicht. Damit ist die Teilungsquote der städtischen Einnahmen, wie sie in Ex reditibus formuliert wurde, in CTh 15, 1, 18, dem „Finanzausgleichsgesetz“, schon vorausgesetzt: Die Stadt kann über die eigenen Einkünfte nur zu einem Drittel verfügen, den

am canon aufwenden zu dürfen. Die Petition wurde wiederholt, aber auch beim zweiten Versuch abgelehnt. Die Zugehörigkeit dieser drei Konstitutionen zu einem Vorgang ist nicht nur wegen ihres geringen Zeitabstandes wahrscheinlich, sondern angesichts der fast wörtlichen sprachlichen Bezüge nicht zu bezweifeln: vgl. insbesondere CTh 15, 1, 33 (praeter tertiam partem eius canonis, qui ex locis fundisque rei publicae quotannis conferri solet) und CTh 5, 14, 35 (... tertiam portionem eius canonis, qui ex locis fundisve rei publicae annua praestatione confertur). In CTh 15, 1, 33 wird auf Valentinians Quote übrigens mit den Worten sicut divi parentis nostri Valentiniani senioris deputavit auctoritas, „wie die Autorität Unseres seligen Ahnen, des älteren Valentinian bestimmt hat", verwiesen; damit ist ein Beleg gegeben, daß Valentinian tatsächlich als Urheber der Quotierungsregel gelten kann und Ex reditibus nicht bloß ein längst bestehendes Arrangement wiederholte.

30 Eine Wortuntersuchung zeigt, daß die Vokabel canon an dieser Stelle in der Tat keine andere als die prägnante Bedeutung „Pachtzins von städtischem Grundbesitz“ haben kann. Prinzipiell umfaßt die Bedeutung des Begriffs canon das ganze Wortfeld „Abgabe“: Als canon in der Bedeutung von "Steuer" wird grundsätzlich die annona urbis bezeichnet (vgl. diverse Konstitutionen der Titel 14, 15 + 16; außerdem CTh 14, 17, 14; 11, 14, 2; $12,6,24+13,5,27 ; 13,5,35$; NMaj $2 \$ 1$; weiterhin kann jede Art von Steuer so bezeichnet werden, allerdings dann immer mit einem qualifizierenden Zusatz: CTh 14, 6, 3: canon Tarracinensis; $10,19,4$ : canon metallicus; $7,6,2$ : canon vestium, $5,11,11$ : annonarii canonis vectigal; 1, 15, 10: canon annonae; 1, 15, 14: canon Africae, möglicherweise die annona urbis; 6 , 3, 4: canon senatorius, wohl die gleba senatus, $1,12,7$ : annonario ac superindicto canone; 16, 8, 29: canon de Synagogibus; NMaj 7 \$16: omnem canonem tam ad arcam praefecturae pertinentem quam sacris vel privatis largitionibus inferendum. In der überwiegenden Zahl der Fälle meint canon jedoch den „Pachtzins“; wenn der Begriff überdies wie hier ohne einen qualifizierenden Zusatz auftritt, hat er fast immer diese Bedeutung und wird ohne Erläuterung auch beinahe ausschließlich im Zusammenhang von Domänenland benutzt: CTh 5, 15, 17; 5, 13, $4 ; 11,16,13 ; 5,14,30 ; 5,14,34 ; 5,16,29 ; 12,9,3 ; 10,3,5 ; 11,7,19 ; 5,16,33 ; 5,12,2$; $11,5,2 ; 11,20,5 ;$ NTh $5,1 \rrbracket 1 ; 19 ; 5,3 \rrbracket 1 ; 26$; NMarc 3 . Einige wenige Ausnahmen bestätigen die Regel: In CTh 11, 16, 8 meint canon ohne Zusatz eine superindictio; 10, 20, 8 bezeichnet die Abgabe der Leinenweber als publicus canon; in 11, 1, 30 und 31 steht canon ohne Zusatz für die annona, unklar bleibt schließlich, welche Abgaben der Begriff in 1, 10, 1 und 9,42,16 umfaßt. Alle diese Bedeutungen treffen jedoch bei der hier diskutierten Konstitution CTh 15, 1, 18 nicht zu. Pensio dagegen ist ein untechnischer Begriff für alle Arten von Zahlungen und wird an dieser Stelle benutzt, um den Gegensatz zwischen „städtischen Einkünften aller Art" und der Beschränkung auf die Zinseinnahmen zu unterstre ichen. 
Rest kontrolliert der Staat, der ihn gegebenenfalls sogar anderen Städten überweisen kann. Waren die betroffenen Einkünfte in Ex reditibus nicht näher spezifiziert, zeigt CTh 15,1,18, daß dem dort festgehaltenen Aufteilungsschlüssel zumindest der canon unterlag. Die Quotierung betraf jedoch nicht nur die Pachteinnahmen. Im Jahr 431 oder 432 bestimmt die Konstitution CJ 4, 61, 13 an den jüngeren Nicomachus Flavianus, Prätoriumspräfekt von Italien, Afrika und Illyricum: ${ }^{31}$

Exceptis bis vectigalibus, quae ad sacrum patrimonium nostrum quocumque tempore pervenerunt, cetera rei publicae civitatum atque ordinum aestimatis dispendiis, quae pro publicis necessitatibus tolerare non desinunt, reserventur, cum duas portiones aerario nostro conferri prisca institutio disposuerat.

Mit Ausnahme derjenigen vectigalia, die zu einem gewissen Zeitpunkt an Unser kaiserliches patrimonium gelangt sind, sollen die anderen den geschätzten Aufwendungen der Städte und Stadträte, die sie für öffentliche Notwendigkeiten zu bestreiten nicht aufhören, vorbehalten bleiben, wobei eine althergebrachte Verfügung festgesetzt hat, daß zwei Anteile an Unseren Fiskus abgetreten werden.

Die prisca institutio, Valentinians Quotierungsregel, umfaßte also auch Einnahmen aus den vectigalia, den städtischen Steuern und Zöllen. Mit vectigalia und canon wurden demnach zumindest die regulären Einnahmequellen der Städte zwischen Stadt und Fiskus aufgeteilt. Hinsichtlich der übrigen Einkünfte wird man eine äquivalente Regelung annehmen dürfen.

Die Konstitution Ex reditibus vom September 374, CTh 14, 3, 7, kann jedoch nicht derjenige Erlaß gewesen sein, mit dem die Quotierungsregel eingeführt wurde. In der Tat wurde ja bereits im Januar 374 das „Finanzausgleichsgesetz" CTh 15, 1, 18 proponiert, in dem die Quotierung schon vorausgesetzt ist. CTh 14, 3, 7 muß daher wie CTh 15, 1, 18 ein Implementierungszeugnis der Reform sein, in dem das Verfahren wohl aus konkretem Anlaß dem Prokonsul von Africa bestätigt wurde; ein Hinweis darauf mag

31 Nicomachus Flavianus ist in diesem Amt durch CTh 6, 23, 3 und 11, 1, 36 in den Jahren 431 und 432 bezeugt, CJ 4, 61, 13 selbst hat seine Subskription im Zuge der Überlieferung verloren. Seeck, Regesten (wie Anm. 6), 125+358 meint, die Konstitution sei Fragment desselben Originals, von dem auch die Konstitution CTh 11, 1, 36 stammt, und datiert sie daher auf deren Datum, den 29. April 431. Die dafür vorgebrachten inhaltlichen Bezüge sind jedoch alles andere als zwingend: In CTh 11, 1, 36 geht es um die Grundsteuer, hier jedoch um städtische vectigalia. Die Datierung kann also nicht weiter eingegrenzt werden. 
sein, daß das Dokument explizit von „,billigenswerten Ausgaben“ (probabilia expensa) spricht - vielleicht gab es im Einzelfall Streit um die Verwendung der Gelder. Wurde CTh 15, 1, 18 aber bereits im Januar 374 proponiert, also im Spätjahr 373 ausgestellt, muß die Einführung des neuen Verfahrens in das Jahr 373 oder vielleicht schon 372 fallen.

Weiterhin zeigt die Parallelüberlieferung, daß Valentinians Quotierungsregel kein zeitlich oder örtlich begrenzter legislativer Akt war, sondern dauerhaft und im gesamten Reich Geltung besaß. Seine dauerhafte, zumindest bis zum Zeitpunkt der justinianischen Kodifikation währende Gültigkeit geht daraus hervor, daß die soeben zitierte Konstitution an Nicomachus Flavianus aus dem Jahre 431 als Fragment CJ 4, 61, 13 überliefert ist; da der „Codex Iustinianus“ (im Unterschied zum „Codex Theodosianus“) Konstitutionen obsoleten Inhalts nicht aufnahm, wäre sie andernfalls nicht an dieser Stelle überliefert worden. Was den Geltungsraum der Quotierungsregel anbetrifft, zeigt $C J 4$, 61, 13 ebenso wie die Erlasse über den „Finanzausgleich“, insbesondere CTh 15, 1, 18, daß die Quotierungsregel nicht nur, wie man aus dem Adressaten von Ex reditibus schließen könnte, in der Proconsularis, sondern in der gesamten Zentralpräfektur Gültigkeit besaß, und das oben bereits erwähnte Dossier von Erlassen aus dem Jahre 395 liefert den Nachweis, daß die Quotierungsregel auch in der westlichen Präfektur, in Spanien, Gallien und Britannien, also im gesamten Reichsteil Valentinians, Anwendung fand. ${ }^{32}$

32 Die Konstitution CTh 15, 1, 33 ist an einen gewissen Vincentius adressiert, enthält aber keinen Hinweis auf dessen Amt, da nur die Grußformel have Vincenti karissime nobis überliefert ist. Vincentius muß ein Amt in der westlichen Reichshälfte geführt haben, denn erstens sind die beiden anderen Dokumente des Dossiers, CTh 15, 1, 32 und 5, 14, 35, an zwei comites rerum privatarum des Honorius adressiert, und zweitens war im Jahr 397 ein gewisser Fl. Vincentius Präfekt von Gallien, den man gemeinhin für diesel be Person hält wie den Adressaten von CTh 15, 1, 33 (vgl. PLRE II, 1169 s. v. Vincentius 6). 395, als CTh 15, 1, 33 ausgestellt wurde, konnte Vincentius freilich noch nicht Präfekt gewesen sein, da 396 ein anderer in diesem Amt belegt ist (PLRE 1, 435f. s. v. Hilarius 11). Da es als äußerst unwahrscheinlich gelten kann, daß Vincentius noch zwei Jahre vor seiner Präfektur eine Statthalterschaft oder eine subalterne Position in der Finanzverwaltung z. B. als rationalis innehatte, die beiden Finanzcomitivae aber 395 anderweitig besetzt waren (CRP im Juli 395 ist Eulogius, CSL Eusebius oder schon Hadrianus: PLRE I, 294 s. v. Eulogius 2; $306 \mathrm{~s}$. v. Eusebius 32; $406 \mathrm{~s}$. v. Hadrianus 2), bleiben für die Identifizierung seines Amtes nur ein Prokonsulat oder ein Vikariat. Prokonsul von Afrika im Juli 395 ist ein gewisser Ennoius (PLRE I, 278 s. v. Ennoius), als Vikare sind Fabius Pasiphilus als vicarius Italiae und urbis bis zum 6. Januar 395 (PLRE I, 669 s. v. Pasiphilus 2), Hierius im März 395 (CTh 16, 2, 29) und später im Jahr Seranus (PLRE II, 992 s. v. Seranus) als vicarii Africae sowie Petronius als Vikar von Spanien seit dem 27. Juli 395 (PLRE II, 862 s. v. 
Einen Beweis, daß die Quotierungsregel auch im Ostteil des Reiches, der von Valentinians Bruder Valens regiert wurde, Geltung hatte, liefert zwar erst die Übernahme des Dossiers von 395 (CTh 15, 1, 32 als CJ 8, 11, 11, CTh 5, 14, 35 als CJ 11, 70,3) und der verlorenen Vorlage der oben genannten Konstitution CJ 4, 61, 13 in die justinianische Kodifikation. Es gibt allerdings keinen Grund zu bezweifeln, daß das von Anfang an auch im Osten der Fall war.

In den frühen 370er Jahren setzten Valentinian und Valens also gemeinsam einen bis mindestens ins sechste Jahrhundert hinein geltenden Schlüssel fest, nach dem die regulären Einkünfte aus den Einnahmequellen der Städte zwischen Gemeinde und Fiskus aufgeteilt werden sollten. ${ }^{33}$ Die Forschung stellt diese Maßnahme wie selbstverständlich in den Kontext der angeblichen (Re-)Konfiskation der städtischen Einkünfte durch Valentinian und Valens, die hier vorausgesetzt sei. Auch diese Deutung beruht jedoch auf der, wie sich zeigen wird, falschen Prämisse einer Globalkonfiskation. Wiederum fragt man sich nämlich, warum die vergleichsweise sehr dichte historiographische Überlieferung für die Regierungszeit Valentinians und Valens' sich über den Enteignungsakt, sollte er denn stattgefunden haben, ausschweigt. Nach Erklärung verlangt insbesondere auch der Mangel an entsprechendem dokumentarischem Quellenmaterial, zumal gerade die Fiskalpolitik der frühen Regierungsjahre 364 und 365 in den juristischen Quellen dicht bezeugt ist. ${ }^{34}$

Umgekehrt existiert jedoch eine Fülle positiver Quellenbelege bis in die Regierungszeit Justinians, die zeigen, daß die Städte auch nach 364 Eigen-

Petronius 1) belegt. Vincentius kann demnach nur vicarius Britanniarum oder quinque provinciarum gewesen sein, für die im Jahr 395 sonst niemand belegt ist.

33 Unklar ist, ob eine der beiden Parteien die Einkünfte verwaltete und einzog und dann der anderen den ihr zukommenden Anteil übergab, oder ob die Einkommensquellen selbst aufgeteilt wurden. Für ersteres ließen sich I.Ephesos 42; Lib. Or. 50, 5; CJ 4, 61, 13 und 11, 70, 6 sowie eine Reihe anderer Quellen anführen, für letzteres vielleicht die Existenz der Kategorie der fundi rei publicae im Domänenverband (s. dazu unten Anm. 35), die weit überwiegende Zahl der Quellen jedoch läßt keine Entscheidung zu. Vielleicht wurde das Problem auch individuell je nach Art der Einkünfte etc. gelöst. In jedem Fall ist die Quellenlage zu dünn, um mit Roland Delmaire (s. oben Anm. 4) annehmen zu wollen, das Verfahren sei irgendwann im späten vierten Jahrhundert geändert worden.

34 Zuweilen wird auf Valentinians CTh 10, 3, 2 (372), wo Dekurionen die Pacht von Gemeindeland untersagt wird, als Beleg dafür verwiesen, daß die Städte keine Kontrolle mehr über ihr Land besaßen. Dieses Verbot war in seinem Geltungsraum jedoch sicherlich situativ begrenzt, denn anderswo sind Kurialen ganz selbstverständlich als Pächter belegt: z. B. CJ 11, 59, 1; 5; CTh 10,3, 4; 5; 11, 24, $6 \$ 5 ; 15,1,41$. Tatsächlich dürfte es in CTh 10, 3, 2 lediglich um das auch sonst belegte Verbot gehen, daß die Kurien sich in die lokale Domänenverwaltung einmischten: vgl. z. B. CJ 11, 73, 1 in einem Zusatz zu seiner Vorlage und bereits Dig. 50, 8, 2 (Ulpian). 
tumsrechte an den fundi rei publicae und anderen Einkommensquellen ausübten. So halten zahlreiche Gesetzestexte einen Eigentumstitel der Städte fest, wenn sie beispielsweise Ländereien als praedia quae ad ius civile pertinent bezeichnen. ${ }^{35}$ Wenn man nicht Kategorien wie den Konservatismus der römischen Verwaltung oder überholte Vorstellungen von konzeptionellen Aufweichungen oder terminologischen Unschärfen im spätrömischen Recht bemühen möchte, ist es nicht leicht zu erklären, warum noch mindestens ein Jahrhundert nach der angeblich endgültigen Enteignung des städtischen Grundbesitzes eine (dann materiell falsche) Nomenklatur fortgeführt worden sein sollte. Die Evidenz ist dabei im übrigen keineswegs auf juristische Quellen beschränkt: In der Debatte bislang übersehen wurde eine spätrömische Inschrift aus Thessalien, die den Grenzverlauf zwischen einem privaten Großgrundbesitz und $\tau \grave{\alpha} \delta \eta \mu o ́ \sigma 1 \alpha$, städtischem Land, beschreibt, zugleich aber $\tau \grave{\alpha} \delta \varepsilon \sigma \pi 0 \tau 1 \kappa \alpha ́$, kaiserliches Land, von diesen beiden separat ausweist ${ }^{36}$.

35 So NTh 23 (443); vgl. außerdem z.B. CTh 15, 1, 42 (404; iura civium auf innerstädtische ergasteria); NTh 17, $2 \ 5$ (444: ad ius publicum pertinentes); NMarc 3 (451: praedia iuris civilis); CJ 11, 70, 6 (480: canonis civilis reditus ad suam patriam pertinentis). Kaiser Zeno verbot in CJ 8,12, 1 den discussores städtischer Bauprojekte, „die aus städtischen Einkünften (civiles reditus) oder durch freiwillige Munifizenz errichtet wurden oder werden", die Erhebung einer Sportel - die civiles reditus dürften hier ebenfalls Einnahmen aus städtischen Einkommensquellen anstelle von staatlich zugewiesenen Geldern meinen, denn dann läge hier eine Konstitution gegen die Selbstbereicherung an Staatsmitteln vor. Dieses Thema wird freilich mit keinem Wort erwähnt. Die Tatsache, daß bis in die justinianischen Novellen hinein im Domänenverband die separate Kategorie der fundi rei publicae existiert, impliziert für sich alleine keinen Eigentumstitel der Städte, denn auch die fundi iuris templorum werden zumindest bis ins spätere 5. Jahrhundert hinein als separate Kategorie geführt, obwohl sie nach allgemeiner Auffassung ja tatsächlich konfisziert wurden. Allerdings gewinnt die Tatsache vor dem Hintergrund, daß eine Konfiskation im juristisch prägnanten Sinne einer Enteignung des Gemeindebesitzes nicht belegt ist, möglicherweise doch eine gewisse Signifikanz: Vielleicht weist die Nomenklatur im Domänenverband darauf hin, daß diese Güter vom Fiskus eben nur verwaltet, nicht aber als Eigentum besessen wurden. J. H.W.G. Liebeschuetz, Civic finance in the Byzantine period, BZ 89, 1996, 389407, hier: 389-393 deutet die genannten und Quellen des fünften und sechsten Jahrhunderts so, daß es sich dabei um Gelder handele, die zwar vom Staat erhoben, dann aber den Städten für bestimmte Zwecke wieder zurücküberwiesen worden seien (und insofern mit Recht z. B. als civiles reditus bezeichnet worden sein könnten). Selbst wenn das der Fall wäre, scheitert diese Interpretation an den gleich noch vorzustellenden Quellen, die zweifelsfrei die Erhebung von Einkünften unter städtischer von der unter staatlicher Regie abgrenzen.

36 F. Gschnitzer, Eine spätrömische Grenzinschrift aus Thessalien, Demetrias 5, 1987, 339. 351 mit Taf. XXXIV-XXXV (= ders., Kleine Schriften zum griechischen und römischen 
Auch in der administrativen Praxis bestand demnach weiterhin eine klare Trennung der beiden Güterkategorien.

Das offenkundig also fortbestehende Eigentumsrecht der Gemeinden an ihren Besitzungen war indessen kein bloß nominelles. Zahlreiche Quellen belegen nämlich auch die faktische Ausübung von Besitzrechten durch die Städte. Nach einer Reihe von literarischen und juristischen Quellen vom späten vierten bis ins sechste Jahrhundert konnten die Städte Liegenschaften und andere Güter als Legate und Stiftungen empfangen ${ }^{37}$ und als Käufer und Verkäufer ihrer Güter agieren; in einer Konstitution des Jahres 469 heißt es beispielsweise: „Wenn irgend etwas als Erbschaft, Legat, Fideikommiß oder Stiftung, sei es ein Haus, annonae civiles, irgendwelche Gebäude oder Sklaven ... in das Eigentum irgendeiner Stadt gelangen sollte oder schon gelangt ist, soll es den Gemeinden freistehen, darüber Verträge zu ihrem Vorteil abzuschlieBen, damit der daraus erzielte Höchstpreis der Renovierung und Wiederherstellung öffentlicher Gebäude zukomme“. ${ }^{38}$ In den 380er-Jahren erwähnt Libanios einmal, daß die Stadt Antiocheia über Grundbesitz verfüge, den sie an Pächter ihrer Wahl vergeben könne, ${ }^{39}$ und nach dem Säulenkrawall von 387 rühmt er Kaiser Theodosius dafür, daß dieser durch die Rückerstattung der zur Strafe konfiszierten städtischen Ländereien wahrhaft kaiserliche clementia bewiesen habe. ${ }^{40}$ Hier handelte es sich mit Sicherheit weder um ein

Altertum, Bd. II, Stuttgart 2003, 455-469) mit ausführlichem Kommentar. Für den Hinweis auf diese Inschrift danke ich Hans-Ulrich Wiemer.

37 CIL XIV 2934 = ILS 8375 (385); Lib. Or. 50, 5. CJ 11, 32, 3 (469); 1, 11, 9 (nach 472); 1, 4, 26 (530); NJust 38 (535); 160 (undatiert). Andere Einkommensquellen sind: die Güter von Dekurionen, die die Kurienmitgliedschaft aufgeben (NJust 149); Güter eines Dekurionen, der eine Sklavin zur Konkubine hat (CTh 12,1, 6); stra fweise konfiszierter Besitz korrupter Beamten (CJ 8, 12,1).

38 CJ 11, 32, 3 (469): Si qua bereditatis vel legati aut fideicommissi aut donationis titulo domus aut annonae civiles aut quaelibet aedificia vel mancipia ad ius ... cuiuslibet civitatis pervenerunt sive pervenerint, super bis licebit civitatibus venditionis pro suo commodo inire contractum, ut summa pretii exinde collecta ad renovanda sive restauranda publica moenia dispensata proficiat. Vgl. auch CJ 11, 70, 2; NTh $23 \$ 1$ (443); 160 (undatiert).

39 Lib. Or. 52, 33.

40 Lib. Or. 20, 7. Chastagnol, AARC 6, 1986 (wie Anm. 4), 102 behauptet, diese LibaniosStellen würden durch Or. 48, 3 entkräftet, wo der Verlust städtischen Landbesitzes an den Staat unzweifelhaft impliziert sei. Dort steht allerdings nur, daß die Zahl der Dekurionen rückläufig sei und ihre Äcker jetzt von anderen bebaut würden. Auch Delmaire, Largesses sacrées (wie Anm. 4), 654, für den die Städte, wie oben gezeigt, erst im Jahre 431 Eigentum an Liegenschaften hatten, bestreitet die Signifikanz von Or. 20, 7, weil es dort nur um die Restitution städtischen Territoriums gehe, nicht um die Rückgabe städtischer Domänen. Allerdings dürfte die Wiederherstellung des Territoriums bereits in der 
bloß nominelles Eigentum noch um eine Verwaltung der Güter für den Fiskus, denn nach Libanios bezog die Stadt aus den Verpachtungen selbst Einkünfte. Und die Restitution ihrer Güter nach den Krawallen wäre wohl kaum als herausragender Beweis kaiserlicher Milde für die Stadt gepriesen worden, wenn deren Erträge in die Kasse des Fiskus geflossen wären. Eine faktische Verfügungsgewalt der Städte über die Einkünfte ihrer Ländereien bezeugt auch eine Konstitution Zenos (CJ 11, 70, 6), die im Jahre 480 der Stadt Nikaia das ius exactionis, also die eigenverantwortliche Erhebung des Pachtzinses von einigen Gütern, die ihr einige Zeit zuvor genommen worden waren, restituiert. Eigentum und Nutzung der Güter lagen hier also gleichermaßen bei der Stadt.

Jeglichen Zweifel an der Verfügungsgewalt der Städte über ihre Einkünfte räumen schließlich einige Quellen aus, in denen die Rechte von Fiskus und Stadt an den munizipalen Einkommensquellen gegeneinander abgegrenzt werden. In der Konstitution CTh 5, 14, 35 aus dem oben erwähnten Dossier aus dem Jahr 395 werden die Einnahmen aus dem canon, die aus den loci fundique rei publicae erzielt werden, explizit von den vectigalia publica abgesetzt, „die schon immer vollständig die Ausgaben Unseres Fiskus deckten"; von ihnen „etwas unter dem Titel der Städte abzuzweigen“, sei unzulässig. ${ }^{41}$ Anders als gewisse vectigalia floß besagter canon, so läßt sich dieser Anordnung im Umkehrschluß entnehmen, also nicht dem Fiskus zu, sondern in städtische Kassen, ja offenbar galt es sogar zu verhindern, daß diese mehr Einkünfte usurpierten als ihnen zustand.

Dieser Fall einer expliziten Gegenüberstellung staatlich und städtisch verwalteter Gelder steht nicht alleine: In der oben bereits genannten Konstitution CJ 4, 61, 13 an Nicomachus Flavianus sah sich Valentinian III. im Jahr 431 genötigt, den von Valentinian I. und Valens festgesetzten Aufteilungsschlüssel in bezug auf die vectigalia zu wiederholen. Oben wurde die Passage

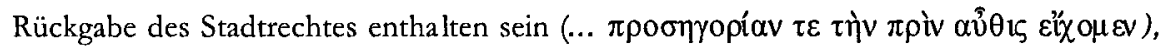
während nun die Rückgabe von Vermögenswerten (darunter auch Gelder für Spiele und die annona) berichtet wird; überdies scheint die Formulierung $\tau \grave{\eta} v$ ai் keren Besitz zu implizieren als lediglich den eines Territoriums. Ebensowenig aussagekräftig sind für Delmaire a. a. O. die anderen Libanios-Stellen, da sie nur agonothetische Güter beträfen, also für die Frage insignifikant seien. Abgesehen von der Frage, warum die agonothetischen Güter von den anderen städtischen Gütern zu trennen sein sollten, geht es in Or. 31, 16-20 zwar durchaus auch, aber keineswegs ausschließlich um agonothetisches Land, und in den anderen Quellen ist von dieser Einschränkung überhaupt keine Rede.

41 De vectigalibus itaque publicis, quae semper ex integro nostri aerarii conferebant expensas, nibil ommino decerpi nomine civitatum permittimus. 
zitiert, in der diejenigen vectigalia, die an den Fiskus gehen, ausdrücklich von den städtischen abgesetzt werden, die im Verhältnis 2:1 zwischen Fiskus und Stadt aufgeteilt wurden. Dann heißt es weiter:

\begin{abstract}
Atque banc tertiam iubemus adeo in dicione urbium municipumque consistere, ut proprii compendii curam non in alieno potius quam in suo arbitrio noverint constitutam. designatae igitur consortium portionis eatenus iuri ordinum civitatumque obnoxium maneat, ut etiam locandi quanti sua interest licentiam sibi noverint contributam.
\end{abstract}

Jenes Drittel soll so weitgehend der Verfügungsgewalt der Städte und Kurialen unterstehen, daß sie wissen, daß die Verantwortung für ihren eigenen Vorteil eher in ihrer eigenen Entscheidungsgewalt als in derjenigen eines anderen gründet. Der Besitz $^{42}$ an dem festgesetzten Drittel bleibe insoweit dem Rechtsanspruch der Kurien und Städte unterworfen, daß sie wissen, daß ihnen auch das Recht der Verpachtung zu dem ihnen angelegentlichen Zinssatz überlassen bleibt.

Die Städte haben für ihren Anteil an den städtischen Einkünften also auch hier ein eigenständiges Verfügungsrecht, das ausdrücklich von dem des Fiskus abgesetzt wird.

Eine explizite Trennung der durch die Gemeinde eingezogenen städtischen Einkünfte von den dem Fiskus zufließenden findet sich auch später noch. Auf Bitten der Stadt Herakleia Salbakes ordnete Kaiser Theodosius II. in der Konstitution NTh 23, 1 aus dem Jahr $443^{43}$ an, unrechtmäßig in Privatbesitz übergegangene Liegenschaften in ihren ursprünglichen Status, also in den Besitz der Stadt, zurückzuführen; ausgenommen davon soll lediglich Besitztum sein, von dem urkundlich bewiesen werden könne, daß es durch die Domänenverwaltung in kaiserlichem Auftrag veräußert wurde. ${ }^{44}$ Die Beispiele lassen sich fortsetzen: Zwei Jahre später, 445, befahl Valentinian III., den Hafenzoll der numidischen Städte Rusicade und Chullu in einer

42 Die Vokabel consortium kann im Sinne eines ,gemeinschaftlichen Besitzes“ (CTh 11, 13, 1; vgl. auch ThlL IV, $488 \mathrm{~s}$. v. consortium I) benutzt werden; ihre Wahl ist hier wohl von der Vorstellung eines „Gemeindebesitzes“ bestimmt gewesen.

$43 \mathrm{Zu}$ Datierung und Ausstellungsort vgl. Ch. Roueché, Theodosius, the Cities, and the Date of the Church History of Sozomen, JThS n. s. 37, 1986, 130-132.

44 Quae ... a procuratore divinae domus vel a viro inlustri comite rerum privatarum iussu nostrae clementiae ... distractae sunt. Die Konstitution sieht außerdem den Sonderfall vor, daß Liegenschaften „auf einmütigen Beschluß der Städte hin“ (communi consensu civitatum) veräußert wurden. 
Quote von 2:3 zwischen Stadt und sacrae largitiones aufzuteilen. ${ }^{45}$ Eine Novelle Marcians im Jahre 451 befiehlt den Pächtern städtischer Güter, die, mit welchem Recht auch immer, keinen Pachtzins gezahlt hatten, diesen von nun an der Stadt zu leisten. Anders liege der Fall jedoch dann, wenn „... die städtischen Güter den Pachtzins der res privata ... schulden [...] - dann sollen sie nicht dieser pragmatischen Sanktion unterliegen, sondern wie gewohnt der res privata den Pachtzins ... zahlen. "46 Noch in der zweiten Hälfte des fünften Jahrhunderts halten die Rechtstexte also eine klare Differenzierung zwischen

45 NVal 13, 1. Daß die Quote nicht der von 372 (1:2) entspricht, mag sich daraus erklären, daß diese das Gesamtaufkommen der städtischen Einkünfte betraf, während die daran beteiligten Einzelposten je nach Situation unterschiedlich aufgeteilt werden konnten. Man muß hier deshalb nicht mit Delmaire, Largesses sacrées (wie Anm. 4), 279f., die Existenz eines gemischt städtisch-staatlichen Zolls annehmen. Die Quellenlage für städtische Zölle in der Spätantike ist ansonsten spärlich: Justinians Edikt 13, 15f, legt zwar die Verwendung eines alexandrinischen Zolles namens exagogion $u$. a. für städtische Zwecke, z. B. Bäder, fest; daraus geht aber nicht hervor, ob das exagogion in der Spätantike ein von der Stadt erhobener oder ein staatlicher Zoll war: vgl. dazu J. Karayannopulos, Das Finanzwesen des frühbyzantinischen Staates, München 1958, 152f. Auch die Zollinschriften der Epoche sind für die Frage nicht hilfreich: I.Mylasa 611 (= CIL III 7151f.) bewahrt eine kaiserliche Antwort auf eine Petition in Sachen Hafenzöllen, die, wie es dort heißt, der Stadt Mylasa ebenso wie dem Fiskus Nutzen bringen solle (Z. 2); da der Rest des Textes jedoch sehr fragmentarisch ist, ist ihm nichts darüber zu entnehmen, ob es sich um Reichs- oder Stadtzölle handelte, wer jeweils das Eigentum daran hatte, wer sie verwaltete und wie sie ggf. zwischen Fiskus und Stadt aufgeteilt wurden (vgl. dazu zuletzt Merola, AARC 13, 2001 (wie Anm. 4), 277-283 und dies., Autonomia locale (wie Anm. 4), 135-137). Eine Inschrift des späten sechsten Jahrhunderts aus Caralis betraf ebenfalls Zölle, die von ihrem Herausgeber J. Durliat, Taxe sur l'entrée de marchandises dans la cité de Caralis (Cagliari) à l'époque byzantine 582-602, DOP 36, 1982, 1-14 als städtisch gedeutet wurden, weil dort auch von gesta municipalia die Rede ist. Der Zustand des Dokument ist freilich so fragmentarisch, daß die Frage, ob hier ein städtischer oder ein staatlicher Zoll erhoben wurde, kaum zu klären ist. Ebenso unergiebig sind die Zollinschriften aus Anazarba, Beirut und Caesarea Maritima: vgl. die Literaturangaben bei Liebeschuetz, Decline (wie Anm. 2), 177 Anm. 45; Quellenüberblick bei Delmaire, Largesses sacrées (wie Anm. 4), 276-278; Merola, Autonomia locale (wie Anm. 4), 134-139. Die Papyri tragen nichts zu der Frage nach einer eigenständigen städtischen Zoll- und Steuererhebung bei, auch die Steuerlisten von Antaiopolis und Aphrodito betreffen nur die Verwendung staatlicher Steuern für staatliche Zwecke: Vgl. dazu zuletzt Liebeschuetz, BZ 89, 1996 (wie Anm. 35), 393-395 mit der Schlußfolgerung, da hier keine städtischen Belange (Bäder etc.) au fgelistet seien, müßten diese aus separaten und dann städtischen Einkünften finanziert worden sein. Dieser Schluß ist nicht zwingend.

46 NMarc $3 \rrbracket 1 \mathrm{f}=\mathrm{CJ} 11,70,5: \ldots$ si quae tamen possessiones iuris civilis canonem privatis largitionibus ... praebent $[. .$.$] , ad banc pragmaticam sanctionem iussionem non pertinebunt, sed privato aerario$ canonem ... inferre ex more debebunt. 
munizipalen Abgabentiteln fest, die dem Fiskus zufließen, und solchen, die den Gemeinden zugute kommen; diese Aufteilung von $\pi 0 \lambda \iota \tau 1 \kappa \grave{\alpha} \chi \rho \eta \mu \alpha \tau \alpha$ zwischen Fiskus und Stadt ist schließlich noch im Jahre 496 durch Anastasius' Erlaß CJ 10, 16, 13, 3 belegt. ${ }^{47}$

Aus diesem Quellenüberblick ergeben sich drei Feststellungen: Erstens zeigt eine Reihe von Quellen vom späten vierten Jahrhundert bis in die Regierungszeit Justinians, daß die Gemeinden auch nach der vermeintlichen (erneuten) Konfiskation unter Valentinian und Valens Eigentum an städtischen Liegenschaften und Steuer- und Zolleinnahmen hatten. Zweitens kann kein Zweifel bestehen, daß dieses Eigentum nicht ein bloß formales war, sondern eine reale Verfügungsgewalt über mindestens einen Teil davon mit sich brachte. Gleichwohl führen die zuletzt genannten Quellen drittens ebenfalls vor, daß es auch städtische Einkünfte gab, die in der Verwaltung des Fiskus lagen und deren Einnahmen er einzog. Wie ist dieser paradoxe Quellenbefund zu deuten? Die Forschung kommt, wie eingangs referiert, $z \mathfrak{u}$ folgender Lösung: Die Städte seien von Valentinian und Valens zwar (wieder) enteignet worden, doch sei man bald davon abgekommen, die Einkünfte auch direkt durch den Fiskus verwalten zu lassen. Denn bei jeder Ausgabe mußten nun die Städte bei den Finanzbehörden vorstellig werden, was langwierig und hauptsächlich der Korruption unter den beteiligten Beamten förderlich gewesen sei. Den Städten sei daher ein Teil der Einkünfte zur eigenständigen Verwaltung und Abgabenerhebung überlassen worden. Dieser Anteil sei zunächst variabel bestimmt, dann aber durch die Quotierungsregel Valentinians Anfang der 370er Jahre pauschal auf ein Drittel festgesetzt worden (wobei das Eigentum an den Abgabentiteln beim Fiskus verblieben sei).

Befriedigen kann auch diese Interpretation nicht. Sie vermag zwar eine Erklärung zu bieten, warum nach der Quellenlage des späteren vierten und fünften Jahrhunderts Städte und Fiskus gleichermaßen über städtische Einkünfte verfügen konnten. Sie kann aber weder die Zeugnisse integrieren, nach denen die Städte auch nach der Reform der 370er Jahre Eigentumsrechte ausübten, noch irgendeinen positiven Beleg für die Konfiskation Mitte der 360er Jahre namhaft machen. Tatsächlich beruft sich die Forschung dafür auf eine einzige Quelle, die die Konfiskation unter Valentinian und Valens zwar wiederum nicht direkt belegt, aus der man aber sowohl die Enteignung sicher

47 Proc. H. A. 26, 6 wirft Justinian vor, die Ausgaben, die Privatleute für die Stadt und das

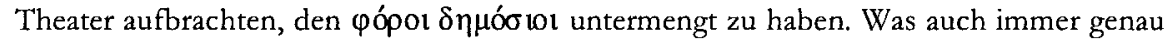
damit gemeint ist, läßt sich daraus doch gewiß keine generelle Konfiskation unter Justinian erschließen, zumal andere Quellen aus seiner Regierungszeit wie gezeigt das Gegenteil belegen. 
erschließen zu können glaubt als auch das beschriebene Arrangement einer partiell eigenständigen Verwaltung der ehemals munizipalen Einkünfte durch die Gemeinden, nun jedoch im Namen des Fiskus. Im folgenden Abschnitt wird indessen nachgewiesen werden, daß besagte Quelle nichts über eine globale Konfiskation städtischen Grundeigentums und auch nichts über seine spätere Verwaltung aussagt, sondern in einem ganz anderen Sachzusammenhang steht. Auf dieser Grundlage wird es möglich sein, auch für die Quotierungsregel der $370 \mathrm{er} \mathrm{Jahre} \mathrm{eine} \mathrm{schlüssigere} \mathrm{Interpretation} \mathrm{zu} \mathrm{finden.}$

\section{Die Inschrift von Ephesos (I.Ephesos 42)}

Seit dem Jahr 1905 ist eine lateinische Inschrift aus der Metropole der Provinz Asia, Ephesos, bekannt, die einen Erlaß Kaiser Valens' an den proconsul Asiae Eutropius überliefert. ${ }^{48}$ Valens' Epistel ist ohne Subskription aufgezeichnet worden und kann deshalb nur anhand der Karriere ihres Adressaten Eutropius, besser bekannt als Verfasser eines Breviariums zur römischen Geschichte, datiert werden; für sein Prokonsulat in Asia und die Abfassungszeit der Epistel kommen demnach nur die Jahre 369 bis spätestens 372 in Frage. ${ }^{49}$

48 I.Ephesos 42. Die heute (trotz einiger Fehler im Text) verbindliche Edition im Kölner Corpus der Inschriften von Ephesos stammt von Hermann Wankel; immer noch nützlich auch für Fragen der Textkonstitution sind die Anmerkungen von R. Heberdey, Zum Erlaß des Kaisers Valens an Eutropius, JÖAI 9, 1906, 182-192, der den Kommentar der ersten Textedition von A. Schulten, ebd. 40-70 in bezug auf mehrere Irrtümer und Fehlschlüsse korrigiert. Keinen Erkenntnisgewinn bringt der (mit stillschweigend vorgenommenen Emendationen versehene) Text bei Chastagnol, AARC 6, 1986 (wie Anm. 4); ebenso wenig zuverlässig auch der Text in FIRA I 108.

49 Über die Identifizierung des Adressaten mit dem Historiker Eutrop herrscht weitestgehend Einigkeit; vgl. B. Malcus, Die Prokonsuln von Asien von Diokletian bis Theodosius, Stockholm 1967, 11-113; PLRE I, 317 s. v. Eutropius 2; G. Bonamente, La biografia di Eutropio „lo storico", AFLM 10, 1977, 179-210; H. W. Bird, The Breviarium of Eutropius, Liverpool 1992, vii-xliv; P. L. Schmidt in: R. Herzog (Hg.), Restauration und Erneuerung: die lateinische Literatur von 284 bis 374 n.Chr., München 1989, 202f. mit weiterer Literatur; dagegen aber R. von Haehling, Die Religionszugehörigkeit der hohen Amtsträger des Römischen Reiches seit Constantins I. Alleinherrschaft bis zum Ende der Theodosianischen Dynastie, Bonn 1978, 211-237. In der Regel werden nur die Jahre 370/1 für das Prokonsulat angesetzt, hier dagegen die breitestmögliche Amtszeit: Eutrop war 369 noch magister memoriae, wurde aber noch im selben Jahr von seinem Rivalen Festus beerbt. Da sonst kein proconsul Asiae in jener Zeit bekannt ist, könnte Eutrop bereits 369 das Amt übernommen haben, in dem er durch Amm. 29, 1, 36 im Zusammen- 
Der Erlaß beginnt ${ }^{50}$ mit dem Referat einer relatio des Eutrop, aus der sich die Vorgeschichte der von Valens getroffenen Entscheidung rekonstruieren läßt: Kaiser Valens hatte, so geht aus dem ersten Abschnitt (Z. 2-4) hervor, gewissen Städten die Einkünfte von fundi rei publicae zu Teilen zur Verfügung gestellt, damit sie daraus die Reparatur von Mauern oder Gebäuden finanzieren konnten, um sie ,aus dem häßlichen Schmutz jüngst erfolgten Schadens“ wiedererstehen zu lassen. ${ }^{51}$ Die Güter wurden, wie ein zweiter Abschnitt (Z. 4-8) festhält, in diesem frühen Stadium durch actores der res privatae ${ }^{52}$ verwal-

hang der Antiochenischen Magieprozesse 370/1 belegt ist. Sein Nachfolger im Prokonsulat war (bis spätestens 378) wieder Festus, dessen Amtsantritt allerdings nur ungefähr zu bestimmen ist (vgl. die Belege bei PLRE I, 334 s. v. Festus 3; Malcus, Prokonsuln, 114-116 sowie vgl. B. Baldwin, Festus the Historian, Historia 27, 1978, 197-217, hier: 197-207; P. L. Schmidt in: Herzog, Restauration, 207f. mit weiterer Literatur): Er ist ebenfalls Adressat einer gemeinsam mit I.Ephesos 42 aufgezeichneten Inschrift, I.Ephesos 43. Damit ist ein - weil der zeitliche Abstand der beiden Dokumente nicht zu bestimmen ist, ungenauer - Terminus post quem für Festus' Amtsübernahme gegeben; das Jahr 372 paßt als grobes Datum für die Amtsübernahme auch insofern gut, als Festus sich im Anschluß an die Antiochenischen Magieprozesse 370/1 in der Verfolgung angeblicher Oppositioneller auszeichnete (Quellen s. PLRE ebd.). Für Eutrops Amtszeit und die Datierung von I.Ephesos kommt also die Zeitspanne 369 bis etwa 372 in Frage.

50 Eine bloße Übersetzung des Dokumentes trägt kaum zum Verständnis seiner komplizierten Struktur bei; stattdessen wird im folgenden eine chronologische Rekonstruktion des darin festgehaltenen Vorgangs gegeben.

51 Ein konkretes Ereignis als Hintergrund der Reparaturmaßnahmen läßt sich nicht benennen: Die zwischen 358 und 368 mehrfach bezeugten Erdbeben traten größtenteils im bithynischen Raum, vereinzelt auch in Zentralkleinasien und Palästina auf, nicht aber in der Provinz Asia; auch das Beben und der Tsunami von 365 haben dort offenbar keine Schäden angerichtet: vgl. die Zusammenstellung der Belege bei N. Lenski, Failure of Empire: Valens and the Roman State in the Fourth Century A.D., Berkeley 2002, 386388; zum Tsunami 365 vgl. aus der intensiven Diskussion der letzten Jahrzehnte J. Bousquet/F. Jacques, Le raz du marée du 21 Juillet 365 . Du cataclysme local à la catastrophe cosmique, MEFRA 96, 1984, 423-461; C. Lepelley, L'Afrique du Nord et le prétendu séisme universel de 21 juillet 365, ebd. 463-491; neuerdings stellt G. Waldherr, Die Geburt der kosmischen Katastrophe. Das seismische Großereignis am 21. Juli 365 n.Chr., OTerr 3, 1997, 169-201, das Ausmaß der Katastrophe generell in Frage. Formulierungen wie die der Inschrift scheinen im übrigen keineswegs unbedingt auf ein konkretes Katastrophenereignis anzuspielen, da spätrömische Baugesetze sich gelegentlich solcher rhetorischen Phrasen befleißigen, ohne daß irgendwelche Hinweise auf einen Unglücksfall entsprechenden Ausmaßes existierten: So Valentinians CTh 15, 1, 11: deformibus ruinis, während in den etwa zeitgleichen 15, 1, 15 und 16 schlicht von Altersschwäche die Rede ist; vgl. auch 15, 1, 14 (390, Unteritalien).

52 Actores rei privatae scheinen - wenngleich auch in einer für uns nicht immer ganz klar von den conductores zu scheidenden Weise - mit der Verwaltung von Domänenland, vielleicht 
tet, die die Einkünfte daraus auf Anfrage an die Städte weitedeiteten. Gegen dieses Verfahren hatte sich eine Gesandtschaft der Stadt Ephesos an den Kaiser gewandt, von der im dritten Abschnitt (Z. 8-12) berichtet wird. Nachdem der Kaiser, so heißt es dort, die vorgetragene Schilderung des Sachverhalts in einer eigenen Untersuchung hatte verifizieren lassen, gestattete er der Stadt Ephesos, hundert inga einschließlich eines schon früher übertragenen Gutes namens Leuce in ihre Verwaltung zu übernehmen. Durch diesen „Testlauf" wollte der Kaiser erproben, ob die Reparaturmaßnahmen unter diesen Umständen besser vorankämen; wenn das der Fall sein sollte, könne das Modell auch auf alle anderen Städte der Provinz angewandt werden.

Dieses Arrangement scheint einige Jahre vor dem Eingreifen Eutrops getroffen worden zu sein; nun, im unmittelbaren Vorfeld des Erlasses, nahm dieser sich der Sache an und schlug dem Kaiser in der oben referierten relatio vor, das Modell der Verwaltung durch die Städte für alle betroffenen fundi rei publicae in der Provinz Asia verbindlich zu machen. Zur Begründung brachte der Prokonsul folgendes vor (Abschnitt II):

Verum non integram grat [iam con]cessi ad urbes singulas beneficii ${ }^{5}[$ perv]enire, siquidem, $<d u m>$ pro partibus praestitis reditus civitatibus potius q[ua]m ipsi cum reditibus fundi fuerint restitu[end]i et ministrandi, idem reditus ab acto[ri]bus ${ }^{6}[\mathrm{pr}]$ ibatae rei nostrae et diu miserabiliterque poscantur et vix aegr $\{a\}$ eque tribuantur adque id quod amplius e $[x$ i]sdem fundis super statutum canonem ${ }^{7}$ colliga $\{n\}$ tur et isdem civitatibus pereat eorundemqu$\{a\}$ e actorum fraudibus devoratum nibil tamen aerario nostro adiciat augmenti possitque ${ }^{8}$ a curialibus vel excultione maiore vel propensiore diligentia nonnullus praestitionis cumulus ad gratiam concessionis acedere.

Den einzelnen Städten fließt freilich nicht die ungeschmälerte Gunst der gewährten Wohltat zu, da ja, solange den Städten eher ein Anteil an den Einkünften zugestanden ist, als daß die Güter selbst mit ihren Einkünften zur Verwaltung zurückgegeben werden, besagte Einkünfte von den actores Unserer res privata lange und umständlich eingefordert werden müssen und sie in geringem Maße und zögerlich zugeteilt werden. Und das, was über den festgesetzten Zins hinaus von besagten Gütern gesammelt wird, ist für besagte Städte ebenso verloren wie es auch Unserem Fiskus keinen Gewinnzuwachs bringt, weil es von den Betrügereien besagter actores aufgezehrt wird. Von Seiten der Kurialen kann sowohl durch bessere Bewirtschaftung als auch durch eifrigere Sorgfalt ein nicht geringer Zuwachs der Schenkung zu dem huldvoll Zugestandenen eintreten.

dem in staatlicher Regie bewirtschafteten, tätig gewesen zu sein: Jones, Later Roman Empire (wie Anm. 3), 414 und 788; Delmaire, Largesses sacrées (wie Anm. 4), 679f. 
Solange die Güter durch den Fiskus verwaltet würden, müßten, so argumentierte Eutrop also, die Städte für jede Ausgabe bei den actores der res privata vorstellig werden, was umständlich sei und hauptsächlich deren Selbstbereicherung zustatten komme. Nähmen dagegen die Kurialen die Verwaltung selbst in die Hand, könne man durch bessere Bewirtschaftung sogar noch einen Gewinnzuwachs erzielen.

Valens ließ sich von diesen Argumenten offenkundig überzeugen, denn nun, im eigentlich dispositiven Teil der Konstitution ab dem vierten Abschnitt (Z. 12-19), wird Eutrop angewiesen (Z. 17-19):

Arbitrio tuo per curias singulas omni ingatione dispersa, retracto eo redituum modo, quem unicuique civitatum propria largitione concen[simus], ${ }^{18}[$ r] $]$ liquam summam per officium tuum rei privatae nostrae inferre festines, ut et omnem usu ram diligentia $\{m\}$ avidis eripiamus actoribus et, siquid extrinsi[cus] 19 [lucri] est, cedat rationibus civitatum.

Nach der Verteilung des Gesamtbestandes an iuga auf die einzelnen Kurien nach Deinem Ermessen sollst Du, nachdem die Einkünfte in derjenigen Höhe, die Wir einer jeden Stadt in der Uns eigenen Freigebigkeit zugestanden haben, abgezogen wurden, unverzüglich die Restsumme durch Deine Behörde an Unsere res privata bringen lassen, damit wir sowohl durch Sorgfalt den begehrlichen actores jeden Eigennutz nehmen als auch, wenn es darüber hinaus irgendeinen Gewinn gibt, er den Finanzen der Städte zukomme.

Eutrop soll also die betroffenen, in Z. 14-16 ihrem Umfang nach genau bezifferten Güter nach eigenem Ermessen auf alle Städte seiner Provinz verteilen. Diese sollen fortan einen individuell festgesetzten Anteil ihrer Einkünfte einbehalten dürfen, den Rest aber an den Fiskus abführen, wobei ihnen ein möglicherweise erwirtschafteter Mehrwert ausdrücklich zugesichert wird. Um den Unterschlagungen der actores vorzubeugen, heißt es dann weiter, solle die Abgabenerhebung von nun an dem Statthalter und seiner Behörde obliegen. Zuletzt ordnet der Kaiser im fünften Abschnitt (Z. 19-24) noch die Erstellung eines umfassenden Katasters an, welches ein offenbar bereits existierendes (Z. 3; 12f.) dadurch vervollständigen soll, daß es exakte Angaben über die Pachtverhältnisse auf jeder einzelnen Parzelle verzeichnet.

Auf den ersten Blick scheint die herkömmliche Deutung der Inschrift recht zu behalten: Der Konstitution muß eine Konfiskation der betroffenen fundi rei publicae vorausgegangen sein, die Städte hatten nach Eutrops Reform zwar nicht das Eigentum, wohl aber die Direktverwaltung jener Güter inne, und ihre Einkünfte wurden zwischen Fiskus und Stadt aufgeteilt. Stutzig machen allerdings einige Beobachtungen, die Zweifel aufkommen lassen, ob die 
fundi rei publicae der Inschrift tatsächlich die Gesamtheit des städtischen Grundbesitzes der Provinz Asia meinen können. In Z. 14-16 beziffert das Dokument den Umfang der betroffenen fundi auf 6736 iuga ertragbringenden und 703 inga brachliegenden Landes, also auf insgesamt etwa 7440 inga. ${ }^{53}$ Für das gesamte Gemeindeland der Provinz erscheint diese Zahl äußerst gering, wenn man bedenkt, daß Julian der Stadt Antiochien $3000 \kappa \lambda \hat{\eta} \rho o r$ bzw. iuga Land nur zur Aufzucht von Rennpferden überlie $\beta^{54}$ und daß allein das Territorium der syrischen Kleinstadt Kyrthos 10.000 inga im Besitz der res privata umfaßte; 55 andere Zahlen ließen sich ergänzen. ${ }^{56}$ Diese Angaben sind gewiß nicht direkt vergleichbar, weil das ingum als Steuerhufe zumindest in Syrien mit je nach Qualität und Produkt des Bodens unterschiedlichen Schlüsseln berechnet wurde, also jeweils einer höchst unterschiedlichen realen Bodenfläche entsprach. ${ }^{57}$ Außerdem ist weder die Zusammensetzung der verglichenen Territorien in bezug auf die Qualität ihrer Güter bekannt noch, ob das ingum in Asia überhaupt nach demselben Modus mit denselben Schlüsseln berechnet wurde. Dennoch: Nur mit extrem divergierenden Steuerhufen und Bodenbedingungen ließe sich erklären, daß der gesamte städtische Grundbesitz einer stark urbanisierten Provinz wie Asia nicht einmal 7500, aber allein die

53 Deren Einkünfte das Dokument in Z. 15f. ebenfalls beziffert. Leider ist die entscheidende Textstelle korrupt; auf dem Stein steht statt einer Zahl ein an dieser Stelle sinnloses VINVM. Keiner der diversen Emendationsversuche kann ein zwingendes Argument für sich vorbringen.

54 Iul. Mis. 370D-371B; in 362D wird außerdem erwähnt, Antiocheia besitze $\mu$ víous

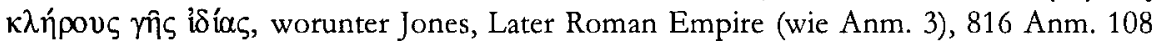
allerdings keine Zahlenangabe (10.000 iuga) erkennen will, sondern ein unspezifisches "sehr viele Landlose“. Zur Verwendung des Begriffs $\kappa \lambda \hat{p} \rho \varsigma_{\varsigma}$ für iugum an dieser Stelle vgl. J. Gascou, KАHPOI AПOPOI (Julien, Misopogôn 370D-371B), BIAO 77, 1977, 235-255.

55 Von 62.000 inga des Gesamtterritoriums: Thdt. Ep. Sip. 42 und 47 ed. Azéma; der große Umfang der Domänen mag darauf zurückzu führen sein, daß der Usurpator Avidius Cassius (gegen Mark Aurel) aus Kyrrhos stammte.

56 Weitere Zahlen bei Jones, Later Roman Empire (wie Anm. 3), $815 f$.

57 Die Berechnungsmodalitäten des syrischen ingum sind aus dem syrisch-römischen Rechtsbuch bekannt: FIRA II, S. 795f;; z. B. entsprechen 1000 itga entweder 5000 iugera Weinland oder 40.000 iugera minderwertigen Ackerlandes, also einer bis um das Achtfache größeren Bodenfläche. Schlüssel für die afrikanische centuria sind nicht bekannt, ebensowenig, wie iuga und centuriae miteinander korrelierten. Die von A. H. M. Jones, Census Records of the Later Roman Empire, JRS 43, 1953, 49-64, hier: 49f.; (= ders., The Roman Economy [hg. von P. A. Brunt], Oxford 1974, 228-256, hier: 228f.) errechneten Schlüssel für das ingum in Asia beruhen auf einer in ihrer Deutung höchst umstrittenen, teilweise ergänzten Inschrift. 
Besitzungen des Fiskus in einer unbedeutenden Provinzstadt Syriens 10.000 iuga umfaßten; das erscheint insgesamt ziemlich unwahrscheinlich.

Weitere Beobachtungen bestärken die Zweifel daran, daß die fundi rei publicae der Inschrift das gesamte Gemeindeland der Provinz meinen. Warum sollte Eutrop, wenn seine Maßnahme den gesamten städtischen Grundbesitz betroffen hätte, den Grundbesitz ,nach eigenem Ermessen“, wie es in Z. 17 heißt, also offenbar ganz neu verteilen? Die einzige praktikable Lösung wäre dann doch wohl diejenige gewesen, den administrativen Status quo ante wiederherzustellen, also den Städten ihren ursprünglichen Besitz zur Verwaltung zu geben. Nicht recht passen will auch die Notwendigkeit, ein umfassendes Kataster anlegen zu lassen, weil offenbar so elementare Dinge wie Pächtername, Pachtstatut und Abgabenhöhe unklar waren. Solche Unklarheiten sind nur denkbar, wenn die Besitzverhältnisse massiv gestört waren. Dann würde man die umfassende Katastrierung des städtischen Grundbesitzes allerdings zum Zeitpunkt der Konfiskation annehmen wollen, nicht erst Jahre später.

Viel besser lassen sich diese Bestimmungen verstehen, wenn man von der Deutung der fundi rei publicae als des gesamten Gemeindelandes der Provinz Abstand nimmt und sie stattdessen mit einer anderen Gütermasse identifiziert: den fundi iuris templorum, dem Tempelland. Dieser Vorschlag kann ein starkes Argument für sich in Anspruch nehmen: Im Falle des Tempelbesitzes ist es tatsächlich sicher verbürgt, daß Valentinian und Valens Julians Restitutionen gleich zu Beginn ihrer Herrschaft rückgängig machten und das Tempelland wieder konfiszierten. In CTh 10, 1, 8, gegeben am 4. September 364 in Mediana an den comes rerum privatarum des Valens, Caesarius, ${ }^{58}$ ist die entsprechende Verfügung für die östliche Reichshälfte überliefert, in CTh 5, 13, 3, gegeben am 23. Dezember diesen Jahres in Mailand an den Präfekten Claudius Mamertinus, die für den Westen:

Universa, quae ex patrimonio nostro per arbitrium divae memoriat Iuliani in possessionem sunt translata templorum, sollicitudine sinceritatis tuae cum omni iure ad rem privatam nostram redire mandamus.

Alles, was aus Unserem Besitz auf Anordnung Julians seligen Angedenkens in den Besitz der Tempel übertragen wurde, soll, so lautet Unser Auftrag, durch den Eifer Deiner Redlichkeit zu vollem Besitz an die res privata zurückgehen.

58 Die Identifizierung des Ausstellungsortes und Adressaten der Konstitution sowie die hier gegebene Datierung unterscheiden sich erheblich von den bisher in der Forschung vertretenen Auffassungen: Vgl. dafür die Marburger Dissertation des Verfassers (wie Anm. 4). Übersetzt wird hier nur CTh $5,13,3$. 
Die Rekonfiskation durch Valentinian und Valens bezog sich übrigens tatsächlich nur auf die von Julian restituierten Tempelgüter, denn noch bis ins frühe fünfte Jahrhundert scheint es unabhängiges Tempelland gegeben zu haben. 59

$\mathrm{Da}$ die ephesische Inschrift die betroffenen Tempelgüter als fundi rei publicae bezeichnet, widerspricht der Identifikation mit dem Tempelland nicht: Wie im Falle des angeblichen Restitutionsgesetzes Julians mag auch in diesem Fall die mangelnde terminologische Prägnanz dem konkreten Entstehungszusammenhang des Textes geschuldet sein, denn das Dokument war das Resultat eines langwierigen Verhandlungsprozesses zwischen Stadt, Prokonsul und Kaiser, an dessen Ende allen Beteiligten die Identität der betroffenen Liegenschaften vertraut gewesen sein dürfte. Abgesehen davon ist die Bezeichnung der Tempelgüter als fundi rei publicae sachlich richtig und war zudem gebräuchlich: Die meisten Heiligtümer lagen in Stadtbesitz, und nicht nur Julians Restitutionsgesetz nennt sie, wie oben gezeigt, possessiones publicae. ${ }^{60} \mathrm{Im}$ Kontext des wechselvollen Schicksals des Tempellandes überzeugt im übrigen auch die Notwendigkeit eines neuen Katasters vollauf: Julians Maßnahme hatte eine Entwicklung rückgängig zu machen versucht, die mit größeren Enteignungen Konstantins begonnen hatte und unter seinen Nachfolgern fortgesetzt worden war; besonders Constantius II. wurde vorgeworfen, seine Günstlinge mit Tempelland geradezu ,gemästet“ zu haben. ${ }^{61} \mathrm{Als}$ Julian diese Güter den Heiligtümern oder Städten restituierte - übrigens wie hier mit der Maßgabe, die Einkünfte für Baumaßnahmen zu nutzen -, wird es vielfach auch zu einem Wechsel jener Besitzer (Pächter) gekommen sein, die bei Julian in Ungnade gefallen waren. ${ }^{62}$

Im Zuge der Rekonfiskation dieser Güter im Jahre 364 ist von einem erneuten Eingriff in die Besitzstrukturen nicht die Rede, und in der Tat wäre er den Absichten Valentinians und Valens' zuwidergelaufen, denen es zuvör-

59 In Symm. Ep. 1, 68 (380) wird ein Gut im Besitz der stadtrömischen pontifices erwähnt; eine weitere Enteignungswelle scheint um das Jahr 382 stattgefunden zu haben (CJ 11, 66, 4; CTh 10, 3, 4; Ambr. Ep. 73, 16 ed. Zelzer), und noch im Jahre 415 ergingen Erlasse zur Konfiskation der Tempelgüter (CTh 16, 10, 20); vgl. allgemein zur Enteignung der Tempelgüter in der Spätantike Delmaire, Largesses sacrées (wie Anm. 4), 693f. und die oben in Anm. 24 gegebenen Literaturve rweise.

60 Vgl. oben Anm. 22.

61 S. oben Anm. 24 und die folgende Anm.

62 Nach Amm. 22, 4, 3 säuberte Julian den Hofstaat von Elementen, die pasti enim ex his quidam templorum spoliis, "gemästet aus der Beute der Tempel“, zu ungeheurem Reichtum gekommen waren. 
derst um die komplikationslose, rasche Erschließung einer Geldquelle für den durch Julians Perserfeldzug ruinierten Staathaushalt gehen mußte. Gleichwohl wird sich das im Laufe der Zeit geändert haben. Nach der Niederschlagung des Prokop-Aufstandes gerieten die Parteigänger Julians und überhaupt die altgläubige Elite in der Präfektur Oriens unter den Generalverdacht, in Opposition zu Valens zu stehen, was in der hysterischen Atmosphäre der Magieprozesse von Antiocheia im Winter 371/372 eine blutige Kulmination fand. Viele Nutznießer der julianischen Tempelgüterrestitution dürften zu den Betroffenen dieser Kampagne gehört haben. Umgekehrt herrschte nun ein günstiges Klima für die Verlierer der julianischen Restitution, die nun, nach sieben oder acht Jahren, Hoffnung schöpfen konnten, die Verluste unter Julian wieder auszugleichen und alte Besitztümer zurückzuerlangen. Es gibt also gute Gründe, warum es Valens in der ephesischen Epistel just in dem Zeitraum, in dem die Spannung eskalierte, für nötig erachten konnte, die Besitzverhältnisse auf Ländereien zu klären, die aus dem Eigentum heidnischer Heiligtümer stammten. Bezeichnenderweise firmiert in den Quellen vor allem Kleinasien als der Raum, in dem es zu regelrechten Verfolgungen der Altglä ubigen kam. ${ }^{63}$

Die hier vorgeschlagene, neue Deutung der Inschrift kann also gute Argumente für sich in Anspruch nehmen. Sie läßt sich folgendermaßen resümieren: Valens ermächtigte Eutrop, den einige Jahre zuvor rekonfiszierten, eigentlich aber schon seit Konstantin in Staatshand befindlichen Grundbesitz der Tempel in der Provinz Asia in die Verwaltung der Städte zu übertragen. Vom Gemeindeland in seiner Gesamtheit ist hier nicht die Rede, und wieder wäre es fahrlässig, aus den besonderen Bedingungen der Tempellandkonfiskation in der aufgeheizten Stimmung nach Julians Tod auf eine globale Enteignung städtischen Grundeigentums schließen zu wollen.

Was bedeutet dieses Ergebnis für die Frage nach der städtischen Finanzautonomie? Mit der Neuinterpretation der ephesischen Inschrift fällt das einzige Zeugnis für die These, Valentinian und Valens hätten im Jahr 364 eine globale Enteignung der städtischen Einnahmequellen durchgeführt. Damit gibt es keinen einzigen Anhaltspunkt mehr für die communis opinio der Forschung, daß die städtischen Einkünfte jemals konfisziert, also in das Eigentum der res privata überführt worden oder wenigstens zur Gänze in staatliche Verwaltung übergegangen seien. Eine globale Konfiskation gab es also nie, und so erklärt sich auf die denkbar einfachste Weise, weshalb sie nir-

63 Ausführliche Schilderung bei F. J. Wiebe, Kaiser Valens und die heidnische Opposition, Bonn 1995, 131 -148; Lenski, Failure of Empire (wie Anm. 51), 223-234. 
gendwo belegt ist, und weshalb im Gegenteil noch Generationen später Städte als Eigentümer und mit Verfügungsgewalt über Liegenschaften und Abgaben begegnen.

Die Quotierung der Einkünfte in den 370er Jahren ebenso wie zahlreiche, oben vorgeführte Quellenaussagen belegen allerdings auch, daß Städte und Fiskus gleichermaßen über munizipale Einkommensquellen verfügen konnten. Die Frage nach Umfang und Gestalt der städtischen Finanzautonomie in der Spätantike und damit auch nach der Einordnung der Quotierungsregel unter Valentinian und Valens besteht also weiterhin - auch wenn gezeigt werden konnte, daß die Hypothese einer Enteignung dabei in die Aporie führt. Eine Antwort liefert der folgende Abschnitt.

\section{Stadt und Staat in der römischen Kaiserzeit}

Da mit der Konfiskation auch eine vermeintliche Zäsur in der Geschichte der munizipalen Finanzverwaltung wegfällt, ist das Verhältnis von Stadt und Staat in diesem Bereich nur dann zu verstehen, wenn man die Entwicklungen der spätrömischen Zeit in Beziehung setzt zu ihren prinzipatszeitlichen Voraussetzungen. Denn in der Tat läßt sich bereits in der Prinzipatszeit beobachten, $\mathrm{da} ß$ die kaiserliche Finanzverwaltung in zunehmendem Maße in die städtische Finanzwirtschaft eingriff. Einige Hinweise müssen hier genügen: Anfang des zweiten Jahrhunderts beginnt die zunächst punktuelle, dann immer weiter um sich greifende Einsetzung von curatores rei publicae, die als kaiserliche Kontrollbeamte für die städtischen Haushalte umfassenden Einfluß auf die Finanzwirtschaft der Städte nehmen konnten. ${ }^{64}$ Mehrmals begegnen Eingriffe der Statthalter in die (Finanz-) Verwaltung städtischer Ländereien; Ulpian folgerte daraus sogar eine Dienstpflicht des Statthalters, sich um die Optimierung der Einkünfte von städtischen Ländereien zu kümmern. ${ }^{65}$ Seit Vespasian begegnen Quellen, nach denen jede Veränderung des städtischen Steuerwesens durch Einführung oder Abschaffung von Steuern oder selbst nur eine Anleihe unter den Bürgern der Stadt einer kaiserlichen Ermächtigung bedurfte. ${ }^{66}$

64 Vgl. unten Anm. 70 f.

65 Dig. 50, 10, $5 \backslash 1$ : curabit praeses provinciae ... publicos potius reditus angere, Beispiele für die Verpachtung städtischer Ländereien durch den Statthalter in AE 1967, 531 (73-75 n. Chr., Apollonia in der Cyrenaica) und Syll. ${ }^{3} 884$ (Thisbe); vgl. auch die unten in Anm. 70 genannte Literatur.

66 CIL II $1421=$ ILS 6092 = FIRA I 74, wo Vespasian die Einführung neuer Steuern durch die Stadt Sabora an eine Genehmigung des Prokonsuls bindet; spätere Beispiele kaiserli- 
Ein wichtiger Aspekt der Mission des jüngeren Plinius in der Provinz Bitbynia et Pontus bestand in der Überprüfung der munizipalen Rechnungsbücher, meist im Zusammenhang mit Bauvorhaben der Städte; Plinius erfüllte damit Aufgaben eines kaiserlichen Sonderbeauftragten mit dem Titel legatus bzw.

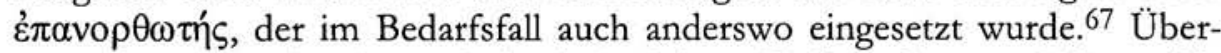
haupt läßt sich das Ausmaß der kaiserlichen Einflußnahme auf die städtischen Finanzen im Bereich des Bauwesens besonders gut verfolgen: Vor allem juristische Texte zeigen, daß seit Ende des ersten Jahrhunderts die $\mathrm{Zu}$ stimmung des Statthalters, später des Kaisers selbst, unabdingbare Voraussetzung städtischer Bauvorhaben wurde, weil man auf diese Weise verhindern wollte, daß sich die Städte durch überzogene Projekte ruinierten. ${ }^{68}$ Die Eingriffe der kaiserlichen Verwaltung gingen dabei so weit, daß Gelder, die testamentarisch für Baumaßnahmen bestimmt waren, für Restaurierungsarbeiten umgewidmet werden konnten. ${ }^{69}$

Diese Entwicklungen dürfen freilich nicht mit einer Tendenz zur totalen Kontrolle der Städte und dem vollkommenen Entzug ihrer Finanzautonomie durch die kaiserliche Verwaltung gleichgesetzt werden, wie dies die eingangs skizzierte, mit dem Namen Wilhelm Liebenams verbundene Forschungstradition will. Diese Auffassung wird in der Forschung ganz im Gegenteil mittlerweile grundsätzlich in Zweifel gezogen. So versteht man das Amt des curator rei publicae heute nicht mehr als Versuch, eine flächendeckende kaiserliche Kontrollinstanz in den Städten zu installieren. Die Quellenlage wird heute

cher oder statthalterlicher Ermächtigungen in SEG XXXVIII 1462, Z. 115f. (Oinoanda); L. Robert, Hellenica 6, Paris 1948, 81 Nr. 26, I, Z. 9f. (Hadrianopolis-Stratonikeia); IG-Bulg. IV 2263; die Zollinschrift von Palmyra CIS II 3913 mit J. Matthews, The Tax Law of Palmyra, JRS 74, 1984, 157-180; CJ 4, 62, 1-3; Dig. 39, 4, 10; Anleihen über eine gewisse Höhe sind genehmigungspflichtig durch den Statthalter nach der Lex Imitana 80 ed. J. Gonzalez, JRS 76, 1986, 174.

67 Plin. Ep. 10, 18;10, 37; 10, 39; 10, 43; 10, 47; 10, 77; 10, 90; 10, 92; 10, 98, meist im Zusammenhang ruinöser Bauvorhaben. Eine Liste weiterer Legaten mit wohl ähnlichem Auftrag bei B. Thomasson, Legatus. Beiträge zur römischen Verwaltungsgeschichte, Stockholm 1991, 80-84; vgl. A. Kolb, Die Einflußnahme des Kaisers auf das städtische Bauwesen, in: R. Frei-Stolba/H. E. Herzig (Hgg.), La politique édilitaire dans les provinces de l'Empire romain. IIème-IVème siècles après J.-C. Actes Berne 1993, Bern u. a. 1995, 272-282, hier: 276-279, sowie W. Eck, Der Kaiser, die Führungsschichten und die Administration des Reiches (von Vespasian bis zum Ende der antoninischen Dynastie), in: ders., Die Verwaltung des Römischen Reiches in der Hohen Kaiserzeit, Bd. 2, Basel 1998, 3-145, hier: $127 \mathrm{f}$.

68 A. Kolb in: Frei-Stolba, Politique édilitaire (wie Anm. 67), 273-276.

69 So z. B. Dig. 50, 10, 7 (Kallistrat); CIL IX 5746 = ILS 5675 (Ricina); IRT 396 (Lepcis Magna). 
vielmehr so gedeutet, daß Kuratoren nur bei Bedarf eingesetzt wurden und in der Regel nur eine lockere Aufsicht vornehmlich über Bausachen ausübten; ${ }^{70}$ oft kamen solche Maßnahmen dem Interesse der Städte entgegen oder erfolgten gar auf ihr Betreiben hin. ${ }^{71}$ Die neuere Forschung geht außerdem davon aus, daß in der gesamten Prinzipatszeit eine zumindest partielle Steuerund Zollhoheit der Städte existierte, die allenfalls einer engeren Aufsicht unterlag (wobei aber auch die volle Autonomie gelegentlich explizit belegt ist). ${ }^{72}$ Die auch in der Prinzipatszeit gelegentlich bezeugte Einflußnahme des Staatsapparates auf die Verwaltung der städtischen Ländereien wurde schon immer lediglich im Sinne einer Oberaufsicht, nicht als Tendenz zu totaler Appropriation gewertet. ${ }^{73}$ Und nicht zuletzt wird die Bedeutung des Euergetismus und anderer Formen der Finanzierung städtischer Aufgaben aus privaten Geldern, die in der Forschung lange deswegen als besonders wichtig galten, weil man sie als die einzige Möglichkeit der Städte ansah, den Verlust der Verfügungsgewalt über Steuern und Abgaben auszugleichen, heute ebenfalls zunehmend relativiert. Die regulären Einkommensquellen scheinen demnach weiterhin für den Großteil des städtischen Finanzbedarfs zur Verfügung gestanden zu haben. ${ }^{74}$

70 Zum neuen Bild des Kuratorenamtes R. Duthoy, Curatores rei publicae en Occident durant le Principat, AS 10, 1979, 171-238; G. P. Burton, The curator rei publicae: towards a reappraisal, Chiron 9, 1979, 465-487; G. Camodeca, Ricerche sui curatores rei publicac, in: ANRW II 13, 1980, 453-534; F. Jacques, Les curateurs de cités dans l'Occident romain de Trajan à Gallien, Paris 1983; M. Sartori, Osservazioni sul ruolo del curator rei publicae, Athenaeum n. s. 67, 1989, 5-20 sowie zuletzt Eck in: ders., Verwaltung (wie Anm. 67), 128-131; Ch. Witschel, Krise - Rezession - Stagnation? Der Westen des Römischen Reiches im 3. Jahrhundert n. Chr., Frankfurt/Main 1999, 129-132.

71 P. Herrmann, Kaiserliche Garantie für private Stiftungen. Ein Beitrag zum Thema „Kaiser und städtische Finanzen“", in: W. Eck u. a. (Hgg.), Studien zur antiken Sozialgeschichte. Festschrift Friedrich Vittinghoff, Köln 1980, 339-356.

72 M. Corbier, City, Territory and Taxation, in: J. Rich ( $\mathrm{Hg})$, City and Country in the Ancient World, London 1991, 211-240 (u. ö. zuvor); G. P. Burton, Was there a long-term trend towards centralisation of authority in the Roman empire?, $\mathrm{RPh} 72$ 1998, 7-24, hier: 10-13; J. France, Les revenues douaniers des communautés municipales dans le monde romain (République et Haut-Empire), in: Finanze municipali (wie Anm. 4), 95-113; P. Le Roux, Vectigalia et revenus des cités en Hispanie au Haut-Empire, ebd. 155-173 und andere Beiträge dieses Sammelbandes; Merola, Autonomia locale (wie Anm. 4), 121-134 + 139-141; H. Schwarz, Soll oder Haben? Die Finanzwirtschaft kleinasiatischer Städte in der Römischen Kaiserzeit am Beispiel von Bithynien, Lykien und Ephesos (29 v. Chr.284 n. Chr.), Bonn 2001 mit der Rezension von L. Migeotte, Gnomon 76, 2004, 341-344.

73 Quellen bei Burton, RPh 32, 1998 (wie Anm. 72), 13-16.

74 W. Eck, Der Euergetismus im Funktionszusammenhang der kaiserzeitlichen Städte, in: M. Christol/O. Masson (Hgg.), Actes du Xe Congrès international d'épigraphie 1992, 
Das Modell, daß die Geschichte der munizipalen Finanzautonomie in der Prinzipatszeit von einer klaren Tendenz zur Monopolisierung durch die Staatsgewalt geprägt gewesen sei, ist also mit Sicherheit zu schematisch. Dieser Befund gilt auch für die Spätantike. Ohne jeden Zweifel finden sich unzählige Belege für eine Kontrolle des städtischen Finanzgebarens durch den Fiskus: So betraute die bereits erwähnte Konstitution Konstantins, die durch eine Inschrift aus Orkistos überliefert ist, einen rationalis, also einen Beamten des Fiskus, mit der Aufsicht darüber, daß die Stadt Nakoleia keine Abgaben mehr von der Gemeinde Orkistos erhob; offenbar gehörte die Kontrolle der lokalen Steuererhebung also zu den Aufgaben der Finanzverwaltung. In den 350er Jahren lagen die Naturaleinkünfte vom Gemeindeland des syrischen Antiocheia in der Verantwortung von Speicherverwaltern, die den Provinzialbehörden unterstanden und die städtischen Bediensteten - wenn man Libanios glauben darf - in demütigender Weise um die Ausgabe ihres Lohns betteln ließen. ${ }^{75}$ Eine Fülle von Konstitutionen insbesondere im Titel 15, 1 des „Codex Theodosianus“ zeigt, daß das munizipale Bauwesen als zweifellos größter Posten der städtischen Haushalte in der Spätantike einer strikten Aufsicht durch die Statthalter unterlag, ${ }^{76}$ und der epigraphische Befund bestätigt das insofern, als der Statthalter nun immer als Hauptakteur bei städtischen Baumaßnahmen firmiert. ${ }^{77}$ Eine ihrem Inhalt nach einmalige Inschrift aus Chalkis, die einen Erlaß des Statthalters der Provinz Acbaia aus dem Jahr 359 überliefert, zeigt, daß dieser die Verantwortlichen, die Materialien, die

Nîmes 1997, 305-331; Witschel, Krise (wie Anm. 71), 129-132 mit Anm. 131; S. Cramme, Die Bedeutung des Euergetismus für die Finanzierung städtischer Aufgaben in der Provinz Asia, Diss. Köln 2001.

75 Lib. Or. 31, 16-20; genannt wird die Behörde des Statthalters (die åp $\chi 0 v \tau \varepsilon \varsigma$ und ihre

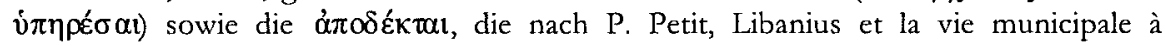
Antioche au IVe siècle après J.C., Paris 1955, 153f. und Liebeschuetz, Antioch (wie Anm. 4), 88 den praepositi horreorum entsprechen, d. h. liturgischen Verwaltern der Getreidemagazine unter Aufsicht der Provinzstatthalter.

76 Allg. für diese Zuständigkeit der Statthalter zuletzt A. Kolb in: Frei-Stolba, Politique édilitaire (wie Anm. 68), 279-281; Lepelley in: Finanze municipali (wie Anm. 4) sowie A. Lewin, Urban Public Building from Constantine to Julian: the Epigraphic Evidence, in: L. Lavan (Hg.), Recent Research in Late-Antique Urbanism, Portsmouth 2001, 27-37; vgl. auch das oben genannte Dossier von 395, CTh 15, 1, 18 sowie den folgenden Abschnitt des Kapitels.

77 Ein Katalog epigraphisch bezeugter Baumaßnahmen in Städten in der Osthälfte des Reiches von Diokletian bis Theodosius bei A. Lewin, Studi sulla città imperiale Romana nell'Oriente tardoantico, Como 1991, 117-135; für Afrika bei Lepelley, Cités de l'A frique (wie Anm. 4), 112-120. 
Finanzierung und andere Details einer Baumaßnahme genehmigen mußte,

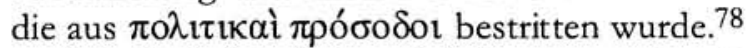

Die Beispiele ließen sich fortsetzen. Aus ihnen allen geht zwar nicht die Konfiskation der städtischen Einkünfte hervor, aber doch die enge Überwachung der städtischen Finanzverwaltung durch die kaiserliche Bürokratie. Gleichwohl zeigen die oben vorgeführten Quellen in unzweideutiger Weise, daß die Städte auch in der Spätantike eine zumindest teilweise unabhängige Verwaltung von Ländereien und Steuereinkünften ausüben konnten. Noch im sechsten Jahrhundert begegnen Konstitutionen, die den Staatsorganen einschärfen, sich nicht in die Finanzverwaltung der Städte einzumischen. ${ }^{79}$ Und die ephesische Inschrift ist ebenso wie die oben bereits erwähnte Konstitution CJ 11, 70, 6 über das ius exactionis einiger Güter der Stadt Nikaia ein Beispiel dafür, daß der Staat seine Einflußnahme auf die städtische Finanzautonomie durch die Rückführung von Liegenschaften in autonome städtische Verwaltung bisweilen durchaus zurücknehmen konnte. Weiterhin darf die Tatsache, daß der Statthalter eine Oberaufsicht über Bausachen führte, nicht $\mathrm{zu}$ dem Schluß verleiten, daß es keinerlei städtisch initiierte und finanzierte Bauprojekte mehr gegeben habe; das Formular einiger Bauinschriften und manch andere Indizien deuten in der Tat auf das Gegenteil. ${ }^{80}$ Und auch wenn bestimmte Anteile der städtischen Einkünfte, seit den 370ern zwei Drittel, vom Fiskus verwaltet wurden, bedeutet das im übrigen ja keineswegs, $\mathrm{da} ß$ er sie einbehielt und nicht-städtischen Zwecken zuleitete. Im Gegenteil waren regelmäßige Zuweisungen von Geldern durch den Fiskus für städtische Belange, vor allem Bausachen, - beispielsweise ein Viertel gewisser vectigalia (CTh 14, 3, 5, 358) oder vectigalia ad angustiarum solacia (CJ 4, 61, 10, 405408) - üblich und sind dicht dokumentiert. ${ }^{81}$ Nichts spricht dagegen, daß solche Gelder aus städtischen Einkünften stammten.

Nicht nur die Konfiskationsthese führt also in die Irre. Ebensowenig wie in der Prinzipatszeit wurde in der Spätantike die eigenständige Finanzverwaltung der Städte vollständig unterdrückt. Stattdessen geht aus der wider-

78 Syll. $^{3}$ 905 = IG XII 9, 907; vgl. dazu A. Lewin, Il dossier di Publio Ampelio, AARC 13, 2001, 621-646.

79 Z.B. CJ 8, 12, 1 (485/6); 1, 4, 26 \ 4 (530); 10, 30, 4 (530); NJust 17, 4 (535); 25, 4 (535); 30,8 (536); 128, 16 (545). Es ist in diesem Zusammenhang unerheblich, ob die Gelder aus städtischen Einkünften stammten oder den Gemeinden vom Staat zugewiesen worden waren.

80 Lepelley in: Finanze municipali (wie Anm. 4), bes. 237-240; so auch Lewin in: Lavan, Late Antique Urbanism (wie Anm. 76), 30f., freilich ohne stichhaltige Belege.

81 Außer den genannten Quellen z. B. CTh 9, 17, 2; 15, 1, 48; CJ 1, 4, 26; 10, $30,4$. 
sprüchlichen Quellenlage eher ein kompliziertes, offenbar je nach Haushaltsposten, Stadt und Zeitumständen ganz unterschiedlich geartetes Wechselspiel von Fiskus und Gemeinde hervor, das keinem reduktionistischen Globalmodell unterworfen werden darf. Das Postulat eines totalen Verlustes der Finanzautonomie und der vollständigen Expropriation der Städte von Steuern, Zöllen, Pachtzinsen etc. muß also aufgegeben werden. Dennoch bleibt es sicherlich richtig, daß die kaiserliche Finanzverwaltung spätestens seit dem zweiten Jahrhundert in zunehmendem Maße Einfluß auf das Finanzgebaren der Gemeinden nahm und dabei auch manche Einkünfte ihrer direkten Regie unterstellte. In der späten Kaiserzeit setzt sich diese Tendenz fort, zweifellos befördert durch den gewaltigen Staatsapparat, der die administrativen Voraussetzungen dafür stärkte, und auch durch den Autonomieverlust, der sich beispielsweise in der Nivellierung der unterschiedlichen munizipalen Rechtsstatute oder in der Unterbindung einer eigenständigen Münzprägung ausdrückte. Die Einflußnahme des Staates auf das Finanzwesen dürfte sich in spätrömischer Zeit in summa also verstärkt haben, doch blieb diese Einflußnahme, so läßt sich resümieren, immer punktuell und je nach Situation von unterschiedlicher Intensität. Zu einer Totalenteignung kam es dabei nie.

Dieses Szenario besitzt gegenüber den bisherigen Versuchen, die Quellenlage in ein reduktionistisches Modell zu pressen, mehrere Vorzüge. Erstens kann es auf das durch die Quellenlage nicht zu rechtfertigende Postulat einer Globalkonfiskation der städtischen Einkünfte verzichten. Zweitens vermag es dieser Lösungsansatz im Gegensatz zu den bisher unterbreiteten, alle gegebenen Quelleninformationen zu inkorporieren, und ist dabei zugleich flexibel genug, um erstmals alle Widersprüche der Quellenlage in einem befriedigenden Modell vereinen zu können. Drittens schließt dieses Modell an aktuelle Ansätze zur Neubewertung des Problems der munizipalen Finanzautonomie in der Prinzipatszeit an, indem es deren Erkenntnis, daß ein systematisches Bestreben zur Zentralisierung der Finanzhoheit niemals existierte, durch den Nachweis untermauert, daß der Endpunkt, auf den diese Entwicklung vermeintlich zulief, der Konfiskationsakt, ein modernes Konstrukt darstellt.

Damit ist der Hintergrund gegeben, vor dem schließlich auch die Quotierungsregel Valentinians und Valens' gedeutet werden muß. Unzweifelhaft kommt darin, daß sie zwei Drittel der städtischen Einkünfte der Regie des Fiskus unterstellte, eine massive staatliche Kontrolle des städtischen Finanzgebarens zum Ausdruck. Das ist jedoch nur eine Seite der Medaille. Denn die Quotierungsregel definiert umgekehrt auch einen Anteil, über den die Gemeinden fortan vollkommen eigenständig verfügen konnten. Das geht so weit, daß den staatlichen Finanzbehörden die Einmischung explizit verboten 
wird: Im Jahre 431 wiederholt die schon mehrmals erwähnte Konstitution CJ 4, 61, 13 an Nicomachus Flavianus die Quotierungsregel und betont dabei ausdrücklich das Recht der Städte, das Drittel aus dem Grundbesitz, das sich in ihrer Verwaltung befindet, eigenständig zu verpachten. Denn, so heißt es in dem oben bereits zitierten zweiten Abschnitt, ,jenes Drittel soll so weitgehend der Verfügungsgewalt der Städte und Kurialen unterstehen, daß sie wissen, $d a ß$ die Verantwortung für ihren eigenen Vorteil eher in ihrer eigenen Entscheidungsgewalt als in derjenigen eines anderen (nämlich des Fiskus) gründet". Auch die ephesische Inschrift rückt in diesem Zusammenhang noch einmal ins Blickfeld: Dort wird ja ausdrücklich das Ziel formuliert, die Städte in bezug auf die Verwaltung bestimmter Liegenschaften fortan vom bürokratischen Apparat, seiner Schwerfälligkeit und seiner Korruptionsanfälligkeit unabhängig zu machen. Die Quotierungsregel ist insofern keineswegs nur das Produkt gesteigerter staatlicher Einflußnahme, sondern muß auch im Kontext einer in den späten $360 \mathrm{er}$ und 370er Jahren offenbar in diversen Einzelsituationen verfolgten Programmatik gesehen werden, den Städten einen größeren, autonomen finanziellen Handlungsspielraum zu geben.

Damit erscheint die von Valentinian und Valens beschlossene Teilung der Verantwortung für die Verwaltung der städtischen Einkünfte zwischen Stadt und Fiskus in gänzlich neuem Licht: Zum ersten Mal - wenigstens nach Ausweis der Überlieferung - in einer über zweihundertjährigen Geschichte ständig zunehmender, aber ohne erkennbare Regelhaftigkeit erfolgender Einflußnahme des Kaisers auf das städtische Finanzwesen wurden die Kompetenzen von Fiskus und Stadt in allgemeingültiger Weise definiert. Dabei ging es nach dem Zeugnis der genannten, programmatischen Aussagen weniger um eine Beschränkung der Städte als vielmehr darum, eine (zumindest partielle) Finanzautonomie der Städte dauerhaft festzuschreiben. Den Gemeinden wurde auf diese Weise ermöglicht, über die vom Kaiser und seinen Vertretern genehmigten und gegebenenfalls finanzierten Ausgaben hinaus in einem beschränkten, aber verläßlichen Rahmen - autonome finanzielle Entscheidungen zu treffen, ohne beständig mit staatlichen Behörden Rücksprache halten oder Änderungen der Budgetsituation befürchten zu müssen.

Auch für den Fiskus war diese Regelung im übrigen vorteilhaft: Wie die Inschrift von Ephesos sagt, entzog man mittels der Verwaltung größerer Gütermassen durch die Gemeinden korrupten Beamten eine Gelegenheit zu Unterschlagungen, ja man konnte sogar auf höhere Einnahmen hoffen; zugleich aber hatte man dadurch, daß der Staat weiterhin den größeren Teil der Einkünfte kontrollierte (was wie gesagt nicht heißt, daß er sie nur für seine Zwecke verwendete), das Risiko dabei minimiert. Überhaupt zeigt die Tatsache, daß den Städten nur ein Drittel der Einkünfte zur freien Verfügung 
überlassen wurde, wie unverzichtbar die Kontrolle des Staates über das Finanzgebaren der Gemeinden mittlerweile erschien. Insofern behält Valentinians Quotierungs regel trotz der hier vorgeschlagenen Neuinterpretation einen ambivalenten Charakter. Sie entspricht damit vollauf dem Bild, das die Untersuchung von der Geschichte der städtischen Finanzautonomie in der römischen Kaiserzeit ergeben hat.

Die Einsicht, daß die Quotierungsregel der 370er Jahre nicht auf den Entzug von Autonomierechten reduziert werden darf, sondern diese umgekehrt auch dauerhaft festschrieb, rundet das Gesamtergebnis dieser Untersuchung ab: Es fordert erstens dazu auf, einen bis heute als zentral angesehenen Faktor in der Entwicklung des spätantiken Städtewesens, den Verlust finanzieller Handlungsspielräume, einer grundsätzlichen Neubewertung zu unterziehen. Zweitens zwingt es dazu, die herkömmliche Auffassung, daß der spätrömische Staat als hochbürokratisiertes Staatswesen mit einer ausgeprägt zentralistischen und etatistischen Tendenz immer weniger Raum für eigenständiges politisches Handeln der Städte ließ, in einem zentralen Punkt zu relativieren. Drittens schließlich zeigt die Untersuchung ein weiteres Mal, daß die traditionelle Epochengrenze zwischen Prinzipatszeit und Spätantike den Blick auf die Gesamtentwicklung römischer Staatlichkeit in der Kaiserzeit verstellt: Wie so viele andere Problemfelder steht auch der spätrömische Antagonismus von Stadt und Staat im Bereich der Finanzautonomie in einer weit in die Prinzipatszeit zurückreichenden Kontinuitätslinie. Und umgekehrt erscheint jetzt auch die prinzipatszeitliche Stadtgeschichte in einem neuen Licht: Die Niedergangsthese steht nun mehr denn je zur Debatte. Der vermeintliche Endpunkt der Entwicklung nämlich, Enteignung und Totalverlust der Finanzautonomie unter Diokletian oder Konstantin, hat sich als Chimäre der Forschung erwiesen. 


\title{
Kaiser und Katastrophe. Zur Bewältigung von Versor- gungskrisen im spätrömischen Reich ${ }^{1}$
}

\author{
Hans-Ulrich Wiemer
}

\section{Einleitung}

Theodor Mommsen hat in seiner „Römischen Geschichte“ geurteilt, die Kaiserzeit bezeichne für manche Gegenden des Orients wie des Okzidents den ,an sich sehr bescheidenen, aber doch vorher wie nachher nie erreichten Höhepunkt des guten Regiments".2 Mommsen meinte damit vor allem die Verbreitung städtischer Lebensformen in weiten Teilen des Imperium Roma-

1 Ich danke Andrea Jördens, Hartmut Leppin, Andreas Luther, Sebastian Schmidt-Hofner, Michal Stachura und Andreas Victor Walser für Hinweise und Kritik. - Hungersnöte in antiken Städten sind schon mehrfach in monographischer Form untersucht worden: vgl. neben P. Garnsey, Famine and Food Supply in the Graeco-Roman World: responses to risk and crisis, Cambridge 1988 auch den wertvollen Überblick von H. P. Kohns, Hungersnot, RAC 16, 1994, 828-893. Derselbe Verfasser hatte 30 Jahre zuvor bereits „Versorgungskrisen und Hungerrevolten im spätantiken Rom" eingehend untersucht (Bonn 1961). Zu der materialreichen, aber methodisch problematischen Untersuchung von D. Ch. Stathakopoulos, Famine and Pestilence in the Late Roman and Early Byzantine Empire. A Systematic Survey of Subsistence Crises and Epidemics (Birmingham Byzantine and Ottoman Studies 9), Aldershot 2004 vgl. meine Rezension in: Sehepunkte 4, 2004, Nr. 6. Der Versorgungskrise, die 362/3 n. Chr. im syrischen Antiocheia herrschte, habe ich ein Kapitel meiner von Malcolm Errington betreuten Dissertation gewidmet, in dem auch alle anderen Nachrichten über Versorgungsprobleme in dieser Stadt besprochen werden: Libanios und Julian. Studien zum Verhältnis von Rhetorik und Politik im 4. Jahrhundert v. Chr. (Vestigia. Beiträge zur Alten Geschichte 46), München 1995, $269 \mathrm{ff}$.

2 Th. Mommsen, Römische Geschichte, Bd. 5, Berlin ${ }^{41884}$, 4f. Zur historiographischen Tradition dieser Beurteilung vgl. K. Bringmann, Zur Beurteilung der römischen Kaiserzeit in der deutschen Historiographie des 19. Jahrhunderts, in: K. Christ/E. Gabba (Hgg.), Römische Geschichte und Zeitgeschichte in der deutschen und italienischen Altertumswissenschaft während des 19. und 20. Jahrhunderts, Teil II: L'impero romano fra storia generale e storia locale (Biblioteca di Athenaeum 11), Como 1991, 57-81; auch in: K. Bringmann, Ausgewählte Schriften, Frankfurt/Main 2001, 361-378. 
num: In der Tat wiesen viele Provinzen des Reiches einen Urbanisierungsgrad auf, der dort erst im 20. Jahrhundert wieder erreicht oder übertroffen wurde; vor allem in Afrika ${ }^{3}$ und in Kleinasien ${ }^{4}$ waren die Städte nach Hunderten zu zählen. Die Lebensmittelversorgung dieser städtischen Siedlungszentren war und blieb jedoch stets prekär. Mißernten waren außerhalb Ägyptens eine in recht kurzen Abständen wiederkehrende Erscheinung, und selbst auf den Nil war nicht immer Verlaß. ${ }^{5} \mathrm{Da}$ das Produktivitätsniveau bei allen lokalen und regionalen Unterschieden insgesamt relativ niedrig ${ }^{6}$ und zudem der Landtransport langsam und im Verhältnis zum Warenwert teuer war, ${ }^{7}$ wirkten sich Mißernten sogleich spürbar auf die Ernährungssituation breiter Kreise aus. Der Hunger war darum für sehr viele Reichsbewohner ein vertrauter Begleiter.

Die Aufgabe, solche Krisensituationen zu bewältigen, fiel in den griechisch geprägten Städten der östlichen Reichshälfte seit jeher der Bürgergemeinde und ihren Organen zu. Das Ende der römischen Republik brachte ihnen auf diesem Gebiet kaum Veränderungen. Zwar nahm bereits Augustus die Getreideversorgung Roms unter seine Obhut und schuf schließlich im praefectus annonae ein speziell für diese Aufgabe zuständiges Amt. ${ }^{8}$ Die Städte in den Provinzen jedoch waren und blieben auf Selbsthilfe angewiesen. In der hohen Kaiserzeit bestellte eine Vielzahl kleinasiatischer Städte „Getreidekommissare" (sitonal), die im Auftrage der Stadt Getreide aufkauften und der Bürgerschaft zur Verfügung stellten. ${ }^{9}$ Mancherorten existierten auch städtische "Getreidekassen“, die der Finanzierung von Getreidekäufen dienten. ${ }^{10}$

3 C. Lepelley, Les cités de l'Afrique romaine au Bas-Empire, 2 Bde., Paris 1979-1981.

4 A. H. M. Jones, The Cities of the Eastern Roman Provinces, Oxford 21971.

5 G. Casanova, Epidemie e fame nella documentazione greca d'Egitto, Aegyptus 64, 1984, 163-201.

6 Vgl. dazu Garnsey, Famine (wie Anm. 1), 8-16.

7 Dazu ist grundlegend A. Kolb, Transport und Nachrichtentransfer im Römischen Reich (Klio. Beiträge zur Alten Geschichte. Beihefte N.F. 2), Berlin 2000.

8 Vgl. dazu etwa H. Pavis d'Escurac, La préfecture de l'annone. Service administratif impérial d'Auguste à Constantin (Bibliothèque des Écoles Françaises d'Athènes et de Rome 226), Paris 1976, 3-42; G. Rickman, The Corn Supply of Ancient Rome, Oxford 1980, 55-66; Garnsey, Famine (wie Anm. 1), 231-243; P. Eich, Zur Metamorphose des politischen Systems in der römischen Kaiserzeit. Die Entstehung einer „personalen Bürokratie" im langen dritten Jahrhundert (Klio. Beiträge zur Alten Geschichte. Beihefte N. F. 9), Berlin 2005, 189-210.

9 Vgl. dazu vor allem J. H. M Strubbe, The sitonia in the cities of Asia Minor under the principate, EA 10, 1987, 45-87 + 13, 1989, 99-122.

10 Zusammenfassung des Forschungsstandes bei H.-C. Dirscherl, Die Verteilung von kostenlosem Getreide in der Antike vom 5. Jh. v. Chr. bis zum Ende des 3. Jhs. n. Chr., 
Auch wo es sie gab, reichten sie jedoch in der Regel nicht aus, wenn eine starke Verknappung und Verteuerung des Angebotes an Lebensmitteln eintrat. Darum mußten die Städte bei Mißernten zumeist auf wohlhabende Bürger zählen, die bereit waren, ihren Mitbürgern Getreide unter dem Marktpreis zu verkaufen oder der Gemeinde zu einem günstigen Zins Geld zu leihen, damit auf der Gemarkung der Stadt oder auch außerhalb Getreide gekauft werden konnte; ja manchmal verzichteten sie sogar auf jedes Entgelt. ${ }^{11}$ Solche Wohltaten wurden in der sicheren Erwartung geleistet, daß die Bürgerschaft, der sie zugute kam, die Wohltäter mit öffentlichen Ehren belohnen würde; sie waren also eine Ausdrucksform jenes auf einem symbolischen Tausch beruhenden Verhaltensmusters, für das sich der Name Euergetismus eingebürgert hat. ${ }^{12}$

Mit all dem hatte der Kaiser in der Regel nichts zu schaffen. Zwar zählte es nach Auffassung des Juristen Ulpian zu den Aufgaben eines Provinzstatthalters, gegen Getreidewucher vorzugehen. ${ }^{13}$ Vom Kaiser gingen jedoch so gut wie keine normativen Regelungen zur Bewältigung von Versorgungskrisen in den Provinzstädten aus, und erst recht unterhielt er keinen administrativen Apparat, der primär für diese Aufgabe zuständig gewesen wäre. ${ }^{14} \mathrm{Al}$ lerdings konnte eine Stadt sich darum bemühen, das Privileg zur Einfuhr von Getreide aus Ägypten zu erhalten, dessen Überschüsse für die Versorgung Roms reserviert waren, indem sie sich an den praefectus annonae oder an den Kaiser selbst wandte. ${ }^{15}$ Die Kosten des Getreidekaufes wurden jedoch in der

MBAH 19, 1, 2000, 1-33; vgl. auch dens., Die sitonia von Oxyrhynchos, MBAH 18, 1, 1999, 57-90 für die sitonia im kaiserzeitlichen Ägypten.

11 Vgl. dazu etwa F. Quaß, Die Honoratiorenschicht in den Städten des griechischen Ostens. Untersuchungen zur politischen und sozialen Entwicklung in hellenistischer und römischer Zeit, Stuttgart 1993., $229 \mathrm{ff}$.

12 Vgl. dazu die klassische Analyse von P. Veyne, Le pain et le cirque. Sociologie d'un plumlisme politique, Paris 1976.

13 Dig. 47, 11, 6; 48, 12, 2; vgl. 47, 19, 37 (Paulus). Vgl. dazu P. Herz, Studien zur römischen Wirtschaftsgesetzgebung. Die Lebensmittelversorgung (Historia. Einzelschriften 55), Stuttgart 1988, 147-150.

14 Eine Ausnahme bildet das bekannte Reskript der Kaiser Mark Aurel und Verus, das den decuriones verbot, Getreide billiger an ihre Mitbürger zu verkaufen, als es die Versorgungslage erfordere: Dig. 48, 12, 3; 50, 1, 8; 50, 8, 7, pr. Die Annahme, das Edikt des L. Antistius Rusticus sei nach Absprache mit Kaiser Domitian erlassen worden, ist unbegründet: vgl. H.-U. Wiemer, Das Edikt des L. Antistius Rusticus: Eine Preisregulierung als Antwort auf eine überregionale Versorgungskrise?, AnSt 47, 1997, 195-215, hier: $205-$ 206.

15 Wie groß der Entscheidungsspielraum des praefectus annonae war, ist umstritten und nicht sicher zu entscheiden: Nach M. Wörrle, Ägyptisches Getreide für Ephesos, Chiron 1, 
Regel nicht vom Kaiser, sondern von der Stadt getragen. Wenn der jüngere Plinius Kaiser Trajan hochleben läßt, weil er der Provinz Ägypten nach einer Mißernte einen Teil des Getreides zur Verfügung gestellt hatte, das dort als Steuer erhoben worden war, setzt er stillschweigend voraus, daß dieses Getreide nicht umsonst abgegeben wurde. ${ }^{16}$ Gewiß kam es gelegentlich vor, daß ein Kaiser einer Stadt Getreide geradezu schenkte, doch waren das seltene Ausnahmefälle. Die Belege für kaiserliche Getreideschenkungen sind $\operatorname{rar}^{17}$ und stehen zudem meist im Zusammenhang mit einem Aufenthalt des kaiserlichen Heeres, der zu einer lokalen Knappheit geführt hatte. ${ }^{18}$

\section{Reguläre Unterstützung der städtischen Lebensmittelversorgung durch spätrömische Kaiser?}

Auch wenn die neuere Forschung den spätrömischen Staat zumeist als Produkt einer weit zurückreichenden Entwicklung auffaßt, bleibt doch unbestritten, daß die Reformen Diokletians und Konstantins für die Entwicklung der römischen Staatsverwaltung einen deutlichen Einschnitt markieren. Die im Auftrag und Namen des Kaisers agierenden Funktionsträger in den Provinzen bildeten nun ein sehr viel dichteres Netz. Die Zahl der Provinzen und mit ihnen die Zahl der Provinzstatthalter wurde nahezu verdoppelt; in den Prätoriumspräfekturen entstanden dem Kaiser direkt unterstehende Behörden, in denen die zivile Verwaltung ganzer Reichsteile zentralisiert war. Bald traten auch noch die Diözesen als mittlere Instanzen zwischen Prätoriumspräfekturen und Provinzen hinzu. Diese hierarchisch gegliederte, zentralisierte Behördenorganisation eröffnete dem Kaiser einen umfassenderen und direkteren Zugriff auf die Reichsangehörigen; seine Hand war in den Provinzen nun deutlicher zu spüren.

1971, 325-340 konnte er über überschüssiges Getreide frei disponieren, während Pavis d'Escurac, Préfecture de l'annone (wie Anm. 8), 262-263 und Eich, Metamorphose (wie Anm. 8), 198 meinen, daß die Entscheidung grundsätzlich dem Kaiser vorbehalten gewesen sei.

16 Plin. Pan. 30-32, bes. 31, 3: Refudimus Nilo suas copias: recepit frumenta quae miserat, deportatasque messes revexit. Kaiser Hadrian stundete der Provinz nach zwei unzureichenden Nil-

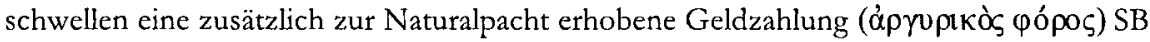
III 6944 = Oliver, Constitutions, Nr. 88; neuer Beleg in P.Heid. VII 396.

17 Vgl. dazu R. Ziegler, Münzen Kilikiens als Zeugnis kaiserlicher Getreidespenden, JNG 27, 1977, 29-67.

18 Auf diesen Kausalnexus wird in den Quellen häufiger hingewiesen; vgl. etwa Dio Chrys. 35, 15; Exp. 58; HA Pius 7, 11; Socr. H. E. 3, 17, 2; Cass. Var. 2, 20. 
Angesichts dieses Sachverhaltes stellt sich die Frage, ob und, wenn ja, in welcher Weise sich der Formwandel der Staatlichkeit auf die Lebensmittelversorgung der Städte auswirkte. Folgt man dem Verfasser der maßgeblichen Monographie über die Lebensmittelversorgung der frühbyzantinischen Stadt, liegt zwischen der Epoche vor Diokletian und der Spätantike ein tiefer Einschnitt. Jean Durliat vertritt die Auffassung, der spätrömische Kaiser habe in jeder größeren Stadt der östlichen Reichshälfte kostenlose Brotverteilungen finanziert; für die Verwaltung der zu diesem Zweck eingerichteten Getreidekassen sei ein eigener Amtsträger der kaiserlichen Verwaltung, der sitones, verantwortlich gewesen. ${ }^{19}$ Bevor wir uns daher der Frage zuwenden, was sich über Art und Umfang kaiserlicher Hilfe bei Versorgungskrisen ausmachen läßt, müssen wir die Rolle klären, die der spätrömische Kaiser für die reguläre Lebensmittelversorgung der städtischen Siedlungen des Imperium Romanum spielte.

Nun ist in der Tat nicht zu bestreiten, daß Rom in der Spätantike nicht mehr die einzige Stadt war, die von der kaiserlichen Verwaltung mit subventioniertem Getreide versorgt wurde. Nicht bloß die stadtrömische plebs frumentaria wurde in der Spätantike auf Kosten des Kaisers mit dem Grundnahrungsmittel Brot versorgt, wozu dann noch die Verteilung von subventioniertem Schweinefleisch und Wein kam. ${ }^{20}$ Neben die Roma aeterna am Tiber

$19 \mathrm{~J}$. Durliat, De la ville antique à la ville byzantine. Le problème des subsistances (Collecti-

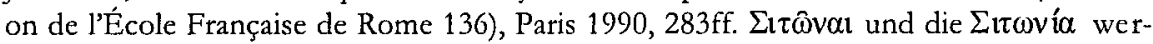
den im "Codex Theodosianus" kein einziges Mal erwähnt. Ein Gesetz des Anastasius zeigt jedoch, daß die Institution in der Spätantike nicht völlig verschwunden war: $C J 10$, 27, 3; vgl. CJ 1, 4, 26, pr. (530); Nov. Iust. 128, 16 (545). A. J. Boudewijn Sirks/P. J. Sijpestein/Klaas A. Worp, Ein frühbyzantinisches Szenario für die Amtswechslung in der Sitonie. Die griechischen Papyri aus Pommersfelden (PPG) mit einem Anhang über die Pommersfeldener Digestenfragmente und die Überlieferungsgeschichte der Digesten (Münchener Beiträge zur Papyrusforschung und Antiken Rechtsgeschichte 86), München 1996 edieren und kommentieren Papyri aus dem byzantinischen Italien, die ein Muster-

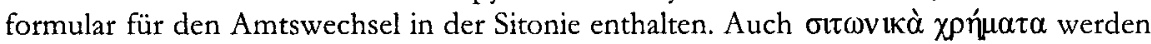
unter Anastasius und Justinian noch gelegentlich erwähnt, ohne daß man deswegen darauf schließen dürfte, es habe sie überall gegeben: $\mathrm{CJ} 10,27,2, \S 12$ (Anastasius); 10, 30, 4 (530).

20 Vgl. dazu A. Chastagnol, La préfecture urbaine à Rome sous le Bas-Empire (Publications de la Faculté des Lettres et Sciences Humaines d'Alger 34), Paris 1960, 296-334; A. H. M. Jones, The Later Roman Empire 284-602. A Social, Economic and Administrative Survey, Bd. 2, Oxford 1964, 695-705; J.-M. Carrié, Les distributions alimentaires dans les cités de l'Empire Romain Tardif, MEFRA 87, 1975, 995-1101, hier: 996-1070; Rickman, Corn Supply (wie Anm. 8), 198-209; (A. J.) B. Sirks, The Size of the Grain Distribution in Imperial Rome and Constantinople, Athenacum n. s. 79, 1991, 215-237, hier: 217-225 
trat unter Konstantin das neue Rom am Bosporos. ${ }^{21}$ Auch hier kam nun ein erheblicher Teil der Einwohnerschaft in den Genuß einer Brotverteilung, deren Kosten aus kaiserlichen Mitteln gedeckt wurden. Um den Bedarf der Neugründung decken zu können, die sich binnen eines Jahrhunderts zu einer Großstadt mit mindestens einer Viertelmillion Einwohnern entwickelte, 22

(vgl. auch dens., Bread for the People. The Legal Structure of the Transportation and Processing of Supplies for the Imperial Distributions in Rome and Constantinople (Studia Amstelodamensia ad epigraphicam, ius antiquum et papyrologicam pertinentes 31), Amsterdam 1991). Die Zahl der zum Empfang kostenlosen oder stark verbilligten Brotes Berechtigten schätzt Sirks (221) auf ca. 85.000, Carrié (1069 Anm. 2) auf 116.000, Jones (696) und Chastagnol (292) auf ca. 120.000. Die Berechnungen von Sirks und Carrié beruhen jedoch auf einem Mißverständnis von Olymp. F 25 Blockley (= Phot. Cod. 80, 59b): Wenn der Historiker berichtet, Rom habe sich nach der Eroberung durch Alarich

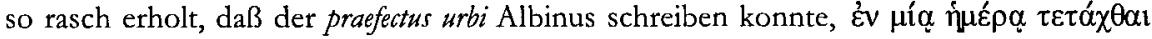

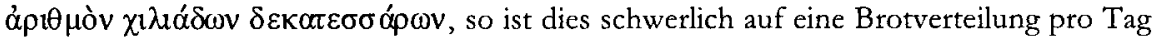
zu beziehen; der Text fordert die Deutung, daß hier von Personen die Rede ist, die an einem Tag registriert wurden. Daß die Zahl von 120.000 Empfangsberechtigten nicht zu hoch gegriffen ist, geht daraus hervor, $\mathrm{da} ß$ sich die Zahl derjenigen, die verbilligtes Schweinefleisch bezogen, ebenfalls auf 120.000 belief: CTh 14, 4, 10 (419).

Die Einwohnerzahl Roms in der Spätantike wird von Jones (698) auf etwa 600.000 geschätzt. Chastagnol (182 Anm. 1) dagegen geht von 300.000-350.000 Einwohnern bis zur Belagerung durch Alarich aus, für die Zeit danach von nur noch 200.000 .

21 Vgl, dazu etwa Jones, Later Roman Empire II (wie Anm. 20), 695-701; G. Dagron, Naissance d'une capitale. Constantinople et ses institutions de 330 à 451 (Bibliothèque Byzantine. Études 7), Paris 1974, 530-541; Carrié, Distributions alimentaires (wie Anm. 20), 1071-1073; Sirks, Athenaeum n. s. 79, 1991 (wie Anm. 20), 225-235. Die Zahl derjenigen, die Anspruch auf kostenloses Brot hatten, wurde von Konstantin I. auf 80.000 festgesetzt (Socr. H. E. 2, 13, 5) und von Theodosius I. leicht erhöht (CJ 11, 25, 2); wie hoch sie im 5. und 6. Jahrhundert war, ist unbekannt. Iust. Ed. 13, 8 beziffert die Menge des aus Ägypten nach Konstantinopel gelieferten Getreides auf acht Millionen einer ungenannten Maßeinheit, die, weil im Text sonst stets von Artaben die Rede ist, als Artabe zu identifizieren sein dürfte. Je nachdem, wie man das Verhältnis zwischen Artabe und modius bestimmt, führt die Angabe Justinians auf 27 oder 36 Millionen modii. Wie schwierig es ist, allein aufgrund dieser Angabe die Bevölkerungszahl Konstantinopels zu berechnen, zeigt A. E. Müller, Getreide für Konstantinopel. Überlegungen zu Justinians Edikt XIII als Grundlage für Aussagen zur Einwohnerzahl Konstantinopels im 6. Jh., JÖB 43, 1993, $1-20$.

22 Vgl. dazu etwa Jones, Later Roman Empire II (wie Anm. 20), 698 (600.000 zur Zeit Justinians); Dagron, Naissance d'une capitale (wie Anm. 21), 525-530 (200.000-300.000 um 430); C. Mango, Le développement urbain de Constantinople (IVe-VIIe siècles) (Travaux et Mémoires du Centre de Recherche d'Histoire et Civilisation de Byzance. Collège de France. Monographies 2), Paris 1985, 50-51 (300.000-400.000 um die Mitte des 5. Jahrhunderts); Müller, JÖB 43, 1993 (wie Anm. 21), 17-19 (Doxographie). 200.000 ist die 
wurden die Getreideüberschüsse Ägyptens nun für sie reserviert. Das Imperium Romanum der Spätantike ernährte nicht nur eine, sondern zwei Kaiserstädte.

Nicht zu bestreiten ist weiterhin, daß sich der Kaiser in der Spätantike auch an der regulären Lebensmittelversorgung einiger Provinzstädte beteiligte. Aus einem der Berichte, die Symmachus als Stadtpräfekt an Kaiser Valentinian II. schickte, erfahren wir, daß Kaiser Konstantin der Stadt Puteoli, deren natürlicher Hafen auch damals noch eine gewisse Rolle für die Getreideversorgung Roms spielte, ${ }^{23} 150.000$ modii Getreide jährlich in alimoniam civitatis zur Verfügung gestellt hatte; die Zuteilung wurde später reduziert, bestand aber noch im Jahre $384 .{ }^{24}$ Neben Puteoli erhielten im 4. Jahrhundert auch Tarracina und Capua zeitweise Staatsgetreide, jedoch in äußerst geringen Mengen. Da die Begünstigung dieser kampanischen Städte von Symmachus ausdrücklich mit ihren Leistungen für die Stadt Rom begründet wird, darf ihre Situation jedoch nicht verallgemeinert werden, wie es bei Durliat geschieht. Zweifelsfrei bezeugt ist in der Spätantike weiterhin eine vom Kaiser subventionierte Brotverteilung für das ägyptische Alexandreia. ${ }^{25}$ Diese Einrichtung geht möglicherweise auf das 3. Jahrhundert zurück; seit 302 bestand sie kontinuierlich bis ins 7. Jahrhundert. ${ }^{26}$ Umfang und Empfängerkreis der Zuteilung sind indessen unbekannt. Ansonsten läßt sich die Exi-

niedrigste Zahl, die in der Forschung überhaupt erwogen wird; die Schätzungen reichen bis zu einer Million.

23 Einen procurator portus Puteolanorum bezeugt um die Wende vom 3. zum 4. Jahrhundert die Inschrift AE 1972, 79; vgl. dazu J. D'Arms, A New Inscribed Base from 4th Century Puteoli, PP 27, 1972, 255-270; dens., Puteoli in the Second Century of the Roman Empire: A Social and Economic Study, JRS 64, 1974, 104-124, bes. 118-121; G. Camodeca, Puteoli porto annonario e il commercio del grano in età imperiale, in: Le ravitaillement en blé de Rome et des centres urbains des débuts de la République jusqu'au Haut Empire, Neapel 1994, 103-128, hier: 113-115 (Datierung).

24 Symm. Rel. 40.

25 Barbarus Scaligeri s. a. 302 (MGH AA IX, 290); Chron. Pasch. s. a. 302, 514, Z. 16-17 Dindorf; Proc. H. A. 26, 40-44; CTh 14, 26, 2 (436); Nov. Iust. 7, 7; 13, 4; 6; Euagr. H. E. 2, $5=$ Priscus F. 22 Müller $=28$ Blockley. Wie in Rom und Konstantinopel gab es auch in Alexandreia Brotverteilungen, die mit Häusern verbunden waren: WChr 96; SB II 9023 = P.Abinn. 22 mit V. Martin/D. van Berchem: Le panis aedium d'Alexandrie, $\mathrm{RPh}$ $16,1942,5-21$.

26 Dionysios von Alexandreia bei Euseb. H. E. 7, 21, 9. In der hohen Kaiserzeit überwachte

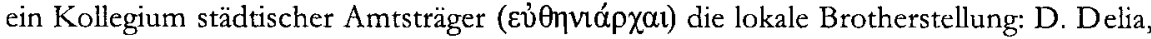
Alexandrian Citizenship during the Roman Principate (American Classical Studies 23), Atlanta, Georgia 1991, 102-103; dort (151) findet sich auch eine Liste der datierten Amtsinhaber, die mit dem Jahr 158 einsetzt und 284 endet. 
stenz einer staatlichen Brotverteilung in der Spätantike noch für das syrische Antiocheia nachweisen, mit Sicherheit jedoch erst für das 6. Jahrhundert. Zwar ist im Zusammenhang mit dem sogenannten Säulenkrawall von 387 davon die Rede, daß der Kaiser die Stadt bestraft habe, indem er den Armen ihre Nahrung genommen habe. ${ }^{27}$ Wir wissen aber nicht, wann und von wem diese Versorgungseinrichtung ins Leben gerufen wurde. Im Jahre 438 hat dann die Kaiserin Eudokia den Antiochenern Geld für eine „Getreidekasse“ (eis sitonikon) zur Verfügung gestellt.. ${ }^{28}$ Erst zur Zeit Justinians ist in den Quellen eine staatliche Brotverteilung großen Umfangs zweifelsfrei bezeugt. ${ }^{29}$ Ganz unsicher ist dagegen, ob es eine ähnliche Einrichtung auch in Karthago gab. Ein unter dem Titel „De frumento Carthaginiensi“ überliefertes Gesetz Konstantins mit Regelungen für ein frumentum aeneum, das an den proconsul Africae Anullinus gerichtet ist, ${ }^{30}$ widersteht bislang jeder schlüssigen Deutung. Auch wenn es sich bei diesem frumentum aeneum um eine vom Kaiser subventionierte Getreideverteilung handeln sollte, lassen sich über Umfang und Empfängerkreis dieser Verteilung keine Aussagen treffen.

Man darf also gegen Durliat festhalten, daß von einem reichsweiten, alle Provinzstädte umfassenden System kaiserlicher Brotverteilungen auch in der Spätantike keine Rede sein kann. Immerhin aber beschränkte sich die kaiserliche Fürsorge in der Spätantike nicht mehr auf die Lebensmittelversorgung Roms, sondern bezog unter Justinian neben Konstantinopel auch die beiden anderen Metropolen der östlichen Reichshälfte mit ein, seit Diokletian das ägyptische Alexandreia und zumindest unter Justinian auch das syrische Antiocheia. Gewiß kann man nicht ausschließen, daß auch die eine oder andere „gewöhnliche" Provinzstadt zumindest zeitweise in den Genuß staatlich subventionierten Getreides kam, wie dies auch in der früheren Kaiserzeit mitunter der Fall gewesen war. ${ }^{31}$ Das Beispiel der kampanischen Städte lehrt jedoch, daß diese Art der Begünstigung besondere Umstände voraussetzte.

27 Lib. Or. 20, 7.

28 Chron. Pasch. s. a. 444, 585, Z. 14-16 Dindorf.

29 Euagr. H. E. 6, 8; Nov. Iust. 7, 9.

30 CTh $14,25,1$.

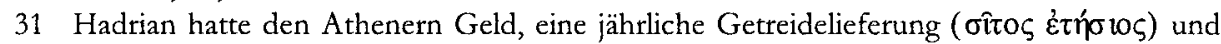
die Insel Kephallenia geschenkt: Cass. Dio 69, 16, 1-3; die Modalitäten sind unklar. Als später Constans den Athenern mehrere Inseln schenkte, waren diese dem überlieferten, in der Ausgabe von Giangrande (Rom 1956) jedoch willkürlich geänderten Wortlaut zu-

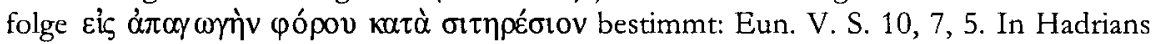
Neugründung Antinoopolis gab es eine Alimentarstiftung des Kaisers: M. Zahrnt, Antinoopolis in Agypten: Die hadrianische Gründung und ihre Privilegien in der neueren Forschung, ANRW II, 10, 1, 1988, 669-706, hier: 696-697. 
Zudem war die Menge des an die Puteolaner abgetretenen Staatsgetreides so gering, daß man kaum von einer substantiellen Ergänzung des Angebotes an Nahrungsmitteln sprechen kann, was im Falle Tarracinas und Capuas natürlich a fortiori gilt.

Allerdings ist zu berücksichtigen, daß der spätrömische Kaiser nicht bloß dadurch zur Lebensmittelversorgung provinzialer Städte beitrug, daß er an den genannten Orten durch seine Beauftragten im eigenen Namen Getreide oder Brot verteilen ließ. Seit Konstantin erhielt auch eine Reihe von Kirchen des Reiches staatliche Zuwendungen, die für die Unterstützung der Armen bestimmt waren. ${ }^{32}$ Leider sind wir außerstande, eine vollständige Liste der Kirchen zu erstellen, die vom Kaiser für die Armenfürsorge bestimmte $\mathrm{Zu}$ wendungen erhielten, und auch in den Fällen, in denen die Tatsache der staatlichen Dotierung feststeht, bleibt unbekannt, welche Höhe sie hatte. ${ }^{33}$ $\mathrm{Daß}$ alle Bischofskirchen des Reiches solche Zuwendungen erhielten, wie Durliat meint, ${ }^{34}$ dürfte aber ganz unwahrscheinlich sein. Aus der ,Kirchengeschichte" Theodorets erfahren wir zwar, daß die von Konstantin gewährten Subventionen von Kaiser Jovian auf ein Drittel ihres ursprünglichen Umfanges reduziert wurden, können diesen ursprünglichen Umfang aber nicht quantifizieren. ${ }^{35}$ Immerhin kann man sich im Falle des syrischen Antiocheia eine ungefähre Vorstellung vom Empfängerkreis bilden, da Johannes Chrysostomos, der 386 bis 398 Presbyter der Kirche Antiocheias war und daher wußte, wovon er sprach, erklärt, die antiochenische Kirche habe zu seiner Zeit 3.000 Arme versorgt. ${ }^{36} \mathrm{Da}$ wir für Antiocheia von mindestens 150.000

32 Jones, Later Roman Empire II (wie Anm. 20), 898-899; J. H. W. G. Liebeschuetz, The Decline and Fall of the Roman City, Oxford 2001, 150; 167-168.

33 Wenn die in den Akten des Konzils von Chalkedon (Eduard Schwartz [Hg.], Acta conciliorum oecumenicorum, 4 Bde., Berlin 1914-1984, im folgenden zitiert als ACO mit Angabe des Bandes und des Faszikels, hier: ACO II 1, 3, 405, Z. 13; 406, Z. 20) erwähnten Épavópюr Empfänger einer kirchlichen Brotverteilung waren (so C. Foss, Ephesus after Antiquity: A Late Antique, Byzantine and Turkish City, Cambridge 1979, 25), gab es auch dort im 5. Jahrhundert einen fest umrissenen Empfängerkreis der kirchlichen Armenfürsorge. Für Edessa vgl. unten Anm. 78.

34 Durliat, Subsistances (wie Anm. 19), 313-317; ders., Les finances publiques de Dioclétien aux Carolingiens (284-889) (Beihefte der Francia 21), Sigmaringen 1990, 55-63; dagegen mit Recht Liebeschuetz, Decline and Fall (wie Anm. 32), 167.

35 Thdt. H. E. 4, 4, 2; vgl. 3, 6, 5.

36 Joh. Chrys. Hom. 66, 3 in Matth., PG 58, 630. Nach Theoph. a. m. 5824, S. 29, Z. 13-23 de Boor erhielt die Kirche Antiocheias von Konstantin I. jährlich 36.000 modii zur Verteilung an Witwen, Fremde, Arme und Kleriker. 
Einwohnern ausgehen müssen, ${ }^{37}$ ist klar erkennbar, daß die kirchliche Armenfürsorge nur einen kleinen Teil des Bedarfes an Lebensmitteln befriedigen konnte; ihr Sinn und ihre Aufgabe bestand darin, die Not der völlig mittellosen Bettler zu lindern, die es in allen spätrömischen Städten in großer Zahl gab. ${ }^{38}$

II. Der Bericht des Josua Stylites über die edessenische Hungersnot der Jahre 500 bis 502

Wir haben bislang die Frage betrachtet, in welchem Umfang und auf welche Weise der spätrömische Kaiser zur regulären Lebensmittelversorgung der Städte seines Reiches beitrug. Welche Rolle aber spielte der Kaiser in der Spätantike bei der Bewältigung akuter Versorgungskrisen und Hungersnöte ${ }^{39}$ Ich möchte dieser Frage anhand einer Quelle nachgehen, die in ihrer Art einzigartig ist, einem häufig als Chronik bezeichneten Geschichtswerk, ${ }^{40}$ das unter Kaiser Anastasius von einem Einwohner der von den Griechen Edessa genannten Hauptstadt der Provinz Osrboene - der einheimische Name lautete Orhai (heute Urfa) ${ }^{41}$ - in syrischer Sprache abgefaßt wurde. ${ }^{42}$ Diese

37 Belege und Argumente bei Wiemer, Libanios und Julian (wie Anm. 1), 304 mit Anm. 217.

38 Nach Joh. Chrys. Hom. 66, 3 in Matth., PG 58, 630 machten die Bettler ein Zehntel der Bevölkerung Antiocheias aus; zum Pauperismus in spätantiken Städten vgl. allgemein E. Patlagean: Pauvreté économique et pauvreté sociale à Byzance 4ême-7ême siècles (Civilisations et Sociétés 48), Paris 1977; P. Brown, Power and Persuasion in Late Antiquity. Towards a Christian Empire, Madison, Wisc. 1992, bes. $89 \mathrm{ff}$.

39 Zur idealtypischen Unterscheidung von Versorgungskrisen (,food crisis") und Hungersnot (,Famine“) vgl. Garnsey, Famine (wie Anm. 1), 6.

40 Zum historiographischen Konzept vgl. J. W. Watt, Greek Historiography and the „Chronicle of Joshua the Stylite“, in: G. J. Reinink/A. C. Klugkist (Hgg.), After Bardaisan. Studies on Continuity and Change in Syriac Christianity in Honour of Professor Han J. W. Drijvers (Orientalia Lovaniensia Analecta 89), Louvain 1999, 317-328; A. Luther, Die syrische Chronik des Josua Stylites (Untersuchungen zur antiken Literatur und Geschichte 49), Berlin - New York 1997, 245-255.

41 Zur Geschichte und Topographie des spätantiken Edessa vgl. E. Kirsten, Edessa, RAC IV, 1959, 552-597; dens., Edessa, eine römische Grenzstadt des 4. bis 6. Jh. im Orient, JbAC 6, 1963, 144-172 (zur Topographie); J. B. Segal, Edessa, the Blessed City, Oxford 1970, 110-191. Für die frühere Kaiserzeit vgl. jetzt S. K. Ross, Roman Edessa. Politics and Culture on the Eastern Fringes of the Roman Empire, 114-242 CE, London - New York 2001.

42 Der Text ist nur deswegen überliefert, weil der Autor der sog. Chronik von Zuqnin ihn unverändert in sein eigenes Werk übernahm. Die Frage, ob der vom Schreiber eines 
sogenannte Chronik, die unter dem Namen des Josua Stylites geläufig ist, will nach eigenem Bekunden Zeugnis ablegen von der Not, die unter diesem Kaiser in Edessa, Amida und ganz „Mesopotamien“ herrschte. Sieht man ab von Proömium und Epilog, so zerfällt das Werk in drei Teile: Auf das Proömium, das an einen sonst unbekannten Abt namens Sergius gerichtet ist, folgt eine Darstellung der Beziehungen zwischen Ostrom und dem Reich der Sassaniden vom Perserfrieden Jovians im Jahre 363 bis zum Beginn des Perserkrieges des Anastasius im Jahre 502 ( $\$ 7-24)$. Dieser historischen Einleitung schließt sich eine annalistisch geformte Darstellung der Geschicke der Stadt Edessa in den Jahren 494 bis 502 an (\$ 25-46a). Der dritte und umfangreichste Teil $(\$ 46 \mathrm{~b}-100)$ behandelt den Krieg, den Anastasius in den Jahren 502 bis 506 gegen den persischen König Kavad führte.

Für meine Fragestellung kommt es auf den zweiten Teil des Werkes an, der so etwas wie eine edessenische Stadtchronik darstellt. In ihm finden wir den ausführlichsten und genauesten Bericht über eine Hungerkrise, der uns aus der gesamten griechisch-römischen Antike überliefert ist. ${ }^{43}$ Dieser Bericht muß als wohlinformiert gelten, da er bald nach den geschilderten Ereignissen von einem Augenzeugen niedergeschrieben wurde, der Land und Leute sehr gut kannte. Dies bedeutet natürlich nicht, daß der Verfasser auf alle Fragen, die wir stellen, eine Antwort bereithält. Insbesondere bleibt uns Jo-

nachträglich in den testis unicus eingefügten Blattes genannte Stylit Josua als Verfasser unseres Textes oder der bis zum Jahr 775 reichenden Chronik, in der er überliefert ist, oder aber nur als Schreiber der Handschrift zu gelten hat, ist und bleibt umstritten; vgl. dazu die gegensätzlichen Positionen von W. Wright, The Chronicle of Joshua the Stylite composed in Syriac A.D. 507 with a translation into English and notes, Cambridge 1882, IX (Josua der Autor der "Chronik"); A. Palmer, Who wrote the Chronicle of Josua the Stylite?, in: Lingua restituta orientalis. Festgabe Julius Aßfalg, Wiesbaden 1990, 272-284 (Josua der Schreiber der Handschrift; der Verfasser der "Chronik" sei der in $\ 42$ als oikonomos der Bischofskirche von Edessa erwähnte Stratonikos); Luther, Josua Stylites (wie Anm. 40), 10-16 (Josua der Autor der „Chronik"); F. R. Trombley/J. W. Watt, The Chronicle of Pseudo-Joshua the Stylite. Translated with Introduction and Notes (Translated Texts for Historians 32), Liverpool 2000, XXI-XXVI (Josua der Schreiber der Handschrift und zugleich der Verfasser der Chronik von Zuqnin). Leider läßt sich nicht einmal mit Sicherheit feststellen, ob der Verfasser Kleriker war, wenngleich dies nahezuliegen scheint; vgl. einerseits Palmer a. a. O. 276-279; Luther a. a. O. 16-19 (Kleriker), andererseits Trombley/Watt a. a. O. XXVI-XXVIII (Kleriker oder Laie).

43 Der Text ist in letzter Zeit gleich zweimal übersetzt und kommentiert worden. Indessen geht nur der Kommentar von Trombley/Watt, Joshua the Stylite (wie Anm. 42) näher auf den hier behandelten Teil des Textes ein; zudem enthält die Ausgabe ein sehr nützliches Glossar. Luther, Josua Stylites (wie Anm. 40) kommentiert dagegen schwerpunktmäßig die Abschnitte des Textes, die den römisch-persischen Beziehungen gewidmet sind. 
sua für fast alle Variablen, die in die Rekonstruktion ökonomischer Kausalitäten eingehen, konkrete Zahlenangaben schuldig. Er nennt zwar eine große Anzahl von Preisen für das Grundnahrungsmittel Weizen, um damit das Ausmaß der Katastrophe zu verdeutlichen, ${ }^{44}$ unternimmt aber keinen Versuch, so elementare Faktoren wie die landwirtschaftliche Produktion oder den städtischen Bedarf an Lebensmitteln zu quantifizieren; ebensowenig beschreibt er die Besitz- und Einkommensverhältnisse in Stadt und Land, von denen die Verteilung des Agrarprodukts gerade in Notzeiten wesentlich abhing. Josua konnte und wollte keinen Beitrag zur wertfreien Analyse sozialökonomischer Zusammenhänge leisten; ihm ging es um die moralische und theologische Bedeutung der schlimmen Ereignisse, deren Zeuge er geworden war. Josua war fest überzeugt, daß die Hungersnot, die die Edessener heimgesucht hatte, eine von Gott gesandte Strafe war, und er glaubte auch, den konkreten Anlaß benennen zu können, der den Zorn Gottes herausgefordert hatte: die im Mai 498 auf eine ganze Woche ausgedehnte Feier eines Festes, das mit theatralischen Darbietungen verbunden war und Josua als heidnisch galt. ${ }^{45}$ Insofern diese Deutung einen Kausalnexus zwischen heidnischem Götzendienst und einer Mißernte herstellt, ist sie durchaus repräsentativ für die Art und Weise, wie Hungerkrisen im christlichen Imperium Romanum gedeutet wurden. ${ }^{46}$ Für Josua war die Frage nach den Ursachen deshalb von

44 Zur Auswertung dieser Preisreihe vgl. Patlagean, Pauvreté (wie Anm. 38), 74-92; H. Leclainche, Crises économiques à Édesse (494-506) d'après la chronique du pseudo Josué le Stylite, Pallas 27, 1980, 89-100; J. M. Beyer, Sie legten lediglich eine nicht unbeträchtliche Menge Eier in unser Land. Heuschreckenplagen in der Spätantike und die Chronik des Josua Stylites, Byzantina 21, 2000, 57-83; Garnsey, Famine (wie Anm. 1), 20-36 und Durliat, Subsistances (wie Anm. 19), 406-421 versuchen dagegen eine qualitative Analyse des Berichtes.

$45 \mathrm{Zu}$ diesem Fest und dem Verhältnis, in welchem es zu den andernorts unter dem Namen Brytai und Maiuma bezeugten Festen steht, vgl. G. Greatrex/J. W. Watt, One, two or three Feasts? The Brytac, the Maiuma and the May Festival at Edessa, Oriens Christianus $83,1999,1-21$, die sich für die Identität aussprechen. Es ist freilich sehr unwahrscheinlich, daß diejenigen, die das von Josua verurteilte Fest feierten, es ebenfalls als heidnisch betrachteten. Daß die Urteile kirchlicher Autoren auch im spätantiken Syrien kaum repräsentativ sind, zeigt W. Cramer, Irrtum und Lüge. Zum Urteil des Jakob von Sarug über die Reste paganer Religion und Kultur, JbAC 23, 1980, 96-107, hier: 105-106 anhand einer Homilie des Jakob von Sarug (Hom. 5), die von C. Moss, Jacob of Serugh's homilies on the spectacles of the theatre, Muséon 48, 1935, 87-112, hier: 108-109 herausgegeben und übersetzt worden ist.

46 Vgl. etwa Joh. Chrys. De S. Babyla 22, 118; Pan. Bab. 2, 2; Laud. Pauli 4, 6; Hom. 4, 1 in Matth., PG 57, 41; Nov. Theod. 3, 8. Umgekehrt deuten Symm. Rel. 3, 15-17; Lib. Or. 30, 35-36 Mißernten als Folge der Vernachlässigung ,heidnischer“ Kulte. 
brennender Aktualität, weil unter den Betroffenen selbst eine andere Deutung verbreitet war, die besagte, daß sich in der Hungersnot und einer in ihrem Gefolge aufgetretenen Seuche das nahe Weltende ankündige. ${ }^{47}$ Denn viele Christen rechneten damals damit, daß die 6.000 Jahre, auf die man die Zeit von der Schöpfung bis zum Auftreten des Antichrist berechnete, um das Jahr 500 herum abliefen; und da in der sog. synoptischen Apokalypse der Evangelien ${ }^{48}$ Hunger, Seuchen und Kriege als Vorzeichen des Weltendes bezeichnet werden, sahen sie in der Hungersnot, die sie an der Wende von der ersten zur zweiten Jahrtausendhälfte durchlebten, eine Bestätigung dieser Berechnung des Weltendes. ${ }^{49}$ Diese eschatologische Deutung der Hungersnot will Josua widerlegen, wenn er darauf besteht, daß sie als Strafe und Züchtigung für konkrete Sünden aufzufassen sei. Ich referiere zunächst den Bericht des Josua:

Nach Josua waren im Mai des Jahres 499, genau an jenem Tag, an welchem das sündhafte Fest mit Theateraufführungen gefeiert $z u$ werden pflegte, riesige Heuschreckenschwärme von Süden her in das Land der Edessener gekommen und hatten dort ihre Eier gelegt. Danach hätten sich Erdbeben ereignet, die die Menschen an ihre Sünden hätten erinnern sollen, aber ebenso unbeachtet geblieben seien $(\$ 33)$ wie auch eine Reihe anderer Zeichen, die Gott später gesandt habe, um die Menschen zur Umkehr zu bewegen. Als dies alles jedoch nichts fruchtete, habe Gott eine schreckliche Plage über die Menschen geschickt. Im März des Jahres 500 sei eine gewaltige Anzahl von Heuschrecken aus der Erde gestiegen und habe binnen kurzer Zeit die Felder in einem Umkreis kahlgefressen, der in etwa den Provinzen Osrboene und Mesopotamia entsprach $(\$ 38),{ }^{50}$ Nachdem die Ernte vernichtet war, stiegen die Preise für Getreide sogleich steil an; bereits im April wurden für die uns

47 Jos. Styl. $₫ 49$.

48 Matth. 24; Mk. 13; Luk. 21. Entscheidend war der Passus „Wenn ihr dann von Kriegen hört und Nachrichten über Kriege euch beunruhigen, laßt euch nicht erschrecken! Das muß geschehen. Es ist aber noch nicht das Ende. Denn ein Volk wird sich gegen das andere erheben und ein Reich gegen das andere. Und an vielen Orten wird es Erdbeben und Hungersnöte geben. Doch das ist erst der Anfang der Wehen."

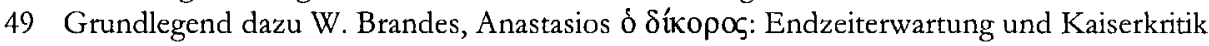
in Byzanz um 500 n. Chr., ByzZ 90, 1997, 24-64.

$50 \mathrm{Zu}$ Heuschreckenplagen in der griechisch-römischen Antike vgl. H. Graßl, Heuschrekkenplagen in der Antike, in: E. Olshausen/H. Sonnabend (Hgg.), Naturkatastrophen in der antiken Welt. Stuttgarter Kolloquium zur Historischen Geographie des Altertums 6, 1996 (Geographica Historica 10), Stuttgart 1998, 439-447; Beyer, Byzantina 21, 2000 (wie Anm. 44), 57-83; Stathakopoulos, Famine and Pestilence (wie Anm. 1), 36-45. 
als solidus bekannte Goldmünze ${ }^{51}$ nur noch vier modii Weizen verkauft, während es bei einer guten Ente bis zu 30 modii waren. Der Weizenpreis hatte sich also mehr als versiebenfacht. Die erste Reaktion der Bauern bestand nach Josua darin, daß sie Hirse säten. Da sie jedoch schlecht gediehen sei, habe die Hirseernte bei weitem nicht ausgereicht, und bald habe bitterer Hunger geherrscht. Zum Jahresende hätten daher viele Menschen ihre Heimatdörfer verlassen und seien nach Norden und nach Westen geflüchtet. Die Alten, Kranken und Schwachen, die Kinder und die Frauen jedoch hätten sich in die Städte begeben, um dort zu betteln $(\$ 38) .^{52}$

Nach diesem Blick auf die engere und weitere Umgebung Edessas richtet sich die Aufmerksamkeit des Chronisten nunmehr auf die Stadt Edessa selbst. Josua beschreibt die Reaktion verschiedener städtischer Instanzen auf die Hungerkrise. Der Bischof Edessas, ein Mann namens Petros, sei nach Konstantinopel gereist, um Kaiser Anastasius zu veranlassen, der Stadt die Zahlung der in Gold erhobenen Grundsteuer (synteleia) zu erlassen. Der Statthalter der Osrboene, der den klassizistischen Namen Demosthenes trug, habe jedoch das Ergebnis dieser Bittgesandtschaft nicht abgewartet, sondern die Steuer von den „Herren der Dörfer“, den marai kurjane, eingetrieben und das Gold nach Konstantinopel geschickt. ${ }^{53}$ Wie es möglich war, die Steuer trotz der Mißernte einzutreiben, verrät uns Josua nicht. ${ }^{54}$ Klar scheint jedoch, daß in dieser Situation weder Pächter noch freie Kleinbauern ihre Steuern zahlen konnten, ${ }^{55}$ ohne ihre Vorräte anzugreifen. So büßten Pächter und freie Kleinbauern, deren Ernte vernichtet worden war, nun auch noch ihre Rücklagen ein, während diejenigen, die über Gold verfügten, den Ernte-

51 Josua bezeichnet sie durchweg als denarius .

52 Daß die Landbevölkerung bei Hungersnöten in die Städte kam, ist häufig bezeugt: Antiocheia (Syrien) 362/3: Jul. Mis. 369C; Edessa 372/373: Pallad. H. L. 40 (S. 126 Butler); Sozom. H. E. 3, 16, 12-15; Antiocheia (Syrien) 384/385: Lib. Or. 27, 6; 14.

53 Nach Durliat, Subsistances (wie Anm. 19), 412 Anm. 286 schickte Demosthenes keineswegs Gold nach Konstantinopel, sondern eine Aufstellung sämtlicher eingegangenen und geleisteten Zahlungen.

54 Zum Jahr 504/505 berichtet Josua, die Bewohner der Stadt Edessa hätten sich beklagt, daß der von Anastasius gewährte Nachlaß der synteleia nur den Herren der Dörfer (marai kurjane) nütze, und verlangt, daß man sie von der Last der Einquartierung der Soldaten befreie ( $(92-93)$.

55 Die Agrarverfassung Edessas, insbesondere die Frage, in welchem zahlenmäßigen Verhältnis Pächter und Freibauern zueinander standen, bedarf weiterer Untersuchung; Ansätze dazu finden sich bei Segal, Edessa (wie Anm. 41), 141-142; Trombley/Watt, Joshua the Stylite (wie Anm. 42), XLI-XLIV. Der Terminus marai kurjane schließt jedenfalls Pächter aus, denn sie waren es, die von einem Nachlaß der Grundsteuer unmittelbar profiticrten (Jos. Styl. (92-93). 
ausfall wenigstens teilweise durch Getreidekäufe ausgleichen konnten. Die Steuereintreibung verschärfte also die Wirkungen der Mißernte, indem sie dazu beitrug, $\mathrm{da}$ ßie bestehende Ungleichheit in der Verteilung der Nahrungsmittelvorräte noch weiter zunahm. Dieser sachliche Zusammenhang wird jedoch in der Darstellung gerade nicht betont: Josua erhebt keinen Vorwurf gegen den Statthalter, der die Steuer im Auftrag des Kaisers eingetrieben hatte, und erst recht nicht gegen den Kaiser selbst, der das Gold nicht mehr herausgeben wollte, sobald er es einmal hatte. Josua ist ein kaisertreuer Autor, der Anastasius an anderer Stelle $(\$ 6)$ ausdrücklich gegen den Vorwurf in Schutz nimmt, er sei für den verheerenden Perserkrieg verantwortlich, der in den Jahren 502 bis 506 die Grenzprovinzen Osrboene und Mesopotamia verwüstete. Darum hebt er hervor, der Kaiser habe auf Bitten des edessenischen Bischofs immerhin den Landbewohnern die Versorgung der Armeepferde (pabulatio) erlassen und den Stadtbewohnern das Schöpfen von Wasser für die Soldaten, ${ }^{56}$ obwohl diese Akte kaiserlicher Freigebigkeit natürlich bloße Trostpflästerchen waren (\$39).

Inzwischen wurden auf lokaler Ebene erste Maßnahmen gegen die Not ergriffen. Der Statthalter war - ich referiere noch immer Josua -, nachdem er die Grundsteuer eingetrieben hatte, schließlich doch auch persönlich nach Konstantinopel zum Kaiser gereist, hatte aber in Edessa einen Stellvertreter zurückgelassen. Dieser Stellvertreter, ein Mann namens Eusebius, hob das Monopol der in einer Korporation zusammengeschlossenen Bäcker auf, indem er es jedermann freistellte, Brot zu backen; einer Gruppe jüdischer Frauen übergab er Weizen aus dem staatlichen Getreidemagazin (apotheton) und ließ daraus Brot backen. Als Grund für diese Maßnahmen nennt der Chronist die hohe Zahl von Landbewohnern, die in Edessa Zuflucht gesucht hatten. Diese Sichtweise ist bei einem Stadtbewohner verständlich, darf uns aber nicht den Blick auf die Tatsache verstellen, daß in Edessa selbst wohl mindestens 20.000 Menschen beheimatet waren, die von Handwerk und Handel lebten und sich daher auf dem städtischen Lebensmittelmarkt versorgten. ${ }^{57}$ Josua unterstreicht nachdrücklich, daß die Aufhebung des Bäcker-

56 An dieser Stelle ist der Text offenbar korrupt. Wright und Trombley/Watt übersetzen "he remitted two folles to the villagers and the price(s) which they were paying", Luther dagegen „erließ er den Bewohnern der Dörfer die Fourage und das Geld, das sie gaben“. Geschrieben steht $B P L S$, worin der lateinische Begriff follis zu stecken scheint. Weil diese Deutung indessen nicht dazu paßt, daß gleich anschließend von Geld die Rede ist, dessen Zahlung den Dorfbewohnern erlassen wurde, übernimmt Luther die Konjektur PBLS, die sich als Transkription des lateinischen Begriffs pabulatio deuten läßt.

57 Nach Jos. Styl. $₫ 31$ belief sich das von Gewerbetreibenden in einem vierjährigen Zyklus erhobene chrysaryyron in Edessa bei seiner Aufhebung im Jahre 498 auf 140 Pfund Gold, 
monopols nicht den erwünschten Effekt hatte: $\mathrm{Da}$ die Hungernden aus Geldmangel nicht in der Lage gewesen seien, Brot zu kaufen, hätten sie zunächst auf Rettich, Kohl und Malven zurückgegriffen ( $(40)$, dann aber Pflanzen gegessen, die so gut wie keinen Nährwert besitzen $(\$ 41)$, in den Dörfern Wicken und geröstete Weinbeerenkerne, in der Stadt Wurzeln und Pflanzenblätter $(\$ 42)$. Dagegen verzichtet er darauf, dieses Scheitern einzelnen Personen anzulasten; ${ }^{58}$ auch die jüdischen Frauen werden jedenfalls nicht ausdrücklich zu Sündenböcken gemacht, obwohl die Beziehungen zwischen Christen und Juden in Edessa zur Abfassungszeit äußerst gespannt waren. 59

Wohl im November 500 traf der Statthalter wieder in Edessa ein, nachdem er dem Kaiser in Konstantinopel persönlich Bericht erstattet und von ihm eine beträchtliche, doch nicht näher spezifizierte Geldsumme zur Vertei-

was 10.080 solidi entspricht. Wenn ein Gewerbetreibender im Durchschnitt anderthalb solidi pro Zyklus zahlte, wie Jones, Later Roman Empire II (wie Anm. 20), 871-872 vermutet, führte dies auf die Zahl von 6.000 bis 7.000 Gewerbetreibenden in Edessa; nimmt man fünf Personen pro Haushalt an, kommt man so auf eine Zahl von mindestens 30.000 Personen, deren Lebensunterhalt durch handwerkliche und/oder kommerzielle Tätigkeiten bestritten wurde. R. S. Bagnall, Egypt in Late Antiquity, Princeton, N. J. 1993, 153-154 mit Anm. 31 geht aufgrund der Steuerleistung ägyptischer Goldschmiede von einer durchschnittlichen Höhe von 2, 28 solidi aus und kommt daher zu entsprochend niedrigeren Zahlen (4.421); vgl. dagegen jedoch Trombley/Watt, Joshua the Stylite (wie Anm. 42), $30 \mathrm{Anm}$. 145. Daß in Edessa eine große Anzahl wohlhabender Händler ansässig war, bemerkt auch die "Expositio totius mundi“ $(\$ 22)$, doch ist andererseits zu berücksichtigen, daß Josua auch davon zu berichten weiß, daß sich unter den $18.500 \mathrm{Ge}$ fangenen, die der in persischen Diensten stehende Lakhmidenfürst Naaman bei einem Plünderungszug in den Gemarkungen von Karrhai und Edessa nahm, zahlreiche Stadtbewohner waren, die wegen der Weinernte auf die Felder hinausgezogen waren (\$52); demnach trugen also auch landwirtschaftliche Tätigkeiten zum Lebensunterhalt der städtischen Bevölkerung bei.

58 Welche Absicht Eusebius verfolgte, als er das Bäckermonopol aufhob, wird von Josua nicht ausdrücklich gesagt, und auch wenn er es täte, wäre seine Interpretation für uns nicht verbindlich. Vermutlich sollte die Aufhebung des Bäckermonopols die rechtliche Grundlage dafür schaffen, daß die im Text erwähnten jüdischen Frauen Getreide aus dem kaiserlichen Speicher zu B rot backen durften. Denkbar ist jedoch auch, daß Euscbius hoffte, daß eine Belebung der Konkurrenz den Brotpreis drücken würde. Gleichgültig, für welche Interpretation man sich entscheidet, ist festzustellen, daß Eusebius verkannte, $\mathrm{da} ß$ es den Flüchtlingen nicht bloß an Brot, sondern auch an Geld mangelte.

59 Josua selbst $(\$ 48)$ berichtet, daß die edessenischen Juden, die man verdächtigte, mit den Persern im Bunde zu stehen, im Jahre 502/3 Opfer eines Massakers wurden; vgl. dazu Segal, Edessa (wie Anm. 41), 100-104. 
lung an die Armen erhalten hatte. ${ }^{60}$ Demosthenes richtete mit diesem Geld eine kostenlose Brotverteilung ein: Er legte nach Kriterien, die wir nicht kennen, einen Kreis von Unterstützungsberechtigten fest, der durch um den Hals getragene Bleimarken gekennzeichnet wurde, und verteilte an ihn pro Tag ein Pfund Brot. Demosthenes muß also erhebliche Mengen Getreides gekauft haben, doch sagt uns Josua nicht, ob er es zu Marktpreisen kaufte, wie Anastasius es seinen Statthaltern um diese Zeit in einem Gesetz einschärfte, ${ }^{61}$ und wer die Verkäufer waren. Angesichts des astronomischen Preisniveaus für Lebensmittel, das zu dieser Zeit in Edessa und seinem Umland herrschte, dürften sie jedoch auch dann ein gutes Geschäft gemacht haben, wenn Demosthenes auf das Mittel des Zwangsverkaufes zurückgegriffen haben sollte.

Auch diese vom Kaiser finanzierte und von seinem Statthalter organisierte Brotverteilung vermochte die Not jedoch kaum zu lindern. Als der Winter hereinbrach und die Temperaturen unter den Gefrierpunkt sanken, setzte ein Massensterben unter den obdachlosen und vom Hunger geschwächten Flüchtlingen ein: Nach Josua wurden zwischen Anfang November 500 und Ende März 501 täglich zwischen 100 und 130 Leichen bestattet; das führt auf eine Zahl von weit über 12.000 , vielleicht bis zu 20.000 Toten in nur vier Monaten. Josua registriert ohnmächtige Bemühungen, dem Sterben Einhalt zu gebieten. So ließ der Statthalter die Tore der Portiken beim öffentlichen Bad blockieren und Stroh und Matten hinein werfen, um wenigstens einem Teil der Flüchtlinge, die unter freiem Himmel schliefen, ein Obdach zu bieten. Die "Großen der Stadt" (raurßane dmedita) seien seinem Vorbild gefolgt und hätten ebenfalls Krankenlager bereitgestellt. Ja sogar die in der Stadt befindlichen „Römer“ (rbomaje), also die in Edessa einquartierten Soldaten, sollen sich um Kranke gekümmert haben. In der Hauptkirche der Stadt wurde von zwei Klerikern eine improvisierte Krankenstation eingerichtet $(\delta$ 42). ${ }^{62}$

60 Nach Durliat, Subsistances (wie Anm. 19), 415 gab der Kaiser dem Statthalter kein Gold, sondern gewährte ihm einen Kredit: „Ce crédit correspond à l'affectation d'une certaine part de l'impôt, exprimée en or, mais qui n'a pas nécessairement été levée sous cette forme; le gouverneur a pu exiger du blé en guise de paiement de la part de telle ou telle personne, selon un principe constant de la comptabilité publique".

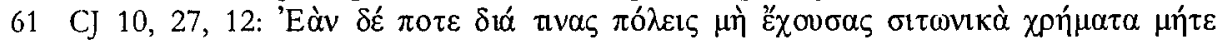

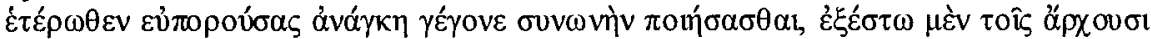

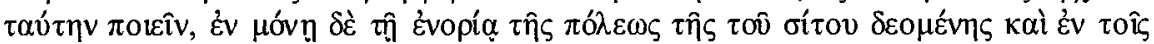

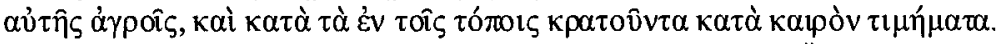

62 Zur baulichen Gestalt und Geschichte dieser, 524 durch eine Überschwemmung zerstörten Kirche vgl. Kirsten, JbaC 6, 1963 (wie Anm. 41), 162; 166-171, bes. 166-167. 
Wegen der außerordentlich hohen Sterberate wurde die Bestattung der Leichen zu einem Problem, das nicht mehr von den Angehörigen selbst bewältigt werden konnte. $\mathrm{Da}$ die im Gebrauch befindlichen Friedhöfe nicht mehr ausreichten, erteilte der Statthalter die Erlaubnis, alte Gräber zu öffnen und neu zu belegen. Nach Josua nahm sich der Vorsteher des kirchlichen Hospitals (xenodocheion), ein Mann namens Nonnos, der Aufgabe an, die Bestattung der Leichen zu organisieren. Die „ganze Stadt“ habe den Toten unter geistlichen Gesängen auf dem Weg aus der Stadt in die vor ihren Mauern gelegenen Friedhöfe das Geleit gegeben; an ihrer Spitze sei der Bischof gegangen, gefolgt vom Statthalter und den Freigeborenen (bnaj cb'ire). ${ }^{63}$ Not schweißt zusammen, diese Lehre will der Chronist vermitteln $(\$ 43)$.

Im Februar 501 erreichte der Getreidepreis seinen Höchststand, im April brach eine Seuche aus, die, wie Josua feststellt, auch viele Reiche ('alire) dahinraffte, die nicht Hunger gelitten hatten, sowie viele "Große der Stadt" (raupane dmedita). Nach der im Juni 501 eingebrachten Getreideernte erholten sich die Lebensmittelpreise nur leicht; für einen solidus wurden nun fünf statt wie im Vorjahr vier modii Weizen verkauft $(\$ 44)$. Das Los der Hungernden wurde jedoch dadurch gebessert, daß im Oktober/November 501 eine reiche Traubenernte eingebracht wurde; die Armen aßen nunmehr gedörrte Trauben. Die Ereignisse des folgenden Frühjahres interpretiert Josua als sichtbaren Beweis göttlicher Gnade: Obwohl nämlich ein heißer Wind im Mai 502 die gesamte Getreideernte auf dem Halm vernichtet habe - ,außer an wenigen Orten" $(\$ 45)$-, sei der Weizenpreis im Juni auf 12 modii pro solidus gesunken, nachdem Anastasius die sündhaften Aufführungen der Tänzer im ganzen Reich verboten hatte. ${ }^{64}$ Das Fest, dessen ausgelassene Feier Gott bewogen hatte, die Edessener so fürchterlich zu züchtigen, war damit beseitigt. Man muß freilich kein Agnostiker sein, um zu vermuten, daß die Getreideernte eben doch nicht ganz so vollständig vernichtet worden war, wie Josua behauptet; das Sinken des Weizenpreises von 5 auf 12 modii pro solidus fällt jedenfalls in den Erntemonat Juni $(\$ 45)$.

IV. Die Interaktion städtischer, kirchlicher und kaiserlicher Instanzen

Mit dem durch Gottes Gnade bewirkten Sinken des Getreidepreises endet der als edessenische Stadtchronik anzusprechende Teil des Werkes. Josuas

63 Von Wright und Luther irrtümlich mit „nobles“ bzw. „Leuten der Vornehmen“ übersetzt.

64 Dieses Verbot belegt auch Proc. Gaz. Pan. 16. 
Bericht, der im Faktischen durchaus zuverlässig wirkt, stellt dem modernen Historiker auf eindringliche Art und Weise vor Augen, was eine Hungersnot dieses Ausmaßes für die Betroffenen bedeutet. Hier soll der Blick jedoch auf die strukturellen Aspekte der Situation gelenkt werden, auf die Interaktion städtischer, kirchlicher und kaiserlicher Instanzen im Angesicht einer Hungersnot von katastrophalem Ausmaß. Der nur auf den ersten Blick kunstlos wirkende Text hält ein komplexes Geflecht von aufeinander bezogenen Handlungen fest, das ich im folgenden zu entwirren versuchen möchte, indem ich 1) die Rolle städtischer Institutionen und Eliten, 2) diejenige der Kirche, 3) diejenige des Statthalters und 4) diejenige des Kaisers betrachte.

\section{1) Städtische Institutionen und Eliten}

Städtische Institutionen und Eliten spielen in Josuas Bericht nur eine bescheidene Nebenrolle. Nichts deutet darauf hin, daß die Stadt über einen Getreidekommissar oder eine Getreidekasse verfügt hätte, deren Existenz Durliat für alle größeren Provinzstädte, namentlich auch für Edessa postuliert. Erst als Demosthenes Geld vom Kaiser erhält, kann er Getreide kaufen, um es an Bedürftige zu verteilen. Der Stadtrat Edessas glänzt während der Hungerkrise von 499 bis 501 durch Abwesenheit. Hier darf man sich durch die ansonsten sehr verdienstvollen Übersetzungen des Textes durch Andreas Luther und durch Frank Trombley und John Watt nicht täuschen lassen. Der von ihnen als Bezeichnung für die curiales bzw. decuriones gedeutete syrische Begriff raußßane dmedita ist keineswegs in diesem technischen Sinn zu verstehen. 65 Josua spart nicht mit griechischen Fremdwörtern, wenn er administrative Realien bezeichnen möchte. Raurßane dmedita bezeichnet vielmehr ganz allgemein die „Großen der Stadt“: Die „Edessenische Chronik“ (\$ 105) nennt so die Männer, die im Jahre 540 den Sassaniden Chosrau dazu veranlaßten, gegen die Zahlung von 200 Pfund Gold auf eine Belagerung Edessas $\mathrm{zu}$ verzichten. ${ }^{66}$ Nun wissen wir aber, daß die Kurie das Stadtregiment zur

65 So aber Luther, Josua Stylites (wie Anm. 40), 176 Anm. 294; Trombley/Watt, Joshua the Stylite (wie Anm. 42), 141 s. v. Rulers (of the city, i. e. Edessa).

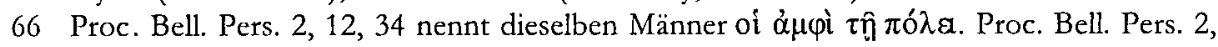
26, 14-15 berichtet über die Belagerung von 544, die Edessener hätten vier Männer aus

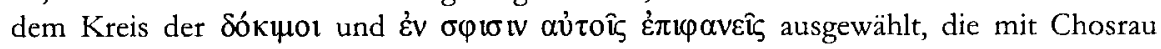
verhandeln sollten; dabei dürfte es sich um bonorati von senatorischem Rang gehandelt haben. 
Zeit des Anastasius längst an eine informelle Versammlung ortansässiger Notabeln verloren hatte; ${ }^{67}$ ein Gesetz des Kaisers Leo fordert bereits im Jahre 469, daß der Verkauf städtischen Landes durch die Zustimmung von curiales, honorati und possessores bestätigt werden müsse. ${ }^{68}$ Für Edessa selbst läßt sich der Bedeutungsverlust des Stadtrates an amtlichen Dokumenten schon um die Mitte des 5. Jahrhunderts nachweisen: Wir besitzen nämlich in syrischer Übersetzung den Text einer Petition, die dem Statthalter der Osrhoene im Jahre 449 im Namen der gesamten Stadt unterbreitet wurde. Am Ende der Petition steht eine Unterschriftenliste, in der die Ratsherren (politeuomenot) keineswegs an erster Stelle stehen; sie zeichneten nach den Klerikern, Mönchen und honorati (axiomatikor) und vor den Lehrern und Vertretern der Handwerkergilden. ${ }^{69}$ Wenn daher Josua raurßane dme $\delta i t a$ schreibt, so meint er ohne Zweifel eben die städtischen Notabeln insgesamt und keineswegs etwa nur die Ratsherren.

Josuas Bericht zufolge traten die edessenischen Ratsherrn während der Versorgungskrise also nicht als Repräsentanten der Kurie in Erscheinung. Kollektive Maßnahmen gegen die Not wurden vom Statthalter und vom Bischof, aber nicht vom Stadtrat oder städtischen Beamten initiiert. ${ }^{70}$ Diese

Dagegen sind bei Josua $\int 86$ mit den „einheimischen Großen“ (rischane bnai 'aAira), von denen er sagt, sie hätten die Einquartierung von Soldaten zu organisieren gehabt, offenbar Ratsherren gemeint (so auch Liebeschuetz, Decline and Fall [wie Anm. 32], 107; Trombley/Watt, Joshua the Stylite [wie Anm. 42], 105 Anm. 489).

67 Vgl. A. Laniado, Recherches sur les notables municipaux dans l'empire protobyzantin (Travaux et mémoires du Centre de Recherche d'Histoire et Civilisation de Byzanze. Collège de France. Monographies 13), Paris 2002.

68 CJ 11, 32, 3; vgl. MAMA III 197A; CJ 1, 4, 17; 10, 27, 3 (Bestellung des sitones).

$69 \mathrm{~J}$. Flemming (Hg.), Akten der Ephesinischen Synode vom Jahre 449. Syrisch mit Georg Hoffmanns deutscher Übersetzung und seinen Anmerkungen, in: Abh. d. Kgl. Gesellschaft d. Wiss. zu Göttingen, phil.-hist. Kl., N. F. 15, Nr. 1, Berlin 1917, im folgenden zitiert als Flemming, Akten, hier: 23; Liebeschuetz, Decline and Fall (wie Anm. 32), 106.

70 Welche städtischen Ämter Edessa im 6. Jahrhundert überhaupt (noch) besaß, ist unbe-

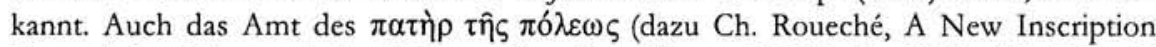

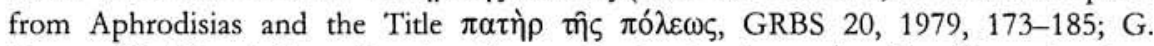

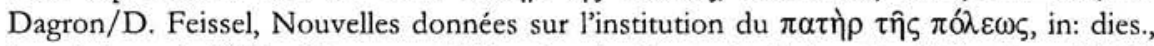
Inscriptions de Cilicie [Travaux et Mémoires du Centre de Recherche d'Histoire et Civilisation de Byzance. Collège de France. Monographies 4], Paris 1987, 215-220) ist für Edessa wie für ganz Syrien nicht sicher zu belegen. Zwar erzählt die „Vita Alexandri Acoe-

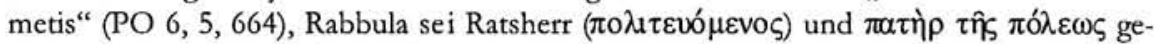
wesen, bevor er Bischof von Edessa wurde, doch ist diese Aussage wohl eher auf Chalkis zu beziehen, woher Rabbula ja stammte, und überdies von zweifelhafter Glaubwürdigkeit, da der Passus dem Text nachträglich hinzugefügt wurde. 
Inaktivität hängt gewiß auch damit zusammen, daß Edessa ein Statthaltersitz war. Im syrischen Antiocheia, dem Sitz der Verwaltung der Provinz Syria Coele und der Diözese Oriens, kann man bereits im vierten Jahrhundert beobachten, daß die Ratsherren es gerne Statthaltern oder Kaisern überließen, Maßnahmen gegen Lebensmittelknappheit zu ergreifen; anders als der edessenische Stadtrat an der Wende vom 5. zum 6. Jahrhundert traten sie jedoch mitunter sehr entschieden als Kollektiv auf, wenn es galt, Höchstpreisfestsetzungen zu bekämpfen. ${ }^{71}$ Aus späterer Zeit werden Ratsherren im Zusammenhang mit Versorgungskrisen gar nicht mehr erwähnt. Der Stadtrat war in der Spätantike, jedenfalls im 5. und 6. Jahrhundert, und im Gegensatz zur früheren Kaiserzeit nicht mehr in der Lage, in einer Krisensituation die politische Führung der Stadt zu gewährleisten. Auch der soziale Habitus der städtischen Elite hatte sich grundlegend verändert: In der früheren Kaiserzeit waren aus ihren Reihen „Wohltäter" hervorgegangen, die die Bürgerschaft finanziell unterstützten, und von ihr dafür mit Ruhm und Ehre belohnt wurden. Zur Zeit des Anastasius hatte sich dieser Euergetismus, der sich an Mitbürger wandte, in ein karitatives Engagement für Arme und Kranke verwandelt: Josua berichtet zwar, daß Mitglieder der von ihm als „Große der Stadt“ bezeichneten Elite Edessas während der Hungers not Krankenlager bereitstellten, nicht aber von Geld- oder Getreidespenden für die Bürgerschaft.

$D a$ die Ratsherren einer Stadt sich in aller Regel überwiegend aus lokalen Grundbesitzern rekrutierten, war ihr Verhalten bei Versorgungskrisen stets von gegensätzlichen Interessen geprägt gewesen: Dieselbe soziale Gruppe, aus der die gefeierten Wohltäter stammten, machte als Kollektiv einen guten Schnitt, wenn die Kornpreise infolge von Knappheit in die Höhe schnellten. Der Vorwurf, daß Versorgungskrisen durch Hortung von Getreide entweder hervorgerufen oder zumindest verschärft würden, ist darum schon in der früheren Kaiserzeit erhoben worden. ${ }^{72}$ In der Spätantike hat sich daran nichts geändert, zumal sich die Kritik nun auf biblische Aussagen berufen

71 Vgl. dazu Wiemer, Libanios und Julian (wie Anm. 1), 205-208; $315 \mathrm{ff}$.

72 Provinz Asia (51 v. Chr.): Cic. Att. 5, 21, 8; Antiocheia in Pisidien (unter Domitian): AE 1925, 162b mit Wiemer, AnSt 47, 1997 (wie Anm. 14), 195-213; Aspendos (unter Tiberius): Philostr. V. S. 1, 15 (dazu J. Raeymaekers, The Grain Hoarders of Aspendus. Philostratus on the Intervention of Apollonius of Tyana (Vita Apollonii I 15), in: L. Mooren (Hg.), Politics, Administration and Society in the Hellenistic and Roman World [Studia Hellenistica 36], Leuven 2000, 275-286); Oxyrhynchos: P.Oxy. XLII 3048 (246); P.Oxy. XLVII 3339 (191); vgl. dazu Herz, Wirtschaftsgesetzgebung (wie Anm. 13), 186-189; Wiemer a. a. O. 201-202. Um den Vorwurf der Getreidehortung geht es auch bei Dio Chrys. Or. 46. 
konnte. ${ }^{73}$ Die unter Justin II. verfaßte Chronik, die unter dem Namen des Pseudo-Zacharias geht, berichtet, der Bischof der Stadt Amida, die 502 belagert wurde und unter einer schrecklichen Hungersnot litt, ${ }^{74}$ habe die lokalen Notabeln aufgefordert, ihre Getreidevorräte an die Armen zu verkaufen. ${ }^{75}$ Darum ist es durchaus bemerkenswert, daß Josua in dieser Hinsicht ganz schweigsam ist. Die Erklärung könnte darin liegen, daß Josua den egalitären Eifer des amidenischen Bischofs mißbilligte; vielleicht aber wollte er lediglich vermeiden, alte Wunden neu aufzureißen, zumal er auf einen Neuanfang nach dem endlich überstandenen Strafgericht Gottes hoffte.

\section{2) Kirchliche Instanzen}

Wenn wir uns der Kirche zuwenden, betreten wir einen Bereich, der das Reich der Spätantike grundlegend von dem der früheren Kaiserzeit unterscheidet. Bischof Ibas von Edessa gebot im Jahre 451 über etwa 200 Kleriker; ${ }^{76}$ bereits sein Vorgänger Rabbula hatte, wie wir aus seiner anonymen „Vita“ wissen, ${ }^{77}$ eine nicht näher spezifizierte Anzahl von Armen unterstützt,

73 Antiocheia in Syrien (362/363): Jul. Mis. 368C; Lib. Or. 18, 195; vgl. dazu Wiemer, Libanios und Julian (wie Anm. 1), 294; 308-309; Kaisareia in Kappadokien (369): Bas. Hom. 6, PG 31, 261-277; Greg. Naz. Or. 43, 34-35 (dazu J. Bernardi, La prédication des pères cappadociens. Le prédicatur et son auditoire (Publications de la Faculté des lettres et sciences humaines de l'Université de Montpellier 30), Paris o. J. (1968), 60-66; S. R. Holman, The Hungry Are Dying. Beggars and Bishops in Roman Cappadocia, Oxford 2001, 64-98; 182-192); Edessa (372): Pallad. H. L. 40 (S. 126 Butler); Sozom. H. E. 3, 16, 12-15; Rom (410): Zos. 6, 11, 1-2. Auch Johannes Chrysostomos klagte die antiochenischen Grundherren an, bei Mißernten auf den Getreidepreis zu spekulieren: Hom. 39, 8 in Ep. 1 ad Cor., PG 61, 343.

74 Vgl. dazu S. A. Harvey: Asceticism and Society in Crisis: John of Ephesus and the Lives of the Eastern Saints, Berkeley u. a. 1990, 57-75.

75 Ps.-Zach. H. E. 7, 4 (S. 154-155 Hamilton-Brooks).

76 ACO II 1, 3, 386, Z. 32-33; dazu Jones, Later Roman Empire II (wie Anm. 20), 911-912.

77 Gegen die destruktive Analyse von P. Peeters, La vie de Rabboula, évêque d'Édesse ( 7 août 436), Recherches de Sciences Religieuses 18, 1928, 170-204; auch in: Ders., Recherches d'histoire et de philologie orientales (Subsidia hagiographica 27), Bd. 1, Brüssel 1951, 139-170 vgl. F. Nau, Les „belles actions“ de Mar Rabboula, évêque d'Édesse de 412 au 7 août 435 (ou 436), Revue de l'histoire de Religions 52, 1931, 97-135; G. G. Blum, Rabbula von Edessa. Der Christ, der Bischof, der Theologe (Corpus Scriptorum Christianorum Orientalium 300. Subsidia 34), Louvain 1969, bes. 5-14; G. W. Bowersock, The Syriac Life of Rabbula and Syrian Hellenism, in: T. Hägg/P. Rousseau (Hgg.), Greek Biography and Panegyric in Late Antiquity, Berkeley u. a. 2000, 255-272. 
die in ein offizielles Register eingetragen waren. ${ }^{78}$ Diese Armenfürsorge tritt bei Josua zweifellos deswegen nicht in Erscheinung, weil sie durch das Ausmaß der Hungersnot überfordert war und in den Ereignissen zusammenbrach. Josua berichtet aber davon, daß das kirchliche Fremdenhospital der Stadt zu einem Krankenlager umfunktioniert wurde, und hebt hervor, daß es Kleriker waren, die dafür sorgten, daß auch die Opfer des Massensterbens im Winter 500 auf 501 ordentlich bestattet wurden. Dieses karitative Engagement gehörte durchaus zur syrischen Vorstellung von Heiligkeit ${ }^{79}$ und hat in diesem Raum prominente Vorbilder: So wird von dem Asketen und Dichter Ephraim berichtet, er habe (kurz vor seinem Tod im Jahre 373) während einer Hungersnot in Edessa ein Krankenlager mit 300 Betten eingerichtet. ${ }^{80}$ In der um 470 verfaßten „Vita“ des älteren Symeon Stylites erhält der Mann Gottes vom Propheten Elias persönlich den Auftrag, sich der Armen und Unterdrückten anzunehmen, ${ }^{81}$ und die „Vita“ des Rabbula stilisiert den Bischof zum rastlosen Vorkämpfer der Armen. ${ }^{82}$

Dem Bischof Edessas schreibt Josua eine prominente Rolle zu. Petros ist nicht bloß der spirituelle Führer seiner Gemeinde, der im verheerenden Winter 500 auf 501 Tag für Tag die Leichenzüge anführt, sondern zugleich der Mann, der sich nach Konstantinopel begibt und sich dort vergeblich bemüht, den Kaiser zum Nachlaß der Grundsteuer zu bewegen. Insofern der Bischof hier zwischen Kaiser und Stadt bzw. Provinz vermittelt, nimmt er eine Auf-

78 V. Rabbulae 190, Z. 7-8 Overbeck = 429, Z. 9-10 Bedjan (syrischer Text); deutsche Übersetzung bei G. Bickell, Ausgewählte Schriften der syrischen Kirchenväter. Aphraates, Rabulas und Isaak von Ninive, Kempten 1874, 194.

79 Harvey, John of Ephesus (wie Anm. 74), 43-56 betont mit Recht, daß die Sorge um die Welt für Johannes von Ephesos anders als für Palladios und Theodoret ein integraler Bestandteil seiner Vorstellung von Heiligkeit ist, und in der Tat war die Institutionalisierung des Mönchtums im 6. Jahrhundert weit fortgeschritten. Die im folgenden angeführten Texte zeigen jedoch, daß Fürsorge für die Armen von heiligen Männern und Frauen im syrischen Kulturraum auch schon früher erwartet wurde.

80 Pallad. H. L. 40 (S. 126 Butler); Sozom. H. E. 3, 16, 12-15.

81 V. Sym. Styl. (Syr.), 572-573 Bedjan (syrischer Text) = S. 126, Z. 25-S. 128, Z. 17 der deutschen Übersetzung von $\mathrm{H}$. Hilgenfeld bei $\mathrm{H}$. Lietzmann $(\mathrm{Hg}$.), Das Leben des heiligen Symeon Stylites, Leipzig 1908.

82 Vgl. dazu S. A. Harvey, The Holy and the Poor: Models from Early Syriac Christianity, in: E. A. Hanawalt/C. Lindberg (Hgg.), Through the Eye of a Needle: Judeo-Christian Roots of Social Welfare, Kirksville, Mo. 1994, 43-66. Jedoch weist H. J. W. Drijvers, The Man of God of Edessa, Bishop Rabbula and the Urban Poor. Church and Society in the Fifth Century, Journal of Early Christianity 4, 1996, 235-248 mit Recht daraufhin, daß die „Vita“ Rabbula bewußt zum Bischof der Armen stilisiert und deshalb nicht für bare Münze zu nehmen ist. 
gabe wahr, die noch im 4. Jahrhundert in der Regel von Stadträten und Provinzialversammlungen erfüllt worden war. ${ }^{83}$ Gleichwohl führt es in die Irre, den Bischof „als Chef der lokalen Verwaltung“ zu bezeichnen, wie Durliat dies tut. ${ }^{84}$ Nach Josua war das Verhältnis zwischen dem Statthalter und dem Bischof keineswegs konfliktfrei, solange kaiserliche Belange auf dem Spiel standen: Seinem Bericht zufolge wurde nämlich die Mission des Petros durch Demosthenes geradezu hintertrieben, weil der Statthalter dafür sorgte, daß die Grundsteuer eingezogen wurde, während der Bischof noch auf dem Weg zum Kaiser war. Später suchte der Statthalter selbst Anastasius auf und erhielt von diesem Geldmittel, um im Namen des Kaisers Brot zu verteilen. Indem Anastasius die Brotverteilung durch seinen Statthalter und nicht durch den Bischof vornehmen ließ, wahrte er den Anspruch, selbst als Urheber einer solchen „Wohltat" zu gelten. Darum tadelte er Petros sogar ausdrücklich, als dieser vier Jahre später noch einmal zu ihm kam und erneut darum bat, den Edessenern die Grundsteuer zu erlassen; Anastasius belehrte den Bischof, er solle sich lieber um die Armen kümmern statt zum Kaiser zu reisen, der selbst wisse, was Gottes Wille sei. Anastasius erließ damals zwar der gesamten Provinz die Grundsteuer, ließ die frohe Botschaft aber nicht durch den Bischof überbringen. 85

83 Vgl. dazu J. H. W. G. Liebeschuetz, Antioch. City and Imperial Administration in the Later Roman Empire, Oxford 1972, 107-109; 266-269.

84 Durliat, Subsistances (wie Anm. 19), 315: „dès le début du VIe siècle il est le chef de toute l'administration locale, le porte-parole officiel de la cité", in der dazugehörigen Anm. 88 wird ausdrücklich auf das Beispiel des Petros verwiesen; vgl. auch Durliat, Finances publiques (wie Anm. 34), 55 („Les évêques furent considérés comme des fonctionnaires avec les avantages que confère ce statut social“). Ähnlich wie Durliat urteilt auch Kirsten, Edessa (wie Anm. 41), 558 („Im 5. Jh. kommt die Verwaltung der Stadt immer mehr in die Hände des Bischofs"). Dietrich Claude dagegen meinte zwar, daß die Entwicklung der oströmischen Städte in justinianischer Zeit „deutlich in Richtung auf die bischöfliche Stadtherrschaft" (Die byzantinische Stadt im 6. Jahrhundert [Byzantinisches Archiv 13], München 1969, 157) geführt habe. Er verstand unter „Stadtherrschaft" aber den Sachverhalt, daß der Bischof „nicht nur aufgrund kaiserlicher Gesetzgebung, sondern vor allem durch seine moralische Autorität zum vornehmsten Repräsentanten der Stadt nach außen und zum angesehensten und einflußreichsten Mann nach innen wird“ (157 Anm. 356); vgl. dagegen A. Hohlweg, Bischof und Stadtherr im frühen Byzanz, JÖB 2, 1971, 51-62; Liebeschuetz, Decline and Fall (wie Anm. 32), 137-168. Die Rivalität zwischen Demosthenes und Petros hat Claude durchaus gesehen und beim Namen genannt (148), jedoch ohne Quellenbeleg angenommen, der Bischof habe in Edessa zugleich das Amt des defensor civitatis ausgeübt (121).

85 Jos. Styl. $\$ 78$. 
Bischof und Statthalter erscheinen bei Josua also als zwei voneinander unabhängige Instanzen, die selbst angesichts verheerender Notsituationen keineswegs immer an einem Strang ziehen, weil ihre Aufgaben sich zwar teilweise überschneiden, aber doch ihrem Wesen nach verschieden sind: Gewiß wurde in der Spätantike von einem Bischof erwartet, daß er sich bei einer Versorgungskrise für seine Gemeinde einsetzte. So schrieb beispielsweise um 431 Firmus, der Bischof Kaisareias, der Hauptstadt der Provinz Cappadocia Prima, an einen hochgestellten kaiserlichen Funktionär mit der Bitte, er möge sich dafür einsetzen, daß der von einer Hungersnot geplagten Stadt die Einquartierung von Soldaten bis auf weiteres erspart bleiben möge. ${ }^{86}$ Es war nach allgemeinem Empfinden aber nicht seine Aufgabe, sich um die administrative Bewältigung von Versorgungskrisen zu kümmern.

Dies läßt sich an einem weniger bekannten Zeugnis verdeutlichen. In den kirchenrechtlichen Sammlungen, die unter dem Namen „Konzilsakten“ geläufig sind, hat sich eine Abschrift des Briefes erhalten, mit dem sich Johannes, der Bischof des syrischen Antiocheia, bei Kaiser Theodosius II. dafür entschuldigte, daß er zu dem im Jahre 431 nach Ephesos einberufenen Konzil nicht pünktlich erschienen war. Der Bischof wies auf die Beschwerlichkeit des Landweges hin, aber auch auf eine Hungersnot, die damals in der Stadt geherrscht habe; täglich sei es zu Unruhen des Volkes gekommen. Wir dürfen folgern, daß für einen Bischof während einer Hungerkrise sozusagen Präsenzpflicht galt. ${ }^{87}$ Wie diese „Präsenzpflicht“ genau zu verstehen ist, zeigt jedoch erst ein weithin fiktionaler Text, der unter dem mißbräuchlichen $\mathrm{Na-}$ men „Koptische Akten zum ephesinischen Konzil“ bekannt ist. Wie Eduard Schwartz vor vielen Jahren gezeigt hat, ${ }^{88}$ handelt es sich dabei um eine in alexandrinischem Milieu entstandene Parteischrift aus der Mitte des 5. Jahrhunderts, die einen ägyptischen Mönch namens Viktor zum Helden des Kampfes gegen die in Antiocheia verwurzelte Lehre des Nestorius stilisiert; Schwartz hat sie daher als den Roman vom Apa Viktor bezeichnet. Diesem Apa Viktor nun wird im Roman eine eingehenden Unterredung mit dem Kaiser angedichtet. Theodosius II. verteidigt in diesem Gespräch den antiochenischen Bischof Johannes gegen den Vorwurf, er sei zum Konzil von Ephesos vorsätzlich zu spät gekommen, indem er auf die Hungersnot hin-

86 Firmus Ep. 12.

87 Während des Persereinfalls von 502/503 schrieb der peribodeutes Jakob von Sarug ,an alle Städte“ der betroffenen Region, sie sollten auf Gott vertrauen und ihre Städte nicht verlassen: Jos. Styl. $\$ 54$. Der an die Edessener gerichtete Brief ist erhalten: Jac. Sarug. Ep. 20 (S. 129-135 Olinder).

88 E. Schwartz, Cyrill und der Mönch Viktor, SAWW 208, Nr. 4, Wien - Leipzig 1928. 
weist. Apa Viktor läßt diese Entschuldigung jedoch nicht gelten und weist den Kaiser darauf hin, daß der Bischof der Stadt keine körperliche Nahrung (trophe) verschaffen (choregein) könne; dies sei die Aufgabe der Behörden (arcbontes), die für die öffentlichen Angelegenheiten (demosia) zuständig seien und für die Erhaltung der Stadt sorgten. ${ }^{89}$

\section{3) Die Rolle des Statthalters}

Demosthenes erscheint bei Josua als ein Mann, der seine erste Pflicht darin sieht, den Ertrag der Grundsteuer ordnungsgemäß abzuliefern. Darum wartet er den Ausgang der ersten Bittgesandtschaft, die der Bischof zum Kaiser unternimmt, erst gar nicht ab, sondern veranlaßt die unverzügliche Eintreibung der Grundsteuer. Dadurch gerät er in ein Konkurrenzverhältnis zum Bischof, der sich für seine Schäfchen einsetzen kann, ohne auf den Fiskus Rücksicht zu nehmen. Sobald er den Steuerertrag einmal abgeliefert hat, tritt er jedoch beim Kaiser für die Interessen seiner Provinz ein: Er bringt Gold für eine Brotverteilung aus Konstantinopel zurück nach Edessa, wo er es zuvor als Steuer eingetrieben hatte; später nutzt er seine Aufsichtsrechte über die öffentlichen Bauten der Stadt, um Notquartiere für Obdachlose einrichten zu lassen. Während des Massensterbens im Winter des Jahres 500 auf 501 bringt er durch seine Beteiligung an den täglichen Leichenzügen seine Verbundenheit mit den Provinzbewohnern zum Ausdruck.

Vergleicht man die Vorgehensweise des Demosthenes mit derjenigen anderer spätrömischer Statthalter, von deren Eingreifen bei Versorgungskrisen wir Kenntnis haben, fällt auf, daß er der einzige ist, von dem berichtet wird, er habe den Kaiser persönlich aufgesucht, bevor er aktiv wurde; in ähnlich gelagerten Fällen lassen die Quellen den Statthalter sonst stets als selbständig Handelnden erscheinen. So berichtet Libanios in seiner „Autobiographie" für das Jahr 382, die Statthalter (archontes) hätten Getreideimporte nach dem syrischen Antiocheia veranlaßt; gemeint sind offenbar der comes Orientis Philagrius und der namentlich unbekannte consularis Syriae. ${ }^{90}$ Dem in den Jahren 384

89 W. Kraatz (Hg.): Koptische Akten zum Ephesinischen Konzil vom Jahre 431. Übersetzung und Untersuchungen (Texte und Untersuchungen N. F. 11, 2), Leipzig 1904, 20-22; der referierte Ausspruch steht auf S. 22.

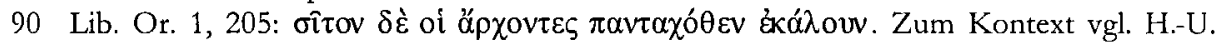
Wiemer, Der Sophist Libanios und die Bäcker von Antiocheia, Athenaeum n. s. 74, 1996, 527-548, hier: 531-533; zur Person des Philagrius PLRE I, 693 Nr. 4. 
bis 385 amtierenden comes Orientis Icarius ${ }^{91}$ wirft Libanios vor, er sei nicht bereit gewesen, die Bettler, die während einer Hungersnot in Antiocheia zusammengeströmt waren, zu unterstützen, obwohl der consularis Syriae Eumolpius ihm mit gutem Beispiel vorangegangen sei. ${ }^{92}$ Hier könnte die Verteilung von Steuergetreide gemeint sein, aber auch ein behördlich angeordneter Verkauf von Getreide. Der proconsul Asiae Anthemius Isidorus führte zu Beginn des 5. Jahrhunderts ägyptisches Getreide nach Ephesos ein und wurde dafür mit einer Statue geehrt, ${ }^{93}$ deren Widmungsepigramm uns die Kunde von seiner Wohltat bewahrt hat.

Nun hängt die Tatsache, daß Demosthenes sich direkt an den Kaiser wandte, zweifellos damit zusammen, daß Anastasius sich vorbehielt, alle Entscheidungen über Steuernachlässe persönlich zu treffen. ${ }^{94}$ Daraus darf aber nicht gefolgert werden, daß spätrömische Statthalter bei Versorgungskrisen in der Regel frei schalten und walten konnten. Denn in den referierten Texten, die auf den ersten Blick für diese Annahme zu sprechen scheinen, werden die konkreten administrativen Vorgänge bewußt ausgeblendet, weil es ihren Verfassern um ganz andere Dinge geht; für sie stehen Personen im Vordergrund, nicht Verwaltungsabläufe. Daher müssen wir zumindest bei den Statthaltern, die einem Prätoriumspräfekten unterstanden, wohl davon ausgehen, daß sie nur dann Steuergetreide verteilen oder mit kaiserlichen Mitteln Getreide kaufen konnten, wenn sie zuvor durch den Prätoriumspräfekten dazu ermächtigt worden waren. Dank der „Variae“ Cassiodors können wir im ostgotischen Italien ausnahmsweise einmal verfolgen, wie der vom Herrscher ausgehende Befehl, in zwei Provinzen, in denen Mangel herrschte, Hirse aus staatlichen Speichern unter dem Marktpreis zu verkaufen, vom Prätorianerpräfekten an untergeordnete Instanzen weitergegeben wurde. ${ }^{95}$

91 Zur Person vgl. PLRE I, 455-456 Nr. 2.

92 Lib. Or. 27, 6. Zum Kontext vgl. Wiemer, Athenaeum n. s. 74 (wie Anm. 90), 533-543; zur Person des Eumolpius PLRE I, 295.

93 L. Robert, Hellenica. Recueil d'épigraphie de numismatique et d'antiquités grecques, Bd. 4: Épigrammes du Bas-Empire, Paris 1948, 43-44. Zur Person vgl. PLRE II, 631-633 Nr. 9.

94 CJ 10, 16, 13 (496); vgl. Cyr. Scyth. V. Sabae 54: Anastasius sei auf Bitten des Abtes Sabas bereit gewesen, den Klöstern und possessores Jerusalems eine im Rahmen einer epibole fällige zusätzliche Steuerleistung zu erlassen, doch habe ihn der Prätorianerpräfekt Marinus davon wieder abgebracht. Zur Finanzpolitik des Anastasius vgl. Jones, Later Roman Empire I (wie Anm. 20), 235-237.

95 Cass. Var. 10, 27 (Senatori PPO Theodahadus rex); 12, 26 (Paulo viro strenuo Senator PPO); 12, 27 (Datio episcopo Mediolanensi Senator PPO); 12, 28 (Edictum). Die betrof- 
Anders dürfte es lediglich bei den Prokonsuln von Afrika und von Asien gewesen sein, weil diese direkt dem Kaiser unterstanden. Aus dem Geschichtswerk des Ammianus Marcellinus wissen wir von einem proconsul Africae, der während einer Versorgungskrise ein ungewöhnliches Maß an Eigeninitiative entwickelte. Der Historiker erzählt nämlich, der proconsul Africae Iulius Festus Hymetius habe während einer Hungersnot in den staatlichen Kornspeichern gelagertes und für Rom bestimmtes Getreide zum Dreifachen des Preises auf den Markt gebracht, den er selbst dafür zahlte. Hymetius erwarb sich dadurch die Dankbarkeit der Provinzbewohner, die ihm zwei vergoldete Statuen weihten, eine in Karthago und eine in Rom, handelte sich aber die Mißgunst Kaiser Valentinians ein, der seinem Statthalter nicht glauben wollte, daß er die Differenz zwischen Kosten und Einnahmen tatsächlich in voller Höhe an den Fiskus abgeführt hatte. ${ }^{96}$

\section{4) Die Rolle des Kaisers}

Anastasius war nach Josuas Bericht durchaus bemüht, sein Ansehen als fürsorglicher Patron seiner Untertanen zu wahren. Darum übergab er dem Statthalter im Winter 500 auf 501 Geld für eine kostenlose Brotverteilung, die in seinem Namen erfolgte, und legte Wert darauf, die Dankbarkeit seiner Untertanen für den Steuernachlaß, den er im Jahre 503 endlich gewährte, nicht mit dem Bischof teilen zu müssen. Die Interessen des Fiskus hatten für den Kaiser jedoch höchste Priorität. Da er für einen Krieg gegen das Perserreich rüstete, war er nicht bereit, der Provinz Osrboene die Grundsteuer zu erlassen, solange noch irgendwelche Hoffnung bestand, sie eintreiben zu können. Erst nachdem dieser Krieg, der 502 ausbrach und bis 506 dauerte, ${ }^{97}$ die Grenzprovinzen vollkommen verwüstet hatte, verzichtete er auf Steuern, die ohnehin nicht mehr einzutreiben waren, indem er zeitlich eng befristete Steuerbefreiungen gewährte. ${ }^{98}$ Gewiß, nicht alle spätrömischen Kaiser waren

fenen Provinzen waren einerseits Ligurien und andererseits Venetien. Der geforderte Preis lag um mehr als die Hälfte unter dem damals verlangten Marktpreis, aber über dem bei einer guten Ernte üblichen.

96 Amm. Marc. 28, 1, 17-18; CIL VI $1736=$ ILS 1256.

97 Zum Perserkrieg des Anastasius vgl. G. Greatrex, Rome and Persia at War, 502-532, Leeds 1998, $73 \mathrm{ff}$.

98 Josua erwähnt drei gesonderte Steuernachlässe für die Provinzen Mesopotamia und Osrboene: $₫ 66(503 / 504) ; § 92(504 / 505) ; \$ 99(505 / 506)$; in diesem Jahr mußte die Osrboene jedoch bereits wieder die Hälfte der synteleia zahlen. Ps.-Zacharias H. E. 7, 5 und Proc. Bell. Pers. 1, 7, 35 sprechen jedoch davon, daß Amida ein siebenjähriger Nachlaß aller Steuern 
so sparsam wie Anastasius, der seinem Nachfolger eine prall gefüllte Staatskasse hinterließ. ${ }^{99}$ Sein Verhalten fällt jedoch keineswegs völlig aus dem Rahmen dessen, was für andere Kaiser überliefert ist. Von Steuerbefreiungen, die allein aufgrund von Mißernten gewährt wurden, ist in unserer Überlieferung auch sonst kaum die Rede; sie waren offenbar sehr selten. ${ }^{100}$

Immerhin ist mehrfach überliefert, daß Kaiser bei Versorgungskrisen für ein verbessertes Angebot an Lebensmitteln sorgten. Ammianus Marcellinus wirft dem Caesar Gallus, der von 353 bis Frühjahr 354 im syrischen Antiocheia residierte, sogar vor, er habe angesichts einer drohenden Hungersnot keine der Maßnahmen ergriffen, mit denen Kaiser gewöhnlich lokalen Notständen begegneten, und kein Getreide aus Nachbarprovinzen importieren lassen. ${ }^{101}$ Diese Äußerung des Historikers sollte jedoch nicht zu der Schlußfolgerung verleiten, daß jede Stadt des Reiches eine realistische Chance gehabt hätte, in den Genuß dieser Art von Fürsorge zu kommen. Vielmehr ist festzustellen, daß Getreideimporte, wenn wir vom Sonderfall Rom einmal absehen, in der Regel Städten zugute kamen, die Kaiser beherbergten. In Konstantinopel wurde der Kaiser von der Bevölkerung für die Versorgungslage ebenso selbstverständlich persönlich haftbar gemacht, ${ }^{102}$ wie es in der früheren Kaiserzeit in Rom der Fall gewesen war. Nach wie vor pflegte sich der Unwille des Volkes zu artikulieren, wenn sich der Kaiser bei den Spielen seinem Volke zeigte. Und wie einst Augustus als Triumvir während einer Hungersnot in Rom von einer mit Steinen werfenden Menge beinahe getötet

gewährt worden sei. Demnach war die Provinz Mesopotamia durch die Kriegsfolgen so stark verwüstet, daß man die Untertanen hier erst 510/511 wieder zur Kasse bitten konnte.

99 Nach Proc. H. A. 19, 7 befanden sich beim Regierungsantritt Iustinus' I. nicht weniger als 320.000 Pfund Gold im Schatz des Kaisers; vgl. Joh. Lyd. Mag. 3, 51. Wie das Volk von Konstantinopel auf diese Sparsamkeit reagierte, zeigen die sowohl bei Joh. Lyd. Mag. 3, 46 als auch in der „Anthologia Palatina“ $(11,270+271)$ überlieferten Spottepigramme.

100 Eine Ausnahme findet sich im ostgotischen Italien, wo Cassiodor als Prätoriumspräfekt wegen einer Mißernte der Provinz Aemilia et Liguria die Hälfte der gesamten Steuerleistung (dimidiam fiscalis calculi functionem) und den venetischen Städten Concordia, Aquileia und Forum Iulii die Stellung von Wein und Korn (aber nicht die von Fleisch) für die Soldaten erließ: Cass. Var. 12, 26 (Veneti); 12, 28, 7 (Aemilia et Liguria).

101 Amm. Marc. 14, 7, 5: (Gallus) non, ut mos est principibus quorum diffusa potestas localibus subinde medetur aerumnis, disponi quicquam statuit, vel ex provinciis alimenta transferri conterminis, sed consularem Syriae Theophilum, prope adstantem, ultima metuenti multitudini dedit, id adsidue replicando quod, invito rectore, nullus egere poterit victu.

102 Eunap. V. S. 6, 2, 9-12 (Konstantin I., 330/337); Joh. Mal. 18, 12, 1, S. 488 Dindorf; Theoph. a. m. 6048, S. 230 de Boor (Justinian I., 555); Joh. Ephes. H. E. 3, 45, S. 133 Brooks (Tiberius II., 581/582). 
worden wäre, als er sich auf dem Forum zeigte, ${ }^{103}$ wurde auch Theodosius II. einmal bei der zeremoniellen Inspektion der Kornspeicher Konstantinopels mit Steinen beworfen, als in der Stadt Mangel an Weizen herrschte. ${ }^{104}$

Konstantinopel war freilich im vierten Jahrhundert nicht die einzige Stadt des griechischen Ostens, in der ein Kaiser für längere Zeit residierte. Wir wissen von zwei Versorgungskrisen im syrischen Antiocheia, die mit der Anwesenheit eines Kaisers zusammenfielen: 354 hatte der Caesar Gallus sich zwar geweigert, Getreideimporte zu veranlassen, aber doch einen Maximaltarif erlassen, ${ }^{105}$ 362/363 dann der Augustus Julian ebenfalls Höchstpreise fixiert, zugleich aber in großem Stile Getreide importiert. ${ }^{106}$ Als Konstantinopel zur einzigen Kaiserresidenz des oströmischen Reiches wurde, büßten die Einwohner von Städten wie Antiocheia jedoch die Möglichkeit ein, den Kaiser im Hippodrom unter Druck zu setzen, und entsprechend sanken ihre Chancen, der kaiserlichen Fürsorge teilhaftig zu werden. Darum ist es wohl kein Zufall, daß nach unserer Überlieferung von allen Städten, die nicht Kaiserresidenzen waren, allein Rom, das noch immer als symbolischer Fokus des Reiches galt, bei Versorgungskrisen häufiger in den Genuß kaiserlicher Unterstützung kam. So schickte Julian während seiner Usurpation gegen Constantius II. afrikanisches Getreide, das teils als Steuergetreide erhoben worden war, teils aus den Erträgen kaiserlicher Domänen stammte und teils im Wege der coemptio beschafft worden war, nach Rom, wo damals Hunger herrschte; freilich wurden die Getreidefrachter abgefangen und nach Konstantinopel umgeleitet. ${ }^{107}$ Symmachus bat als Stadtpräfekt Valentinian II. um einen Beitrag zur Getreidekasse der ewigen Stadt, ${ }^{108}$ der Heermeister Stilicho ließ während der Erhebung des comes Africae Gildo Getreide aus Germanien, Gallien, Spanien und Sardinien nach Rom bringen, ${ }^{109}$ der ostgotische König

103 Cass. Dio 48, 1, 1; 48, 31; App. Bell. Civ. 5, 67, 281-5, 68, 289. Vgl. dazu Garnsey, Famine (wie Anm. 1), 202.

104 Marc. Comes s. a. 431 (MGH AA XI, 78): Hoc tempore dum ad borrea publica Theodosius processum celebrat, tritici in plebem ingruente penuria imperator ab esuriente populo lapidibus inpetitur. Zur Zeremonie vgl. Constant. Porphyr. De caerim. 2, 51, S. 700, Z. 16-18 Reiske.

105 Amm. Marc. 14, 7, 2-8; 15, 13, 2; Lib. Or. 1, 96-97; 103; Or. 19, 47; Jul. Mis. 370C.

106 Vgl. dazu Wiemer, Libanios und Julian (wie Anm. 1), 301-311.

107 Pan. 3 (11), 14, 1-6; vgl. dazu H. Gutzwiller, Die Neujahrsrede des Konsuls Claudius Mamertinus vor dem Kaiser Julian (Basler Beiträge zur Altertumswissenschaft 10), Basel 1942, 166-172.

108 Symm. Rel. 37.

109 Claud. In Eutr. 401-409 mit Kohns, Versorgungskrisen (wie Anm. 1), 194-210. 
Theoderich veranlaßte 526 einen Getreideimport aus Spanien, ${ }^{110}$ und noch Kaiser Justin II. schickte ägyptisches Getreide an den Tiber. ${ }^{111}$

\section{Zusammenfassung}

Auch wenn verallgemeinernde Aussagen über einen so komplexen Gegenstand wie die Lebensmittelversorgung der frühbyzantinischen Städte angesichts der begrenzten Aussagekraft unserer Quellen gefährlich sind, lassen sich im diachronen Vergleich doch wohl einige für den spätrömischen Osten charakteristische Züge benennen. Einerseits trifft es zu, daß sich die kaiserliche Verwaltung in der Spätantike in weit höherem Maße für die Lebensmittelversorgung großer Städte engagierte, als dies in der früheren Kaiserzeit der Fall gewesen war: Nicht mehr nur die Lebensmittelversorgung Roms wurde nun durch einen dem Kaiser unterstehenden Apparat gewährleistet, sondern auch diejenige Konstantinopels. Auch zur Lebensmittelversorgung des ägyptischen Alexandreia und des syrischen Antiocheia leistete die kaiserliche Verwaltung in der Spätantike einen erheblichen Beitrag. Dieses kontinuierliche, institutionell abgesicherte Engagement stellt der Regelungskapazität des spätrömischen Staates kein schlechtes Zeugnis aus. Die Fähigkeit und Bereitschaft der kaiserlichen Verwaltung, in diesem Bereich eine vorausschauende, planvoll gestaltende Politik zu betreiben, hatte gegenüber der früheren Kaiserzeit erheblich zugenommen.

Andererseits ist jedoch festzuhalten: Auch wenn die kaiserliche Verwaltung im Bereich der Lebensmittelversorgung ein für vormoderne Verhältnisse außerordentlich hohes $\mathrm{Maß}$ an politischer Gestaltungskraft entwickelte, war sie weit entfernt davon, alle Reichsangehörigen in ein flächendeckendes System zur Sicherung gegen das Risiko von Mißernten einzubeziehen. Die Annahme, die kaiserliche Verwaltung habe alle größeren Städte mit kostenlosem Brot beliefert und dafür gesorgt, daß sie im Bedarfsfall auf speziell für Getreidekäufe geführte, dem Fiskus angegliederte Kassen zurückgreifen konnten, läßt sich an den Quellen nicht erhärten. „Gewöhnliche“ Provinzstädte versorgten sich im spätrömischen Reich im Normalfall noch immer ohne kaiserliche Unterstützung. ${ }^{12} \mathrm{Um}$ es pointiert $z u$ formulieren: Sowenig

110 Cass. Var. 5, 35.

111 Liber pontificalis $64,1$.

112 In welchem Umfang spätrömische Städte auf eigene Getreidekassen zurückgreifen konnten, ist beim Fehlen aussagekräftiger Quellen schwer abzuschätzen. Da sich die Finanzautonomie der Städte seit dem 2. Jahrhundert jedoch beträchtlich reduziert hatte, ist davon 
das spätrömische Imperium Romanum ein „Zwangsstaat" war, der alle Lebensbereiche reglementieren wollte oder konnte, so wenig war es ein „Wohlfahrtsstaat", der allen Reichsbewohnern ein Existenzminimum zu sichern versuchte.

Die Verhaltensmuster, die den Umgang zwischen princeps und plebs Romana seit jeher geprägt hatten, wurden in der Spätantike auf die neuen Residenzen übertragen; für die Einwohner dieser Städte blieb der Kaiser auch in der Spätantike der direkte Ansprechpartner, wenn es zu einer akuten Knappheit an Lebensmitteln kam. Von dieser besonderen Konstellation abgesehen, etablierten sich jedoch vielfach neue Verhaltensmuster. Auch wenn der spätrömische Kaiser es sich nicht nehmen ließ, immer wieder einmal an seiner Bürokratie vorbei persönlich $\mathrm{zu}$ intervenieren, ${ }^{113}$ hatten es die Einwohner der Provinzstädte nun in erster Linie mit seinen Statthaltern zu tun. Der Handlungsspielraum spätrömischer Statthalter war indessen merklich geringer als derjenige, dessen sich die Statthalter der früheren Kaiserzeit erfreut hatten, weil sie lediglich untere Instanzen einer zentralisierten Verwaltung waren und dafür zu sorgen hatten, daß ein im Voraus festgesetztes Steuerquantum abgeliefert wurde. ${ }^{114}$

Es versteht sich von selbst, daß der Handlungsspielraum der kaiserlichen Zentrale davon abhing, ob sie über Goldreserven und/oder hinreichende Lebensmittelvorräte verfügte. Generell wird man dazu zweierlei sagen können: Zum einen war der Anteil an der ägyptischen Getreideproduktion, über den die kaiserliche Verwaltung frei verfügen konnte, in der Spätantike zweifellos geringer als in der früheren Kaiserzeit, da allein für die Versorgung Konstantinopels eine erheblich größere Menge an ägyptischem Getreide benötigt wurde als zuvor für diejenige Roms. Zum anderen ist davon auszugehen, daß die Interessen des Fiskus erste Priorität genossen: Auch bei verheerenden Hungersnöten wurde erst dann auf die Steuern verzichtet, wenn bei den Untertanen ohnehin nichts mehr zu holen war.

Tiefgreifende Veränderungen vollzogen sich schließlich auch auf der lokalen Ebene. Der auf die Bürgergemeinde bezogene Euergetismus städti-

auszugehen, daß ihre Fähigkeit, solche Kassen zu füllen, in der Spätantike im Durchschnitt noch geringer war als in der hohen Kaiserzeit. Vgl. dazu oben den Beitrag von S. Schmidt-Hofner.

113 Dieses strukturelle Dilemma des spätrömischen Kaisertums beleuchtet jetzt C. Kelly, Ruling the Later Roman Empire, Cambridge, Mass. London 2004, bes. $186 \mathrm{ff}$.

$114 \mathrm{Zu}$ den Verhältnissen der hohen Kaiserzeit vgl. W. Eck, Provinzialverwaltung und Steuern, in: ders., Die Verwaltung des römischen Reiches in der hohen Kaiserzeit, Bd. 2, Basel - Berlin 1998, 107-145, bes. 132ff. 
scher Honoratioren, die dem lokalen Stadtrat angehörten, hatte einer Mentalität Platz gemacht, die von jedermann Almosen für die Armen und Kranken forderte. Der Stadtrat büßte seine Bedeutung als Organ kollektiver Interessenvertretung ein und spielte darum bei der Bewältigung von akuten Versorgungskrisen seit dem 5. Jahrhundert keine nennenswerte Rolle mehr. Dagegen konnten Bischöfe sich gerade in solchen Situationen als geistliche Oberhäupter der Gemeinde und als Anwälte der Armen profilieren. Die kirchliche Armenfürsorge war bei Versorgungskrisen jedoch überfordert, und die Hoffnung auf materielle Hilfe richtete sich in dieser Situation auch nicht in erster Linie an die Kirche, sondern an die weltliche Obrigkeit. 



\section{Index}

\section{Orte}

Achaia, Provinz 244

Ägypten 28, 30, 41, 44, 50-51, 73, 87$89,92,94,98,100-102,104,108-$ 109, 146, 157 Anm. 36, 162, 209, 215, 250-252, 254-256, 279-280

Africa Proconsularis (Provinz) 221, 224-225, 256, 276

Aizanoi 72 Anm. 68, 75, 78-79, 81

Alexandreia (Troas) 113, 130, 140, 146148

Alexandreia (Ägypten) 37, 73 Anm. 73, 92-93, 98- 99, 104, 108, 182, 197, 199, 201, 203, 207, 215, 231 Anm. 45, 255 Anm. 25, 256, 279

Amida 187, 259, 270, 276 Anm. 98

Amphipolis 135 Anm. 55

Anazarba 231 Anm. 45

Andriake 109, 110

Ankyra 133, 143

Antaiopolis 231 Anm. 45

Antinoopolis 28, 44, 49-52, 96, 256 Anm. 31

Antiocheia (Pisidien) 269 Anm. 72

Antiocheia (Syrien) 37, 133, 141, 193194, 197, 200, 207 Anm. 79, 215, 234 Anm. 49, 237, 240, 244, 249 Anm. 1, 256-258, 262 Anm. 52, 269-270, 272 Anm. 83, 274-275, 277

Apameia (Phrygien) 130-131, 133, 135 Anm. 55

Aphrodisias (Karien) 54 Anm. 40, 130131, 135 Anm. 55, 268 Anm. 70 Aphrodito 231 Anm. 45

Apollonia (Cyrenaica) 241 Anm. 65
Aquileia 147, 277

Arsinoe 73 Anm. 74

Arsinoïtes, Gau 50

Arsinoitonpolis 94

Asia, Provinz 31, 36, 38, 78, 103, 108, $110,114,118,120,233-235,237$, 240, 269 Anm. 72, 275

Aspendos 269 Anm. 72

Athen 28, 44, 46-49, 52-53, 126 Anm. 13, 135 Anm. 55, 161, 192, 256 Anm. 31

Augusta Traiana (Thrakien) 139

Beirut (Berytos) 231 Anm. 45

Bisanthos 137 Anm. 65

Bithynia et Pontus, Provinz 32, 60 Anm. 18, 127, 134-135, 140, 234 Anm. 52, 242

Britannien 59-60, 65-66, 222 Anm. 29, 225

Byzantion 79 Anm. 101

Byzanz, s. Konstantinopel

Caesarea Maritima 231 Anm. 45

Capua 255, 257

Caralis 231 Anm. 45

Chalkedon, Konzil von 33, 35-36, 187 -

190, 192, 194-201, 203, 205-208

Chalkis (Euboia) 244

Chalkis (Syrien) 218 Anm. 21, 268 Anm. 70

Chullu (Numidien) 230

Cirta 81

Concordia 277 Anm. 100

Delos, Emporion 126

Dia 134, 142

Dionysion, Emporion 126 Anm. 13 
Discoduraterae, Emporion (Thrakien) 139

Edessa (Urfa) 38, 258-274

Elaios, Emporion (Bithynien) 134 Anm. 49, 142

Eleusis 28, 47-48

Ephesos 36, 109-110, 117, 120, 131-132, 135 Anm. 55, 157, 187, 191 Anm. 17, 210-212, 226 Anm. 33, 233-235, 239-240, 245, 247, 273, 275

Forum Iulii (Fréjus) 277 Anm. 100

Galatien 103

Gallien 65-66, 70, 183, 222 Anm. 29, 225,278

Hadrianopolis-Stratonikeia (Lydien) 242 Anm. 66

Herakleia Pontike 132, 140-143

Herakleia Salbakes 230

Hermopolites, Gau 215

Hippo Regius 168

Issos 62

Jerusalem 197

Kaisareia (Kappadokien) 270 Anm. 73, 273

Kalos Agros, Emporion (Bithynien) 134

Kales, Emporion (Bithynien) 134 Anm. 49,142

Karthago 170, 256, 276

Kaunos 31, 107, 110-111, 114-121

Kephallenia 256 Anm. 31

Kieros 141

Komana Pontike 141

Konstantinopel (Byzanz) 17, 34, 36-37, $171-172, \quad 175-176,179,181-185$, $187-188,190,193-194,198-205$, 214, 253 Anm. 21, 255-256, 262, $271,274,277-280$

Kopaïsbecken 28, 44-46

Koptos 147

Koroneia (Boiotien) 44-46

Ktesiphon 72

Kyrrhos (Syrien) 237

Kyzikos 62, 123, 132, 137-138
Laodikeia am Lykos 125 Anm. 7, 132 133

Lilaios, Emporion 134 Anm. 49, 142

Lycia et Pamphylia (Provinz) 31, 103, $110,114,118,121$

Lyon (Lugdunum) 29, 55, 57, 65, 70-73, 80-81

Mâcon (Matisco) 158 Anm. 19

Mailand (Mediolanum) 173 Anm. 60, 184,238

Mainz (Mogontiacum) 70, 221

Mesopotamia (Provinz) 38, 72, 79 Anm. 101, 259, 263, 277 Anm. 98

Milet 135 Anm. 55

Moesia Inferior, Provinz 139

Mopsouestia 162

Mylasa 229 Anm. 45

Myra 31, 110-114, 117-120

Mysia, Provinz 32, 134

Nakoleia 134, 216, 244

Nicopolis ad Istrum 139

Nikaia (Bithynien) 133, 136, 143-144, 229,245

Nikomedeia 134, 137

Nisibis 72 Anm. 69, 81 Anm. 112

Nizäa, Konzil von 199

Oinoanda 114, 242 Anm. 66

Orchomenos (Boiotien) 45

Orkistos 216, 244

Osrhoene, Provinz 38, 258, 261-263, 268,276

Ostia 74 Anm. 81

Oxyrhynchites, Gau 95 Anm. 17, 97, 269

Palmyra 109-110, 242 Anm. 66

Pannonia Superior, Provinz 59, 61

Panormos, Hafen 131-132

Patara 113

Pavia (Ticinum) 78, 185

Perge 162

Perinthos 132 Anm. 40, 137 Anm. 65

Pessinous 141

Piräus, Hafen 47, 126, 128

Pistiros, Emporion (Thrakien) 129-130 Anm. 24 
Pizos, Emporion (Thrakien) 32, 129, 131 Anm. 31, 135 Anm. 55, 137 Anm. 60, 139-140

Prokonnesos 132, 137 Anm. 65

Prusias ad Hypium 132, 134, 138-139, 141-142, 148 Anm. 116

Psylla, Emporion (Bithynien) 134 Anm. 49

Ptolemais (Ägypten) 50

Puteoli 145, 147 Anm. 112, 255

Raetien 70

Ravenna 181

Rom 22, 24, 33-34, 37, 46 Anm. 10, 58, 60-62, 64 Anm. 37, 66, 68, 71, 75 Anm. 82, 110, 120-121, 145, 168$169,171,175,177,179-183,185$ 186, 197, 199 Anm. 45, 201, 204, 239 Anm. 59, 249-251, 253-256, 276-280

Rusicade (Numidien) 230

Sabora 241 Anm. 66

Sagalassos 103

Sardeis 141

Serdica 163-164

Side 134-136, 138

Sigus (Numidien) 81
Sinope 140

Smyrna 134, 140, 146

Susa 141

Syria Coele, Provinz 59, 105, 109, 237. 238, 260, 268-269

Takina 103

Tanaïs, Emporion 145

Tarracina 255, 257

Tataion, Emporion (Bithynien) 133, $136,143-144$

Thisbe 241

Thouidas, Emporion (Thrakien) 139

Thrakien 32, 126-127, 129, 131 Anm. $31,135,139,148$

Thugga (Dougga) 73-74

Thyateira (Lydien) 52

Tios 141

Tomis 145

Trier (Treveri) 70

Turicum (Zürich) 109

Tyana 162

Ulcisia castra (Szentendre) 75, 77-78

Viminacium (Kostolac) 67, 77-78

Volubilis 74 Anm. 81

Xanthos 115

\section{Antike Namen}

Römische Bürger bis ca. $260 \mathrm{n}$. Chr. sind wie in PIR unter dem nomen gentile, solche aus der Zeit danach wie in PLRE unter einem cognomen eingeordnet, Kaiser und Autoren aber unter der vertrauten Namensform. Alle Daten verstehen sich $\mathbf{n}$. Chr., wenn nicht anders angegeben.

L. Aelius Caesar, Kaiser 136-138 61 Anm. 20

L. Aemilius Iuncus, cos. suff. 12746

L. Aemilius Rectus, praef. Aegypti 414299 Anm. 28, 100 Anm. 37

Q. Aemilius Saturninus, praef. Aegypti $197-199 / 20097$

Agapet I., Papst 535-536 36, 201-208

Alarich, gotischer König 33, 168-169, 172,254
Alypia, Tochter des Anthemius 184

Ambrosius, Bischof von Mailand 374397173 Anm. 60, 202

Ammianus Marcellinus, Historiograph 214-215, 219-220, 276-277

Anastasius, Kaiser 491-518 38, 189 Anm. 7, 196 Anm. 39, 232, 253 Anm. 19, 258-259, 262-263, 265266, 268-269, 272, 275-277

Fl. Anthemius Isidorus, cos. 436275 
Procopius Anthemius, Kaiser 467-472 $27,34-35,175-186,275$

Anthimos, Bischof von Konstantinopel 535-536 201-206

Antipatros, Reichsverweser Alexanders III. 43

L. Antistius Rusticus, cos. suff. unter Domitian 251 Anm. 14

Antoninus Pius, Kaiser 138-161 61, 104, 147

Anullinus, procos. Africae 313256

C. Sollius Apollinaris Sidonius, PUR 468 34, 180-183, 185

Arvandus, PPO Galliarum 464-468 34, $180,182,185$

Asellius Aemilianus, leg. Aug. pr. pr. Syriae ca. 185-190 62

Aurelius Augustinus, Bischof von Hippo Regius 395-430 33, 153-154, 156, 168-172

Augustus, Kaiser 27 v. Chr. - $14 \mathrm{n}$. Chr. 2, 4, 14-15, 17, 21, 26, 29, 42, 53 Anm. 39, 56, 99, 165 Anm. 40, 250, 277

Aurelian, Kaiser 270-275 17 Anm. 48, 73, 102, 139

Aurelius Appius Sabinus, praef. Aegypti 249-250 91 Anm. 7

M. Aurelius Chrysenius Damatrius, Bityhniarch und Pontarch 138

C. Avidius Cassius, Kaiser 175 71, 105, 237 Anm. 55

C. Avidius Heliodorus, praef. Aegypti 137-142 91 Anm. 7, 95 Anm. 16 u. 18, 100 Anm. 36, 105

A. Avillius Flaccus, praef. Aegypti 323893 Anm. 11, 100 Anm. 38

Avitus, Kaiser 455-456 182

L. Baebius Aurelius Iuncinus, praef. Aegypti 21293 Anm. 11, 100 Anm. 39

Berenicianus, miaphysitischer Mönch 187 Anm. 2

C. Iulius Caesar, Diktator 22

Caesarius, CRP 363-364 238
Calpurnius Longus, procos. Achaiae unter Hadrian (?) 45

Caracalla, Kaiser 211-217 64, 67, 71-72, 74-82, 103

Fl. Magnus Aurelius Cassiodorus Senator, PPO Italiae 533-537 275, 277

Anm. 100

M. Cassius Poplianus Nicadas, Emporiarch von Tataion 136

Chosrau (Chosroes) I., Schah 531-579 267

Claudius, Kaiser 41-54 93, 110, 121

Ti. Claudius Balbillus, praef. Aegypti 55-59 93

Ti. Claudius Pompeianus, cos. II 173 58 Anm. 12

Ti. Claudius Subatianus Aquila, praef. Aegypti 206-210 93 Anm. 11, 95 Anm. 15, 100 Anm. 37

D. Clodius Albinus, Kaiser 193-197 27, 29-30, 55, 57, 59-71, 73-74, 78 Anm. 114, 254 Anm. 20

Commodus, Kaiser 180-192 29, 57, 61, $66-67,78,104$

Constans, Kaiser 337-350 163, 267 Anm. 31

Constantius I., Kaiser 293-306 163

Constantius II., Kaiser 337-361 213, $217,239,278$

Paulus Constantius, procos. Africae 374221

Demetrios Poliorketes, König 306-283 v. Chr. 43

Demosthenes, praeses Osrhoenae 498$501262,265,267,272,274-275$

Didius Iulianus, Kaiser 193 58, 60-61, 63 Anm. 30

Diokletian, Kaiser 284-305 7, 14, 17-18, 20, 23, 27, 37, 39, 158 Anm. 19, 202, 209, 216, 218 Anm. 21, 248, 252-253, 256

Dionysios, Bischof von Alexandreia 247/8-264/5 255 Anm. 26

Domitian, Kaiser 81-96 103, 251 Anm. 14, 269 Anm. 72 
Drakon, athenischer Gesetzgeber 48

Magnus Felix Ennodius, Bischof von Pavia 514-521 34, 178-180, 185

Ennoius, procos. Africae 395225 Anm. 32

Epameinondas, Euerget von Akraiphia 45

Ephraim der Syrer, Poet und Theologe 193, 207 Anm. 79, 271

Epiphanius, Bischof von Pavia 466-496 178-180, 185, 196

Eudokia, Augusta 423-460 256

Eulogius, CRP 395225 Anm. 32

Eumolpius, cons. Syriae 384/5 275

Euphemios, Patriarch von Konstantinopel 489-495 199

Eurich, König der Westgoten 466-486 180

Eusebius, Stellvertreter des praeses Osrhoenae 500 263-264

Eusebius, CSL 395225 Anm. 32

Eutropius, cos. 387 36, 233, 234-236, 238,240

Eutyches, Presbyter und Abr 192, 197, 199

Eutyches, servus Caesaris 147

Fabius Pasiphilus, Stellvertreter für PPO et PUR 394/5 225 Anm. 32

Faustina II., Augusta 147-176 67

Felix II. (III.), Papst 483-492 179 Anm. 8

Festus, procos. Asiae 372-378 233-234, 276

Firmus, Bischof von Kaisareia ca. 431 273

T. Flavius Titianus, praef. Aegypti 126133 + 164- 16795 Anm. 16, 98 Anm. 25

Galba, Kaiser 68-69 92, 94

Gallus, Kaiser 351-354 277, 278

Gelasius I., Papst 492-496 179

P. Septimius Geta, Kaiser 197-211 67 Anm. 54, 72, 77 Anm. 94

Gildo, MUM per Africam 386-398 278

Grepes, Herulerkönig 193 Anm. 26
Grod, Hunnenkönig 193 Anm. 26

Hadrian, Kaiser 117-138 20, 27-28, 31, $39,41-54,61,95-97,102-103,110-$ 111, 114, 119, 252 Anm. 16, 256 Anm. 31

Hadrianus, CSL 395222 Anm. 29, 225 Anm. 32

T. Haterius Nepos, praef. Aegypti 119 12497 Anm. 23, 104

Herodian, Historiograph 63, 102

Herodot, Historiograph 128

Hieronymus, Kirchenschriftsteller 48 Anm. 16, 171 Anm. 54

Hierius, vic. Africae 395225 Anm. 32

Hilarus, Papst 461-468 179 Anm. 8, 182

Hilarius, PPO Galliarum 396225 Anm. 32

Honorius, Kaiser 395-423 153, 170, 225 Anm. 32

Hormisdas, Papst 514-523 190

Iulius Festus Hymetius, procos. Africae 366-368 276

Ibas, Bischof von Edessa 435-457 270

Icarius, comes Orientis 384-385 275

Innocentius, Bischof von Maroneia 533 194-197

Iulia Domna, Augusta 210-217 29, 63 64, 73-74

Ti. Iulius Alexander, praef. Aegypti 6669/70 30, 91, 96, 99-100, 104

C. Iulius Postumus, praef. Aegypti 45 4791 Anm. 6

Decimus Iunius Zenodotus, Emporiarch und Demiurg in Side 136

Jakob von Sarug, Kirchenschriftsteller 260 Anm. 45, 273 Anm. 87

Johannes I., Bischof von Antiocheia 429-441/2 273

Johannes II., Papst 533-535 199-200

Johannes Chrysostomos, Bischof von Konstantinopel 397-408 257, 270 Anm. 73

Johannes von Ephesos, Hagiograph 187, 194, 271 Anm. 79 
Josua Stylites, Chronist 37-38, 258-274, 276

Jovian, Kaiser 363-364 257, 259

Julian, Kaiser 355-363 36, 201, 210-211, 214-220, 237-240, 278

Justin I., Kaiser 518-527 189 Anm. 7

Justin II., Kaiser 565-578 270, 279

Justinian, Kaiser 527-565 2, 6, 10-11, 17, 26-27, 35-37, 39, 166, 175, 187-208, 225-227, 231-233, 253-254, 256, 272,277

Kavad, Schah 488-531259

Konstantin I., Kaiser 306-337 17, 70

Anm. 51, 102, 233

Laetus, Feldherr des Septimius Severus 71

Laktanz, Rhetor und Theologe 216

Larcius Memor, praef. Aegypti 192-193 93 Anm. 11

Leo I., Kaiser 457-474 34-35, 157 Anm. $17,176,181,184-185,268$

Libanios, Sophist 161 Anm. 22, 215, 217, 220, 228-229, 244, 274-275

Liberatus von Karthago, Kirchenschriftsteller 205 Anm. 73

C. Licinius Mucianus, leg. Aug. pr. pr. Syriae 68/69 110

Lucius Verus, Kaiser 161-16961

L. Lusius Geta, praef. Aegypti 5491 Anm. 6

Macrianus, alamannischer König 221 Anm. 26

Claudius Mamertinus, PPO Italiae, Illyrici et Africae 364-365 238, 278 Anm. 107

Marc Aurel, Kaiser 161-180 58 Anm. $12,61,64-65,67,71-72,76,78,104-$ 105

Marcellinus, MUM 461-468 182, 184

Marcian, Kaiser 451-457 231

Mares, miaphysitischer Mönch 208 Anm. 81

Marinus, PPO Orientis $512 / 5+519$ 275 Anm. 94

Marius Maximus, Biograph 61 Anm. 21
Maximian, Kaiser 285-305 69 Anm. 59

Maximinus Thrax, Kaiser 235-238 73

Menas, Patriarch von Konstantinopel 536-552 202, 204, 207 Anm. 79

Fl. Messius Phoebus Severus, PUR 470 180 Anm. 10, 182

M. Mettius Rufus, praef. Aegypti 8991/2 95 Anm. 17, 97, 104

L. Munatius Felix, praef. Aegypti 150 15296

Naaman, arabischer König 499-503 264 Anm. 57

Nero, Kaiser 54-68 93 Anm. 12, 107$108,110,121$

Nestorius, Bischof von Konstantinopel 428-431 199, 273

Nicomachus Flavianus, PPO Italiae 431-432 224-225, 229, 247

Numerianus, Lehrer in Rom 68 Anm. 57

Odoaker, König 476-493 178

Fl. Anicius Olybrius Kaiser 472185

Perikles, athenischer Demagoge 53

P. Helvius Pertinax, Kaiser 192-193 58, 60-63, 65, 102

Pescennius Niger, Kaiser 193-194 59-52, $65-66$

Petronius, vic. Hispaniarum 395-397 225 Anm. 32,

M. Petronius Mamertinus, praef. Aegypti 133-137 91, 93 Anm. 11, 95, 100 Anm. 37

Petronius Quadratus, praef. Aegypti unter Hadrian 95 Anm. 15

Petros, Bischof von Edessa 498-510 262, 271

Petros, Patriarch von Jerusalem 524552202 Anm. 60

Philagrius, comes Orientis 382274

Philipp II., makedonischer König 359336 v. Chr. 43

Philotheus, makedonianischer Kleriker in Rom 182

Plinius der Ältere, Enzyklopädist 147 
Plinus der Jüngere, Epistolograph 242, 252

Plutarch, Biograph und Essayist 53

Polemius, PPO Italiae et Illyrici 390 222 Anm. 28

C. Pompeius Planta, praef. Aegypti 9810094

Sextus Claudius Petronius Probus, PPO IV (Italiae) 383222

Rabbula, Bischof von Edessa 411-435 $268,270-271$

Fl. Ricimer, MUM 456-472 35, 177 $179,181,184-185$

M. Rutilius Lupus, praef. Aegypti 11311796 Anm. 19

Sabas, chalkedonischer Abt in Palästina 188-189, 202, 275 Anm. 94

Saturninius Salutius Secundus, PPO Orientis 361-365 + 365-367 214

M. Sempronius Liberalis, praef. Aegypti 154-158/9 30, 89-91, 94-96, 99, 102

L. Septimius Severus, Kaiser 193-211 20, 29-30, 55-82, 95 Anm. 15

Seranus, procos. Africae 397225 Anm. 32

Sergius, Abt 259

Servius, Vergil-Kommentator 161

Fl. Messius Phoebus Severus, PUR 470 182

Severus, Patriarch von Antiocheia 512 518 194, 198, 200

Q. Sicinnius Clarus, leg. Aug. pr. pr. Thraciae 202140

Sokrates, Kirchenhistoriker 165 Anm. $39,171,198$

Solon, athenischer Gesetzgeber 48

Q. Sosius Falco, cos. 19358 Anm. 12

Sex. Sotidius Strabo Libuscidianus, leg.

Aug. pr. pr. Galatiae 14/21 103

Sozomenos, Kirchenhistoriker 165 Anm. 39

Fl. Stilicho, Mag. Mil. 394-408 278

Strabon, Geograph 141

Strategius, CSL 535-538 195-196
Ser. Sulpicius Similis, praef. Aegypti 107-112 95 Anm. 18, 100 Anm. 36

Symeon Stylites der Ältere 271

Q. Aurelius Symmachus, PUR 384-385 255, 278

Tacitus, Kaiser 275-276 162

T. Taius Sanctus, praef. Aegypti 178 . 180104

Theodahat, ostgotischer König 534-536 201

Theodora, Augusta 527-548 18, 191 Anm. 18, 194, 200 Anm. 53, 202 Anm. 60, 205 Anm. 70

Theoderich, ostgotischer König 474526 178, 179 Anm. 8

Theodoret, Kirchenhistoriker 257, 271 Anm. 78

Theodoros, referendarius 204

Theodoros von Sykeon, Heiliger 134 Anm 48

Theodosios I., Patriarch von Alexandreia 535-567 201, 203

Theodosius I., Kaiser 378-395 182, 254 Anm. 21

Theodosius II., Kaiser 408-450 10-14, 3, $39,151-174,244,253,273,278$

Thukydides, Historiograph 129

Q. Tineius Demetrius, praef. Aegypti 189-190 95 Anm. 15, 99 Anm. 35

Titius Honoratus, praef. Aegypti 29029295 Anm. 15

Trajan, Kaiser 98-117 46, 93, 252

Ulpian, Jurist 226 Anm. 34, 241251

Valens, Kaiser 364-378 36, 210-211, 213 , $220,226,229,232-234,236,238$ 241, 246-247

Valentinian I., Kaiser 364-375 211, 212 Anm. 4, 213, 220-221, 223 Anm. $29,224,226,229,232,238-241$, 246-248

Valentinian II., Kaiser 375-392 166 Anm. 44, 255, 278

Valentinian III., Kaiser 423-455 21 Anm. 60, 176, 181, 184, 229 
C. Valerius Eudaemon, praef. Aegypti 142-143 95 Anm. 15, 99, 100 Anm. 36

L. Valerius Proculus, praef. Aegypti 144-147 100 Anm. 38

Q. Veranius, leg. Aug. pr. pr. Lyciae et Pamphyliae 43-48 103-104

Cn. Vergilius Capito, praef. Aegypti 47-52 95 Anm. $15 \& 18,100$ Anm. 37

Vespasian, Kaiser 68-79 107 Anm. 1, 241-242

C. Vibius Maximus, praef. Aegypti 103-10799

Vigilius, Papst 537-555 196 Anm. 38, 207

Viktor, Mönch 273-274
Fl. Vincentius, PPO Galliarum 397-400 222 Anm. 29, 225-226

Virius Lupus, leg. Aug. pr. pr. Britanniae 19768 Anm. 57

L. Volusius Maecianus Laetus, praef. Aegypti 160-161 104

(Pseudo-)Zacharias von Mytilene, Kirchenhistoriker 193, 203, 270, 276 Anm. 98

Zeno, Kaiser 474-491 191 Anm. 17, 227 Anm. 35, 229

Zonaras, Chronist 163

Zoras, miaphysitischer Mönch 187-189, 193 Anm. 27, 193, 196, 201-203, 205-207

Zosimos, Historiograph 216

\section{Moderne Namen}

Alföldi, Andreas 21-22

Bean, George E. 111, 117

Bleicken, Jochen 4-6, 25-26, 42-43

Bresson, Alain 126-127

Brock, Sebastian 194

Burkhalter, Fabienne 147

Burton, Graham P. 6

Bury, John B. 16-17

Claude, Dietrich 272 Anm. 84

Corcoran, Simon 7-8

Cotton, Hannah 7

Debord, Pierre 127, 141

Delmaire, Roland 212 Anm. 4, 217 Anm. 18, 226 Anm. 33, 228 Anm. 40, 231 Anm. 45

Ducloux, Anne 153-154, 156 Anm. 15, 160 Anm. 21, 163 Anm. 33

Durliat, Jean 37, 213 Anm. 5, 231 Anm. 45, 253, 255-257, 260 Anm. 44, 262 Anm. 53, 265 Anm. 60, 267,272

Eck, Werner 6, 105 Anm. 56, 107

Eich, Peter 6-7, 27, 252 Anm. 15
Engelmann, Helmut 113, 118, 146 Anm. 106

Errington, R. Malcolm 13

Finley, Moses I. 115, 123-124, 149

Gaudemet, Jean 12

Hartmann, Ludo Moritz 19-20

Heuß, Alfred 9, 14 Anm. 37, 19 Anm. 55

Hohl, Ernst 14-15; 19 Anm. 54

Jones, A. H. M. 10-12, 211, 237 Anm. 54, 254 Anm. 20, 264 Anm. 57

Jones, Christopher P. 51-52

Kelly, Christopher 27

Langenfeld, Hans 33, 152-157, 159-161, 163, 165 Anm. 41, 167-174

Lendon, John E. 8

Liebenam, Wilhelm 210, 242

Luther, Andreas 259 Anm. 43, 263 Anm. 56, 266 Anm. 63, 267

Maier, Franz-Georg 9

Meyer, Ernst 23-24 
Millar, Fergus 3-7, 12, 28, 36, 39, 41-44, 53, 56, 64 Anm. 37, 87, 172-172, 212

Mommsen, Theodor 2-3, 14-17, 19-21, 23-24, 29, 56, 249

O'Flynn, John Michael 177, 180, 186

Polanyi, Karl 125

Ostrogorsky, Georg 23

Reynolds, Joyce 131

Rilinger, Rolf 9

Robert, Louis 32, 127, 131 Anm. 33, 132 Anm. 40

Rogers, Guy 7

Rostovtzeff, Michail I. 17-19, 126

Schmitt, Carl 2 Anm. 3

Schuler, Christof 127

Schulz, Armin 146

Schumacher, Leonhard 82 Anm. 114

Schwarz, Hertha 113-114, 118

Schwartz, Eduard 157 Anm. 16, 170, 189, 203 Anm. 65, 205, 273

Schwertheim, Elmar 123, 138 Anm. 67

Seeck, Otto 16, 214 Anm. 6, 224 Anm. 31
Siems, Harald 152

Soproni, Sándor 75-76, 78

Spawforth, Anthony 51-53

Stein, Ernst 19-21

Syme, Ronald 56

Takmer, Burak 110

Thiess, Frank 175-176

Traulsen, Christian 152 Anm. 8, 155 Anm. 14, 159 Anm. 20, 162 Anm. 28

Trombley, Frank 259 Anm. 42 \& 43, 262 Anm. 55, 263 Anm. 56, 264 Anm. 57, 267

Uthemann, Karl-Heinz 190

Vasiliev, Aleksandr Aleksandrovic 191

Watt, John W. 258-260, 262, 263-264, 267

Weber, Max 4

Weber, Wilhelm 23

Wenger, Leopold 152, 154 Anm. 9

Wieacker, Franz 12

Wiemer, Hans-Ulrich 215, 219

Wörrle, Michael 31, 111-114, 251 Anm. 17 
